\title{
Morpho-molecular characterization of microfungi associated with marine based habitats
}

\section{Dayarathne $\mathrm{MC}^{1,2,3,4}$, Jones EBG ${ }^{6}$, Maharachchikumbura $\mathrm{SSN}^{5}$, Devadatha $\mathrm{B}^{7}$, Sarma $V^{7}$, Khongphinitbunjong $\mathrm{K}^{2}$, Chomnunti $\mathrm{P}^{1,2}$ and Hyde $\mathrm{KD}^{1,3,4^{*}}$}

\author{
${ }^{1}$ Center of Excellence in Fungal Research, Mae Fah Luang University, Chiang Rai 57100, Thailand \\ ${ }^{2}$ School of Science, Mae Fah Luang University, Chiang Rai57100, Thailand \\ ${ }^{3}$ World Agro forestry Centre East and Central Asia Office, 132 Lanhei Road, Kunming 650201, China \\ ${ }^{4}$ Key Laboratory for Plant Biodiversity and Biogeography of East Asia (KLPB), Kunming Institute of Botany, Chinese \\ Academy of Science, Kunming 650201, Yunnan, China \\ ${ }^{5}$ School of Life Science and Technology, University of Electronic Science and Technology of China, Chengdu 611731, \\ People's Republic of China \\ ${ }^{6}$ Department of Botany and Microbiology, King Saudi University, Riyadh, Saudi Arabia \\ ${ }^{7}$ Department of Biotechnology, School of Life Sciences, Pondicherry University, Kalapet, Pondicherry-605014, India
}

Dayarathne MC, Jones EBG, Maharachchikumbura SSN, Devadatha B, Sarma VV, Khongphinitbunjong K, Chomnunti P, Hyde KD 2020 - Morpho-molecular characterization of microfungi associated with marine based habitats. Mycosphere 11(1), 1-188, Doi 10.5943/mycosphere/11/1/1

\begin{abstract}
Our investigation of saprobic marine fungi in India, Thailand, Sweden and the UK yielded 57 species accommodated in 26 families. In the present study, we describe two new genera, 37 new species and 15 new host records. Novel genera, Halocryptosphaeria and Halotestudina are introduced within Diatrypaceae (Xylariales) and Testudinaceae (Pleosporales), respectively. The new species, Amarenographium ammophilicola, Asterodiscus mangrovei, Boeremia maritima, Chaetopsina aurantisalinicola, Chloridium salinicola, Coniochaeta arenariae, C. krabiensis, Diaporthe krabiensis, D. marina, D. salinicola, Dictyosporium marinum, Dyfrolomyces neothailandicus, Fusicolla gigantispora, Halorosellinia krabiensis, H. xylocarpi, Halotestudina muriformis, Hypoxylon aurantium, H. mangrovei, Lasiodiplodia krabiensis, Nectria marina, Nemania phetchaburiensis, $N$. viridis, Neocamarosporium artemisiae, $N$. maritimae, Neocosmospora rhizophorae, Nigrograna samueliana, N. rhizophorae, Patellaria apiculatae, Periconia salina, Peroneutypa indica, P. polysporae, Phaeoseptum carolshearerianum, $P$. manglicola, Rhytidhysteron bruguierae, Rimaconus multiguttulatus, Salsuginea rhizophorae and Xenoacremonium brunneosporum are introduced based on multigene analyses and morphological studies. This study also provides insights into the diversity of fungi from marine based habitats and confirm that they occupy diverse marine niches. We also demonstrate how marine based substrates, including sand dunes, are fascinating substrates for discovering novel taxa. All taxa described herein are based on morphological examination of fresh specimens supported by multigene phylogenies to better integrate taxa into higher taxonomic framework and infer their phylogenetic relationships as well as establish new species.
\end{abstract}

Key words - 37 new taxa - Ascomycetes - Diversity - Dothideomycetes - DNA sequences Ecology - Saline water - Sordariomycetes 
Table of contents

The numbers of taxa characterized in this study associated with marine habitats are organized as in the "Outline of Ascomycetes" (Wijayawardene et al. 2018).

Phylum Ascomycota Caval.-Sm.

Class Dothideomycetes O.E. Erikss \& Winka

Subclass Pleosporomycetidae C.L. Schoch et al.

Hysteriales Lindau

Hysteriaceae Chevall

1. Hysterium rhizophorae Dayarathne \& K.D. Hyde, in Hyde et al., Fungal Diversity 87: 42 (2017)

2. Hysterium thailandicum Jayasiri \& K.D. Hyde, in Jayasiri, Hyde, Jones, Peršoh, Camporesi \& Kang, Mycosphere 9(4): 817 (2018)

3. Rhytidhysteron bruguierae Dayarathne, sp. nov.

Pleosporales Luttrell ex M.E. Barr

Aigialaceae Suetrong et al.

4. Aigialus grandis Kohlm. \& S. Schatz, Trans. Br. mycol. Soc. 85(4): 699 (1986) [1985]

5. Aigialus mangrovei Borse, Trans. Br. mycol. Soc. 88(3): 424 (1987)

6. Aigialus parvus S. Schatz \& Kohlm., in Kohlmeyer \& Schatz, Trans. Br. mycol. Soc. 85(4): 704 (1986) [1985].

7. Ascocratera manglicola Kohlm., Can. J. Bot. 64(12): 3036 (1986)

8. Rimora mangrovei (Kohlm. \& Vittal) Kohlm., Volkm.-Kohlm., Suetrong, Sakay. \& E.B.G. Jones, Stud. Mycol. 64: 166 (2009)

Caryosporaceae Huang Zhang, K.D. Hyde \& Ariyaw

9. Acrocordiopsis patilii Borse \& K.D. Hyde, Mycotaxon 34(2): 536 (1989)

Dictyosporiaceae Boonmee \& K.D. Hyde

10. Dictyosporium marinum Dayarathne \& E.B.G. Jones, sp. nov.

Didymellaceae Gruyter, Aveskamp \& Verkley

11. Boeremia maritima Dayarathne \& E.B.G. Jones, sp. nov.

Neocamarosporiaceae Wanas., Wijayaw., Crous \& K.D. Hyde

12. Neocamarosporium artemisiae Dayarathne \& E.B.G. Jones, sp. nov.

13. Neocamarosporium maritimae Dayarathne \& E.B.G. Jones, sp. nov.

Nigrogranaceae Jaklitsch \& Voglmayr

14. Nigrograna samueliana Devadatha, V.V. Sarma \& E.B.G. Jones, sp. nov.

15. Nigrograna rhizophorae Dayarathne, E.B.G. Jones \& K.D. Hyde, sp. nov.

Periconiaceae Nann.

16. Periconia salina Dayarathne \& E.B.G. Jones, sp. nov.

Phaeoseptaceae S. Boonmee, Thambugala \& K.D. Hyde

17. Phaeoseptum carolshearerianum Devadatha, V.V. Sarma \& E.B.G. Jones, sp. nov.

18. Phaeoseptum manglicola Devadatha, V.V. Sarma \& E.B.G. Jones, sp. nov.

Phaeosphaeriaceae M.E. Barr

19. Amarenographium ammophilicola Dayarathne, E.B.G. Jones \& K.D. Hyde, sp. nov. 
Salsugineaceae K.D. Hyde \& Tibpromma

20. Salsuginea rhizophorae Dayarathne, E.B.G. Jones \& K.D. Hyde, sp. nov.

Testudinaceae Arx

21. Halotestudina Dayarathne \& K.D. Hyde gen nov.

22. Halotestudina muriformis Dayarathne \& K.D. Hyde, sp. nov.

23. Verruculina enalia (Kohlm.) Kohlm. \& Volkm.-Kohlm., Mycol. Res. 94(5): 689 (1990)

Dothideomycetes orders incertae sedis

Botryosphaeriales C.L. Schoch et al.

Botryosphaeriaceae Theiss. \& H. Syd.

24. Lasiodiplodia krabiensis Dayarathne, sp. nov.

Dyfrolomycetales K.L. Pang et al.

Pleurotremataceae Walt. Watson (= Dyfrolomycetaceae K.D. Hyde et al.)

25. Dyfrolomyces neothailandicus Dayarathne, Jones E.B.G. \& K.D. Hyde, sp. nov.

26. Dyfrolomyces thailandicus Dayar., E.B.G. Jones \& K.D. Hyde, in Hyde et al., Fungal Diversity: 78(1): 1-237 (2016

Patellariales D. Hawksw. \& O.E. Erikss.

Patellariaceae Corda

27. Patellaria apiculatae Dayarathne \& K.D. Hyde, sp. nov.

Stigmatodiscales Voglmayr \& Jaklitsch

Stigmatodiscaceae Voglmayr \& Jaklitsch

28. Asterodiscus mangrovei Dayarathne, E.B.G. Jones \& K.D. Hyde, sp. nov.

Tubeufiales Boonmee \& K.D. Hyde

Tubeufiaceae M.E. Barr

29. Kamalomyces mangrovei Dayarathne \& K.D. Hyde, in Hyde et al., Fungal Diversity: 96:1-242 (2019)

Class Sordariomycetes O.E. Erikss. \& Winka

Subclass Diaporthomycetidae Senan. et al.

Diaporthales Nannf.

Diaporthaceae Höhn. ex Wehm.

30. Diaporthe salinicola Dayarathne, sp. nov.

31. Diaporthe krabiensis Dayarathne, sp. nov.

32. Diaporthe marina Dayarathne, sp. nov.

Subclass Hypocreomycetidae O.E. Erikss. \& Winka

Hypocreales Lindau

Nectriaceae Tul. \& C. Tul.

33. Chaetopsina aurantisalinicola Dayarathne, E.B.G. Jones \& K.D. Hyde, sp. nov.

34. Xenoacremonium brunneosporum Dayarathne, E.B.G. Jones \& K.D. Hyde, sp. nov.

35. Fusicolla gigantispora Dayarathne, E.B.G Jones \& K.D. Hyde, sp. nov.

36. Nectria marina Dayarathne, E.B.G Jones \& K.D. Hyde, sp. nov.

37. Neocosmospora rhizophorae Dayarathne, sp. nov. 
Ophiocordycipitaceae G.H. Sung et al.

38. Purpureocillium lilacinum (Thom) Luangsa-ard, Houbraken, Hywel-Jones \& Samson, FEMS Microbiol. Lett. 321(2): 144 (2011)

Subclass Sordariomycetidae O.E. Erikss \& Winka

Boliniales P.F. Cannon

Boliniaceae Rick

39. Camarops ustulinoides (Henn.) Nannf., Svensk bot. Tidskr. 66(4): 370 (1972)

Chaetosphaeriales Huhndorf et al.

Chaetosphaeriaceae Réblová et al.

40. Chloridium salinicola Dayarathne \& E.B.G. Jones, sp. nov.

41. Rimaconus multiguttulatus Dayarathne \& K.D. Hyde, sp. nov.

Coniochaetales Huhndorf et al. (= Cordanales M. Hern.- Rest. \& Crous)

Coniochaetaceae Malloch \& Cain

42. Coniochaeta arenariae Dayarathne \& E.B.G Jones, sp. nov.

43. Coniochaeta krabiensis Dayarathne \& E.B.G Jones, sp. nov.

Subclass Xylariomycetidae O.E. Erikss \& Winka

Xylariales Nannf.

Diatrypaceae Nitschke

44. Diatrype mangrovei Dayarathne \& K.D. Hyde, Cryptog. Mycol. (2019)

45. Halocryptosphaeria Dayarathne, Devadatha, Sarma, V.V. \& K.D. Hyde, gen nov.

46. Halocryptosphaeria bathurstensis (Dayarathne \& K.D. Hyde) Dayarathne, V.V. Sarma, Devadatha \& K.D. Hyde, comb. nov.

47. Halocryptovalsa avicenniae (Abdel-Wahab, Bahkali \& E.B.G. Jones) Dayarathne \& K.D. Hyde, Cryptog. Mycol. (2019)

48. Halodiatrype salinicola Dayarathne \& K.D. Hyde, Mycosphere 7(5): 617 (2016)

49. Peroneutypa scoparia (Schwein.) Carmarán \& A.I. Romero, in Carmarán, Romero \& Giussani, Fungal Diversity 23: 84 (2006)

50. Peroneutypa indica Devadatha V.V. Sarma \& E.B.G Jones, sp. nov.

51. Peroneutypa polysporae Devadatha, V.V. Sarma \& E.B.G Jones, sp. nov.

Hypoxylaceae DC.

52. Hypoxylon aurantium Dayarathne, E.B.G. Jones \& K.D. Hyde, sp. nov.

53. Hypoxylon mangrovei Dayarathne, E.B.G. Jones \& K.D. Hyde, sp. nov.

Xylariaceae Tul. \& C. Tul. (= Clypeosphaeriaceae G. Winter)

54. Halorosellinia rhizophorae Dayarathne, E.B.G. Jones \& K.D. Hyde

55. Halorosellinia krabiensis Dayarathne, \& K.D. Hyde, sp. nov.

56. Halorosellinia xylocarpi Dayarathne \& K.D. Hyde, sp. nov.

57. Nemania maritima Y.M. Ju \& J.D. Rogers, Nova Hedwigia 74(1-2): 102 (2002)

58. Nemania viridis Dayarathne, E.B.G. Jones \& K.D. Hyde, sp. nov.

59. Nemania phetchaburiensis Dayarathne, E.B.G. Jones \& K.D. Hyde, sp. nov.

\section{Introduction}

Mangrove forests are considered "biodiversity hotspots" for fungi (Shearer et al. 2007). The first fungus from a marine mangrove habitat was described in the middle of the nineteenth century by Durieu \& Montagne (1846-1850). However, no further reports of mangrove fungi were published until 1955 when Cribb and Cribb collected fungi on mangrove bark, roots and wood from 
Australia (Cribb \& Cribb 1955). Extensive investigations on mangrove fungi have been carried out in the Caribbean and Pacific Islands (Kohlmeyer 1984, Kohlmeyer \& Kohlmeyer 1993, Jones \& Abdel-Wahab 2005) and in South East Asia (Sarma \& Hyde 2001). When compared to other parts of the world, currently most mangrove associated fungi are described from South East Asia (Schmit \& Shearer 2003). Marine fungi in Asia have been relatively well investigated in Brunei, India, Malaysia, Taiwan, Seychelles \& Thailand (Hyde and Jones 1988, Hyde 1993a, 1988, Maria \& Sridhar 2003, Prasannarai \& Sridhar 2003, Sakayaroj et al. 2004, Alias et al. 2010, Pang et al. 2016).

Jones et al. (2019) listed accepted names and classification of marine fungi, which included 1257 marine species that belonged in 539 genera, majority of which are Ascomycota. To date 943 marine ascomycetes species are known and distributed over 353 genera (Abdel-Wahab et al. 2010, Jones et al. 2009, Pang et al. 2010, Abdel-Wahab \& Nagahama 2011, Jones et al. 2015, Dayarathne et al. 2016, www. marinefungi.org). The marine Ascomycota are found in eight classes, Dothideomycetes, Eurotiomycetes, Laboulbeniomycetes, Lecanoromycetes, Leotiomycetes, Lichinomycetes, Arthoniomycetes and Sordariomycetes, of which the Dothideomycetes and the Sordariomycetes are the two largest groups (Jones \& Pang 2012, www. marinefungi.org). This study will focus on the latter two subclasses. They are well-adapted for growth in marine habitats, mostly by bearing spores with appendages which facilitate buoyancy in water and their entrapment and adherence to substrates (Jones 1995). Sordariomycetes are characterized predominantly by perithecial ascomata and inoperculate unitunicate asci, often deliquescing at maturity (Jones et al. 2015, Maharachchikumbura et al. 2015, 2016). Marine Sordariomycetes have been classified into several orders based on their morphology and phylogeny including Coronophorales, Chaetosphaeriales, Diaporthales, Hypocreales, Koralionastetales, Lulworthiales, Magnaporthales, Microascales, Ophiostomatales, Phyllachorales, Savoryellales, Sordariales, Tirisporellales, Torpedosporales, and Xylariales (Jones et al. 2015, Maharachchikumbura et al. 2016). Among them, the orders Lulworthiales and Koralionastetales comprise exclusively marine taxa. The majority of marine Dothideomycetes are intertidal, primarily from mangrove habitats and rely on the active discharge of their ascospores (Suetrong et al. 2009). According to the review by Suetrong et al. (2009) marine Dothideomycetes have representatives in the orders Capnodiales, Hysteriales, Jahnulales, Mytilinidiales, Patellariales and Pleosporales.

Marine fungi have been identified from different marine substrata such as wood and leaves of mangrove plants, algae (seaweeds), driftwood, saltmarsh plants (Spartina), dead coral and sand grains on beaches (Sutherland 1915a, 1916, Barghoorn \& Linder 1944, Jones \& Moss 1978, Kohlmeyer 1984, Kohlmeyer \& Kohlmeyer 1993, Hyde et al. 1990, Jones 1995, Chatmala et al. 2004, Jones et al. 2006, 2015, Dayarathne et al. 2016), as well as extreme marine environments, such as hydrothermal vents, deep-sea trenches, cold methane seeps, the deep-sea subsurfaces and hypersaline, anoxic and suboxic waters (Raghukumar \& Ravindram 2012, Xu et al. 2018). Marine fungi exhibit a distinct geographical distribution, generally being referred to as tropical/subtropical and temperate, while others are known to be cosmopolitan in their distribution e.g. Aniptodera cheasapeakensis, Ceriosporopsis halima, Corollospora maritima, Lignincola laevis, Savoryella lignicola, Torpedospora radiata and Lulwoana uniseptata (= as the asexual Zalerion maritima) (Hughes 1974) or cold water species (Pugh \& Jones 1986). Schmit \& Shearer (2004) investigated mangrove fungal diversity and concluded there were fewer mangrove taxa within a single ocean basin than between different ocean basins; although many mangrove-associated species have wide longitudinal distributions (Alias \& Jones 2009, Pang et al. 2010). Any piece of wood, which is submerged for a certain period in marine or estuarine waters, can be colonized by marine fungi (Hyde et al. 2000a). A number of biological, chemical and physical factors can influence the diversity of marine fungi, including the availability of substrata for colonization, nature of the substratum, interference competition, water temperature, $\mathrm{pH}$ and salinity (Jones 2000). However, water temperature is regarded as the most significant physical factor effecting the occurrence of marine fungi at different geographical locations (Booth \& Kenkel 1986, Hughes 1986). Booth \& Kenkel (1986) also classified marine fungi into six groups based on temperature and salinity of 
habitats, such as warm water homeothermic euryhaline, warm water euryhalothermic, cool water eurythermic homohaline, cool water euryhalothermic, cool water homeothermic euryhaline and eurytolerant species.

\section{Taxonomic history of marine ascomycetes}

The first record of a marine fungus appears to date back to 1846, when Durieu de Monzonneuvo and Montagne described the ascomycete Sphaeria posidoniae (=Halotthia posidonniae) from the seagrass Posidonia oceanica (Montagne 1856). Subsequent reports on marine fungi was by the Crouan brothers (Kohlmeyer 1974), who described five marine fungi as early as 1867, and Sutherland (1915a, b, c, 1916) who published a series of papers dealing exclusively with marine fungi on marine algae. Marine mycology research was stimulated by the studies of Barghoorn \& Linder (1944), wherein they described 25 species of lignicolous marine fungi. This motivated mycologists all over the world to undertake research on marine fungi. Hence $90 \%$ of all recognized marine fungi have been described in the following five decades. The majority of literature on the higher marine fungi were initial contributions from Wilson (Great Britain), Höhnk (Germany), Meyers (USA), Cribb and Herbert (Australia), Johnson (USA), Feldmann (France), Kohlmeyer (Germany and later USA) and Jones (United Kingdom). Later, many researchers contributed to the study of marine fungi including their taxonomy, phylogeny, ontogeny, physiology, vertical and geographical distribution and ecological groups (Jones \& Pang 2012). The first classification of marine fungi by Johnson \& Sparrow (1961) and was amended by Kohlmeyer \& Kohlmeyer (1979). Jones (1976) published the edited volume entitled "Recent advances in aquatic mycology" and Kohlmeyer published a key to marine species in 1971. Spatafora \& Blackwell (1994) published the first sequence of a marine Sordariomycetes (Halosphaeriopsis mediosetigera). Jones et al. (2009) published the first formal classification of higher orders of marine fungi supported by phylogenetic data. Subsequentially, there has been a dramatic increase in molecular phylogenetic data available for this group. For instance, reports by Sakayaroj et al. (2011) and Pang (2012) on Halosphaeriaceae, a family extensively studied with 75 $\%$ of species with sequence data; and major reviews of the marine Dothideomycetes by Suetrong et al. (2009) and Hyde et al. (2013). Other major studies, both on the morphology and phylogeny of marine fungi include those of Jones \& Pang (2012), Boonyuen et al. (2011), Jones (2011), Raghukumar \& Ravindram (2012), Singh et al. (2012), Orsi et al. (2013), Jones et al. (2014), Lepelletier et al. (2014), Manohar et al. (2014), Rämä et al. (2014) and Richards et al. (2015). These studies yielded sequences of marine fungi that were used in major revisions of the classification of Dothideomycetes and Sordariomycetes (Hyde et al. 2013, Wijayawardene et al. 2014, Ariyawansa et al. 2015a, Maharachchikumbura et al. 2015, 2016, Senanayake et al. 2015). These studies have highlighted many new lineages of marine fungi (Jones et al. 2015).

\section{Studies on marine ascomycetes in Thailand}

This study focuses on the marine based taxa from India, Sweden Thailand and UK, especially the taxonomic history of marine ascomycetes. A number of studies have been carried out on collections of marine fungi made in Thailand, starting with Kohlmeyer (1984), Koch (1986), Hyde (1988, 1989a, b, 1992, 1995), Hyde et al. (1990), Chalermpongse (1991), Hyde \& Jones (1992), Sundari et al. (1996) and Ito et al. (2001). Jones et al. (2006) introduced two novel species from mangroves in Thailand. Sakayaroj et al. (2010) reported on the diversity of marine fungi on the sea grass Enhalus acoroides from Thailand which includes Ascomycota (98\%): Sordariomycetes (36\%), Eurotiomycetes (33\%) and Dothideomycetes (24\%). Sakayaroj et al. (2011) also carried out a survey at Hat Khanom-Mu Ko Thale Tai National Park and listed 112 marine fungi representing 79 ascomycetes and 30 asexual morphs. Dayarathne et al. (2016) introduced a novel marine genus, Halodiatrype with two novel species from southern Thailand. The numbers of marine ascomycete species recorded from Thailand totals 154 (Jones et al. 2006), 125 (Suetrong et al. 2009, unpublished data), 152 (Dethoup \& Manoch 2009), and 112 species (Sakayaroj et al. 2011), indicating a high species richness. Hence, it is worthy to conduct further investigations on Thai 
marine ascomycetes for the identification of novel taxa, re-collecting of existing species to provide molecular data and to designate new types where necessary.

\section{Morphological diversity of marine ascomycetes}

\section{Ascoma}

Traditional ascomatal characters used in the classification of marine fungi include colour, shape, texture, neck length and size (Pang 2012). Ascomata may be cleistothecial, perithecial, apothecial or hysterothecial (Koch \& Jones 1989, Jones et al. 2015, Dayarathne et al. 2018). Perithecial ascomata can be immersed, becoming erumpent or superficial. The most prominent ascomatal type is immersed perithecia (e.g. Bathyascus, Halobyssothecium, Rhizophila) (Hyde \& Mouzouras 1988, Hyde \& Jones 1989a, Dayarathne et al. 2018). Superficial perithecia are found in Corollospora species (Kohlmeyer 1986). In members of the Halosphaeriaceae, ascomata can be immersed or superficial (e.g. Remispora, Thalassogena). In addition, ascomata can be short to long necked or with an indistinct neck region (Suetrong et al. 2009, Jones et al. 2015, Dayarathne et al. 2019a, b). Orientation of ascomata varies among different species, such as vertical (in Coronopapilla), or horizontal (in Savoryella species and Lautospora gigantea). Ascoma shape and colour are mostly consistent in most families (Koch \& Jones 1989, Jones et al. 2015). The presence of a pseudostroma or clypeus may also aid in identifying marine ascomycetes (Hyde et al. 2000a). Fig. 1 illustrates the different morphologies of ascomata of marine fungal species.

\section{Asci}

Ascus morphology is particularly interesting and an important criterion for the discrimination of genera. Unitunicate asci can be different from each other in a number of ways including their apical structures. For example, the ascus apex may be thickened, or thickened with a refractive pore or plate (Fig. 2). In some genera (e.g. Buergenerula, Linocarpon) the ascus is composed of a subapical ring-like structure. They usually exist as two oval refractive bodies and a subapical apical apparatus in Marinosphaera (Hyde 1989). An ocular chamber or ocular chamber and a ring can be seen in bitunicate ascomycetes. The shape of the ascus may also be important, saccate, clavate or cylindrical asci are found among various marine taxa (Hyde et al. 2000a). The number of ascospores per ascus varies from 2-multi spores, two-spored asci (Savoryella paucispora), 4-spored (Passeriniella savoryellopsis), 6-spored asci (Phycomelaina), 8-spored (most marine ascomycetes), 16 spored asci (Sedecimiella taiwanensis) and polysporous (Cryptovalsa) (Hyde 1993b).

\section{Ascospores}

The ascospores of marine taxa are remarkable in their morphologies and hence, important in defining the boundaries at the generic and species level. Ascospore colour (mostly hyaline, brown, greenish and yellow), shape and the septation are all useful taxonomic characters at the species level. In most genera ascospores are unevenly thickened, while Lautospora has muriform spores with very thick walls (Hyde \& Jones 1989b). Diverse ascospore appendages and sheaths are fascinating characters of marine ascomycetes that are important in adhesion, dispersal and in colonizing marine substrata (Jones 1973, Kohlmeyer \& Kohlmeyer 1979, Rees 1982, Hyde \& Jones 1989b, Dayarathne et al. 2019a, b). The morphological characters mostly found among the marine ascomycete taxa include asci which are mostly deliquescing and mostly hyaline ascospores with appendages or sheaths (Jones \& Moss 1978) (Fig. 3).

\section{Asexual morphs}

Saccardo (1880) described the first asexual morph of a marine fungus, Camarosporium roumeguerii on the salt marsh plant Salicornia herbacea. Both hyphomycetes and coelomycetes have been reported from various marine habitats (Chatmala et al. 2004, Jones et al. 2009, 2015). Fifty species of native asexual marine fungi were recorded by Kohlmeyer \& Kohlmeyer (1979). The number increased to 60 by Kohlmeyer \& Volkmann-Kohlmeyer (1991) and later to 94 by 
Jones et al. (2009). Abdel-Wahab \& Bahkali (2012) reported 143 marine asexual morphic taxa while, Kurtzman et al. (2011a, b) reported 72 sexual and 14 asexual marine yeasts (Taphrinomycotina, Saccharomycotina) and Jones et al. (2015) listed 43 asexual filamentous fungi in 26 genera. Conidial fungi constitute approximately one fourth of all described filamentous marine fungi (Cole \& Kendrick 1981). Jones et al. (2015) assigned asexual genera to their higher order position based on molecular studies. However, sequence data from conidial stages of fungi from marine habitats are lacking in GenBank and it is necessary to link asexual and sexual morphs.

\section{Ecological and economic significance of marine ascomycetes}

Marine ascomycetes are parasites, saprobes, endophytes or symbionts on a wide variety of substrates in oceans and estuaries (Hyde et al. 2000b, Chatmala et al. 2004). Hosts or substrates for marine fungi includes marine algae, submerged parts of tropical mangrove trees and temperate salt marsh halophytes, dead wood and other cellulosic substances, polyurethane panels (Jones \& Le Campion-Alsumard (1970) and even animal chitin and conchyolin (Cole \& Kendrick 1981, Hyde et al. 2000b, Chatmala et al 2004, Hyde et al 2015, Jones 2015, Li et al. 2016). They play an important role in decomposition and recycling nutrients of variety of substrates (Hyde et al. 2015, Jones et al. 2019). Saprobic marine ascomycetes are responsible for transformation of the polymeric compounds into dissolved or particulate organic matter utilizable by other consumers in the food web (Fell \& Master 1973, Newell 1976, Nakagiri et al. 1996, Hyde et al. 1998, 2015), such as amino acids lysine and methionine, various vitamins and sterols (an important precursor for the manufacture of cholesterols in marine animals (Phillips 1984, Velmurugen \& Lee 2012). Furthermore, some marine ascomycetes such as Lignincola laevis and Stagonospora spp. are important due to their ability to completely decolourize polymeric dyes by utilizing either glucose or cellulose as a primary carbon source (Pointing et al. 1998). Mangrove leaves are rich in lignocellulosic and cellulosic structural polymers, soluble organics, phenolics and tannins, making them highly resistant to degradation by many microbes. However, fungi such as Pestalotiopsis and Cladosporium, common primary saprotrophs, are often recovered from mangrove leaves (Raghukumar et al. 2004). The microbes also serve as food for some bottom dwelling organisms hence they are an essential trophic level in detritus marine food webs (Das et al. 2007). Cawthorn (2011) identified Fusarium spp. as a disease causal agent in American lobsters noting its opportunistic nature and propensity to invade through damaged or dead tissues. There has been a significant increase in the rate of discovery of natural products from marine and marine-derived fungi over the past decade with a total of over 1000 novel secondary metabolites (Rateb \& Ebel 2011, Jones et al. 2019). Marine fungi are an untapped source of novel chemical structures and compounds for drug discovery and nutraceutical research (Pang et al. 2015, Liao et al. 2019). The additional stress of salinity might induce structurally diverse compounds from marine derived fungi. However, chemical structures produced by fungi in vitro are possibly different, implying direct extraction from tissues of plants or seaweeds (Pang et al. 2015). Examples of secondary metabolites produced by mangrove fungi includes a 14-membered resorcylic acid lactone, the known metabolite of hypothemycin and novel aigialomycins, isolated from Aigialus parvus with antiplasmodial activity (Isaka et al. 2002) and cytotoxicity against human cell lines (Barluenga et al. 2006).

\section{Aim of the paper}

The taxonomic placement of numerous marine ascomycetes is still unclear and many of them have been tentatively placed in a higher rank until more sequence data are available to confirm their exact placement. Some $50 \%$ of described marine fungi have no sequence data and this seriously limits interpretation in taxonomic projects (Xu et al. 2018, Hassett et al. 2019 published on line). Furthermore, it has been estimated that the percentage of unexplored marine taxa is high (Jones 2011, Jones et al. 2019). Therefore, the objectives of this study are to evaluate the taxonomy and phylogeny of some marine fungal taxa with multiple loci sequence data (LSU, SSU, ITS rDNA and protein genes) and to introduce novel taxa along with comprehensive morpho molecular accounts. 

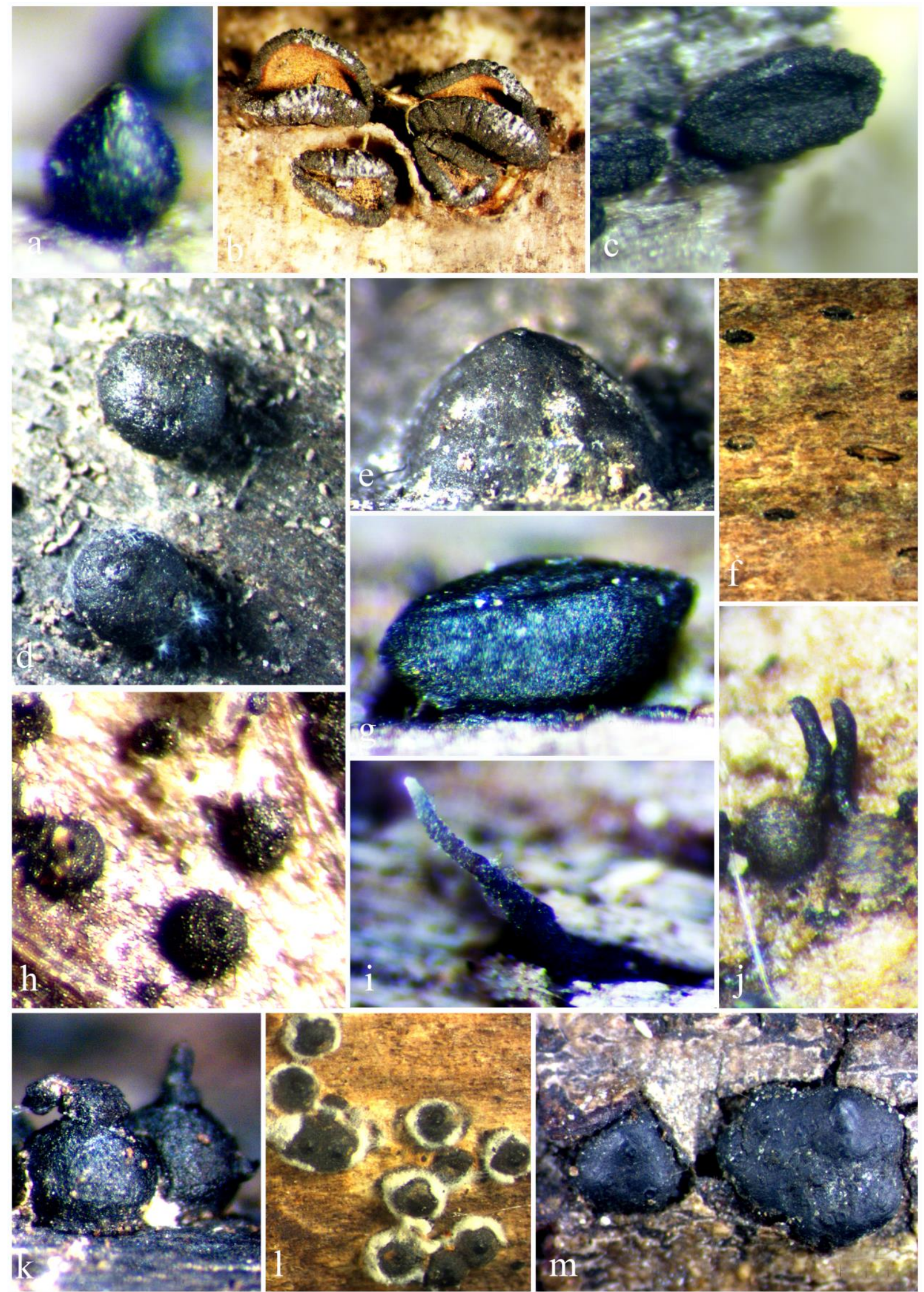

Figure 1 - Different morphological features of ascomata/stromata of marine based ascomycetes: a Chaetosphaeria mangrovei (MFLU 18-0146) - superficial, ovoid perithecia. b Rhytidhysteron bruguierae (MFLU 18-0571) - superficial, boat-shaped hysterothecia. c Patellaria apiculatae (MFLU 19-1236) - superficial, circular apothecia. d Nemania viridis (MFLU 17-2600) - 
superficial, sub-globose ascomata occur on black stroma. e Acrocordiopsis patilii (MFLU 18-0533) - semi immersed, hemisphaerical ascomata. f Halodiatrype avicenniae (MFLU 16-1185) - deeply immersed, globose to subglobose ascomata in a darkened pseudostroma. g Hysterium thailandicum (MFLU 18-0551) - superficial, elongate and depressed hysterothecia. h Coniochaeta marina (MFLU 17-2653) - semi-immersed to superficial, globose to ovoid perithecia with setae. i Halosphaeria sp. (MFLU 16-1223) - semi-immersed ascomata with a long neck. j Jattaea mucronata (MFLU 16-0534) - superficial, ascomata with a long neck. k Caryosporella rhizophorae (MFLU 18-0536) - superficial, ascomata with a medium neck. 1 Nemania maritima (MFLU 16-1236) - immersed to half-erumpent stromata, coated with or surrounded by a waxy whitish tissue. m Diatrype mangrovei (MFLU 17-0412) - erumpent stromata arising through cracks on the bark.

\section{Material \& Methods}

\section{Fungal sampling and morphology}

Fresh materials were collected from various marine habitats in Krabi, Phang-nga, Phetchaburi, Phuket and Ranong Provinces, in southern Thailand, Sweden and the UK. Specimens collected from Muthupet, Parangipettai and Pondicherry mangroves in India were examined and characterized as detailed in Devadatha et al. (2017). Specimens were brought to the laboratory in Zip-lock plastic bags and incubated at room temperature in the laboratory. Fungal specimens were examined with a Motic SMZ 168 stereomicroscope. Rehydrated fruiting bodies were used to observe characteristics of ascomata, asci, ascospores and other tissues and characters were photographed with a Canon 550D digital camera fitted to the Nikon ECLIPSE 80i compound microscope. Photomicrographs were arranged with Adobe Photoshop v. CS6 and all measurements were made with Tarosoft v. 0.9.0.7. Specimens were preserved and deposited at the Mae Fah Luang University Herbarium (MFLU), BIOTEC Bangkok Herbarium (BBH), Thailand and Ajrekar Mycological Herbarium (AMH), India.

Fruiting bodies were removed from the substrate using a sterilized needle and placed in a few drops of sterilized distilled water on a sterilized cavity slide and spore suspensions were prepared as described in Chomnunti et al. (2014). Germinating ascospores were aseptically transferred to Petri-dishes containing Potato Dextrose Agar (PDA) or Malt Extract Agar (MEA) media prepared in $50 \%$ or $100 \%$ concentrations of sterilized natural seawater (Atla 2006). Colonies were photographed and characters were recorded after two weeks. Living cultures were deposited at Mae Fah Luang University Culture Collection (MFLUCC) and Thailand, National Fungal Culture Collection of India (NFCCI), India. New species were established using modern criteria and standards (Taylor 2011, Seifert \& Rossman 2010, Jeewon \& Hyde 2016). Faces of fungi and Index Fungorum numbers were registered according to Jayasiri et al. (2015) and Index Fungorum (2019).

\section{DNA extraction, PCR amplification and phylogeny}

Fresh fungal mycelia grown on MEA/PDA or seawater PDA/MEA for 4 weeks at $18-25{ }^{\circ} \mathrm{C}$ were scraped from the colony margin and sometimes perithecial contents of fresh specimens were used for genomic DNA extraction following the protocol outlined by Dayarathne et al. (2019c). DNA extraction kit (E.Z.N.A. ${ }^{\circledR}$ Forensic, DNA kit, D3591-01, Omega Bio-Tek) was used to extract DNA directly from ascomata following the manufacturer's instructions where necessary. PCR amplification and sequencing of the SSU nrDNA region using the primer pair NS1/NS4 (White et al. 1990). LSU nrDNA region using the primer pair LROR/LR5 (Vilgalys \& Hester 1990, Rehner \& Samuels 1994), ITS nrDNA region using primer pair ITS5/ITS4 (White et al. 1990) and TUB gene region using the primer pair $\mathrm{Bt} 2 \mathrm{a} / \mathrm{Bt} 2 \mathrm{~b}$ (Trouillas et al. 2011) were performed. Each amplification reaction contained $0.125 \mu \mathrm{L}$ of 5 units/ $\mu \mathrm{L}$ Ex-Taq DNA polymerase (TaKaRa), 2.5 $\mu \mathrm{L}$ of $10 \times$ PCR buffer, $2 \mu \mathrm{L}$ of $2 \mathrm{mM} \mathrm{MgCl}_{2}, 2.5 \mu \mathrm{L}$ of $2 \mathrm{mM}$ dNTPs, $1 \mu \mathrm{L}$ of $0.2-1.0 \mu \mathrm{M}$ primer, $<500 \mathrm{ng}$ DNA template and was adjusted with double-distilled water to a total volume of $25 \mu \mathrm{L}$. 
Amplification of SSU, LSU, ITS, RPB2, TEF and TUB were accomplished as described in the Table 1.
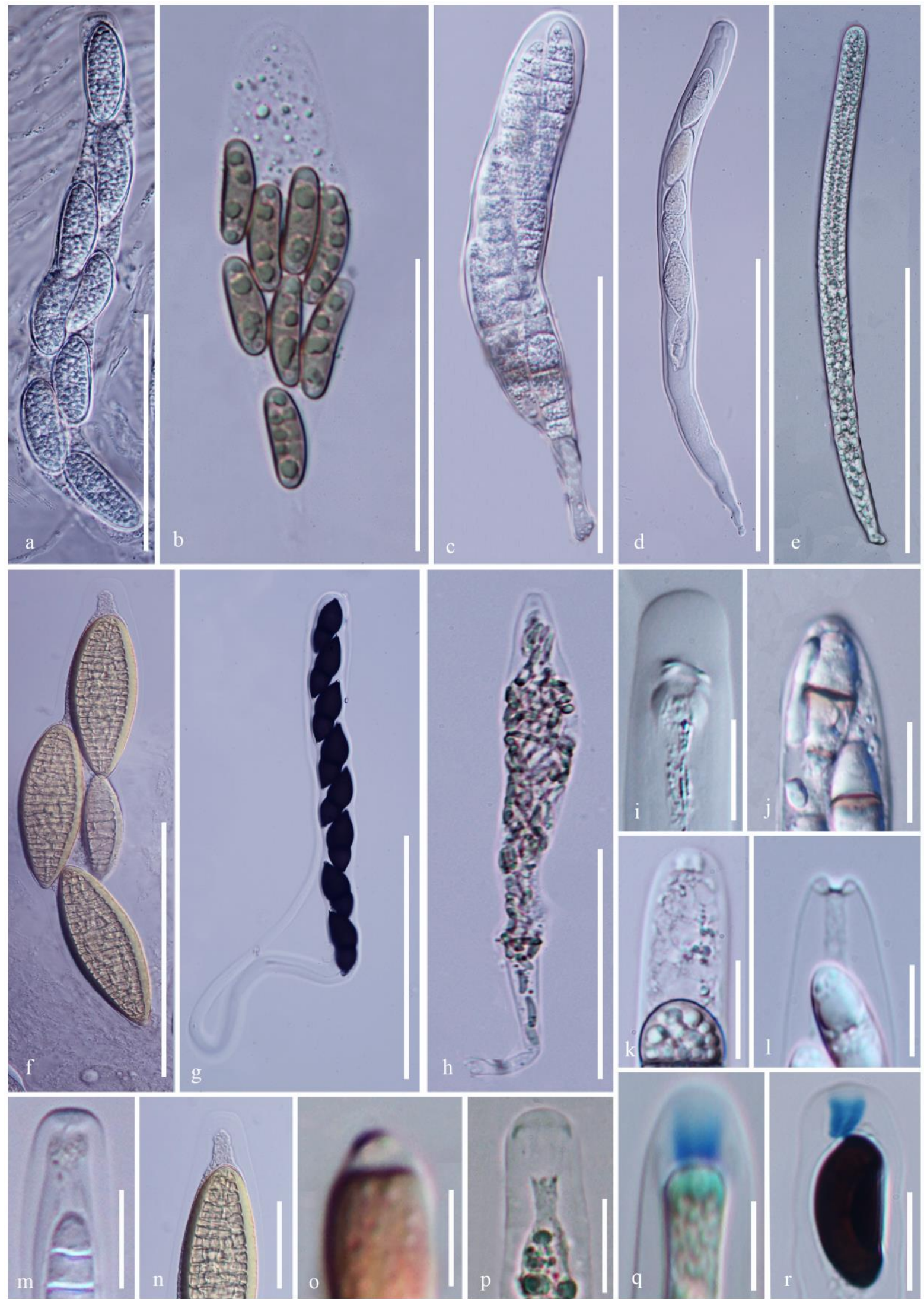

Figure 2 - Different morphological features of asci and apical structures of marine based ascomycetes: a Rimaconus multiguttulatus (MFLU 18-0535) - cylindrical, unitunicate asci. b 
Halodiatrype salinicola (MFLU 17-2595) - clavate, unitunicate asci. c Kamalomyces mangrovei (MFLU 18-0550) - clavate bitunicate asci. d Ascocratera manglicola (MFLU 17-2588) cylindrical bitunicate asci. e Poaceascoma halophila (MFLU 16-1178) - cylindrical to cylindricclavate asci. f Lautospora simillima (J.K. 5532) - 4-spored, short pedicellate asci. g Salsuginea rhizophorae (MFLU 18-0540) - 8-spored, long pedicellate asci. h Halocryptovalsa salicorniae (MFLU 16-0551) - multi-spored, long pedicellate asci. i. Halosphaeria sp. (MFLU 16-1223) lacking an apical apparatus. j Savoryella lignicola (IMI 129784) - truncate apical thickening with a pore. k. Diaporthe marina (MFLU 17-2622) - refractive apical ring. 1 Aniptodera chesapeakensis (MFLU 16-1189) - apically truncate, thin-walled, persistent apical ring with pore. $\mathrm{m}$ Dyfrolomyces thailandicus (MFLU 16-1173) - apically rounded, thickened obvious apical ring. n Lautospora simillima (J.K. 5532) - ocular chamber. o Phaeoacremonium aureum (MFLU 17-1581) - broadly rounded to obtuse, thickened apex. p, q Nemania maritima (MFLU 16-1236) - narrowly cuneiform, $\mathrm{J}+$, sub-apical ring. $\mathrm{r}$ Halorosellinia rhizophorae (MFLU 17-2591) - rectangular, J+, apical apparatus.

All PCR products were visualized by electrophoresis at $120 \mathrm{~V} / \mathrm{cm}$ for $20 \mathrm{~min}$ in $1 \%$ agarose gel stained with ethidium bromide $) 0.5 \mathrm{mg} / \mathrm{mL}$ (. The gel was visualized under a UV transilluminator to estimate the fragment size. PCR products were purified and sequenced with both forward and reverese primers at the Sunbiotech Company, Beijing, China.

\section{Phylogenetic analyses}

Sequences generated from above mentioned primers of the different genes (LSU, SSU, ITS, BTUB, TEF and RPB2) were analyzed with other sequences retrieved from GenBank. Sequences with high similarity indices were determined from a BLAST search to find the closest matches with taxa in relevant families and relying on previous literature. Datasets were initially aligned by using MAFFT version 7 (Katoh \& Standley 2013, http://mafft.cbrc.jp/alignment/server/) and manually corrected where necessary using BioEdit sequence alignment editor (Hall 1999) to minimize the uninformative gaps. Gaps were treated as missing data. Nucleotide substitution models were determined with MrModeltest v. 2.2 (Nylander 2004). The GTR+I+G model was used in each analysis for phylogenetic studies.

Phylogenetic trees were generated using maximum likelihood (ML) and Bayesian inference analyses (BI). The ML trees were generated using the RAxML-HPC2 on XSEDE (v. 8.2.8) (Stamatakis et al. 2008, Stamatakis 2014) in the CIPRES Science Gateway platform (Miller et al. 2010) using the GTR $+\mathrm{I}+\mathrm{G}$ model of evolution. The Bayesian trees for various data sets were generated using MCMC sampling in MrBayes v3.1.2 (Huelsenbeck \& Ronquist 2001, Zhaxybayeva \& Gogarten 2002). Ambiguously aligned regions were excluded and all characters were unordered and given equal weight. The Kishino-Hasegawa tests (Kishino \& Hasegawa 1989) were performed to determine whether the trees inferred under different optimality criteria were significantly different. The resulting trees were viewed with FigTree v.1.4.0 (Rambaut 2012) and the final layout was done with was done with Microsoft power point (2016).

\section{Taxonomy}

\section{Ascomycota R.H. Whittaker}

We use the recent treatments and updated accounts of Ascomycota in Wijayawardene et al. (2017a, 2018).

\section{Class Dothideomycetes sensu O.E. Erikss \& Winka}

Dothideomycetes is considered to be largest and most phylogenetically diverse class in the phylum Ascomycota (Schoch et al. 2009, Hyde et al. 2013). Liu et al. (2017) provided divergence time estimates for the different taxonomic ranks of the class Dothideomycetes with multi-locus phylogeny. Our classification of different Dothideomycete taxa are based on Hyde et al. (2013), 
Wijayawardene et al. (2014) and Liu et al. (2017). Dothideomycete subclasses and their families documened in this study are arrenged alphabetically.
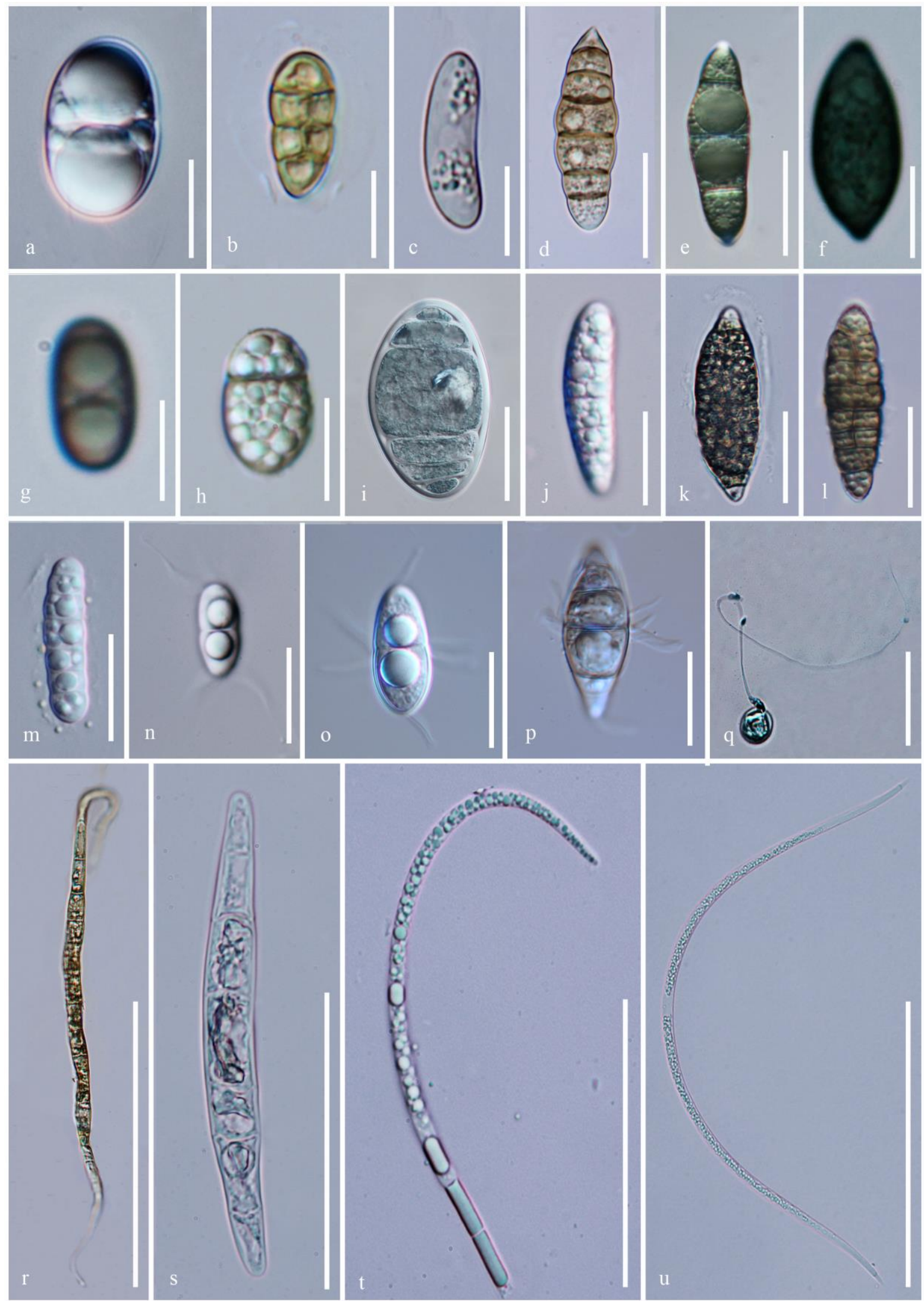

Figure 3 - Different morphological features of ascospores of marine based ascomycetes: a Acrocordiopsis patilii (MFLU 18-0533) - broadly ellipsoidal, hyaline, 1-euseptate ascospore. b 
Neocamarosporium maritimae (MFLU 19-1232) - ellipsoidal, muriform, yellowish brown ascospore. c Halodiatrype avicenniae (MFLU 16-1185) - oblong to allantoid light brown ascospore. d Amarenographium ammophilicola (MFLU 17-2571) - broadly fusiform, 6-septate, pale brown ascospore. e Trematosphaeria pertusa (MFLU 18-0526) -fusiform, 1-3-septate, dark brown ascospore. f Halorosellinia xylocarpi (MFLU 18-0545) - ellipsoidal, olive green ascospore. g Nemania maritima (MFLU 16-1236) - oblong, ellipsoidal, aseptate, brown ascospore. $\mathrm{h}$ Diaporthe marina (MFLU 17-2622) - ovoid, multi guttulate ascospore. i. Koralionasteta ovalis (NY 1317811) - ellipsoidal to oval ascospore with several cross septa. $\mathrm{j}$ Kamalomyces mangrovei (MFLU 18-0550) - elongate cylindrical to fusiform-clavate ascospore. k. Aigialus grandis (MFLU 16-1241) - muriform, ascospore with 16-18 transverse septa and 1-2 longitudinal septa. 1 Halotestudina muriformis (MFLU 17-2634) - muriform, with 7 transverse septa and 0-2 longitudinal septa. m Dyfrolomyces thailandicus (MFLU 16-1173) - ascospore surrounded by a sheath. n Haiyanga salina (MFLU 16-1191) - ascospore with 3-4 sub-polar spoon-shaped appendages. o Halosphaeria appendiculata (MFLU 17-2657) - ascospores with polar and/or lateral appendages. p Amphitrite annulata (UPS 10870) - ascospore with a ring-like collar encloses at the septum. q Moana turbinulata (NY 1347771) - ascospore with a single, uncoiling polar appendage. r Pedumispora rhizophorae (BRIP 19201) - filiform ascospores with a curved or hook-shaped end. s Pontogeneia padinae - filiform, curved, septate ascospore. t Poaceascoma halophila (MFLU 161178) - filiform septate ascospore with a wide base. u Sammeyersia grandispora (MFLU 16-1172) - long filamentous ascospore tapering at each end into an elongate apical chamber, filled with mucus.

Subclass Pleosporomycetidae C.L. Schoch et al.

Hysteriales Lindau

The monotypic order Hysteriales was introduced by Lindau (1897) and has been accommodated within pyrenomycetes and discomycetes (Rehm 1896). Molecular analyses confirmed the placement of Hysteriales in Dothideomycetes (Boehm et al. 2009a, b, Shearer et al. 2009, Suetrong et al. 2009).

\section{Hysteriaceae Chevall}

Fungi classified in the family Hysteriaceae (Chevallier 1826) can be distingushed by thickwalled, hysterothecial ascomata which are navicular and characteristically dehiscing by an invaginated slit or sulcus (Zogg 1962, Clements 1909, Boehm et al. 2009a). Hysteriaceae currently comprises 14 genera, Actidiographium, Coniosporium, Gloniopsis, Gloniella, Graphyllium, Hysterium, Hysterocarina, Hysteropycnis, Hysterobrevium, Hysterodifractum, Oedohysterium, Ostreichnion, Psiloglonium and Rhytidhysteron based on morphology and/or phylogenetic data (Boehm et al. 2009a, b, Wijayawardene et al. 2018, Jayasiri et al. 2018).

\section{Hysterium Pers.}

The genus Hysterium, typified by $H$. pulicare produces darkly pigmented and carbonaceous hysterothecia (Schoch et al. 2009, Hyde et al. 2017). Recent phylogenetic analyses showed that the hysterothecium has been derived number of times and there is an accountable genetic diversity within this group (Boehm et al. 2009b, Jayasiri et al. 2018, 2019).

Hysterium rhizophorae Dayar. \& K.D. Hyde, in Hyde et al., Fungal Diversity 87: 42 (2017) Fig. 5 Facesoffungi number: FoF 02911

Saprobic on bark attached to the living plant of Avicennia sp. Sexual morph: Ascomata 1.52.0 long $\times 0.15-0.25 \mathrm{~mm}$ wide $\times 0.2-0.25$ high, hysterothecial, erumpent to superficial, with a immersed base, solitary to gregarious, straight to flexuous, ellipsoid or elongate, with pointed ends, opening by a depressed longitudinal slit, comprising orange cells, in vertical section subglobose to globose, carbonaceous, black. Peridium 38.5-52 $\mu \mathrm{m}$ wide, carbonaceous, comprising an outer layer of dark brown cells of textura angularis and inner layer of hyaline to pale brown cells of textura 
angularis. Hamathecium comprises $1.5-2 \mu \mathrm{m}$ wide pseudoparaphyses, cellular, septate, flexuous, branched. Asci $40.8-48.6 \times 3.5-5 \mu \mathrm{m}(\overline{\mathrm{x}}=45.2 \times$ $3.7 \mu \mathrm{m}, \mathrm{n}=15), 8$-spored, uni to bi seriate, cylindric to claviform, apex thickened, short pedicellate. Ascospores $14.5-16 \times 4-5.9 \mu \mathrm{m}(\overline{\mathrm{x}}=15.2 \times 5 \mu \mathrm{m}$, $\mathrm{n}=20$ ), overlapping biseriate, light brown, ellipsoidal, slightly curved, with 3 transverse septa, often slightly constricted at medium septum, with a guttule per cell, rounded at both ends. Asexual morph: Undetermined.

Table 1 Genes/loci used in the study with their PCR primers and protocols.

\begin{tabular}{|c|c|c|c|c|c|c|c|c|}
\hline \multirow[b]{2}{*}{ Gene/loci } & \multicolumn{2}{|l|}{ Primer } & \multicolumn{5}{|l|}{ PCR protocol } & \multirow[b]{2}{*}{ References } \\
\hline & Forward & Reverse & \begin{tabular}{|l|} 
Initial \\
Denaturation
\end{tabular} & Denaturation & Annealing & Extension & $\begin{array}{l}\text { Final } \\
\text { extension }\end{array}$ & \\
\hline \multirow{2}{*}{$\begin{array}{l}\text { Internal } \\
\text { transcribed } \\
\text { spacer (ITS) }\end{array}$} & \multirow{2}{*}{ ITS5 } & \multirow{2}{*}{ ITS4 } & \multirow{2}{*}{$\begin{array}{l}94^{\circ} \mathrm{C}, 4 \mathrm{~min} \\
1 \text { cycle }\end{array}$} & $94^{\circ} \mathrm{C}, 45 \mathrm{sec}$ & $56^{\circ} \mathrm{C}, 45 \mathrm{sec}$ & $72^{\circ} \mathrm{C}, 1 \mathrm{~min}$ & \multirow{2}{*}{$\begin{array}{l}72^{\circ} \mathrm{C}, 10 \mathrm{~min} \\
1 \text { cycle }\end{array}$} & \multirow{2}{*}{ White et al. (1990) } \\
\hline & & & & \multicolumn{3}{|l|}{35 cycles } & & \\
\hline \multirow{2}{*}{$\begin{array}{l}\text { Large subunit } \\
\text { (LSU) }\end{array}$} & \multirow{2}{*}{ LROR } & \multirow{2}{*}{ LR5 } & $94^{\circ} \mathrm{C}, 4 \min$ & $94^{\circ} \mathrm{C}, 45 \mathrm{sec}$ & $56^{\circ} \mathrm{C}, 45 \mathrm{sec}$ & $72^{\circ} \mathrm{C}, 1 \mathrm{~min}$ & \multirow{2}{*}{$\begin{array}{l}72^{\circ} \mathrm{C}, 10 \mathrm{~min} \\
1 \text { cycle }\end{array}$} & Rehner \& Samuels (1994) \\
\hline & & & 1 cycle & \multicolumn{3}{|l|}{35 cycles } & & Vilgalys \& Hester (1990) \\
\hline \multirow{2}{*}{$\begin{array}{l}\text { Small subunit } \\
\text { (SSU) }\end{array}$} & \multirow{2}{*}{ NS1 } & \multirow{2}{*}{ NS4 } & $94^{\circ} \mathrm{C}, 4 \min$ & $94^{\circ} \mathrm{C}, 45 \mathrm{sec}$ & $56^{\circ} \mathrm{C}, 45 \mathrm{sec}$ & $72^{\circ} \mathrm{C}, 1 \mathrm{~min}$ & \multirow{2}{*}{$\begin{array}{l}72^{\circ} \mathrm{C}, 10 \mathrm{~min} \\
1 \mathrm{cycle}\end{array}$} & \multirow{2}{*}{ White et al. (1990) } \\
\hline & & & 1 cycle & \multicolumn{3}{|l|}{35 cycles } & & \\
\hline \multirow{2}{*}{$\begin{array}{l}\text { Elongation } \\
\text { factor-1 alpha } \\
(\text { EF } 1-\alpha)\end{array}$} & \multirow{2}{*}{ EF1-728F } & \multirow{2}{*}{ EF1- 986R } & $94^{\circ} \mathrm{C}, 3 \mathrm{~min}$ & $94^{\circ} \mathrm{C}, 30 \mathrm{sec}$ & $55^{\circ} \mathrm{C}, 50 \mathrm{sec}$ & $72^{\circ} \mathrm{C}, 1 \mathrm{~min}$ & \multirow{2}{*}{$\begin{array}{l}72^{\circ} \mathrm{C}, 10 \mathrm{~min} \\
1 \text { cycle }\end{array}$} & \multirow{2}{*}{ Carbone \& Kohn (1999) } \\
\hline & & & 1 cycle & \multicolumn{3}{|l|}{35 cycles } & & \\
\hline \multirow{2}{*}{$\begin{array}{l}\text { RNA } \\
\text { polymerase II } \\
\text { second large } \\
\text { subunit (RBP2) }\end{array}$} & \multirow[b]{2}{*}{ fRPB2-5F } & \multirow[b]{2}{*}{ fRPB2-7cr } & $95^{\circ} \mathrm{C}, 5 \mathrm{~min}$ & $95^{\circ} \mathrm{C}, 45 \mathrm{sec}$ & $55^{\circ} \mathrm{C}, 2 \mathrm{~min}$ & $72^{\circ} \mathrm{C}, 1.5 \mathrm{~min}$ & \multirow{2}{*}{$\begin{array}{l}72^{\circ} \mathrm{C}, 10 \mathrm{~min} \\
1 \mathrm{cycle}\end{array}$} & \multirow[b]{2}{*}{ Liu et al. (1999) } \\
\hline & & & 1 cycle & \multicolumn{3}{|l|}{40 cycles } & & \\
\hline \multirow[b]{2}{*}{$\begin{array}{l}\text { Beta tubulin } \\
\text { (BTUB) }\end{array}$} & \multirow[b]{2}{*}{$\mathrm{Bt} 2 \mathrm{a}$} & \multirow[b]{2}{*}{$\mathrm{Bt} 2 \mathrm{~b}$} & $94^{\circ} \mathrm{C}, 3 \mathrm{~min}$ & $94^{\circ} \mathrm{C}, 30 \mathrm{sec}$ & $55^{\circ} \mathrm{C}, 50 \mathrm{sec}$ & $72^{\circ} \mathrm{C}, 1 \mathrm{~min}$ & \multirow{2}{*}{$\begin{array}{l}72^{\circ} \mathrm{C}, 10 \mathrm{~min} \\
1 \text { cycle }\end{array}$} & \\
\hline & & & 1 cycle & 35 cycles & & & & Glass \& Donaldson (1995) \\
\hline
\end{tabular}




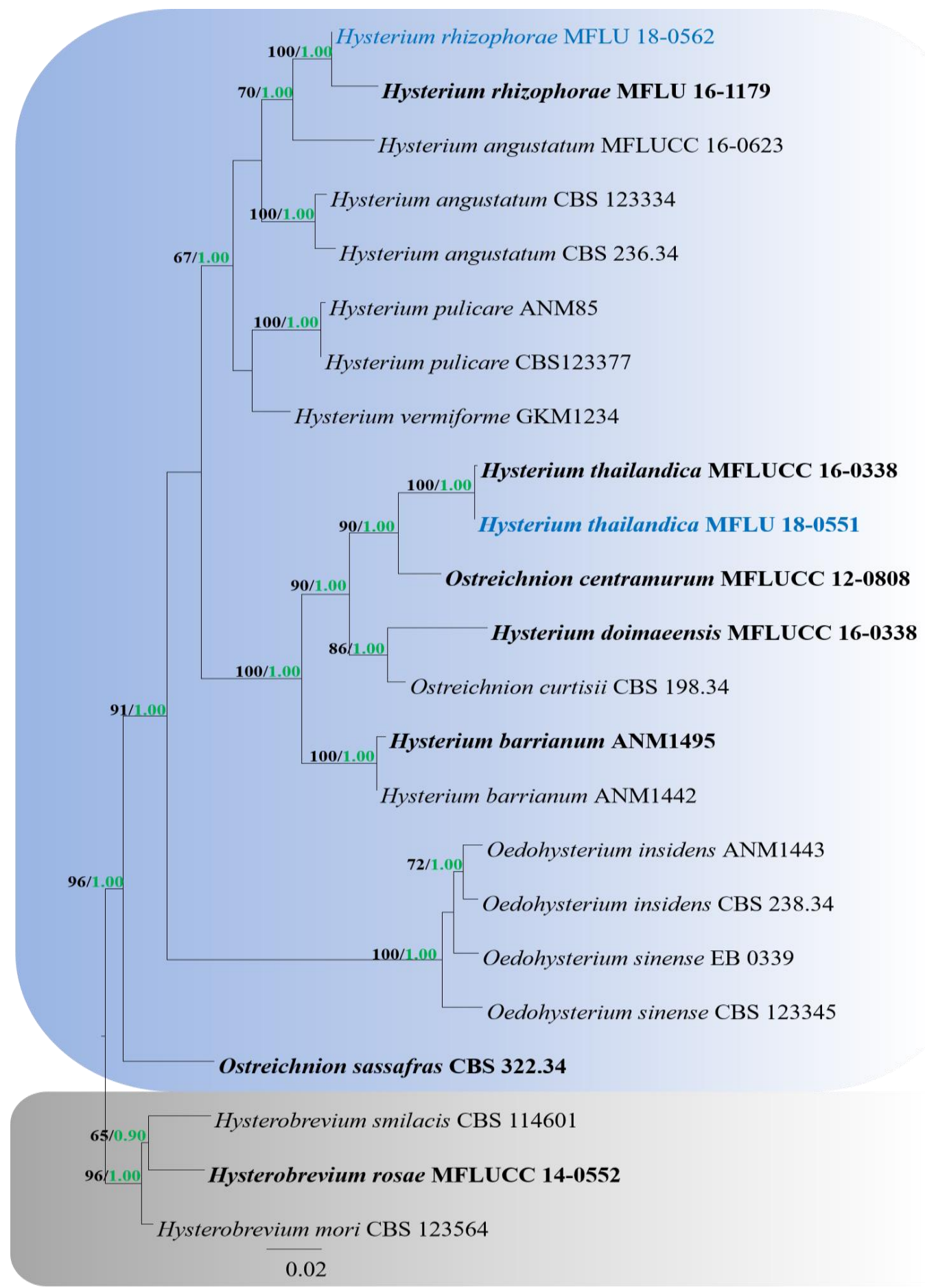

Figure 4 - Maximum likelihood analysis with 1000 bootstrap replicates yielded a best tree with the likelihood value of -12708.949995 . The combined LSU, SSU, TEF and RPB2 sequence datasets comprised 23 strains of Hysterium and related taxa with Hysterobrevium mori (CBS 123564), $H$. rosae (MFLUCC 14-0552) and H. smilacis (CBS 114601) as the outgroup taxa. Tree topology of the ML analysis was similar to the BI. The matrix had 939 distinct alignment patterns, with $36.13 \%$ of undetermined characters or gaps. Estimated base frequencies were as follows; $\mathrm{A}=0.250302, \mathrm{C}=$ $0.237232, \mathrm{G}=0.277079, \mathrm{~T}=0.235387$; substitution rates $\mathrm{AC}=1.506537, \mathrm{AG}=3.785145, \mathrm{AT}=$ 1.471121, $\mathrm{CG}=1.308838, \mathrm{CT}=10.960968, \mathrm{GT}=1.000000$; gamma distribution shape parameter $\alpha=0.148727$. Maximum likelihood bootstrap (ML, black) values $>65 \%$ and Bayesian posterior probabilities (PP, green) $>0.90 \%$ are given above the nodes. The scale bar indicates 0.02 changes. The ex-type strains are in bold and new isolates in blue bold. 


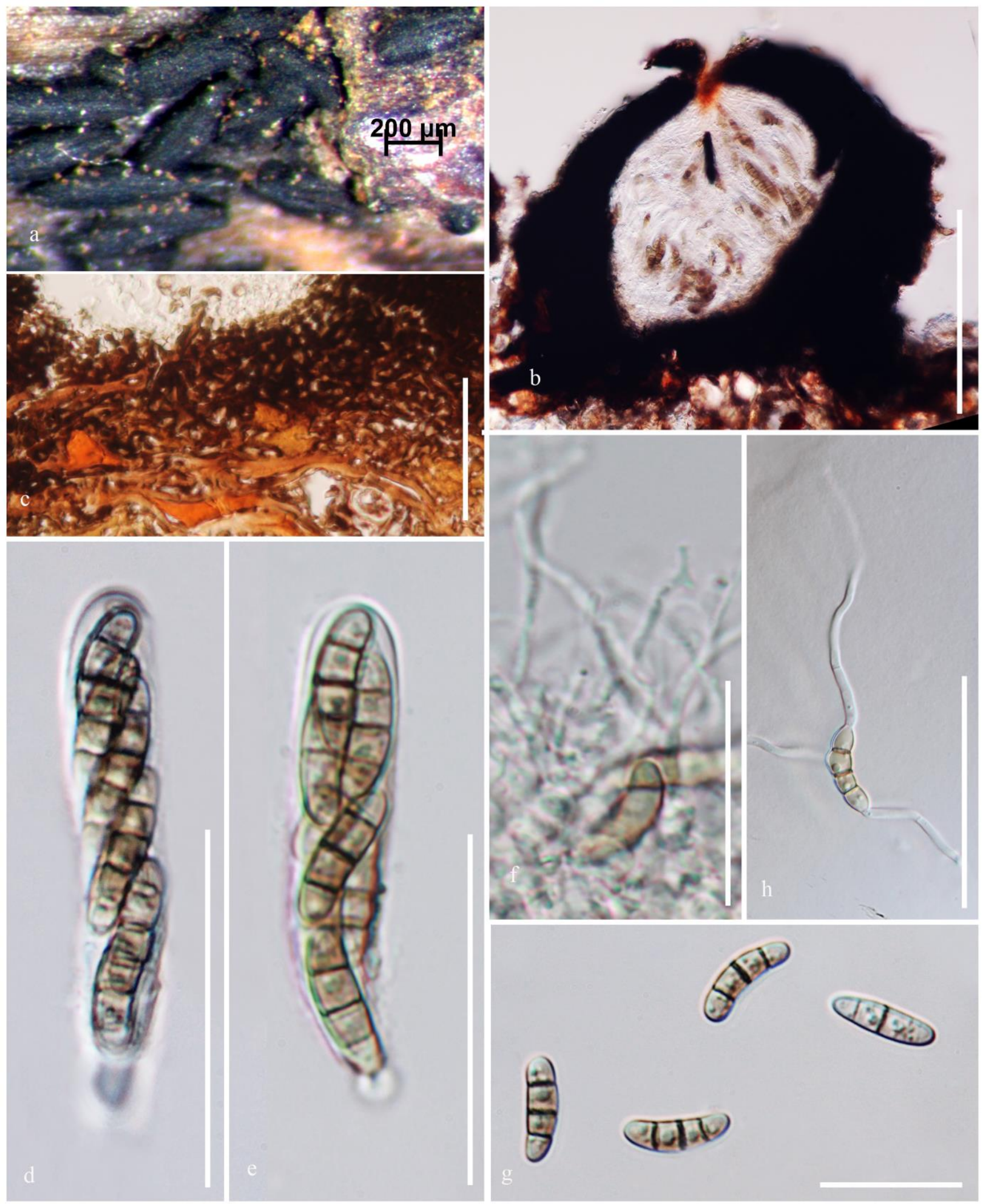

Figure 5 - Hysterium rhizophorae (MFLU 18-0562). a Appearance of hysterothecia on host. b Vertical section through hysterothecium. c Peridium. d, e Asci. f Pseudoparaphyses. g Ascospores. $\mathrm{h}$ Germinating ascospore. Scale bars: $\mathrm{a}=200 \mu \mathrm{m}, \mathrm{b}=100 \mu \mathrm{m}, \mathrm{d}, \mathrm{e}, \mathrm{h}=50 \mu \mathrm{m}, \mathrm{c}, \mathrm{f}, \mathrm{g}=20 \mu \mathrm{m}$.

Material examined - THAILAND, Phetchaburi Province, Cha-am beach, on bark attached to the living plant of Avicennia sp. (Rhizophoraceae), 30 November 2016, M.C. Dayarathne, MCD 090 (MFLU 18-0562, new host record). 
GenBank numbers - LSU: MN017831; SSU: MN017899; TEF: MN433213

Notes - Our second sample collection, from Phetchaburi province, Thailand also yielded $H$. rhizophorae which indicates it is a relatively abundant species in southern Thailand. Devadatha et al. (2018) also reported this species from Aegiceras corniculatum (Primulaceae), collected from Muthupet mangroves in India. This is the first record of this species from Avicennia sp.

Hysterium thailandicum Jayasiri \& K.D. Hyde, in Jayasiri, Hyde, Jones, Peršoh, Camporesi \& Kang, Mycosphere 9(4): 817 (2018

Fig. 6

Facesoffungi number: FoF04580

Saprobic on decaying, submerged mangrove wood. Sexual morph: Hysterothecia 430-500 $\mu \mathrm{m}$ high, 360-410 $\mu \mathrm{m}$ wide, $800-1100 \mu \mathrm{m}$ long $(\overline{\mathrm{x}}=490 \times 400 \times 1000 \mu \mathrm{m}, \mathrm{n}=5)$, scattered, superficial, with a immersed base, elongate and depressed conchate, surface black, shiny, longitudinally striate, apex compressed, opening by longitudinal slit. Peridium $40-82 \mu \mathrm{m}$ wide $(\overline{\mathrm{x}}=$ $60.6 \mu \mathrm{m}, \mathrm{n}=5$ ), comprising carbonaceous, brittle, heavily pigmented, small, prosenchymatous cells. Hamathecium 1-1.5 $\mu \mathrm{m}$ wide, persistent, trabeculate, hyaline, aseptate, branched, borne in a gel matrix, longer than asci. Asci $122-140 \times 24.5-38 \mu \mathrm{m}(\overline{\mathrm{x}}=125.2 \times 28 \mu \mathrm{m}, \mathrm{n}=20), 8$-spored, bitunicate, arising from base, oblong to clavate, with a short pedicel, apex thickened, with refractive ring around cytoplasmic protrusion. Ascospores $45-70.2 \times 8-13 \mu \mathrm{m}(\overline{\mathrm{x}}=59 \times 10.8 \mu \mathrm{m}, \mathrm{n}$ $=30$ ), crowded to biseriate, fusiform when young, oblong at maturity, hyaline to olivaceous brown, 1-septate, highly constricted at the septum, wall greatly thickened, wall smooth. Asexual morph: Conidiogenous cells 7-9 $\times 1.8-3.2 \mu \mathrm{m}$, enteroblastic, phialidic, globose to flask-shaped, hyaline, thin-walled. Conidia 2-4 × 2-3.9 $\mu \mathrm{m}$, fusiform to spherical, hyaline, with a central guttule.

Culture characteristics - Ascospores germinating on sea water PDA within $24 \mathrm{~h}$ and germ tubes produce from one or both ends. Colonies reaching on PDA $5 \mathrm{~cm}$ diam. After 1 week at $25^{\circ} \mathrm{C}$, flat, circular, initially white becoming greenish to reddish brown, smooth surface with undulate edge.

Material examined - THAILAND, Ranong Province, Ranong, on decaying, submerged mangrove wood (Rhizophoraceae), 07 December 2017, M.C. Dayarathne, MCD 70 (MFLU 180551).

GenBank numbers - LSU: MN017832; SSU: MN017900; TEF: MN077055; RPB2: MN077077

Notes - Hysterium thailandicum is morphologically reminiscent of ostreichnion-like Hysterium species. This is shown in our phylogram generated by combined LSU, SSU, TEF and RPB2 data where $H$. thailandica clustered together in a clade comprising ostreichnion-like Hysterium species (Fig. 4). Our new strain (MFLU 18-0551) morphologically resembles the holotype. However, a few morphological differences were observed among these two strains: asci of $\mathrm{H}$. thailandica (MFLU 18-0551) are longer than those of the holotype (800-1100 $\mu \mathrm{m} v \mathrm{~s}$ 500$600 \mu \mathrm{m}$ ) and $\mathrm{H}$. thailandica (MFLU 18-0551) has shorter asci than the holotype (122-140 $\mu \mathrm{m} v \mathrm{~s}$ $155-210 \mu \mathrm{m})$. Furthermore, ascospore colour at maturity is olivaceous brown in $H$. thailandica (MFLU 18-0551) and yellow in the holotype. Habitats of (MFLU 18-0551) and the holotype are also different where the habitat of our strain (MFLU 18-0551) is decaying, submerged mangrove wood and the holotype was found on dead stem of an unknown terrestrial plant. We also observed the asexual morph of this taxon in culture which morphologically resembles the asexual morphs reported for the genus Hysterium (Jayasiri et al. 2018, 2019).

\section{Rhytidhysteron Speg.}

Spegazzini (1881) introduced the genus Rhytidhysteron to accommodate $R$. brasiliense and $R$. viride without designating a type species, while Clements \& Shear (1931) designated $R$. brasiliense as the type species (Samuels \& Müller 1979, Yacharoen et al. 2015). Subsequently, various authors broadened the concept of the genus by adding several species (Spegazzini 1921, Sharma \& Rawla 1986, Barr 1990a, Magnes 1997, Doilom et al. 2016, Thambugala et al. 2016, Hyde et al. 2017) and currently Rhytidhysteron comprises 21 epithets (Kumar et al. 2019). 

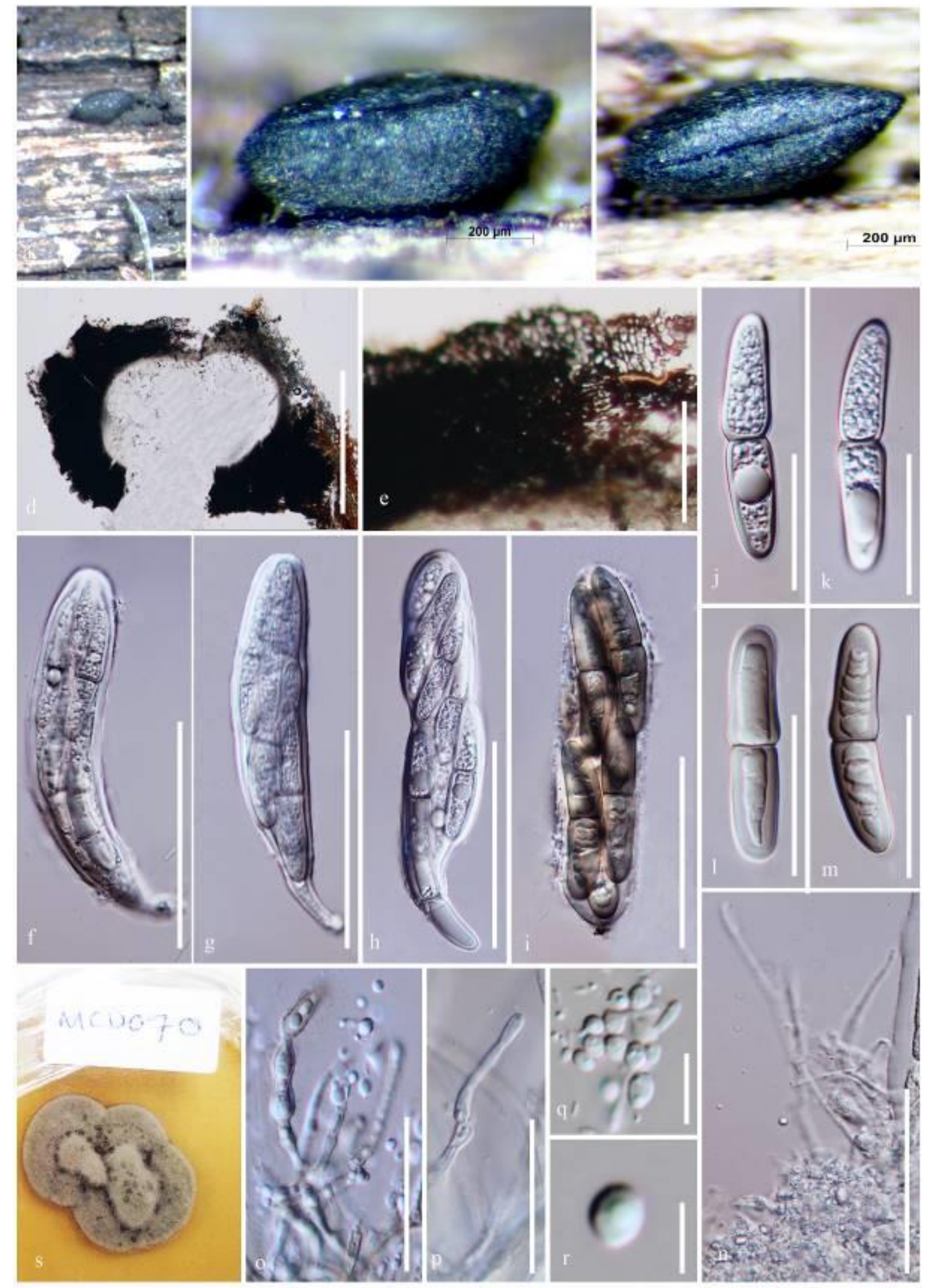

Figure 6 - Hysterium thailandicum (MFLU 18-0551). a-c Hysterothecia on host surface. d Vertical section through hysteriothecium. e Peridium. $\mathrm{f}-\mathrm{i}$ Asci. $\mathrm{j}-\mathrm{m}$ Ascospores. $\mathrm{n}$ Psudoparaphyses. o, p Conidiophores. q, r Conidia. s Sporulating culture on MEA. Scale bars: b, c $=200 \mu \mathrm{m}, \mathrm{e}-\mathrm{i}=50, \mathrm{j}-\mathrm{n}=20 \mu \mathrm{m}$. 


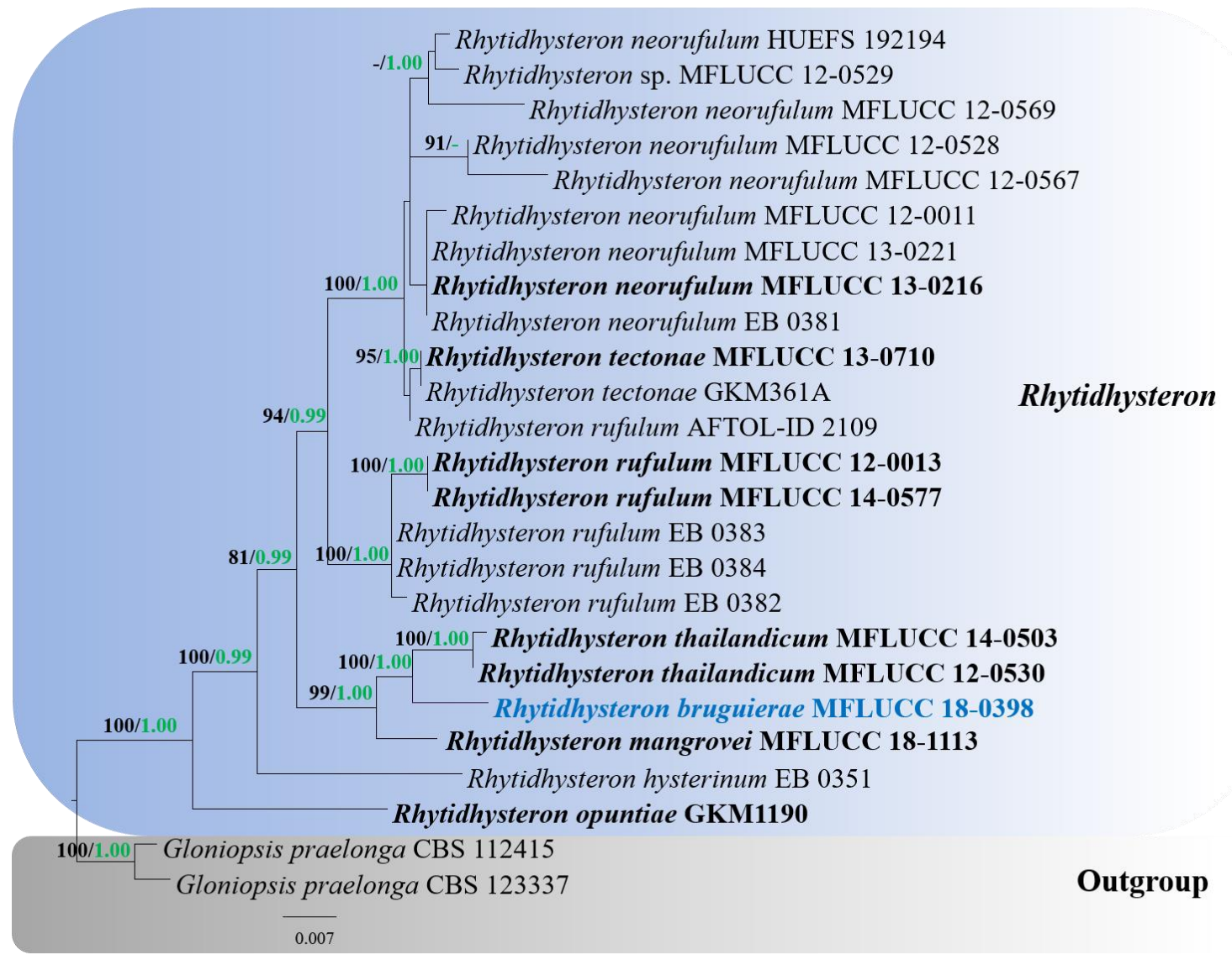

Figure 7 - Maximum likelihood analysis with 1000 bootstrap replicates yielded a best tree with the likelihood value of -6729.544855 . The combined LSU, SSU and TEF sequence datasets comprised 25 strains of Rhytidhysteron and related taxa with Gloniopsis praelonga (CBS 112415) and (CBS 123337 ) as the outgroup taxa. Tree topology of the ML analysis was similar to the BI. The matrix had 388 distinct alignment patterns, with $31.03 \%$ of undetermined characters or gaps. Estimated base frequencies were as follows; $\mathrm{A}=0.249183, \mathrm{C}=0.227333, \mathrm{G}=0.279667, \mathrm{~T}=0.243816$; substitution rates $\mathrm{AC}=1.765891, \mathrm{AG}=2.355479, \mathrm{AT}=1.363094, \mathrm{CG}=0.813735, \mathrm{CT}=$ 10.061233, GT $=1.000000$; gamma distribution shape parameter $\alpha=0.020000$. Maximum likelihood bootstrap (ML, black) values $>65 \%$ and Bayesian posterior probabilities (PP, green) > $0.90 \%$ are given above the nodes. The scale bar indicates 0.007 changes. The ex-type strains are in bold and new isolates in blue bold.

Multi-gene phylogenetic studies have shown that Rhytidhysteron should be placed in Hysteriaceae (Boehm et al. 2009a, b, De Almeida et al. 2014, Wijayawardene et al. 2014, Jayasiri et al. 2018, 2019). This genus is characterized by closed and navicular ascomata, later opening by a longitudinal slit to become irregularly apothecioid at maturity and heavily pigmented, and with thick-walled ascospores (Boehm et al. 2009a, Thambugala et al. 2016). An endophytic Rhytidhysteron sp. from mangroves has been reported by Pudhom \& Teerawatananond (2014), while a recent study by Kumar et al. (2019) introduced $R$. mangrovei from dead twigs of a mangrove species. The present study introduces a novel taxon from submerged decaying wood of Rhizophora sp.

Rhytidhysteron bruguierae Dayarathne, sp. nov.

Fig. 8

Index Fungorum number: IF556574, Facesoffungi number: FoF 06154

Etymology - Epithet derived from the host genus where the fungus was isolated, Bruguiera Holotype - MFLU 18-0571 
Saprobic on decaying, submerged branches of Bruguiera sp. Sexual morph: Ascomata 400 $950 \mathrm{~mm}$ long, 548-570 mm wide, 410-520 mm high $(\mathrm{n}=5)$, hysterothecial, boat-shaped, crowded to aggregate, superficial, brown-black, with exposed, lenticular to irregular, brown-black disc, folded along the margins when dry and forming an elongate slit, perpendicularly striate. Exciple 148-162 $\mu \mathrm{m}$ wide $(\mathrm{n}=5)$, composed of dark brown to black, thick-walled cells of textura angularis. Hamathecium comprised of dense, septate pseudoparaphyses, branched and forming a red epithecium above the asci, fused and slightly swollen at the apex and enclosed in a gelatinous matrix. Asci $128-148 \times 10-14 \mu \mathrm{m}(\overline{\mathrm{x}}=132 \times 13 \mu \mathrm{m}, \mathrm{n}=15), 6-8$-spored, bitunicate, cylindrical, with short, furcate pedicel, rounded at the apex, with distinct ocular chamber, J-. Ascospores 14-26 $\times 6.2-9 \mu \mathrm{m}(\overline{\mathrm{x}}=19.2 \times 7.5 \mu \mathrm{m}, \mathrm{n}=20)$, uniseriate, slightly overlapping, hyaline when immature, becoming yellowish-brown to reddish brown when mature, ellipsoidal to fusiform, rounded to slightly pointed at both ends, 1-3-septate, slightly constricted at the septa, with smooth wall. Asexual morph: Undetermined.

Culture characteristics - Ascospores germinating on sea water PDA within $24 \mathrm{~h}$ and germ tubes produced from one or both ends. Colonies growing on PDA $5 \mathrm{~cm}$ diam. after 1 week at $25^{\circ} \mathrm{C}$, flat, circular, initially white becoming greenish to reddish brown, smooth surface with undulate edge.

Material examined - THAILAND, Phetchaburi Province, Cha-am, on decaying Bruguiera sp. (Rhizophoraceae) wood, 12 January 2018, M.C. Dayarathne, MCD 183 (MFLU 18-0571, holotype); ibid., (HKAS102064, isotype), ex type living culture MFLUCC 18-0398.

GenBank numbers - LSU: MN017833; SSU: MN017901, TEF: MN077056

Notes - Rhytidhysteron bruguierae formed a separate (100\% ML, $1.00 \mathrm{PP})$ and distinct lineage within the genus Rhytidhysteron (Fig. 7) in a clade comprising $R$. thailandicum (MFLUCC 14-0503, MFLUCC12-0530) and R. mangrovei (MFLUCC18-1113). Rhytidhysteron bruguierae shares similar morphological features with $R$. mangrovei and $R$. thailandicum. However, the colour of the epithecium in $R$. bruguierae is red, while in $R$. mangrovei and $R$. thailandicum it is mentioned only as dark (Thambugala et al. 2016, Kumar et al. 2019). The exciple of $R$. bruguierae is relatively thicker than that of $R$. mangrovei and $R$. thailandicum $(148-162.8 \mu \mathrm{m} v s 65-90 \mu \mathrm{m} v \mathrm{~s}$ $72-130 \mu \mathrm{m})$. Hence, we compared the base pair differences of those three taxa following the guidelines of Jeewon \& Hyde (2016). TEF base pair differences of $R$. bruguierae to $R$. mangrovei and $R$. thailandicum are listed in Table 2 and considered to be in the appropriate range for designation of a distinct species (Jeewon \& Hyde 2016). Therefore, we establish our strain as a novel species in Rhytidhysteron.

Table 2 Base pair comparison of Rhytidhysteron bruguierae to related taxa.

\begin{tabular}{ll}
\hline Taxon & TEF \\
\hline R. mangrovei & $3.4 \%$ (32 bp out of 932 \\
& bp) \\
R. thailandicum & $3.2 \%$ (30 bp out of 932 \\
& bp) \\
\hline
\end{tabular}

Pleosporales Luttell ex M.E. Barr

Luttrell (1955) introduced the order Pleosporales to accommodate Dothideomycetes with perithecial ascomata with pseudoparaphyses amongst the asci (Zhang et al. 2009). Among the orders of Dothideomycetes, Pleosporales is the most diverse and the largest that comprises more than 70 families (Wijayawardene et al. 2018). Pleosporales species are endophytes or epiphytes, parasites, lichenicolous or saprobes in terrestrial or aquatic environments including marine habitats (Zhang et al. 2009, Jones et al. 2015, Hyde et al. 2016). 

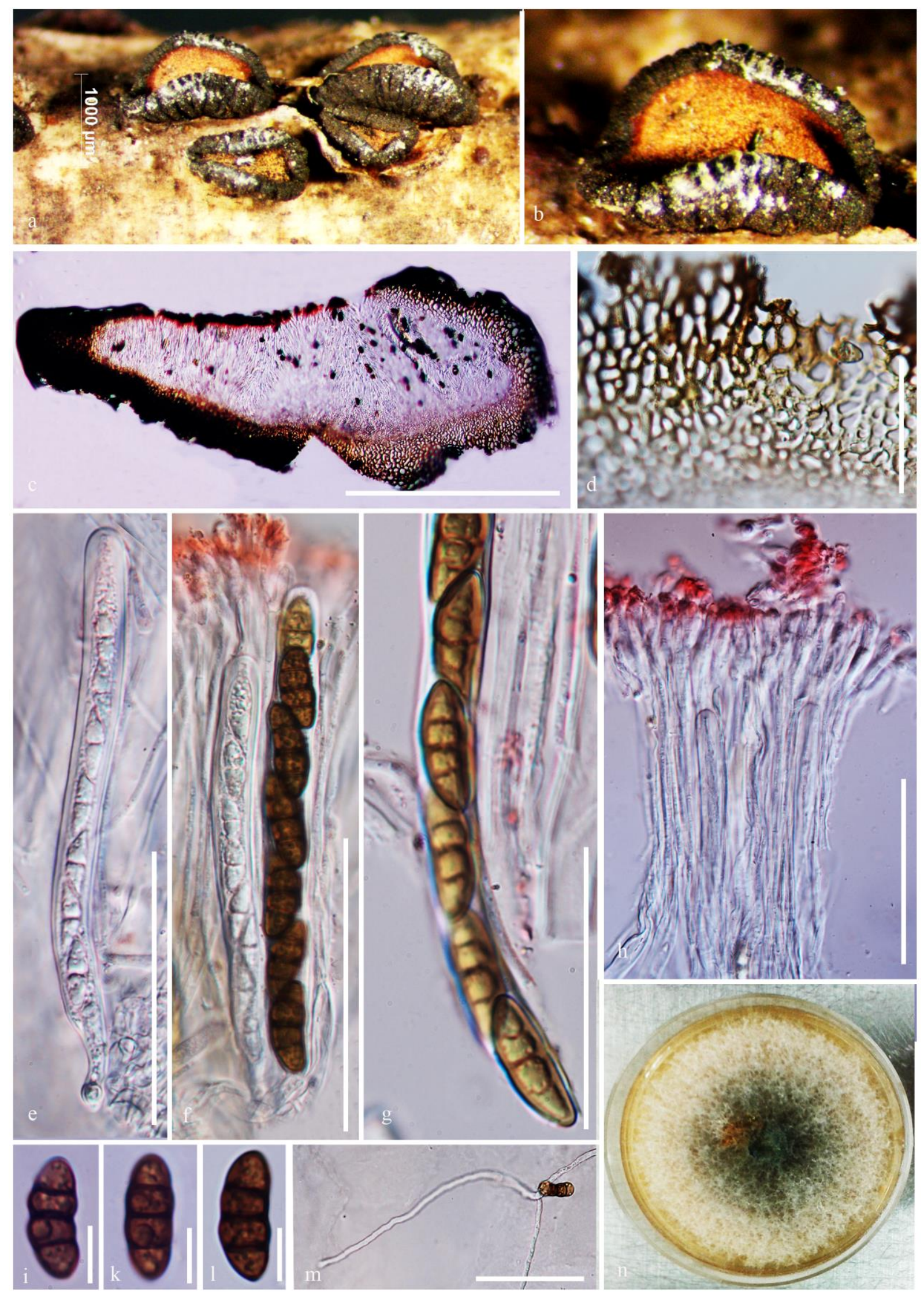

Figure 8 - Rhytidhysteron bruguierae (MFLU 18-0571, holotype). a, b Appearance of hysterothecia on host. c Vertical section through hysteriothecium. $d$ Exciple. e-g Young and mature asci. h Psudoparaphyses with branched swollen reddish tips. i-1 Ascospores. m Germinating ascospore. Scale bars: $\mathrm{a}=1000 \mu \mathrm{m}, \mathrm{c}=500 \mu \mathrm{m}, \mathrm{d}-\mathrm{f}, \mathrm{h}, \mathrm{m}=50 \mu \mathrm{m}, \mathrm{g}=20 \mu \mathrm{m}, \mathrm{i}-\mathrm{k}=10 \mu \mathrm{m}$. 


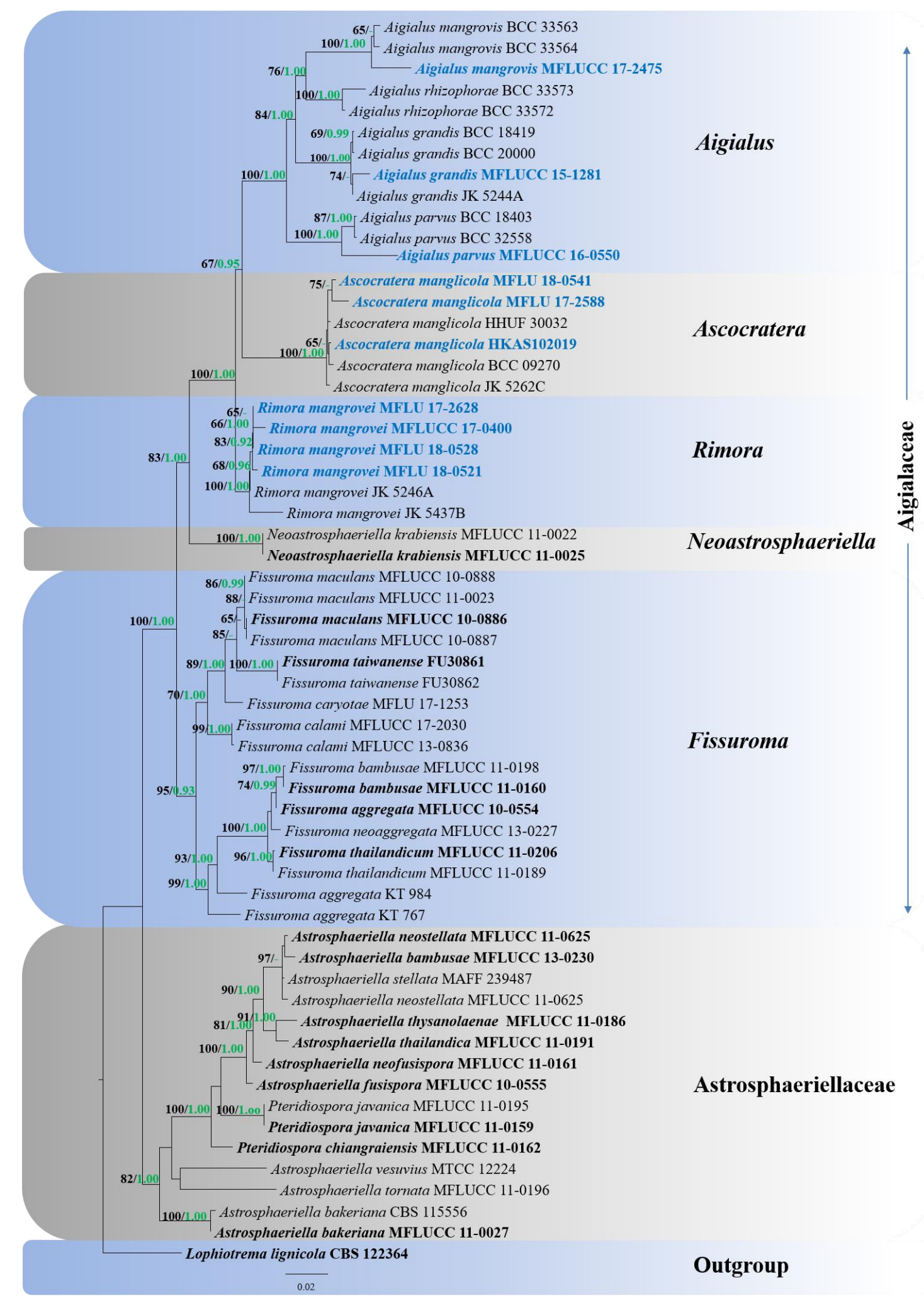

Figure 9 - Maximum likelihood analysis with 1000 bootstrap replicates yielded a best tree with the likelihood value of -13391.717934. The combined LSU, SSU and TEF sequence datasets comprised 59 strains of Aigialaceae and Astrosphaeriellaceae with Lophiotrema lignicola (CBS 122364) as the outgroup taxon. Tree topology of the ML analysis was similar to the BI and in congruent with previous study Tennakoon et al. (2018). The matrix had 947 distinct alignment patterns, with $22.69 \%$ of undetermined characters or gaps. Estimated base frequencies were as follows; $\mathrm{A}=0.246151, \mathrm{C}=0.245354, \mathrm{G}=0.282257, \mathrm{~T}=0.226239$; substitution rates $\mathrm{AC}=$ $1.037052, \mathrm{AG}=3.047760, \mathrm{AT}=0.967727, \mathrm{CG}=1.231952, \mathrm{CT}=10.474608, \mathrm{GT}=1.000000$; 
gamma distribution shape parameter $\alpha=0.177386$. Maximum likelihood bootstrap (ML, black) values $>65 \%$ and Bayesian posterior probabilities (PP, green) $>0.90 \%$ are given above the nodes. The scale bar indicates 0.02 changes. The ex-type strains are in bold and new isolates in blue bold.

Aigialaceae Suetrong, Sakay., E.B.G. Jones, Kohlm., Volkm.-Kohlm. \& C.L. Schoch

Suetrong et al. (2009) introduced the family Aigialaceae to accommodate species having carbonaceous ascomata that lack a papilla, trabeculate pseudoparaphyses (sensu Liew et al. 2000), cylindrical asci comprising an apical ring and ascospores with or without a sheath or gelatinous appendages around the apical cells (Read \& Beckett 1996, Liu et al. 2011, Zhang et al. 2012, Hyde et al. 2013, Jones et al. 2015, Phookamsak et al. 2015, Tennakoon et al. 2018). Initially only marine genera, such as Aigialus, Ascocratera and Rimora were included in the Aigialaceae (Suetrong et al. 2009, Phookamsak et al. 2015, Wijayawardene et al. 2017a). However, later studies reported Aigialaceae species from different habitats including marine, terrestrial and mangroves (Hyde \& Jones 1988, Hyde \& Lee 1995, Liu et al. 2011, Phookamsak et al. 2015, Tennakoon et al. 2018). With the recent inclusion of Fissuroma and Neoastrosphaeriella (Liu et al. 2011), five genera are presently accepted in the Aigialaceae (Wijayawardene et al. 2017a, 2018). All genera in Aigialaceae have trabeculate psudoparaphyses (sensu Liu et al. 2011).

Aigialus Kohlm. \& S. Schatz

Aigialus, the type genus of Aigialaceae is frequently found on mangrove wood in both tropical to subtropical regions (Suetrong et al. 2009). The genus Aigialus was initially accommodated in Melanommatales (sensu Barr 1979), based on the trabeculate pseudoparaphyses, but without assigning it to any family in the Dothideomycetes (Kohlmeyer \& Schatz 1985), based on the possession of a refractive, J- apical ring in the ascus. Hawksworth et al. (1995) assigned the genus to Massariaceae in the order Pyrenulales. Liew et al. (2000) showed that trabeculate pseudoparaphyses were not important at the ordinal level. According to single gene sequence analysis, Tam et al. (2003), referred Aigialus to Pleosporales, and this was followed by Kirk et al. (2008). Classification of this genus is resolved with a higher number of taxon sampling of Dothideomycetes (Schoch et al. 2009, Suetrong et al. 2009, Zhang et al. 2012). There are five species accepted in the genus: A. grandis, A. mangrovei, A. parvus, A. rhizophorae and A. striatispora (Jones et al. 2009). During our investigation of marine mangrove fungi from Thailand we collected three species; A. grandis, A. mangrovei and A. parvus.

Aigialus grandis Kohlm. \& S. Schatz, Trans. Br. mycol. Soc. 85(4): 699 (1986) [1985] ～Fig. 10 Facesoffungi number: FoF 06155

Saprobic on mangrove wood. Sexual morph: Ascomata 900-1200 × 420-1540 $\mu \mathrm{m}$, subglobose to ellipsoidal, laterally compressed, completely or partially immersed in a black stroma, with a longitudinal furrow at the top, carbonaceous to coriaceous, black, gregarious, apapillate. Peridium 60-110 $\mu \mathrm{m}$ wide, coriaceous to carbonaceous, two-layered, outer layer composed of elongate cells, inner layer composed of smaller hyaline cells. Hamathecium comprising 1.5-2 $\mu \mathrm{m}$ wide, trabeculate pseudoparaphyses, unbranched at the base, anastomosing above the asci, embedded in a gelatinous matrix. Asci $320-420 \times 16-32 \mu \mathrm{m}(\overline{\mathrm{x}}=405 \times 22.8 \mu \mathrm{m}, \mathrm{n}=10), 8$-spored, bitunicate, fissitunicate, cylindrical, long-pedicellate, with a refractive non-amyloid, apical ring. Ascospores $62.6-70 \times 12-18 \mu \mathrm{m}(\overline{\mathrm{x}}=68 \times 17 \mu \mathrm{m}, \mathrm{n}=20)$, biseriate, ellipsoidal to broadly fusiform, muriform, 16-18 transverse septa and 1-2 longitudinal septa, dark brown except for hyaline to pale brown apical cells, glabrous, with a gelatinous cap or a mucilaginous sheath. Asexual morph: Unknown.

Culture characteristics - Colonies on MEA reaching $8 \mathrm{~cm}$ diam. after 2 weeks at $25{ }^{\circ} \mathrm{C}$, dense, irregular, slightly raised, surface smooth with undulate edge, submerged, colony from above: grayish black; from below: yellowish at the margin, blackish gray at the center; mycelium hyaline. 
Material examined - THAILAND, Krabi Province, Krabi, 8²5'52" N, 98 $31^{\circ} 42^{\prime \prime}$ E, 0 m asl., on submerged root of Rhizophora sp., 7 December 2014, M.C. Dayarathne, KRB023 (MFLU 161241), living culture, MFLUCC 15-1281.

GenBank numbers - LSU: MN420684; SSU: MN420694

Notes - Our collection is similar to the type of Aigialus grandis in both morphological characters and molecular sequence data (Figs 9, 10).

Aigialus mangrovei Borse, Trans. Br. mycol. Soc. 88(3): 424 (1987)

Fig. 11

Facesoffungi number: FoF 06156

Saprobic on mangrove wood. Sexual morph: Ascomata 600-710 × 550-700.2 $\mu \mathrm{m}$, subglobose, completely or partially immersed, carbonaceous to coriaceous, black, gregarious, ostiolate. Peridium 50-60 $\mu \mathrm{m}$ wide, coriaceous to carbonaceous, two-layered, outer layer composed of elongate cells, inner layer composed of smaller hyaline cells. Hamathecium comprising 0.8-1.4 $\mu \mathrm{m}$ wide, trabeculate pseudoparaphyses, unbranched at the base, anastomosing above the asci, embedded in a gelatinous matrix. Asci $288-400 \times 20-30.4 \mu \mathrm{m}(\overline{\mathrm{x}}=310 \times 27 \mu \mathrm{m}, \mathrm{n}=20)$, 8-spored, bitunicate, fissitunicate, cylindrical, long-pedicellate, with a refractive non-amyloid, apical ring. Ascospores 30-42.4 $\times 14-16.8 \mu \mathrm{m}(\overline{\mathrm{x}}=35.5 \times 13.1 \mu \mathrm{m}, \mathrm{n}=20)$, biseriate, ellipsoidal to broadly fusiform, muriform, with 6-7 transverse septa and 1-2 longitudinal septa, dark brown, with hyaline to pale brown apical cells, glabrous, with a gelatinous cap or a mucilaginous sheath. Asexual morph: Unknown.

Culture characteristics - Colonies on PDA reaching $8 \mathrm{~cm}$ diam. after 2 weeks at $20-25{ }^{\circ} \mathrm{C}$, dense, irregular, slightly raised, surface smooth with undulate edge, cottony, colony from above: white; from below: yellowish white at the margin, yellow to pale brown at the center; mycelium hyaline, not produced pigment on PDA media.

Material examined - THAILAND, Phetchaburi Province, Cha-am, on decaying Rhizophora sp. (Rhizophoraceae) wood, 30 August 2017, M.C. Dayarathne, MCD 127 (MFLU 17-2608); ibid., HKAS102046, living culture MFLUCC 17-2475.

GenBank numbers - LSU: MN017834; SSU: MN017902

Notes - Aigialus mangrovei was introduced by Borse et al. (1987) from India. This fungus is also commonly found in Thailand (Suetrong unpublished data). Our strain MFLUCC 17-2475 is morphologically reminiscent of the protologue of A. mangrovei (Borse et al. 1987) and clustered in a clade comprising other A. mangrovei strains BCC 33563 and BCC 33564 (Fig. 9).

Aigialus parvus S. Schatz \& Kohlm., in Kohlmeyer \& Schatz, Trans. Br. mycol. Soc. 85(4): 704 (1986) [1985].

Fig. 12

Facesoffungi number: FoF 06201

Saprobic on mangrove wood. Sexual morph: Ascomata 500-1440 × 900-1500 $\mu \mathrm{m}$, ellipsoidal to globose to subglobose, immersed to semi immersed, solitary to gregarious, carbonaceous, dark brown to black, ostiolate. Peridium 56-104 $\mu \mathrm{m}$, carbonaceous, two-layered, outer layer composed of elongate cells, inner layer composed of smaller hyaline cells. Hamathecium comprising 1.2-2 $\mu \mathrm{m}$ wide, trabeculate pseudoparaphyses, unbranched at the base, extending above the asci, embedded in a gelatinous matrix. Asci 350-455 $\times 19-28 \mu \mathrm{m}(\overline{\mathrm{x}}=400 \times$ $24 \mu \mathrm{m}, \mathrm{n}=20$ ), 8-spored, bitunicate, fissitunicate, cylindrical, long-pedicellate, with a refractive non-amyloid, apical ring. Ascospores $42-56 \times 12.6-16 \mu \mathrm{m}(\overline{\mathrm{x}}=46.3 \times 15.1 \mu \mathrm{m}, \mathrm{n}=20)$, biseriate, ellipsoidal to broadly fusiform, muriform, with 8-12 transverse septa and 1-2 longitudinal septa, dark brown, with hyaline to pale brown apical cells, glabrous, with a gelatinous cap or a mucilaginous sheath. Asexual morph: Unknown.

Culture characteristics - Colonies on PDA reaching $6.5 \mathrm{~cm}$ diam. after 2 weeks at $25{ }^{\circ} \mathrm{C}$, dense, irregular, slightly raised, surface smooth with undulate edge, submerged, colony from above: greenish black; from below: yellowish at the margin, blackish green at the center; mycelium hyaline, no pigmentation producing on PDA media. 


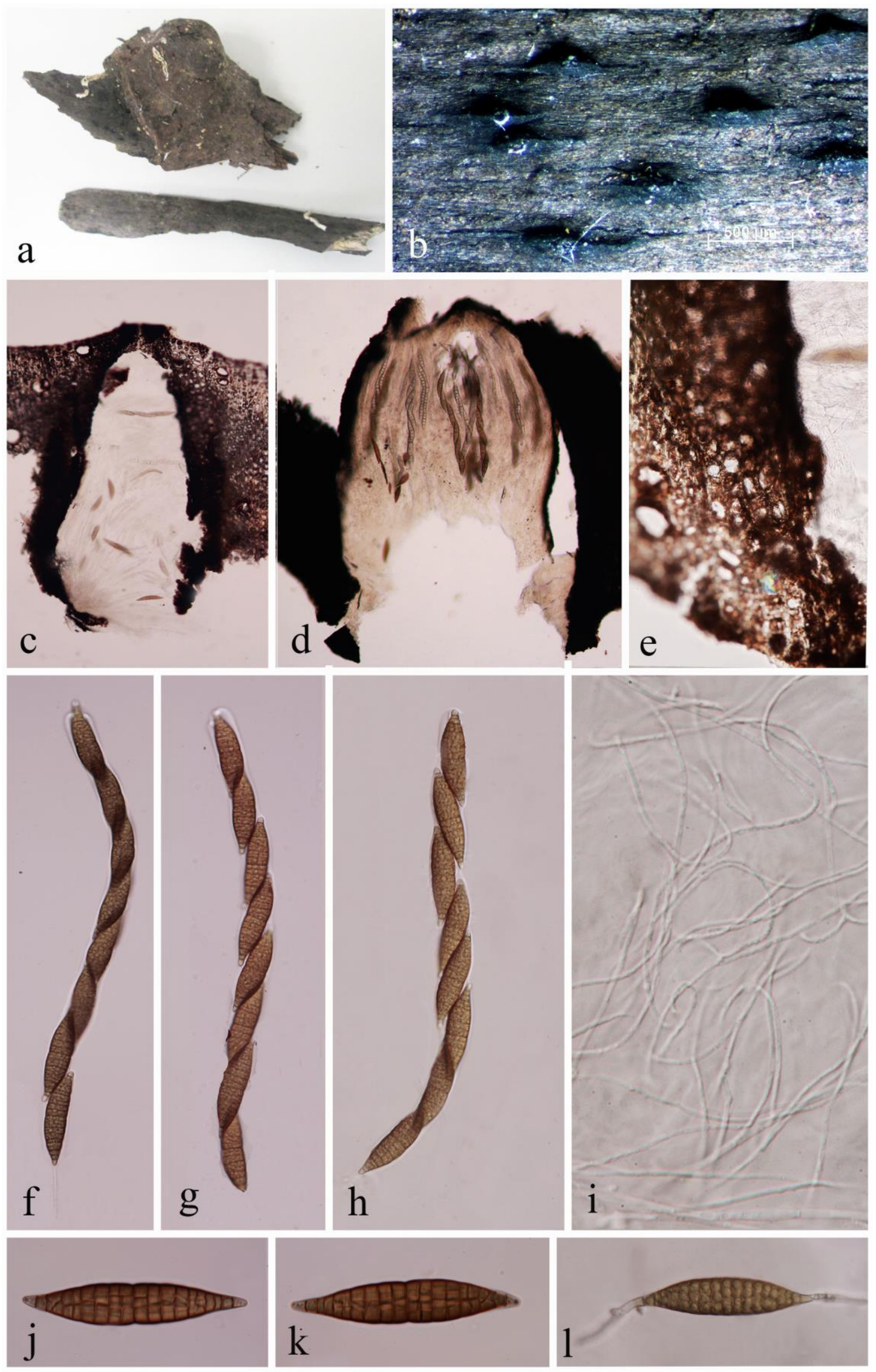

Figure 10 - Aigialus grandis (MFLUCC 15-1281). a Host. b Ascomata on host. c, d Sections of ascomata. e. Peridum. d. Trabeculate pseudoparaphyses. e-g. Immature and mature asci. $\mathrm{j}-\mathrm{j}$. Immature to mature ascospores. k. Germinating ascospore. Scale bars: $b-d=500 \mu \mathrm{m}, \mathrm{f}-\mathrm{h}=200$ $\mu \mathrm{m}, \mathrm{e}, \mathrm{i}-1=50 \mu \mathrm{m}$. 


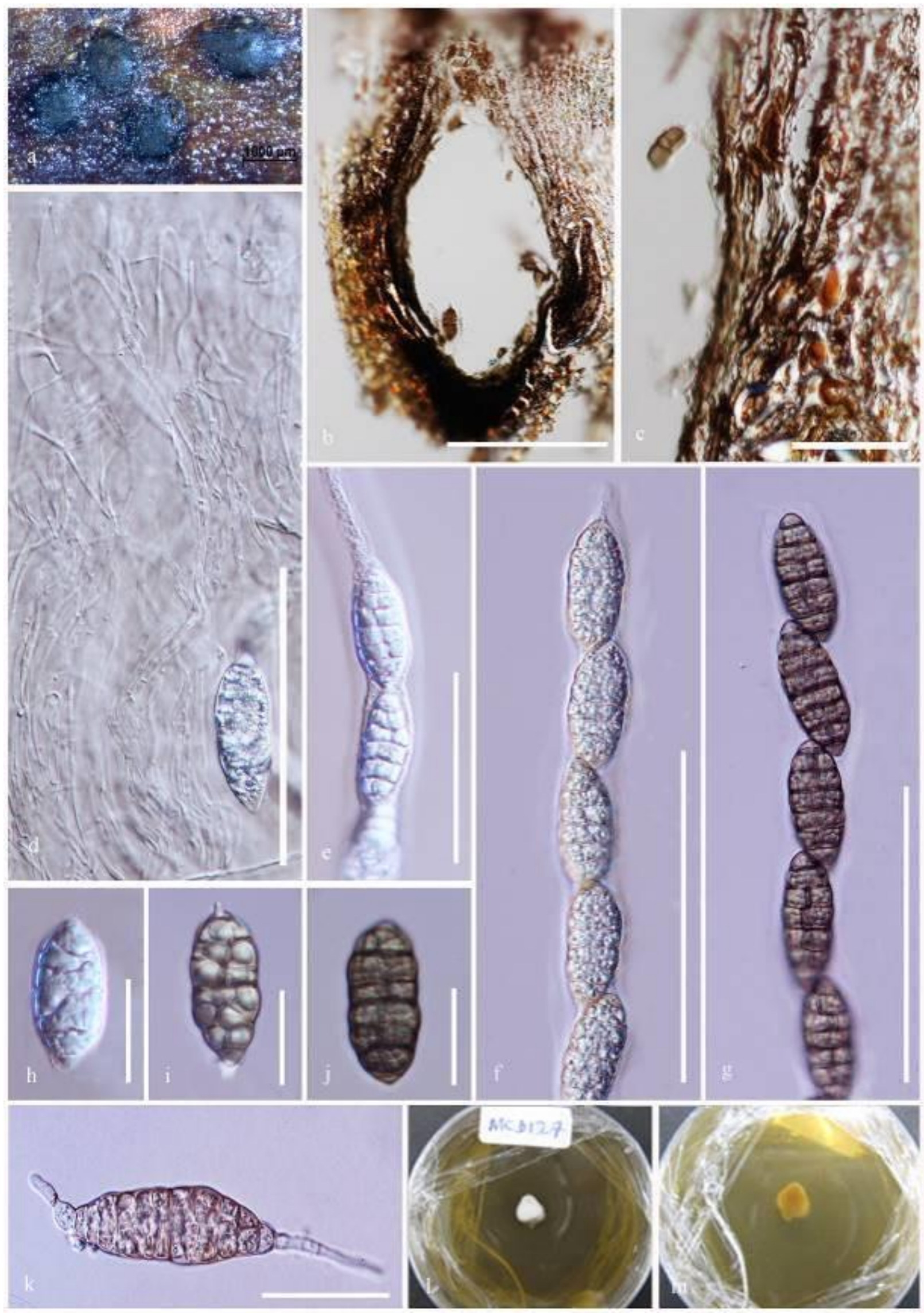

Figure 11 - Aigialus mangrovei (MFLU 17-2608). a Ascomata on decaying wood. b Section of ascoma. c Peridium. $d$ Trabeculate pseudoparaphyses. e-g Immature and mature asci. $\mathrm{j}-\mathrm{j}$ Immature to mature ascospores. $\mathrm{k}$ Germinating ascospore. Scale bars: $\mathrm{a}=1000 \mu \mathrm{m}, \mathrm{b}=100 \mu \mathrm{m}, \mathrm{c}-\mathrm{q}=10$ $\mu \mathrm{m}$. 


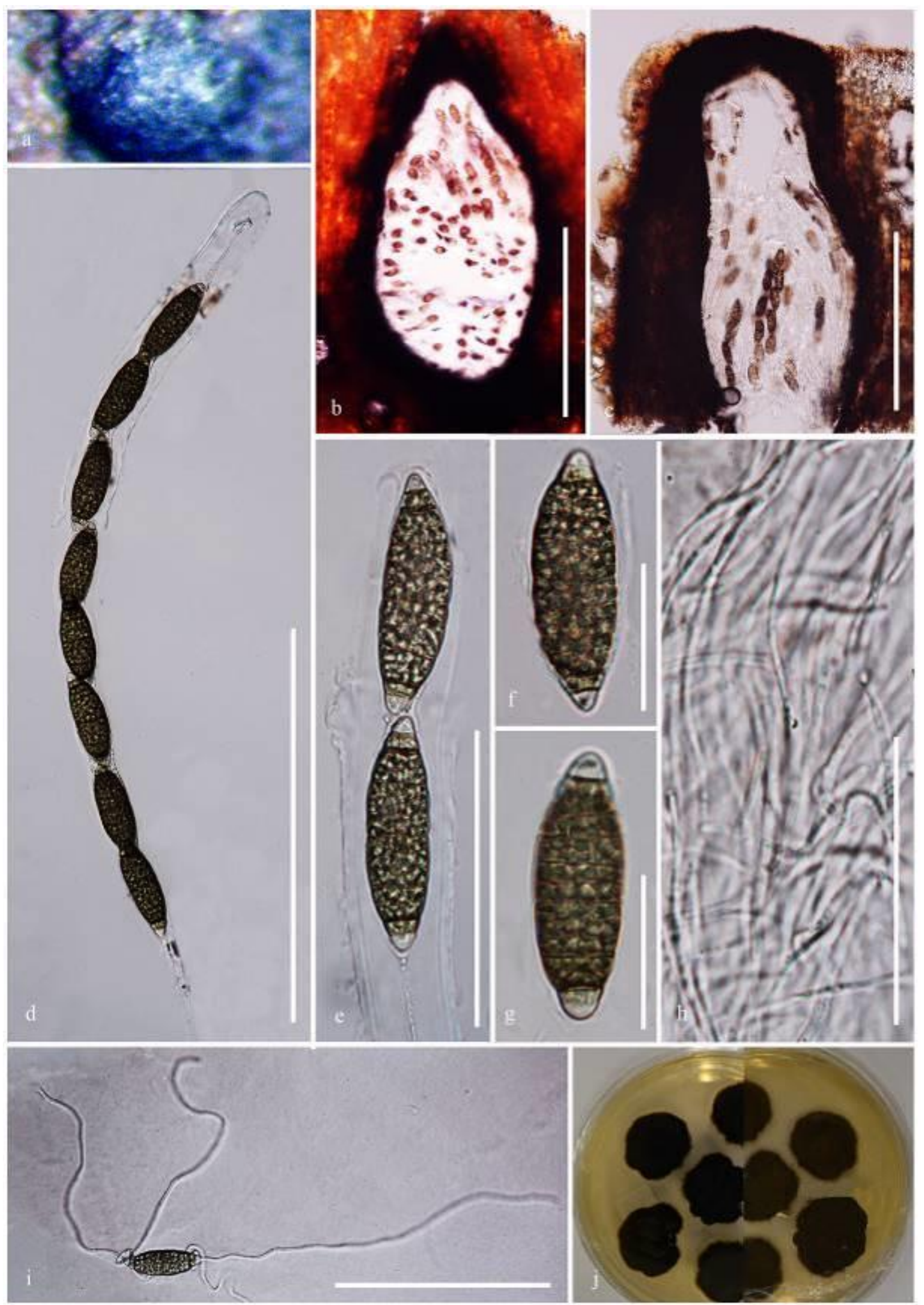

Figure 12 - Aigialus parvus (MFLUCC 16-0550). a Ascomata on decaying wood. b, c Sections of ascomata. d. Ascus. e-g Ascospores. h Trabeculate pseudoparaphyses. i. Germinating ascospore. Scale bars: $\mathrm{a}=1000 \mu \mathrm{m}, \mathrm{b}=100 \mu \mathrm{m}, \mathrm{c}-\mathrm{q}=10 \mu \mathrm{m}$. 
Material examined - THAILAND, Phetchaburi Province, Hat Chao Samran, on submerged Rhizophora apiculata (Rhizophoraceae) wood, 28 July 2015, M. C Dayarathne, CHAM 008 (MFLU 16-1175), living culture MFLUCC 16-0550.

GenBank numbers - LSU: MN017835; SSU: MN017903

Notes - Aigialus parvus can be distinguished from other Aigialus species by the number of septa in ascospores, which comprises more than 7(8-12) transverse septa (Fig. 12), while A. grandis has more than 12 transverse septa in the ascospores and deeply constricted at the median septum. Aigialus mangrovei has 6-7 transversely septate and 1-2 vertically septate ascopores and A. rhizophorae has more than 12 transversely septate ascospores with a single vertical septum (Borse et al. 1987). Aigialus striatisporus is different from all of the above species by having vertical striations along the ascospore wall (Hyde 1992b, Jones et al. 2009).

\section{Ascocratera Kohlm.}

The monotypic genus Ascocratera was established by Kohlmeyer (1986) with A. manglicola collected on dead wood of mangrove trees (Avicennia germinans, Conocarpus erecta, Laguncularia racernosa and Rhizophora mangle) in the Atlantic and Pacific Oceans. Kohlmeyer (1986) referred this genus to Massariaceae in Melanommatales and was subsequently studied by Suetrong et al. (2009) who accommodated this genus in the family Aigialaceae (Pleosporales).

Ascocratera manglicola Kohlm., Can. J. Bot. 64(12): 3036 (1986)

Fig. 13

Facesoffungi number: FoF 06157

Saprobic on mangrove wood. Sexual morph: Ascomata 752-890 × 1000-1300 $\mu \mathrm{m}$, conical with a flat base, crater-like, erumpent from the substrate and superficial when mature, seated on a thin stroma, ostiole cells of the host enclosed in the lower part of the peridium. epapillate, carbonaceous, black, with irregular bulges or ridges around the ostiole, gregarious, single or sometimes two or more attached to each other. Ostiole circular, depressed, ostiolar canal filled with short hyaline branching periphyses, embedded in a gelatinous matrix. Peridium 84-150 pm thick on the sides, 45-75 $\mu \mathrm{m}$, wide, composed of small irregular cells, encrusted with melanin particles, forming a textura angularis, cells of the host are incorporated in the peridium, especially in the basis of the lateral part; a textura intricata, composed of loose, thick hyaline hyphae, forms a wedge between the lateral and basal part of the peridium. Pseudoparaphyses: $1.5-3 \mu \mathrm{m}$ in diam., trabeculate, septate, simple at the base and embedded in a gelatinous matrix, free at the tips, branched and anastomosing above the asci. Asci 300-430 $\times 20-28 \mu \mathrm{m}(\overline{\mathrm{x}}=350 \times 24.7 \mu \mathrm{m}, \mathrm{n}=20)$, 8-spored, cylindrical, pedunculate, thick-walled, fissitunicate, arising from a basal ascogenous tissue, with a refractive apical ring in the endoascus, J-. Ascospores 40.8-60. $\times 14.2-20 \mu \mathrm{m}(\overline{\mathrm{x}}=46$ $\times 16.1 \mu \mathrm{m}, \mathrm{n}=20$ ), overlapping uni-seriate, ellipsoidal, at first one-, later three-septate, constricted at the central primary septum, hyaline, surrounded by a gelatinous evanescent sheath. Asexual morph: Unknown.

Material examined - THAILAND, Krabi Province, Phang Nga, on mangrove sp. (Rhizophoraceae) wood, 31 August 2017, M.C. Dayarathne MCD 105 (MFLU 17-2588); ibid., HKAS102035. THAILAND, Krabi Province, Krabi, 8²5'52" N, 98³1'42" E, $0 \mathrm{~m}$ asl., on submerged root of Rhizophora sp., 7 December 2014, M.C. Dayarathne, KRB 012 (MFLU 191228); ibid., HKAS102019. THAILAND, Ranong Province, Amphoe Maung, Mu 4 Tombol Ngao, Ranong Mangrove Research Center (GPS: $9^{\circ} 43^{\prime}$ to $9^{\circ} 57^{\prime} \mathrm{N}$; $98^{\circ} 29^{\prime}$ to $98^{\circ} 39^{\prime} \mathrm{E}$ ) on decaying wood of Rhizophora sp. (Rhizophoraceae), 7 December 2016, M.C. Dayarathne, MCD 056 (MFLU 180541); ibid., HKAS102080.

GenBank numbers - LSU: MN017836, MN017837, MN017838; SSU: MN017904, MN017905, MN017906; TEF: MN077057, MN077058

Notes - Ascocratera manglicola is a unique genus in Aigialaceae by having carbonaceous, black, gregarious ascomata that are conical, crater-like, superficial on wood, on a black stroma, with trabeculate pseudoparaphyses, asci with a refractive apical ring, and hyaline ascospores, surrounded by a gelatinous evanescent sheath (Kohlmeyer 1986). This species has often been found 
on mangrove wood in the intertidal zone, and known from various tropical localities (Schmit \& Shearer 2003, Suetrong et al. 2009). Our strains MFLU 17-2588, MFLU 18-0541 and HKAS102019 nested together with other A. manglicola strains (HHUF 30032, BCC 09270 and JK 5262C). Our strains are mostly similar in characters to those described in the protologue (Kohlmeyer 1986).

Rimora Kohlm., Volkm.-Kohlm., Suetrong, Sakay. \& E.B.G. Jones

The genus Rimora was introduced by Suetrong et al. (2009) based on phylogeny to accommodate single species $R$. mangrovei.

Rimora mangrovei (Kohlm. \& Vittal) Kohlm., Volkm.-Kohlm., Suetrong, Sakay. \& E.B.G. Jones, Stud. Mycol. 64: 166 (2009).

Facesoffungi number: FoF 06158

Fig. 14

Saprobic on decaying mangrove wood. Sexual morph: Ascomata $213-432 \times 268-535.5 \mu \mathrm{m}$, black, carbonaceous, gregarious, forming on a black stromatic crust, broadly oblong with a flat top in frontal view, opening with a cleft-like ostiolum at the flattened top, apapillate, immersed to erumpent or superficial. Ostiole cleft-like, central, periphysate. Peridium up to $138 \mu \mathrm{m}$ wide, black, base comprising a mixture of fungal and host cells. Pseudoparaphyses up to $2 \mu \mathrm{m}$, trabeculate, numerous, branched. Asci 144-234 × 14.5-19 $\mu \mathrm{m}(\overline{\mathrm{x}}=191 \times 16.6 \mu \mathrm{m}, \mathrm{n}=20), 8$-spored, bitunicate, fissitunicate, cylindrical, short pedicellate, thick-walled, without an apical apparatus. Ascospores 44.5-50 $\times 7.5-12 \mu \mathrm{m}(\overline{\mathrm{x}}=48 \times 8.5 \mu \mathrm{m}, \mathrm{n}=30)$, fusiform, hyaline, initially 1-septate, later becoming 3-septate, pale brown or brown, constricted at the central primary septum, biseriate, surrounded by an evanescent sheath. Asexual morph: undetermined.

Culture characteristics - Colonies on PDA reaching $8 \mathrm{~cm}$ diam. after 2 weeks at $25{ }^{\circ} \mathrm{C}$, dense, irregular, slightly raised, surface smooth with circular edge, submerged, colony from above: greenish black; from below: blackish green; mycelium hyaline, not produced pigmentation on PDA media.

Material examined - THAILAND, Phetchaburi Province, Cha-am, on mangrove sp. (Rhizophoraceae) wood, 31 August 2017, M.C. Dayarathne MCD 154 (MFLU 17-2628); ibid., HKAS102059. THAILAND, Ranong Province, Amphoe Maung, Mu 4 Tombol Ngao, Ranong Mangrove Research Center (GPS: $9^{\circ} 43^{\prime}$ to $9^{\circ} 57^{\prime} \mathrm{N}$; $98^{\circ} 29^{\prime}$ to $98^{\circ} 39^{\prime} \mathrm{E}$ ) on decaying wood of Rhizophora sp. (Rhizophoraceae), 07 December 2016, M.C. Dayarathne, MCD 041 (MFLU 180528); ibid., HKAS102074, living culture MFLUCC 17-0400. THAILAND, Phetchaburi Province, Hat Chao Samran, on submerged Rhizophora apiculata (Rhizophoraceae) wood, 28 July 2015, M.C. Dayarathne, CHAM 031 (MFLU 18-0521).

GenBank numbers - LSU: MN017839, MN017840, MN420682, MN420683; SSU: MN017907, MN017908, MN420692, MN420693; TEF: MN077059, MN077060

Notes - Rimora mangrovei was initially described from the bark and wood of mangrove trees from Belize and India by Kohlmeyer \& Vittal (1986) as Lophiostoma mangrovei. Subsequently, Hyde et al. (2002) transferred R. mangrovei to Astrosphaeriella based on the trabeculate morphology of the pseudoparaphyses (sensu Liu et al. 2011). However, subsequent authors conceded that A. mangrovei (and A. asiana) differed from other Astrosphaeriella species by their round flattened ascomata, slit-like ostioles and dicotyledonous hosts (Liu et al. 2011). Suetrong et al. (2009) established the genus Rimora to accommodate this species based on its molecular phylogeny.

Dictyosporiaceae Boonmee \& K.D. Hyde

Dictyosporiaceae was introduced by Liu et al. (2015) and was formally accepted by Boonmee et al. (2016) along with Dictyosporium as the type genus. Species of Dictyosporiaceae are mostly saprobes found on decaying wood in aquatic and terrestrial habitats (Boonmee et al. 2016). Asexual morphs of this family are cheirosporous hyphomycetes (Boonmee et al. 2016). Twelve genera are currently accepted in this family (Wijayawardene et al. 2017a, 2018). 


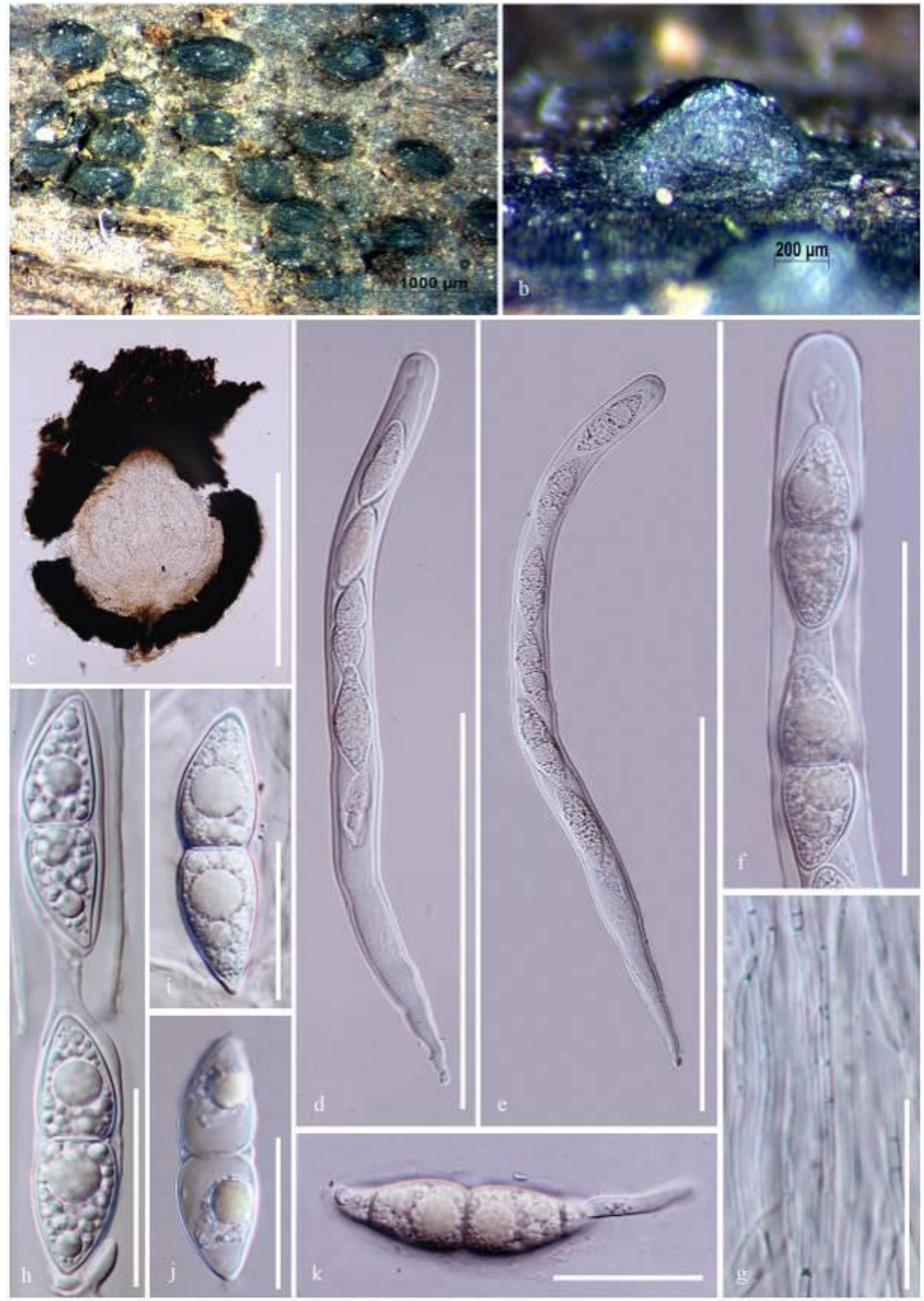

Figure 13 - Ascocratera manglicola (MFLU 17-2588). a, b Ascomata on decaying wood. c Section of ascoma. d, e Asci. f Ascal apical ring. g Pseudoparaphyses. $\mathrm{h}-\mathrm{j}$ Ascospores. $\mathrm{k}$ Germinating ascospore. Scale bars: $\mathrm{a}=1000 \mu \mathrm{m}, \mathrm{b}=100 \mu \mathrm{m}, \mathrm{c}-\mathrm{q}=10 \mu \mathrm{m}$. 

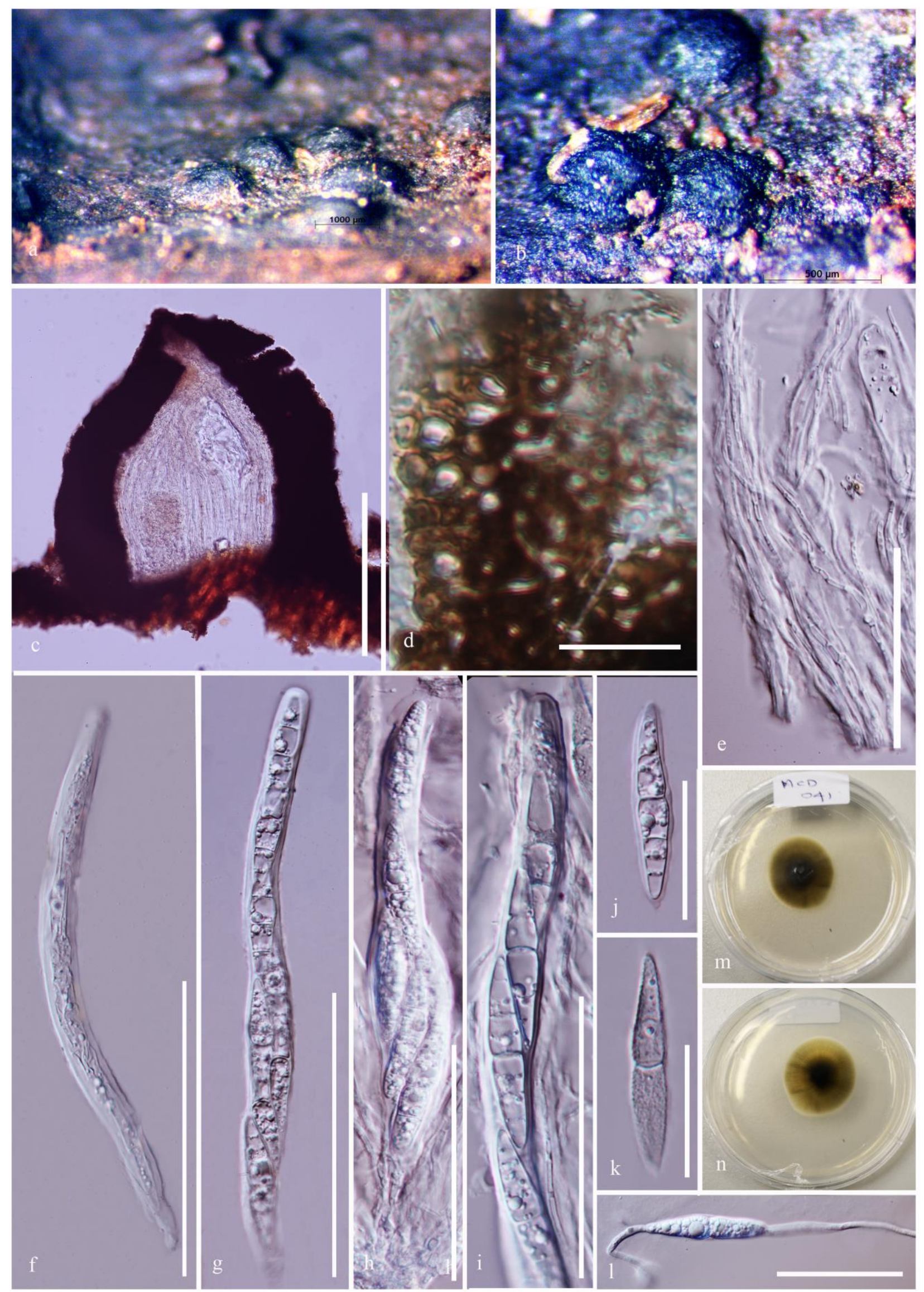

Figure 14 - Rimora mangrovei (MFLU 17-2628), a, b Ascomata on decaying wood. c Section of ascoma. d Peridium. e Pseudoparaphyses. f, i Asci. j, k Ascospores. 1 Germinating ascospore. m, $n$ Cultures on PDA (m upper, $\mathrm{n}$ lower). Scale bars: $\mathrm{b}, \mathrm{c}=500 \mu \mathrm{m}, \mathrm{e}, \mathrm{f}-\mathrm{h}=100 \mu \mathrm{m}, \mathrm{d}, \mathrm{i}-\mathrm{k}=20 \mu \mathrm{m}$. 


\section{Dictyosporium Corda}

Dictyosporium species occur on dead wood and plant litter in terrestrial and aquatic habitats (Ho et al. 2002, Pinnoi et al. 2006, Pinruan et al. 2007, Tibpromma et al. 2018). Dictyosporium was established by Corda (1836) with D. elegans as the type species. Members of this genus are saprobes mostly in terrestrial or aquatic environments (Hyde et al. 2011), while D. pelagicum has been reported from marine habitats (Jones et al. 2015). In this study, a novel species Dictyosporium marinum is described from a decaying wood buried in beach sand in the UK.

Dictyosporium marinum Dayarathne \& E.B.G. Jones, sp. nov.

Fig. 16

Index Fungorum number: IF556575; Facesoffungi number: FoF 06159

Holotype - MFLU 19-1229

Saprobic on buried wood in sandy beach. Sexual morph: Undetermined. Asexual morph: Hyphomycetous. Conidiomata sporodochial on natural substrate in small groups, dark brown, with base attached on surface of substrate. Conidiophores micronematous, reduced to conidiogenous cell. Conidiogenous cells $1.5-3 \times 1-2 \mu \mathrm{m}(\overline{\mathrm{x}}=2.7 \times 2.4 \mu \mathrm{m}, \mathrm{n}=5)$, holoblastic, cylindrical, pale hyaline to light brown. Conidia $34-50 \times 22-28 \mu \mathrm{m}(\overline{\mathrm{x}}=43.5 \times 24.5 \mu \mathrm{m}, \mathrm{n}=20)$, solitary, oval to ellipsoid, cheiroid, not complanate, consisting of 35-40 cells arranged in 4-5 rows, with a basal conical shaped connecting cell, not easy to separate, brown, guttulate, subhyaline at the tip of peripheral rows, smooth-walled.

Material examined - UK, Carmarthenshire, Llanstephan beach, on buried wood in sand, 12 May 2017, E.B. Gareth Jones, GJ357 (MFLU 19-1229, holotype); ibid., (BBH, isotype).

GenBank numbers - LSU: MN017841

Notes - Dictyosporium marinum was isolated from buried wood in sand. It is characteristic of the genus Dictyosporium, such as having sporodochial colonies, micronematous to macronematous conidiophores and cheiroid, digitate complanate conidia with several parallel rows of cells (Goh et al. 1999). Dictyosporium marinum shows a close phylogenetic affinity to Dictyosporium nigroapice which was isolated from wood of Machilus velutina submerged in streams in Hong Kong (Fig. 15). Base pair difference between D. marinum and D. nigroapice is $1.5 \%$ (786/798) of LSU. Furthermore, the two species are morphologically distinct especially in their conidial morphology. Conidia of D. nigroapice are narrower $(15-20 \mu \mathrm{m})$ and comprise outer rows with a hyaline appendage (Goh et al. 1999), whereas D. marinum has relatively wider conidia (22-28 $\mu \mathrm{m})$ that lacks appendages. A number of Dictyosporium species have been reported from the marine habitats including D. pelagicum, D. inflatum and D. toruloides (Kirschner et al. 2013, Jones et al. 2015). Dictyosporium marinum is different from $D$. pelagicum mainly by the conidial morphology, whereas conidia of $D$. marinum are larger than that of D. pelagicum $(34-50 \times 22-28 \mu \mathrm{m} v \mathrm{~s} 12-66$ $\times 9-28 \mu \mathrm{m}$ ) (www. marinfungi.org). Furthermore, cells of $D$. marinum are arranged in 4-5 rows, while cells of $D$. pelagicum are initially in three and become 3-8 irregular rows (www. marinfungi.org). We could not obtain any other gene sequences apart from LSU data for this species. We establish this collection as a novel species based on morphological differences and LSU phylogeny.

\section{Didymellaceae Gruyter et al.}

The family Didymellaceae was introduced by De Gruyter et al. (2009) to accommodate Didymella, Phoma and phoma-like genera. Twenty-seven genera are currently assigned to Didymellaceae based on morphology and phylogenetic analyses (Chen et al. 2015, Jayasiri et al. 2017, Thambugala et al. 2017, Wijayawardene et al. 2018). Species of this family are known from a broad range of environments while the majority of Didymellaceae are economically important plant pathogens causing leaf and stem spots. Didymella and Leptosphaerulina species have previously been reported from marine habitats (Jones et al. 2015, Thambugala et al. 2017, Valenzuela-Lopez et al. 2018). 


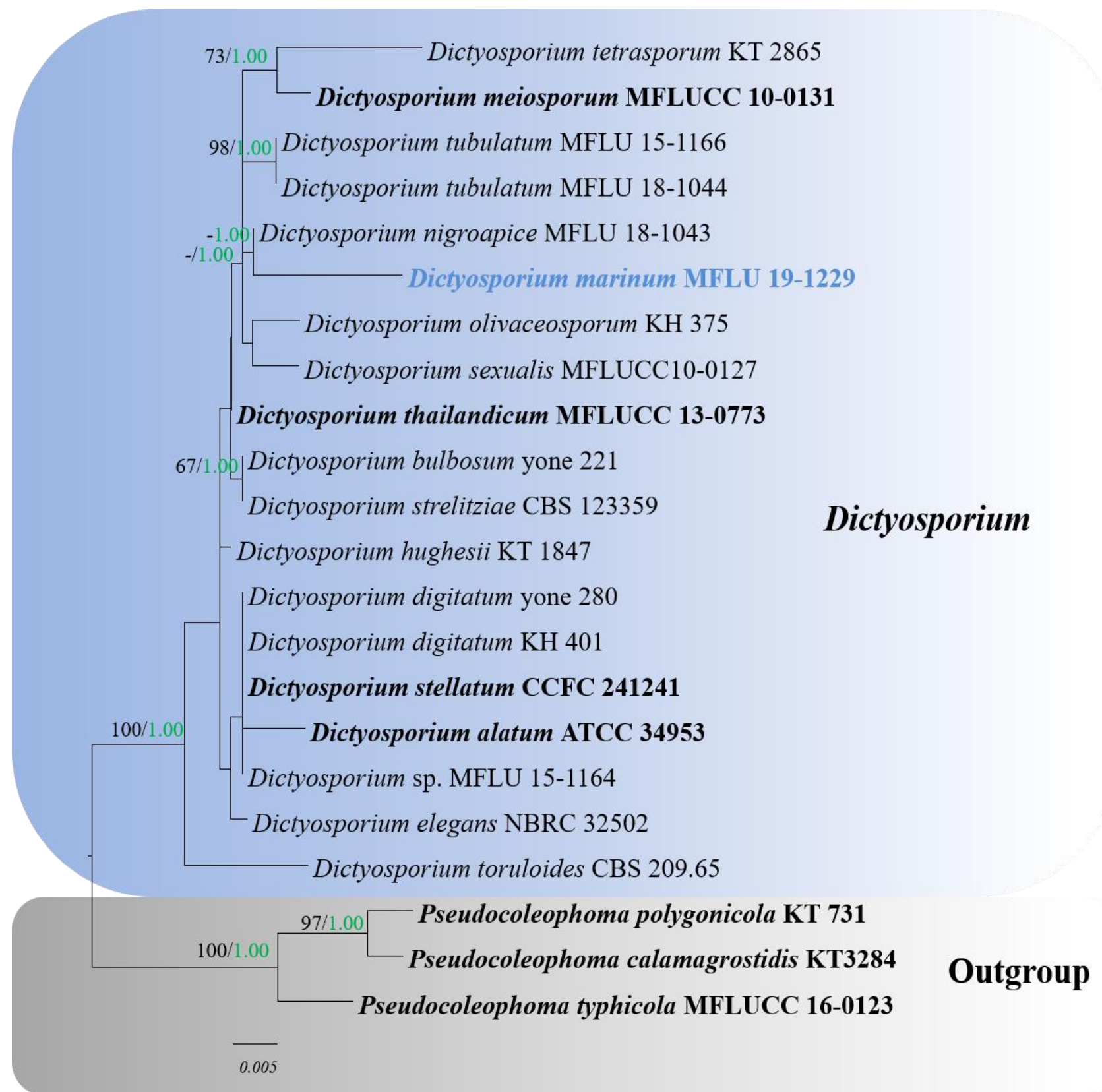

Figure 15 - Maximum likelihood analysis with 1000 bootstrap replicates yielded a best tree with the likelihood value of -1710.267074 . LSU sequence dataset comprised 22 strains of Dictyosporiaceae and Pseudocoleophoma calamagrostidis (KT 731), P. polygonicola (KT 3284) with P. typhicola (MFLUCC 16-0123) as the outgroup taxon. Tree topology of the ML analysis was similar to the BI and in congruent with previous study Tribpromma et al. (2018). The matrix had 93 distinct alignment patterns, with $6.90 \%$ of undetermined characters or gaps. Estimated base frequencies were as follows; $\mathrm{A}=0.249746, \mathrm{C}=0.212290, \mathrm{G}=0.312691, \mathrm{~T}=0.225274$; substitution rates $\mathrm{AC}=4.557369, \mathrm{AG}=7.848767, \mathrm{AT}=3.376704, \mathrm{CG}=0.304332, \mathrm{CT}=$ $10.397771, \mathrm{GT}=1.000000 ;$ gamma distribution shape parameter $\alpha=0.020000$. Maximum likelihood bootstrap (ML, black) values > 65\% and Bayesian posterior probabilities (PP, green) > $0.90 \%$ are given above the nodes. The scale bar indicates 0.005 changes. The ex-type strains are in bold and new isolates in blue bold. 

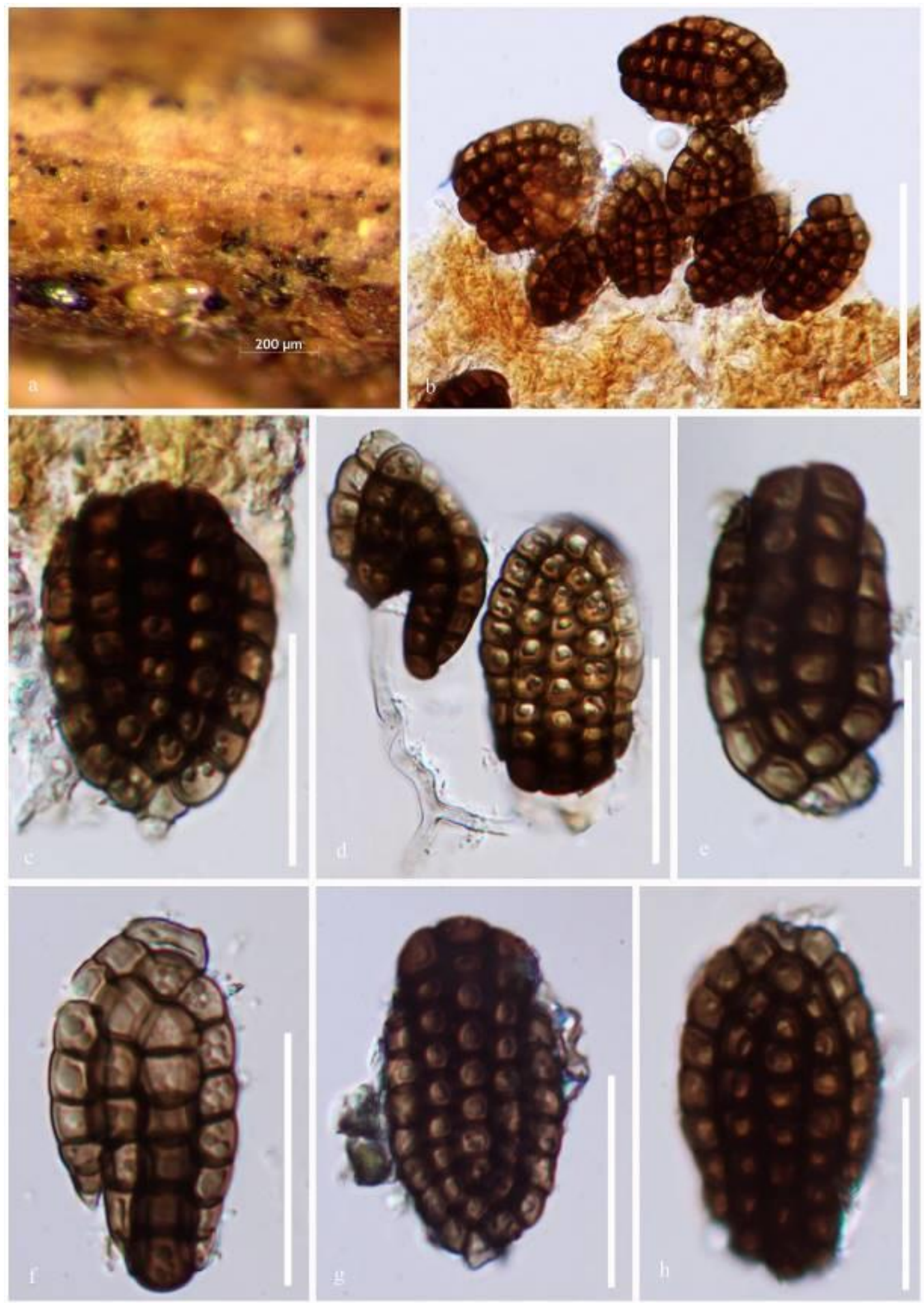

Figure 16 - Dictyosporium marinum (MFLU 19-1229, holotype). a Colonies on submerged wood. b-d Conidia and conidiophores. e- $\mathrm{h}$ Conidia. Scale bars: $\mathrm{a}=200 \mu \mathrm{m}, \mathrm{e}=50 \mu \mathrm{m}, \mathrm{c}-\mathrm{h}=20 \mu \mathrm{m}$. 
Boeremia Aveskamp, Gruyter \& Verkley

Aveskamp et al. (2010) determined the boundaries of Didymellaceae and redefined the genera Epicoccum, Peyronellaea and Stagonosporopsis, and established the genus Boeremia. The genus Boeremia represents the species that are most similar to Phoma exigua (Aveskamp et al. 2010), but it has been phylogenetically shown that they are two distinct groups (Aveskamp et al. 2010, Chen et al. 2017). Identification of Boeremia species, and varieties of Boeremia exigua, are mainly based on host association (Berner et al. 2015) while Jayawardena et al. (2019) raised the most of Boeremia exigua varities upto species level. There are no previous records of Boeremia from Artemisia maritima or any marine based habitats. We herein introduce a new species Boeremia maritima from a marine based habitat.

Boeremia maritima Dayarathne \& E.B.G. Jones, sp.nov.

Fig. 18

Index Fungorum number: IF556576; Facesoffungi number: FoF 06160

Holotype - MFLU 19-1230

Saprobic on Artemisia maritima. Sexual morph: Undetermined. Asexual morph: Conidiomata 140-280 × 100-260 $\mu \mathrm{m}$, pycnidial conidiomata variable in shape and size, mostly globose to subglobose, glabrous, solitary. Ostioles apappillate. Pycnidial wall 8-14.8 $\mu \mathrm{m}$ wide, pseudoparenchymatous, comprising 2-3 cell layers of brown pigmented cells becoming light brown toward inner. Conidiogenous cells ca. 3-5.5 × 2-3.2 $\mu \mathrm{m}$, phialidic, hyaline, simple, smooth, ampulliform to doliiform. Conidia 6-10.3 $\times 2-4 \mu \mathrm{m}$, ellipsoidal to oblong, hyaline, thin walled, smooth, 0-1-euseptate, with small guttules.

Culture characteristics - Colonies on PDA reaching 50-75 mm diam after 14 days, irregular. immersed mycelium completely covered by a compact aerial mat, surface smooth, floccose, with fimbriate margins, upper smoke-grey with some mouse-grey zones; reverse black. Phylogenetic results obtained in the present study reveal genetic similarity between the present starin and the Boeremia exigua species complex.

Material examined - SWEDEN, Bohuslän, Tjärnö par., Koster Islands, Sydkoster, 0.7 km

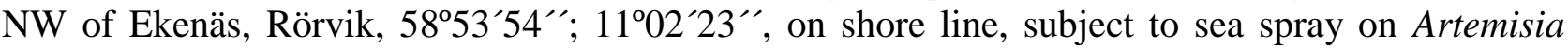
maritima, 20 June 2017, E.B. Gareth Jones, GJ 389b (MFLU 19-1230, holotype); ibid., (BBH, isotype), ex-type living culture (MFLUCC 18-0411).

GenBank numbers - LSU: MN017842; ITS: MN047082; BTUB: MN431491

Notes - Boeremia maritima is similar to the B. exigua in having mostly globose to subglobose, pycnidial conidiomata, apappillate ostioles, phialidic, ampulliform to doliiform conidiogenous cells and ellipsoidal to oblong, 0-1-septate conidia with guttules (Boerema et al. 2004, Van der Aa et al. 2000, De Gruyter \& Boerema 2002, Aveskamp et al. 2010). The new strain shows close phylogenetic affinities to Boeremia opuli (Fig. 17) and pairwise sequence alignment of LSU, ITS and BTUB reveals a difference of 6 bp (out of $1000 \mathrm{bp}$ ), 2 bp (out of $486 \mathrm{bp}$ ) and $3 \mathrm{bp}$ (out of $330 \mathrm{bp}$ ) base pairs respectively. Boeremia maritima can be distinguished from Boeremia opuli by the measurements of conidiomata, conidiogenous cells and conidia (140-280 $\times 100-260$ $\mu \mathrm{m} v s$ 245-360 × 200-305 $\mu \mathrm{m}, 3-5.5 \times 2-3.2 \mu \mathrm{m} v s 4-9(-10) \times 4-7.5 \mu \mathrm{m}, 6-10.3 \times 2-4 \mu \mathrm{m} v s$ 5.5-9.5 $\times 2.5-4 \mu \mathrm{m})($ Chen et al. 2017). Boeremia exigua has a wide host range, while some species often appear to be host specific to a certain group of plants, such as Coffea arabica (Rubiaceae), Forsythia hybrids (Oleaceae), Nerium oleander and Vinca spp. (Apocynaceae), Linum usitatissimum (Linaceae), Populus and Salix (Salicaceae), and Viburnum spp. and occasionally Lonicera sp. (Caprifoliaceae) (Boerema et al. 2004, Van der Aa et al. 2000, De Gruyter \& Boerema 2002, Aveskamp et al. 2010, Chen et al. 2017). Boeremia exigua has previously been reported from Artemisia species while B. exigua has been found from a marine habitat earlier (Jones et al. 2019).

Neocamarosporiaceae Wanas., Wijayaw., Crous \& K.D. Hyde

The family Neocamarosporiaceae was introduced by Wanasinghe et al. (2017) which comprises the genera Dimorphosporicola and Neocamarosporium. Here we introduce two new 
Neocamarosporium marine species; $N$. artemisiae and $N$. maritimae which were collected from Sweden.

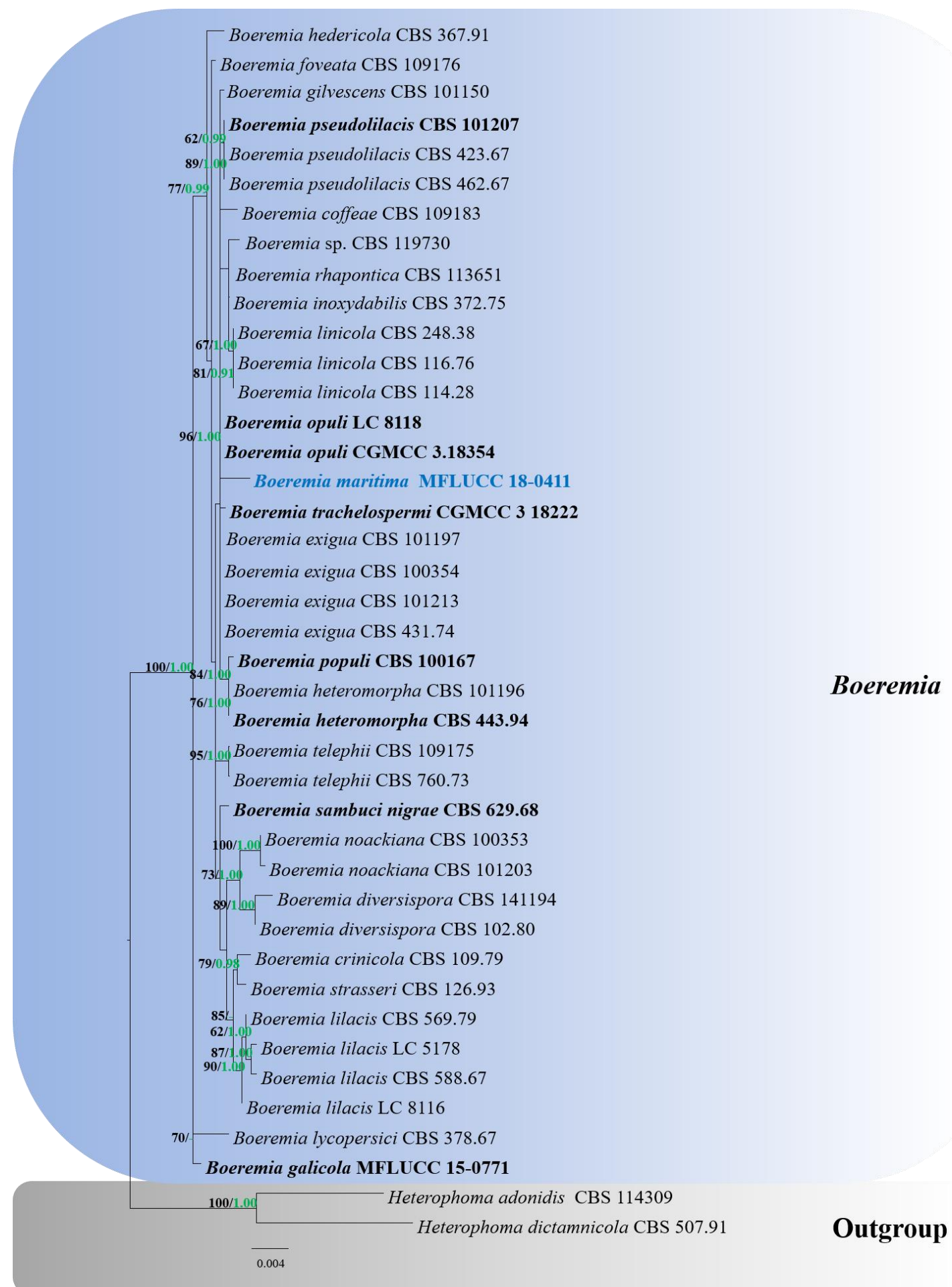

Figure 17 - Maximum likelihood analysis with 1000 bootstrap replicates yielded a best tree with the likelihood value of -4071.792778 . The combined LSU, ITS and BTUB sequence datasets comprised 41 strains of Boeremia and related taxa with Heterophoma adonidis (CBS 114309) and $H$. dictamnicola (CBS 507.91) as the outgroup taxa. Tree topology of the ML analysis was similar to the BI. The matrix had 141 distinct alignment patterns, with $9.23 \%$ of undetermined characters or gaps. Estimated base frequencies were as follows; $\mathrm{A}=0.242756, \mathrm{C}=0.237654, \mathrm{G}=0.269612$, $\mathrm{T}=0.249978$; substitution rates $\mathrm{AC}=1.780840, \mathrm{AG}=2.011469, \mathrm{AT}=1.626630, \mathrm{CG}=0.439694$, $\mathrm{CT}=9.798781, \mathrm{GT}=1.000000$; gamma distribution shape parameter $\alpha=0.020000$. Maximum 
likelihood bootstrap (ML, black) values $>65 \%$ and Bayesian posterior probabilities (PP, green) $>$ $0.90 \%$ are given above the nodes. The scale bar indicates 0.004 changes. The ex-type strains are in bold and new isolates in blue bold.
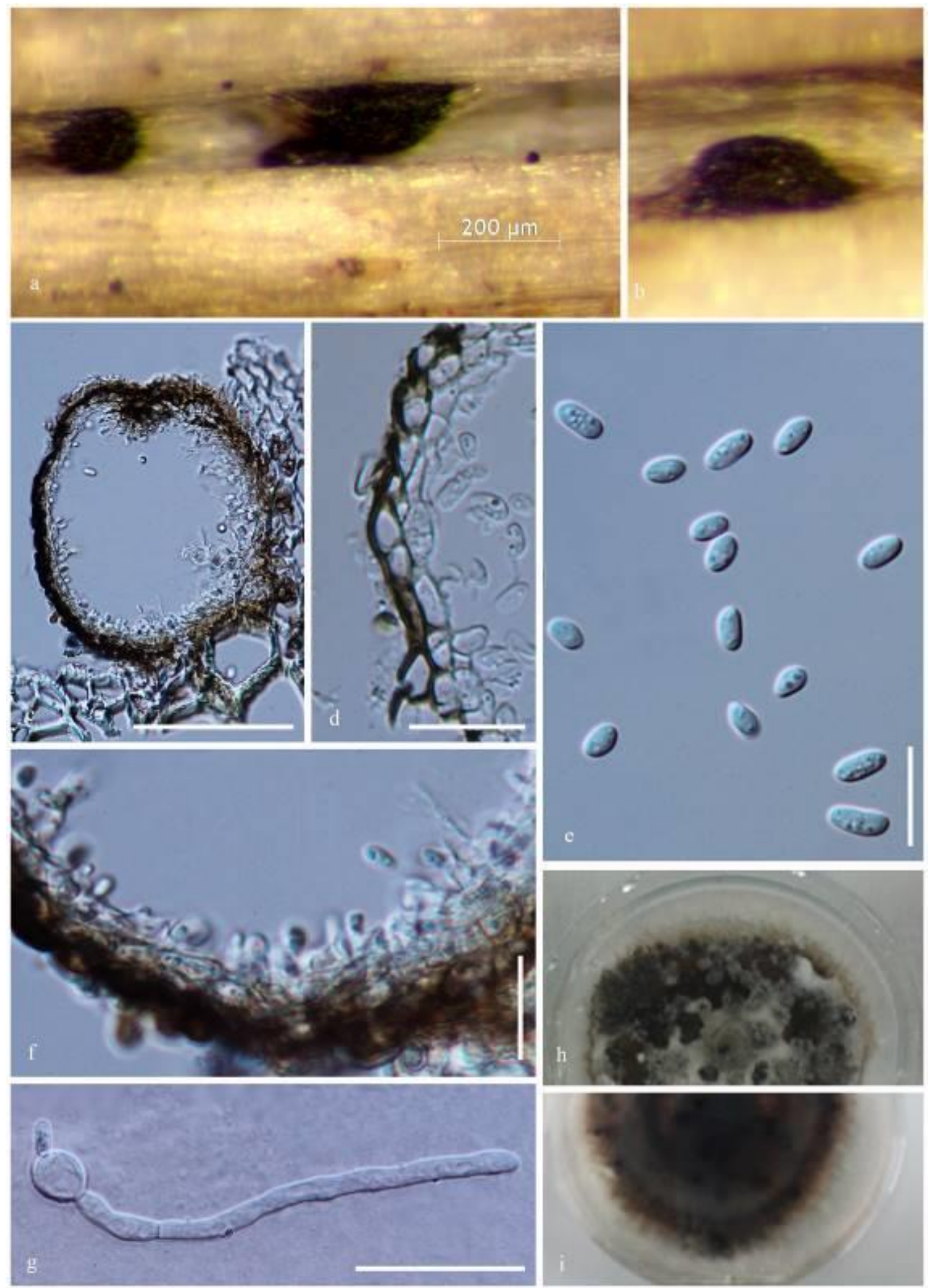

Figure 18 - Boeremia maritima (MFLU 19-1230, holotype). a, b Pycnidial conidiomata on host. c Section through conidioma. d Conidiomal wall. e Conidia. f Conidia attached to the conidiogenus 
cells. g Germinating conidium. $\mathrm{h}$, i Colonies on PDA (h-upper, i-lower). Scale bars: $\mathrm{a}, \mathrm{c}=200 \mu \mathrm{m}$, $\mathrm{g}=50 \mu \mathrm{m}, \mathrm{e}, \mathrm{f}=20 \mu \mathrm{m}, \mathrm{d}=10 \mu \mathrm{m}$.

Neocamarosporium Crous \& M.J. Wingf.

Neocamarosporium was introduced to accommodate Neocamarosporium goegapense collected from South Africa, that morphologically resembles Camarosporium (Crous et al. 2014). In a recent study, Wanasinghe et al. (2017) expanded this genus to include its sexual morphs. Currently there are 18 accepted species in Neocamarosporium (Wanasinghe et al. 2017).

Neocamarosporium artemisiae Dayarathne \& E.B.G. Jones, sp. nov.

Fig. 20

Index Fungorum number: IF556577; Facesoffungi number: FoF 06161

Etymology - Epithet derived from the host genus Artemisia.

Holotype - MFLU 19-1231

Saprobic on woody branches. Asexual morph: Conidiomata pycnidial, 125-150 $\times 200-225$ $\mu \mathrm{m}(\overline{\mathrm{x}}=138 \times 220 \mu \mathrm{m}, \mathrm{n}=10)$, solitary to gregarious, black, superficial, unilocular, with a papillate ostiole. Pycnidial wall 35-45 $\mu \mathrm{m}$ wide, multi-layered, thick, comprising 4-6 layers, outer layer heavily pigmented, thick-walled, comprising blackish to dark brown cells of textura angularis, with setae $80-100 \times 3-5 \mu \mathrm{m}$, cells towards the inside lighter, inner layer composed of 23 layers, hyaline, thin-walled cells of textura angularis. Conidiophores reduced to conidiogenous cells. Conidiogenous cells enteroblastic, annellidic, doliiform, integrated, solitary, hyaline, smoothwalled, and formed from the inner layer of pycnidium wall. Conidia $12-16 \times 3-6 \mu \mathrm{m}(\overline{\mathrm{x}}=14 \times 4.5$ $\mu \mathrm{m} ; \mathrm{n}=30$ ), oblong, straight to slightly curved, rounded at both ends, aseptate when immature becoming 1-septate, smooth-walled, initially hyaline, becoming yellowish brown at maturity. Sexual morph: Undetermined.

Material examined - SWEDEN, Bohuslän, Tjärnö par., Koster Islands, Sydkoster, 0.7 km

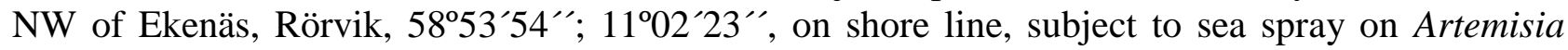
maritima, 20 June 2017, E.B. Gareth Jones, GJ 392 (MFLU 19-1231, holotype); ibid., (BBH, isotype).

GenBank submissions: LSU: MN017843; SSU: MN017910; ITS: MN047083; TEF: MN077062

Notes - Phylogenetic results of the novel taxon Neocamarosporium artemisiae (MFLU 191231) shows it grouped in a clade comprising $N$. calvescens (CBS 246.79), N. chenopodii (CBS 344.78), N. halimiones (CBS 432.77), N. obiones (CBS 432.77), N. phragmitis (MFLUCC 170756) and $N$. maritimae sp. nov. with low statistical support (Fig. 19). However, the basepair differences of ITS of $N$. artemisiae to $N$. obiones and $N$. phragmitis are $0.81 \%$ (4 bp out of $489 \mathrm{bp}$ ) and $3.0 \%$ (16 bp out of $522 \mathrm{bp}$ ), respectively. While TEF base pair difference of $N$. artemisiae to $N$. phragmitis is $1.3 \%$ (12 bp out of $897 \mathrm{bp}$ ). There are no ITS and TEF DNA sequence data for $N$. calvescens and $N$. chenopodii for comparison. Asexual morphs of Neocamarosporium mostly produce muriform conidia, however, ascochyta-like and phoma-like asexual morphs have also been reported (Wanasinghe et al. 2017). Apart from our new strain, an asexual morph is only known from $N$. obiones among members of this clade. Conidial characteristics of $N$. obiones, such as, shape, colour and septation are similar to those of $N$. artemisiae (Verkley et al. 2014). However, the conidia of $N$. obiones are shorter (8-)9-12(-14) $\mu \mathrm{m}$ than those of $N$. artemisiae $(12-16 \mu \mathrm{m})$. Furthermore, conidiomata of the new taxon comprises setae that are 80-100 $\mu \mathrm{m}$ in length, a character not observed in other Neocamarosporium species. Several Neocamarosporium taxa have been reported form marine to saline habitats while only $N$. obiones and $N$. salicorniicola have been identified to species level (Wanasinghe et al. 2017). Only 6 bp out of 896 bp of TEF loci are different $(0.7 \%)$ in between newly introducing $N$. artemisiae and $N$. maritimae species while, there are no base pair differences in ITS regions. 


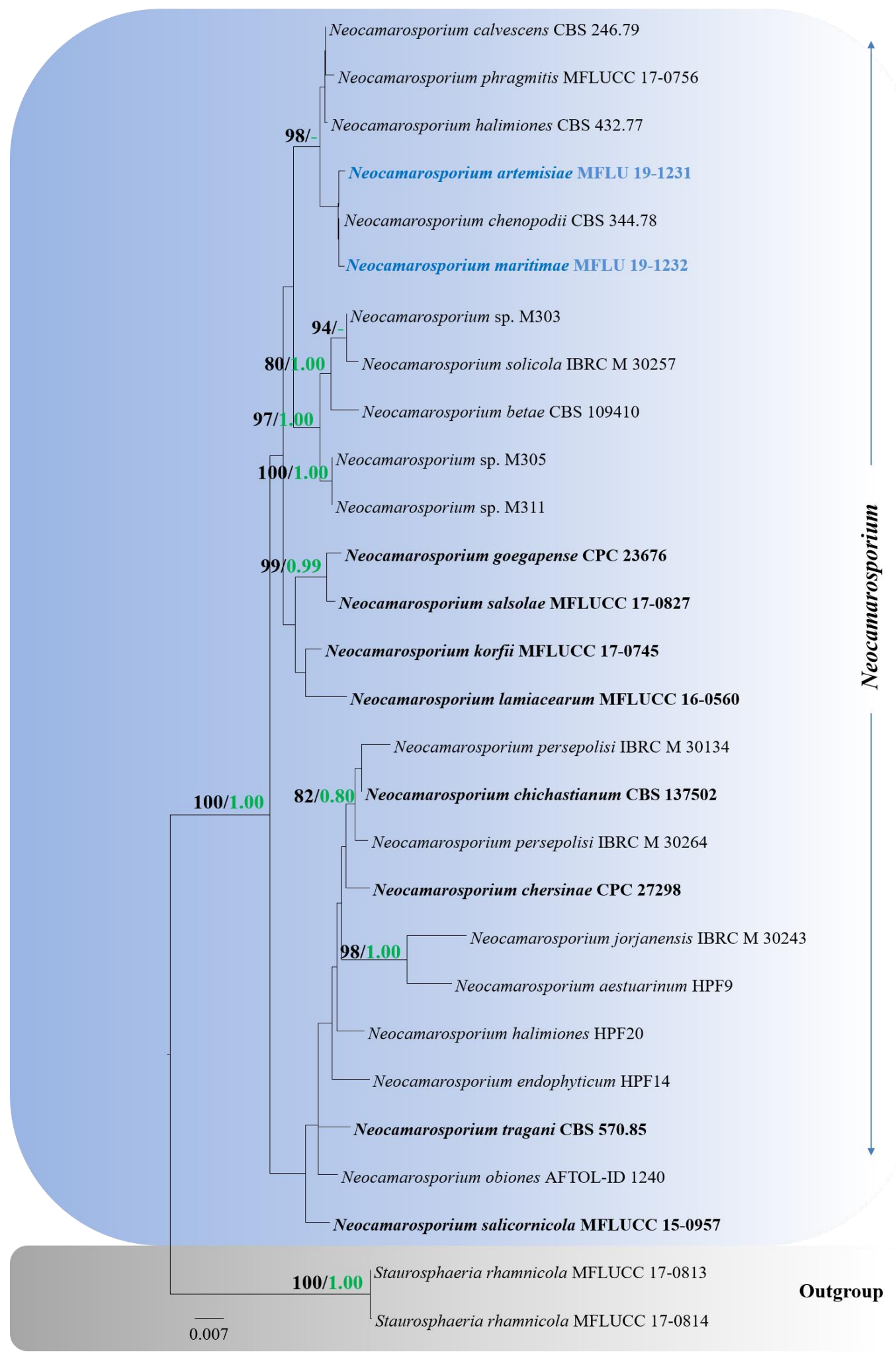

Figure 19 - Maximum likelihood analysis with 1000 bootstrap replicates yielded a best tree with the likelihood value of -7374.727686 . The combined LSU, SSU, ITS and TEF sequence datasets comprised 28 strains of Neocamarosporiaceae and related taxa with Staurosphaeria rhamnicola (MFLUCC 17-0813) and (MFLUCC 17-0814) as the outgroup taxa. Tree topology of the ML analysis was similar to the BI. The matrix had 346 distinct alignment patterns, with $36.49 \%$ of undetermined characters or gaps. Estimated base frequencies were as follows; $\mathrm{A}=0.244178, \mathrm{C}=$ $0.240851, \mathrm{G}=0.266682, \mathrm{~T}=0.248290$; substitution rates $\mathrm{AC}=1.508884, \mathrm{AG}=1.935890, \mathrm{AT}=$ 1.274607, $\mathrm{CG}=0.778421, \mathrm{CT}=6.799020, \mathrm{GT}=1.000000$; gamma distribution shape parameter $\alpha$ 
$=0.020000$. Maximum likelihood bootstrap (ML, black) values $>65 \%$ and Bayesian posterior probabilities (PP, green) $>0.90 \%$ are given above the nodes. The scale bar indicates 0.008 changes. The ex-type strains are in bold and new isolates in blue bold.
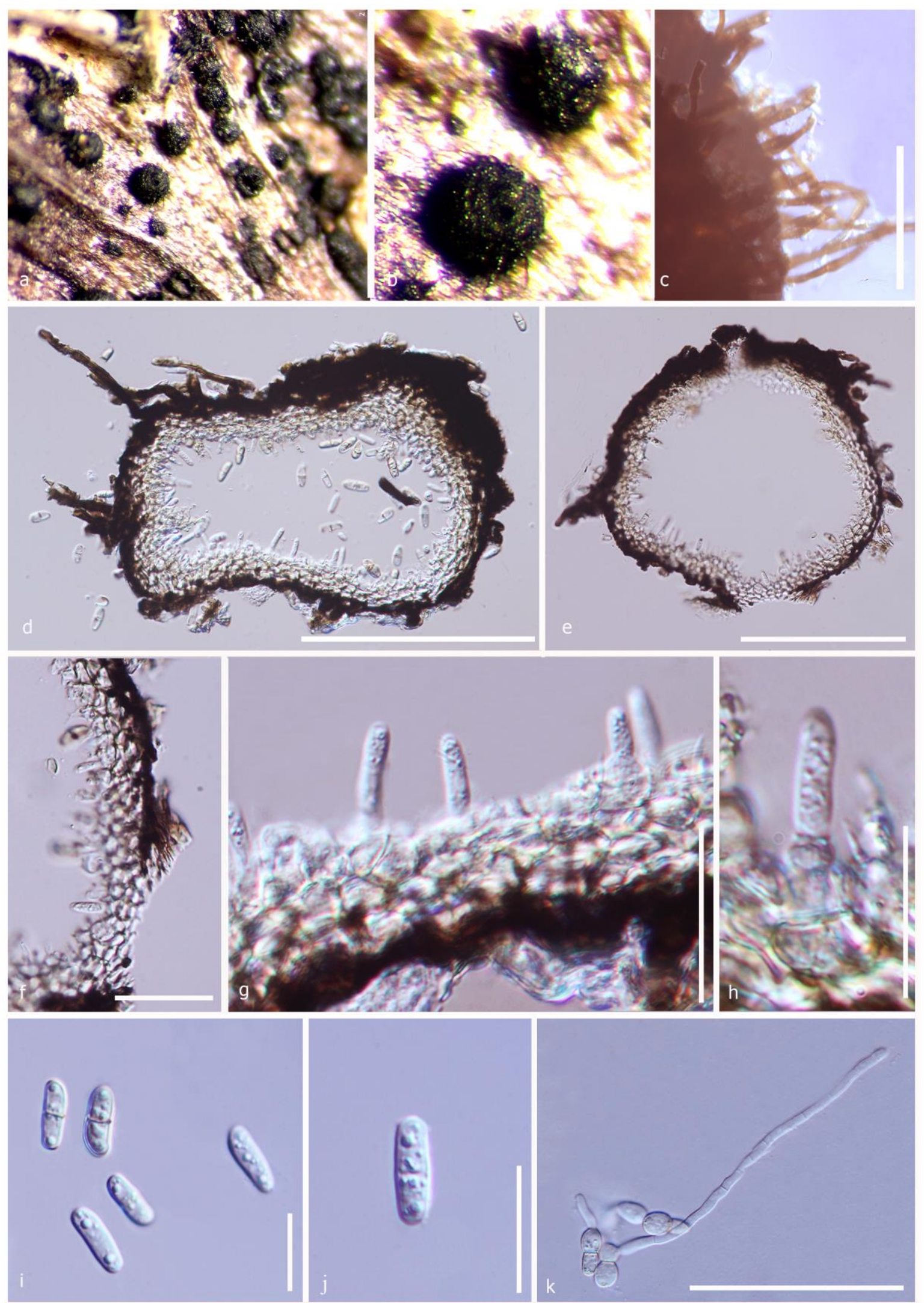

Figure 20 - Neocamarosporium artemisiae (MFLU 19-1231, holotype). a, b Appearance of ascomata on host. c Setae. d, e Sections through pycnidial conidiomata. f Pycnidial wall. g, h 
Conidia attached to the conidiogenus cells. $\mathrm{i}-\mathrm{k}$ Conidia. 1 Germinating conidia. Scale bars: $\mathrm{c}-\mathrm{e}=$ $100 \mu \mathrm{m}, \mathrm{l}=50 \mu \mathrm{m}, \mathrm{f}-\mathrm{h}=20 \mu \mathrm{m}, \mathrm{i}-\mathrm{k}=10 \mu \mathrm{m}$.

Neocamarosporium maritimae Dayarathne \& E.B.G. Jones, sp. nov.

Fig. 21

Index Fungorum number: IF556578; Facesoffungi number: FoF 06162

Etymology - Epithet derived from the host habitat epithet maritima.

Holotype - MFLU 19-1232

Saprobic on Artemisia maritima subjected to sea spray. Asexual morph: Undetermined. Sexual morph: Ascomata 200-250 $\mu \mathrm{m}$ high, 180-200 $\mu \mathrm{m}$ diam $(\overline{\mathrm{x}}=240.1 \times 190.4 \mu \mathrm{m}, \mathrm{n}=5)$, black, superficial to semi-immersed, confluent, gregarious, cupulate when dry, globose, uniloculate, with an apapillate ostiole. Ostiole central, short, slightly sunken, minute and inconspicuous at the surface, smooth, ostiolar canal filled with hyaline cells. Peridium 20-35 $\mu \mathrm{m}$ wide, thin, comprising 2-3 layers, reddish brown to brown, cells towards the inside lighter, flattened, thin walled cells of textura angularis. Hamathecium comprising numerous, 2-3.6 $\mu \mathrm{m}$ (n $=40)$ wide, filamentous, branched, septate, pseudoparaphyses. Asci 75-100 × 11-16 $\mu \mathrm{m}(\overline{\mathrm{x}}=88.5$ $\times 14 \mu \mathrm{m}, \mathrm{n}=40), 8$-spored, bitunicate, fissitunicate, cylindrical-clavate to cylindrical, pedicellate, apex rounded with a minute ocular chamber. Ascospores $12-20 \times 6-8 \mu \mathrm{m}(\overline{\mathrm{x}}=18 \times 8.4 \mu \mathrm{m}, \mathrm{n}=$ 30), overlapping uniseriate, muriform, mostly ellipsoidal, with 3 transversely septate, with one longitudinal septum, deeply constricted at the middle septum, slightly constricted at remaining septa, initially hyaline, becoming yellowish brown at maturity, upper part wider than lower part, slightly paler, rounded at both ends, conical at lower end, surrounded by a mucilaginous sheath.

Material examined - SWEDEN, Bohuslän, Tjärnö par., Koster Islands, Sydkoster, 0.7 km

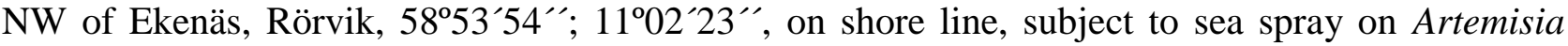
maritima, 20 June 2017, E.B. Gareth Jones, GJ 389a (MFLU 19-1232 holotype); ibid., (BBH, isotype).

GenBank submissions: LSU: MN017844; SSU: MN017911; ITS: MN047084; TEF: MN077061

Notes - Neocamarosporium maritimae best fits Neocamarosporium by having superficial to semi-immersed, confluent, gregarious ascomata with an apapillate ostiole, a hamathecium comprising numerous, filamentous, branched septate, pseudoparaphyses, cylindrical-clavate to cylindrical asci with an apex rounded with a minute ocular chamber, muriform ascospores that deeply constricted at the middle septum and slightly constricted at remaining septa, with a mucilaginous sheath (Wanasinghe et al. 2017). Neocamarosporium maritimae is phylogenetically closely related to $N$. chenopodii in our phylogenetic analyses with combined ITS, LSU, SSU and TEF data (Fig. 19) However, N. maritimae can be clearly distinguished from $N$. chenopodii by having muriform ascospores with 3-transverse septa and a one longitudinal septum whereas, $N$. chenopodii has only 3 -transverse septa and lacks longitudinal septa (Ellis \& Kellerm 1888). There are no ITS and TEF data generated for $N$. chenopodii (CBS 344.78) to compare the base pair differences following the guidelines of Jeewon \& Hyde (2016). However, there are no base pair differences in LSU and SSU regions of those two species. Neocamarosporium maritimae shares morphological similarities to $N$. lamiacearum (Wanasinghe et al. 2017) by the presence of cylindrical-clavate to cylindrical asci and muriform ascospores. They can easily be distinguished by asci and ascospore measurements. Asci of $N$. maritimae are shorter than those of $N$. lamiacearum (75-100 $\mu \mathrm{m} v s$ 100-120 $\mu \mathrm{m})$ and ascospores of $N$. maritimae are narrower than those of $N$. lamiacearum (6-8 $\mu \mathrm{m}$ vs 8-11 $\mu \mathrm{m}$ ) (Wanasinghe et al. 2017). Neocamarosporium calvescens (=Sphaeria calvescens) also have similar morphologies to $N$. maritimae. Neocamarosporium calvescens can be clearly distinguished from $N$. maritimae in having ascomata covered with a velvety tomentum of stiff brown hyphae (Wehmeyer 1961).

Nigrogranaceae Jaklitsch \& Voglmayr

Jaklitsch \& Voglmayr (2016) introduced the family Nigrogranaceae to accommodate the genus Nigrograna based on morphology and phylogeny. 


\section{Nigrograna Gruyter, Verkley \& Crous}

Nigrograna was introduced by Jaklitsch \& Voglmayr (2016) as a monotypic genus comprising the asexual species, N. mackinnonii. Ahmed et al. (2014) showed the sequence similarity of $N$. mackinnonii to the isolate labelled Biatriospora marina (type), hence, Nigrograna was considered a synonym of Biatriospora (Jaklitsch \& Voglmayr 2016). Subsequently, four plant endophytic species (B. antibiotica, B. carollii, B. peruviensis and B. yasuniana) with unknown sexual states were introduced by Kolař́k et al. (2017). Jaklitsch \& Voglmayr (2016) observed several sexual morph strains that were phylogenetically related to $N$. mackinnonii, but produced entirely morphologically different ascospores from Biatriospora marina. Therefore, they questioned the validity of the B. marina strain used by Ahmed et al. (2014) and recognized that these two genera are distinct (Kolařík 2018). Following this generic concept, Tibpromma et al. (2017) introduced new sexual species, $N$. cangshanensis, as a saprobe on decaying wood in China. Phylogenetic analyses based on ITS DNA sequence data by Kolařík et al. (2017) showed that the species described by Kolařík et al. (2017), Borman et al. (2016), Jaklitsch \& Voglmayr (2016), Travadon et al. (2016) and Tibpromma et al. (2017 formed distinct phylogenetic lineages. Therefore, this genus currently comprises 12 species (Kolařík 2018, Index Fungorum 2019). In this study, we are introducing two novel species to this genus from marine based habitats.

Nigrograna samueliana Devadatha, V.V. Sarma \& E.B.G. Jones sp. nov.

Figs 23, 24 Index Fungorum number: IF555779; Facesoffungi number: FoF 06163

Etymology - Specific epithet in honor of Dr. Samuel P. Meyers for his great contributions to marine mycology.

Holotype - AMH-10018

Saprobic on decaying mangrove wood. Sexual morph Ascomata $200-520 \times 120-320 \mu \mathrm{m}(\overline{\mathrm{x}}=$ $340 \times 230 \mu \mathrm{m}, \mathrm{n}=5$ ), sub-globose to oval, semi-immersed to immersed in bark and wood, black spots on host surface, subiculate, papillate, ostiolate, aggregated in small groups, brown to black often associated with pycnidia. Ostiole 75-120 × 60-80 $\mu \mathrm{m}(\overline{\mathrm{x}}=99 \times 70 \mu \mathrm{m}, \mathrm{n}=5)$, central, apex rounded. Peridium 15-35 $\mu \mathrm{m}$ wide $(\overline{\mathrm{x}}=25 \mu \mathrm{m}, \mathrm{n}=5)$, comprising several layers of thick-walled cells of textura angularis, brown. Hamathecium 1-2 $\mu \mathrm{m}$ wide, pseudoparaphyses, dense, filamentous, septate, branched, anastomosing between and above the asci, embedded in a mucilaginous matrix. Asci $65-75 \times 6-8 \mu \mathrm{m}(\overline{\mathrm{x}}=68 \times 6 \mu \mathrm{m}, \mathrm{n}=20), 8$-spored, bitunicate, fissitunicate, thick-walled, clavate to cylindric-clavate, short pedicellate, apically rounded with a small ocular chamber. Ascospores $9-13 \times 2-4 \mu \mathrm{m}(\overline{\mathrm{x}}=10 \times 2 \mu \mathrm{m}, \mathrm{n}=25)$, uniseriate, overlapping at the apex of asci, fusoid to ellipsoidal, with upper cells slightly wider than lower cells, straight, thick-walled, outer walls verrucose, initially reddish brown, becoming pale greyish-brown at maturity, 1-2 septate when young, becoming 3-septate with age, highly pigmented and constricted at the median septum in contrast to other septa. Asexual morph Coelomycetous on the natural host: Pycnidia similar to ascomata, internally white, but smaller, 95-175 $\times 125-300 \mu \mathrm{m}(\overline{\mathrm{x}}=120 \times 207$ $\mu \mathrm{m}, \mathrm{n}=5)$, globose to sub-globose, immersed. Pycnidial wall $25-60 \mu \mathrm{m}$ wide $(\overline{\mathrm{x}}=35 \mu \mathrm{m}, \mathrm{n}=5)$, pseudoparenchymatous, brown cells. Conidiophores 10-30 × 1-2.5 $\mu \mathrm{m}(\overline{\mathrm{x}}=20 \times 1.5 \mu \mathrm{m}, \mathrm{n}=10)$, arising from the wall in palisadic arrangement, filamentous, septate, hyaline, unbranched, with a terminal phialide. Solitary minute pegs and lageniform to sub-cylindrical phialides are arranged apically on the conidiophores. Conidia $2-4 \times 1-2 \mu \mathrm{m}(\overline{\mathrm{x}}=3 \times 1.3 \mu \mathrm{m}, \mathrm{n}=15)$, oblong to cylindrical, unicellular with 1-2 small granules, hyaline, smooth conidia are produced from the terminal ends of the conidiophores.

Culture characteristics - Ascospores germinating on 50\% sea water agar within 24 hours, with germ tubes developed from both end cells and lateral sides of ascospores. Colonies on MEA slow growing, reaching 10-15 mm diam. after 15 days of incubation at $25^{\circ} \mathrm{C}$, surface pale greyish to light brown on the surface, reverse pale brown, filamentous, circular, umbonate.

Material examined - INDIA, Tamil Nadu, Parangipettai mangroves $\left(11.59^{\circ} \mathrm{N} 79.5^{\circ} \mathrm{E}\right)$, on decaying wood of Avicennia marina (Acanthaceae), 23 April 2018, B. Devadatha, (AMH-10018, holotype) ex-type living culture, NFCCI-4383. 

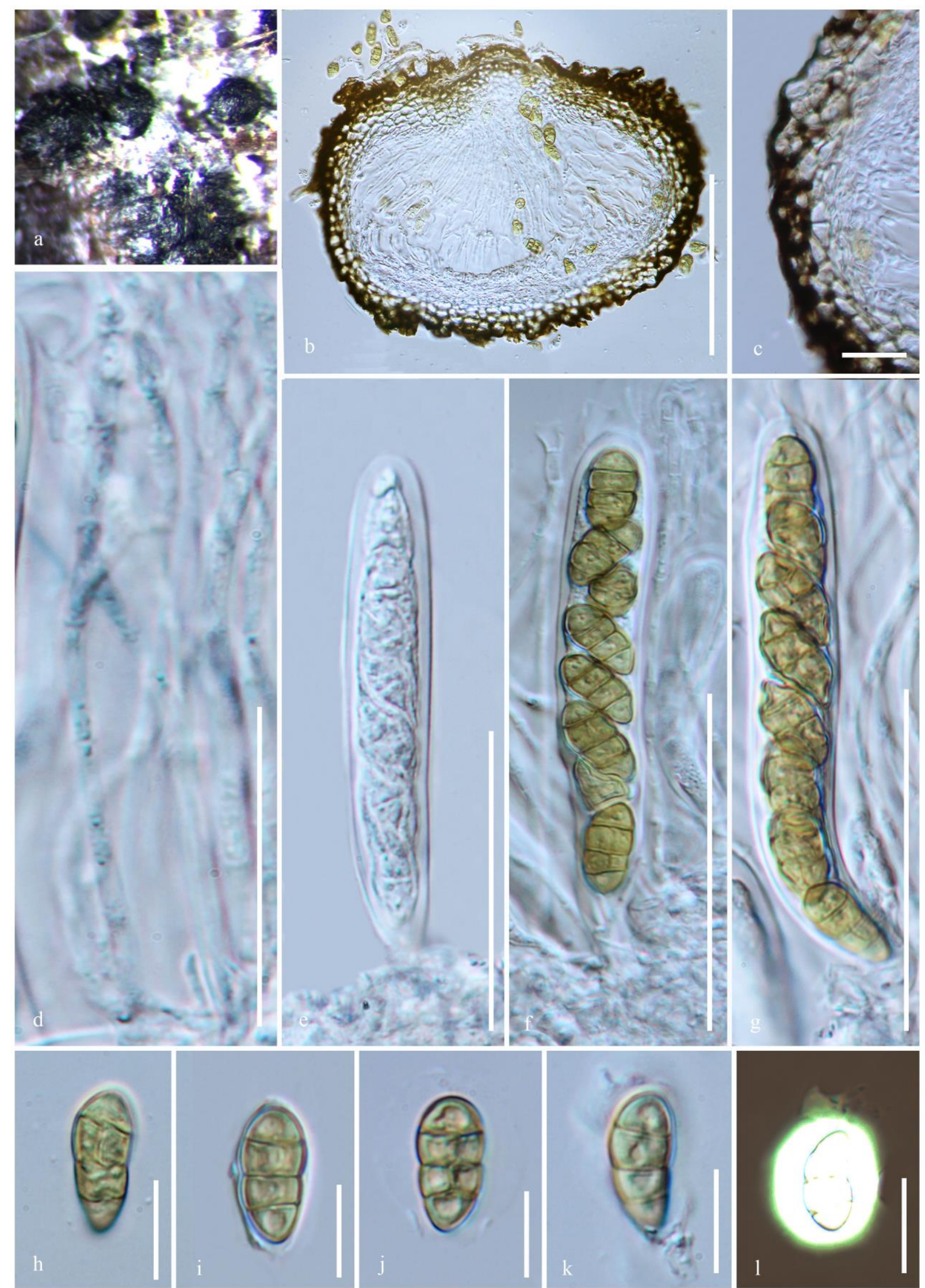

Figure 21 - Neocamarosporium maritimae (MFLU 19-1232, holotype). a Ascomata on stems of Artemisia maritima. b Section of ascoma. c Peridium. d Pseudoparaphyses. e-g Asci. h-k Ascospores. 1 Ascospore stained with India ink to highlight the sheath. Scale bars: $b=100 \mu \mathrm{m}, \mathrm{d}-\mathrm{g}$ $=50, \mathrm{c}=20 \mu \mathrm{m}, \mathrm{h}-1=10 \mu \mathrm{m}$. 


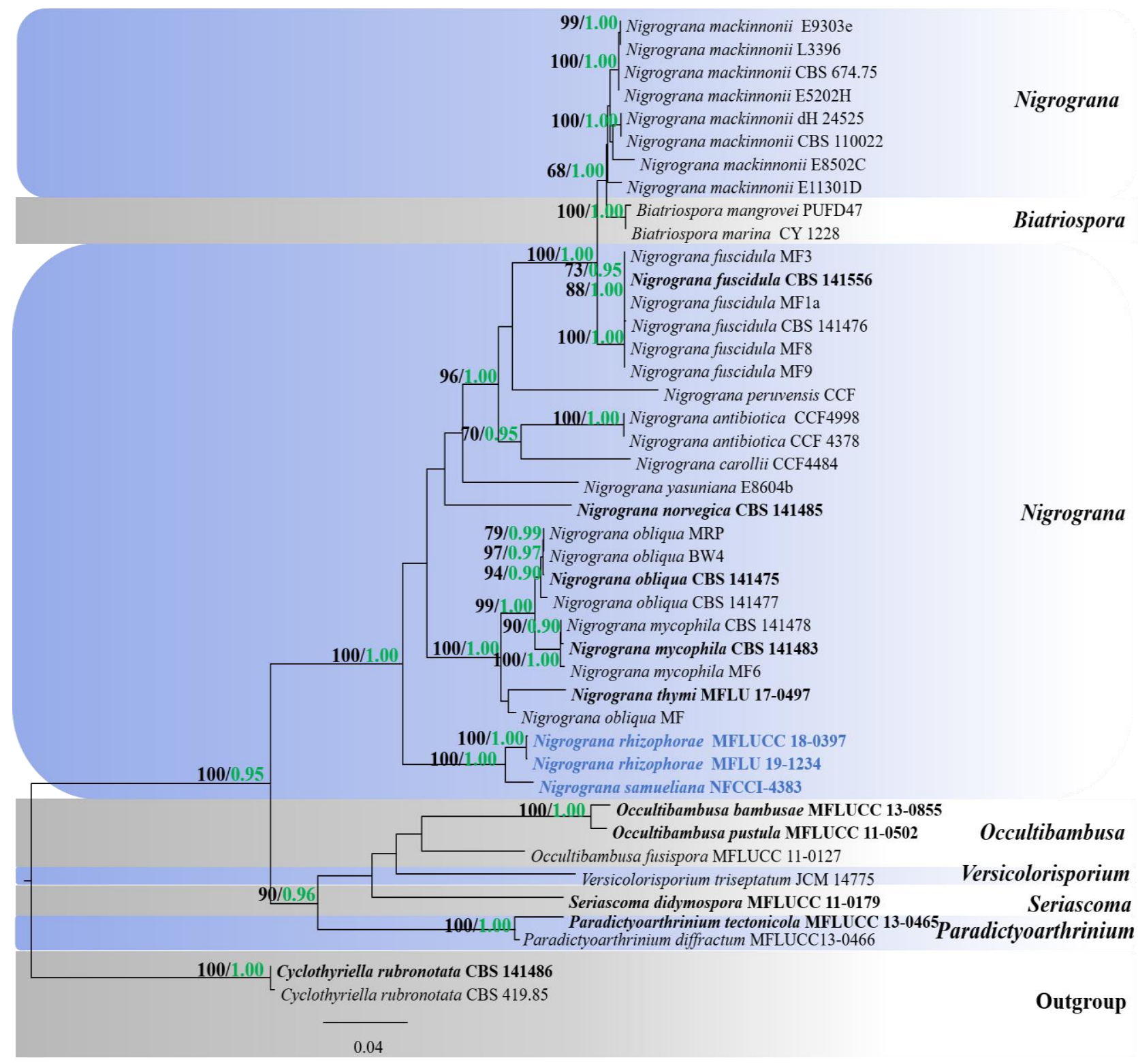

Figure 22 - Maximum likelihood analysis with 1000 bootstrap replicates yielded a best tree with the likelihood value of -16401.828168 . The combined LSU, ITS, TEF and RPB2 sequence datasets comprised 43 strains of Nigrogranaceae, Occultibambusaceae and Parathyridariaceae with Cyclothyriella rubronotata (CBS 141486 and CBS 419.85) as the outgroup taxa. Tree topology of the ML analysis was similar to the BI and in congruent with previous studies (Jaklitsch \& Voglmayr 2016, Ahmed et al. 2018, Hyde et al. 2013). The matrix had 1171 distinct alignment patterns, with $26.12 \%$ of undetermined characters or gaps. Estimated base frequencies were as follows; $\mathrm{A}=0.248016, \mathrm{C}=0.252034, \mathrm{G}=0.270020, \mathrm{~T}=0.229930$; substitution rates $\mathrm{AC}=$ 1.619520, $\mathrm{AG}=4.018583, \mathrm{AT}=1.649857, \mathrm{CG}=1.110080, \mathrm{CT}=11.161648, \mathrm{GT}=1.000000$; gamma distribution shape parameter $\alpha=0.550382$. Maximum likelihood bootstrap (ML, black) values $>65 \%$ and Bayesian posterior probabilities (PP, green) $>0.90 \%$ are given above the nodes. The scale bar indicates 0.04 changes. The ex-type strains are in bold and new isolates in blue bold. 


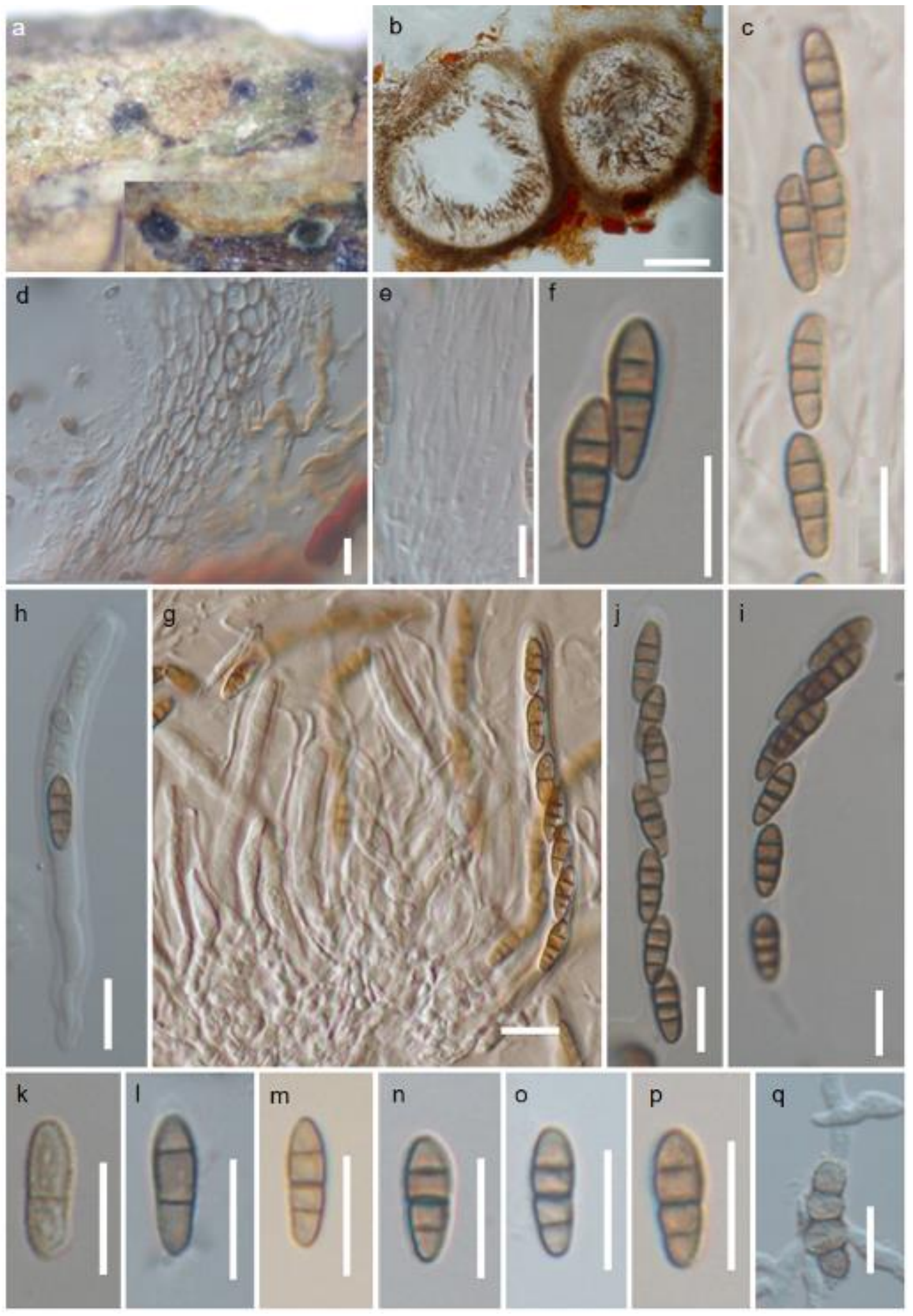

Figure 23 - Sexual morph of Nigrograna samueliana (AMH-10018, holotype). a Ascomata semi-immersed in decaying wood. b Vertical section of ascomata. d Peridial wall layers. e Filamentous pseudoparaphyses. g-i Immature and mature asci. c, f, k-p Immature and mature ascospores. $\mathrm{q}$ Germinating ascospore. Scale bars: $\mathrm{b}=100 \mu \mathrm{m}, \mathrm{c}-\mathrm{q}=10 \mu \mathrm{m}$. 

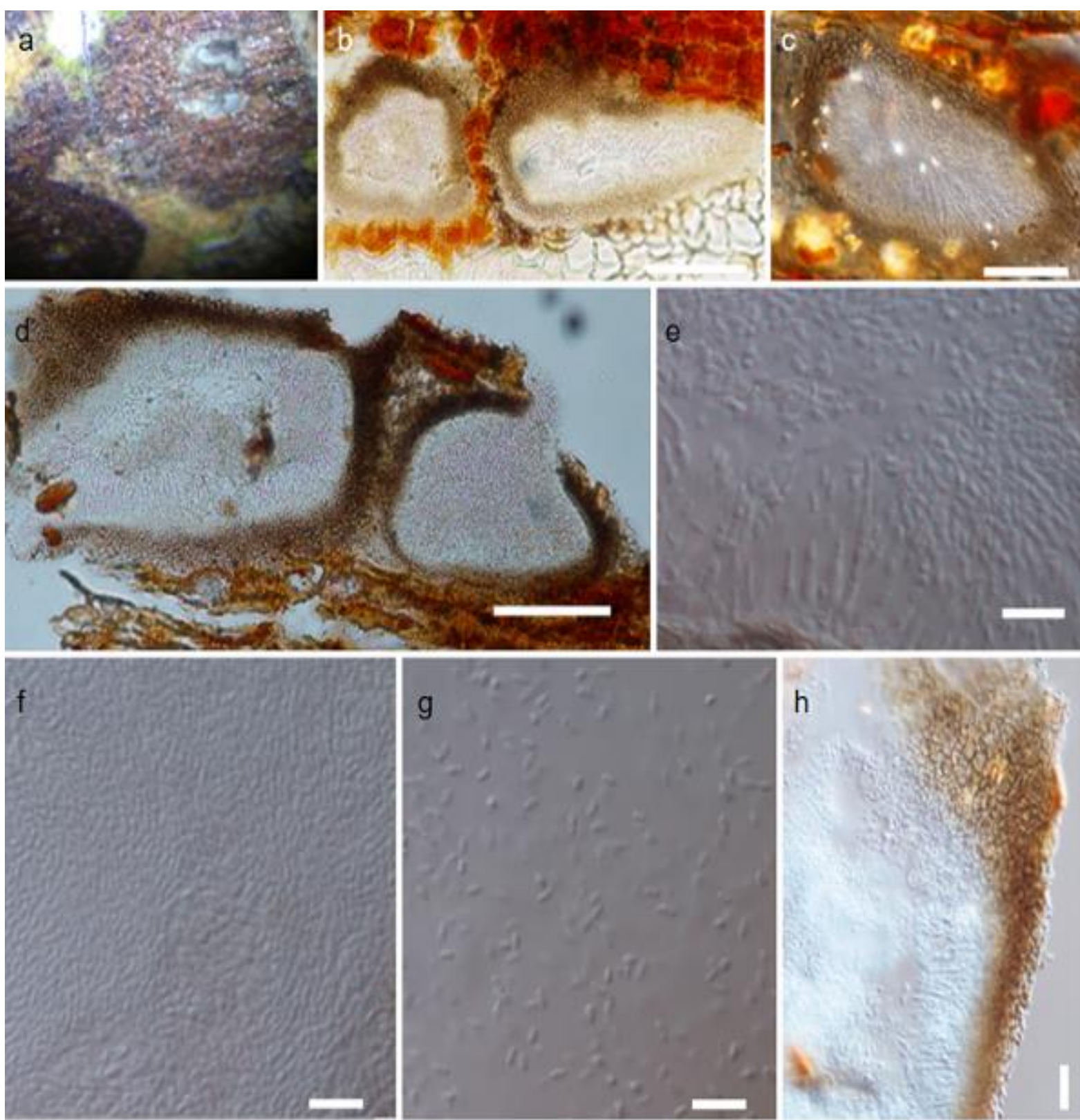

g

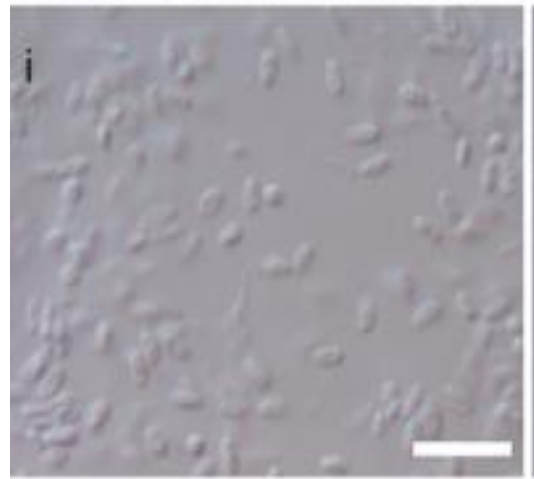

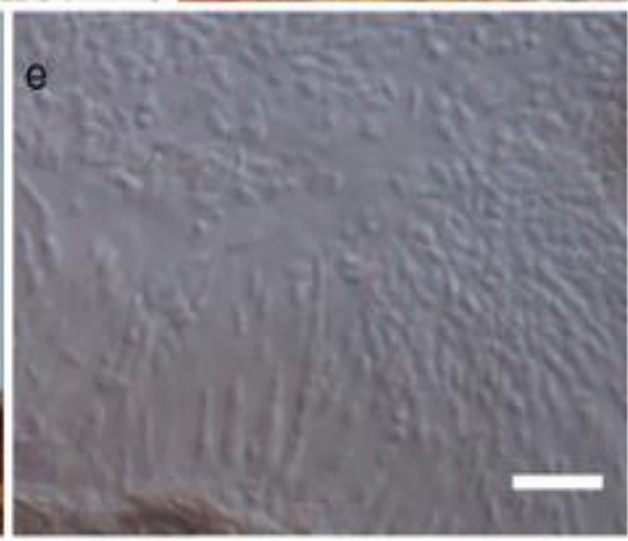
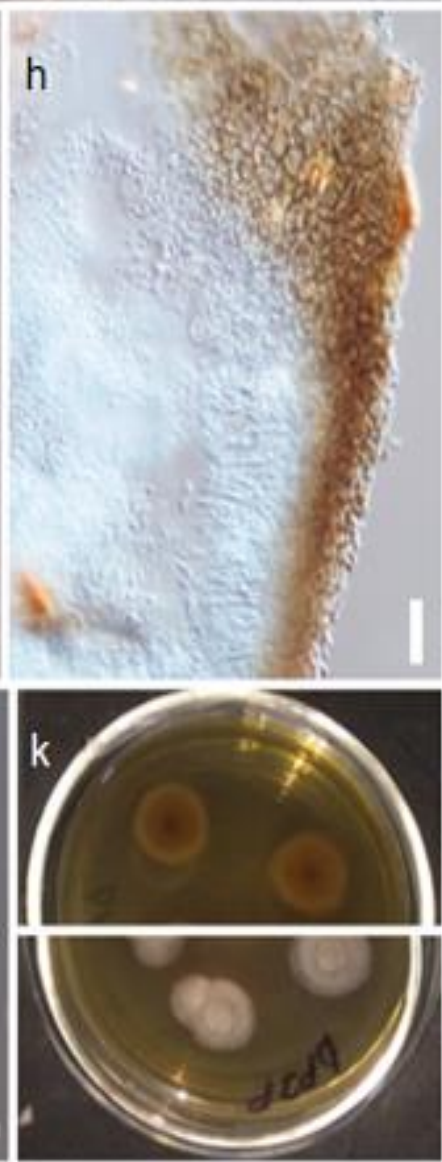

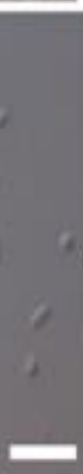

Figure 24 - Asexual morph of Nigrograna samueliana (AMH-10018). a Asexual morph on the natural host showing pycnidia. b-d Pycnidia in vertical section. e Conidiophores with phialides. $h$ Peridium. f, g, i, j Immature and mature conidia. $k$ Reverse and front view of culture. Scale bars: $b-$ $\mathrm{d}=100 \mu \mathrm{m}, \mathrm{e}-\mathrm{j}=10 \mu \mathrm{m}$.

GenBank numbers - ITS: MG947599; LSU: MG947595; SSU: MG947598; TEF: MG968955; RPB2: MG948547 
Notes - Most Nigrograna species have indistinguishable morphological characters such as subiculate ascomata and apically free paraphyses among immature asci and hence, Jaklitsch \& Voglmayr (2016) treated them as cryptic species. Blast search results of LSU and ITS sequence data revealed that our taxon belongs to Nigrograna. Furthermore, combined LSU, ITS, TEF and RPB2 phylogeny, including taxa from Nigrograna and Biatriospora, showed that Nigrograna samueliana clusters together with the novel species Nigrograna rhizophorae in a strongly supported phylogenetic clade (ML 100\% and 1.00 PP) (Fig. 22). Nigrograna samueliana shares similar ascomata, asci and ascospore characters in addition to sharing pycnidial and conidial characters with the existing Nigrograna species. However, Nigrograna samueliana is distinct from $N$. cangshanensis, $N$. fuscidula, $N$. mycophila, $N$. novergica, $N$. obliqua and $N$. thymi in lacking a subiculum and ostiolar necks and by its occurrence in marine habitats (Jaklitsch \& Voglmayr 2016, Tibpromma et al. 2017). Nigrograna novergica differs from $N$. samueliana as it occurs on pseudostromata of Diaporthe sp., and has ascospores that are fusoid to clavate with acute ends (Jaklitsch \& Voglmayr 2016). Nigrograna thymi can be easily distinguished from N. samueliana and other species in having 4-5 septate, dark brown ascospores (Hyde et al. 2017). Both N. obliqua and N. mycophila are distinct from $N$. samueliana in having dark brown ascospores (Jaklitsch \& Voglmayr 2016). Nigrograna fuscidula has immersed ascomata in contrast to $N$. samueliana that has semi-immersed and erumpent ascomata (Jaklitsch \& Voglmayr 2016). Nigrograna cangshanensis has smaller, immersed ascomata, a thicker peridium and ascospores that are olive gray to yellowish-brown when compared to N. samueliana (Hyde et al. 2017). The asexual morph of Nigrograna rhizophorae is different from $N$. samueliana by having unbranched, relatively shorter $(10-30 \mu \mathrm{m} v s$ 20-35 $\mu \mathrm{m})$ conidiophores and smaller conidia $(2-4 \mu \mathrm{m} v s$ 3-4.5 $\mu \mathrm{m})$. (See notes under $N$. rhizophorae for the comparison of asexual morph). Based on the distinct morphology, habitat and phylogenetic relationships, Nigrograna samueliana could be delineated from the other species reported. Hence, we introduce it as a novel species under Nigrograna in this paper. Furthermore, ITS, TEF and RPB2 base pair differences of $N$. samueliana and $N$. rhizophorae are $3.5 \%$ (out of $542 \mathrm{bp}$ ), $2.06 \%$ (out of $1000 \mathrm{bp}$ ) and $9.8 \%$ (out of $750 \mathrm{bp}$ ) which are indicative of two different species according to the guidelines of Jeewon \& Hyde (2016).

Nigrograna rhizophorae Dayarathne, E.B.G. Jones \& K.D. Hyde, sp. nov.

Fig. 25

Index Fungorum number: IF556579, Facesoffungi number: FoF 06164

Etymology - Specific epithet derived from the host genus

Holotype - MFLU 19-1233

Saprobic on decaying wood of Rhizophora sp. Sexual morph: Undetermined. Asexual morph: Coelomycetous. Pycnidia $0.9-1 \mathrm{~mm} \times 0.6-0.8 \mathrm{~mm}(\overline{\mathrm{x}}=0.92 \times 0.85 \mathrm{~mm}, \mathrm{n}=5)$, globose to subglobose, immersed to semi immersed, scattered or aggregated in small groups, appearing as black spots on host surface. Peridium $60-80 \mu \mathrm{m}$ diam. wide $(\overline{\mathrm{x}}=72 \mu \mathrm{m}, \mathrm{n}=5)$, pseudoparenchymatous, brown. Conidiophores 20-35 $\times 1.5-2.0 \mu \mathrm{m}$ diam. $(\overline{\mathrm{x}}=25 \times 1.5 \mu \mathrm{m}, \mathrm{n}=10)$, arising from the wall in palisadic arrangement, filamentous, septate, hyaline, sparsely branched, with a terminal phialide. Solitary minute pegs and lageniform to sub-cylindrical phialides are arranged apically on the conidiophores. Conidia 3-4.5 $\times 1-2 \mu \mathrm{m}(\overline{\mathrm{x}}=3.5 \times 1.5 \mu \mathrm{m}, \mathrm{n}=30)$ diam., ellipsoidal to cylindrical, unicellular with 1-2 small granules, subhyaline, smooth conidia are produced from the terminal ends of the conidiophores.

Culture characteristics - Ascospores germinating on 50\% sea water agar within 24 hours, with germ tubes developed from lower side of ascospores. Colonies on MEA slow growing, reaching 10-20 mm diam., after 15 days of incubation at $25{ }^{\circ} \mathrm{C}$, circular, grey at the center becoming black, black at the margins, spreading, flattened, fluffy, sparse, aerial, surface smooth with filamentous edge, reverse black, filamentous, circular, umbonate.

Material examined - THAILAND, Phetchaburi Province, Cha-am District, on submerged propagule of Rhizophora sp. (Rhizophoraceae), 18 January 2018, M.C. Dayarathne, MCD 180 (MFLU 19-1233, holotype); ibid., (HKAS102066, isotype), ex-type living culture (MFLUCC 180397). THAILAND, Phetchaburi Province, Cha-am District, on decaying wood of Rhizophora sp. 
(Rhizophoraceae) wood, 18 January 2018, M.C. Dayarathne, MCD 185 (MFLU 19-1234); ibid., (HKAS102066).
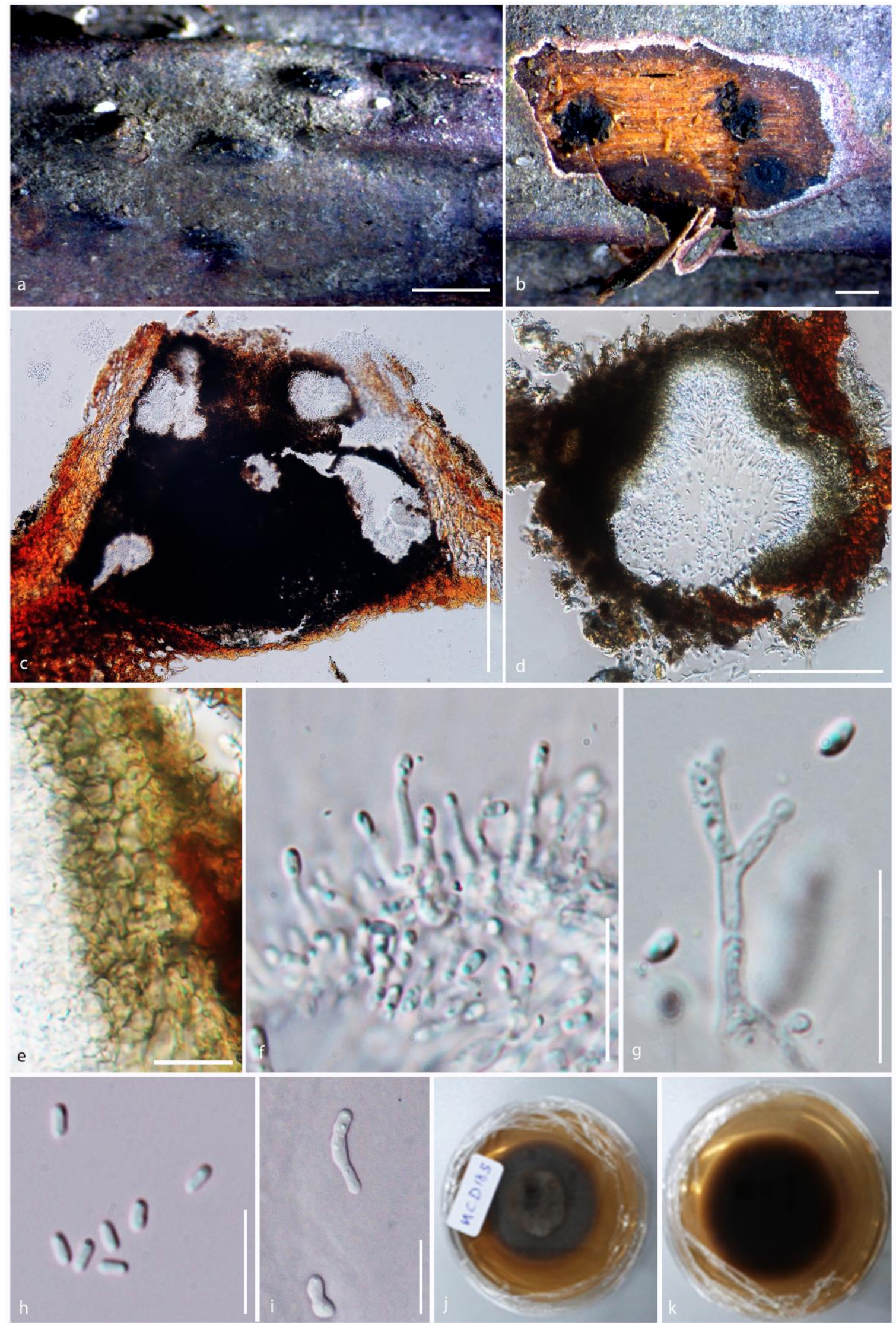

Figure 25 - Nigrograna rhizophorae (MFLU 19-1233, holotype). a, b Pycnidia on host surface. c Pycnidia in vertical section. e Pycnidial wall. f, g Conidiophores with phialides. h Conidia. 
i Germinating conidia. j. Front and reverse views of culture. Scale bars: $a, b=1000 \mu \mathrm{m}, \mathrm{c}, \mathrm{d}=200$ $\mu \mathrm{m}, \mathrm{e}, \mathrm{f}, \mathrm{h}=20 \mu \mathrm{m}, \mathrm{g}, \mathrm{i}=10 \mu \mathrm{m}$.

GenBank numbers - LSU: MN420686, MN017845; ITS: MN047085; ITS: TEF: MN077063, MN077064; RPB2: MN431490, MN431489

Notes - Nigrograna rhizophorae best fits the genus Nigrograna by being coelomycetous and comprising globose to sub-globose, immersed to semi immersed pycnidia with a brown, pseudoparenchymatous peridium, filiform, simple to sparsely branched conidiophores with pegs along one or two sides and solitary terminal, lageniform to sub-cylindrical phialides and oblong, cylindrical, subhyaline, 1-celled conidia. Phylogenetic analyses based on LSU, ITS, TEF and RPB2 data showed that $N$. rhizophorae (MFLU 19-1234, MFLUCC 18-0397) formed a well separated (ML100\% and $1.00 \mathrm{PP}$ ) sister clade to $N$. samueliana (Fig. 22). The asexual morph of $N$. samueliana can be easily distinguished from $N$. rhizophorae by having unbranched, relatively shorter (10-30 $\mu \mathrm{m} v s$ 20-35 $\mu \mathrm{m})$ conidiophores and smaller conidia $(2-4 \mu \mathrm{m} v s$ 3-4.5 $\mu \mathrm{m})$. Furthermore, ITS, TEF and RPB2 base pair differences of $N$. samueliana and $N$. rhizophorae are $3.5 \%$ (19 out of $542 \mathrm{bp}$ ), 2.06\% (20 out of $1000 \mathrm{bp}$ ) and $9.8 \%$ (74 out of $750 \mathrm{bp}$ ) which are indicative of two different species according to the guidelines of Jeewon \& Hyde (2016).

\section{Periconiaceae Nann.}

The family Periconiaceae (Nannizzi 1934) has long been ignored and placed as a member of Massarinaceae (Zhang et al. 2012, Hyde et al. 2013, Liu et al. 2017). However, Tanaka et al (2015) revised Massarineae and established it as a distinct family based on their phylogenetic analysis (Phukhamsakda et al. 2016). Liu et al. (2017) showed that Massarineae and Periconiaceae are sister taxa to Massarinaceae which diverged in the Cretaceous period (around 70 Mya) (Liu et al. 2017).

\section{Periconia Tode}

Periconia was introduced by Tode (1791) and is typified by $P$. lichenoides and has been shown to produce valuable bioactive compounds (Li et al. 1998, Kim et al. 2004, Harnpicharnchai et al. 2009, Zhang \& Wang 2015, Zhang et al., 2016). There are 187 species epithets in Index Fungorum (2019) and more than 20 have been transferred to other genera. Currently ca. 50 species are recognized as truly belonging to Periconia (Carmarán \& Novas 2003, Seifert et al. 2011, Markovskaja \& Kačergius 2014, Tanaka et al. 2015, Liu et al. 2017, Thambugala et al. 2017, Hyde et al. 2018). Periconia species are common plant pathogens on various crops (Leukel 1948) and they are cosmopolitan in distribution as saprobes and endophytes colonizing herbaceous plants in various ecosystems including marine environments (Mason \& Ellis 1953, Ellis 1976, Rao \& Rao 1964, Matsushima 1996, Minter et al. 2001, Carmarán \& Novas 2003, Cantrell et al. 2007, Markovskaja \& Kačergius 2014, Liu et al. 2017).

Periconia salina Dayarathne \& E.B.G. Jones, sp. nov.

Index Fungorum number: IF556580; Facesoffungi number: FoF 06165

Fig. 27

Etymology - Epithet refers to the saline environment where the species was found

Holotype - MFLU 19-1235

Saprobic on unidentified bark, buried in sand dune. Sexual morph: Undetermined. Asexual morph: Colonies on substrate numerous, effuse, dark brown to black, floccose. Mycelium partly superficial composed of branched, septate, hyaline hyphae 1-2 $\mu \mathrm{m}$ wide. Conidiophores 385-400 $\times$ 20-25 $\mu \mathrm{m}$, macronematous, mononematous, unbranched, erect, straight or slightly flexuous, forming spherical heads at apex, $80-98 \mu \mathrm{m}$ diam $(\overline{\mathrm{x}}=82.5 \mu \mathrm{m}, \mathrm{n}=10)$, single, grayish brown to dark brown, 5-6-septate, smooth to minutely verruculose, thick-walled. Conidiogenous cells holoblastic, polyblastic, acropetally proliferating, terminal, integrated or discrete, ovoid to globose, pale brown, smooth, collapsing when old. Conidia $16.4-18.4 \times 15-18 \mu \mathrm{m}$ diam $(\overline{\mathrm{x}}=16.8 \times 16.5$ $\mu \mathrm{m}, \mathrm{n}=30$ ), solitary, subglobose to globose, dark brown, verruculose, aseptate. 


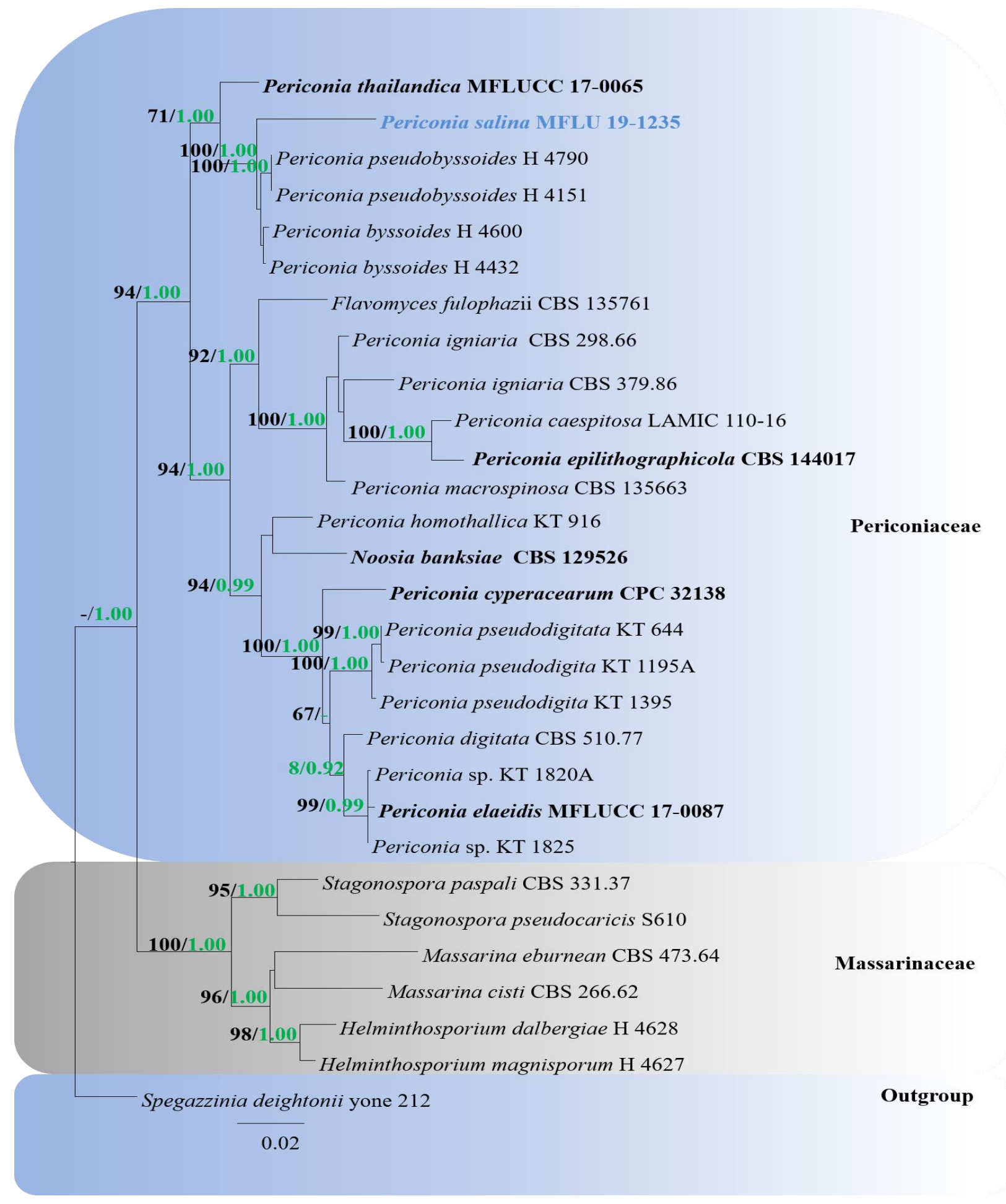

Figure 26 - Maximum likelihood analysis with 1000 bootstrap replicates yielded a best tree with the likelihood value of -7756.450937. The combined LSU, SSU and ITS sequence datasets comprised 29 strains of Periconiaceae and Massarinaceae and Spegazzinia deightonii (yone 212) as the outgroup taxon. Tree topology of the ML analysis was similar to the BI. The matrix had 467 distinct alignment patterns, with $18.89 \%$ of undetermined characters or gaps. Estimated base frequencies were as follows; $\mathrm{A}=0.248100, \mathrm{C}=0.227570, \mathrm{G}=0.275219, \mathrm{~T}=0.249111$; substitution rates $\mathrm{AC}=2.574509, \mathrm{AG}=3.950406, \mathrm{AT}=2.257360, \mathrm{CG}=1.199888, \mathrm{CT}=$ 10.821629 , GT $=1.000000$; gamma distribution shape parameter $\alpha=0.127888$. Maximum likelihood bootstrap (ML, black) values $>65 \%$ and Bayesian posterior probabilities (PP, green) $>$ $0.90 \%$ are given above the nodes. The scale bar indicates 0.02 changes. The ex-type strains are in bold and new isolates in blue bold. 

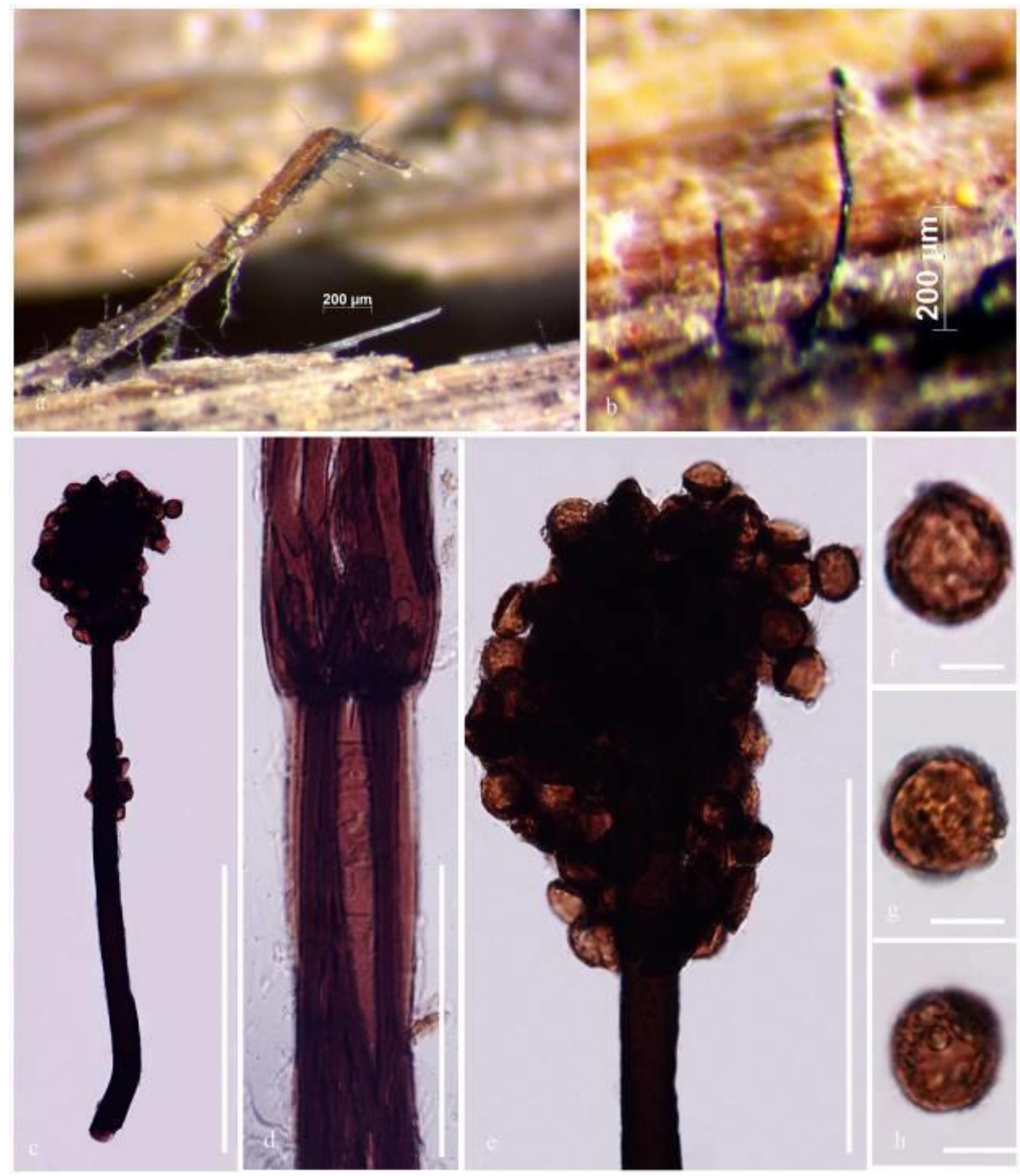

Figure 27 - Periconia salina (MFLU 19-1235, holotype). a Substrate. b Colonies on substrate. c, d Conidiophores. e Conidial masses at the apex of conidiophores. $\mathrm{f}-\mathrm{h}$ Conidia. Scale bars: $\mathrm{a}-\mathrm{c}=200$ $\mu \mathrm{m}, \mathrm{d}, \mathrm{e}=100 \mu \mathrm{m}, \mathrm{f}-\mathrm{h}=10 \mu \mathrm{m}$.

Material examined - UK, Carmarthenshire, Wales, Llanstephan, on unidentified bark, buried in sand dune, 12 May 2017, E.B. Gareth Jones, GJ374 (MFLU 19-1235, holotype); ibid., (BBH, isotype).

GenBank numbers - LSU: MN017846; SSU: MN017912; ITS: MN047086

Notes - Periconia salina best fits the genus Periconia in having pale to dark brown, unbranched, smooth or verruculose, macronematous conidiophores, monoblastic or polyblastic conidiogenous cells and spherical, aseptate, catenate or solitary, verruculose, pale to dark brown conidia (Carmarán \& Novas 2003, Markovskaja \& Kačergius 2014). Periconia salina shows close phylogenetic affinities to $P$. byssoides and $P$. pseudobyssoides, but is distinct as a new species (Fig. 
26). Base pair differences of $P$. byssoides and the new species are $4 \%$ (34 bp out of $855 \mathrm{bp}$ ) LSU, $3.5 \%$ (30 bp out of $871 \mathrm{bp}$ ) SSU and $0.8 \%$ (42 bp out of $526 \mathrm{bp}$ ) ITS. The new species is morphologically different from $P$. byssoides and $P$. psudobyssoides. The conidia of $P$. salina are larger than those of $P$. byssoides (15-18 $\mu \mathrm{m}$ diam. vs 10-15 $\mu \mathrm{m}$ diam). (Ellis 1971). Spherical heads at the apex of conidiophores of $P$. pseudobyssoides are smaller than those of $P$. salina (30-70 $\mu \mathrm{m} v s$ 80-98 $\mu \mathrm{m}$ diam.) (Markovskaja \& Kačergius 2013).

Phaeoseptaceae S. Boonmee, Thambugala \& K.D. Hyde

The family Phaeoseptaceae was established by Hyde et al. (2018) to accommodate Phaeoseptum, Lignosphaeria and Neolophiostoma. Multigene phylogenetic analyses by Phukhamsakda et al. (2019) revealed that Neolophiostoma forms a distinct lineage and is also distantly related to both Halotthiaceae and Phaeoseptaceae. Members of the Phaeoseptaceae are saprobic on decaying wood and are distributed across different habitats such as terrestrial, freshwater and marine (Zhang et al. 2013, Hyde et al. 2018, Phukhamsakda et al. 2019).

Phaeoseptum Ying Zhang, J. Fourn. \& K.D. Hyde

Phaeoseptum was introduced by Zhang et al. (2013) to accommodate P. aquaticum which is most comparable to the maritime fungus Mauritiana rhizophorae. Zhang et al. (2013) showed that the genera Halotthia, Mauritiana, Pontoporeia and Phaeoseptum aquaticum formed a monophyletic clade in phylograms generated from LSU sequence analyses. The genera Halotthia, Mauritiana Phaeoseptum, Pontoporeia initially placed within Halotthiacaeae but Phaeoseptum has now been transferred to Phaeoseptaceae (Hyde et al. 2018). This genus is characterized by semiimmersed to immersed ascomata, narrowly cellular, anastomosed pseudoparaphyses, cylindricalclavate, pedicellate asci and fusiform to ellipsoidal or vermiform, asymmetrical and brown muriform ascospores (Zhang et al. 2013, Hyde et al. 2018). Currently three species are accepted in this genus. The phylogram, constructed based on combined LSU, SSU, TEF, ITS and RPB2 marker gene data sets in this study, also strongly supports the establishment of the family Phaeoseptaceae by Hyde et al. (2018). Furthremore, we introduce two novel species to the genus Phaeoseptum.

Phaeoseptum carolshearerianum Devadatha, V.V. Sarma \& E.B.G. Jones sp. nov.

Fig. 29 Index Fungorum number: IF555721; Facesoffungi number: FoF 06166

Etymology - Specific epithet in honour of the mycologist Dr. Carol A. Shearer on her great contributions to aquatic mycology.

Holotype - AMH-9909

Saprobic on decayingwood of Avicennia marina. Sexual morph Ascomata 290-620 $\mu \mathrm{m}$ high $\times$ $295-400 \mu \mathrm{m}$ in diam. $(\overline{\mathrm{x}}=392 \times 339 \mu \mathrm{m}, \mathrm{n}=10)$, semi-immersed to immersed, aggregate to solitary, globose to subglobose, emerging as dark brown to black prolonged parts on surface of the host. Peridium unequal in thickness $35-80 \mu \mathrm{m}(\overline{\mathrm{x}}=54 \mu \mathrm{m}, \mathrm{n}=10)$ wide at the base, $30-70 \mu \mathrm{m}(\overline{\mathrm{x}}=$ $48 \mu \mathrm{m}, \mathrm{n}=10)$ at the sides, comprising several, inner layers of hyaline to light brown cells of textura angularis, outer layers of thick-walled pale brown to reddish brown cells of textura angularis and fusing at the outside with the host tissues. Hamathecium 1-2.5 $\mu \mathrm{m}$ wide, numerous rarely branched, septate pseudoparaphyses anastomosing above the asci, embedded in a gelatinous matrix. Asci 103-195 $\times 18-23 \mu \mathrm{m}$ diam. $(\overline{\mathrm{x}}=139 \times 21 \mu \mathrm{m}, \mathrm{n}=20), 8$-spored bitunicate, fissitunicate, long pedicellate, cylindrical to cylindric clavate, apically rounded and thickened at the apex with a small ocular chamber. Ascospores $29-37.5 \times 8.5-12.5(\overline{\mathrm{x}}=33.4 \times 10 \mu \mathrm{m}, \mathrm{n}=50)$, unito bi-seriate, muriform, asymmetric oblong to broadly fusiform, with convex ends, enlarged at the 4 th and $5^{\text {th }}$ cell, tapering towards the end cells, 1-2 longitudinal or vertical septa in each segment except in the end cells, 8-10-transversely septate, slightly constricted at the $5^{\text {th }}$ septum, initially hyaline, turning into pale brown at maturity, guttulate, flattened, roughened surface, often moderately twisted from apical region to the ends, sometimes straight and rounded at the apex, lacking mucilaginous sheath. Asexual Morph: Undetermined. 


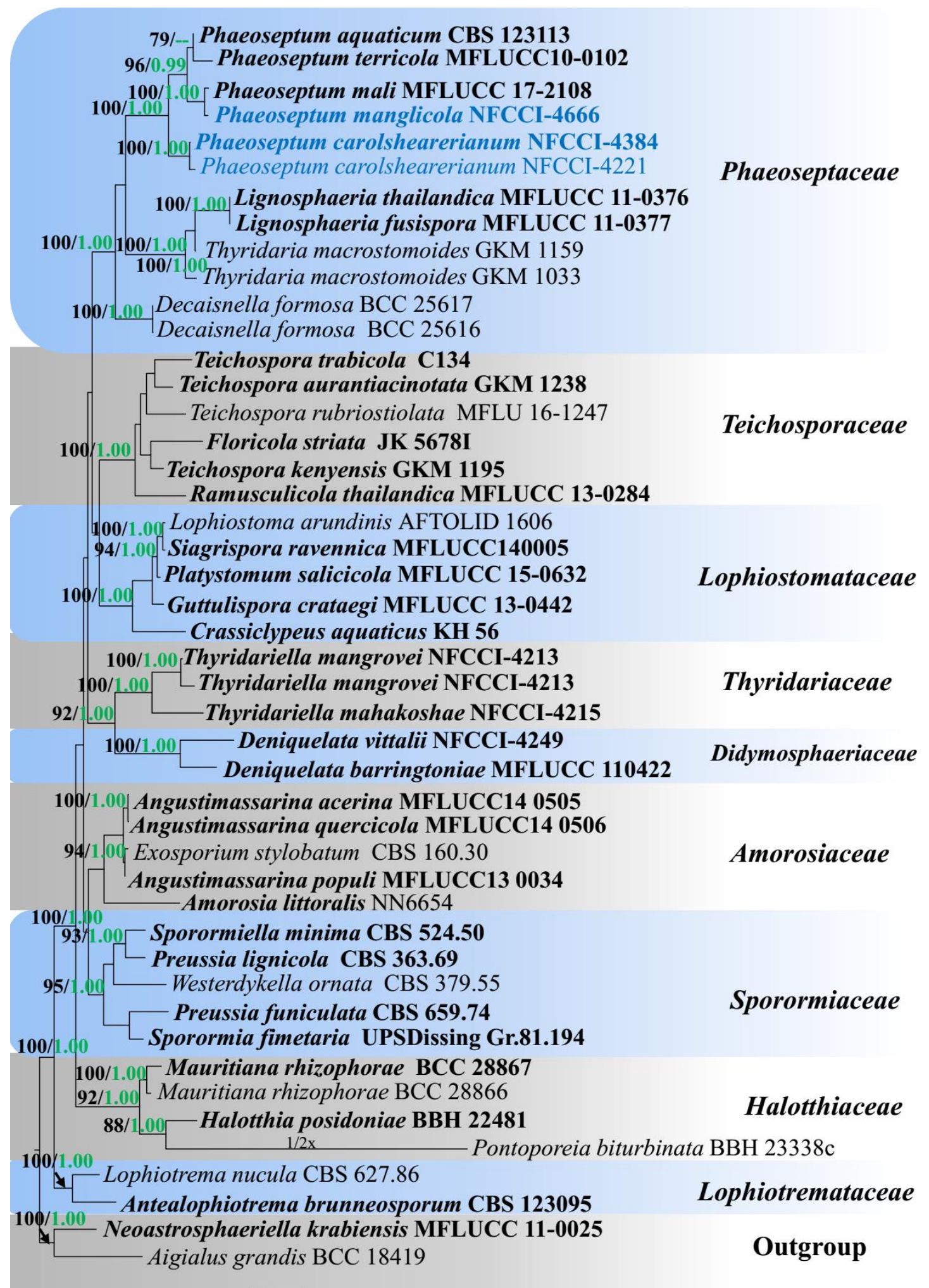

Figure 28 - Phylogenetic analyses is carried out using combined LSU, SSU, TEF, ITS, and RPB2 sequence datasets composed of 46 strains of taxa in Phaeoseptaceae and other representative genera of the families in Pleosporales with Aigialus grandis BCC 18419 and Neoastrosphaeriella krabiensis MFLUCC 11-0025 as outgroup taxa. Maximum likelihood analysis with 1000 bootstrap replicates yielded a best tree with the likelihood value of -32398.659815 . The matrix had 1977 distinct alignment patterns, with $37.40 \%$ of undetermined characters or gaps. Estimated base frequencies were as follows; $\mathrm{A}=0.246116, \mathrm{C}=0.252481, \mathrm{G}=0.273616, \mathrm{~T}=0.227787$; substitution rates $\mathrm{AC}=1.276855, \mathrm{AG}=2.793720, \mathrm{AT}=1.537700, \mathrm{CG}=1.158693, \mathrm{CT}=$ 6.112503 , GT $=1.000000$; proportion of invariable sites $\mathrm{I}=0.326300$; gamma distribution shape 
parameter $\alpha=0.470687$. Phylogenetic trees obtained from ML and BI were topologically similar and congruent with previous studies (Hyde et al. 2018, Phukhamsakda et al. 2019). Maximum likelihood bootstrap (ML, black) values > 70\% and Bayesian posterior probabilities (PP, green) > $0.95 \%$ are given above the nodes. The scale bar indicates 0.08 changes. The ex-type strains are in bold and new isolates in blue bold.
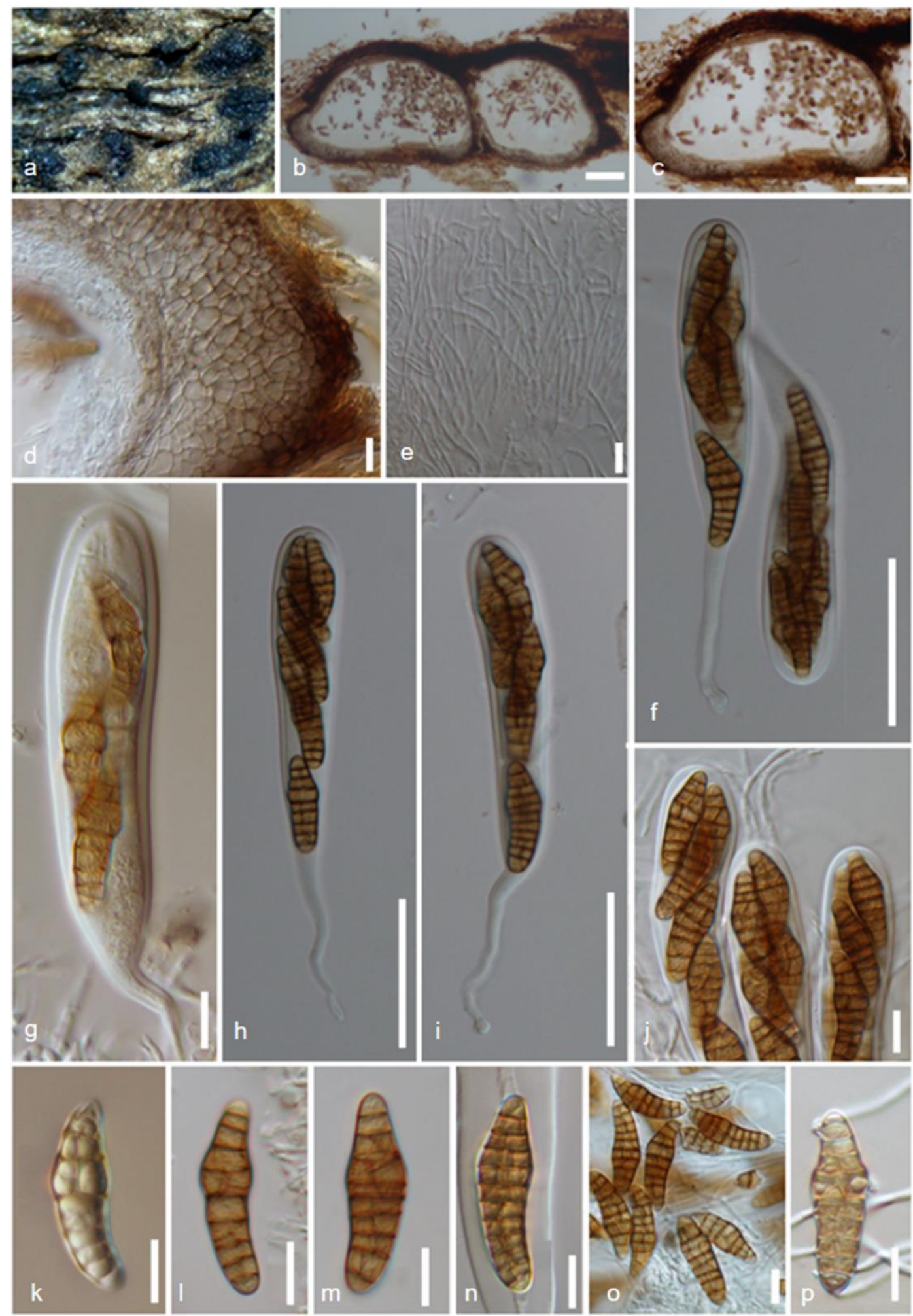

Figure 29 - Phaeoseptum carolshearerianum (AMH-9909, holotype). a Ascomata on decaying wood of Avicennia marina. b, c Longitudinal sections of ascomata. d Section of peridium. e Pseudoparaphyses. $\mathrm{f}-\mathrm{j}$ Immature and mature asci. $\mathrm{k}-\mathrm{o}$ Ascospores. $\mathrm{p}$ Germ tubes developing from 
terminal ends of ascospore. Scale bars: $b, c=100 \mu \mathrm{m}, \mathrm{f}, \mathrm{h}, \mathrm{i}=50 \mu \mathrm{m}, \mathrm{d}, \mathrm{e}, \mathrm{j}-\mathrm{p}=10 \mu \mathrm{m}$.

Culture characteristics - Ascospores germinating on 50\% sea water agar within 24 hours, with germ tubes developed from both end cells of ascospores. Colonies on MEA slow growing, reaching $10-15 \mathrm{~mm}$ diam. on 7 th day, after 15 days of incubation reach $40-55 \mathrm{~mm}$ at $25{ }^{\circ} \mathrm{C}$, surface pale olive grey in centre, dark grey at the margin, olivaceous to black stromata on the surface, olivaceous exudates. Reverse deep mouse grey, convex, granular, circular. Mycelium 2$7.5 \mu \mathrm{m}$ diam., dense, branched, septate, broad, hyaline to pale brown, smooth-walled. Chlamydospores 8-15 $\times 7-12.5 \mu \mathrm{m}$, catenate, highly intact, hyaline to pale brown, oval to ellipsoidal, smooth to rough-walled.

Material examined - INDIA, Tamil Nadu, Tiruvarur, Muthupet mangroves $\left(10.4^{\circ} \mathrm{N} 79.5^{\circ} \mathrm{E}\right)$, on decaying wood of Avicennia marina (Acanthaceae), 28 March 2015, B. Devadatha (AMH-9908, holotype), ex-type living culture NFCCI-4221. ibid., Parangipettai mangroves, on decaying wood of Avicennia marina (Acanthaceae), 28 April 2018, B. Devadatha PUHD57, living culture NFCCI4384.

GenBank numbers - NFCCI-4221, NFCCI-4384: ITS: MK307810, MK307812; LSU: MK307813, MK307815, MK307818; SSU: MK307816, MK307818; TEF: MK309874, MK309876; RPB2: MK309877, MK309879

Notes - Morphological studies suggest that the new species, Phaeoseptum carolshearerianum and $P$. manglicola, share similar characters of the genus Phaeoseptum. Furthermore, the combined LSU, SSU, TEF, ITS and RPB2 phylogeny also revealed that they group together with Phaeoseptum aqauticum, $P$. mali and P. terricola with significant support (100\% ML, 1.00 PP) (Fig. 28). Phaeoseptum carolshearerianum, P. aquaticum, $P$. manglicola, $P$. mali and $P$. terricola share similar dark pigmented, immersed ascomata, cylindrical to clavate, pedicellate asci and muriform brown ascospores. Phaeoseptum carolshearerianum, however, is distinct from other Phaeoseptum species in having larger ascomata, lacking a pseudoclypeus and asymmetric oblong to broadly fusiform ascospores, enlarged at $4^{\text {th }}$ and $5^{\text {th }}$ septa, 8-10 trans-septate. Both morphological and phylogenetic studies suggest that this marine species is clearly distinct from $P$. aquaticum, $P$. manglicola, $P$. mali and $P$. terricola. Furthermore, ITS base pair differences of $P$. carolshearerianum and $P$. manglicola resulted in 9.9\% (43 bp out of $443 \mathrm{bp}$ ) which indicates both are different species (Jeewon \& Hyde 2016). Hence, we introduce the two strains as a novel species in Phaeoseptum.

Phaeoseptum manglicola Devadatha, V.V. Sarma \& E.B.G. Jones sp. nov.

Fig. 30 Index Fungorum number: IF555722; Facesoffungi Number: FoF 06167

Etymology - In reference to its mangrove habitat

Holotype - AMH-9908

Saprobic on decaying mangrove wood. Sexual morph Ascomata 210-420 $\mu \mathrm{m}$ high $\times 170-374$ $\mu \mathrm{m}$ in diam. $(\overline{\mathrm{x}}=321 \times 238, \mathrm{n}=10)$, aggregate to solitary, semi-immersed to immersed, erumpent through the host tissue, ostiolate, short papillate, globose to subglobose, irregular, clypeate, raised as dark brown to black spots on surface of the host. Ostiole 28-94 $\mu \mathrm{m}$ high, 39-96 $\mu \mathrm{m}$ diam., short, pale brown. Peridium 30-85 $\mu \mathrm{m}(\overline{\mathrm{x}}=56 \mu \mathrm{m}, \mathrm{n}=7)$ wide at the base, $24-69 \mu \mathrm{m}(\bar{x}=48 \mu \mathrm{m}, \mathrm{n}=7)$ on the sides, comprising 4-6 layers, of outer thick-walled and brown cells and inner thin-walled layer of hyaline to pale brown cells of textura angularis, fusing at the outside with the host tissues. Hamathecium composed of 1-2.5 $\mu \mathrm{m}$ wide, several, branched, cellular, septate, narrow pseudoparaphyses, anastomosing above the asci, embedded in a gelatinous matrix. Asci $102-212 \times$ 17-27.5 $\mu \mathrm{m}(\overline{\mathrm{x}}=138 \times 23 \mu \mathrm{m}, \mathrm{n}=25), 8$-spored, bitunicate, fissitunicate, cylindrical to clavate, long pedicellate, apically rounded and thickened, with a refractive plate in the ectoascus and a refractive apical plate in the endoascus. Ascospores $27-36 \times 7.5-13 \mu \mathrm{m}(\overline{\mathrm{x}}=32 \times 11 \mu \mathrm{m}, \mathrm{n}=50)$, uniform, $2-$ 3 -seriate at the apex, 1-seriate at the base, overlapping, initially hyaline, becoming pale brown to yellowish brown at maturity, smooth-walled, flattened, lacking a mucilaginous sheath, often straight, sometimes slightly curved, rarely constricted at the middle septum, oblong to broadly 
fusiform, with rounded to convex ends, 9-13 transverse septa, 1-2 longitudinal septa in each row, Y-shaped septum present or absent in the end cells, end cells hyaline to pale brown. Asexual morph: Undetermined.
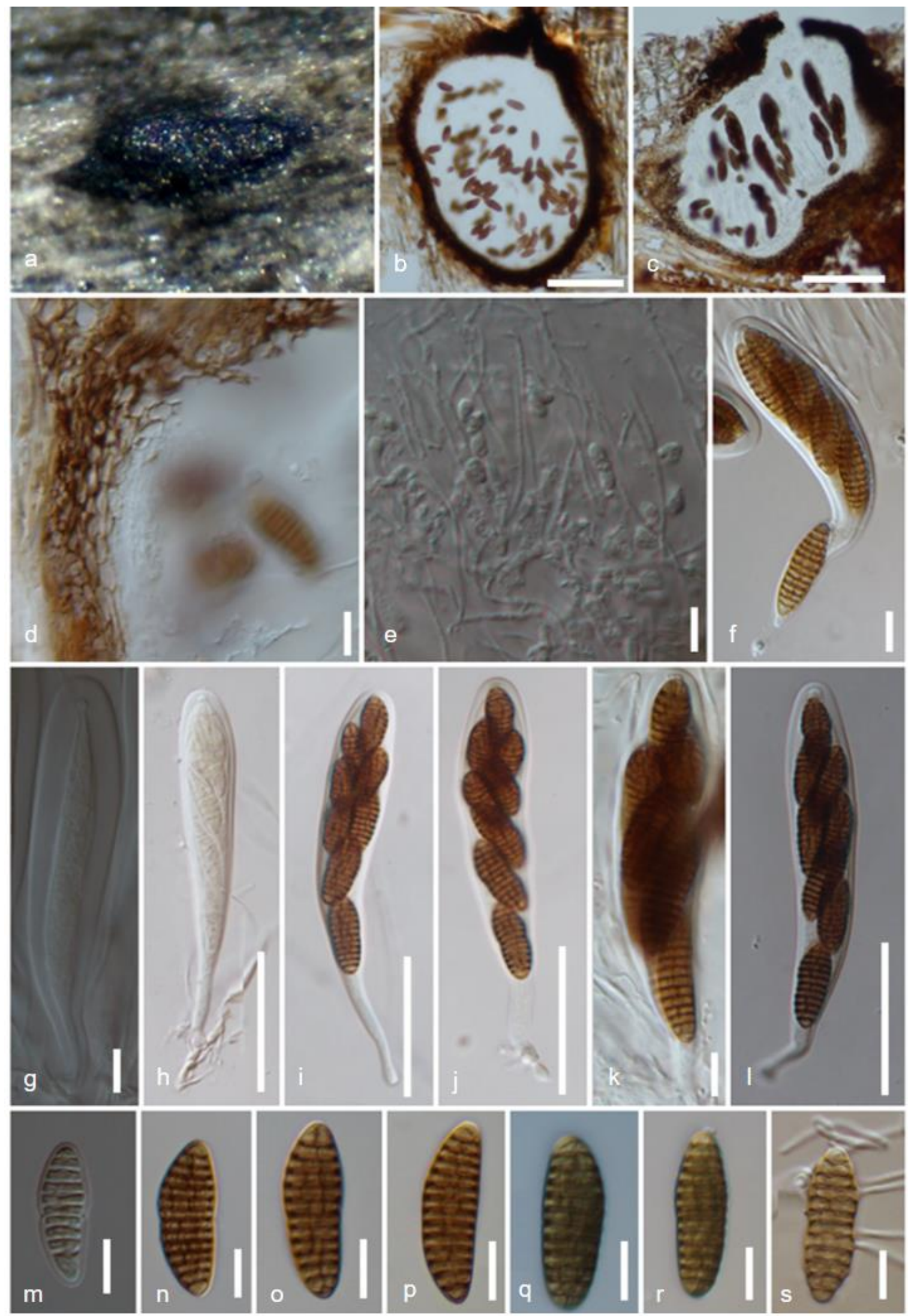

Figure 30 - Phaeoseptum manglicola (AMH-9908, holotype). a Ascomata on decaying wood of Avicennia marina. b-c Longitudinal sections of ascomata. $\mathrm{d}$ Section of peridium. e 
Pseudoparaphyses. f-1 Immature and mature asci. m-r Ascospores. s Germ tubes developed from terminal ends of ascospore. Scale bars: $\mathrm{b}-\mathrm{c}=100 \mu \mathrm{m}, \mathrm{h}-\mathrm{j}, \mathrm{l}=50 \mu \mathrm{m}, \mathrm{d}-\mathrm{f}, \mathrm{g}, \mathrm{k}, \mathrm{m}-\mathrm{s}=10 \mu \mathrm{m}$.

Culture characteristics - Ascospores germinating on $50 \%$ sea water agar producing germ tubes from both ends of the ascospores within 24 hours. Colonies on MEA slow growing, surface pearl grey to dawn grey, reaching $9-15 \mathrm{~mm}$ in diam. on the $7^{\text {th }}$ day, after incubation for 25 days attains $41-50 \mathrm{~mm}$ in diam. and turn into pale brown to dark brown, stromatic, reverse warm blackish brown with olive buff at margins, moderate growth, cottony, undulate, umbonate, and irregular. Mycelium 0.5-4 $\mu \mathrm{m}$, aerial, dense, stromatic, pale brown to dark brown, septate, branched, smooth-walled, hyaline to pale brown. Chlamydospores 13-28 $\times 10-16 \mu \mathrm{m}$, obovoid to ellipsoidal, hyaline to dark brown, smooth-walled when young becoming verrucose at maturity, highly pigmented on the walls and at the septum.

Material examined - INDIA: Tamil Nadu, Tiruvarur, Muthupet mangroves $\left(10.4^{\circ} \mathrm{N} 79.5^{\circ} \mathrm{E}\right)$, on decaying wood of Avicennia marina (Acanthaceae) (AMH-9908, holotype), 28 March 2015, Suaeda monoica (Amaranthaceae) 24 December 2016 (PUHD9, paratype), B. Devadatha (AMH9908, holotype), ex-type living culture NFCCI-4666.

GenBank numbers - ITS: MK307811; LSU: MK307814; SSU: MK307817; TEF: MK309875; RPB2: MK309878.

Notes - Phaeoseptum manglicola clusters with P. mali with significant support from ML $100 \%$ and 1.00 PP. Phaeoseptum manglicola resembles P. aquaticum in having similar ascomata, asci and ascospores that are broadly fusoid with broadly rounded ends, mutli-transverse septa and longitudinal septa with a Y-shaped septum in the end cells. However, $P$. manglicola differs from $P$. aquaticum in having ascomata that are narrower $(170-374 \mu \mathrm{m} v s 400-600 \mu \mathrm{m})$, with a thick-walled peridium (30-85 $\mu \mathrm{m} v s 20-30 \mu \mathrm{m})$, slightly shorter ascospores $(30.5-383 \times 9.5-12 \mu \mathrm{m} v s 27-36 \times$ 7.5-13 $\mu \mathrm{m})$ and 1-2 longitudinal septa in many cells, producing obovoid to ellipsoidal chlamydospores in culture and in its occurrence in a marine habitat (Zhang et al. 2013). Phaeoseptum manglicola and P. mali share similarities in their ascomata, asci and ascospore characters and their overlapping dimensions. However, $P$. manglicola is distinguishable from $P$. mali in having globose to subglobose or irregular $v s$ globose ascomata, thick-walled peridium (30$85 \mu \mathrm{m} v s$ 5-19 $\mu \mathrm{m}$ ) and ascospores that are oblong to broadly fusiform $v s$ broadly cylindrical with (9-13 vs 11-14) longitudinal septum in many cells and habitat marine vs terrestrial (Phukhamsakda et al. 2019). Furthermore, a notable nucleotide differences of $1.48 \%$ (out of $405 \mathrm{bp}$ ) were found within ITS gene region of $P$. manglicola and $P$. mali which was in agreement with guidelines outlined by Jeewon \& Hyde (2016) to establish new species based on DNA sequence data. Phaeoseptum terricola is different from $P$. manglicola in having smaller ascomata, asci and ascospores, ascospores that are allantoid or cylindrical and in its occurrence in terrestrial habitats (Hyde et al. 2018). Decaisnella formosa has fusiform to elongated ascospores that are distoseptate when young, with (8-) 9-13 transverse septa and 1-6 longitudinal septa in all cells, slightly constricted at the septa in contrast to Phaeoseptum carolshearerianum and P. manglicola (AbdelWahab \& Jones 2003). Mauritiana rhizophorae, another marine species, can be distinguished from $P$. carolshearerianum and P. manglicola as it produces phragmosporous ascospores (Poonyth et al. 2000). Platystomum scarbidisporum is a muriformed marine fungus which differs from Phaeoseptum carolshearerianum and P. manglicola in producing smaller ascospores, fusiform, with 5-7 (-8) transverse septa and 1-2(-3) longitudinal septa constricted at the central septum, brown with a rough or verrucose ascospores (Abdel-Wahab \& Jones 2000). Therefore, based on both morphological and phylogenetic evidence we established this species as a novel taxon within Phaeoseptum.

\section{Phaeosphaeriaceae M.E. Barr}

Barr (1979) introduced the family Phaeosphaeriaceae, which was initially characterized by immersed to superficial, globose to subglobose ascomata, short papilla, bitunicate asci and hyaline, yellowish or brown, fusiform to ellipsoidal, filiform, or muriform, septate ascospores (Barr 1979, 
Shoemaker 1984, Zhang et al. 2012, Hyde et al. 2013, Phookamsak et al. 2014). Phaeosphaeriaceae comprise more than 60 sexual and asexual genera (Phookamsak et al. 2014, 2017, 2019, Wijayawardene et al. 2014, 2017a, 2018, Hyde et al. 2016, Yang et al. 2019, Bakhshi et al. 2019, Maharachchikumbura et al. 2019, Marin-Felix et al. 2019). Species in this family are often necrotrophic pathogens or saprobes on plants (Shoemaker \& Babcock 1989, Carson 2005, Stukenbrock et al. 2006, Cannon \& Kirk 2007, Tibpromma et al. 2017).

\section{Amarenographium O.E. Erikss}

Eriksson (1982) introduced the genus Amarenographium to accommodate Camarosporium metableticum whose morphology differed from the definition of Camarosporium. The conidiophores are much longer and branched, with phialidic conidiogenesis with solitary conidia that are provided with a characteristic polar gelatinous appendage. Eriksson (1982) described the morphological similarity between Amarenographium metableticum and Amarenomyces ammophilae and suggested these taxa might be the same biological species. Nag Raj (1993) also considered Amarenomyces as the sexual morph of Amarenographium. However, these genera were not connected by molecular data or culture-based methods, thus Phookamsak et al. (2014) and Wijayawardene et al. (2014) treated Amarenographium and Amarenomyces as distinct genera in Phaeosphaeriaceae. Taylor et al. (2003) described a second species of Amarenographium, A. sinense from a dead petiole of Trachycarpus fortuneifrom Hubei Province, China. Sequence data is available only for A. solium and A. ammophilae, while the type species of Amarenographium lacks sequence data. However, A. solium did not group within Phaeosphaeriaceae in previous studies by Hodhod et al. (2012), Wijayawardene et al. (2014) and Wanasinghe et al. (2018), hence, Amarenographium was considered as a polyphyletic genus in Pleosporales (Wijayawardene et al. 2014, Wanasinghe et al. 2018). In this study, we introduce the first sexual morph for Amarenographium, which was collected from a marine based habitat.

Amarenographium ammophilicola Dayarathne, E.B.G. Jones \& K.D. Hyde, sp. nov. Figs 32, 33 Index Fungorum number: IF556581; Facesoffungi Number: FoF 06168

Etymology - The species epithet based on the host Ammophila arenaria on which the fungus was collected.

Holotype - MFLU 17-2571

Saprobic on leaf of Marram grass (Ammophila arenaria) in sand dune. Sexual morph: Ascomata 300-320 $\times 150-170 \mu \mathrm{m}$ semi-immersed to erumpent through host tissue, solitary or scattered, uniloculate, coriaceous, globose to subglobose, black. Ostiole central, with short papilla. Peridium 25-30 $\mu \mathrm{m}$ wide, comprising of 3-4 layers of light brown cells of textura angularis. Hamathecium comprising 1-2 $\mu \mathrm{m}$ wide, cylindrical to filiform, septate, branched, pseudoparaphyses. Asci $130-138 \times 30-35 \mu \mathrm{m}(\overline{\mathrm{x}}=132 \times 32 \mu \mathrm{m}, \mathrm{n}=10), 8$-spored, bitunicate, cylindrical, short pedicellate, with small ocular chamber. Ascospores 40-45 $\times 15-18 \mu \mathrm{m}(\overline{\mathrm{x}}=4216$ $\mu \mathrm{m}, \mathrm{n}=20$ ), overlapping, broadly fusiform, 6-septate, widest at the middle cells, hyaline to pale brown, constricted at the septa. Asexual morph: Conidiomata 161-185 × 150-170 $\mu \mathrm{m}$, pycnidial, scattered, solitary, immersed to erumpent, visible as black spots on host surface, uniloculate, globose to subglobose, glabrous, dark brown, ostiole central, with short papilla. Conidiomata wall 22-30 $\mu \mathrm{m}$ wide, thin walled, of equal thickness, composed of 3-5 layers of flattened, brown to dark brown, pseudoparenchymatous cells, arranged in a textura angularis. Conidiophores arising from basal cavity of conidioma, mostly reduced to conidiogenous cells, hyaline to brown, septate. Conidiogenous cells 5-9 $\times 3.5-5.5 \mu \mathrm{m}(\overline{\mathrm{x}}=7 \times 4.6 \mu \mathrm{m}, \mathrm{n}=10)$, holoblastic, phialidic, discrete, oblong to ampulliform, hyaline to brown, 1-septate at the base, smooth-walled. Conidia $20-48 \times 7-$ $16 \mu \mathrm{m}(\overline{\mathrm{x}}=46 \times 15.4 \mu \mathrm{m}, \mathrm{n}=30)$, solitary, dictyosporous, muriform, ellipsoidal, ovoid, or lageniform, with obtuse ends or sometimes truncate at the basal cell, initially hyaline, becoming brown to yellowish-brown at maturity, mostly 7-8 transverse septa, 0-2 longitudinal septa, with several segments, smooth and thick-walled, with a mucoid appendage. 


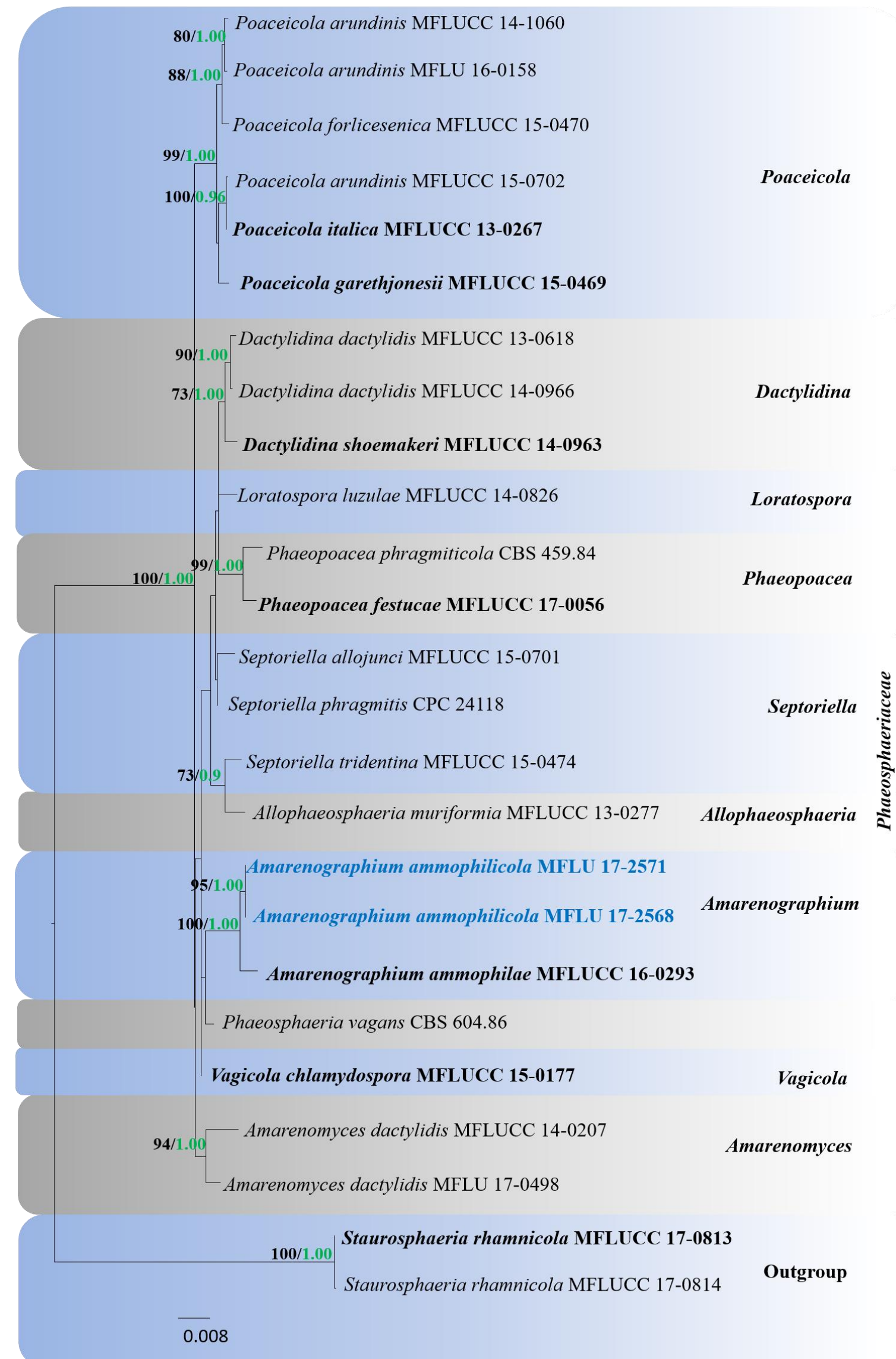

Figure 31 - Maximum likelihood analysis with 1000 bootstrap replicates yielded a best tree with the likelihood value of -7756.450937. The combined LSU, SSU, ITS and TEF sequence dataset comprised 26 strains and Staurosphaeria rhamnicola (MFLUCC 17-0813, MFLUCC 17-0814). as 
the outgroup taxa. Tree topology of the ML analysis was similar to the BI. The matrix had $18.89 \%$ of undetermined characters or gaps. Estimated base frequencies were as follows; $\mathrm{A}=0.248100, \mathrm{C}=$ $0.227570, \mathrm{G}=0.275219, \mathrm{~T}=0.249111$; substitution rates $\mathrm{AC}=2.574509, \mathrm{AG}=3.950406, \mathrm{AT}=$ 2.257360, $\mathrm{CG}=1.199888, \mathrm{CT}=10.821629, \mathrm{GT}=1.000000$; gamma distribution shape parameter $\alpha=0.127888$. Maximum likelihood bootstrap (ML, black) values $>65 \%$ and Bayesian posterior probabilities (PP, green) $>0.90 \%$ are given above the nodes. The scale bar indicates 0.008 changes. The ex-type strains are in bold and new isolates in blue bold.

Culture characteristics - Culture on MEA slow growing, reaching $40 \mathrm{~mm}$ diam., after three weeks, circular, olivaceous-grey at the center, yellowish white at the margins, spreading, flattened, felt-like, sparse, aerial, surface, smooth with filamentous edge; reverse blackish-grey at the center, yellowish white at the margins.

Material examined - UK, Wales, Carmarthenshire, Cefn Sidan, on leaf of Marram grass (Ammophila arenaria) in sand dune, 15 October 2017, E.B. Gareth Jones, GJ448 (MFLU 17-2571, holotype); ibid., on leaf of Marram grass (Ammophila arenaria) in sand dune, 15 October 2017, E.B. Gareth Jones, GJ445a (MFLU 17-2568, paratype).

GenBank numbers - LSU: MN017847, MN017848; SSU: MN017913, MN017914; ITS: MN047087, MN047088; TEF: MN077065, MN077066

Notes - In a phylogenetic analysis based on concatenated LSU, SSU, ITS and TEF sequence data, Amarenographium ammophilicola groups within Phaeosphaeriaceae and sister to $A$. ammophilae in a well-separated clade (100\% ML, 1.00 PP) (Fig. 31). We obtained sexual and asexual morphs of this species from the same host but from different specimens. They formed sister lineages in our phylogram and there are no significant base pair differences among those two strains. Amarenographium ammophilicola is morphologically somewhat similar to Amarenomyces ammophilae, the type species of Amarenomyces which was earlier considered as the sexual morph of Amarenographium. Our phylogenetic analyses showed that A. ammophilicola does not group with any of the Amarenomyces species. Amarenographium ammophilicola is phenotypically different from Amarenomyces ammophilae by the relatively larger ascomata (300-320 $\mu \mathrm{m} v \mathrm{~s} 170$ 290), and the absence of hyaline gelatinous sheath surrounding ascospores and the ascospore guttulation pattern (Nag Raj 1993). This is further confirmed by their base pair differences in ITS and TEF gene loci (Table 3). The asexual morph of A. ammophilicola shows typical asexual morph characteristics of Amarenographium such as, pycnidial, papillate, ellipsoidal to subglobose, glabrous, brown to dark brown conidiomata, hyaline to brown, septate, branched, ampulliform conidiogenous cells, dictyosporous, brown to dark brown, muriform, conidia which are paler at the end cells with a mucoid appendage at the apex (Phookamsak et al. 2014). The asexual morph of $A$. ammophilicola is morphologically reminiscent of the type Amarenographium metableticum but can be easily distinguish by measurements of conidiogenous cells and ascospores septation. Conidiogenous cells and conidia (3-4 $\mu \mathrm{m} \times 1.5-2.5 \mu \mathrm{m}$ and 24-27 $\mu \mathrm{m} \times 12-15 \mu \mathrm{m})$ of $A$. metableticum are smaller than those of A. ammophilicola $(5-9 \times 3.5-5.5 \mu \mathrm{m}$ and 20-48 $\times 7-16 \mu \mathrm{m})$ (Phookamsak et al. 2014). Furthermore, A. metableticum has 3-4 transverse septa, 1-4 longitudinal septa in their conidia while, A. ammophilicola has 7-8 transverse septa, 0-2 longitudinal septa (Phookamsak et al. 2014).

Table 3 Base pair differences of Amarenographium ammophilicola to related taxa.

\begin{tabular}{lll}
\hline \multicolumn{1}{c}{ Taxon } & \multicolumn{1}{c}{ ITS } & TEF \\
\hline $\begin{array}{l}\text { Amarenographium } \\
\text { ammophilae }\end{array}$ & $1.8 \%(10$ bp out of 538 & - \\
$\begin{array}{l}\text { Amarenomyces } \\
\text { ammophilae }\end{array}$ & bp) & \\
\hline
\end{tabular}



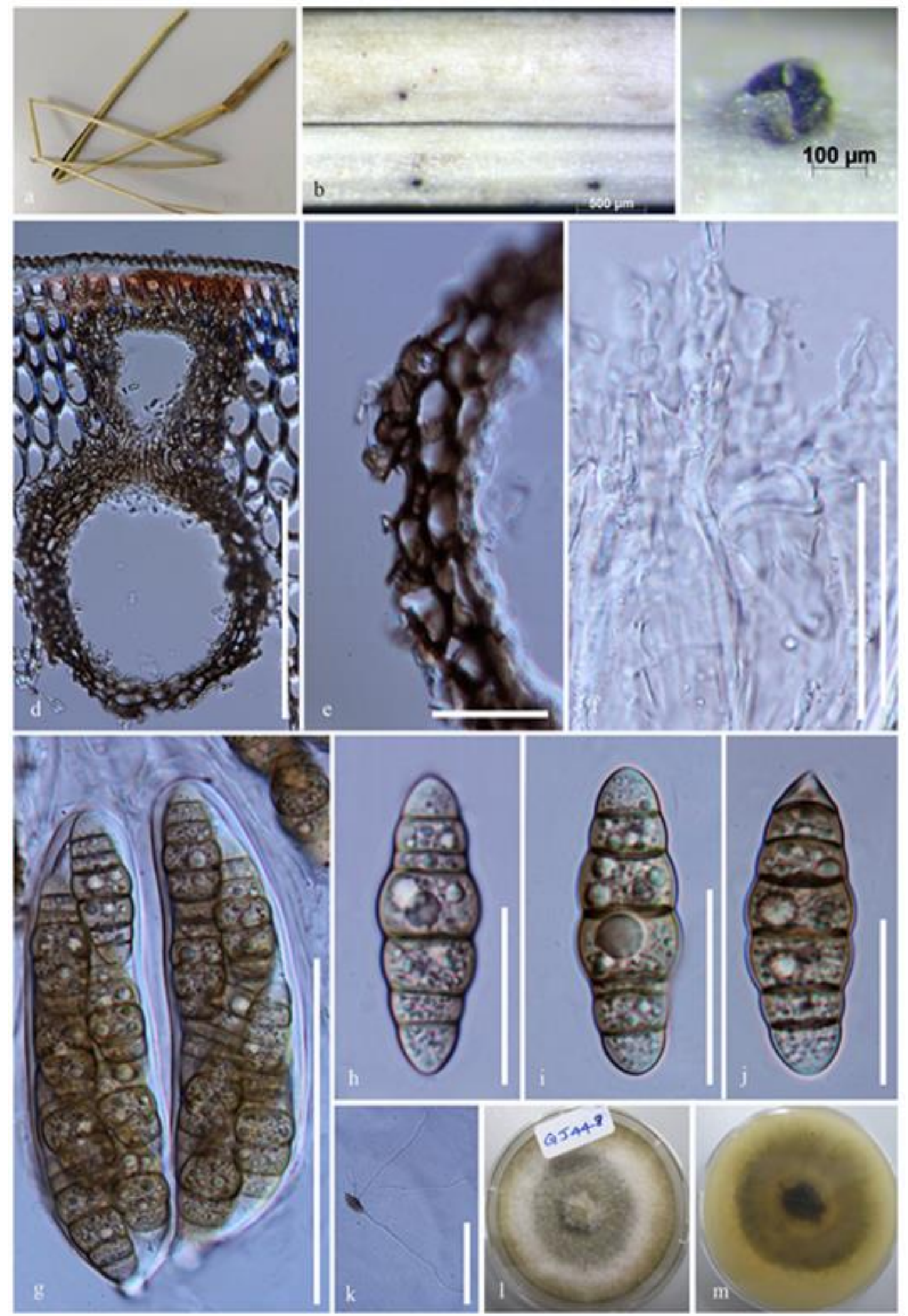

Figure 32 - Sexual morph of Amarenographium ammophilicola (MFLU 17-2571, holotype). a Host. b, c Appearance of ascomata on host. d Section of ascomata. e Peridium. f Psudoparaphyses. $\mathrm{g}$ Asci. $\mathrm{h}-\mathrm{j}$ Ascospores. $\mathrm{k}$ Germinating ascospore. 1 , m Cultures on MEA (l-upper, m-lower). Scale bars: $\mathrm{b}=500 \mu \mathrm{m}, \mathrm{c}, \mathrm{d}, \mathrm{f}, \mathrm{g}=100 \mu \mathrm{m}, \mathrm{k}=50 \mu \mathrm{m}, \mathrm{e}, \mathrm{h}-\mathrm{j}=20 \mu \mathrm{m}$. 


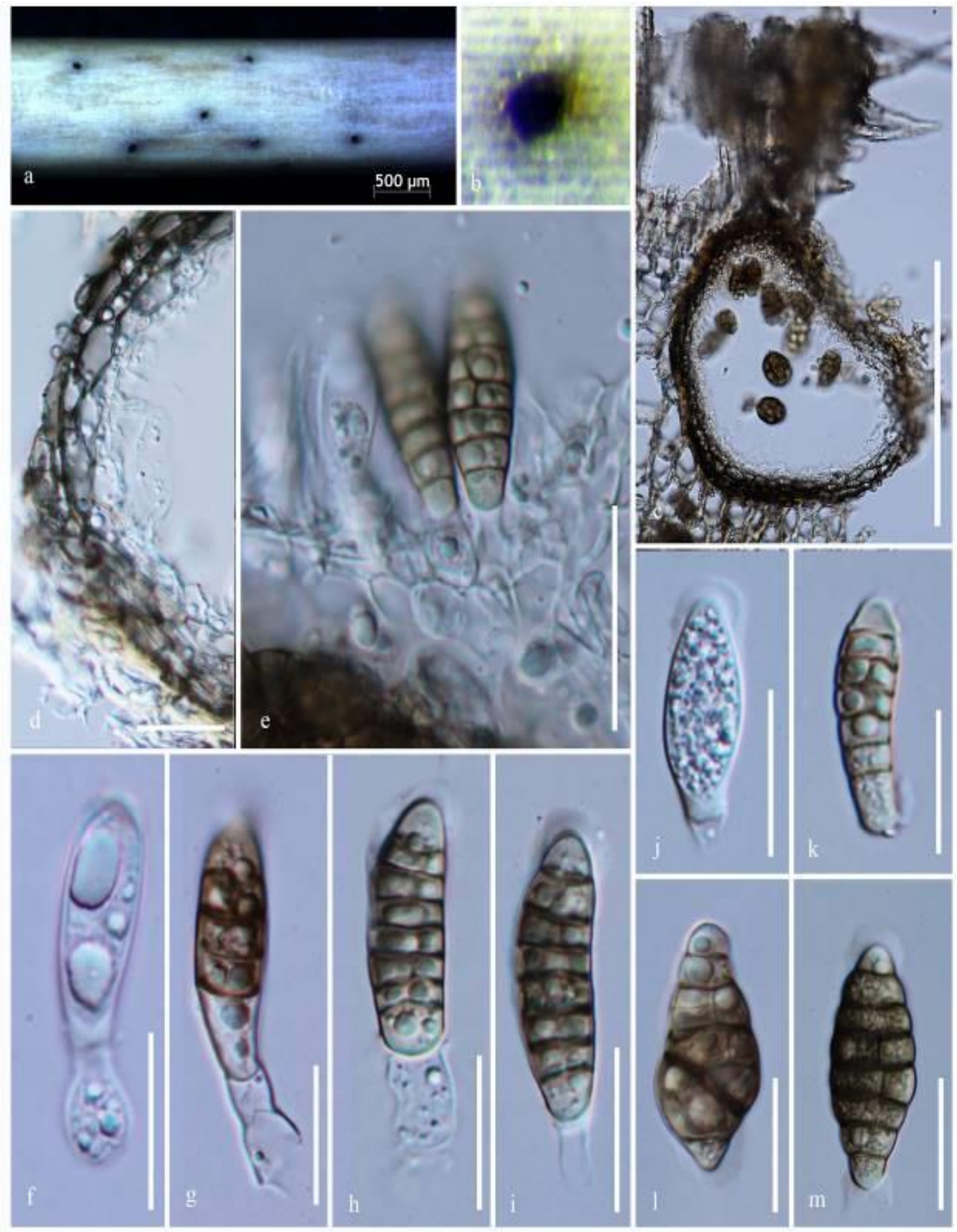

Figure 33 - Asexual morph of Amarenographium ammophilicola (MFLU 17-2568). a Host. b Appearance of conidioma on host. c Section of pycnidium. d Pycnidial wall. e-i Conidia attached to the conidiogenous cells. $\mathrm{j}-\mathrm{m}$ Immature to mature conidia. Scale bars: $\mathrm{a}=500 \mu \mathrm{m}, \mathrm{c}, \mathrm{d}, \mathrm{f}, \mathrm{g}=100$ $\mu \mathrm{m}, \mathrm{k}=50 \mu \mathrm{m}, \mathrm{e}, \mathrm{h}-\mathrm{j}=20 \mu \mathrm{m}$.

Caryosporaceae Huang Zhang, K.D. Hyde \& Ariyaw.

Ariyawansa et al. (2015a) introduced the new family Caryosporaceae to accomodate Acrocordiopsis and Caryospora based on phylogenetic analyses. Wijayawardene et al. (2018) referred Acrocordiopsis in Salsugineaceae following Hyde et al. (2013). Jones \& Pang (2012) 
considered the phylogenetic placement of A. patilii as unresolved. Zhang et al. (2018) showed that the phylogenetic placement of the taxa Acrocordiopsis, Astrosphaeriella, Astrosphaeriellopsis and Caryospora are not well resovled.

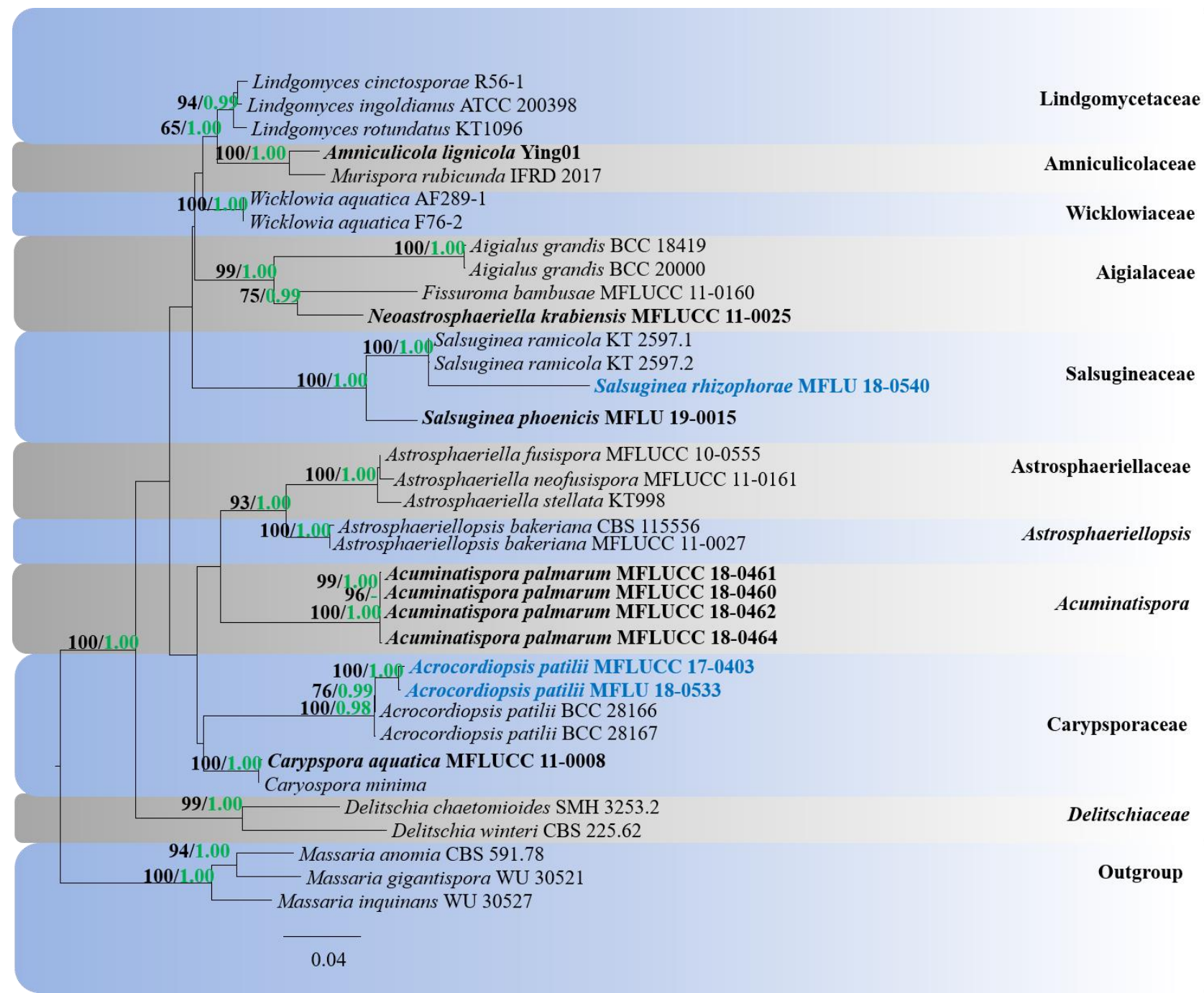

Figure 34 - Maximum likelihood analysis with 1000 bootstrap replicates yielded a best tree with the likelihood value of -16446.792988 . The combined LSU, SSU, TEF and RPB2 sequence datasets comprised 29 strains of Salsugineaceae and related taxa with Massaria inquinans (WU 30527), M. anomia (CBS591.78) and M. gigantispora (WU 30521) as the outgroup taxa. Tree topology of the ML analysis was similar to the BI and. The matrix had 1170 distinct alignment patterns, with $39.14 \%$ of undetermined characters or gaps. Estimated base frequencies were as follows; $\mathrm{A}=0.253912, \mathrm{C}=0.231759, \mathrm{G}=0.277414, \mathrm{~T}=0.236915$; substitution rates $\mathrm{AC}=$ 1.596685, $\mathrm{AG}=4.432406, \mathrm{AT}=1.238993, \mathrm{CG}=1.541040, \mathrm{CT}=9.176903, \mathrm{GT}=1.000000$; gamma distribution shape parameter $\alpha=0.178423$. Maximum likelihood bootstrap (ML, black) values $>65 \%$ and Bayesian posterior probabilities (PP, green) $>0.90 \%$ are given above the nodes. The scale bar indicates 0.04 changes. The ex-type strains are in bold and new isolates in blue bold.

Acrocordiopsis Borse \& K.D. Hyde

Acrocordiopsis patilii was phylogenetically first treated by Suetrong et al. (2009) who demonstrated that $A$. patilii grouped as a residual paraphyletic assemblage within the class Dothideomycetes and could not be assigned to any of the families in this class. Subsequently, this was supported by Jones \& Pang (2012). Hyde et al. (2013) assigned Acrocordiopsis to Salsugineaceae based on sequence data of Suetrong et al. (2009). Ariyawansa et al. (2015b) accommodated Acrocordiopsis in the family Caryosporaceae along with Caryospora, while, 
Wijayawardene et al. (2018) listed A. patilii in Salsugineaceae following Hyde et al. (2013). There are two accepted species in this genus (Index Fungorum 2019). However according to our phylogenetic analyses Acrocordiopsis grouped within Caryosporaceae. Hence, we reinstate Acrocordiopsis within Caryosporaceae. However, type species of Caryospora, C. putaminum has not been sequenced.

Acrocordiopsis patilii Borse \& K.D. Hyde, Mycotaxon 34(2): 536 (1989)

Fig. 35

Index Fungorum number - IF 135664, Facesoffungi Number - FoF 00787

Saprobic on submerged wood of Rhizophora apiculata and Xylocarpus sp. Sexual morph: Ascomata up to $2.5 \mathrm{~mm}$ diam., conical or semi-globose, occur on black stroma, gregarious, black, carbonaceous, superficial, axis vertical, base flattened, epapillate, ostiolate. Peridium 160-200 $\mu \mathrm{m}$ wide, composed of several layers of thick-walled, melanized cells, appearing black. Pseudoparaphyses 1.2-3 $\mu \mathrm{m}$ wide, numerous, filiform, anastomosing and septate, trabeculate, branched. Asci 175-200 × 13.5-15 $\mu \mathrm{m}(\overline{\mathrm{x}}=178 \times 14.2 \mu \mathrm{m}, \mathrm{n}=30), 8$-spored, cylindrical, bitunicate, thick-walled, pedicellate, with an apical thickening and an ocular chamber. Ascospores 15-20 $\times 10-15 \mu \mathrm{m}(\overline{\mathrm{x}}=16.2 \times 13.4 \mu \mathrm{m}, \mathrm{n}=30)$, uni-seriate, bi-celled, broadly ellipsoidal, hyaline, 1-euseptate, slightly constricted at the septum, with a large guttule in each cell, with small granules concentrated near the septum, thick walled. Asexual morph: Undetermined.

Culture characteristics - Ascospores germinating on 50\% sea water agar within 24 hours, with germ tubes developed from lower side of ascospores. Colonies on PDA slow growing, reaching 10-20 mm diam., after 15 days of incubation at $25^{\circ} \mathrm{C}$, filamentous, greenish black at the center becoming black, yellowish at the margins, spreading, flattened, fluffy, sparse, reverse black, yellowish at the margins.

Material examined - THAILAND, Ranong Province, Ranong District, on decaying, submerged wood of Xylocarpus sp. (Meliaceae), 07 December 2016, M.C. Dayarathne, MCD 64 (MFLU 18-0547); ibid., (HKAS102085), living cultures MFLUCC 17-0403). THAILAND, Ranong Province, Ranong, on decaying, submerged wood of Rhizophora apiculata (Rhizophoraceae) 06 December 2016, M.C. Dayarathne, MCD 46 (MFLU 18-0533).

GenBank numbers - LSU: MN017849, MN017850; SSU: MN017915, MN017916; TEF MN077067; RPB2: MN077078

Notes - Our two strains (MFLUCC 17-0403, MFLU 18-0533) are morphologically and phylogenetically (Fig. 34) similar to Acrocordiopsis patilii and there are no accountable base pair differences of LSU, SSU, and RPB2 data. Acrocordiopsis patilii phenotypically closely resembles A. sphaerica but differs in having smaller and narrower asci (Table 4). Furthermore, ascospores of A. sphaerica are often spherical and wider in diameter and not constricted at the septum, while in $A$. patilii ascospores are narrower (Table 4) and slightly constricted at the septum. However, no sequence data are available for A. sphaerica to determine their phylogenetic relationships. In this study we provide a new host record of this species from Xylocarpus sp.

Salsugineaceae K.D. Hyde \& Tibpromma

Hyde et al. (2013) introduced the family Salsugineaceae to accommodate the genera Acrocordiopsis and Salsuginea (family type). In the phylogenetic analyses of Hyde et al. (2013) Salsuginea ramicola clusters with Acrocordiopsis patilii in a clade within the Pleosporales with weak support. However, Zhang et al. (2018) showed that these two genera were distantly placed and this is supported by our data.

Salsuginea K.D. Hyde, Bot. Mar. 34(4): 315 (1991)

Salsuginea was introduced with $S$. ramicola as the type species on mangrove wood of intertidal Aegiceras sp. collected in Thailand (Hyde 1991a). Zhang et al. 2009 and in Jones et al. (2019) introduced the second species, S. phoenicis to the genus. In this study we introduce a novel species $S$. rhizophorae from decayed mangrove wood. 

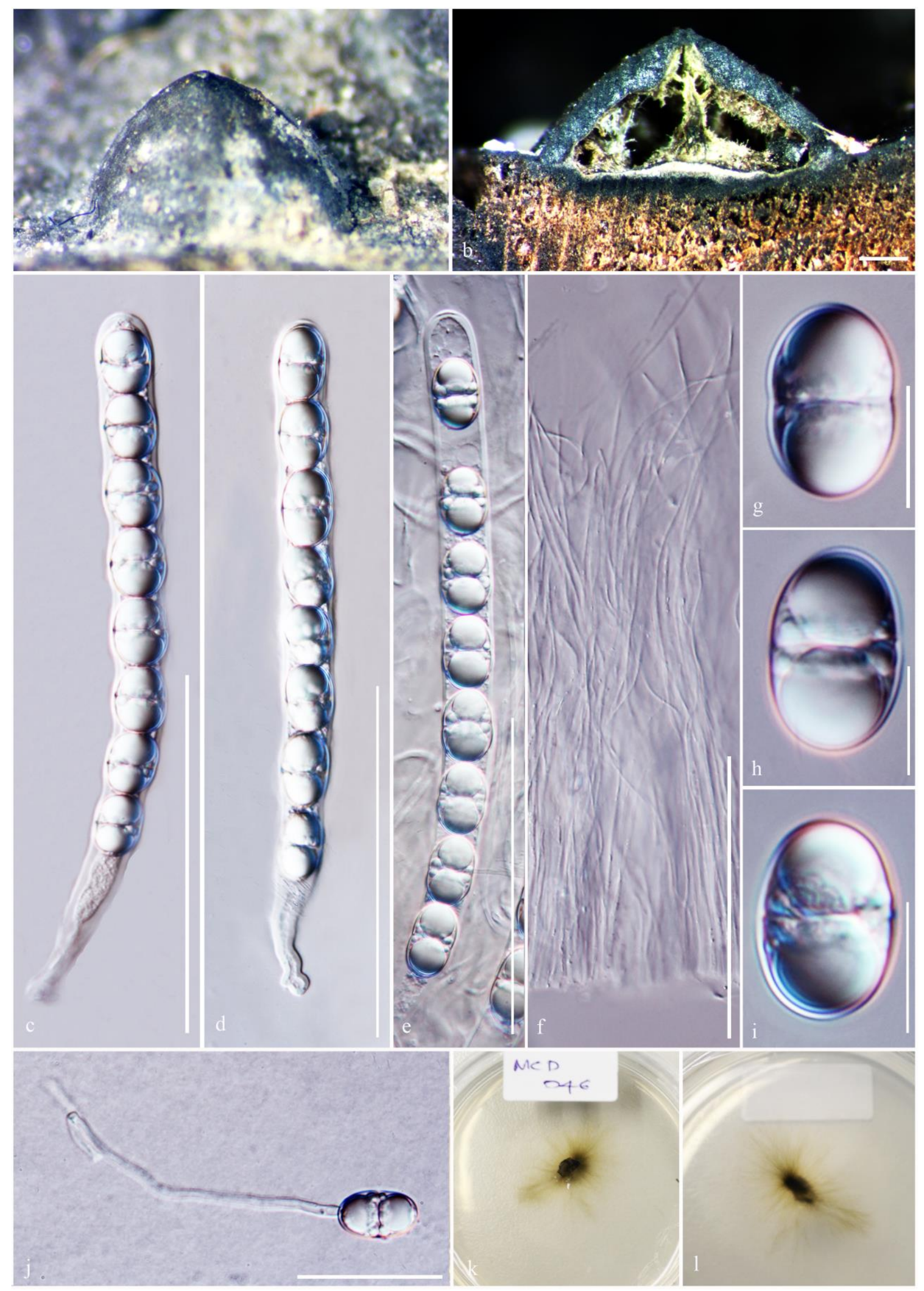

Figure 35 - Acrocordiopsis patilii (MFLU 18-0547). a Appearance of ascomata on host. b Vertical section of ascomata. c-e Asci f Psudoparaphyses. g-i Ascospores. j Germinating ascospore. k, 1 Cultures on PDA. (k-upper, l-lower). Scale bars: $b=200 \mu \mathrm{m}, \mathrm{c}-\mathrm{f}=100 \mu \mathrm{m}, \mathrm{g}-\mathrm{i}=10 \mu \mathrm{m}, \mathrm{j}=50$ $\mu \mathrm{m}$. 
Table 4 Synopsis of the morphological characteristics of Acrocordiopsis species.

\begin{tabular}{lllll}
\hline Species & $\begin{array}{l}\text { Ascomata } \\
(\mathbf{m m})\end{array}$ & Asci $(\boldsymbol{\mu m})$ & Ascospores $(\boldsymbol{\mu m})$ & Reference \\
\hline A. patilii & 2.5 diam. & $175-198 \times 13.5-$ & $15.8-20.5 \times 11.2-$ & This study \\
& & 14.8 & 14.4 & \\
A. sphaerica & $1-2$ high & $180-270 \times 19.5-$ & $18-27 \times 15-24$ & $\begin{array}{l}\text { Alias et al. } \\
(1999)\end{array}$ \\
\hline
\end{tabular}

Salsuginea rhizophorae Dayarathne, E.B.G. Jones \& K.D. Hyde, sp.nov.

Fig. 36 Index Fungorum number: IF556582; Facesoffungi Number: FoF 06169

Etymology - Species epithet refers to the host genus where the fungus was isolated

Holotype - MFLU 18-0540

Saprobic on decaying wood submerged in brackish waters in mangroves. Sexual morph: Ascomata 590-725 × 620-680 $\mu \mathrm{m}(\overline{\mathrm{x}}=684 \times 653 \mu \mathrm{m}, \mathrm{n}=5)$, immersed beneath a raised dark brown to black pseudoclypeus, brown to black, carbonaceous, comprising host cells and dark fungal hyphae, solitary, in section flask-shaped, with a protruding papilla. Papilla conspicuous, central, cone-shaped, brown to black, ostiolate. Peridium 84-115 $\mu \mathrm{m}$ wide, comprising a single layer of light brown cells of textura globulosa, emerging at the outside with the host, where cells of fungus become irregular and contorted and intermingle with host cells. Hamathecium 0.9-1.8 $\mu \mathrm{m}$ wide, comprising numerous, filiform, trabeculate, branched, septate, hyaline pseudoparaphyses. Asci $175-200 \times 10-15 \mu \mathrm{m}(\overline{\mathrm{x}}=178 \times 14.2 \mu \mathrm{m}, \mathrm{n}=30), 8$-spored, bitunicate, fissitunicate, cylindrical to clavate, with an apical apparatus, rounded, with an ocular chamber. Ascospores 80 $95 \times 28-42 \mu \mathrm{m}(\overline{\mathrm{x}}=178 \times 30 \mu \mathrm{m}, \mathrm{n}=30)$, partially overlapping uni-seriate, fusciform, symmetrical, tapering toward acute ends, 1-septate, constricted at the septum, hyaline when immature becoming brown to dark brown with age, with subhyaline germ pores at both ends, smooth-walled, with a large guttule per each cell and numerous small granules. Asexual morph: Undetermined.

Material examined - THAILAND, Ranong Province, Ranong District, on decaying, submerged wood of Rhizophora apiculata (Rhizophoraceae), 07 December 2016, M.C. Dayarathne, MCD 055 (MFLU 18-0540, holotype); ibid., (BBH, isotype).

GenBank numbers - LSU: MN017851

Notes - Salsuginea rhizophorae is morphologically comparable to S. ramicola and their characters summarized in Table 5. Both species having conical ascomata but the ascomatal base of S. ramicola is considerably wider (elongated horizontally than vertical axis) (Hyde 1991a) and ascomata of $S$. rhizophorae are flask shaped which is elongated in vertical axis rather than the horizontal axis. Base pair differences between $S$. rhizophorae and $S$. ramicola are $22 \mathrm{bp}$ of LSU out of $769 \mathrm{bp}(2.8 \%$ ) and SSU 3.8\% (36 bp out of $936 \mathrm{bp}$ ). Base pair differences of LSU of $S$. phoenicis and S. rhizophorae are 5.7\% (44 bp out of $769 \mathrm{bp}$ ) for LSU.

\section{Testudinaceae Arx}

von Arx (1971) introduced the family Testudinaceae to include the genera Testudina (type), Neotestudina, Lepidosphaeria, Argynna (later transferred to Argynnaceae) and Pseudophaeotrichum (synonymized as Neotestudina). Testudinaceae is characterized by astomatous ascomata with a dark peridium, bitunicate asci and dark, 1-septate ascospores (about 10 $\mu \mathrm{m}$ long) (Phookamsak et al. 2015, Wanasinghe et al. 2017). Hawksworth \& Booth (1974) synonymized Testudinaceae under Zopfiaceae. Subsequently, Hawksworth (1979), considered Zopfiaceae as a synonym of Testudinaceae on the basis of the size and more especially the shape and type of sculpturing of the ascospores in SEM studies. Eriksson (1981) accepted both families and Zopfiaceae was validated by Eriksson \& Hawksworth (1992). Hyde et al. (2013) considered Testudinaceae as a family in Dothediomycetes and included five genera: Lepidosphaeria, Neotestudina, Testudina, Ulospora and Verruculina (Suetrong et al. 2009). 


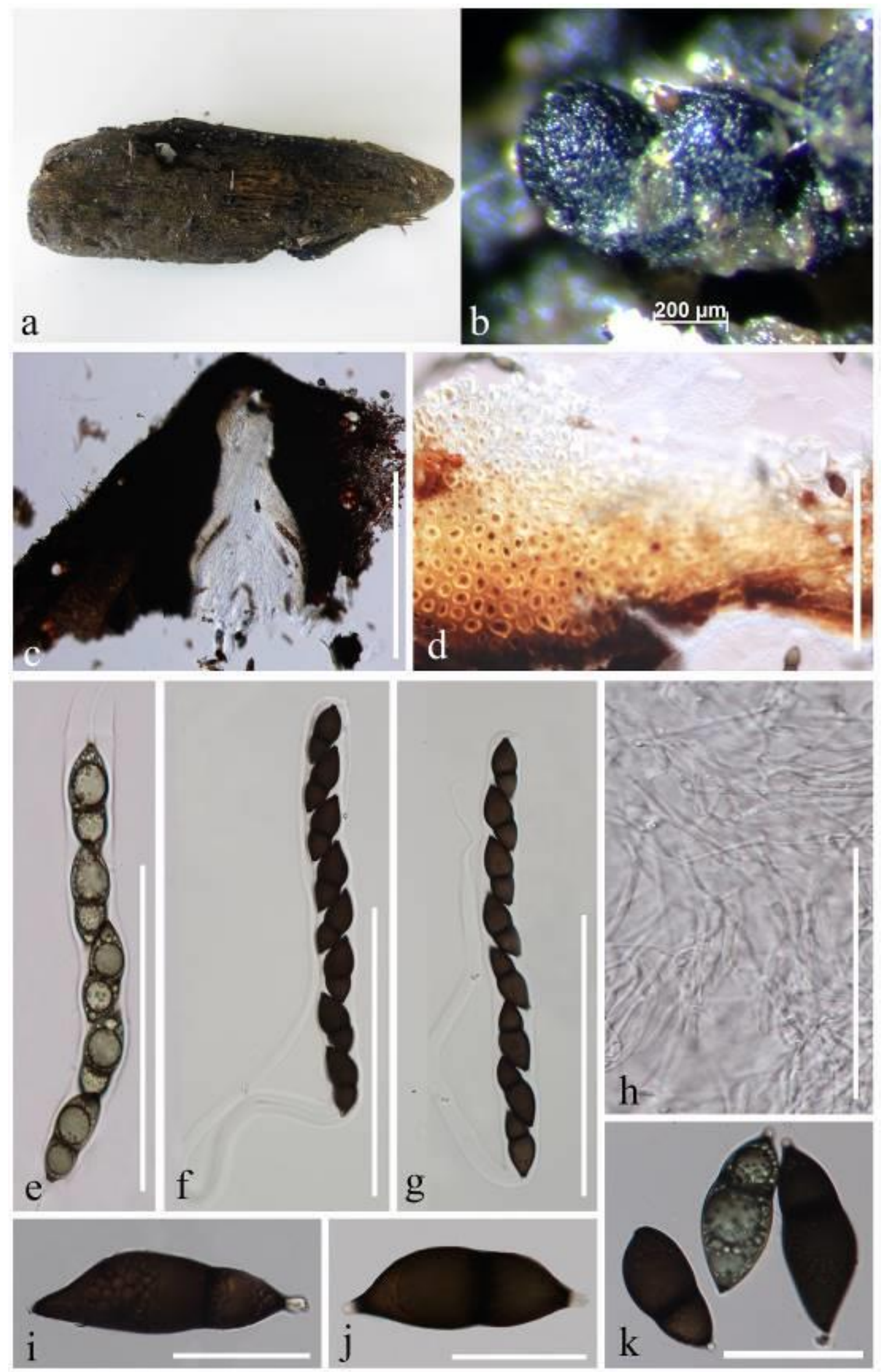

Figure 36 - Salsuginea rhizophorae (MFLU 18-0540, holotype). a Host. b Appearance of ascomata on Rhizophora apiculata. c Section through ascoma. d Peridium. e-g Asci. 
h Psudoparaphyses. i-k Ascospores. Scale bars: $\mathrm{b}=200 \mu \mathrm{m}, \mathrm{c}=500 \mu \mathrm{m}, \mathrm{e}-\mathrm{h}=100 \mu \mathrm{m}, \mathrm{d}, \mathrm{i}-\mathrm{k}=50$ $\mu \mathrm{m}$.

Currently, Testudinaceae includes the genera Angustospora, Lepidosphaeria, Lojkania, Muritestudina, Neotestudina, Testudina, Ulospora and Verruculina (Hyde et al. 2013, Wanasinghe et al. 2017). This paper introduces a novel genus Halotestudina and a novel species to the family Testudinaceae which was collected from mangrove habitats.

Table 5 Measurements of the ascomata, asci and ascospores of Salsuginea species.

\begin{tabular}{|c|c|c|c|c|}
\hline Species & Ascomata (mm) & Asci $(\mu \mathrm{m})$ & $\begin{array}{l}\text { Ascospores } \\
(\mu \mathrm{m})\end{array}$ & Reference \\
\hline S. ramicola & $\begin{array}{l}1040-2600 \times 455- \\
1430\end{array}$ & $440-512 \times 29-34$ & $59-72 \times 24-30$ & Hyde 1991a \\
\hline $\begin{array}{l}\text { S. } \\
\text { rhizophorae }\end{array}$ & $\begin{array}{l}590-725.4 \times 620- \\
680\end{array}$ & $\begin{array}{l}175-198 \times 13.5- \\
14.8\end{array}$ & $80-94 \times 28-42$ & This study \\
\hline S. phoenicis & $410-480 \times 680-980$ & $140-275 \times 23-30$ & $46-62 \times 16-24$ & $\begin{array}{l}\text { Jones et al. } \\
\text { (2019) }\end{array}$ \\
\hline
\end{tabular}

Halotestudina Dayarathne \& K.D. Hyde, gen. nov.

Index Fungorum number: IF IF556584; Facesoffungi number: FoF 06170

Saprobic on mangrove wood. Sexual morph: Ascomata subglobose, completely or partially immersed, carbonaceous to coriaceous, black, gregarious, ostiolate. Peridium coriaceous to carbonaceous, two-layered, outer layer composed of elongate cells, inner layer composed of smaller hyaline cells. Hamathecium comprising trabeculate pseudoparaphyses, unbranched at the base, anastomosing above the asci, embedded in a gelatinous matrix. Asci 8-spored, bitunicate, fissitunicate, cylindrical, long-pedicellate, with a refractive non-amyloid, apical ring. Ascospores biseriate, ellipsoidal to broadly fusiform, muriform, pale brown to brown, with hyaline to pale brown apical cells, glabrous, with a gelatinous cap or a mucilaginous sheath. Asexual morph: Unknown.

Type - Halotestudina muriformis Dayarathne \& K.D. Hyde

Notes - Halotestudina can be easily distinguish from other Testudinaceae genera by its brown muriform ascospores that are constricted at each septum. The genus Muritestudina resembles Halotestudina by having muriform ascospores but it can be clearly distinguished as it has hyaline ascospores surrounded by a thick, mucilaginous sheath (Wanasinghe et al. 2017). Verruculina is clearly different form Halotestudina in ascospore morphology which are 1-septate, while ascospores of Halotestudina are muriform. In our phylogenetic analyses they formed a moderately-supported (73\% ML) clade (Fig. 37). Halotestudina and Verruculina are two marine genera referred to Testudinaceae. Halotestudina shows a close phylogenetic placement to the genera Trematosphaeria and the Angustospora. Trematosphaeria species are different form Halotestudina in having a trabeculate hamathecium embedded in a gelatinous matrix and reddishbrown ellipsoid to fusoid transversely septate ascospores sometimes with paler end cells (Boise 1985, Barr 1990b, Mckeown et al. 2001). Angustospora is morphologically quite different from Halotestudina in having large ascospores with a median septum and additional septa near the poles of the ascospores (Li et al. 2016).

Halotestudina muriformis Dayarathne \& K.D. Hyde, sp. nov.

Fig. 38

Index Fungorum number: IF556583; Facesoffungi number: FoF 06171

Holotype - MFLU 17-2634

Saprobic on mangrove wood. Sexual morph: Ascomata 750-990 $\times 700-750 \mu \mathrm{m}(\overline{\mathrm{x}}=880 \times$ $740 \mu \mathrm{m}, \mathrm{n}=5$ ), globose to subglobose, semi immersed, carbonaceous to coriaceous, black, gregarious, ostiolate. Peridium 70-90 $\mu \mathrm{m}$ wide, coriaceous to carbonaceous, two-layered, outer 
layer composed of elongate cells, inner layer composed of smaller hyaline cells. Hamathecium comprising 0.6-1.5 $\mu \mathrm{m}$ wide, hyaline, branched, aseptate, pseudoparaphyses, anastomosing above the asci, embedded in a gelatinous matrix. Asci 180-240 $\times 15-27 \mu \mathrm{m}(\overline{\mathrm{x}}=200 \times 22 \mu \mathrm{m}, \mathrm{n}=20), 8$ spored, bitunicate, fissitunicate, cylindrical, short-pedicellate, with a non-amyloid, apical ring. Ascospores 30-45 $\times 10-17 \mu \mathrm{m}(\overline{\mathrm{x}}=34 \times 12 \mu \mathrm{m}, \mathrm{n}=20)$, uniseriate, ellipsoidal to broadly fusiform, muriform, with 7 transverse septa and 0-2 longitudinal septa, brown, with pale brown apical cells, constricted at the septa, smooth-walled. Asexual morph: Unknown.

Material examined - THAILAND, Krabi Province, Krabi, on decaying wood of Rhizophora sp. (Rhizophoraceae) wood, 31 August 2017, M.C. Dayarathne, MCD 163 (MFLU 17-2634, holotype), ex type living culture MFLUCC 18-0392; THAILAND, Phetchaburi Province, Cha-am beach, on bark attached to the living plant of Bruguiera sp. (Rhizophoraceae), 06 December 2016, M.C. Dayarathne, MCD 035 (MFLU 18-0524), living culture MFLUCC 17-0395.

GenBank numbers - LSU: MN017852, MN017894, MN017853, MN017854; SSU: MN017918, MN017947, MN017919, MN017920; TEF: MN077068: RPB2: MN077079

Notes - Halotestudina muriformis is characterized by globose to subglobose, semi immersed, carbonaceous to coriaceous ascomata, branched, aseptate, pseudoparaphyses, anastomosing above the asci and ellipsoidal to broadly fusiform, brown, muriform ascospores with 7 transverse septa and 0-2 longitudinal septa, with pale brown apical cells, constricted at the septa. Four isolates of $H$. muriformis formed a moderately supported $(73 \% \mathrm{ML})$ clade within Testudianace sister to Angustospora nilensis (MFLU 15-1511) and Trematosphaeria wegeliniana (CBS 123124) (Fig. 37). Morphologically, genera of Testudinaceae are highly diverse especially by having different ascospore morphologies and this is the first record of brown muriform ascospores in Testudinaceae. TEF and RPB2 base pair differences of Halotestudina muriformis to Muritestudina chiangraiensis and Verruculina enalia are given in Table 6.

Verruculina (Kohlm.) Kohlm. \& Volkm-Kohlm.

Kohlmeyer \& Volkmann-Kohlmeyer (1990) introduced the obligate marine monotypic genus Verruculina with $V$. enalia as the type species. The type species was originally described as Didymosphaeria enalia. Later, Barr (1990b) assigned it to Lokjania and finally to Verruculina (Kohlmeyer \& Volkmann-Kohlmeyer 1990). Molecular studies confirmed its placement in Testudinaceae (Suetrong et al. 2009, Hyde et al. 2013, Phookamsak et al. 2015, Wanasinghe et al. 2017).

\section{Key to genera of Testudinaceae}

1. Ascospores muriform.

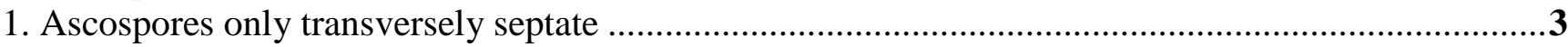

2. Ascospores hyaline

Muritestudina

2. Ascospores brown

Halotestudina

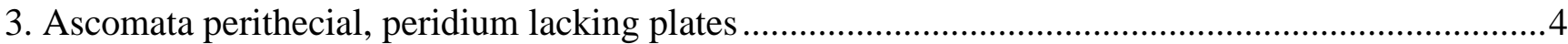

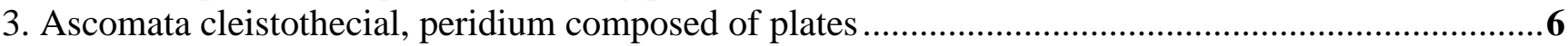

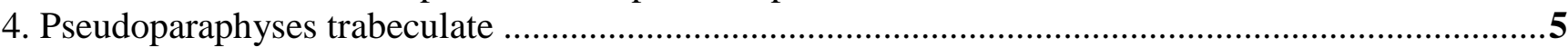

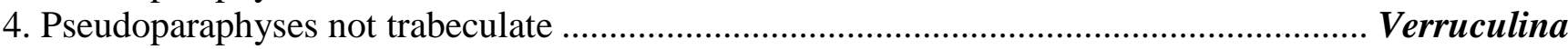

5. Ascospores one septate Lojkania

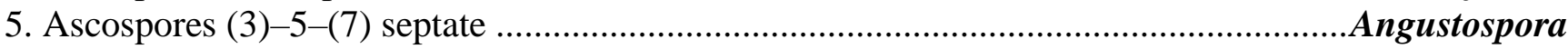

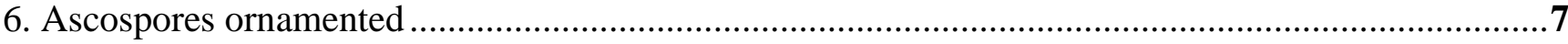

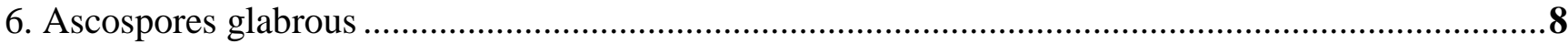

7. Asci obovate or broadly clavate, ascospores reticulate ................................................... Testudina

7. Asci clavate, with a long stalk, ascospores finely echinulate, darker near the septum.

8. Asci obovate or nearly sphaerical, ascospores not darker near the septum

8. Ascospores with germ-slits

Lepidosphaeria . Neotestudina Ulospora 


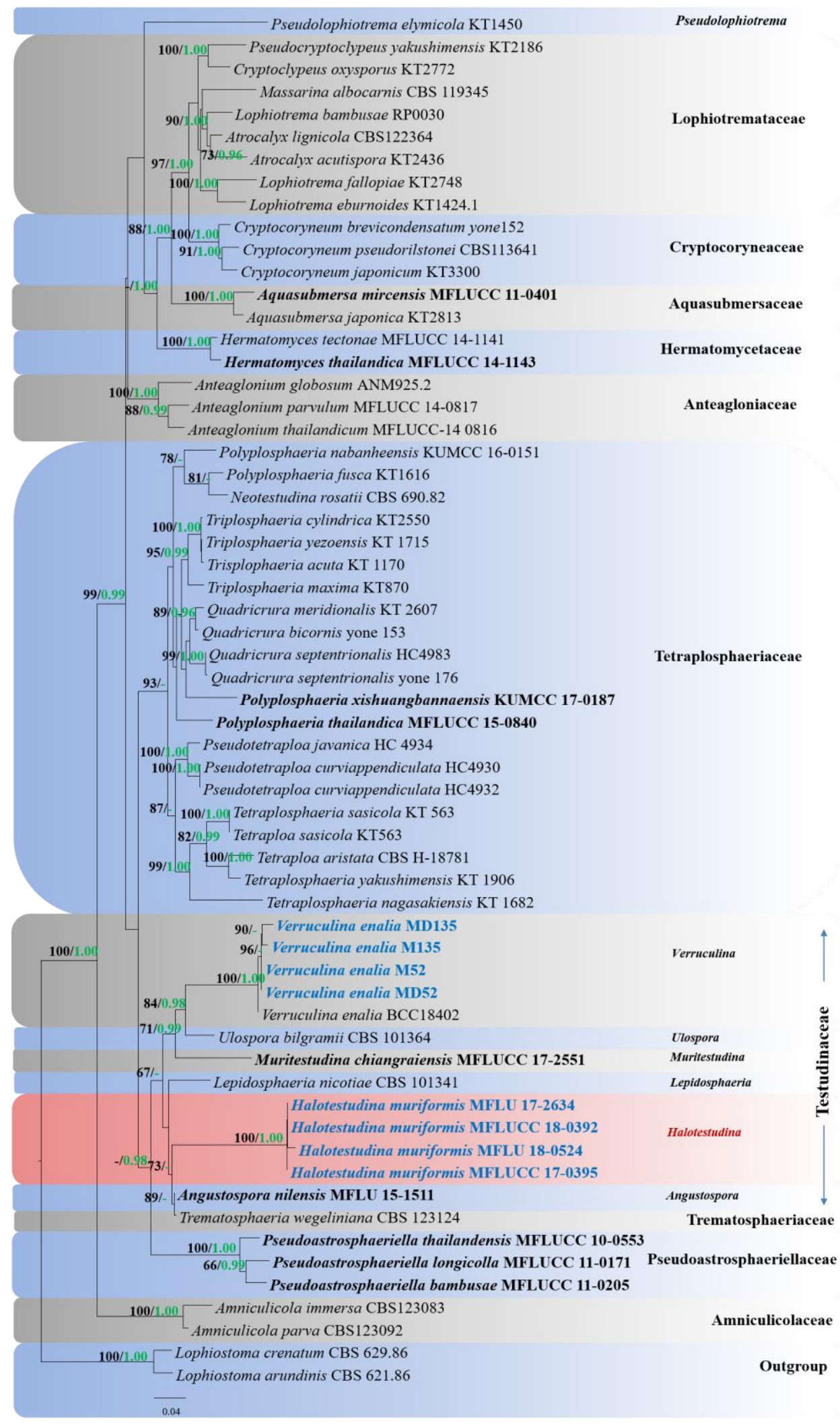

Figure 37 - Maximum likelihood analysis with 1000 bootstrap replicates yielded a best tree with likelihood value of -31642.769668 . The combined LSU, SSU, TEF and RPB2 sequence datasets comprised 61 strains with Lophiostoma crenatum (CBS 629.86) and L. arundinis (CBS 621.86) as the outgroup taxa. Tree topology of the ML analysis was similar to the BI and in congruent with previous study Wanasinghe et al. (2017). The matrix had 1742 distinct alignment patterns, with $33.77 \%$ of undetermined characters or gaps. Estimated base frequencies were as follows; $\mathrm{A}=$ $0.247462, \mathrm{C}=0.247183, \mathrm{G}=0.271298, \mathrm{~T}=0.234057$; substitution rates $\mathrm{AC}=1.697785, \mathrm{AG}=$ 
4.459687, $\mathrm{AT}=1.614825, \mathrm{CG}=1.267576, \mathrm{CT}=9.339520, \mathrm{GT}=1.000000$; gamma distribution shape parameter $\alpha=0.184250$. Maximum likelihood bootstrap (ML, black) values $>65 \%$ and Bayesian posterior probabilities (PP, green) $>0.80 \%$ are given above the nodes. The scale bar indicates 0.04 changes. The ex-type strains are in bold and new isolates in blue bold.

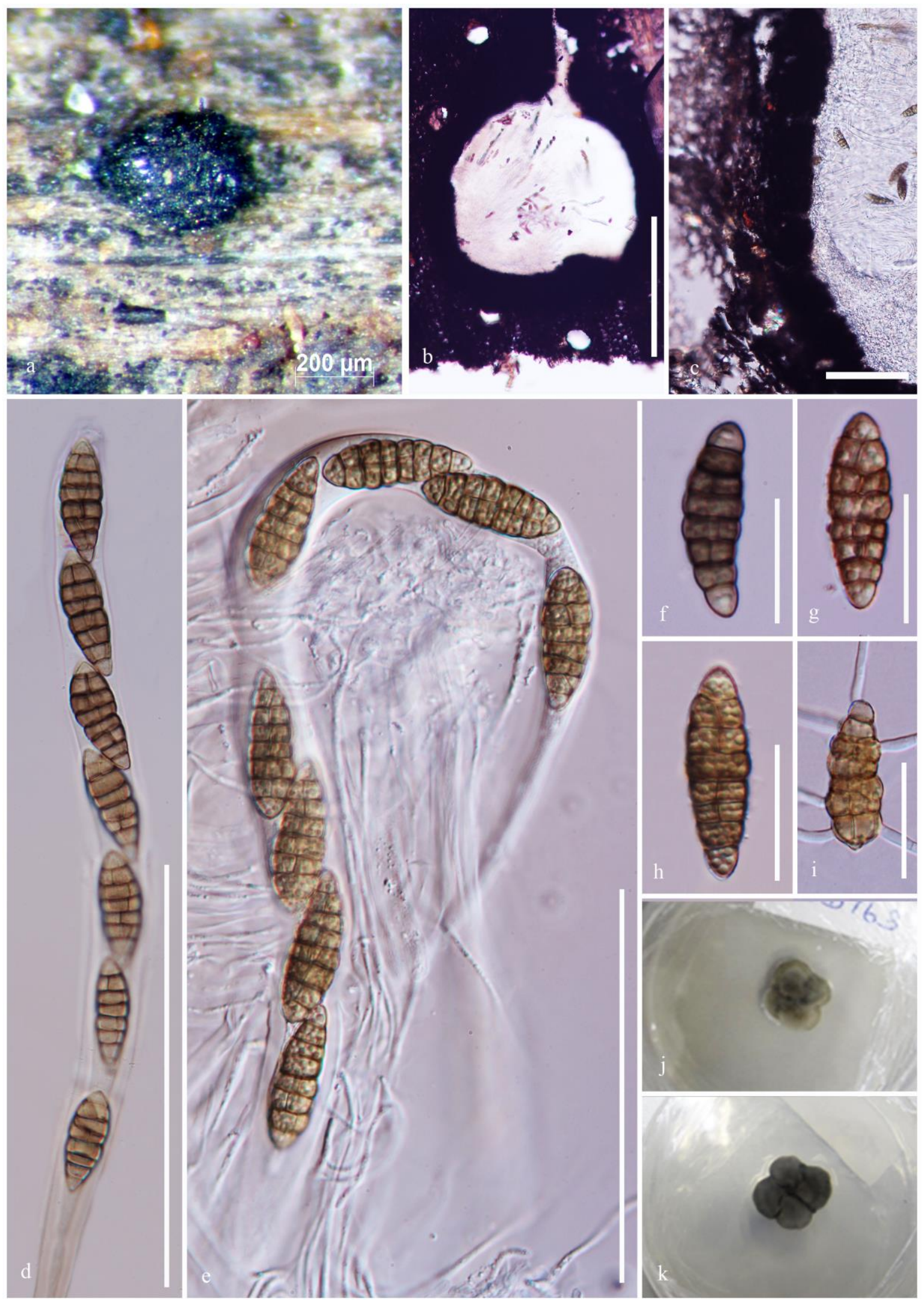

Figure 38 - Halotestudina muriformis (MFLU 17-2634, holotype). a Ascoma on host surface. b 
Section of ascoma. c Peridium. d, e Asci and pseudoparaphyses. f-h Immature and mature ascospores. s Germinating ascospore. n, o Cultures on sea water PDA (n-upper, o lower). Scale bars: $\mathrm{a}, \mathrm{b}=200 \mu \mathrm{m}, \mathrm{d}, \mathrm{e}=100 \mu \mathrm{m}, \mathrm{c}=50 \mu \mathrm{m}, \mathrm{f}-\mathrm{i}=20 \mu \mathrm{m}$.

Table 6 Base pair differences of Halotestudina muriformis and related taxa.

\begin{tabular}{llll}
\hline \multicolumn{1}{c}{ Taxon } & \multicolumn{1}{c}{ LSU } & \multicolumn{1}{c}{ TEF } & \multicolumn{1}{c}{ RPB2 } \\
\hline Muritestudina & $6.8 \%(60 \mathrm{bp}$ out of & $26 \%(136 \mathrm{bp}$ out of & $21 \%(202 \mathrm{bp}$ out of \\
chiangraiensis & $874 \mathrm{bp})$ & $515 \mathrm{bp})$ & $1011 \mathrm{bp})$ \\
Verruculina enalia & $7.2 \%(63 \mathrm{bp}$ out of & $111.3 \%(103 \mathrm{bp}$ out & $19.6 \%(156 \mathrm{bp}$ out of \\
& $874 \mathrm{bp})$ & of 912$)$ & $792 \mathrm{bp})$ \\
\hline
\end{tabular}

Verruculina enalia (Kohlm.) Kohlm. \& Volkm.-Kohlm., Mycol. Res. 94(5): 689 (1990)

Fig. 39

Facesoffungi number: FoF 05281

Saprobic on Rhizophora sp. Sexual morph: Ascomata 800-1200 $\mu \mathrm{m}$ high, 410-520 $\mu \mathrm{m}$ diam., $(\overline{\mathrm{x}}=780 \times 460 \mu \mathrm{m}, \mathrm{n}=10)$ subglobose, ampulliform or depressed ellipsoidal, black, carbonaceous, partly or completely immersed, clypeate, solitary, ostiolate, papillate. Ostiole periphysate. Peridium 80-142 $\mu \mathrm{m}$ thick, one-stratum, composed of about six or more layers of irregular roundish or elongate, thick-walled cells, forming a textura angularis. Pseudoparaphyses 2-2.6 $\mu \mathrm{m}$ diam., septate, rarely branched. Asci 130-156 × 10.2-12.4 $\mu \mathrm{m}(\overline{\mathrm{x}}=146 \times 10.8 \mu \mathrm{m}, \mathrm{n}=$ 15), thick-walled, bitunicate, 8 -spored, cylindrical, persistent, pedicellate, fissitunicate, with a faint apical apparatus. Ascospores 17.0-21 $\times 8.3-10 \mu \mathrm{m}(\overline{\mathrm{x}}=18.5 \times 9.4 \mu \mathrm{m}, \mathrm{n}=30)$, overlapping uniseriate, hayaline when immature becoming dark-brown, ellipsoidal, 1-septate, constricted at the septum, verrucose to verruculose, with a large guttule in each cell.

Culture characteristics - Ascospores germinating on sea water agar within $24 \mathrm{~h}$ with germ tubes produced from terminal ends. Colonies reaching $6 \mathrm{~cm}$ in diam. in 25 days at room temperature. Colonies on sea water PDA fast growing, grayish white, brown at margins, reverse yellowish brown, filamentous, lobate.

Material examined - THAILAND, Phetchaburi Province, Cha-am beach, on bark attached to the living Rhizophora sp. (Rhizophoraceae), 06 December 2016, M.C. Dayarathne, MCD 052 (MFLU 18-0538); ibid., HKAS102078. living culture MFLUCC 17-0406, THAILAND, Krabi Province, Krabi, on decaying wood of Rhizophora sp. (Rhizophoraceae), 30 August 2017, M.C. Dayarathne, MCD 135 (MFLU 17-2614), living culture (MFLUCC17-2478).

GenBank numbers - LSU: MN017855, MN017877, MN017856,. MN017895; SSU: MN017921, MN017935, MN017922, MN017948; ITS: MN047089, MN047090, MN047091, MN047092

Notes - Verruculina enalia is distinct in having papillate ascomata and ascospores that are verrucose or verruculose (Suetrong et al. 2009). The new isolates MFLUCC 17-0406 and MFLUCC17-2478 have similar morphologies to Verruculina enalia described by Kohlmeyer \& Volkmann-Kohlmeyer (1990) and clustered in a single clade in our phylogram (Fig. 37). However, we could not observe hyaline tubercle at each apex which is sometimes present in ascospores of this species.

\section{Pleosporomycetidae genera incertae sedis \\ Botryosphaeriales C.L. Schoch et al. \\ Botryosphaeriaceae Theiss. \& H. Syd.}

Theissen \& Sydow (1918) erected the family Botryosphaeriaceae with Botryosphaeria as the type genus. Botryosphaeriaceae species are well-known as saprobes, endophytes and opportunistic pathogens and many species are causative agents of disease on ecologically and economically important plants (Slippers \& Wingfield 2007, Mehl et al. 2014, Tibpromma et al. 2018) and cosmopolitan in distribution but absent in polar regions (Hyde et al. 2013, 2014, Phillips et al. 2013, 2019, Slippers et al. 2013, Dissanayake et al. 2016). 

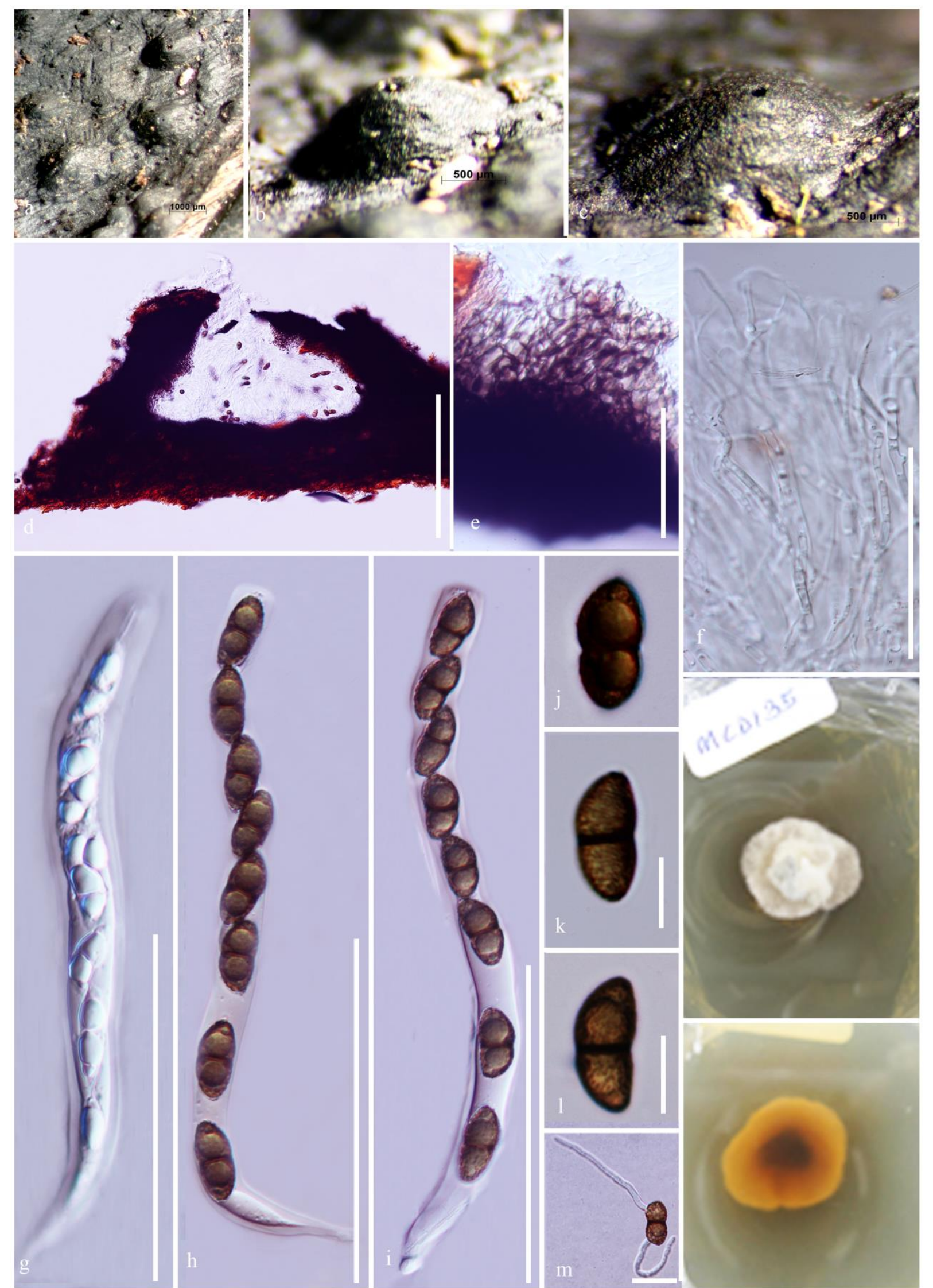

Figure 39 - Verrculilna enalia (MFLU 18-0538). a-c Ascomata on host surface. d Longitudinal section of ascoma. e Peridium. f Pseudoparaphyses. g-i Immature and mature asci. $j-i$ Verrucose to verruculose ascospores. s. Germinating ascospore. $\mathrm{n}$, o Cultures on sea water PDA. Scale bars: $\mathrm{a}=$ $1000 \mu \mathrm{m}, \mathrm{b}=500 \mu \mathrm{m}, \mathrm{d}=100 \mu \mathrm{m}, \mathrm{g}-\mathrm{i}=50 \mu \mathrm{m}, \mathrm{c}=20 \mu \mathrm{m}, \mathrm{j}-\mathrm{i}=10 \mu \mathrm{m}$. 
According to Wijayawardene et al. (2018), there are 28 genera included in this family. The family has been revised by many authors both on morphological and phylogenetic basis (Phillips et al. 2008, 2013, 2019, Slippers et al. 2013, Hyde et al. 2014, Dissanayake et al. 2017, Tibpromma et al. 2018). There are several reports on the presence of Botryosphaeriaceae species from terrestrial mangroves (Osorio et al. 2016) such as Botryosphaeria ribis from Hibiscus tiliaceus, a mangrove associate, in the Hawaiian Islands (Stevens \& Shear 1929), Fusicoccum sp. from symptomatic branches and stems of Rhizophora mangle in South Florida (Rayachhetry et al. 1996), Botryosphaeria sp., Lasiodiplodia sp. and Neofusicoccum sp. from mangroves in Brazil (De Souza et al. 2013), Neofusicoccum sp. from Sonneratia ovata in China (Xing et al. 2011), 14 taxa Diplodia estuarina, D. sapinea, Lasiodiplodia. avicenniae, L. bruguierae, L. gonubiensis, L. theobromae, $N$. cryptoaustrale, $N$. kwambonambiense, $N$. lumnitzerae, $N$. luteum, $N$. mangroviorum, $N$. parvum, $N$. umdonicola and a Botryosphaeria sp. as endophytes of mangroves from South Africa (Osorio et al. 2016) and. Lasiodiplodia mangrovei from aerial dead twigs of Rhizophora apiculata in Thailand (Hyde et al. 2019).

\section{Lasiodiplodia Ellis \& Everh.}

Lasiodiplodia was introduced by Ellis \& Everhart (1894) without a description. Clendenin (1896) provided a description and attributed the genus to Ellis \& Everhart. The type species is $L$. theobromae (Phillips et al. 2013). Most members of this genus are plant pathogens that cause cankers, die-back, fruit or root rot, branch blight or discolouration on a wide range of woody hosts that are mostly distributed in tropical and subtropical regions (Punithalingam 1980, Ismail et al. 2012, Phillips et al. 2013). We herein introduce the second species associated with Bruguiera sp., but as the first saprobic species from submerged, decaying Bruguiera wood, whereas, the previous species was reported as an endophyte (Osorio et al. 2016).

Lasiodiplodia krabiensis Dayarathne, sp. nov.

Fig. 41

Index Fungorum number: IF556586; Facesoffungi number: FoF 06173

Etymology - Epithet refers to the geographical region, Krabi, Thailand, where the species was found.

Holotype - MFLU 17-2617

Saprobic on submerged wood of Bruguiera sp. Sexual morph: unknown. Asexual morph: Conidiomata pycnidial $680-740 \times 300-360 \mu \mathrm{m}(\overline{\mathrm{x}}=718 \times 326.5 \mu \mathrm{m}, \mathrm{n}=5)$, scattered to gregarious, immersed to semi immersed, conspicuous on host surface with a short neck, dark brown, solitary, uniloculate, globose to subglobose, ostiolate, papillate. Pycnidial wall 64-82 $\mu \mathrm{m}$ wide, composed of several layers of thick-walled, hyaline to dark brown cells of textura angularis. Paraphyses 20-51 $\mu \mathrm{m}$ wide, aseptate, hyaline, straight Conidiogenous cells $10-14 \times 3-5.3 \mu \mathrm{m}(\overline{\mathrm{x}}=$ $13 \times 3.6 \mu \mathrm{m}, \mathrm{n}=20$ ), annellidic, cylindrical, thick-walled, smooth. Conidia 24-26.8 $\times 13.2-16.6$ $\mu \mathrm{m}(\overline{\mathrm{x}}=25 . \times 14 \mu \mathrm{m}, \mathrm{n}=20)$, subglobose to oval, aseptate, hyaline to subhyaline with age, guttulate, without longitudinal striations and mucilaginous sheath.

Culture characteristics - Conidia germinating on sea water PDA within $12 \mathrm{~h}$. Colonies on seawater PDA, white at first, becoming black with age, circular, with entire edge, raised, velvety, black in reverse, with smooth margin.

Material examined - THAILAND, Krabi Province, Phang Nga, on decaying submerged wood of Bruguiera sp. (Rhizophoraceae), 30 August 2017, M.C. Dayarathne, MCD 142 (MFLU 17-2617, holotype); ibid., (HKAS102051, isotype), ex-type living culture (MFLUCC 17-2480).

GenBank numbers - ITS: MN047093; TEF: MN077070

Additional GenBank numbers - LSU: MN017859; SSU: MN017924

Notes - Lasiodiplodia krabiensis differs from its closest phylogenetic neighbor L. brasiliense (Fig. 40) by subglobose to oval conidia with rounded ends, while L. brasiliense comprises conidia mostly with a truncate base. Additionally, conidia of L. krabiensis are hyaline throughout the life cycle and conidia of $L$. brasiliense become brown with the age (Netto et al. 2014). 


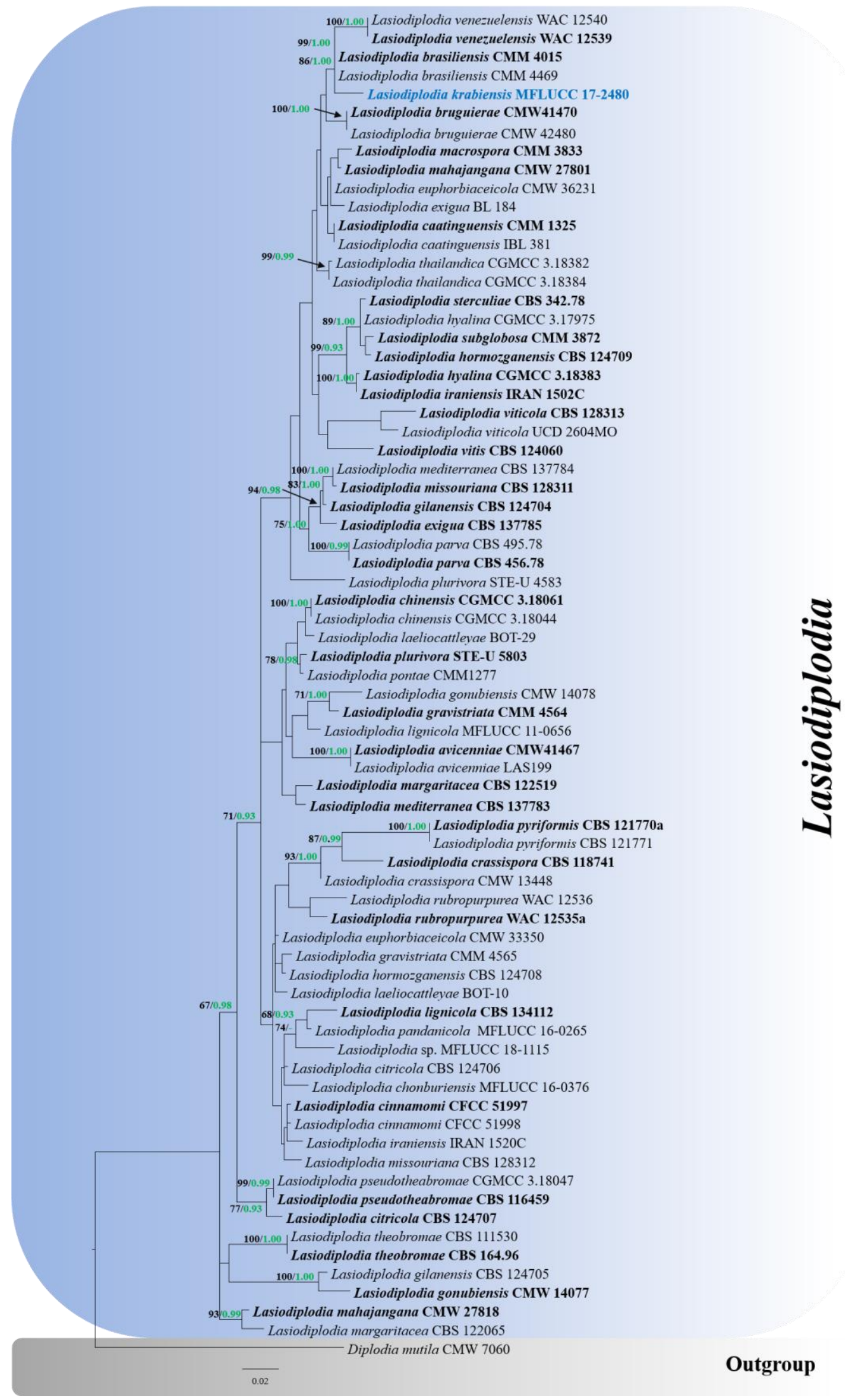

Figure 40 - Maximum likelihood analysis with 1000 bootstrap replicates yielded a best tree with the likelihood value of -4346.694438 . The combined ITS and TEF sequence datasets comprised 72 strains of Lasiodiplodia with Diplodia mutila (CMW 7060) as the outgroup taxon. Topology of the ML tree was similar to the BI. The matrix had 258 distinct alignment patterns, with $46.36 \%$ of undetermined characters or gaps. Estimated base frequencies were as follows; $\mathrm{A}=0.213332, \mathrm{C}=$ 
$0.288271, \mathrm{G}=0.257830, \mathrm{~T}=0.240567 ;$ substitution rates $\mathrm{AC}=1.221116, \mathrm{AG}=5.177782, \mathrm{AT}=$ 2.334654, $\mathrm{CG}=1.157416, \mathrm{CT}=7.150251, \mathrm{GT}=1.000000$; gamma distribution shape parameter $\alpha$ $=0.139994$. Maximum likelihood bootstrap (ML, black) values $>65 \%$ and Bayesian posterior probabilities (PP, green) $>0.90 \%$ are given above the nodes. The scale bar indicates 0.02 changes. The ex-type strains are in bold and new isolates in blue bold.

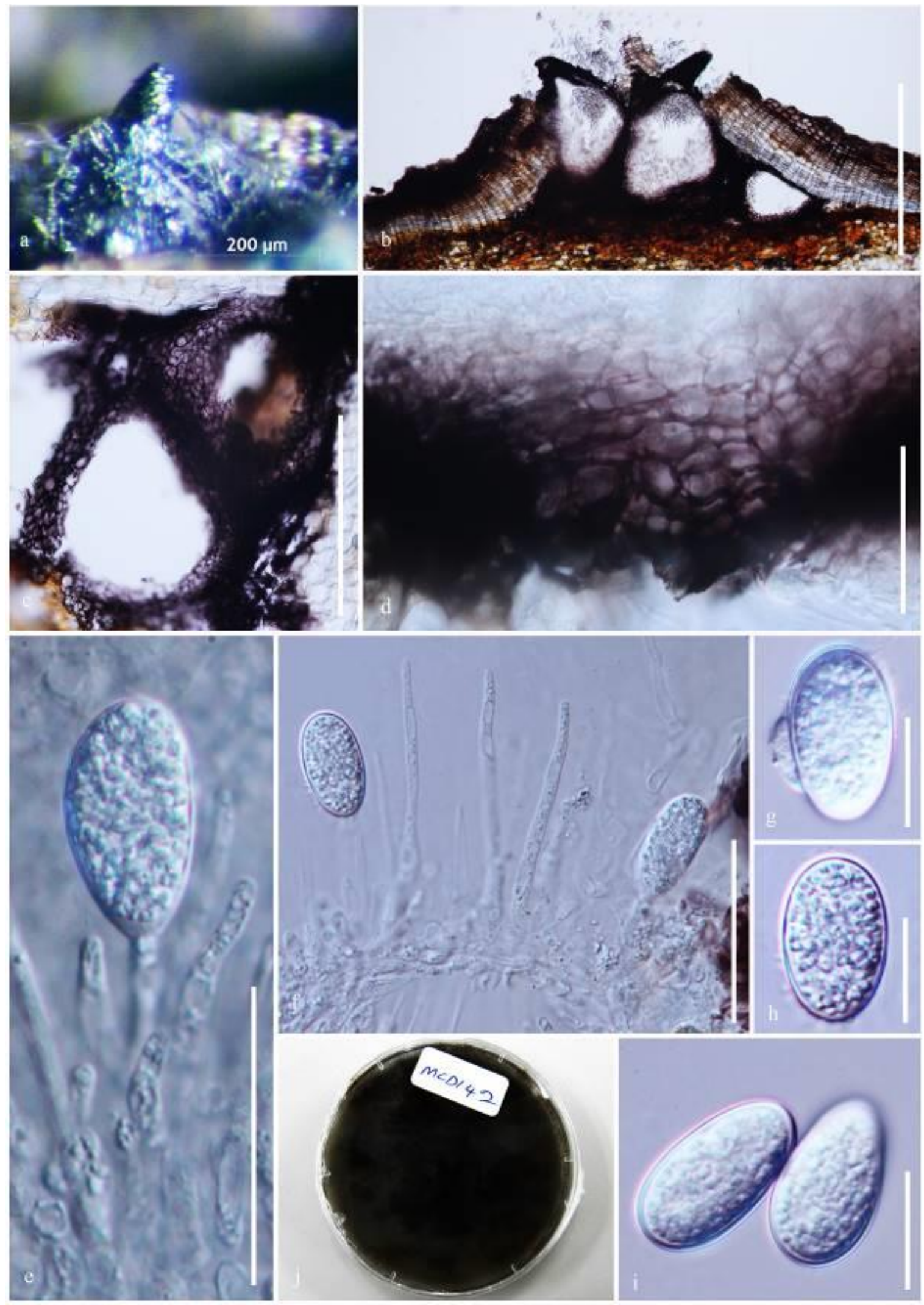

Figure 41 - Lasiodiplodia krabiensis (MFLU 17-2617, holotype). a Conidiomata on host tissue. b, 
c Vertical sections through conidiomata. d Pycnidial wall. e, $\mathrm{f}$ Conidia attached to the conidiogenous cells and paraphyses. $\mathrm{g}-\mathrm{i}$ Conidia. $\mathrm{j}$ Mature culture on sea water PDA. Scale bars: $\mathrm{a}$, $\mathrm{b}=200 \mu \mathrm{m}, \mathrm{c}=100 \mu \mathrm{m}, \mathrm{d}-\mathrm{f}=50 \mu \mathrm{m}, \mathrm{g}-\mathrm{i}=10 \mu \mathrm{m}$.

The base pair difference of the TEF locus is in the range of $2.5 \%$ (7 bp out of 280) and they can be considered as two distinct species using the guidelines of Jeewon \& Hyde (2016). Lasiodiplodia bruguierae, which has been reported as an endophyte of Bruguiera gymnorhiza, is clearly different from this novel taxon by having brown pigmented conidia with striations (Osorio et al. 2016). We believe that both phenotypic and phylogenetic distinctness of this strain is sufficient to introduce it as a novel taxon within the genus Lasiodiploidia.

Dyfrolomycetales K.L. Pang et al.

Pleurotremataceae Walt. Watson

Pleurotremataceae was controversial and reinstated with re-observation of the isotype of Pleurotrema polysemum, and eradication of Dyfrolomycetaceae from the class Sordariomycetes (Maharachchikumbura et al. 2016). Sequence data of the type of Pleurotrema is still inadequate (Maharachchikumbura et al. 2016). Pleurotremataceae comprises three genera Dyfrolomyces, Melomastia and Pleurotrema (Pang et al. 2013, Norphanphoun et al. 2017, Zhang et al. 2017). In this study, a new Dyfrolomyces species collected from unidentified mangrove wood in Krabi, Thailand and a new host record of $D$. thailandica are provided with detailed morphological information and support from combined multi-gene phylogenetic analysis of SSU, LSU and TEF data.

Dyfrolomyces K.D. Hyde et al.

Dyfrolomyces was established by Pang et al. (2013) with species characterized by a clypeus on the substrate, immersed ascomata and multi-septate ascospores with/without a sheath in bitunicate/fissitunicate asci, to accommodate $D$. tiomanensis. Nine species are recognized within this genus, which have mostly been collected from marine habitats on mangrove wood (Hyde 1992b, Pang et al. 2013, Hyde et al. 2017, Norphanphoun et al. 2017, Zhang et al. 2017, Wijayawardene et al. 2017a, Hyde et al. 2018).

Dyfrolomyces neothailandicus Dayarathne, Jones E.B.G. \& K.D. Hyde, sp. nov.

Fig. 43

Index Fungorum number: IF556585; Facesoffungi number: FoF 06172

Etymology - Name reflects the similarity to Dyfrolomyces thailandicus

Holotype - MFLU 17-2589

Saprobic on submerged decaying wood of Rhizophora sp. in mangrove vegetation. Sexual morph: Ascomata 480-496 $\mu \mathrm{m} \times 580-620 \mu \mathrm{m}(\overline{\mathrm{x}}=485 \times 585 \mu \mathrm{m}, \mathrm{n}=10)$, solitary, semiimmersed, clypeate, globose to subglobose, dark brown to black, ostiolate, ostiolar canal filled with dark cells, apapillate. Peridium 26-35 $\mu \mathrm{m}$ wide, comprising an outer layer of dark brown cells of textura angularis, becoming lighter inwardly. Hamathecium 0.4-0.8 $\mu \mathrm{m}$ wide, comprising numerous, septate pseudoparaphyses embedded in a gelatinous matrix. Asci 165-190 × 10-12 $\mu \mathrm{m}$ $(\overline{\mathrm{x}}=168 \times 10.8 \mu \mathrm{m}, \mathrm{n}=10), 8$-spored, bitunicate, cylindrical, short-pedicellate, with a thickened apex. Ascospores $26-28 \times 7.2-8 \mu \mathrm{m}(\overline{\mathrm{x}}=28 \times 6.5 \mu \mathrm{m}, \mathrm{n}=20)$, slightly overlapping uniseriate, hyaline, ellipsoidal narrower towards the ends, 5-septate, with a large guttule in each cell, slightly constricted at septa, surrounded by a thick gelatinous sheath, 3.6-4 $\mu \mathrm{m}$ thick. Asexual morph: Undetermined.

Culture characteristics - Colonies on sea water PDA slow growing at $25-28{ }^{\circ} \mathrm{C}$, reaching 5 $\mathrm{cm}$ in 14 days, white at first, becoming yellowish when mature, undulate and reverse yellowish white.

Material examined - THAILAND, Krabi Province, Phang Nga, on decaying submerged wood of Rhizophora sp. (Rhizophoraceae), 31 August 2017, M.C. Dayarathne, MCD 106 (MFLU 17-2589, holotype); ibid., (HKAS102031, isotype), ex type living culture (MFLUCC 17-2463). 


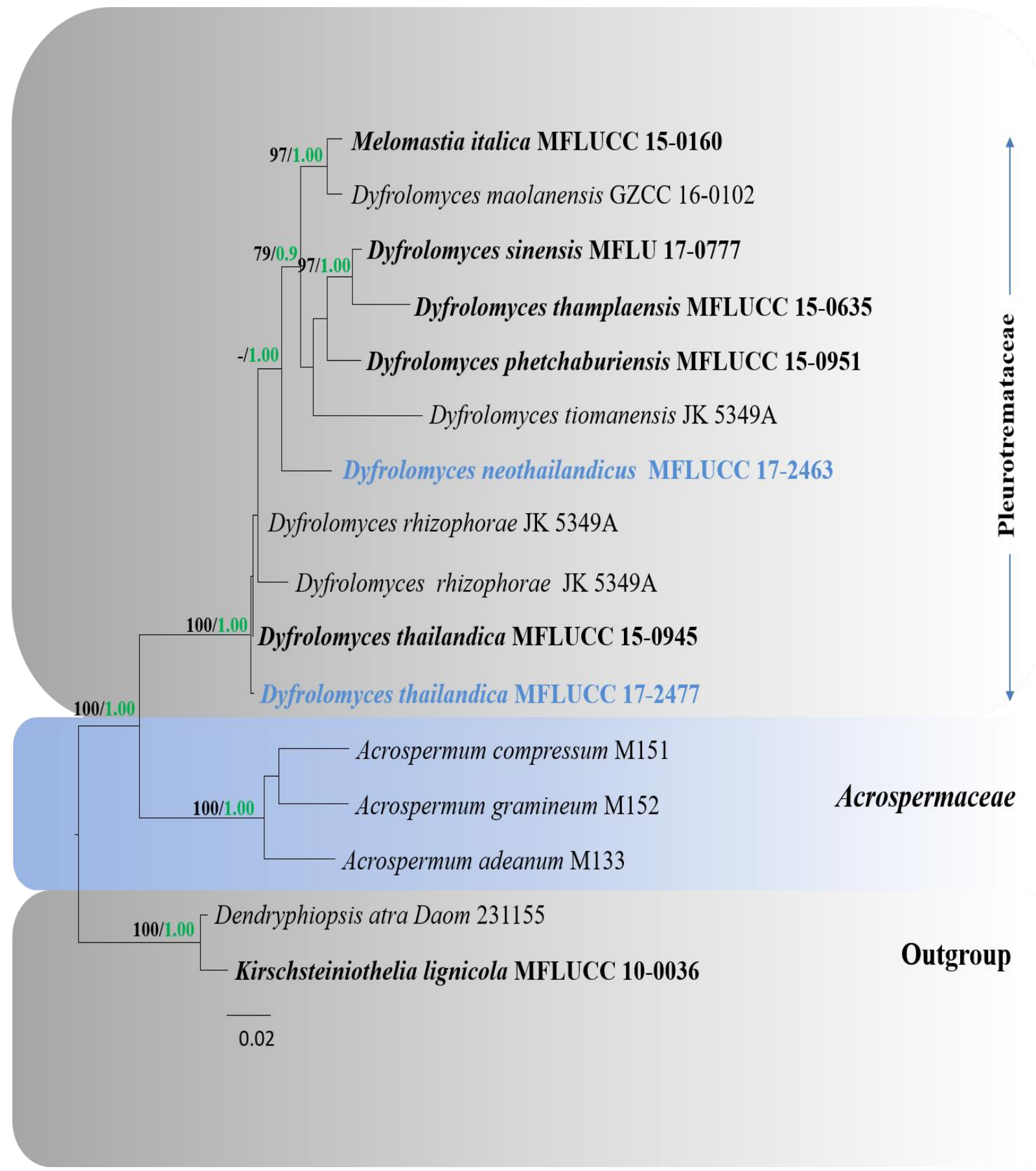

Figure 42 - Maximum likelihood analysis with 1000 bootstrap replicates yielded a best tree with the likelihood value of -8949.656165 . The combined SSU, LSU and TEF sequence datasets comprised 16 strains including Dendryphiopsis atra (Daom 231155) and Kirschsteiniothelia lignicola (MFLUCC 10-0036) as the outgroup taxa. Tree topology of the ML analysis was similar to the BI. The matrix had 560 distinct alignment patterns, with $29.47 \%$ of undetermined characters or gaps. Estimated base frequencies were as follows; $\mathrm{A}=0.245187, \mathrm{C}=0.247290, \mathrm{G}=0.292101$, $\mathrm{T}=0.215422$; substitution rates $\mathrm{AC}=1.089829, \mathrm{AG}=2.835107, \mathrm{AT}=1.002128, \mathrm{CG}=1.479574$, $\mathrm{CT}=8.823891, \mathrm{GT}=1.000000$. Maximum likelihood bootstrap $(\mathrm{ML}$, black) values $>65 \%$ and Bayesian posterior probabilities (PP, green) $>0.90 \%$ are given above the nodes. The scale bar indicates 0.02 changes. The ex-type strains are in bold and new isolates in blue bold. 


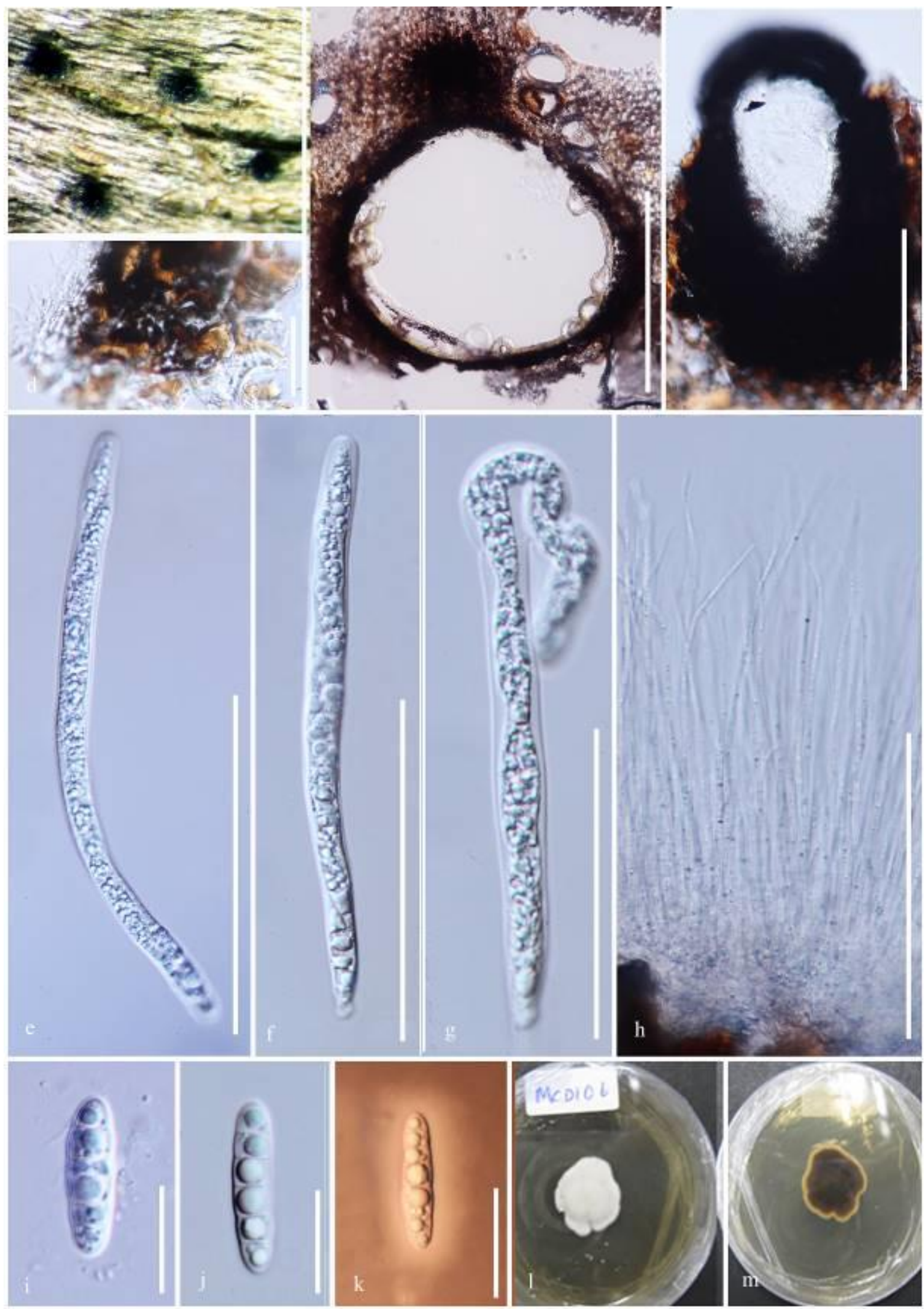

Figure 43 - Dyfrolomyces neothailandicus (MFLU 17-2589, holotype). a Appearance of ascomata on host surface. b Vertical sections through ascoma. c Section through neck region. d Peridium. e-g Asci. h Pseudoparaphyses. i, j Ascospores with sheath. $\mathrm{k}$ Ascospore stained with Indian ink to show gelatinous sheath. $\mathrm{k}, 1$ Cultures on PDA (k-upper, l-lower). Scale bars: $\mathrm{b}=200 \mu \mathrm{m}, \mathrm{e}-\mathrm{h}=100 \mu \mathrm{m}$, $\mathrm{c}=50 \mu \mathrm{m}, \mathrm{d}, \mathrm{i}-\mathrm{k}=20 \mu \mathrm{m}$. 
Notes - Dyfrolomyces neothailandicus closely resembles $D$. thailandica and only differs in the dimensions of the asci $(165-190 \times 10-12 \mu \mathrm{m} v s$ 146-158 $\times 7-9 \mu \mathrm{m})$, ascospores $(26-28 \times 7.2-$ $8 \mu \mathrm{m} v s$ 24-32 $\times 6-8 \mu \mathrm{m}$ ) and pattern of ascospore guttulation (Hyde et al. 2016). Ascospores of $D$. neothailandicus comprise a large guttule per each cell and $D$. thailandica has small numerous guttules in the ascospores (Hyde at al. 2016). Furthermore, they have distant placement in our phylogram (Fig. 42). Furthermore, 22 bp of LSU sequences are different out of 824 bp (2.7\%). Dyfrolomyces neothailandicus differs from all the other species by ascospore characteristics, in particular ascospore septation, and measurements. Ascospores of D. neothailandicus are 5-septate, those of D. tiomanensis, D. marinospora, D. rhizophorae, D. thamplaensis, D. phetchaburiensis and D. maolanensis have 20-24, 3, 4-6, 8-10 and 3 septa, respectively (Hyde 1992b, Pang et al. 2013, Hyde et al. 2017, Norphanphoun et al. 2017, Zhang et al. 2017, Hyde et al. 2018). While the terrestrial species $D$. sinensis is different from $D$. neothailandicus in lacking a gelatinous sheath around the ascospores (Hyde et al. 2018). However, we could not obtain SSU and TEF data for this species, therefore further taxon sampling is recommended.

Dyfrolomyces thailandicus Dayar., E.B.G. Jones \& K.D. Hyde, in Hyde et al., Fungal Diversity: 78(1): 1-237 (2016)

Fig. 44

Facesoffungi number: FoF02445

Saprobic on pneumatophores of Avicennia marina in mangrove vegetation. Sexual morph: Ascomata 340-428 $\mu \mathrm{m} \times 200-267 \mu \mathrm{m}(\overline{\mathrm{x}}=380 \times 250 \mu \mathrm{m}, \mathrm{n}=5)$, solitary, semi-immersed, clypeate, globose to subglobose, dark brown to black, ostiolate, ostiolar canal filled with dark cells, apapillate. Peridium 22-30 $\mu \mathrm{m}$ wide, comprising an outer layer of dark brown cells of textura angularis, becoming lighter inwardly. Hamathecium comprising numerous, 2.1-3.0 $\mu \mathrm{m}$ wide, septate pseudoparaphyses embedded in a gelatinous matrix. Asci $140-156 \times 7.4-9 \mu \mathrm{m}(\overline{\mathrm{x}}=150 \times$ $8.2 \mu \mathrm{m}, \mathrm{n}=10), 8$-spored, bitunicate, cylindrical, short-pedicellate, with a thickened apex. Ascospores $24.2-34 \times 6.1-7 \mu \mathrm{m}(\overline{\mathrm{x}}=28.2 \times 6.5 \mu \mathrm{m}, \mathrm{n}=20)$, slightly overlapping uniseriate, hyaline, ellipsoidal, mostly 3-5-septate, with several small guttules, slightly constricted at septa, surrounded by a thick gelatinous sheath, 1.2-2.4 $\mu \mathrm{m}$ thick. Asexual morph: Undetermined.

Culture characteristics - Colonies on sea water PDA slow growing at $25^{\circ} \mathrm{C}$, reaching $2 \mathrm{~cm}$ in 14 days, white at first, becoming yellowish when mature, undulate and reverse yellowish white.

Material examined - THAILAND, Ranong Province, Ranong, on decaying, submerged Rhizophora sp. wood (Rhizophoraceae) wood, 29 August 2018, M.C. Dayarathne, MCD 131 (MFLU 17-2610); ibid., (HKAS102048), living culture MFLUCC 17-2477.

GenBank numbers - LSU: MN017858; SSU: MN017923; TEF: MN077069

Notes - Our new isolate (MFLUCC 17-2477) resembles Dyfrolomyces thailandicus which was introduced by Hyde et al. (2016). According to our phylogenetic analysis based on combined LSU, SSU and TEF sequenced data, $D$. thailandica formed distinct lineage sister to $D$. thailandica (Fig. 42). SSU and LSU base pairs sequences of our new isolate and D. thailandica are exactly similar to each other. However, we are herein provided new TEF data for this species and this is the first record of this species from Rhizophora sp. While the earlier record was from Avicennia marina (Hyde et al. 2016).

Patellariales D. Hawksw. \& O.E. Erikss.

Patellariaceae Corda

Based on the structure of the apothecial fruiting bodies Patellariaceae was introduced by Corda (1838) to accommodate three genera, Cryptodiscus, Mellitiosporium and Patellaria (generic type). Kutorga \& Hawksworth (1997) accepted 12 genera in Patellariaceae. Based on morphology, Zhang \& Hyde (2009) transferred the genus Pseudoparodia to Patellariaceae. Yacharoen et al. (2015) monographed the family accepting 13 genera, while Wijayawardene et al. (2018) listed 21 genera. Patellariaceae species are saprotrophs or weak pathogens on wood, and bark of a range of trees, and shrubs and are characterized by superficial apothecioid ascomata, cupulate or discoid, exciple pseudoparenchymatous or prosenchymatous hypothecium, with 8-spored, bitunicate, 
fissitunicate, clavate to cylindric asci and usually ascospores varying in shape (Yacharoen et al. 2015, Hernández-Restrepo et al. 2016). So far only two marine Patellariaceae species (Banhegyia setispora and Patellaria atrata) have been reported while we introduce the third Patellariaceae species collected from mangroves in southern Thailand.

Patellaria Fr., Syst. mycol. (Lundae) 2(1): 158 (1822)

Patellaria is characterized by superficial, black, apothecioid ascomata, with a greenish-black epithecium formed from the branched and swollen paraphyses, bitunicate, fissitunicate asci, and hyaline, clavate to cylindrical, phragmo-septate ascospores (Kutorga \& Hawksworth 1997). However, Patellaria species are vary in the number of asci, spore size, and number of ascospores within the asci. Sequence data are available only for Patellaria atrata and P. quercus (Boehm et al. 2009a, b, Schoch et al. 2009, Suetrong \& Jones 2006, Suetrong et al. 2009). Patellaria cf. atrata has been reported from various mangrove woody species collected in Hong Kong and Thailand (Suetrong et al. 2009).

Patellaria apiculatae Dayarathne \& K.D. Hyde, sp. nov.

Fig. 46

Index Fungorum number: IF556587; Facesoffungi number: FoF 06174

Etymology - Epithet refers to the host epithet "apiculata"

Holotype - MFLU 19-1236

Saprobic on fallen decaying Rhizophora apiculata wood. Sexual morph: Ascomata 450-540 $\times 230-270 \mu \mathrm{m}(\overline{\mathrm{x}}=505 \times 248 \mu \mathrm{m} ; \mathrm{n}=5)$, apothecial, superficial, scattered, sessile, closed at first and opening at maturity, longitudinally wide, exposing the dark hymenium at the center, circular, flattened, with a carbonaceous rim, black. Exciple 30-42 $\mu \mathrm{m}$ wide $(\bar{x}=35 \mu \mathrm{m} ; \mathrm{n}=5)$, 2-layered, outer layer pseudoparenchymatous, bluish-black, inner layer composed of thick-walled cells of texxtura prismatica, gelatinous, blue-black at the base (hypothecium) with cells of textura angularis, greenish-blue to colourless. Hamathecium composed of 1-5 $\mu \mathrm{m}$ wide, thick, cylindrical, hyaline, septate, branched paraphyses, slightly swollen and rounded at the apex, forming a bluishblack and thick epithecium over the asci. Asci $60-75 \times 12-18 \mu \mathrm{m}(\bar{x}=62 \times 16 \mu \mathrm{m} ; \mathrm{n}=10), 8$ spored, bitunicate to fissitunicate, cylindrical, clavate, with a short and slightly curved pedicel, apically rounded, with an ocular chamber. Ascospores 25-30 $\times 6-7.5 \mu \mathrm{m}(\bar{x}=26 \times 7 \mu \mathrm{m} ; \mathrm{n}=20)$, seriate overlapping, clavate to fusiform, slightly curved, narrowed at the lower end, 5-6-septate, hyaline. Asexual morph: Unknown.

Material examined - THAILAND, Phetchaburi Province, Cha-am, on decaying Rhizophora apiculata (Rhizophoraceae) wood, 31 November 2016, M.C. Dayarathne, MCD 096 (MFLU 191236, holotype); ibid., (HKAS102097, isotype).

GenBank numbers - LSU: MN017860; SSU: MN017925; ITS: MN047094

Notes - This saprotrophic fungus preferentially colonizes decaying Rhizophora apiculata wood. Patellaria apiculatae resembles Patellaria species by having superficial, black, apothecioid ascomata, with a greenish-black epithecium formed from the branched and swollen paraphyses, bitunicate, fissitunicate asci, and hyaline, clavate to cylindrical, phragmo-septate ascospores (Kutorga \& Hawksworth 1997). Phylogenetic analyses of combined LSU, ITS and SSU data established the placement of this novel species within the genus Patellaria (ML 90\% and 1.00 PP) (Fig. 45). Patellaria apiculatae showed close phylogenetic affinities to Patellaria atrata (BCC 28877, CBS 958.97) and Patellaria quercus (CPC 27232). Patellaria apiculatae can be clearly distinguish from Patellaria atrata by the size of ascomata $(450-540 \mu \mathrm{m} v s 675-1160 \mu \mathrm{m})$ shorter asci (60-75 $\mu \mathrm{m} v s$ 98-135 $\mu \mathrm{m}$ ) and ascospore septation (5-6 vs 5-11-septate) (Yacharoen et al. 2015). Patellaria quercus is only known from its asexual morph and Hernández-Restrepo et al. (2016) showed that it has a $99 \%$ similarity of LSU sequence data to Patellaria atrata (BCC28876). Considering the base pair differences of $P$. apiculatae and $P$. quercus, $45 \mathrm{bp}$ of ITS are different out of $568(7.9 \%)$ and $7 \mathrm{bp}$ of LSU are different out of $830 \mathrm{bp}(1 \%)$ hence, depending on both morphological, phylogenetic and differences of molecular sequence data, we establish our strain as a novel taxon within the genus Patellaria. 


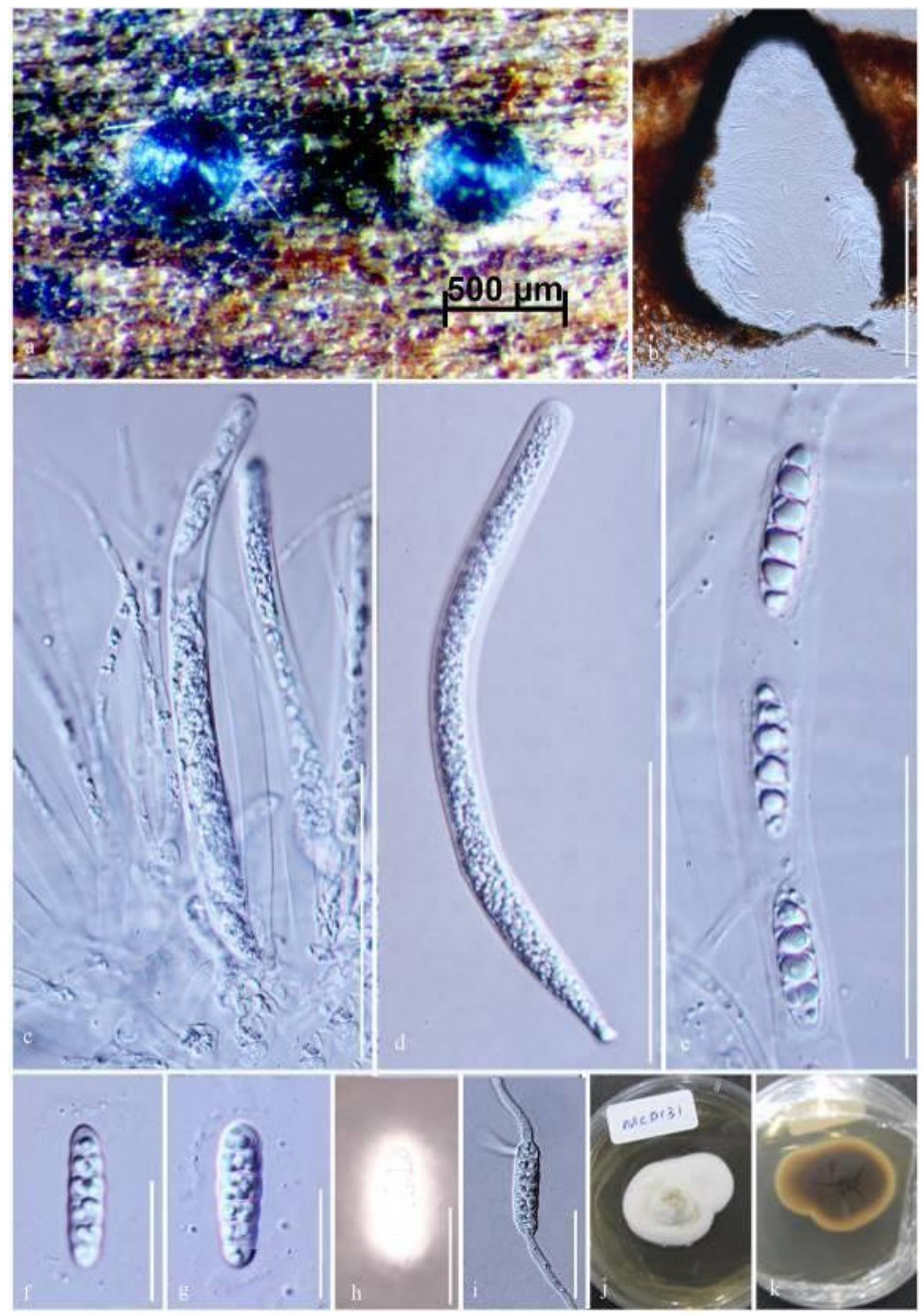

Figure 44 - Dyfrolomyces thailandicus (MFLU 17-2610). a Appearance of ascomata on host surface. $b$ Vertical sections through ascoma e Immature asci attached with psudoparaphyses. d, e Asci. f, g Ascospores with sheath. h Ascospore stained with Indian ink. i Germinating ascospore. j, $\mathrm{k}$ Cultures on sea water PDA (j-upper, k-lower). Scale bars: $\mathrm{a}=500 \mu \mathrm{m}, \mathrm{b}=200 \mu \mathrm{m}, \mathrm{c}, \mathrm{d}=50 \mu \mathrm{m}$, $\mathrm{e}-\mathrm{i}=10 \mu \mathrm{m}$. 


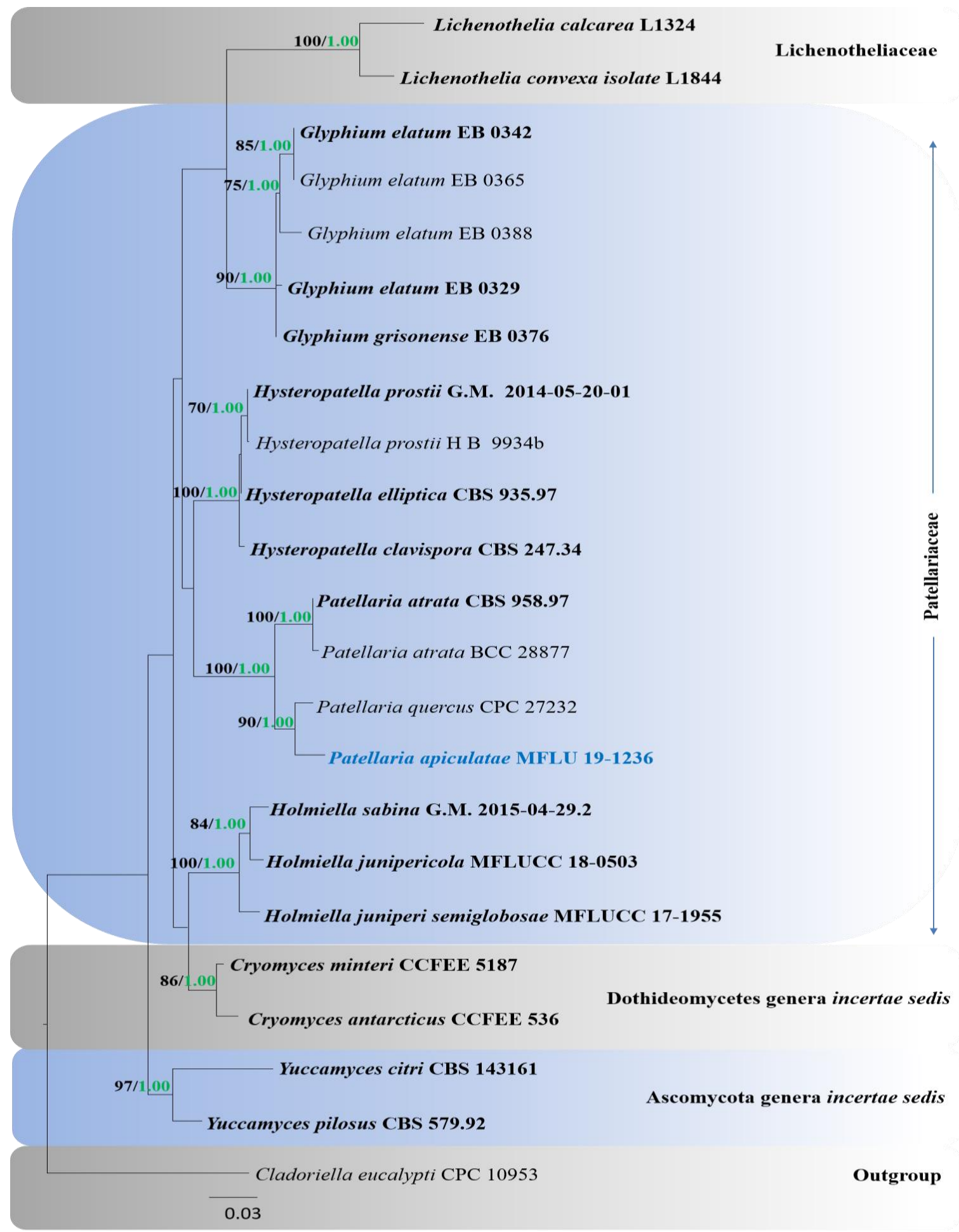

Figure 45 - Maximum likelihood analysis with 1000 bootstrap replicates yielded a best tree with the likelihood value of -16392.233800. The combined LSU, ITS, and SSU sequence datasets comprised 25 strains of Patellariales and related taxa with Cladoriella eucalypti (CPC 10953) as the outgroup taxon. Tree topology of the ML analysis was similar to the BI. The matrix had 505 distinct alignment patterns, with $46.36 \%$ of undetermined characters or gaps, with $26.87 \%$ of undetermined characters or gaps. Estimated base frequencies were as follows; $\mathrm{A}=0.251078, \mathrm{C}=$ $0.225448, \mathrm{G}=0.286828, \mathrm{~T}=0.236646$; substitution rates $\mathrm{AC}=1.704084, \mathrm{AG}=3.719431, \mathrm{AT}=$ 1.560107, $\mathrm{CG}=1.583619, \mathrm{CT}=9.108690, \mathrm{GT}=1.000000$; gamma distribution shape parameter $\alpha$ $=0.139994$. Maximum likelihood bootstrap (ML, black) values $>65 \%$ and Bayesian posterior probabilities (PP, green) $>0.90 \%$ are given above the nodes. The scale bar indicates 0.03 changes. The ex-type strains are in bold and new isolates in blue bold. 

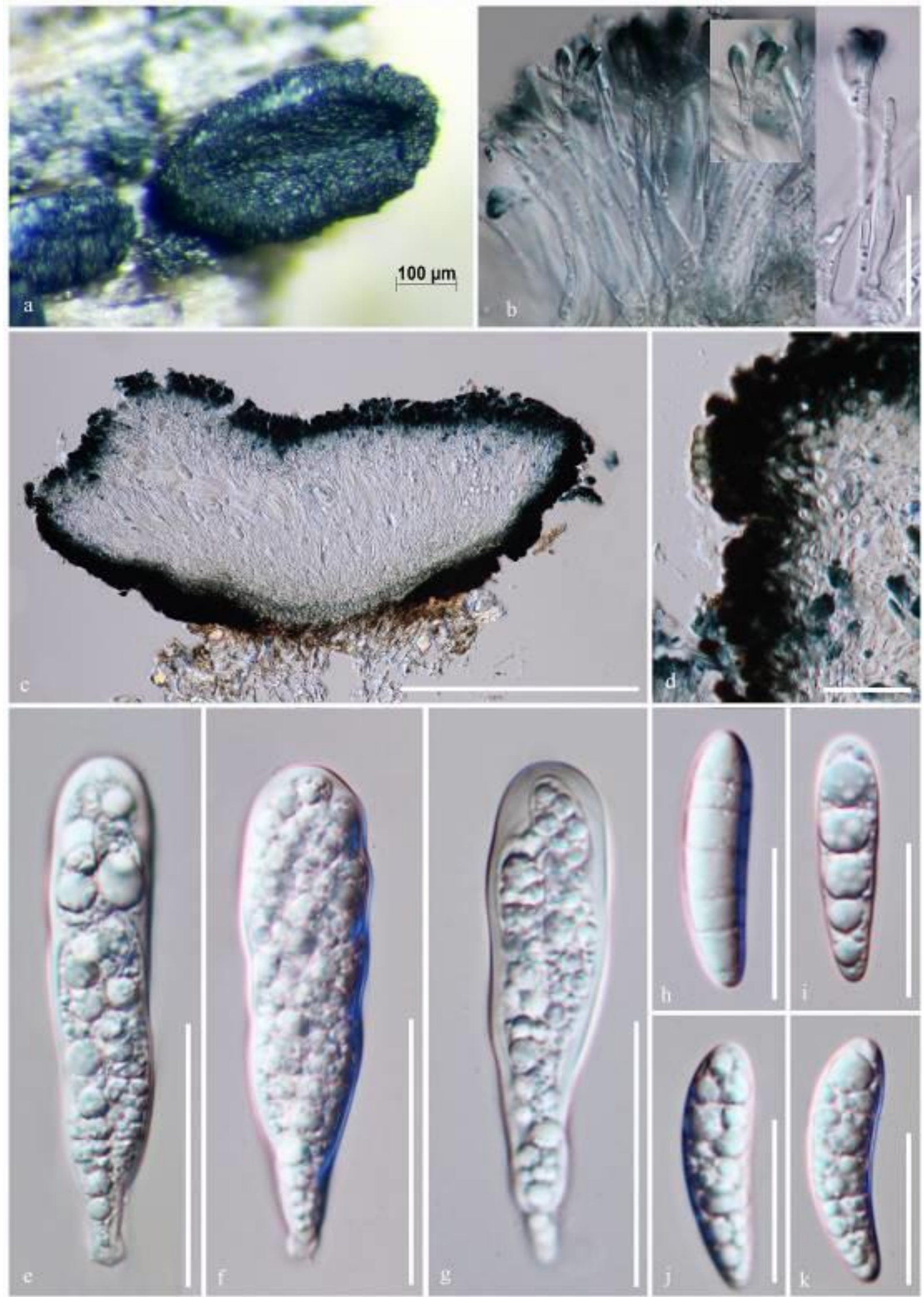

Figure 46 - Patellaria apiculatae (MFLU 19-1236, holotype). a Apothecia on host tissue. b Hamathecial tissue; note: pseudoparapahyses branching at their tips. c Hand section of apothecium. $\mathrm{d}$ Peridium with elongated and rounded cells. e-g Young and mature asci. $\mathrm{h}-\mathrm{k}$ Ascospores. Scale bars: $\mathrm{c}=200 \mu \mathrm{m}, \mathrm{a}=100 \mu \mathrm{m}, \mathrm{e}-\mathrm{g}=50 \mu \mathrm{m}, \mathrm{b}, \mathrm{d}, \mathrm{h}-\mathrm{k}=20 \mu \mathrm{m}$. 
Stigmatodiscales Voglmayr \& Jaklitsch

The order Stigmatodiscales was introduced by Voglmayr et al. (2016) for a new family Stigmatodiscaceae to encompass asteromassaria-like and stigmatomassaria-like taxa. A phylogenetic analysis by Voglmayr et al. (2016) showed that Stigmatodiscales grouped within Dothideomycetes, but their closest relatives remain obscure and unresolved. Phylogenetically Stigmatodiscales forms a poorly supported relationship to the orders Acrospermales, Dyfrolomycetales and Monoblastiales, but are morphologically and ecologically clearly distinguishable (Voglmayr et al. 2016).

\section{Stigmatodiscaceae Voglmayr \& Jaklitsch}

A dothideomycetous family with apothecial ascomata embedded in host tissue lacking an excipulum, saccate fissitunicate asci, large, 3-septate ascospores with an eccentric euseptum and two additional distosepta, surrounded by a large gelatinous sheath, characterizes Stigmatodiscaceae (Voglmayr et al. 2016). This family comprises the genera Asterodiscus and Stigmatodiscus reported from dead corticated twigs of Acer, Carpinus and Tamarix.

\section{Asterodiscus Voglmayr, Gardiennet \& Jaklitsch}

Asterodiscus is a monotypic genus which is found on corticated dead twigs of Tamarix spp. with ascospores matching the genus Asteromassaria (Barr 1982). However, it is unique by having apothecial ascomata with apically swollen paraphyses (Voglmayr et al. 2016). We introduce a second species to this genus collected from a mangrove strand in Krabi Province, Thailand.

Asterodiscus mangrovei Dayarathne, E.B.G. Jones \& K.D. Hyde, sp. nov.

Fig. 48

Index Fungorum number: IF556588; Facesoffungi number: FoF 06175

Etymology - Epithet refers to the mangrove environment where the species found

Holotype - MFLU 16-1216

Saprobic on submerged mangrove wood. Asexual morph: Ascomata 220-300 $\mu \mathrm{m}$ high, apothecial, embedded in cortex of dead twigs, lifting the bark as a black bump, globose, apically covered by black cells of textura intricata, dark brown to black, without distinct margin. Hamathecium of hyaline, septate paraphyses, 1-2.8 $\mu \mathrm{m}$ wide, often branched and anastomosing above, with swollen free apical ends, embedded in a gel matrix and covered by a yellowish-brown amorphous matrix forming an epithecium. Asci $60-72 \times 12-16 \mu \mathrm{m}(\overline{\mathrm{x}}=66 \times 13.5 \mu \mathrm{m} ; \mathrm{n}=5), 8$ spored, seriate, bitunicate, fissitunicate, J-, broadly fusoid to saccate, with thin ecto- and thick endotunica; with a wide ocular chamber. Ascospores 20-26 $\times 6-10 \mu \mathrm{m}(\overline{\mathrm{x}}=22.5 \times 9.5 \mu \mathrm{m} ; \mathrm{n}=10)$, asymmetric, upper portion slightly larger than the lower part, ends rounded to subacute, hyaline to light brown with age, 1-euseptate when immature, becoming 3-septate at maturity, distinctly constricted at the septa, wall thick, smooth to slightly verruculose, surrounded by a sheath widely expanding in water after spore discharge. Sexual morph: Undetermined.

Material examined - THAILAND, Krabi Province, Tha Pom Khlong Nam, on decaying wood at a mangrove strand, 16 December 2015, M.C. Dayarathne, KLA025 (MFLU 16-1216, holotype); ibid., (BBH, isotype).

GenBank numbers - LSU: MN017861; SSU: MN017926; ITS: MN047095

Notes - Asterodiscus mangrovei comprises characteristics of the genus Asterodiscus such as apothecial ascomata with apically swollen paraphyses, broadly fusoid to saccate asci, asymmetric ascospores with upper portion slightly larger than the lower part and surrounded by a gelatinous sheath (Voglmayr et al. 2016). This novel taxon can be clearly distinguished from A. tamaricis (type) by its paraphyses, covered by a yellowish-brown amorphous incrustation while paraphyses of A. tamaricis are covered by an olivaceous to deep blue amorphous incrustation (Voglmayr et al. 2016). Their ITS base pair difference is $7.1 \%$ (43 bp out of $537 \mathrm{bp}$ ) which is adequate to consider them as two different species according to the guidelines of Jeewon \& Hyde (2016). The habitat of the new species is different from the existing members of the family Stigmatodiscaceae. Hence, by 
considering all these factors we establish this new strain as a novel taxon in the genus Asterodiscus (Fig. 47).

Tubeufiales Boonmee, Rossman \& K.D. Hyde

Boonmee et al. (2014) introduced the monotypic order Tubeufiales to accommodate family Tubeufiaceae. Subsequently, Suetrong et al. (2014) established the family Wiesneriomycetaceae into Tubeufiales. However, Bezerra et al. (2017) excluded the family Wiesneriomycetaceae and included in Tubeufiales based on morphological and phylogenetic analyses and transferred the family to a new order Wiesneriomycetales.

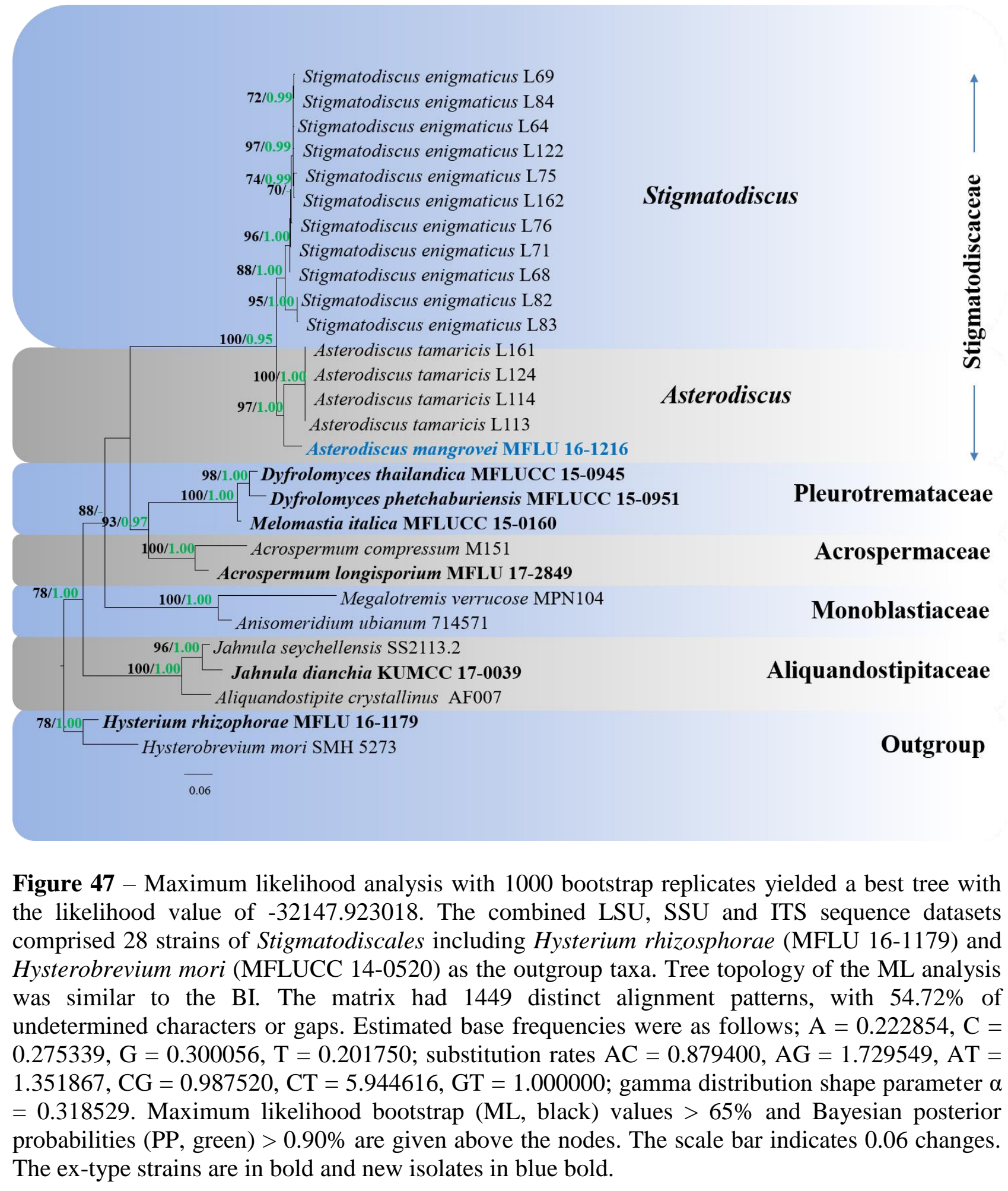



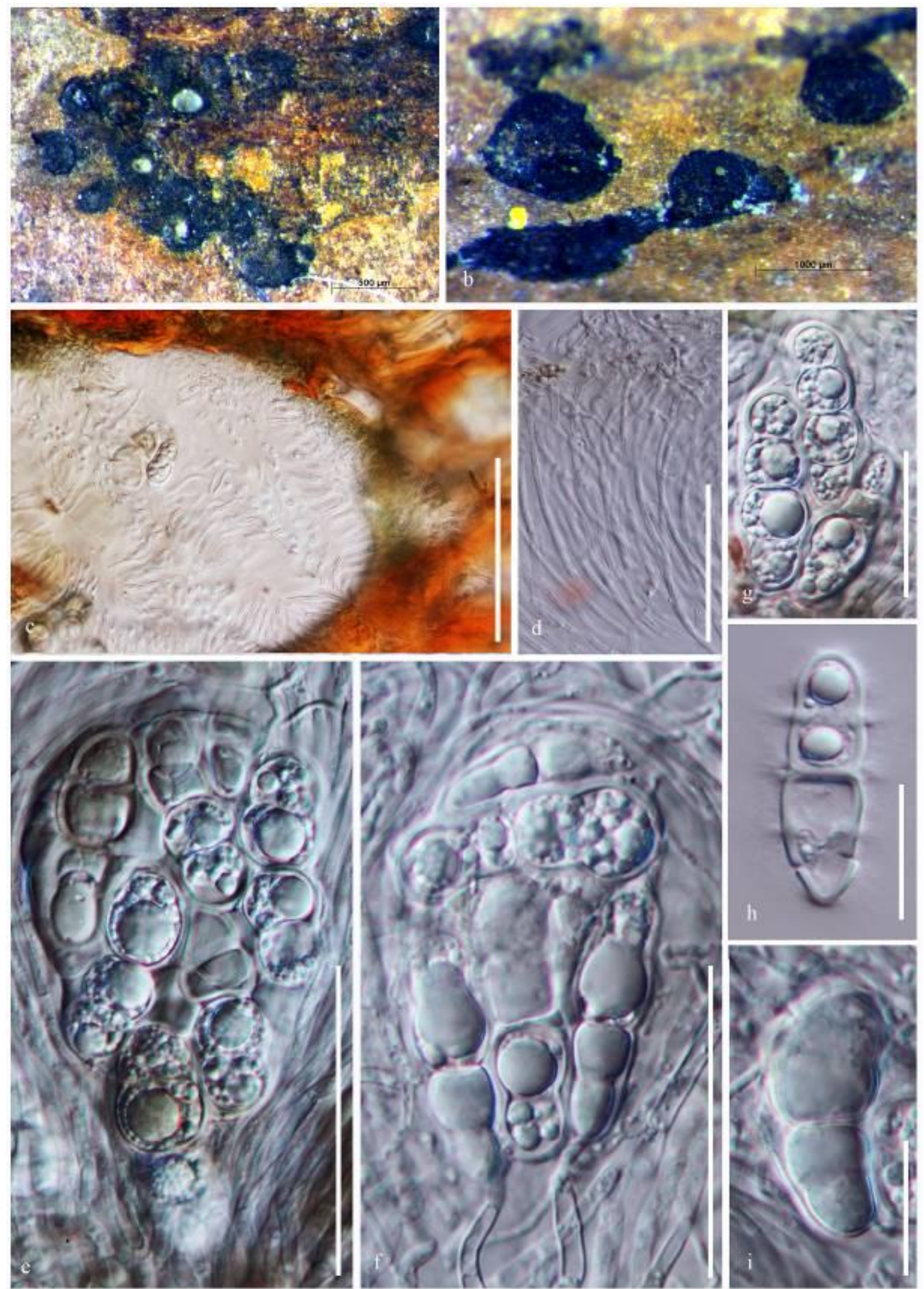

Figure 48 - Asterodiscus mangrovei (MFLU 16-1216, holotype). a, b Apothecial ascomata on host. c Section through apothecium (partial). d Apically inflated septate paraphyses, covered by a 
yellowish-brown amorphous incrustation. e, $\mathrm{f}$ Asci embedded in gel matrix with paraphyses. $\mathrm{g}-\mathrm{i}$ Hyaline ascospores. Scale bars: $\mathrm{b}=1000 \mu \mathrm{m}, \mathrm{a}=500 \mu \mathrm{m}, \mathrm{c}=100 \mu \mathrm{m}, \mathrm{d}-\mathrm{f}=50 \mu \mathrm{m}, \mathrm{g}-\mathrm{i}=10 \mu \mathrm{m}$.

\section{Tubeufiaceae M.E. Barr}

Tubeufiaceae is typified by Tubeufia and was introduced by Barr (1979). Lu et al. (2018b) recently revised this family and listed 42 genera under this familiy. Tubeufiaceae species are characterized by superficial ascomata, pseudoparaphysate hamathecium, bitunicate asci and multiseptate, hyaline to pale brown cylindrical ascospores (Brahmanage et al. 2017, Lu et al. 2017, 2018a, b, Liu et al. 2018, Phookamsak et al. 2018). Asexual morphs of Tubeufiaceae are hyphomycetes and are often helicosporous, while some are chlamydosporous and phragmosporous (Boonmee et al. 2011, 2014, Brahmanage et al. 2017, Doilom et al. 2017, Lu et al. 2018a, b, Liu et al. 2018).

\section{Kamalomyces R.K. Verma, N. Sharma \& Soni}

Verma et al. (2008) introduced the genus Kamalomyces which is typified by K. indicus. Ascomata on a subiculum of black hyphae, with solitary, gregarious, subglobose to lemoniform ascomata with short stalks and lacking ostioles, bitunicate, broadly cylindrical to clavate asci and hyaline, vermiform, crowded, septate ascospores are the characteristic features of Kamalomyces (Verma et al. 2008, Boonmee et al. 2011, 2014, Phookamsak et al. 2018, Lu et al. 2018a, b). Kamalomyces currently comprises six species and phylogenetic relationship of Kamalomyces was reported by Phookamsak et al. (2018). In this study, we introduce a new record for the recently introduced $K$. mangrovei collected from Xylocarpus sp.

Kamalomyces mangrovei Dayarathne \& K.D. Hyde, in Hyde et al., Fungal Divers.: 96:1-242 (2019)

Facesoffungi number: FoF 04946

Fig. 50

Saprobic on decaying wood of Xylocarpus sp. Sexual morph: Ascomata 278-300 × 240-280 $\mu \mathrm{m}$, superficial, solitary to gregarious, embedded in a subiculum of crowded, black, septate, thickwalled hyphae, superficial, solitary, gregarious, globose to subglobose, glabrous, short-stalked, apapillate, with indistinct ostiolate. Peridium 30-42 $\mu \mathrm{m}$ wide, comprising light brown cells of textura angularis, and inwardly small, subhyaline cells of textura prismatica. Hamathecium comprising numerous, 1.5-2 $\mu \mathrm{m}$ wide, filiform, septate, branched, hyaline pseudoparaphyses. Asci 140-175 $\times 16.2-20 \mu \mathrm{m}(\overline{\mathrm{x}}=162 \times 17.5 \mu \mathrm{m}, \mathrm{n}=20), 8$-spored, bitunicate, fissitunicate, cylindrical to clavate, short pedicellate, apically rounded, with an ocular chamber. Ascospores 50-64 $\times$ 6.4-7.5 $\mu \mathrm{m}(\overline{\mathrm{x}}=62 \times 7 \mu \mathrm{m}, \mathrm{n}=30), 2-3$-seriate, hyaline becoming light brown when mature, elongate cylindrical to fusiform-clavate, tapering towards the lower cells, enlarged at the $4^{\text {th }}$ and $5^{\text {th }}$ cell, straight or slightly curved, 8-9 septa, distoseptate. Asexual morph: Undetermined.

Culture characteristics - Colonies on PDA reaching $3 \mathrm{~cm}$ diam. after 30 days at $25{ }^{\circ} \mathrm{C}$, circular, smooth margin white at first, dark gray to black after 6 weeks, flat on the surface, without aerial mycelium, reverse brownish black.

Material examined - THAILAND, Ranong Province, Amphoe Maung, Mu 4 Tombol Ngao, Ranong Mangrove Research Center (GPS: $9^{\circ} 43^{\prime}$ to $9^{\circ} 57^{\prime} \mathrm{N}$; $98^{\circ} 29^{\prime}$ to $98^{\circ} 39^{\prime} \mathrm{E}$ ) on decaying wood of Xylocarpus sp. (Meliaceae), 06 December 2016, M.C. Dayarathne, MCD 066 )MFLU 18-0549); ibids., MCD 068 )MFLU 18-0550); (HKAS102087).

GenBank numbers - LSU: MN017862, MN017863; SSU: MN017927, MN017928; ITS: MN047096, MN047097; TEF: MN077071, MN077072

Notes - Solitary to gregarious, globose to subglobose, short-stalked ascomata, lacking ostioles embedded in a subiculum of black hyphae, bitunicate, cylindrical to clavate asci and hyaline, elongate cylindrical to fusiform-clavate, septate ascospores are the characteristic features of Kamalomyces mangrovei. Our new collection MFLU 18-0549 and MFLU 18-0550 are morphologically and phylogenetically referred to K. mangrovei (Figs 48, 49) (Hyde et al. 2019). 


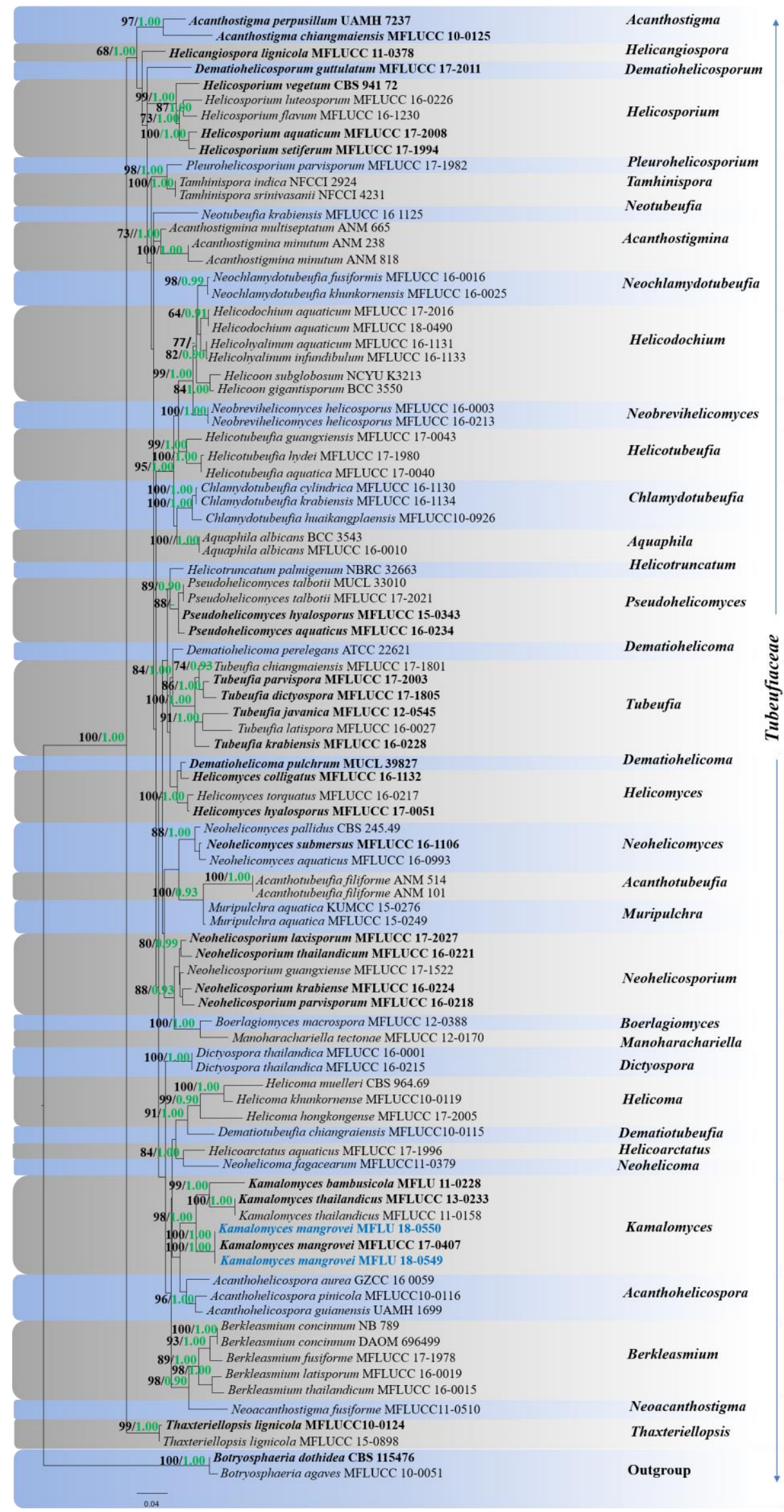

Figure 49 - Maximum likelihood analysis with 1000 bootstrap replicates yielded a best tree with the likelihood value of -32147.923018 . The combined LSU, ITS and TEF sequence datasets 
comprised strains of Tubeufiaceae including Botryosphaeria agaves (MFLUCC 10-0051) and Botryosphaeria dothidea (CBS 115476) as the outgroup taxa. Tree topology of the ML analysis was similar to the BI. The matrix had 1449 distinct alignment patterns, with $54.72 \%$ of undetermined characters or gaps. Estimated base frequencies were as follows; $\mathrm{A}=0.222854, \mathrm{C}=$ $0.275339, \mathrm{G}=0.300056, \mathrm{~T}=0.201750$; substitution rates $\mathrm{AC}=0.879400, \mathrm{AG}=1.729549, \mathrm{AT}=$ 1.351867, $\mathrm{CG}=0.987520, \mathrm{CT}=5.944616, \mathrm{GT}=1.000000$; gamma distribution shape parameter $\alpha$ $=0.318529$. Maximum likelihood bootstrap (ML, black) values $>65 \%$ and Bayesian posterior probabilities (PP, green) $>0.90 \%$ are given above the nodes. The scale bar indicates 0.04 changes. The ex-type strains are in bold and new isolates in blue bold.

Class Sordariomycetes O.E. Erikss. \& Winka

Subclass Diaporthomycetidae Senan. et al.

Diaporthales Nannf.

Species in Diaporthales are saprobes and soil inhabitants, plant and animal pathogens, parasites or endophytes in plants (Zhang et al. 2006, Rossman et al. 2007, Maharachchikumbura et al. 2015). There are 21 families within this order (Senanayake et al. 2017, 2018, Xavier et al. 2019, Guterres et al. 2019). Diaporthalean species are characterized by yellowish brown to black valsoid or diatrypoid pseudo- or asco-stromata, brown to black perithecial fruiting bodies, regularly immersed in stromata of leafy or woody substrates with papillate ostioles swollen at the apex. The mature 2-32-spored asci with a J-, refractive apical apparatus, float freely and become dehiscent at maturity (Barr 1978, Samuels \& Blackwell 2001, Senanayake et al. 2017, Hyde et al. 2019). Coelomycete or rarely hypomycete asexual morphs of this order comprises conidiophores which arise from the top most cell layer of basal or parietal tissue or from under the developing scutellum or else reduced to enteroblastic, holoblastic, phialidic or annellidic hyaline or olivaceous conidiogenous cells (Senanayake et al. 2017, 2018, Hyde et al. 2019).

Diaporthaceae Höhn. ex Wehm.

The family Diaporthaceae includes numerous pathogenic, endophytic, and saprobic species associated with terrestrial habitats, while there are few reports on marine species (Maharachchikumbura et al. 2016, Senanayake et al. 2017). A recent study by Senanayake et al. (2017) introduced the genera Chiangraiomyces, Hyaliappendispora and Paradiaporthe to this family based on phylogeny and morphology in addition to the 11 accepted genera in Maharachchikumbura et al. (2016) and Wijayawardene et al. (2018) who list 15 genera under this family.

\section{Diaporthe Nitschke}

Diaporthe was established by Nitschke (1870) to accommodate a group of species with stromatic ascomata, ellipsoid to fusiform spores and enclosed asexual morphs with unilocular pycnidia (Wehmeyer 1933). Diaporthe is an economically significant genus with plant pathogenic, endophytic and saprobic fungi (Udayanga et al. 2011, 2012, 2014, 2015, Hyde et al. 2016, Dissanayake et al. 2017). Rossman et al. (2015) proposed the protection of the older name Diaporthe over Phomopsis for application of a single name for one fungus. Diaporthe (= Phomopsis) mangrovei is reported from intertidal prop roots of Rhizophora apiculata in Thailand as a marine derived Diaporthaceae species (Hyde 1991b, Jones et al. 2015). Diaporthe (= Phomopsis) pittospori also has been reported from marine habitat (Jones et al. 2019). However, there are no sequence data available for any marine derived Diaporthe species. An updated phylogenetic tree for Diaporthe species with three novel species is presented in this paper (Fig. 51).

Diaporthe salinicola Dayarathne, sp. nov.

Fig. 52

Index Fungorum number: IF556589; Facesoffungi number: FoF 06176

Etymology - Name reflects the saline environment where the taxon was found and "-cola" means inhabiting. 


\section{Holotype - MFLU 18-0553}

Saprobic on decaying submerged mangrove wood. Sexual morph: Stroma absent. Ascomata 2100-3150 × 680-790 $\mu \mathrm{m}$, globose to subglobose, black, coriaceous, semi-immersed, single to clustered. Neck 1100-2200 × 100-130 $\mu \mathrm{m}$, cylindrical, black, ostiole canal lined with periphyses. Peridium 35-55 mm thick, comprising compressed cells of textura angularis, outer layers composed of black brown, thick-walled cells, inner layers composed of pale brown to hyaline thinwalled cells. Paraphyses 1-2.5 $\mu \mathrm{m}$ wide, longer than asci, hyaline, cylindrical, septate. Asci 80-115 $\times 14-16.4 \mu \mathrm{m}(\overline{\mathrm{x}}=90.6 \times 16, \mathrm{n}=10), 8$-spored, unitunicate, thin-walled, apedicellate, broad cylindrical to obclavate, with a minute apical ring, ca. $1 \mathrm{~mm}$ high and $2 \mathrm{~mm}$ diam. Ascospores 16$18.2 \times 5.8-7 \mu \mathrm{m}(\overline{\mathrm{x}}=16.4 \times 7, \mathrm{n}=20)$, overlapping biseriate, Obpyriform to ovoid, hyaline, oneseptate, constricted at the septum, thin-walled, smooth-walled, with numerous guttules. Asexual morph: Undetermined.

Culture characteristics - Colonies on sea water added PDA reaching $10 \mathrm{~cm}$ diam. after 2 weeks at $25{ }^{\circ} \mathrm{C}$, dense, circular, slightly raised, surface smooth with entire edge, fluffy, colony from above: gray at the center reddish gray at the margin; from below: black at the center ash at the margin, not produced pigmentation on PDA media.

Material examined - THAILAND, Ranong Province, Amphoe Maung, Mu 4 Tombol Ngao, Ranong Mangrove Research Center (GPS: $9^{\circ} 43^{\prime}$ to $9^{\circ} 57^{\prime} \mathrm{N}$; $98^{\circ} 29^{\prime}$ to $98^{\circ} 39^{\prime} \mathrm{E}$ ) on decaying wood of Xylocarpus sp. (Meliaceae), 06 December 2016, M.C. Dayarathne, MCD 072 )MFLU 18-0553, holotype); ibid., (BBH, isotype), ex-type living culture, MFLUCC 17-0413. THAILAND, Krabi Province, Krabi beach, on decaying submerged wood, 31 August 2017, M.C. Dayarathne, MCD 109 (MFLU 17-2592).

GenBank numbers - ITS: MN047098, MN047099, TEF: MN077073, MN077074

Additional GenBank numbers - LSU: MN017864, MN017865

Notes - Diaporthe salinicola is the first sexual species of Diaporthe isolated as a true marine species from Thailand. Long necks $(1100-2200 \times 100-130 \mu \mathrm{m})$ of the ascomata is a significant character for this species among other Diaporthe species. Diaporthe aquatica, which was isolated from wood submerged in a small ditch in China, shows close morphological characteristics in ascomatal morphology such as absence of stromata and having long necks. However, D. salinicola is different from $D$. aquatica by the size $(16-18.2 \times 5.8-7 \mu \mathrm{m} v$ s $10-123$ 3-4 $\mu \mathrm{m})$ and the shape of the ascospores. Whereby, ascospores of D. salinicola are obpyriform while the ascospores of D. aquatica are ellipsoidal to fusiform (Hu et al. 2012). This is confirmed as they group distantly in our phylogram (Fig. 51). According to our phylogenetic analysis Diaporthe salinicola showed close affinities to D. lithocarpus which is only known in its asexual morph. We compared the ITS and TEF base pair differences of D. salinicola to D. lithocarpus and are $3.04 \%$ (16 bp out of $525 \mathrm{bp}$ ) and $3.01 \%$ (9 bp out of 299). Therefore, according to the guidelines of Jeewon \& Hyde (2016), basepair differences of D. salinicola and D. lithocarpus are in the recommended range to consider them as two distinct taxa. However, cultures did not get sporulate to observe asexual morph.

Diaporthe krabiensis Dayarathne, sp. nov.

Fig. 53

Facesoffungi number: FoF 06177

Etymology - Epithet refers to the marine environment where the species was collected.

Holotype - MFLU 17-2618

Saprobic on submerged wood of Bruguiera sp. Sexual morph: Undetermined. Asexual morph: Conidiomata 117-145 × 130-140 $\mu \mathrm{m}$, pycnidial or multiloculate, scattered, globose or irregular, black. Peridium 15-18 $\mu \mathrm{m}$ wide consisting of brown cells of textura angularis in surface view. Paraphyses 1.5-18 $\mu \mathrm{m}$ wide, hyaline, septate, branched. Conidiophores 2-3-septate, branched, densely aggregated, cylindrical, straight to sinuous rarely reduced to conidiogenous cells, hyaline, smooth-walled. Conidiogenous cells $8-16 \times 0.5-2 \mu \mathrm{m}(\overline{\mathrm{x}}=8 \times 1.8, \mathrm{n}=10)$, phialidic, subcylindrical, tapering towards the apex, hyaline, with periclinal thickening, and a flared 
collarette. Beta conidia 15-32 $\times 0.9-1.4 \mu \mathrm{m}(\overline{\mathrm{x}}=28.5 \times 1.2, \mathrm{n}=20)$, fusiform to hooked, aseptate, hyaline, smooth-walled. (alpha and gamma conidia not observed)
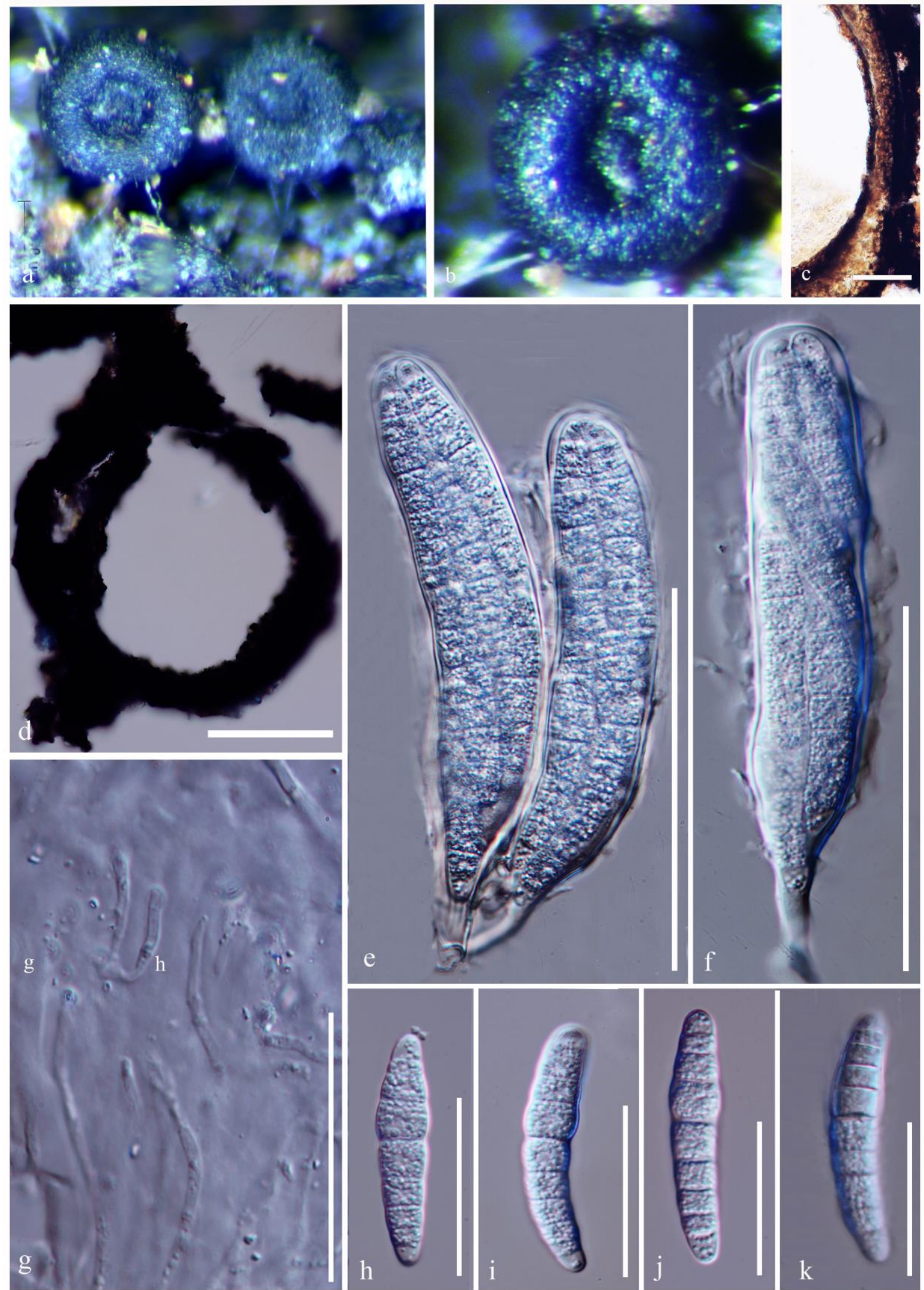

e
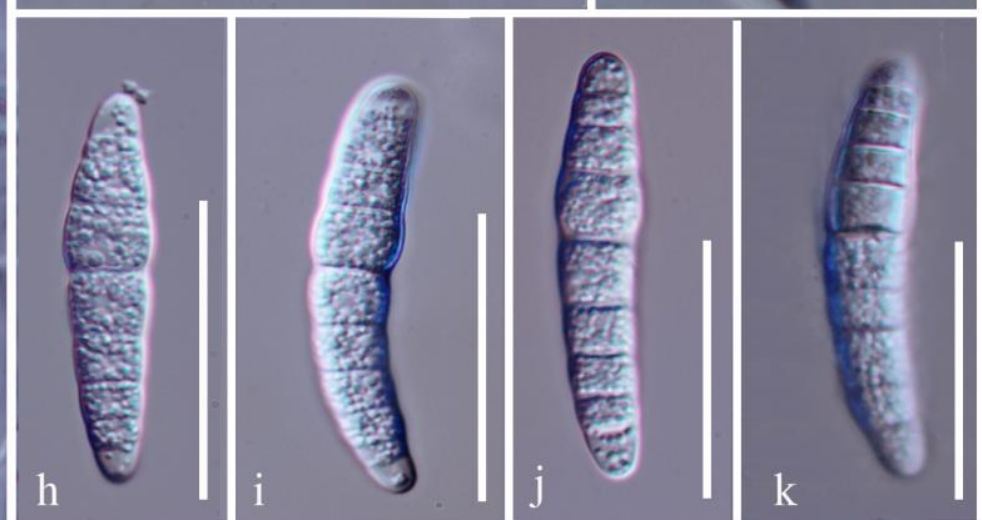

Figure 50 - Kamalomyces mangrovei (MFLU 18-0550). a, b Ascomata. c Peridium. d Section through ascoma. e-f Asci. g Psudoparaphyses. h-k Ascospores. Scale bars: $d=100 \mu \mathrm{m}, \mathrm{e}-\mathrm{f}=50$ $\mu \mathrm{m}, \mathrm{c}, \mathrm{g}-\mathrm{j}=20 \mu \mathrm{m}$. 


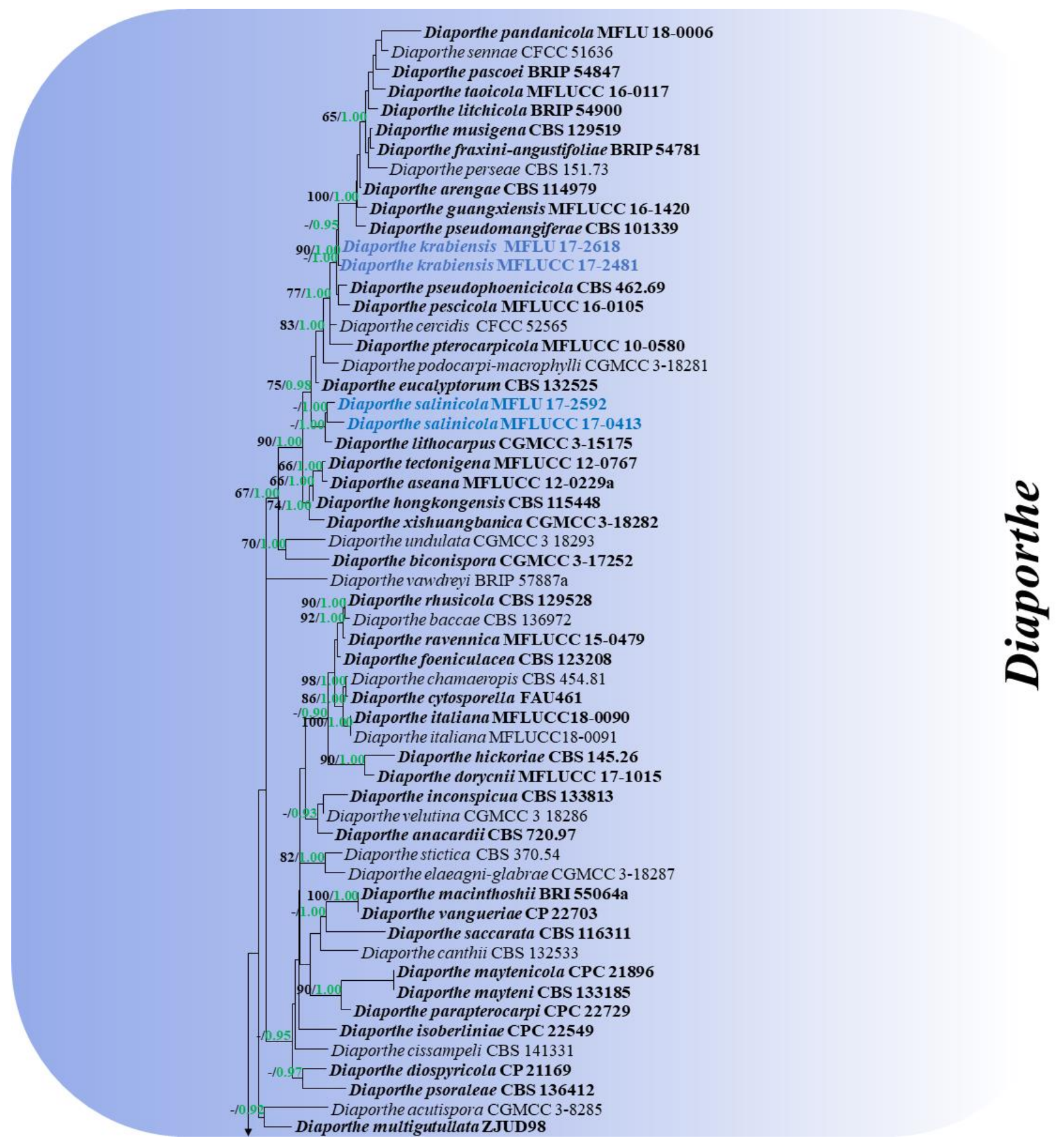

Figure 51 - Maximum likelihood analysis with 1000 bootstrap replicates yielded a best tree with the likelihood value of -26084.946068 . The combined ITS, TEF, BTUB sequence datasets comprised 206 strains of Diaporthe with Diaporthella corylina (CBS 121124) as the outgroup taxon. Tree topology of the ML analysis was similar to the BI. The matrix had 806 distinct alignment patterns, with $46.36 \%$ of undetermined characters or gaps. Estimated base frequencies were as follows; $\mathrm{A}=0.229079, \mathrm{C}=0.298623, \mathrm{G}=0.236340, \mathrm{~T}=0.235958$; substitution rates $\mathrm{AC}$ $=1.382163, \mathrm{AG}=3.309173, \mathrm{AT}=1.349227, \mathrm{CG}=0.945554, \mathrm{CT}=4.934047, \mathrm{GT}=1.000000 ;$ gamma distribution shape parameter $\alpha=0.449392$. Maximum likelihood bootstrap (ML, black) values $>65 \%$ and Bayesian posterior probabilities (PP, green) $>0.90 \%$ are given above the nodes. The scale bar indicates 0.2 changes. The ex-type strains are in bold and new isolates in blue bold. 

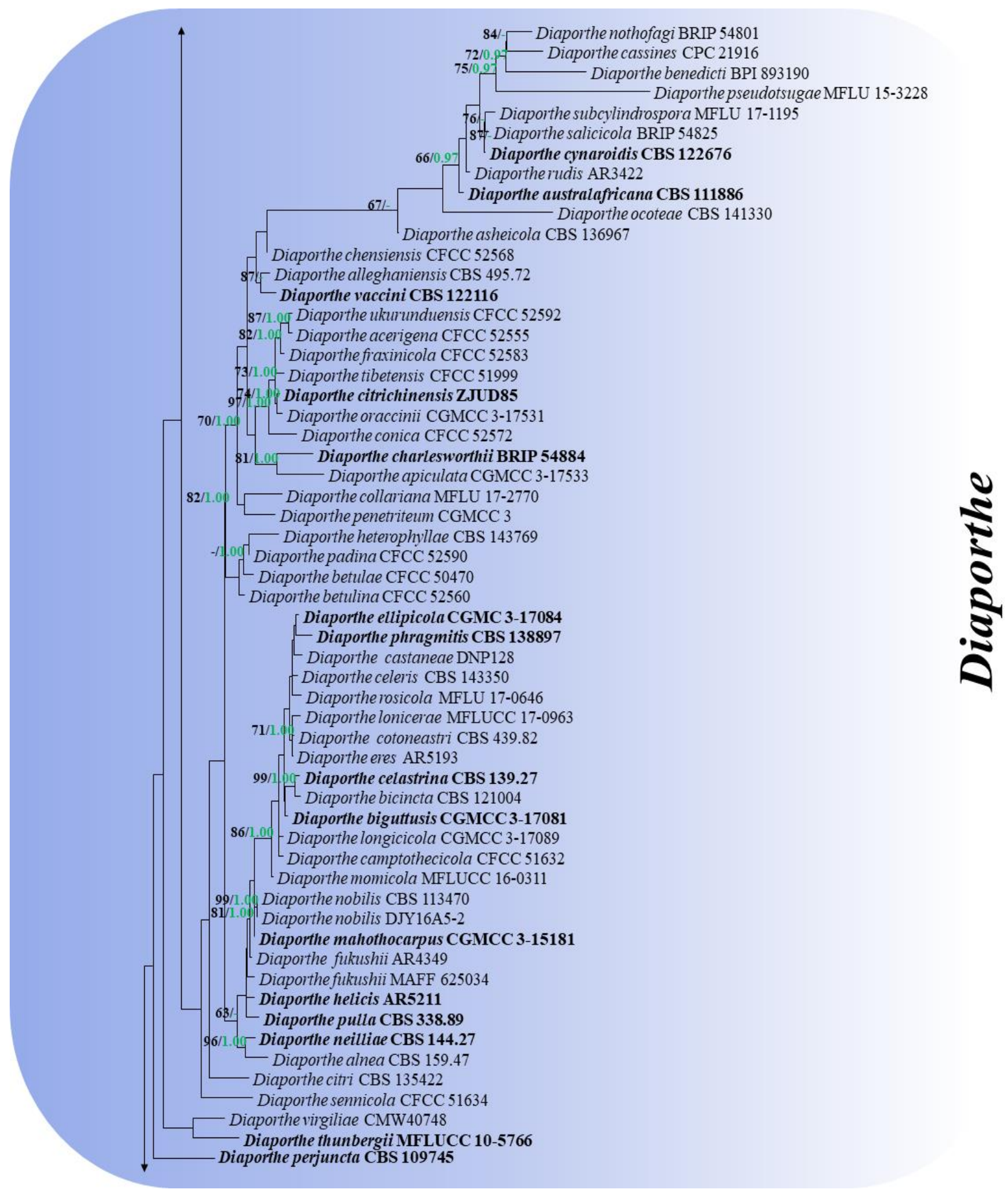

Figure 51 - Continued. 


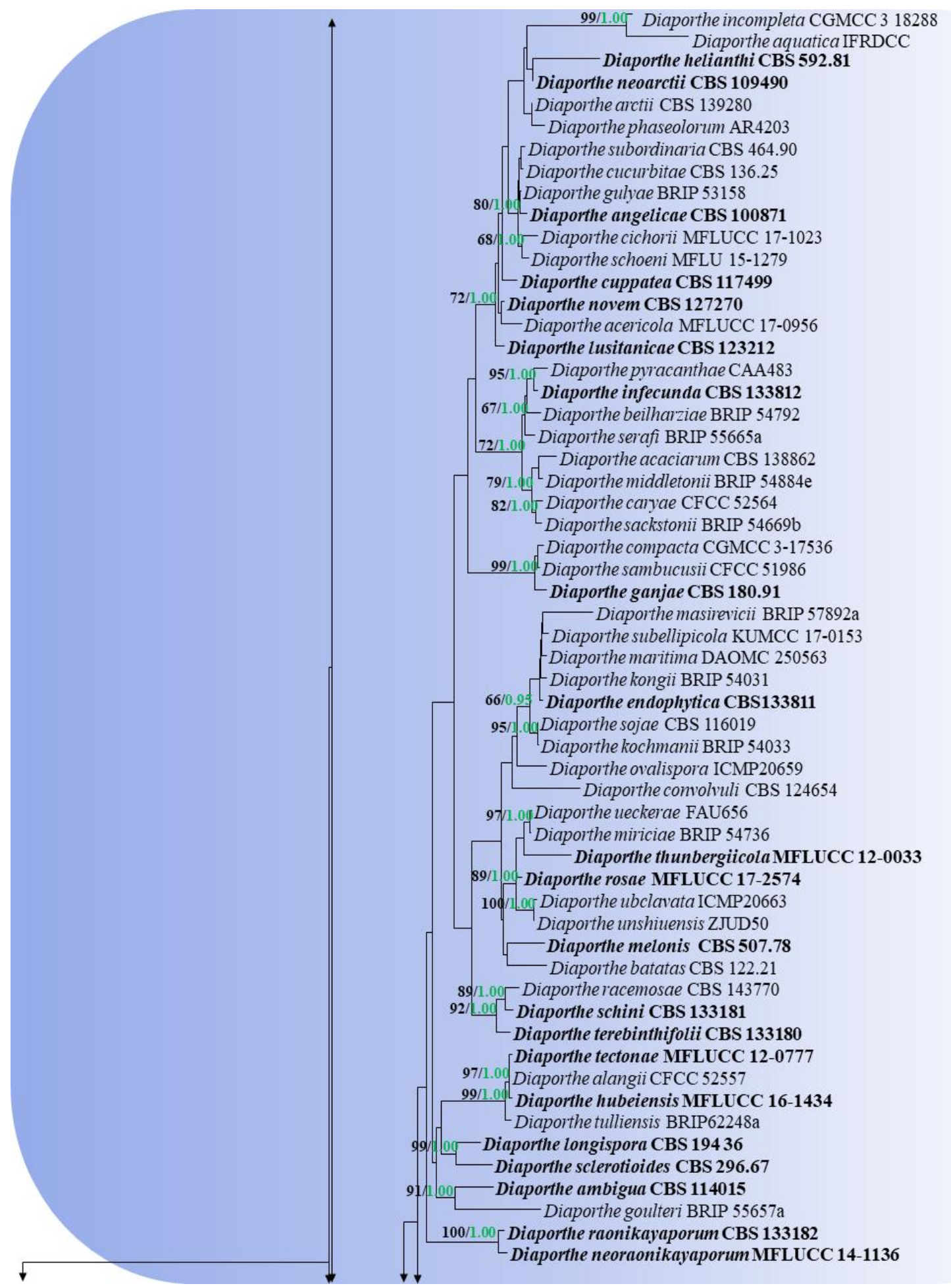

Figure 51 - Continued. 


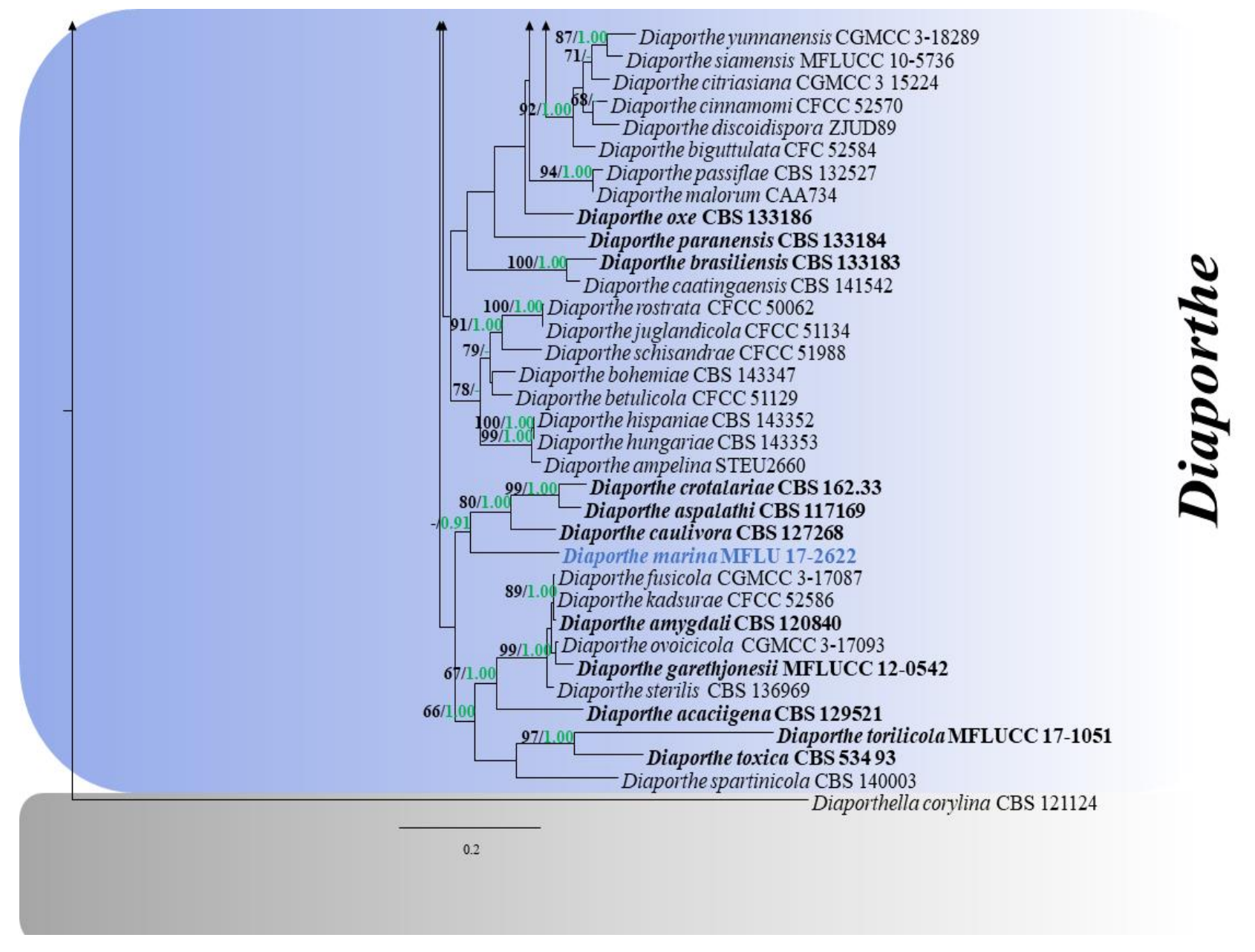

Figure 51 - Continued.

Culture characteristics - Colonies on sea water MEA reaching $15 \mathrm{~cm}$ diam. after 2 weeks at $25^{\circ} \mathrm{C}$, dense, circular, slightly raised, surface smooth with entire edge, fluffy, colony from above: white; from below: yellowish white, not produced pigmentation on MEA media.

Material examined - THAILAND, Krabi Province, Phang Nga, on decaying submerged wood of Bruguiera sp. (Rhizophoraceae), 30 August 2017, M.C. Dayarathne, MCD 143 (MFLU 17-2618, holotype); ibid., (HKAS102052, isotype), ex-type living culture MFLUCC 17-2481.

GenBank numbers - ITS: MN047100, MN047101; TEF: MN433215; BTUB: MN431495

Additional GenBank numbers - LSU: MN017866; SSU: MN017929

Notes - Asexual morphs of Diaporthe are difficult to differentiate as most have similar morphologies (Santos et al. 2011, Dissanayake et al. 2017, Perera et al. 2018). A new taxon collected from Phang Nga, Thailand proved difficult to identify as alpha conidia were also not observed (Dissanayake et al. 2017, Perera et al. 2018). We observed conidial germination of beta conidia. However, beta conidia are sterile tissues and usually do not germinate and produce cultures. We could not observe any other type (alpha or gamma) conidia. Cultures did not sporulate with any of methods we used. Furthermore, sequence data obtained from both mycelial scraps and direct sequencing of the frutting bodies are identical. However, more taxon sampling is needed confirm this observation. Based on phylogenetic differences, we establish this as a novel species, D. krabiensis. Diaporthe pseudophoenicicola and D. pescicola showed close phylogenetic relationship to Diaporthe krabiensis. Base pair differences of ITS regions of D. krabiensis to D. pescicola and D. pseudophoenicicola are 1.4\% (7 bp out of $518 \mathrm{bp}$ ) and 1.9\% (10 bp out of 524 bp). Diaporthe pseudophoenicicola and $D$. pescicola have relatively wider conidiomata than $D$. krabiensis (400 $\mu \mathrm{m}, 300 \mu \mathrm{m}, 130-140 \mu \mathrm{m}$ ) (Gomes et al. 2013, Dissanayake et al. 2017). There are no beta conidia described for D. pseudophoenicicola. 

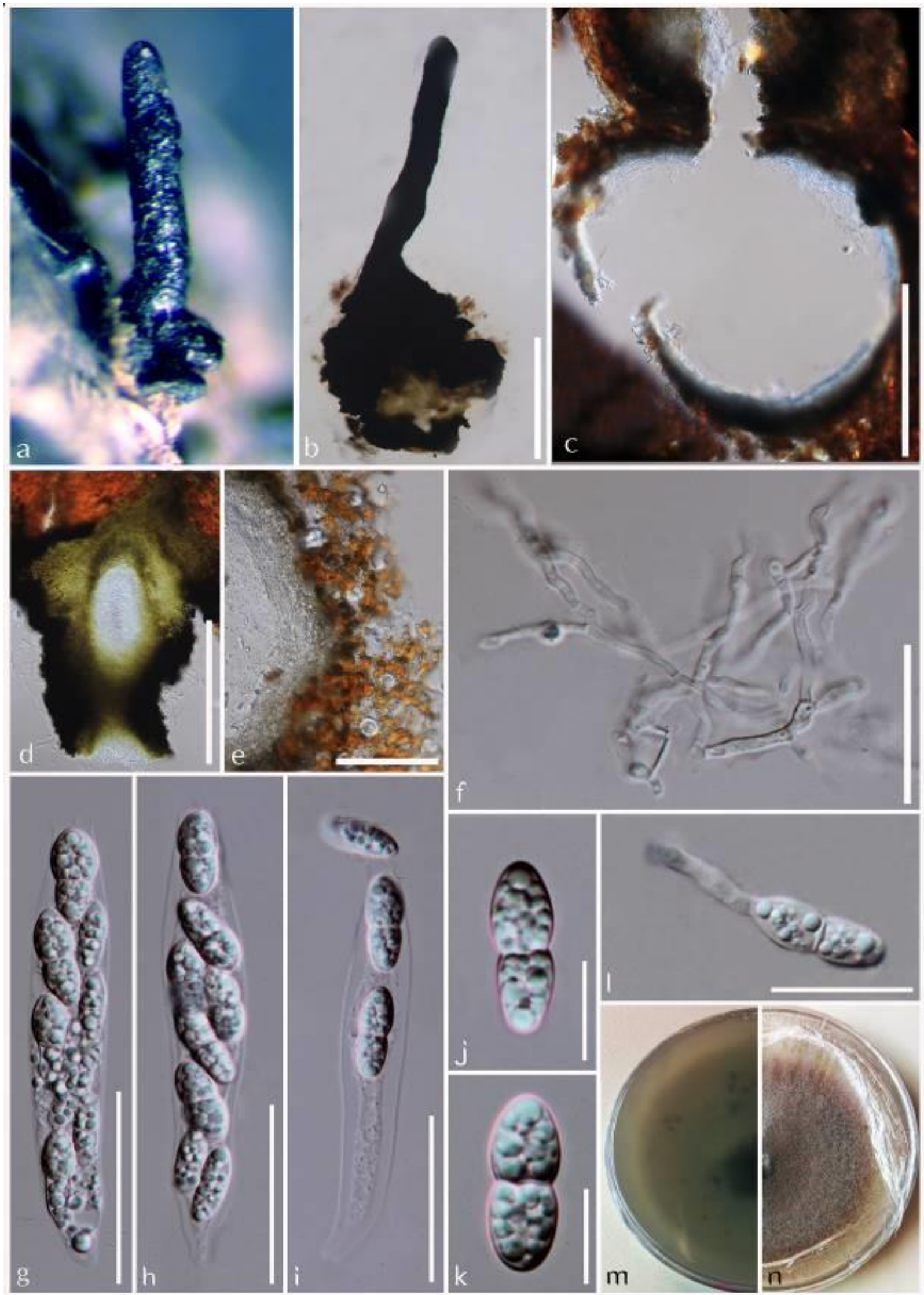

Figure 52 - Diaporthe salinicola (MFLU 18-0553, holotype). a, b Ascoma with a long neck. c Vertical sections through ascoma. d Section through neck region. e Peridium. f Paraphyses. g-i Asci. j, k Ascospores. 1 Germinating ascospore. $\mathrm{m}, \mathrm{n}$ Mature culture on sea water PDA (m lower, $\mathrm{n}$ upper). Scale bars: $\mathrm{b}, \mathrm{c}=200 \mu \mathrm{m}, \mathrm{d}, \mathrm{g}, \mathrm{h}=50 \mu \mathrm{m}, \mathrm{f}, \mathrm{i}=20 \mu \mathrm{m}, \mathrm{j}-\mathrm{k}=10 \mu \mathrm{m}$. 

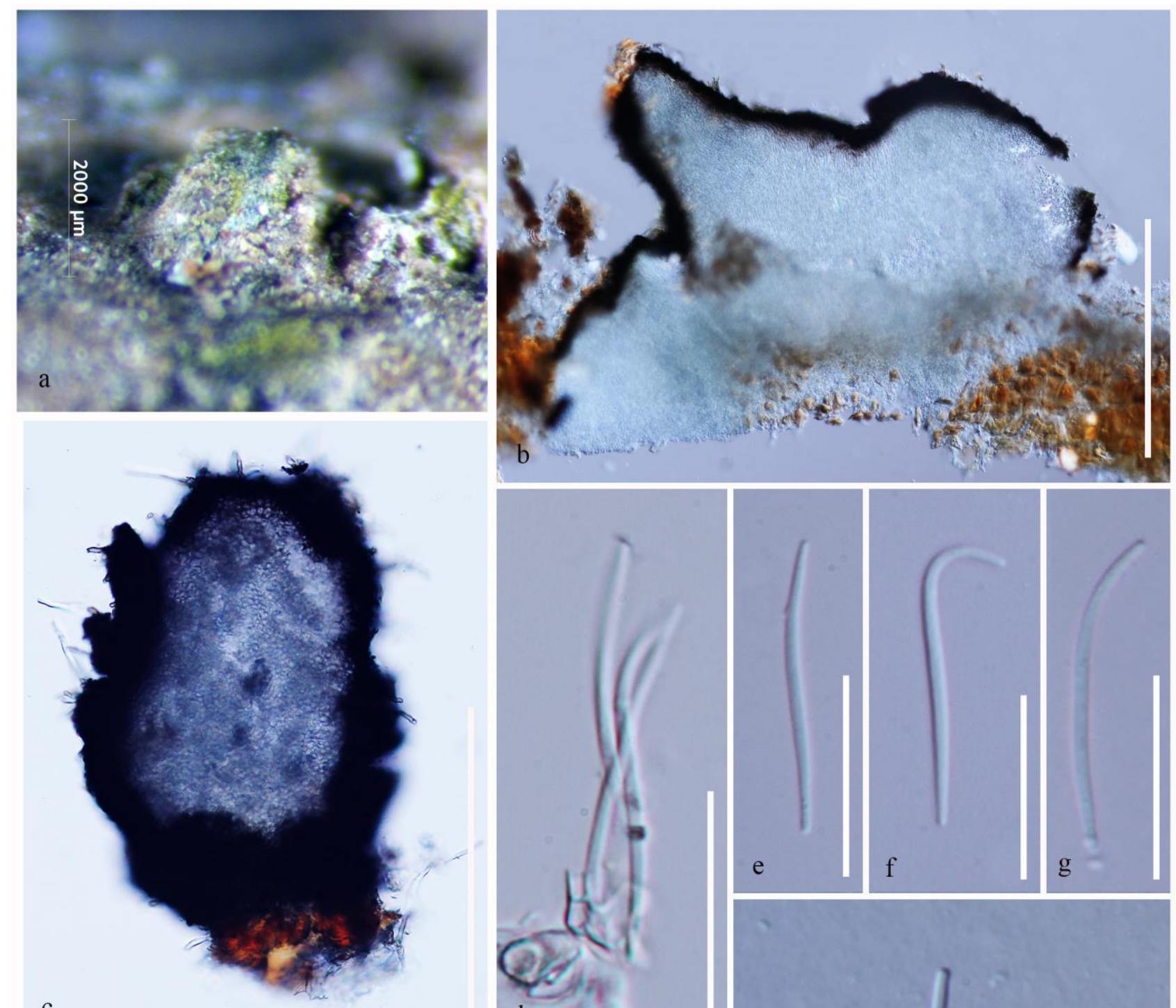

c
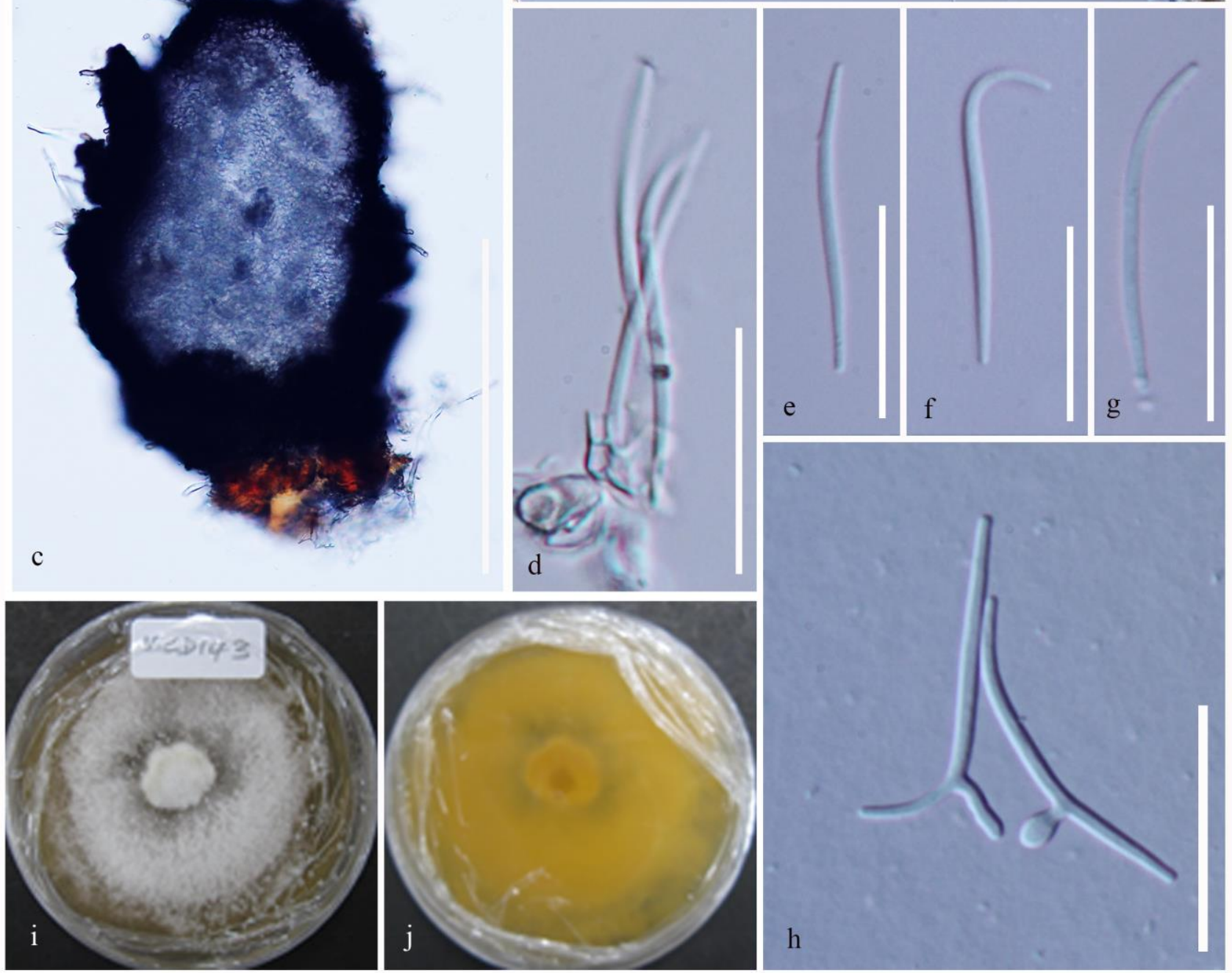

Figure 53 - Diaporthe krabiensis (MFLU 17-2618, holotype). a Pycnidia on host. b, c Section through the pycnidia. $d$, f Conidiophores with beta conidia. $d$ Conidiophores with beta conidia. e- $g$ Beta conidia. $h$ Germinating beta conidium. i, $\mathrm{j}$ Cultures on sea water PDA (i upper, $\mathrm{j}$ lower). Bars: $\mathrm{b}, \mathrm{c}=100 \mu \mathrm{m}, \mathrm{d}-\mathrm{h}=10 \mu \mathrm{m}$.

Diaporthe marina Dayarathne, sp. nov.

Fig. 54

Index Fungorum number - IF556591, Facesoffungi number - FoF 06178

Etymology - Name reflects the marine environment where the taxon was found

Holotype - MFLU 17-2622 
Saprobic on decaying submerged Rhizophora sp. (Rhizophoraceae) wood. Sexual morph: Stroma absent. Ascomata 390-500 × 200-300 $\mu \mathrm{m}$, globose to subglobose, black, coriaceous, semiimmersed, single to clustered. Neck 180-220 × 78-85 $\mu \mathrm{m}$, cylindrical, black, ostiole canal filled with periphyses. Peridium 35-55 mm thick, comprising compressed cells of textura intricata, outer layers composed of black, thick-walled cells, inner layers composed of black to hyaline thinwalled, textura intricata. Paraphyses not observed. Asci 150-164.5 $\times 15-18 \mu \mathrm{m}(\overline{\mathrm{x}}=160 \times 16, \mathrm{n}=$ 10), 8-spored, unitunicate, thin-walled, apedicellate, cylindrical to clavate, with a apical ring, ca. 1 $\mathrm{mm}$ high and $2 \mathrm{~mm}$ diam. Ascospores 16-18 $\times 10-13 \mu \mathrm{m}(\overline{\mathrm{x}}=17 \times 12.5, \mathrm{n}=25)$, overlapping uniseriate, ovoid, initially hyaline becoming light brown to brown at maturity, one-septate, upper cell small lower cell enlarged (ratio upper/lower 1:2), constricted at the septum, thin-walled, smooth-walled, with numerous guttules becoming non guttulate at maturity. Asexual morph: Undetermined.

Material examined - THAILAND, Krabi Province, Phang Nga, on decaying submerged wood of Rhizophora sp. (Rhizophoraceae), 30 August 2017, M.C. Dayarathne, MCD 147 (MFLU 17-2622, holotype); ibid., (HKAS102054, isotype).

GenBank numbers - ITS: MN047102

Additional GenBank numbers - LSU: MN017867; SSU: MN017930

Notes - Diaporthe marina is characterized by having long necked ascomata which lack stromatic tissue, peridium with textura intricata, cylindrical asci and ovoid, one-septate, ascospores with a small upper cell and an enlarged lower cell. Diaporthe marina differs from D. aquatica and D. salinicola, by having a peridium of textura intricata and ascospores with a small upper cell and an enlarged lower cell with a prominent septum, whereas the other two species have a peridium of textura angularis and ellipsoidal to obpyriform ascospores (Hu et al. 2012). Furthermore, the phylogenetic placements of these three species are distant to each other (Fig. 51). Diaporthe caulivora shows a close phylogenetic affinity to $D$. marina but morphologically they differ from each other by ascomatal, asci and ascospore morphologies (Santos et al. 2011). However, no culture could be obtained for this species therefore, DNA was extracted directly from the sexual morph on the host

Subclass Hypocreomycetidae O.E. Erikss. \& Winka

\section{Hypocreales Lindau}

Currently, Hypocreales comprises nine families: Bionectriaceae, Clavicipitaceae, Cordycipitaceae, Hypocreaceae, Nectriaceae, Niessliaceae, Ophiocordycipitaceae, Stachybotriaceae and Tilachlidiaceae (Wijayawardene et al. 2017a, 2018).

Nectriaceae Tul. \& C. Tul.

Tulasne \& Tulasne (1865) erected the family Nectriaceae with Nectria as the type genus. Nectriaceae comprises uniloculate, pigmented ascomata and phialidic amerosporous to phragmosporous conidia and includes pathogens, saprobes, or fungicolous or insecticolous fungi (Rossman et al. 1999, Rossman 2000, Chaverri et al. 2011, Hyde et al. 2014, Lombard et al. 2015, Tribpromma et al. 2018). Petch (1938) recognized Nectriaceae as a family of Hypocreales but subsequently Nectriaceae was synonymized under Hypocreaceae (Miller 1949, von Arx 1954, Rogerson 1970, Barr 1990a). However, Lumbsch \& Huhndorf (2010), Maharachchikumbura et al. (2015) and Lombard et al. (2015) reinstated Nectriaceae and included 66 genera (Wijayawardene et al. (2018). We herein introduce five novel marine Nectriaceae taxa based on morphology and sequence data analyses (Figs 55, 56, 57). 


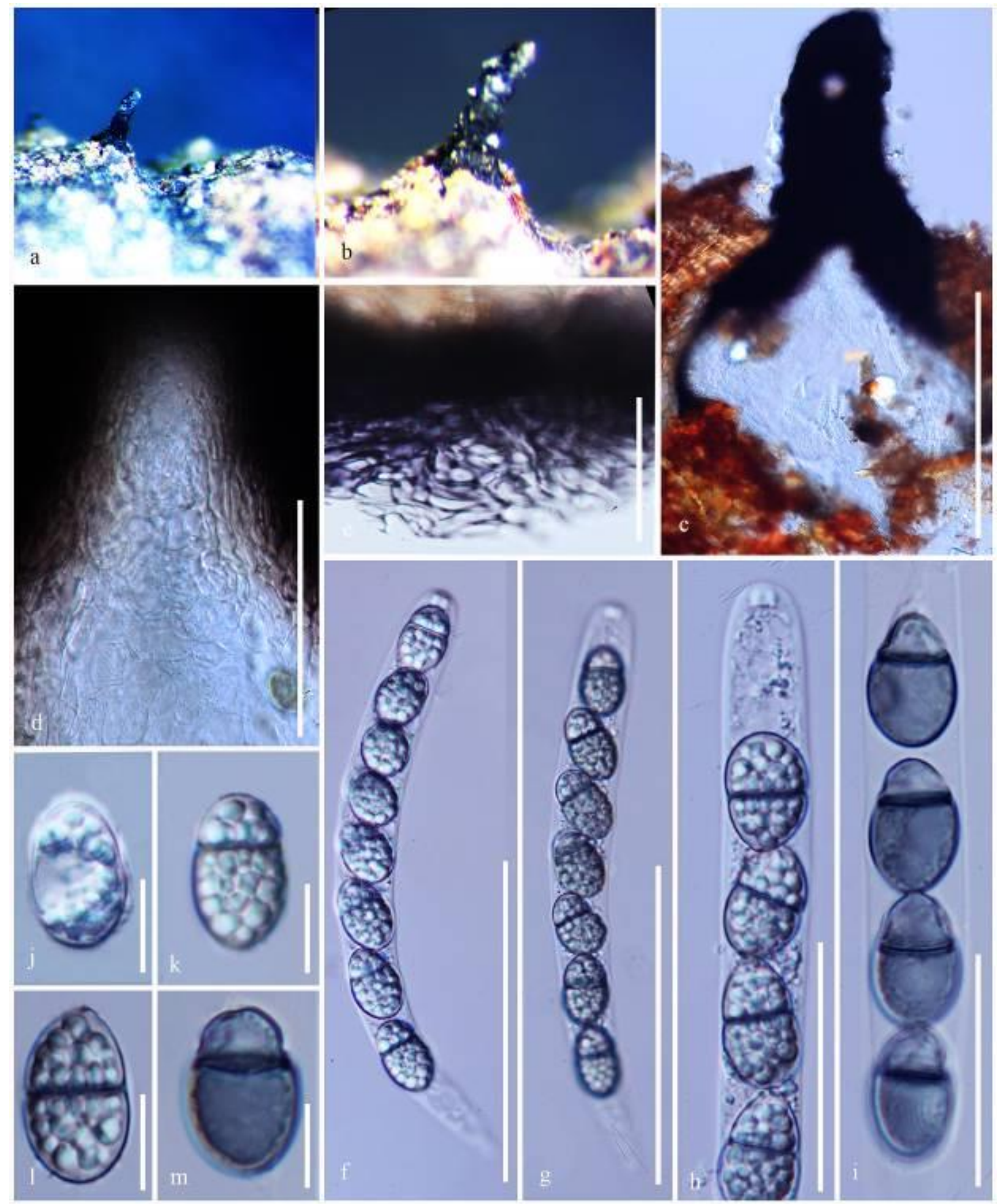

Figure 54 - Diaporthe marina (MFLU 17-2622, holotype). a, b Asomata with long necks. c Vertical sections through ascoma. d Section through neck region. e Peridium. f-i Asci. j-m Aseptate to septate ascospores. Scale bars: $\mathrm{c}=200 \mu \mathrm{m}, \mathrm{f}-\mathrm{g} 100 \mu \mathrm{m}, \mathrm{d}, \mathrm{h}, \mathrm{i}=50 \mu \mathrm{m}, \mathrm{f}, \mathrm{i}=20 \mu \mathrm{m}, \mathrm{j}-$ $\mathrm{m}=10 \mu \mathrm{m}$.

Chaetopsina Rambelli

Chaetopsina is a dematiaceous hyphomycete which was introduced by Rambelli (1956) to 
include C. fulva and this genus remained monotypic for 25 years. Later Matsushima (1971) introduced C. ramifera. Later, several other species have been added by Sutton \& Hodges (1976), Rambelli \& Lunghini (1976, 1979), Morgan-Jones (1979), Crane \& Schoknecht (1982), Kirk \& Sutton (1985), Kirk \& Sutton (1985), Samuels (1985), Wingfield (1987), Merli et al (1992), Zucconi \& Rambelli (1993), and Holubova-Jechova (1990). Hence, currently the genus comprises 19 species. Chaetopsina is characterized by mononematous, erect, septate, pigmented, setiform, apically sterile conidiophores (Rambelli 1956). The conidiogenous cells are discrete, ampulliform or lageniform, phialidic, and produce unicellular, hyaline, smooth conidia, which are aggregated in slimy masses (Ellis 1971). Samuels (1985) proposed that Chaetopsina should be restricted to asexual morphs of Nectria sensu lato with reddish-brown setose conidiophores that turn yellow in lactic acid. This was accepted by Kirk \& Sutton (1985), who further restricted Chaetopsina to species with unicellular, fusiform, smooth-walled conidia, and fertile regions situated terminally or along the axes of the setiform conidiophores. Based on these amended generic concepts, only five species were accepted in the genus by Kirk \& Sutton (1985). Only six Chaetopsina species have sequence data in GenBank (2019 June).

Chaetopsina aurantisalinicola Dayarathne, E.B.G. Jones \& K.D. Hyde, sp. nov.

Fig. 56 Index Fungorum number: IF556592; Facesoffungi number: FoF 06179

Etymology - Epithet refers to the orange ('aurantiaco' in Latin) conidiophores and culture and the "salinicola" means salt inhabiting.

Holotype - MFLU 18-0566

Saprobic on submerged Rhizophora wood. Sexual morph: Undetermined. Asexual morph: Colonies tomemtose, pale yellow-orengish brown. Mycelium partly superficial and partly immersed in the substratum, composed of irregularly branches, septate, smooth, subhyaline to yellowish or pale red-brown hyphae. Conidiophores 150-200 $\mu \mathrm{m}$ long, macronematous, mononematous, orengish brown, paler towards the apex, erect, straight or slightly curved, thickwalled, smooth, 6-8-septate, with a bulbose base 35-45 $\mu \mathrm{m}$ wide, subulate, $12-14.8 \mu \mathrm{m}$ wide just above the bulbose base, tapering gradually to $4.2-5 \mu \mathrm{m}$ wide at the apex. Fertile region yellow to orngish brown, apical, comprising loosely and regularly arrenged penicillate, smooth-walled, 2septate branches bearing conidiogenous cells, arrenged in several whorls. Conidiogenous cells 3$16.5 \mu \mathrm{m}$ long, discrete, ampulliform, hyaline, blastic. Conidia 10-26 $\times 3.5-6.8(\overline{\mathrm{x}}=18.7 \times 5 \mu \mathrm{m}, \mathrm{n}$ =30), solitary, unicellular, cylindrical to cylindro-fusoid or ellipsoidal, hyaline, smooth.

Culture characteristics - Colonies on sea water MEA reaching $10 \mathrm{~cm}$ diam. after 2 weeks at $25{ }^{\circ} \mathrm{C}$, dense, circular, slightly raised, surface smooth with entire edge, fluffy, colony from above: red, yellow and brown whorls; from below reddish yellow.

Material examined - THAILAND, Ranong Province, Ranong, on decaying submerged wood of Rhizophora sp. (Rhizophoraceae), 02 December 2017, M.C. Dayarathne, MCD 21Y (MFLU 180566, holotype); ibid., (BBH, isotype), ex type living culture MFLUCC 17-0414.

GenBank numbers - LSU: MN017868; ITS: MN047103

Notes - Chaetopsina aurantisalinicola is the only marine species of this genus. Chaetopsina aurantisalinicola is characterized by having tomemtose, pale yellow-oraengish brown colonies, oraengish brown, 6-8-septate conidiophores. Chaetopsina aurantisalinicola differs from other Chaetopsina species by orangish brown, smooth, 6-8 septate conidiophores and relatively larger conidia $(10-26 \times 3.5-6.8 \mu \mathrm{m})$. Chaetopsina aurantisalinicola forms a strongly supported distinct clade (100\% ML, $1.00 \mathrm{PP})$ neighboring $C$. penicillata in our phylogram (Fig. 54). However, $C$. penicillata is different from $C$. aurantisalinicola by having setose conidiophores, phialides with a periclinal thickening and a flared collarette and elliptic to sub-fusoid conidia with a protuberant abscission scar at the base (Samuels 1985), whereas, $C$. aurantisalinicola has smooth conidiophores, phialides without periclinal thickening and a flared collarette and cylindrical to cylindro-fusoid or ellipsoidal conidia without a protuberant abscission scar at the base. In addition, Chaetopsina aurantisalinicola and C. penicillata have 1.3\% (11 bp out of $840 \mathrm{bp}$ and 9\% (52 bp out of $568 \mathrm{bp}$ ) base pair differences in LSU and ITS loci, respectively. 


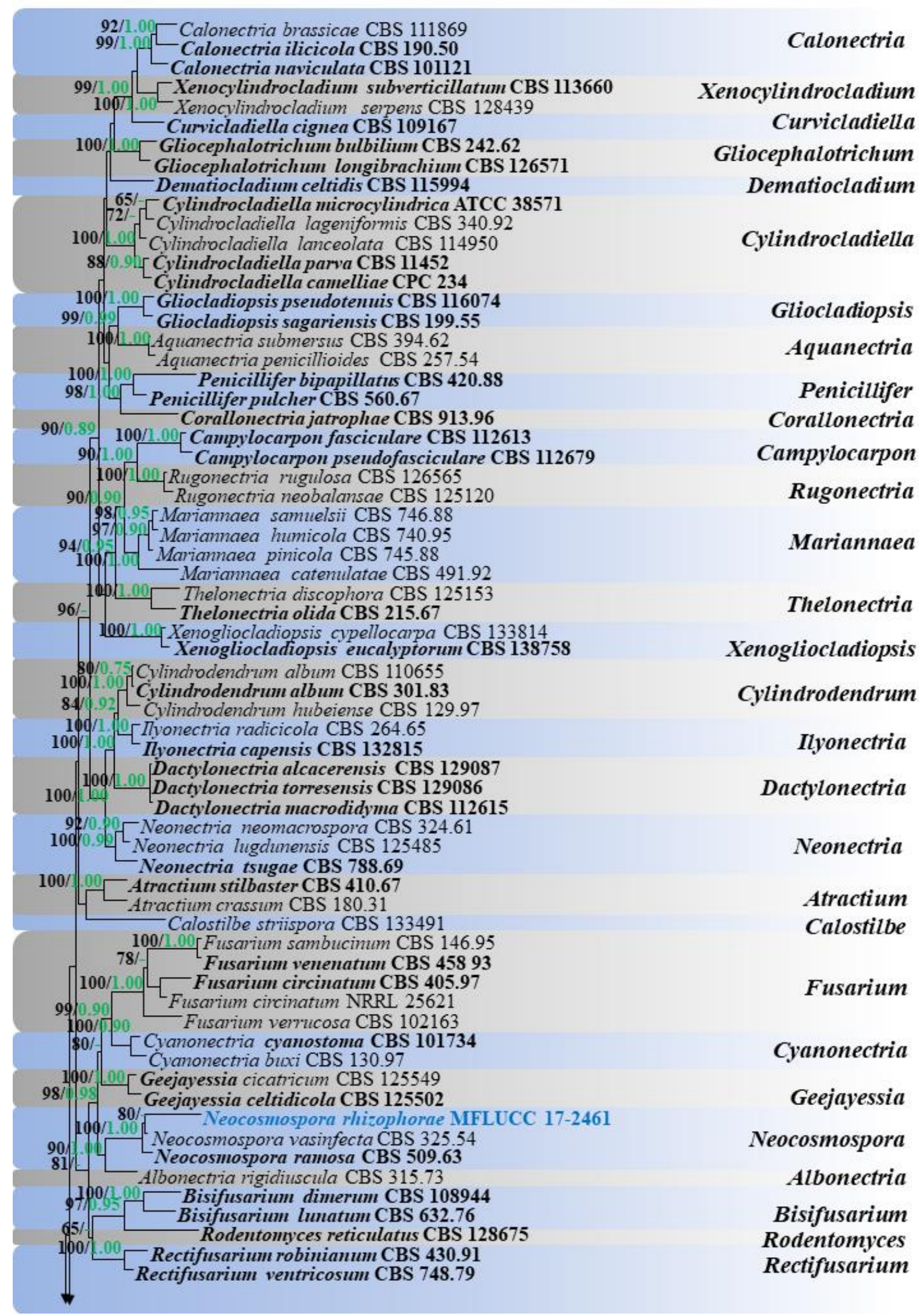

Figure 55 - Maximum likelihood analysis with 1000 bootstrap replicates yielded a best tree with the likelihood value of -18535.484456. The combined ITS, LSU, TEF and RPB2 dataset comprised 206 strains of Nectriaceae with Bionectria ochroleuca (AFTOL-ID 187) and Clonostachys buxi (CBS 696.93) as the outgroup taxa. Tree topology of the ML analysis was similar to the BI. The matrix had 1104 distinct alignment patterns, with $60.52 \%$ of undetermined characters or gaps. Estimated base frequencies were as follows; $\mathrm{A}=0.228206, \mathrm{C}=0.270125, \mathrm{G}=0.302346, \mathrm{~T}=$ 
0.199324; substitution rates $\mathrm{AC}=0.975608, \mathrm{AG}=1.608474, \mathrm{AT}=1.168311, \mathrm{CG}=0.986748, \mathrm{CT}$ $=5.376529, \mathrm{GT}=1.000000 ;$ gamma distribution shape parameter $\alpha=0.318529$. Maximum likelihood bootstrap (ML, black) values > 65\% and Bayesian posterior probabilities (PP, green) > $0.90 \%$ are given above the nodes. The scale bar indicates 0.3 changes. The ex-type strains are in bold and new isolates in blue bold.

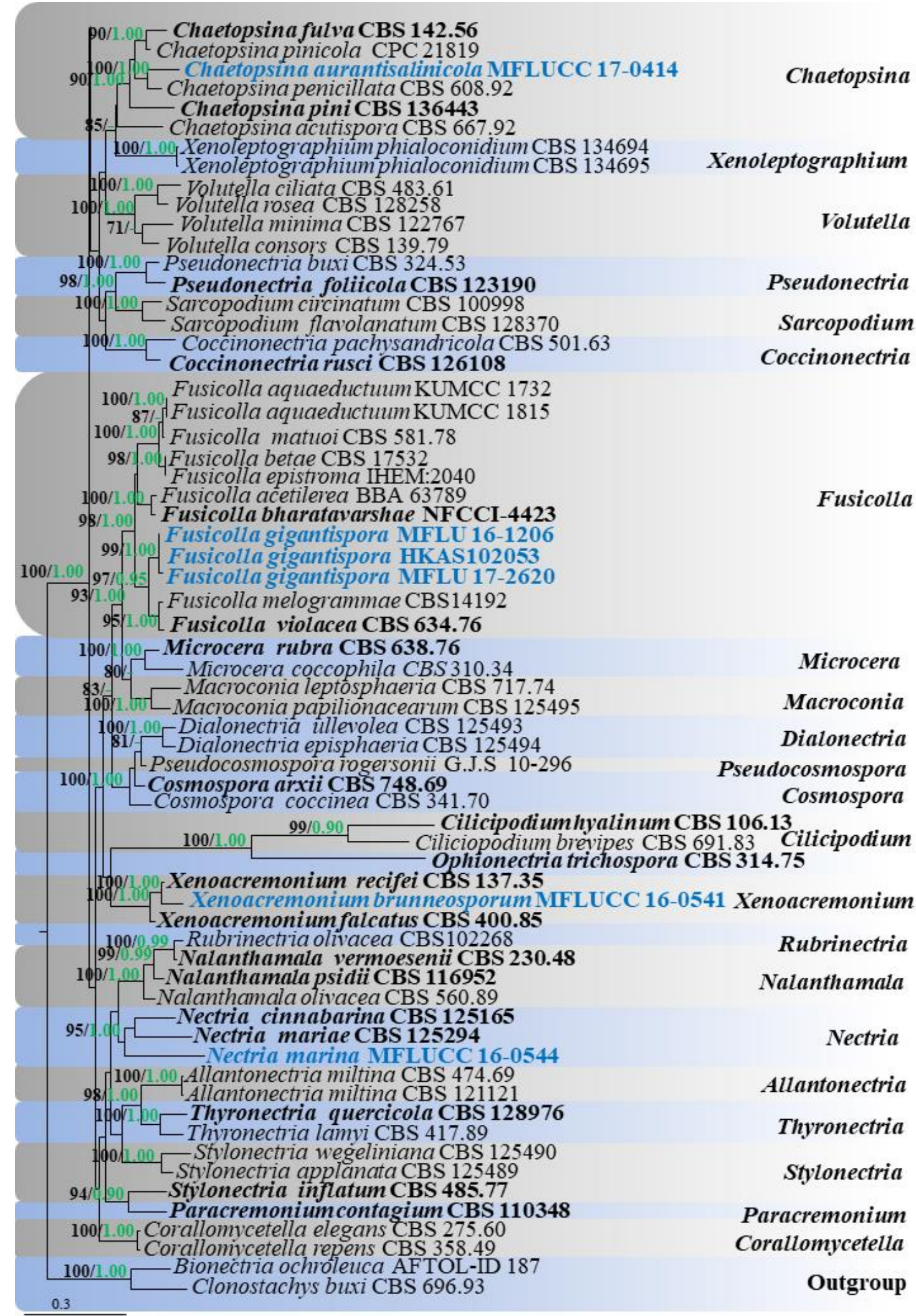

Figure 55 - Continued. 

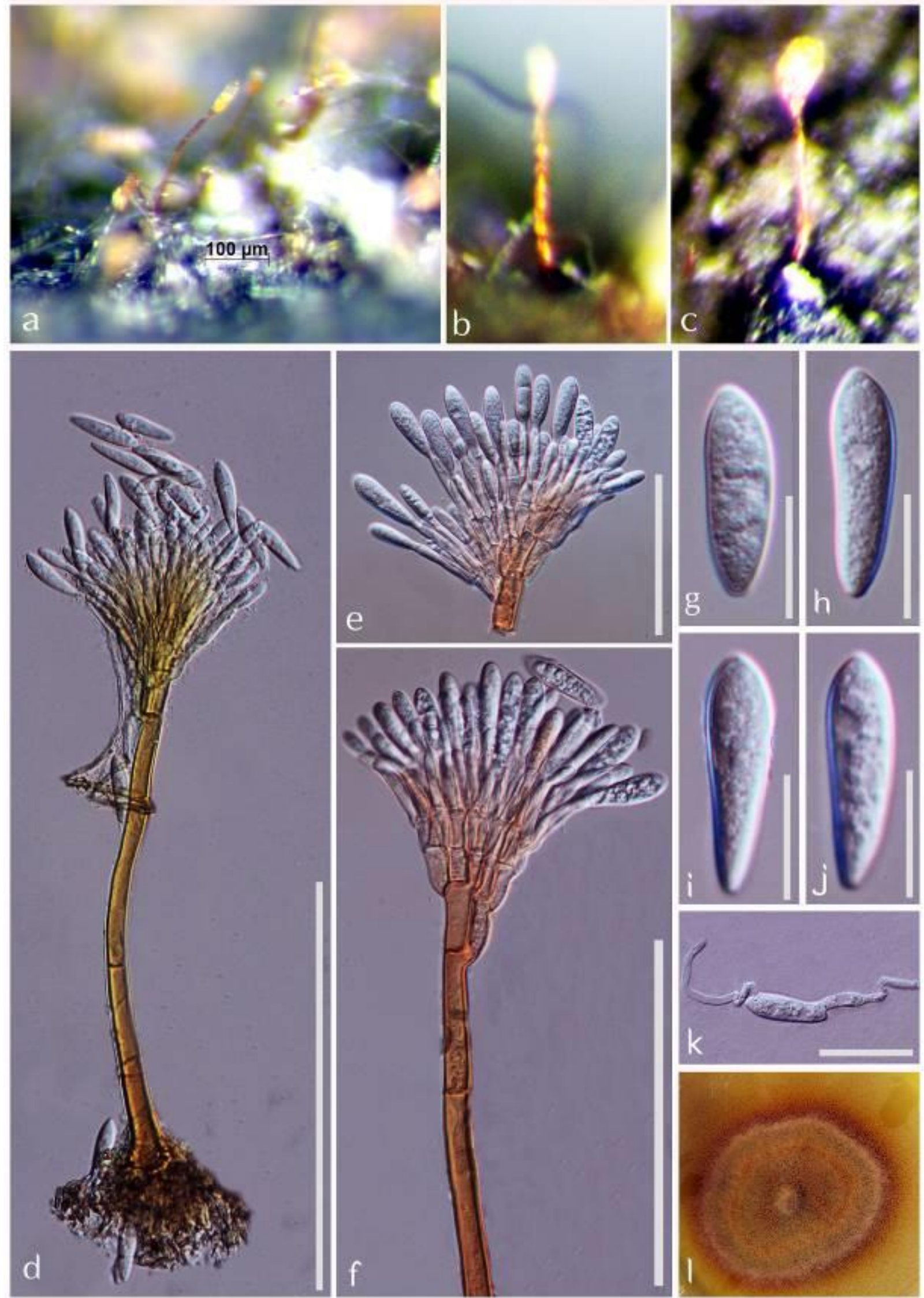

Figure 56 - Chaetopsina aurantisalinicola (MFLU 18-0566, holotype). a-c Colonies on substrate. $\mathrm{d}$ Conidiophores bearing conidia. e, f Conidia attached to the conidiogenus cells. $\mathrm{g}-\mathrm{j}$ Conidia. $\mathrm{k}$ Germinating conidium. i Culture on sea water PDA (upper). Scale bars: $a, d=100 \mu \mathrm{m}$, e, $\mathrm{f}=50$ $\mu \mathrm{m}, \mathrm{j}-\mathrm{k}=10 \mu \mathrm{m}$. 


\section{Fusicolla Bonord.}

The genus Fusicolla, typified by Fusicolla betae, comprises nine accepted species as listed in Index Fungorum (2019). Fusicolla ossicola, F. aquaeductuum, F. bharatavarshae and $F$. melogrammae were reported to have both sexual and asexual states while the other species were reported only as asexual morphs (Gräfenhan et al. 2011). Fusicolla is characterized by superficial, nonstromatic, globose to sub-globose, pale yellow to pale orange ascomata, lacking reaction to $\mathrm{KOH}, 1$-septate, ellipsoidal, hyaline and straight or slightly curved ascospores (Lechat \& Rossman 2017). Jones et al. (2019) introduced a marine species $F$. bharatavarshae which was collected from India.

Fusicolla gigantispora Dayarathne \& K.D. Hyde, sp. nov.

Fig. 57

Index Fungorum number: IF556593; Facesoffungi number: FoF 06180

Etymology - Specific epithet refers to the relatively bigger size of ascospores

Holotype - MFLU 16-1206

Saprobic on dead bark of Avicennia marina and Bruguiera sp. subjected to sea water spray. Sexual morph: Ascomata 280-300 × 235-280 $\mu \mathrm{m}$, perithecial, superficial, solitary to gregarious, non-stromatic, globose to sub-globose, coriaceous pale yellow to pale orange, not developing colour in 3\% KOH, ostiolate. Peridium 20-25 $\mu \mathrm{m}$, thick, two-layered, outer layer of 2-4 layers of textura angularis, inner layer of 3-4 layers of hyaline cells. Paraphyses 4-5 $\mu \mathrm{m}$ wide, septate, deliquescent. Asci $205-250 \times 20-24 \mu \mathrm{m},(\overline{\mathrm{x}}=225 \times 22 \mu \mathrm{m}, \mathrm{n}=20)$, unitunicate, cylindrical to narrowly clavate, short pedunculate, thin-walled, 8-spored, uniseriate, persistent, apically truncate when immature, with a J- apical ring. Ascospores 20-35 $\times 20-28 \mu \mathrm{m},(\overline{\mathrm{x}}=24 \times 24 \mu \mathrm{m}, \mathrm{n}=50)$, rounded or ellipsoidal, sometimes flat at the lower end, aseptate, hyaline when immature becoming dark brown at maturity, slightly constricted at the septum when young, rough walled, without appendage or sheath.

Material examined - THAILAND, Krabi Province, Tha pom Khlong Nam, N 08¹2'50.4”, E 98 $46^{\prime} 42.7^{\prime \prime} \mathrm{N}, 0 \mathrm{~m}$ asl., on dead bark of Avicennia marina at a mangrove stand subjected to sea water spray, 17 December 2015, M.C. Dayarathne, KLA013 (MFLU 16-1206 holotype); ibid., (HKAS102053 isotype). THAILAND, Krabi Province, Tha pom Khlong Nam, on dead bark of Bruguiera sp. subjected to sea water spray at a mangrove stand, 30 August 2017, M.C. Dayarathne, MCD145 (MFLU 17-2620); ibid., (HKAS101990).

GenBank numbers - LSU: MN017869, MN017876, MN017870, ITS: MN047104, MN047105, MN047106

Additional GenBank number - SSU: MN017931

Notes - Phylogenetic analyses indicated that the three strains of the novel Fusicolla gigantispora (MFLU 16-1206 and MFLU 17-2620) clustered with Fusicolla melogrammae (CBS14192) with high statistical support (99\% ML, 1.00 PP) (Fig. 55). However, F. gigantispora is significantly different from other species of Fusicolla in having rounded or ellipsoidal aseptate, relatively larger ascospores $(20-35 \times 20-28 \mu \mathrm{m})$, that are hyaline when immature and becoming dark brown when mature. Furthermore, the ascospores of $F$. melogrammae are ellipsoidal, rounded at ends, 1-septate, $(12-14 \times 4.5-5 \mu \mathrm{m})$, spinulose, hyaline to pale golden brown when mature and slightly constricted at the septum. Base pair differences of $F$. melogrammae and $F$. gigantispora are 12 bp out of $776 \mathrm{bp}(1.6 \%)$ of LSU and $25 \mathrm{bp}$ out of $545 \mathrm{bp}(4.6 \%)$ of ITS which indicates they are two distinct species. The recently introduced asexual species $F$. septimanifiniscientiae also differed in $23 \mathrm{bp}$ out of $526 \mathrm{bp}(4.3 \%)$.

\section{Nectria (Fr.) Fr.}

The genus Nectria is typified by $N$. cinnabarina, a wood-inhabiting fungus common in temperate regions of the Northern Hemisphere (Hirooka et al. 2011). This genus is characterized by red, globose, fleshy, warted perithecia that often become cupulate upon drying, 0-3-septate ascospores (Rossman et al. 1999). We here introduce a novel marine species to Nectria from Thailand. 


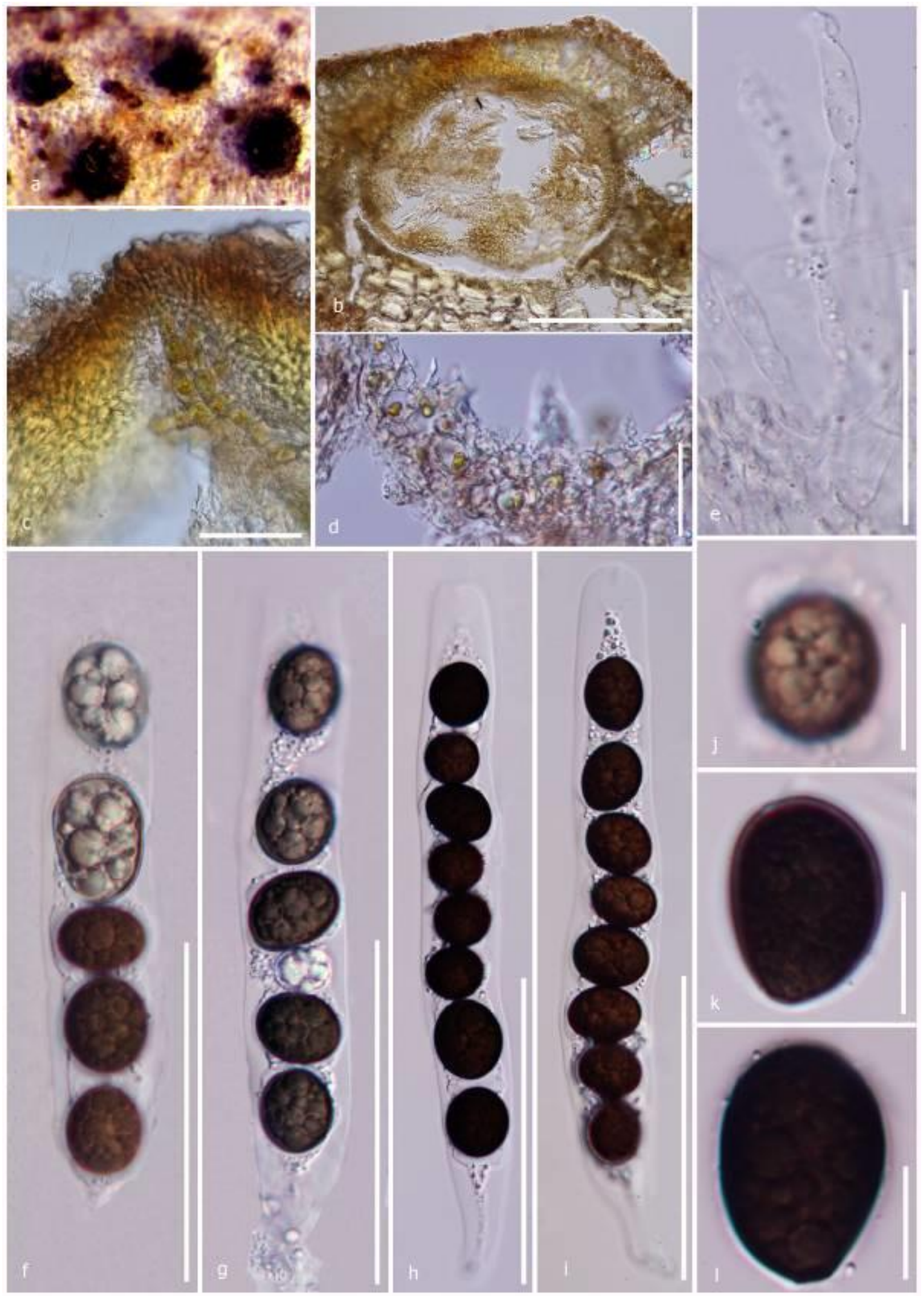

Figure 57 - Fusicolla gigantispora (MFLU 16-1206, holotype). a Ascomata superficial on the dead bark of Avicennia marina. b Section through ascoma. c Section through osteolar region. d Peridium. e Paraphyses. $f-i$ Immature and mature asci. $j-1$ Ascospores. Scale bars: $b=100 \mu m, f-i$ $=50 \mu \mathrm{m}, \mathrm{j}-1=20 \mu \mathrm{m}$. 


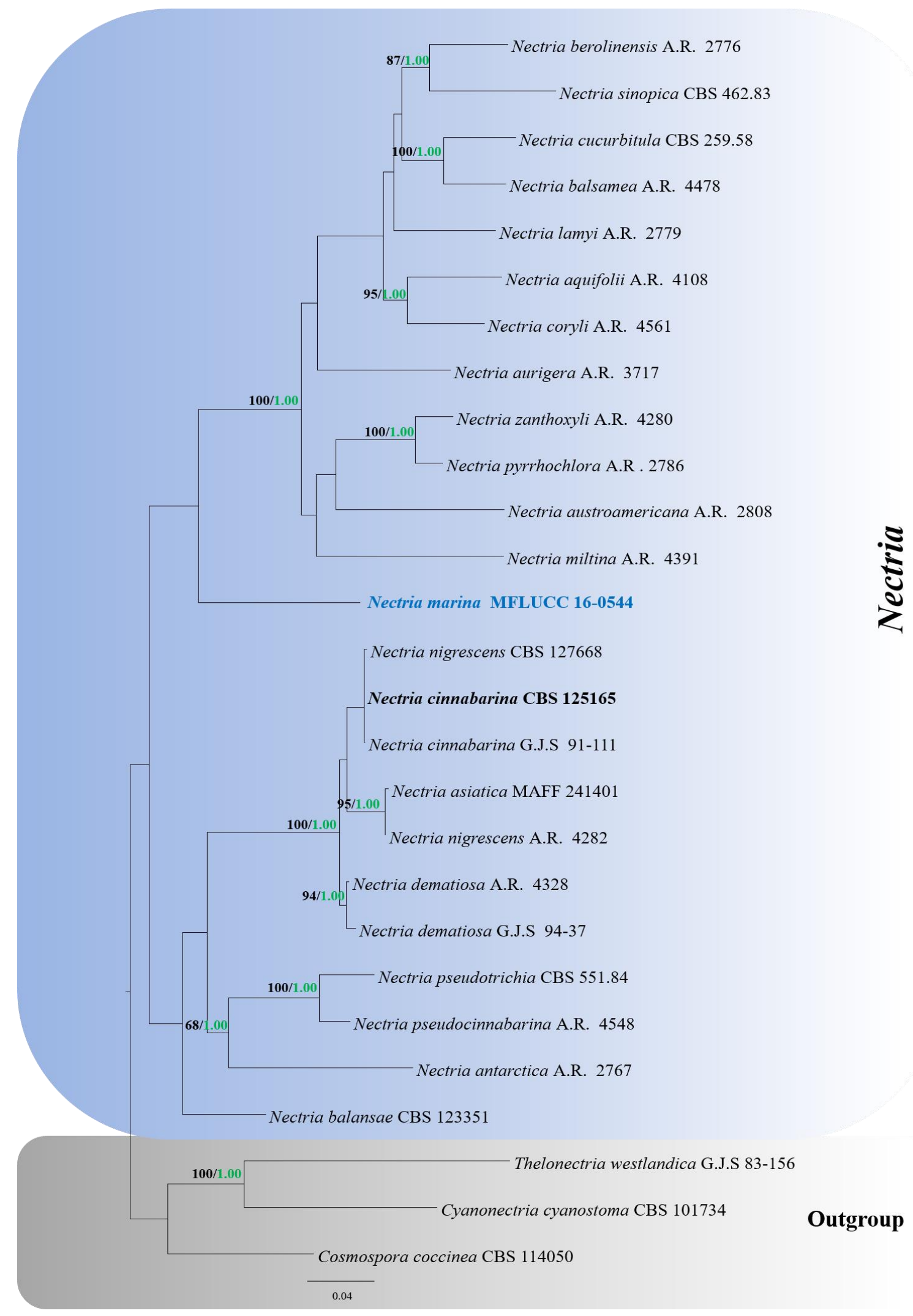

Figure 58 - Maximum likelihood analysis with 1000 bootstrap replicates yielded a best tree with the likelihood value of -14641.704613. The combined ITS and LSU dataset comprised 27 strains of Nectria with Thelonectria westlandica (G.J.S 83-156), Cyanonectria cyanostoma (CBS 101734) and Cosmospora coccinea (CBS 114050) as the outgroup taxa. Tree topology of the ML analysis was similar to the BI. The matrix had 747 distinct alignment patterns, with $8.56 \%$ of undetermined characters or gaps. Estimated base frequencies were as follows; $\mathrm{A}=0.235998, \mathrm{C}=0.272392, \mathrm{G}=$ $0.263123, \mathrm{~T}=0.228487$; substitution rates $\mathrm{AC}=0.997494, \mathrm{AG}=1.911235, \mathrm{AT}=1.488006, \mathrm{CG}=$ 
$0.908697, \mathrm{CT}=4.445539, \mathrm{GT}=1.000000$; gamma distribution shape parameter $\alpha=0.168504$. Maximum likelihood bootstrap (ML, black) values > 65\% and Bayesian posterior probabilities (PP, green) $>0.90 \%$ are given above the nodes. The scale bar indicates 0.04 changes. The ex-type strains are in bold and new isolates in blue bold.

Nectria marina Dayarathne \& K.D. Hyde, sp. nov.

Fig. 59

Index Fungorum number: IF556594; Facesoffungi number: FoF 06181

Etymology - Name refers to the marine environment where the species found.

Holotype - MFLU 16-1180

Saprobic on submerged mangrove wood. Stromata $1.5 \mathrm{~mm}$ high and $3.0 \mathrm{~mm}$ diam, superficial or erumpent, globose to sub globose, orangish red, produce pigment with $\mathrm{KOH}+$, solitary to gregarious, pseudoparenchymatous, cells forming textura angularis, intergrading with ascomatal wall. Ascomata $640-800 \times 500-650 \mu \mathrm{m},(\overline{\mathrm{x}}=720 \times 600 \mu \mathrm{m}, \mathrm{n}=5)$, superficial on welldeveloped stromata, solitary, sub-globose to globose, scarlet to sienna, slightly cupulate upon drying, apical region slightly darker, $\mathrm{KOH}+$ reddish brown, smooth to roughened. Peridium 25-40 $\mu \mathrm{m}$ thick, of three regions: outer region intergrading with stroma, cells forming textura angularis, walls pigmented; middle region cells forming textura prismatica, containing scarlet to bay, pigmented droplets, walls pigmented to gold; inner region, of elongate, thin-walled, hyaline cells, forming textura prismatica. Paraphyses 1.2-1.8 wide, hyaline, branched, septate. Asci 165-180 $\times$ 12-20 $\mu \mathrm{m},(\overline{\mathrm{x}}=175 \times 18 \mu \mathrm{m}, \mathrm{n}=30), 8$-spored, clavate, with inconspicuous ring at apex. Ascospores $25-38 \times 7-9.5 \mu \mathrm{m},(\overline{\mathrm{x}}=30 \times 8.2 \mu \mathrm{m}, \mathrm{n}=30)$, biseriate, ellipsoidal to fusiform, straight, 1-septate, deeply constricted at the septa, hyaline, guttulate, thick walled.

Material examined - THAILAND. Krabi Province: Tha Pom Khlong Song Nam (N 08 12'50.4”, E 98 46'42.7'), submerged mangrove wood, 16 December 2015, M.C. Dayarathne KLA014 (MFLU 16-1180, holotype); ibid., (HKAS102021, isotype), ex-type living cultures MFLUCC 16-0544.

GenBank numbers - LSU: MN017871; ITS: MN047108; TEF: MN433214

Notes - Nectria marina is characterized by red, globose, fleshy ascomata and 1-septate ascospores which are in common with other Nectria species. In our phylogram, Nectria marina formed a distinct basal lineage to a clade comprising, $N$. austroamericana, $N$. aquifolii, $N$. aurigera, $N$. balsamea, $N$. berolinensis, $N$. coryli, $N$. cucurbitula, $N$. lamyi, N. miltina, $N$. pyrrhochlora, N. sinopica and N. zanthoxyli (Fig. 58). Nectria miltina is different form N. marina by having allantoid to short-cylindrical, aseptate, smaller ascospores $(4.3-5.9 \times 1.3-1.9 \mu \mathrm{m})$ (Hirooka et al. 2011) while, ascospores of $N$. marina are ellipsoidal to fusiform, 1-septate, and comparatively larger $(25-38 \times 7-9.5 \mu \mathrm{m})$. However, ascospores of our novel species is well distinguished from all the other Nectria species by being deeply constricted at the septa and sharply pointed at their apices.

\section{Neocosmospora E.F. Sm.}

The genus Neocosmospora was established by Smith (1899) for a single species, Neocosmospora vasinfecta. Since then, a number of other species have been added to the genus (Cannon \& Hawksworth 1984). Neocosmospora is characterized by perithecial, orange to red, rarely dark brown, globose to pyriform, ostiolate ascomata with a short neck lined with periphyses, peridium composed of an outer pigmented layer, sometimes covered with rhizoidal hyphae, and hyaline inner layers, mostly with periphysoids, 8-spored, cylindrical, rarely clavate asci with a short stalk and usually lacking apical structures and uniseriate, rarely biseriate, pale brown to almost hyaline, 1-(2-) celled, globose to ellipsoidal, ornamented ascospores (Cannon \& Hawksworth 1984). The genus Neocosmospora has been a highly renowned fungal group for more than 100 years, mainly because it contains significant number of plant pathogenic species (Sandoval-Denis \& Crous 2018, Sandoval-Denis et al. 2018). It includes causative agents of fruit-rot, root-rot and seedling damping-off, affecting diverse plant hosts (Leslie \& Summerell 2006, Domsch et al. 2007, Nalim et al. 2011). 


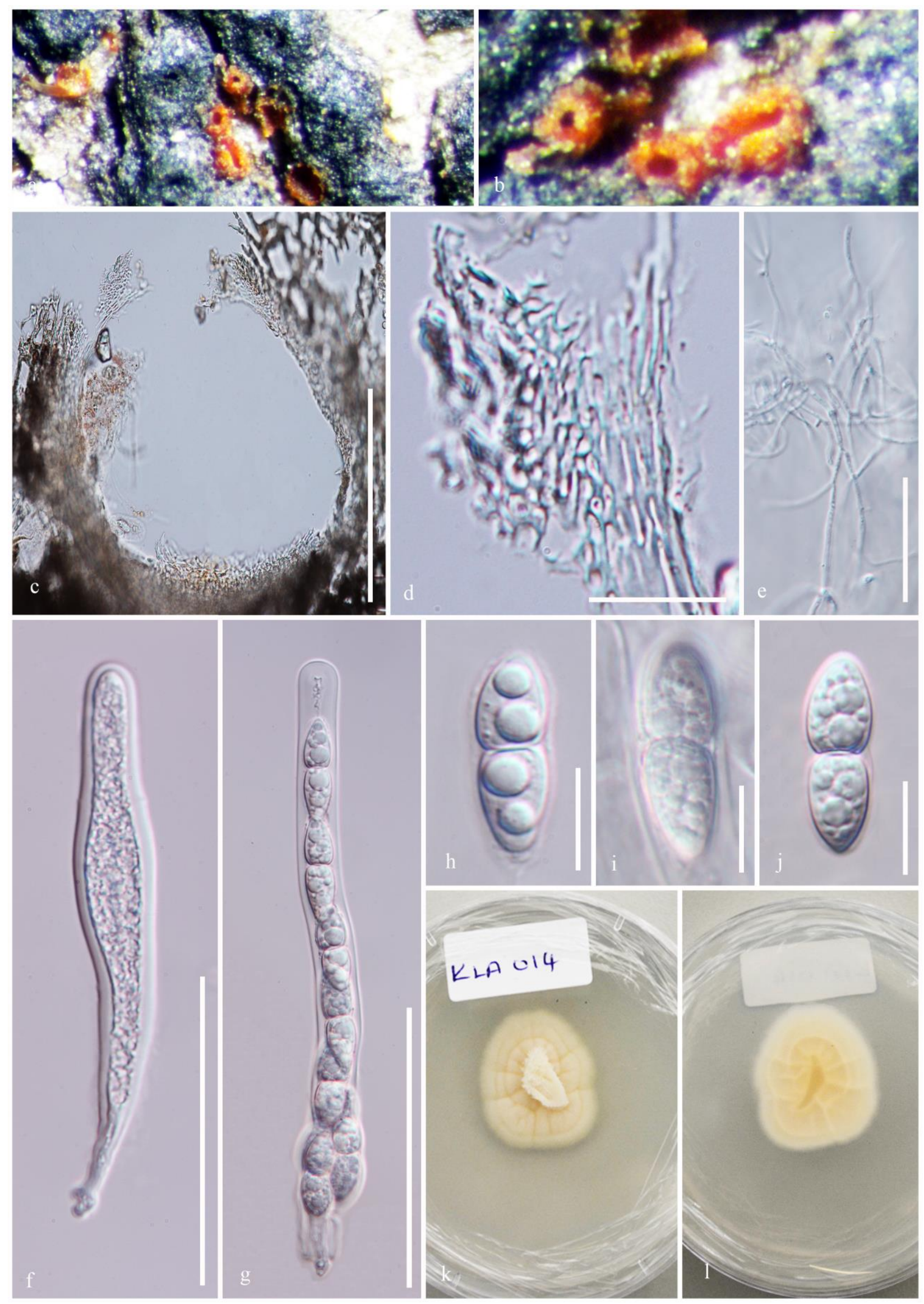

Figure 59 - Nectria marina (MFLU 16-1206, holotype), a, b Stromata superficial on the dead wood. c Section through stroma. d Peridium. e Paraphyses. f, g Immature and mature asci. $\mathrm{h}-\mathrm{j}$ Ascospores. k, 1 Cultures on PDA. Scale bars: $\mathrm{c}=100 \mu \mathrm{m}, \mathrm{e}-\mathrm{g}=50 \mu \mathrm{m}, \mathrm{d}=20 \mu \mathrm{m}, \mathrm{h}-\mathrm{j}=10 \mu \mathrm{m}$. 


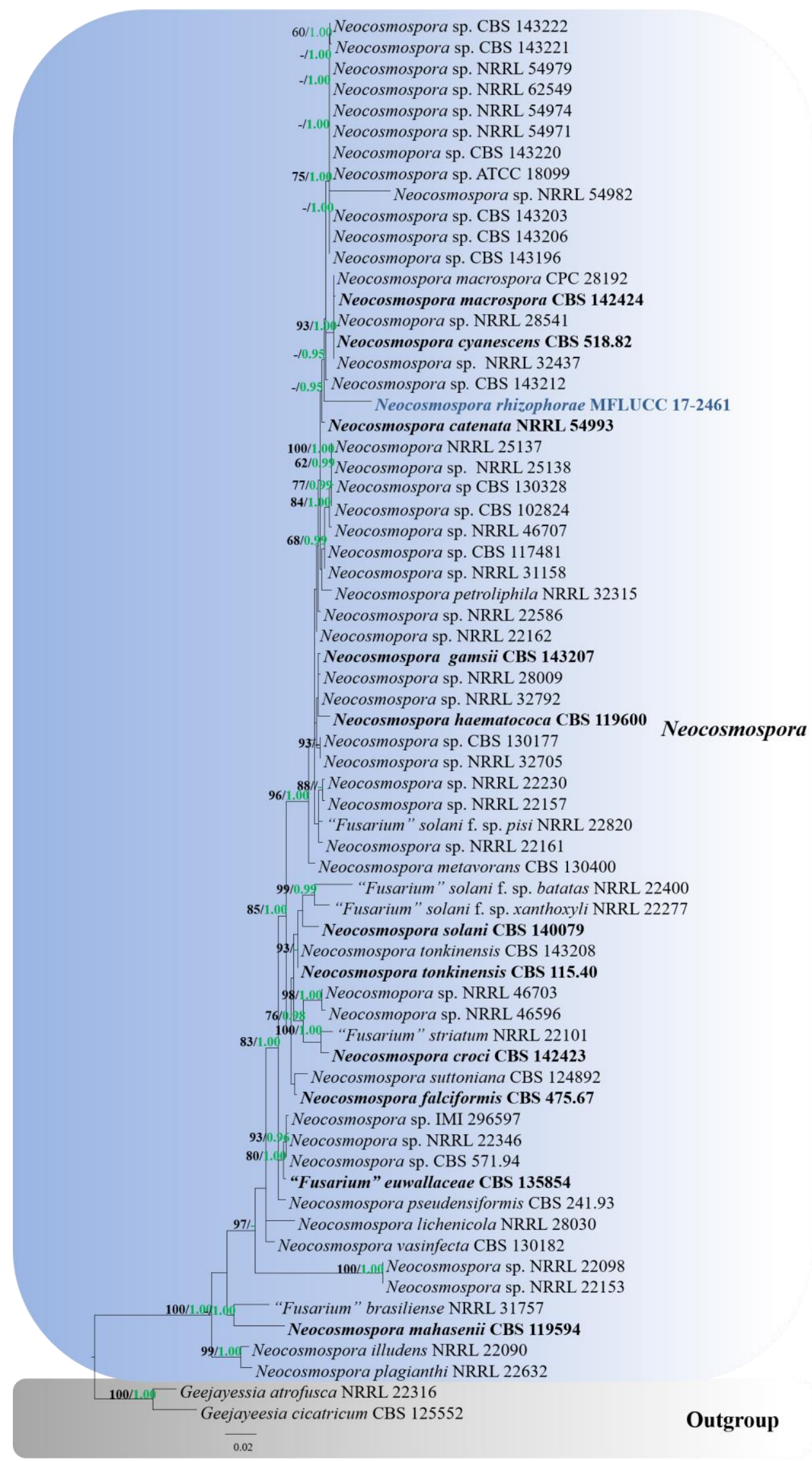

Figure 60 Maximum likelihood analysis with 1000 bootstrap replicates yielded a best tree with the likelihood value of -4264.829108 . The combined ITS and LSU dataset comprised 95 strains of Neocosmopora, several fusarium-like taxa with Geejayessia atrofusca (CBS 125552) and $G$. cicatricum (NRRL 22316) as the outgroup taxa. Tree topology of the ML analysis was similar to 
the BI. The matrix had 308 distinct alignment patterns, with $7.06 \%$ of undetermined characters or gaps. Estimated base frequencies were as follows; $\mathrm{A}=0.250273, \mathrm{C}=0.258917, \mathrm{G}=0.272267, \mathrm{~T}=$ 0.218543; substitution rates $\mathrm{AC}=1.866807, \mathrm{AG}=2.127266, \mathrm{AT}=2.318509, \mathrm{CG}=0.912700, \mathrm{CT}$ $=6.511334, \mathrm{GT}=1.000000$; gamma distribution shape parameter $\alpha=0.168504$. Maximum likelihood bootstrap (ML, black) values $>65 \%$ and Bayesian posterior probabilities (PP, green) > $0.90 \%$ are given above the nodes. The scale bar indicates 0.02 changes. The ex-type strains are in bold and new isolates in blue bold.

Neocosmospora rhizophorae Dayarathne sp. nov.

Fig. 61

Index Fungorum number: IF556595; Facesoffungi number: FoF 06182

Etymology - Epithet refers to the host, Rhizophora sp., where the species found.

Holotype - MFLU 17-2588

Saprobic on submerged wood of Rhizophora sp. Ascomata 330-345 $\times 300-325 \mu \mathrm{m}(\overline{\mathrm{x}}=340$ $\times 320 \mu \mathrm{m}, \mathrm{n}=5$ ), orange to dark brown-red, globose to pyriform, semi immersed, solitary or gregarious, coarsely warted, glabrous. Peridium 50-68 $\mu \mathrm{m}$ wide, composed of thick-walled cells of textura angularis. Paraphyses 1.2-3 $\mu \mathrm{m}$ wide, persistent, narrow, branched, tapering towards the apex. Asci $80-90 \times 15-18 \mu \mathrm{m}(\overline{\mathrm{x}}=85 \times 16 \mu \mathrm{m}, \mathrm{n}=30), 8$-spored, clavate, unitunicate, with a broad and somewhat flattened and simple apex. Ascospores 15-25 $\times 6-9.2 \mu \mathrm{m},(\overline{\mathrm{x}}=20 \times 8 \mu \mathrm{m}, \mathrm{n}=50)$, obliquely uniseriate or irregularly biseriate, obovoid to subfusiform, 1-septate, hyaline, thickwalled, longitudinally finely striated, guttulate, often slightly constricted at the septum.

Material examined - THAILAND, Krabi Province, Phang Nga, on Rhizophora sp. (Rhizophoraceae) wood, 31 August 2017, M.C. Dayarathne, MCD 102 (MFLU 17-2586, holotype); ibid., (HKAS102030, isotype), ex-type living culture (MFLUCC 17-2461).

GenBank numbers - LSU: MN017872; ITS: MN047109

Additional GenBank number - SSU: MN017932

Notes - Neocosmospora rhizophorae is morphologically similar to other members of Neocosmospora by its reddish membranous ascomata and 1-septate, longitudinally finely striate ascospores (Sandoval-Denis \& Crous 2018). Neocosmospora rhizophorae shows close phylogenetic affinities to an unidentified Neocosmospora spp. (CBS 143212), which are important veterinary pathogens, and currently under study (Geiser pers. comm.) (Sandoval-Denis \& Crous 2018). Neocosmospora rhizophorae is morphologically reminiscent of $N$. gamsii but can be clearly distinguish by the size of asci $(80-90 \times 15-18 \mu \mathrm{m} v s 72-87.5 \times 7.5-9 \mu \mathrm{m})$ and ascospores $(15-25$ $\times 6-9.2 \mu \mathrm{m} v s$ 10.5-11.5 $\times 5.0-6.5 \mu \mathrm{m})($ Sandoval-Denis \& Crous 2018). They are distantly placed in our phylogram (Fig. 60). Somewhat similar morphologies are visible in Kallichroma to this novel taxon. However, Kallichroma species can be distinguished from $N$. rhizophorae by epapillate or clypeoid ascomata and ascospores surrounded by mostly a gelatinous sheath (Kohlmeyer \& Kohlmeyer 1965, 1979, Kohlmeyer 1984, Abdel-Wahab et al. 2017).

Xenoacremonium L. Lombard \& Crous

Facesoffungi Number: FoF 06183

Saprobic on wood. Sexual morph: Stromata erumpent, orange to brown, pseudoparenchymatous, cells forming textura angularis, intergrading with ascomatal wall. Ascomata superficial, aggregated in groups of 2-3, brown, subglobose to globose. Peridium 50-90 $\mu \mathrm{m}$ thick, comprises two regions, outer region intergrading with stroma, cells forming textura angularis, inner region elongate, thin-walled, hyaline cells, forming textura prismatica. Paraphyses 2-3 $\mu \mathrm{m}$ wide, persistent, aseptate, not branched, tapering towards the apex. Asci 8-spored, unitunicate, mainly uniseriate to partly biseriate, with inconspicuous ring at apex, clavate. Ascospores ellipsoidal to fusiform with rounded ends, straight or slightly curved, aseptate, hyaline, smooth walled. Asexual morph: Mycelium consisting of hyaline, septate, branched hyphae. Conidiophores either as lateral phialidic pegs or arising laterally from somatic hyphae, erect, cylindrical to subcylindrical, unbranched or rarely branched, aseptate or septate, smooth, hyaline to pale brown. Conidiogenous cells terminal, monophialidic, hyaline, smooth, elongate-ampulliform 
or subcylindrical, tapering towards the apex, with periclinal thickening and inconspicuous collarette. Conidia aseptate, fusiform to ellipsoidal to cylindrical, slightly or strongly curved, forming slimy heads on the conidiophore (Asexual morph description from Lombard et al. 2015).

Notes - The genus Xenoacremonium was established by Lombard et al. (2015) for a group of fungi previously known as Acremonium recifei (Gams 1971). The second species X. falcatus was introduced by Lombard et al. (2015). Members of this genus are presently known only as asexual morphs. Here we introduce the first sexual morph species to Xenoacremonium which was collected from a marine habitat.

Xenoacremonium brunneosporum Dayarathne, E.B.G. Jones \& K.D. Hyde, sp. nov.

Fig. 62

Index Fungorum number: IF556596; Facesoffungi number: FoF 06184

Etymology - Epithet refers derived Latinization of brow ascospores

Holotype - MFLU 16-1204

Saprobic on submerged Rhizophora wood. Sexual morph: Stromata up to $230 \times 570 \mu$ m, erumpent, orange to brown, pseudoparenchymatous, cells forming textura angularis, intergrading with ascomatal wall. Ascomata 261-300 × 124-180 $\mu \mathrm{m}$, superficial, aggregated in groups of 2-3, brown, subglobose to globose. Peridium 30-50 $\mu \mathrm{m}$ thick, comprises two regions, outer region 30$45 \mu \mathrm{m}$ thick, intergrading with stroma, cells forming textura angularis, inner region 15-18 $\mu \mathrm{m}$ thick, of elongate, thin-walled, hyaline cells, forming textura prismatica. Paraphyses $2-3 \mu \mathrm{m}$ wide, persistent, aseptate, not branched, tapering towards the apex. Asci $90-110 \times 12-17(\overline{\mathrm{x}}=92.4 \times 16$ $\mu \mathrm{m}, \mathrm{n}=20$ ), 8 -spored, unitunicate, mainly uniseriate to partly biseriate, with inconspicuous ring at apex, clavate. Ascospores 15.7-20.3 $\times 6-8.5(\overline{\mathrm{x}}=17 \times 7.3 \mu \mathrm{m}, \mathrm{n}=30)$, ellipsoidal to fusiform with rounded ends, straight or slightly curved, aseptate, hyaline to pale brown, smooth walled. Asexual morph: Undetermined

Culture characteristics - Reaching $2 \mathrm{~cm}$ within 10 days on sea water PDA, when incubated at $25{ }^{\circ} \mathrm{C}$, circular, effuse, with diffuse margin, white, and becoming yellowish-white, to dull yellow with age.

Material examined - THAILAND, Krabi Province, Tha Pom Khlong Song Nam (N 08²'50.4”, E 98 46'42.7'), on aerial bark of Rhizophora mucronata, 16 December 2015, M.C. Dayarathne KLA011 (MFLU 16-1204, holotype); ibid., (HKAS101988, isotype), ex-type living cultures MFLUCC 16-0541.

GenBank numbers - LSU MN017873; ITS: MN047107; RPB2: MN077080; TEF: MN077075

Additional GenBank numbers - SSU: MN017933

Notes - Our new isolate MFLU 16-1204 grouped within Xenoacremonium with strong statistical support (100\% ML, 1.00 PP) (Fig. 55). Therefore, we establish this taxon as the first sexual species of this genus. Xenoacremonium brunneosporum has orange to brown stromata, clavate asci and ellipsoidal to fusiform ascospores with rounded ends that are characteristic features of Nectriaceae i.e. Thelonectria lucida. Xenoacremonium brunneosporum shows close phylogenetic affinities to $X$. recifei with 6 bp of ITS loci out of $540 \mathrm{bp}(1.1 \%)$ and $16 \mathrm{bp}$ of RPB2 loci out of $726 \mathrm{bp}(2.3 \%)$ differences between them. Further studies are needed to discover the asexual morph of this species to confirm the morphological relationships of this species to existing taxa in the genus.

\section{Ophiocordycipitaceae G.H. Sung et al.}

Ophiocordycipitaceae was introduced by Sung et al. (2007) and comprises seven genera, Drechmeria, Harposporium, Hymenostilbe, Ophiocordyceps, Polycephalomyces, Purpureocillium and Tolypocladium (Quandt et al. 2014, Wijayawardene et al. 2017a, 2018). Species accommodated in this family are phylogenetically distinct from Cordycipitaceae and Clavicipitaceae (Quandt et al. 2014). Asexual morphs of Ophiocordycipitaceae exhibit a vast range of variation, some of which are confined in phylogenetic distribution while the rest are often found in disparate lineages (Zare et al. 2000, Gams \& Zare 2001, Sung et al. 2001, 2007). 


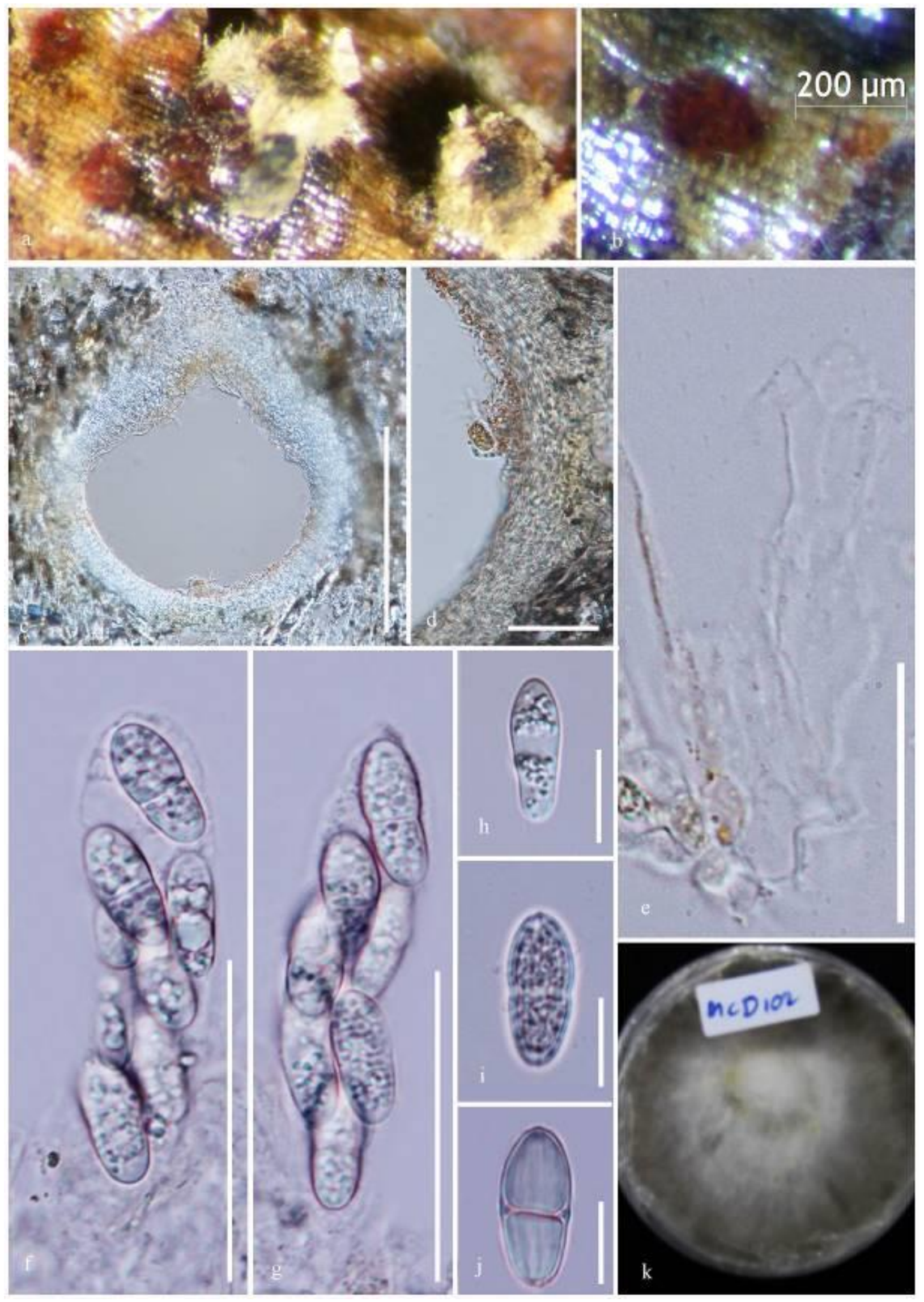

Figure 61 - Neocosmospora rhizophorae (MFLU 17-2588, holotype). a, b Ascomata superficial on the dead wood. c Section through an ascoma. d Peridium. e Paraphyses. f, g Asci. $\mathrm{h}-\mathrm{j}$ Ascospores. $\mathrm{k}$ Culture on sea water PDA. Scale bars: $b, c=200 \mu \mathrm{m}, \mathrm{d}, \mathrm{e}-\mathrm{g}=50 \mu \mathrm{m}, \mathrm{h}-\mathrm{j}=10 \mu \mathrm{m}$. 


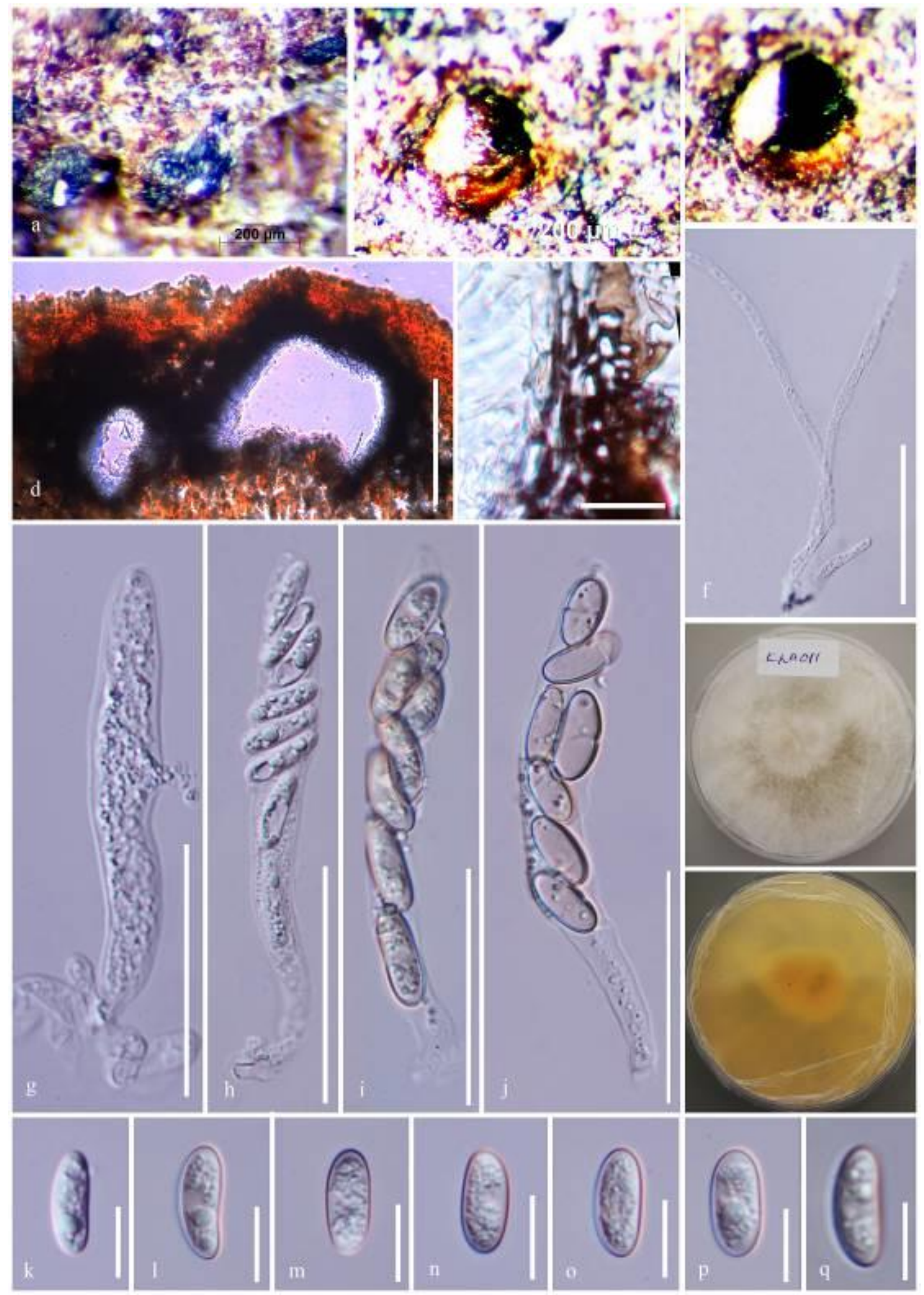

Figure 62 - Xenoacremonium brunneosporum (MFLU 16-1204, holotype). a-c Appearance of stromata on host. $d$ Vertical section through stromata. e Peridium. f Paraphyses. $g-j$ Immature and mature asci. $\mathrm{k}-\mathrm{q}$ Ascospores. Scale bars: $\mathrm{a}, \mathrm{b}, \mathrm{d}=200 \mu \mathrm{m}, \mathrm{f}-\mathrm{j}=50 \mu \mathrm{m}, \mathrm{e}=20 \mu \mathrm{m}, \mathrm{k}-\mathrm{q}=10 \mu \mathrm{m}$. 
Purpureocillium Luangsa-ard et al.

The genus Purpureocillium was introduced by Luangsa-ard et al. (2011) with P. lilacinum as the type species, and has been reported as an important human pathogen. Apart from the type species, Purpureocillium comprises three species viz $P$. atypicola, $P$. lavendulum and $P$. takamizusanense (Index Fungorum 2019). The type, Paecilomyces lilacinus is a ubiquitous, saprobic filamentous fungus often isolated from soil, decaying vegetation, insects, nematodes and laboratory air (as contaminant), and is a cause of infection in man and other vertebrates (Perdomo et al. 2013, Quandt et al. 2014). In addition, it also can colonize material such as catheters and plastic implants and can contaminate antiseptic creams and lotions (Castro et al. 1990, Orth et al. 1996, Itin et al. 1998).

Purpureocillium lilacinum (Thom) Luangsa-ard, Houbraken, Hywel-Jones \& Samson, FEMS Microbiol. Lett. 321(2): 144 (2011)

Fig. 64

Facesoffungi number: FoF 06185

Saprobic on decaying on submerged decaying wood of Bruguiera sp. Sexual morph: Undetermined. Asexual morph: Hyphomycetous. Colonies scattered, black, upright, with abundant, mostly single, sometimes in pairs or multiple, erect synnemata, visible as aerial mycelium on host surface, with cylindrical, dark brown to black stipes, surrounded by hyaline, watery conidial masses. Conidiophores $650-800 \mathrm{~mm}$ in length, growing from the host surface, very long, consisting of a stipe, irregularly branched, hyaline to light brown and smooth-walled, generally verticillate, in multiple whorls, with swollen apex, with 3-4 phialides per branch, septate. Phialides up to 10-12 $\mu \mathrm{m}$ long, with a cylindrical basal portion tapering into a distinct neck. Conidiogenous cells in several whorls, cylindrical to subulate, straight or sometimes slightly curved phialidic, sometimes with percurrent proliferations. Conidia $4.5-6 \times 1.5-2.8 \mu \mathrm{m}(\overline{\mathrm{x}}=5 \times$ $2.2 \mu \mathrm{m} ; \mathrm{n}=20$ ), ) cylindrical to ovoid, with rounded apices and subtruncate to truncate bases, aseptate, hyaline, smooth-walled, in slimy heads.

Culture characteristics - Colonies on seawater MEA fast growing, attaining a diameter of 25$35 \mathrm{~mm}$ after 7 days at $25^{\circ} \mathrm{C}$, consisting of a dense basal felt of numerous conidiophores giving a powdery texture, pale vinaceous, with sparse aerial mycelium, and producing a very faint yellow diffusible pigment. Reverse yellowish to vinaceous.

Material examined - THAILAND, Krabi Province, Mueang Krabi District, Khao Khram, on submerged decaying wood of Bruguiera sp. (Rhizophoraceae) wood, 30 January 2018, M.C. Dayarathne, MCD 152 (MFLU 17-2627); ibid., (HKAS102058), living culture MFLUCC 18-0403.

GenBank numbers - ITS: MN047110; BTUB: MN077052

Additional GenBank number - LSU; MN017874

Notes - Purpureocillium lilacinum has been subjected to many studies because it has biotechnological properties and ability to cause human infections (Pastor \& Guarro 2006, Fiedler \& Sosnowska 2007, van Schooneveld et al. 2008, Wessolossky et al. 2008). This species produces vinaceous colonies, erect, thick and rough-walled conidiophores with verticillate branches, phialides with a swollen basal part tapering into a long, distinct neck, and ellipsoidal to fusiform, smooth to slightly roughened conidia (Samson 1974), and acremonium-like synanamorph (Okada et al. 1995). Our new strain (MFLUCC 18-0403) phylogenetically clustered together with existing $P$. lilacinum strains and also morphologically they are similar (Fig. 63). However, some studies have reported the intraspecific genetic variability of $P$. lilacinum from different habitats (TiganoMilani et al. 1995, Inglis \& Tigano 2006). Luangsa-ard et al. (2011) later compared a large data set of $P$. lilacinum isolates from different sources and showed there was no genetic differences detected among isolates. Perdomo et al. (2013) determined the phenotypic and genetic variability of a set of clinical and environmental isolates of $P$. lilacinum and showed that $P$. lilacinum formed a well-supported phylogenetic clade with low intraspecific variability that was supported by studies of Hyde et al. (2016). Purpureocillium lilacinum is listed in Jones et al. (2015) and www. marinfungi.org and our collection is an additional record of this species from marine habitats. 


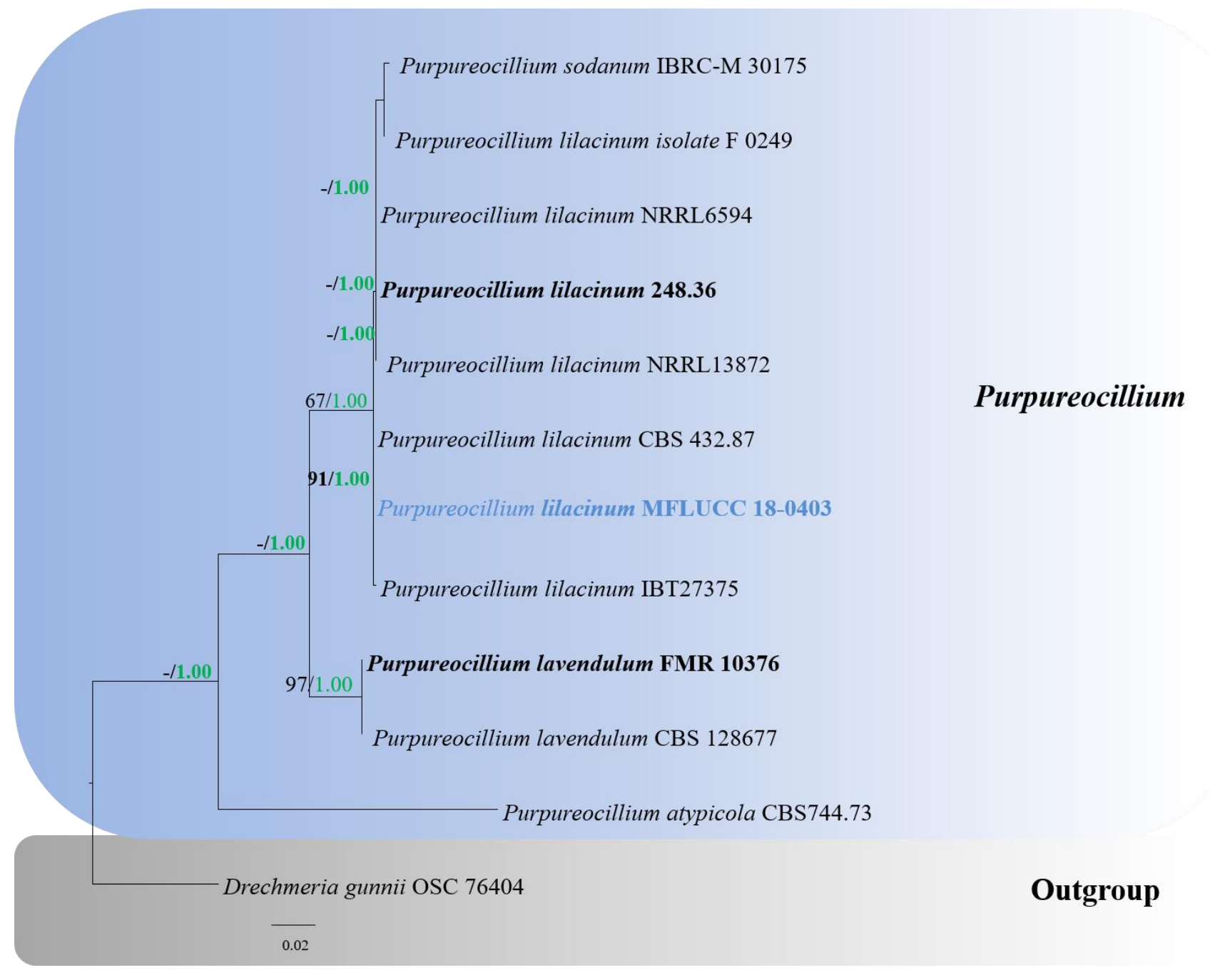

Figure 63 - Maximum likelihood analysis with 1000 bootstrap replicates yielded a best tree with the likelihood value of -16392.233800 . The combined ITS, and BTUB sequence datasets comprised 11 strains of Purpureocillium and Drechmeria gunnii (OSC 76404) as the outgroup taxon. Tree topology of the ML analysis was similar to the BI. The matrix had 145 distinct alignment patterns, with $24.03 \%$ of undetermined characters or gaps. Estimated base frequencies were as follows; $\mathrm{A}=$ $0.215906, \mathrm{C}=0.330368, \mathrm{G}=0.263083, \mathrm{~T}=0.190643$; substitution rates $\mathrm{AC}=2.021294, \mathrm{AG}=$ 3.185081, $\mathrm{AT}=1.100483, \mathrm{CG}=1.557658, \mathrm{CT}=4.402658, \mathrm{GT}=1.000000$; gamma distribution shape parameter $\alpha=0.332093$. Maximum likelihood bootstrap (ML, black) values $>65 \%$ and Bayesian posterior probabilities (PP, green) $>0.90 \%$ are given above the nodes. The scale bar indicates 0.02 changes. The ex-type strains are in bold and new isolates in blue bold.

Subclass Sordariomycetidae O.E. Erikss \& Winka (= Meliolomycetidae P.M. Kirk \& K.D. Hyde)

\section{Boliniales P.F. Cannon}

The order Boliniales, which was introduced by Cannon (Kirk et al. 2001), comprises saprobes within the subclass Sordariomycetidae. Boliniales is a monotypic order which includes a single family Boliniaceae, with nine genera (Maharachchikumbura et al. 2015, 2016, Wijayawardene et al. 2017a, 2018).

\section{Boliniaceae Rick}

The family Boliniaceae was established by Rick (1931) based on black ascostromata and cylindrical asci with smooth ascospores, and the type genus is Camarops (Karsten 1873). Initially, this family was placed in Xylariales based on morphological similarity on ascostromata and 
ascospores (Barr 1990a, Romero \& Samuels 1991). Andersson et al. (1995) showed that Boliniaceae was more closely related to Sordariales based on SSU sequence data. This family was subsequently placed in Boliniales by Kirk et al. (2001). Based on phylogenetic and morphological data nine genera were accepted in Boliniaceae (Untereiner et al. 2013, Wijayawardene et al. 2017a, 2018).

\section{Camarops P. Karst.}

The genus Camarops is characterized by applanate or flat-pulvinate stromata, with separate ostioles at the surface and very long tubular perithecia with a palisade layer of cream or brownish coloured cells (Karsten 1873, Lumbsch \& Huhndorf 2010). Camarops hypoxyloides is the type species of the genus (Karsten 1873). Currently, 30 species are listed in Index Fungorum (2019). Camarops species include members of wood-inhabiting ascomycetous fungi and represent an ecologically important fungal group with many members commonly occurring throughout temperate and tropical regions (Huhndorf \& Miller 2008, Kim et al. 2014). Camarops species have not been reported form marine environments so far. Further collections and sequences are needed to confirm this identification.

Camarops ustulinoides (Henn.) Nannf., Svensk bot. Tidskr. 66(4): 370 (1972)

Fig. 66

Facesoffungi number: FoF 06196

Saprobic on decaying wood of Rhizophora sp. Sexual morph: Stromata 8-20 $\mathrm{mm} \times 4.5-8$ $\mathrm{mm}$, button-shaped, with abrupt angular to rounded margins, bark adhering, upper surface convex to nearly plane, with punctuate ostioles with raised circular rims, externally reddish brown to blackish, internally tan to black, external stromatal layer up to $1 \mathrm{~mm}$ thick, very hard, completely encasing fragile perithecia and entostroma, entostroma cheesy to woody. Ascomata 2.5-3 $\times 0.3-0.4$ $\mathrm{mm}$, perithecial cylindrical to ellipsoidal. Asci $25-40 \mu \mathrm{m} \times 3-6 \mu \mathrm{m}(\overline{\mathrm{x}}=38.2 \times 4.8 \mu \mathrm{m}, \mathrm{n}=10), 8$ spored, overlapping uniseriate, cylindrical, short- or long-stipitate. Ascospores 3.5-5.8 $\times 2.5-3 \mu \mathrm{m}$ $(\overline{\mathrm{x}}=4.2 \times 2.6 \mu \mathrm{m}, \mathrm{n}=20)$, grayish to brown to dark brown, ellipsoidal with one end somewhat acute, mostly with two guttules, with a germ pore at the more pointed end. Asexual morph: Unknown.

Material examined - THAILAND, Prachaub Kiri Khan Province, Pranburi, Sirinath Rajini center for mangrove forest studies on decaying wood of Rhizophora sp. (Rhizophoraceae), 02 December 2016, M. C. Dayarathne, MCD 088 )MFLU 18-0561); ibid., (HKAS102093).

GenBank numbers - LSU: MN017889

Notes - Camarops ustulinoides retains its uniqueness by having brown to blackish stromata adhering to bark, elongated perithecia in section and generally raised circular rims (Kim et al. 2014). Phylogenetic analyses with LSU data showed that our novel strain MFLU 18-0561 grouped together with C. ustulinoides (SMH1988) and their LSU sequence data are identical to each other (Fig. 65). Furthermore, they share similar morphologies as well. However, C. ustulinoides was previously found from trunk of a dead oak tree in Korea (Kim et al. 2014), from Dacryodes excelsa in West Indies (Minter et al. 2001), Costa Rica, French, Guiana, and Puerto Rico (Vasilyeva et al. 2007a, Huhndorf \& Miller 2008) while our novel strain is from decaying wood of Rhizophora sp. in Thailand. This is a new geographical record for $C$. ustulinoides and the first report of $C$. ustulinoides from a marine based environment.

Chaetosphaeriales Huhndorf et al.

Based on molecular analysis of LSU nrDNA sequence data Huhndorf et al. (2004) introduced the order Chaetosphaeriales. This order comprises four families: Chaetosphaeriaceae with 38 genera, Helminthosphaeriaceae with eight genera Leptosporellaceae with one genus and Linocarpaceae with two genera (Wijayawardene et al. 2017a, 2018). 

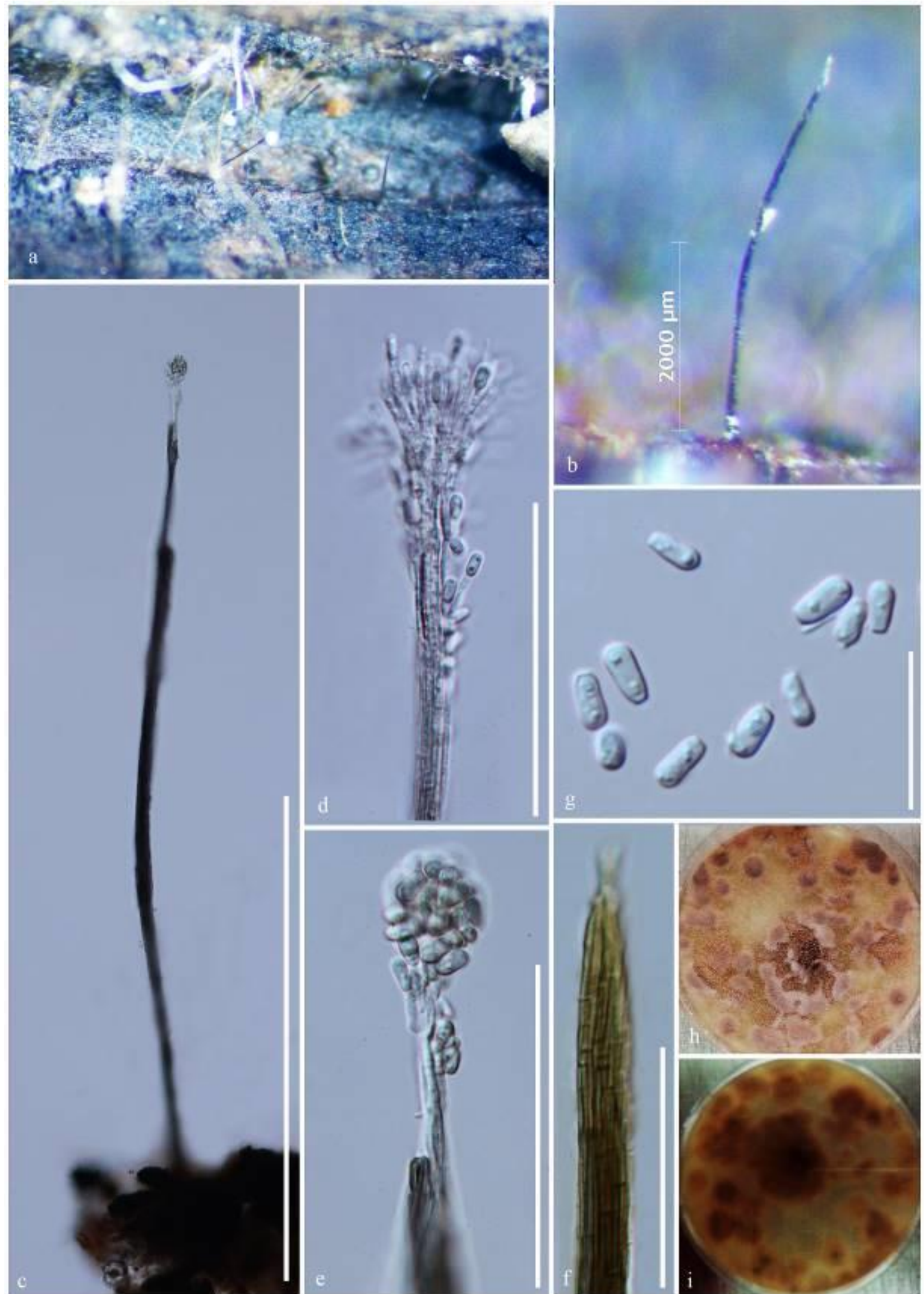

Figure 64 - Purpureocillium lilacinum (MFLU 17-2627). a-c Conidiophores on host substrate. d, e Conidia attached to the phialides. $f$ Erect synnematouse conidiophores. g Conidia. $h$, i Colonies on seawater MEA. (h-upper, i-lower). Scale bars: $b, c=200 \mu \mathrm{m}, \mathrm{d}-\mathrm{f}=100 \mu \mathrm{m}, \mathrm{g}=10 \mu \mathrm{m}$. 


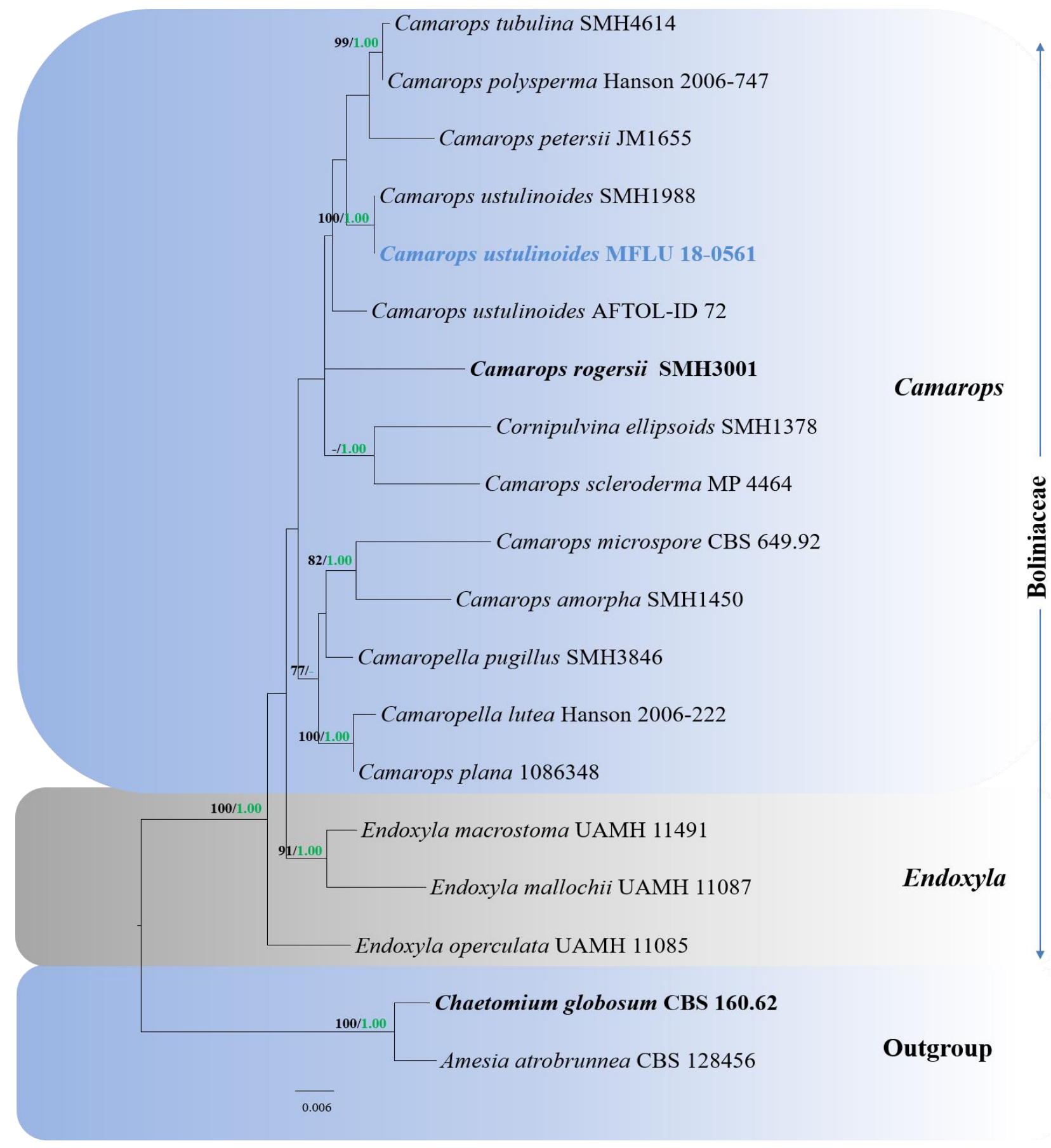

Figure 65 - Maximum likelihood analysis with 1000 bootstrap replicates yielded a best tree with the likelihood value of -2336.436167 . The combined LSU sequence datasets comprised 20 strains of Boliniales and related taxa with Amesia atrobrunnea (CBS 128456) and Chaetomium globosum (CBS160.62) as the outgroup taxa. Tree topology of the ML analysis was similar to the BI. The matrix had 134 distinct alignment patterns, with $4.39 \%$ of undetermined characters or gaps. Estimated base frequencies were as follows; $\mathrm{A}=0.252992, \mathrm{C}=0.241084, \mathrm{G}=0.312231, \mathrm{~T}=$ 0.193693; substitution rates $\mathrm{AC}=1.427241, \mathrm{AG}=2.854867, \mathrm{AT}=1.357021, \mathrm{CG}=0.907692, \mathrm{CT}$ $=16.364766$, GT $=1.000000$; gamma distribution shape parameter $\alpha=0.020000$. Maximum likelihood bootstrap (ML, black) values > 65\% and Bayesian posterior probabilities (PP, green) > $0.90 \%$ are given above the nodes. The scale bar indicates 0.006 changes. The ex-type strains are in bold and new isolates in blue bold. 

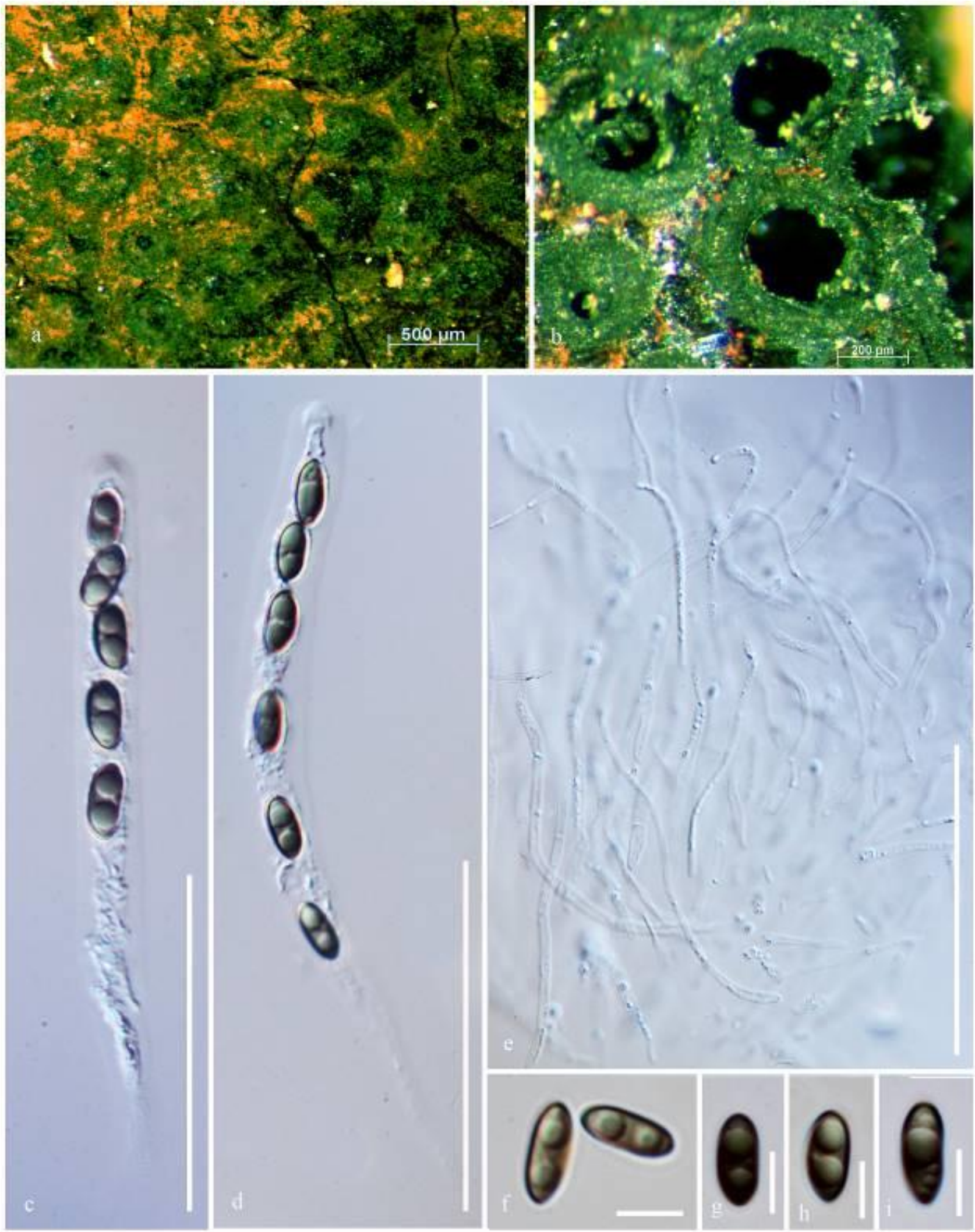

Figure 66 - Camarops ustulinoides (MFLU 18-0561). a Stromata on host tissue. b Horizontal section of ascostromata. c, d Asci. e Paraphyses. $\mathrm{f}-\mathrm{i}$ Ascospores. Scale bars: $\mathrm{a}=500 \mu \mathrm{m}, \mathrm{b}=200$ $\mu \mathrm{m}, \mathrm{c}-\mathrm{e}=20 \mu \mathrm{m}, \mathrm{f}-\mathrm{i}=2 \mu \mathrm{m}$.

Chaetosphaeriaceae Réblová et al.

Réblová et al. (1999) established the family Chaetosphaeriaceae to accommodate Chaetosphaeria (Tulasne \& Tulasne 1863). Catenularia, Cylindrotrichum, Chalara, Chloridium, 
Custingophora, Dictyochaeta, Menispora, Phialophora and Zanclospora are reported as the asexual morphs of this family (Réblová et al. 1999, Ho et al. 2001, Huhndorf et al. 2001, Fernández \& Huhndorf 2005, Fernández et al. 2006, Atkinson et al. 2007, Perera et al. 2016).

\section{Chloridium Link}

The hyphomycetous genus Chloridium, typified by Chloridium viride, is characterized by proliferating macronematous conidiophores (Link 1809). Gams \& Holubová-Jechová (1976) treated $C$. viride as a synonym of $C$. vermicularioides (syn. Melanopsammella vermicularioides) which is congeneric with M. inaequalis (type of Melanopsammella) (Réblová \& Winka 2000, Fernández et al. 2006). Réblová et al. (2016) considered Chloridium and Melanopsammella congeneric and recommended the use Chloridium over Melanopsammella. Chloridium species comprise macronematous or mononematous conidiophores, monophialidic or polyphialidic conidiogenous cells, with a distinct funnel-shaped collarette and hyaline to brown, guttulate or eguttulate conidia, with or without appendages (Seifert et al. 2011, Wei et al. 2018). Seventy-six names are currently listed under Chloridium in Index Fungorum (2019). Chloridium species have never been reported from marine habitats and herein we are introducing a novel Chloridium species from unidentified marine wood from the UK.

Chloridium salinicola Dayarathne \& E.B.G. Jones, sp. nov.

Fig. 68

Index Fungorum number: IF556603; Facesoffungi number: FoF 06197

Etymology - Epithet refers to the saline environment where the species found

Holotype - MFLU 19-1238

Saprobic on unidentified marine wood. Asexual morph: Colonies on natural substrate, effuse, thin hairy, brown. Mycelium partly superficial, partly immersed, consisting of branched, septate, smooth, thin-walled, subhyaline to pale hyphae. Stroma none. Conidiophores 100-300 $\times 5-8 \mu \mathrm{m}$ wide, macronematous, mononematous, scattered, solitary, cylindrical, robust at the base, erect, straight or slightly flexuous, unbranched, brown, fading towards the apex, septate, smooth, percurrently proliferating. Conidiogenous cells monophialidic, integrated, terminal, cylindrical, with a collarette, subhyaline to pale brown. Conidia $18-30 \times 4-6 \mu \mathrm{m}(\overline{\mathrm{x}}=20 \times 5.2 \mu \mathrm{m} ; \mathrm{n}=10)$, acrogenous, formed in slimy masses, ellipsoidal to cylindrical, hyaline, 1-septate, slightly or not constricted at the septa, smooth, thin-walled. Sexual morph: Undetermined.

Material examined - UK, Eastney, Hampshire, on unidentified marine wood, 23 January 2015, E.B Gareth Jones, GJ084 (MFLU 19-1238, holotype); ex-type living culture (MFLUCC 150382); ibid., (BBH, isotype).

GenBank numbers - LSU: MN017890, MN420685; ITS: MN047125; BTUB: MN431494

Additional GenBank number - SSU: MN017944

Notes - Phylogenetic analyses of concatenated ITS, LSU and BTUB sequences data showed that this novel strain grouped in a clade comprising Chloridium species with high statistical support (100\% ML, 1.00 PP) (Fig. 67). Chloridium salinicola shares similar morphologies of the conidiophores, conidiogenous cells and mycelial characters of Chloridium. This novel strain phylogenetically closely resembles $C$. aquaticum, but can be clearly distinguish by conidial morphology. Chloridium salinicola has 1-septate, longer conidia $(18-30 \mu \mathrm{m})$, whereas conidia of C. aquaticum are 1-celled and smaller (9-12 $\mu \mathrm{m}$ ) (Wei et al. 2018). However, only one base pair different in ITS region out of $505 \mathrm{bp}$ and there are no BTUB sequence data generated from $C$. aquaticum to compare the base pair differences.

\section{Chaetosphaeriales genera incertae sedis}

The genera, Calvolachnella, Caudatispora, Erythromada, Lasiosphaeriella, Nawawia, Marvanova and Rimaconus are currently place under Chaetosphaeriales genera incertae sedis (Wijayawardene et al. 2017a, 2018). An updated phylogentic tree to the order is provided in Fig. 69. 
Rimaconus Huhndorf, F.A. Fernández, Joanne E. Taylor \& K.D. Hyde

Huhndorf et al. (2001) introduced the genus Rimaconus to accommodate Rimaconus jamaicensis. Characteristics unique to this genus are immersed to erumpent, conical to hemispherical to applanate ascomata, unitunicate asci with a $\mathrm{J}$-, apical ring, paraphyses with gelatinous coating and cylindrical, multiseptate ascospores (Huhndorf et al. 2001). There are two species $R$. coronatus and $R$. jamaicensis listed under this genus (Index Fungorum 2019) and we introduce a third species to this genus from a marine environment.

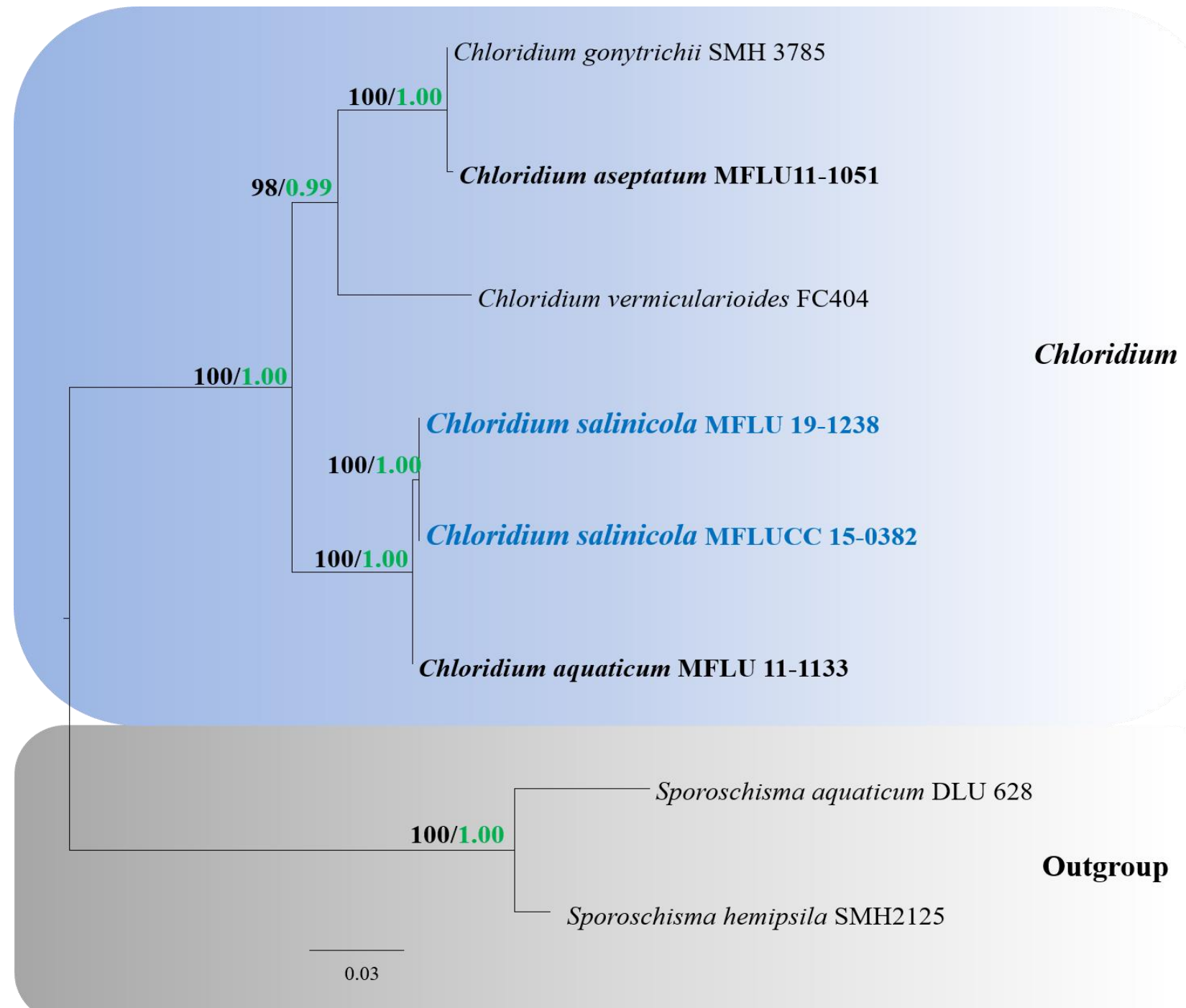

Figure 67 - Maximum likelihood analysis with 1000 bootstrap replicates yielded a best tree with the likelihood value of -4762.191078 . The combined ITS, LSU and BTUB sequence datasets comprised 8 strains of Chloridium including Sporoschisma aquaticum (DLU 628) and S. hemipsila (SMH 2125) as the outgroup taxa. Tree topology of the ML analysis was similar to the BI. The matrix had 1104 distinct alignment patterns, with $60.52 \%$ of undetermined characters or gaps. Estimated base frequencies were as follows; $\mathrm{A}=0.217480, \mathrm{C}=0.280248, \mathrm{G}=0.293417, \mathrm{~T}=$ 0.208855; substitution rates $\mathrm{AC}=0.978466, \mathrm{AG}=1.456047, \mathrm{AT}=1.060375, \mathrm{CG}=1.300170, \mathrm{CT}$ $=7.572057, \mathrm{GT}=1.000000$; gamma distribution shape parameter $\alpha=0.171569$. Maximum likelihood bootstrap (ML, black) values > 65\% and Bayesian posterior probabilities (PP, green) > $0.90 \%$ are given above the nodes. The scale bar indicates 0.03 changes. The ex-type strains are in bold and new isolates in blue bold. 

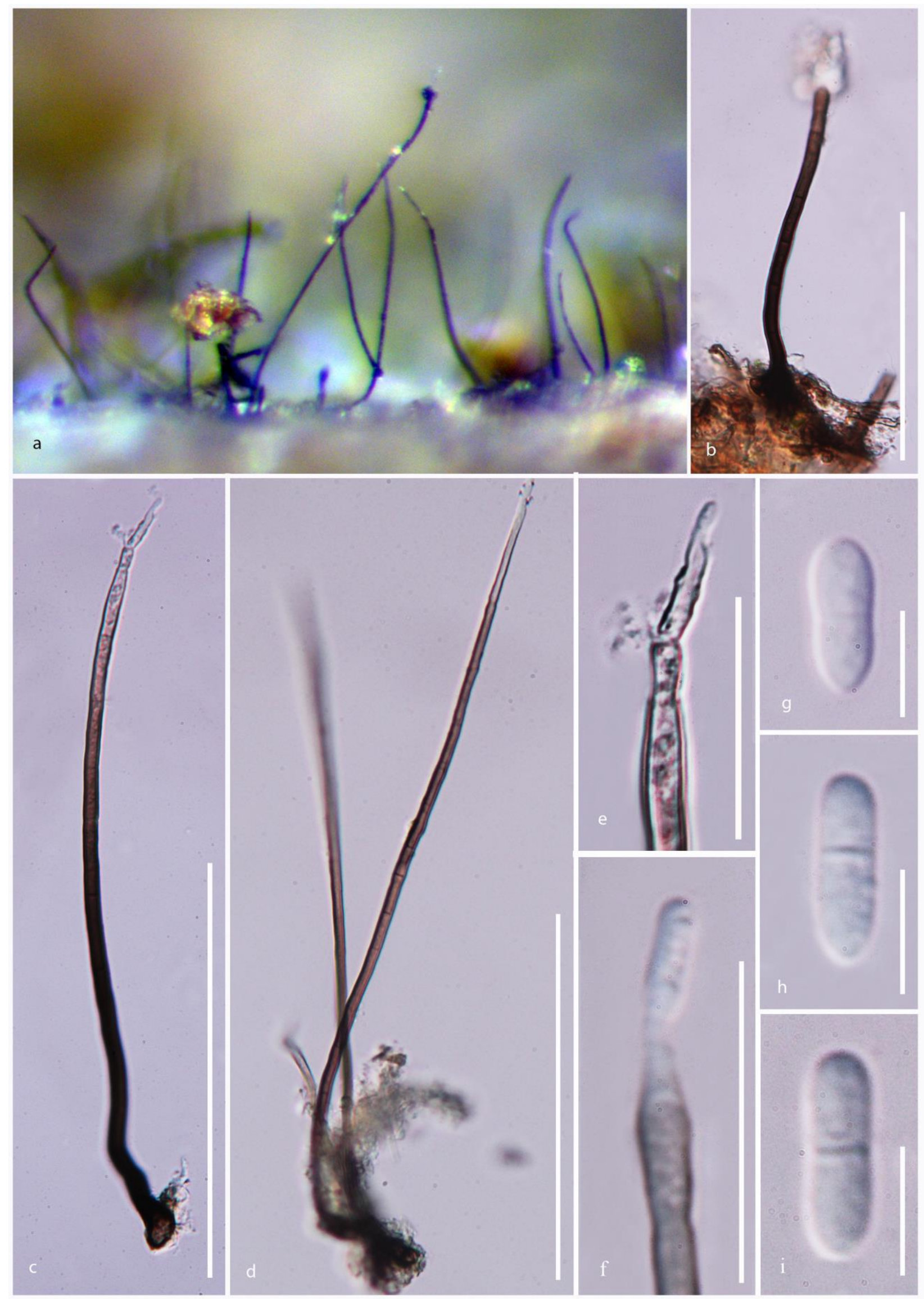

Figure 68 - Chloridium salinicola (MFLU 19-1238, holotype). a-b Colonies on substrate. c, d Conidiophore. e-f Proliferating conidiophores bearing conidia. $g-i$ Conidia. Scale bars: $b-d=100$ $\mu \mathrm{m}, \mathrm{d}, \mathrm{e}, \mathrm{f}=20 \mu \mathrm{m}, \mathrm{g}-\mathrm{i}=10 \mu \mathrm{m}$. 


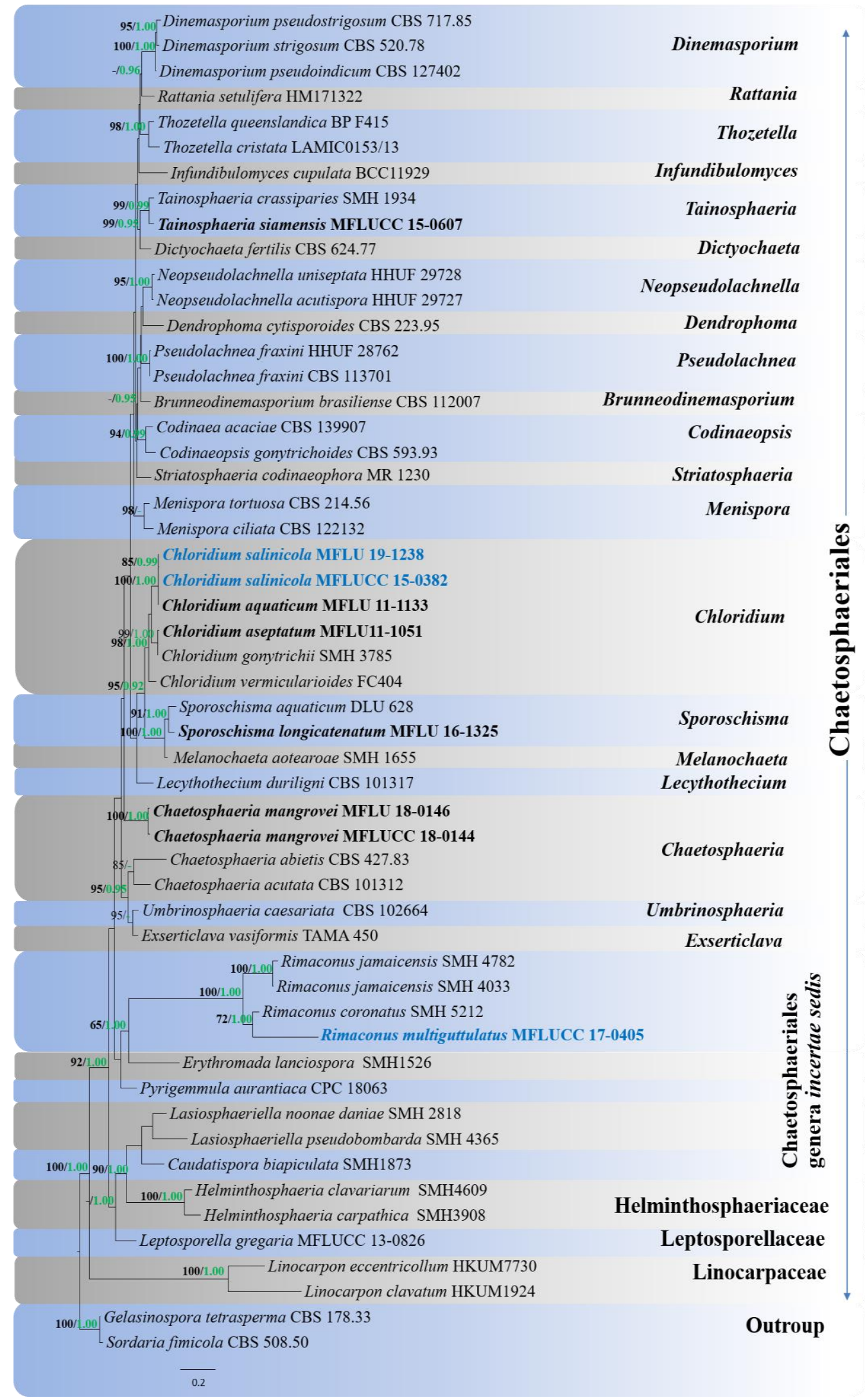

Figure 69 - Maximum likelihood analysis with 1000 bootstrap replicates yielded a best tree with the likelihood value of -13756.917492 . The combined ITS and LSU sequence datasets comprised 53 strains of Chaetosphaeriales including Gelasinospora tetrasperma (CBS 178.33) and Sordaria fimicola (CBS 508.50) as the outgroup taxa. Tree topology of the ML analysis was similar to the BI. The matrix had 1104 distinct alignment patterns, with $60.52 \%$ of undetermined characters or gaps. Estimated base frequencies were as follows; $\mathrm{A}=0.234344, \mathrm{C}=0.260336, \mathrm{G}=0.307692, \mathrm{~T}=$ 
0.197628; substitution rates $\mathrm{AC}=1.089279, \mathrm{AG}=1.587064, \mathrm{AT}=1.252250, \mathrm{CG}=0.834468, \mathrm{CT}$ $=5.520909, \mathrm{GT}=1.000000 ;$ gamma distribution shape parameter $\alpha=0.296739$. Maximum likelihood bootstrap (ML, black) values > 65\% and Bayesian posterior probabilities (PP, green) > $0.90 \%$ are given above the nodes. The scale bar indicates 0.2 changes. The ex-type strains are in bold and new isolates in blue bold.

Rimaconus multiguttulatus Dayarathne \& K.D. Hyde, sp. nov.

Fig. 70

Index Fungorum number: IF556604; Facesoffungi number: FoF 06198

Etymology - Epithet refers to the multiguttulate ascospores

Holotype - MFLU 18-0535

Saprobic on submerged wood of Bruguiera sp. Sexual morph: Ascomata 700-850 × 300-400 $\mu \mathrm{m}$, conical to applanate when young, becoming conical with coronate projections around apical rim, solitary to gregarious in small groups, immersed becoming erumpent, with fragments of host cells adherent to the wall, surface roughened, dark brown appearing black ostiolate, papillate. Peridium 120-160 $\mu \mathrm{m}$ wide, composed of several layers of dark brown cells, with coronate projections around periphery of apex. Paraphyses 2-4 $\mu \mathrm{m}$ wide, abundant, persistent, narrow, branched, with guttules, tapering towards the apex. Asci 160-175 $\times 16-22 \mu \mathrm{m}(\overline{\mathrm{x}}=165 \times 20.5 \mu \mathrm{m}$; $\mathrm{n}=10$ ), 8-spored, overlapping uni or bi seriate, cylindrical, unitunicate, apex tapered, with $\mathrm{J}$ - apical ring. Ascospores $25-42 \times 10-14 \mu \mathrm{m},(\overline{\mathrm{x}}=38 \times 12.5 \mu \mathrm{m}, \mathrm{n}=20)$, broadly fusiform to cylindrical, broadly rounded at the ends, straight or curved, symmetrical, hyaline, 3-septate, without constrictions at septa, septa evenly distributed, with small, numerous guttules, without sheath or appendages. Asexual morph: undetermined.

Culture characteristics - Reaching $2 \mathrm{~cm}$ within 7 days on sea water PDA, when incubated at $25^{\circ} \mathrm{C}$, circular, flat, with diffuse margin, white, and becoming yellowish-white, to dull yellow with age.

Material examined - THAILAND, Ranong Province, Amphoe Maung, Mu 4 Tombol Ngao, Ranong Mangrove Research Center (GPS: $9^{\circ} 43^{\prime}$ to $9^{\circ} 57^{\prime} \mathrm{N}$; $98^{\circ} 29^{\prime}$ to $98^{\circ} 39^{\prime} \mathrm{E}$ ) on decaying wood of Bruguiera sp. (Rhizophoraceae), 06 December 2016, M.C. Dayarathne, MCD 048 )MFLU 180535, holotype), ex-type living culture, MFLUCC 17-0405.

GenBank numbers - LSU: MN017891

Notes - Rimaconus multiguttulatus best fits the genus Rimaconus in having conical to applanate ascomata with coronate projections around the apical rim, persistent paraphyses, tapering towards the apex, cylindrical, unitunicate asci with tapered apex, with J- apical ring and broadly fusiform to cylindrical, 3-septate, ascospores that are broadly rounded at the ends with numerous guttules. The genus clusters with moderate support $(72 \% \mathrm{ML}, 1.00 \mathrm{PP})$ from $R$. coronatus. Ascospores of Rimaconus multiguttulatus can be easily distinguished from $R$. coronatus by its multiguttulate ascospores while in $R$. coronatus has 1-4 large guttules (Huhndorf \& Miller 2011). Furthermore, ascospores of $R$. coronatus appear elongate and narrower than $R$. multiguttulatus (7.5-9 $\mu \mathrm{m} v s$ 10-14 $\mu \mathrm{m})$ (Huhndorf \& Miller 2011). Rimaconus multiguttulatus is the first record of Rimaconus species from a marine based habitat. Their base pair differences in LSU loci (10.8\%). also indicate they are two distinct taxa.

Coniochaetales Huhndorf et al. (= Cordanales M. Hern.-Rest. \& Crous)

Coniochaetaceae Malloch \& Cain

The family Coniochaetaceae comprises two genera, Barrina and Coniochaeta. Species belonging to Coniochaetaceae are cosmopolitan in distribution and exhibiting different modes of nutrition (Samarakoon et al. 2018, Jones et al. 2019). They can be saprobes on dung, plant litter or in soil, strongly acidic water with high heavy metal concentrations and food. As well, they can be pathogenic on plants or animals, and rarely in humans in terrestrial, freshwater and marine habitats (Ramaley 1997, Weber 2002, Weber et al. 2002, Huhndorf et al. 2004, García et al. 2006, Kirk et al. 2008, Damm et al. 2010, Maharachchikumbura et al. 2015, 2016, Wijayawardene et al. 2017a, Wanasinghe et al. 2018, Jones et al. 2019). 

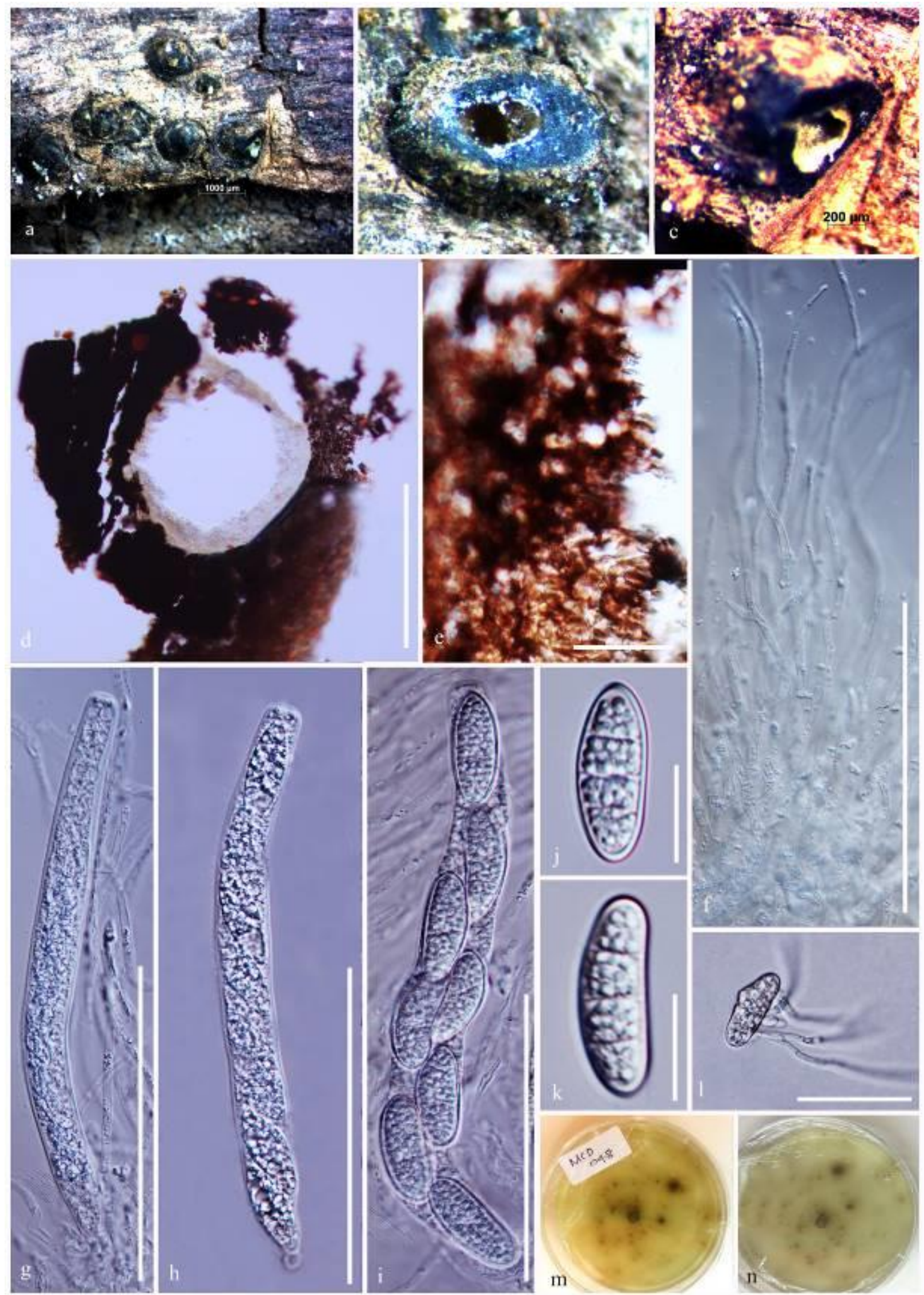

Figure 70 - Rimaconus multiguttulatus (MFLU 18-0535, holotype). a Ascomata erumpent on decaying wood. b Section of ascoma. d Peridial wall layers. e Filamentous pseudoparaphyses. $\mathrm{h}-\mathrm{i}$ Immature and mature asci. $\mathrm{k}-\mathrm{p}$ Immature and mature ascospores. q Germinating ascospore. Scale bars: $b=100 \mu \mathrm{m}, \mathrm{c}-\mathrm{q}=10 \mu \mathrm{m}$. 


\section{Coniochaeta (Sacc.) Cooke}

The genus Coniochaeta, typified by Coniochaeta ligniaria, is characterized by dark brown to black, solitary or aggregated, typically setose, pyriform to globose ascomata, with or without ostioles. The peridium is membranaceous to pseudoparenchymatous, or rarely coriaceous (Damm et al. 2010, Samarakoon et al. 2018, Jones et al. 2019). A paraphysate hamathecium is present or absent. Asci are unitunicate and thin-walled, with a small non-amyloid, apical ring and ascospores are one-celled, usually dark brown and often laterally compressed, with a germ slit (Weber 2002, Asgari et al. 2007). In this study, we introduce two novel taxa to this genus from a marine habitat.

Coniochaeta arenariae Dayarathne \& E.B.G Jones, sp. nov.

Fig. 72

Index Fungorum number: IF556606; Facesoffungi number: FoF 06200

Etymology - Epithet derived from the host epithet "arenaria"

Holotype - MFLU 19-1239

Saprobic on driftwood retrieved from the sea. Sexual morph: Ascomata 200-260 × 154-182 $\mu \mathrm{m}(\overline{\mathrm{x}}$ $=252 \times 174 \mu \mathrm{m}, \mathrm{n}=5$ ), perithecial, solitary to gregarious, non-stromatic, immersed to semiimmersed, globose, ostiolate, without setae. Ostiole central, papillate, with circular outline, lacking periphyses, filled with hyaline cells. Peridium 26-42 $\mu \mathrm{m}$ wide, brittle when dry, soft when rehydrated, two-layered. Inner layer consisting of hyaline to subhyaline, strongly compressed cells, outer layer consisting of densely packed, moderately thick-walled, brown cells of textura prismatica, darker towards outside. Hamathecium comprising numerous, 2-3 $\mu \mathrm{m}$ wide, filamentous, septate, paraphyses. Asci 130-148 $\times 12-16 \mu \mathrm{m}(\overline{\mathrm{x}}=143 \times 15.2 \mu \mathrm{m}, \mathrm{n}=20), 8$-spored, with short stipe, with a J- small apical apparatus. Ascospores $18-24 \times 9.2-10.8 \mu \mathrm{m}(\overline{\mathrm{x}}=22 \times 10$ $\mu \mathrm{m}, \mathrm{n}=30$ ), overlapping uniseriate, ellipsoid, slightly laterally compressed, hyaline at first, becoming olivaceous-brown and finally dark brown and opaque, darker in $3 \% \mathrm{KOH}$, aseptate, with a conspicuous, straight germ slit across the entire length, guttulate, without sheath or appendages. Asexual morph: Undetermined.

Material examined - UK, Carmarthenshire, Wales, Cefn Sidan, Marram grass (Ammophila arenaria) in sand dune, 15 October 2017, E.B. Gareth Jones, GJ 445b (MFLU 19-1239, holotype); ibid., (BBH, isotype), ex-type living culture MFLUCC 18-0405. SWEDEN, Bohuslän. Skaftö par., Fiskebäckskil, Rödbergsviken, $58^{\circ} 15^{\prime} 08^{\prime \prime}$; $11^{\circ} 27^{\prime} 58^{\prime \prime}$, on a large piece of driftwood retrieved from the sea, Leif Tibell, June 2017, GJ 396 (MFLU 19-1240).

GenBank numbers - LSU: MN017893, MN017896; ITS: MN047126

Notes - Coniochaeta arenariae is characteristic of Coniochaeta in its dark brown to black, pyriform ascomata with an ostiole, paraphysate, hamathecium, unitunicate, thin-walled asci with a small non-amyloid apical ring and one-celled, dark brown ascospores with a germ slit (Weber 2002, Asgari et al. 2007, Samarakoon et al. 2018). It grouped in a clade with C. tetraspora (Fig. 71). However, they are morphologically well-distinguished by ascomatal, asci and ascospore characteristics (Cain 1961). Ascomata of C. tetraspora are 135-220 × 80-190 $\mu \mathrm{m}$, superficial, pyriform, ostiolate at the apex, but without a distinct neck region, and with a hairy upper part, while ascomata of $C$. arenariae are 200-260 × 154-182 $\mu \mathrm{m}$, immersed to semi-immersed, globose, ostiolate, without setae at the upper part (Cain 1961). Asci (130-148 $\times 12-16 \mu \mathrm{m} v s$ 50-55 $\times 8-11$ $\mu \mathrm{m})$ and ascospores $(10-15 \times 6.5-8 \mu \mathrm{m} v s$ 18-24 $\times 9.2-10.8 \mu \mathrm{m})$ of $C$. arenariae are larger than those of $C$. tetraspora (Cain 1961). Furthermore, asci of $C$. tetraspora are initially eight spored and become four spored when mature (Cain 1961) and we could not observe four spored mature asci of C. arenariae. However, these species only have LSU data and only 2 base pairs different out of 456 bp $(0.4 \%)$. Depending on considerable morphological differences, we herein introduce this species as a novel taxon within the genus Coniochaeta.

Coniochaeta krabiensis Dayarathne \& E.B.G Jones, sp. nov.

Fig. 73

Index Fungorum number: IF556605; Facesoffungi number: FoF 06199

Etymology - Epithet derived from the location Krabi, Thailand, where the species found.

Holotype - MFLU 16-1230 
Saprobic on decaying submerged wood. Sexual morph: Ascomata $270-300 \times 228-250 \mu \mathrm{m}(\overline{\mathrm{x}}$ $=250 \times 230 \mu \mathrm{m}, \mathrm{n}=5$ ), perithecial, solitary to gregarious, non-stromatic, semi-immersed to superficial, pyriform, ostiolate, withot setae. Ostiole central, papillate, filled with hyaline cells. Peridium 25-35 $\mu \mathrm{m}$ wide, brittle when dry, soft when rehydrated, two-layered. Inner layer consisting of hyaline to subhyaline, strongly compressed cells, outer layer consisting of moderately thick-walled, brown cells of textura angularis, darker towards outside. Hamathecium comprising numerous, $2-3 \mu \mathrm{m}$ wide, filamentous, aseptate, paraphyses. Asci 108-122 $\times 2.8-4.7 \mu \mathrm{m}(\overline{\mathrm{x}}=110 \times$ $4 \mu \mathrm{m}, \mathrm{n}=30), 8$-spored, with short stipe, with a J- small apical apparatus. Ascospores $4.4-6.2 \times$ 2.5-3.6 $\mu \mathrm{m}(\overline{\mathrm{x}}=6 \times 3.1 \mu \mathrm{m}, \mathrm{n}=30)$, uniseriate, ellipsoid, slightly laterally compressed, hyaline at first, becoming olivaceous-brown and finally dark brown and opaque, darker in $3 \% \mathrm{KOH}$, aseptate, with a conspicuous, straight germ slit across the entire length, guttulate. Asexual morph: Undetermined.

Material examined - THAILAND, Phang-nga Province, Mueang Phang-nga District, Tham Nam Phut, 8²5'52" N, 98 31'42" E, 0 m asl., on submerged marine wood, 7 December 2014, M. C Dayarathne, KRB006 (MFLU 16-1230, holotype); ibid., (BBH, isotype).

GenBank numbers - LSU: MN017892

Additional GenBank number - SSU: MN017945

Notes - The novel taxon Coniochaeta krabiensis (MFLU 16-1230) grouped as a basal lineage in a clade comprising $C$. tetraspora (FMR 8167) and C. arenariae strains (MFLU 19-1239 and MFLU 19-1240) (Fig. 71). Coniochaeta krabiensis best fits the genus Coniochaeta by having dark brown to black, solitary or aggregated, pyriform ascomata with an ostiole, paraphysate, hamathecium, unitunicate, thin-walled asci with a small non-amyloid apical ring and one-celled, dark brown ascospores (Weber 2002, Asgari et al. 2007, Samarakoon et al. 2018). Coniochaeta krabiensis shows close phylogenetic affinities to C. tetraspora (Fig. 71). However, C. tetraspora can be clearly distinguished from $C$. krabiensis mainly by having 4-spored asci when immature and ascomata lacking setae. Furthermore, asci of $C$. krabiensis are longer and narrower than those of $C$. tetraspora $(108-122 \times 2.8-4.7 \mu \mathrm{m} v s 50-55 \times 8-11 \mu \mathrm{m})$ and ascospores of C. krabiensis are smaller than those of $C$. tetraspora $(4.4-6.2 \times 2.5-3.6 \mu \mathrm{m} v s$ 10-15 $\times 6.5-8.0 \mu \mathrm{m})$ (Cain 1961). Both concatenated ITS and LSU gene analyses along with morphological characteristics, we establish this taxon as a novel species within the genus Coniochaeta.

Subclass Xylariomycetidae O.E. Erikss \& Winka

Xylariales Nannf.

Xylariales was introduced by Nannfelt (1932) and is the largest order of perithecial ascomycetes. Familial relationships in this order have been investigated (Tang et al. 2009) and currently 34 families are accepted (Wendt et al. 2018, Daranagamaet al. 2018, Voglmayer et al. 2019).

\section{Diatrypaceae Nitschke}

Taxa in Diatrypaceae are characterized by perithecial ascomata, usually embedded in a black stroma, cylindric-clavate to clavate, long pedicellate asci and allantoid ascospores )Glawe \& Rogers 1984, Rappaz 1987, Mehrabi et al. 2015, De Almeida et al. 2016, Dayarathne et al. 2016, 2019c). Both coelomycetes (Cytosporina, Libertella) and hyphomycetes (Phaeoisaria) have been documented as asexual morphs of Diatrypaceae (Glawe \& Rogers 1984, Wijayawardene et al. 2012, 2017a, b, De Almeida et al. 2016, Mehrabi et al. 2016). Kirk et al. (2008)listed 13 genera and 229 species in Diatrypaceae, and two marine saprotrophic genera, Diatrypasimilis and Pedumispora were added to the family by Klaysuban et al. (2014)and Abdel-Wahab et al. (2014), respectively. Later, Monosporascus and Phaeoisaria, were referred to the family by Maharachchikumbura et al. (2015). However, recently Phaeoisaria has been linked to the family Pleurotheciaceae (Luo et al. 2018, Wijayawardene et al. 2018, Hyde et al. 2018). Subsequently, 
Allocryptovalsa, Halodiatrype, and Halocryptovalsa were added to the family by Senwanna et al. (2017) and Dayarathne et al. (2016, 2019c).

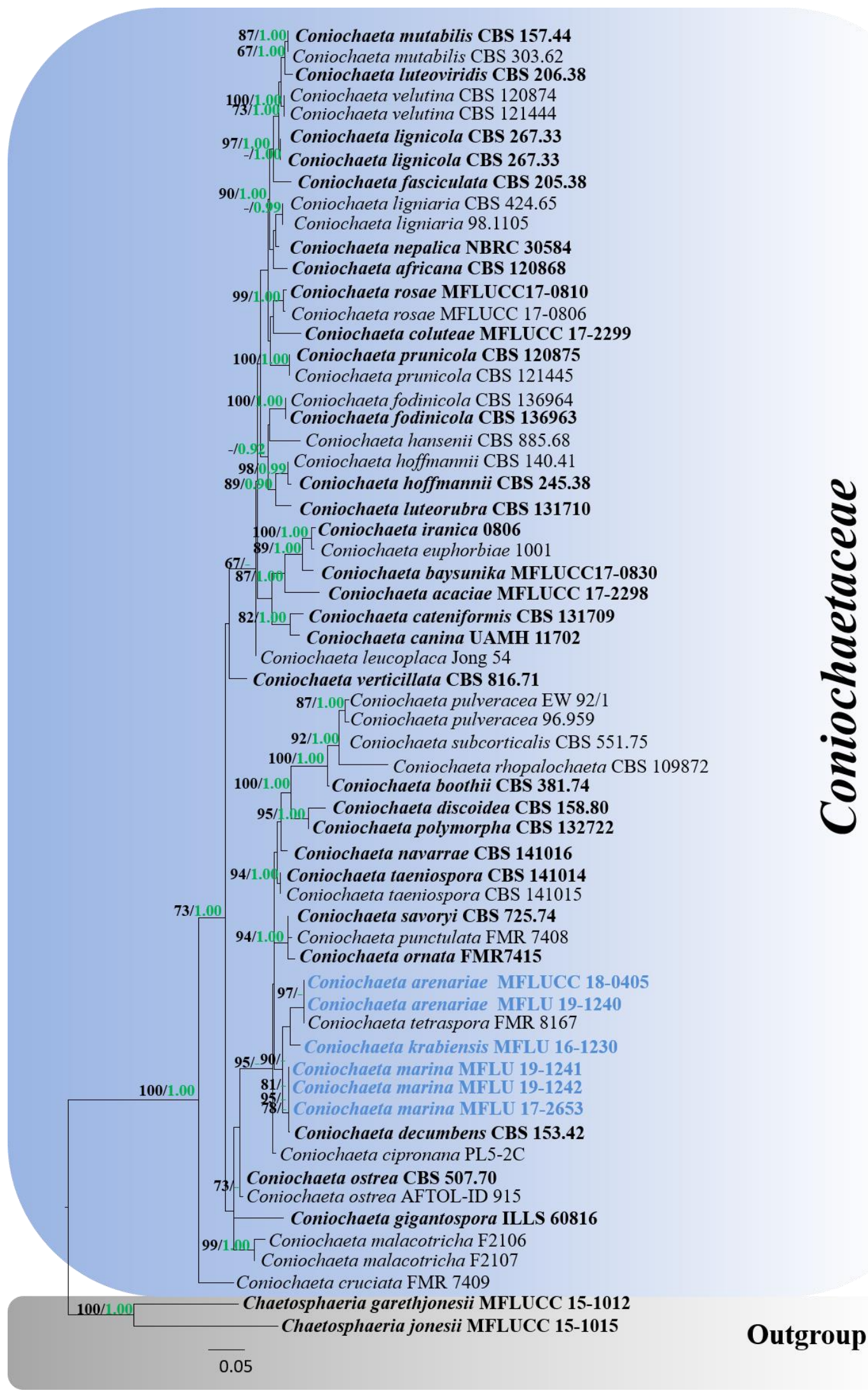

Figure 71 - Maximum likelihood analysis with 1000 bootstrap replicates yielded a best tree with the likelihood value of -6457.852038 . The combined ITS and LSU sequence datasets comprised 59 strains of Coniochaetaceae and Chaetosphaeria jonesii (MFLUCC 15-1015) and C. garethjonesii 
(MFLUCC 15-1012) (Chaetosphaeriaceae) as the outgroup taxa. Tree topology of the ML analysis was similar to the BI. The matrix had 498 distinct alignment patterns, with $32.21 \%$ of undetermined characters or gaps. Estimated base frequencies were as follows; $\mathrm{A}=0.251290, \mathrm{C}=0.238956, \mathrm{G}=$ $0.283749, \mathrm{~T}=0.226005$; substitution rates $\mathrm{AC}=1.232913, \mathrm{AG}=1.735029, \mathrm{AT}=1.048188, \mathrm{CG}=$ $1.456387, \mathrm{CT}=5.779545, \mathrm{GT}=1.000000$; gamma distribution shape parameter $\alpha=0.261744$. Maximum likelihood bootstrap (ML, black) values $>65 \%$ and Bayesian posterior probabilities (PP, green) $>0.90 \%$ are given above the nodes. The scale bar indicates 0.05 changes. The ex-type strains are in bold and new isolates in blue bold.

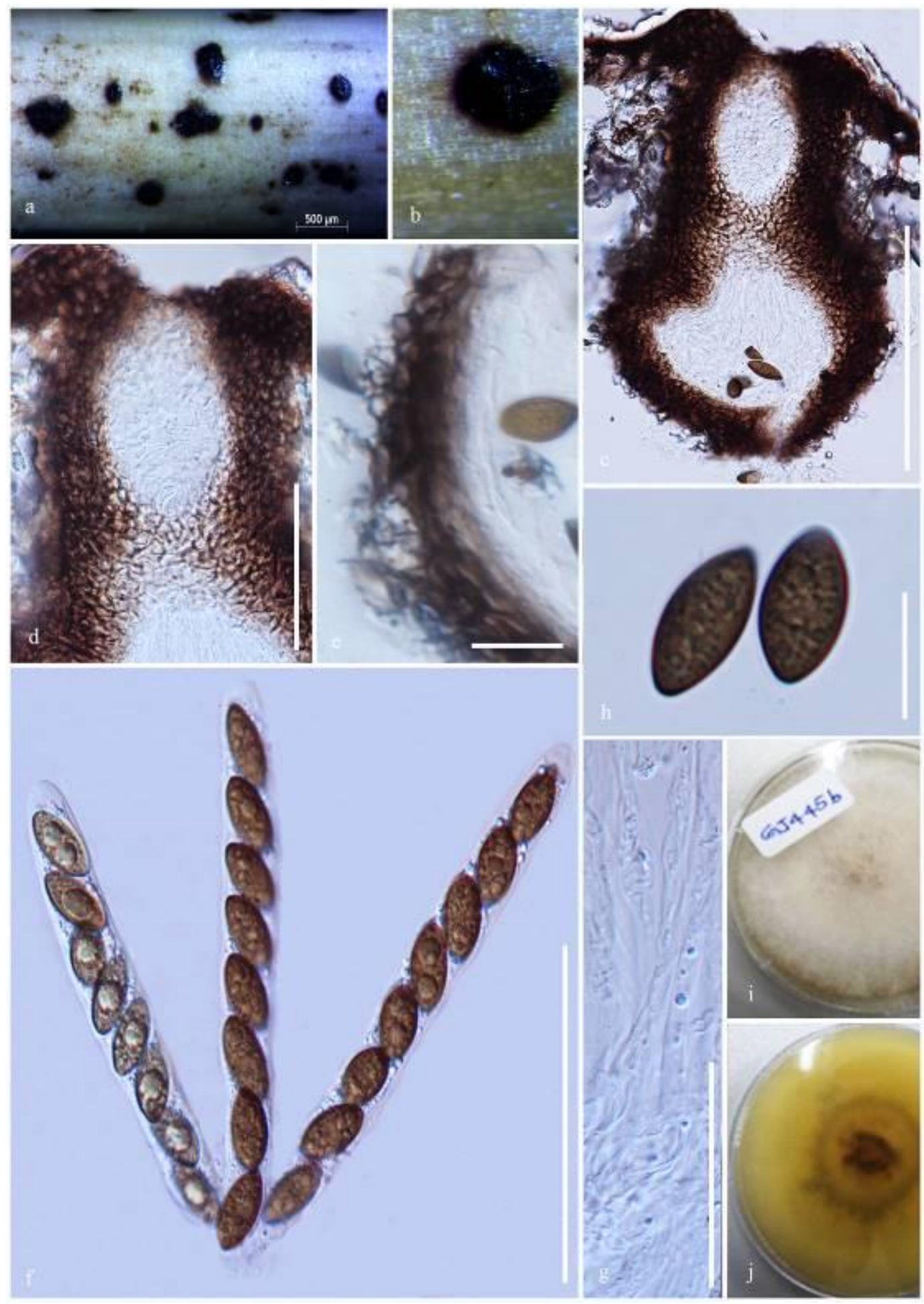

Figure 72 - Coniochaeta arenariae (MFLU 19-1239, holotype). a, b Appearance of ascomata on host. c Section through ascoma. d Section through neck region. e Peridium. f Asci. g Paraphyses. h 
Ascospores. i, $\mathrm{j}$ Cultures on PDA (i upper, $\mathrm{j}$ lower). Scale bars: $\mathrm{a}=500 \mu \mathrm{m}, \mathrm{c}, \mathrm{f},=100 \mu \mathrm{m}, \mathrm{g}=50$ $\mu \mathrm{m}, \mathrm{h}=20 \mu \mathrm{m}, \mathrm{d}, \mathrm{e}=10 \mu \mathrm{m}$.
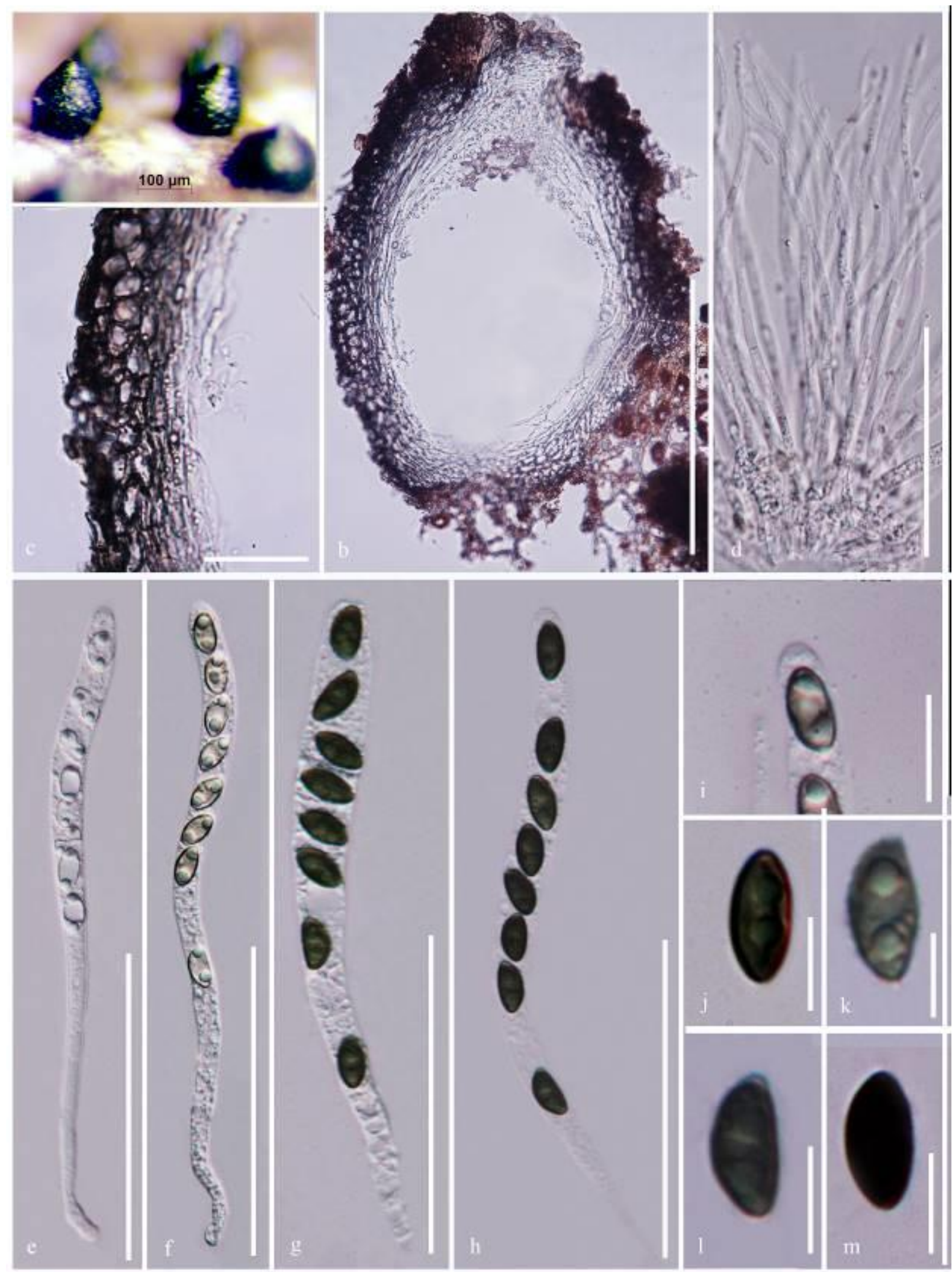

Figure 73 - Coniochaeta krabiensis (MFLU 17-2653, holotype). a Appearance of ascomata on host. b Section through ascoma. c Peridium. d Paraphyses. e- $\mathrm{h}$ Asci. i Small apical apparatus. j-m Ascospores. Scale bars: $\mathrm{a}, \mathrm{d}-\mathrm{h}=100 \mu \mathrm{m}, \mathrm{b}=200 \mu \mathrm{m}, \mathrm{c}=20 \mu \mathrm{m}, \mathrm{i}-\mathrm{m}=10 \mu \mathrm{m}$. 


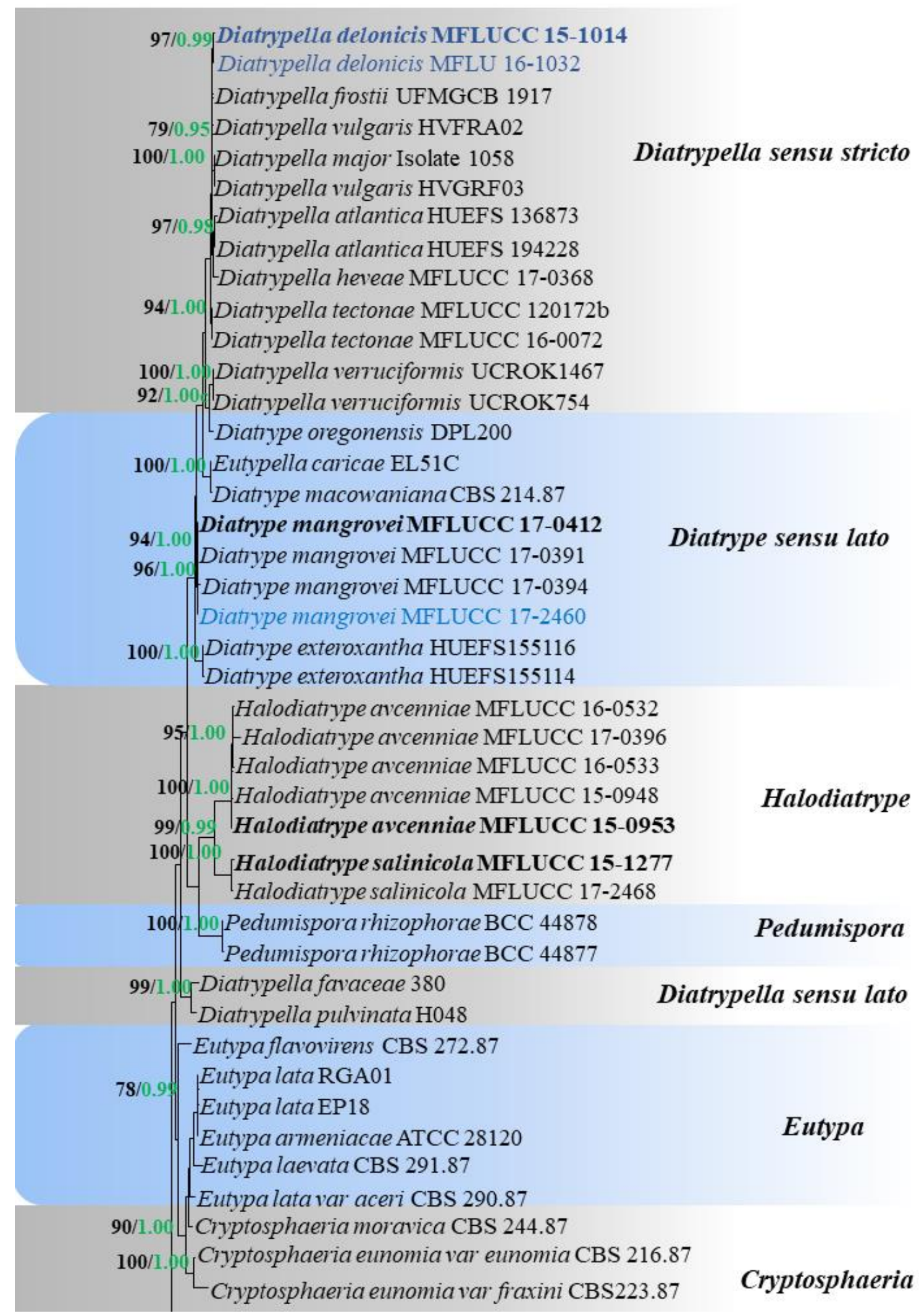

Figure 74 - Maximum likelihood analysis with 1000 bootstrap replicates yielded a best tree with the likelihood value of -16084.142687 . The combined ITS and BTUB sequence datasets comprised 103 strains of Diatrypaceae and Xylaria hypoxylon (CBS 122620) and Kretzschmaria deusta (CBS 826.72 ) as the outgroup taxa. Tree topology of the ML analysis was similar to the BI. The matrix had 702 distinct alignment patterns, with $24.50 \%$ of undetermined characters or gaps. Estimated base frequencies were as follows; $\mathrm{A}=0.224322, \mathrm{C}=0.266497, \mathrm{G}=0.234450, \mathrm{~T}=0.274732$; 
substitution rates $\mathrm{AC}=1.069126, \mathrm{AG}=2.788495, \mathrm{AT}=1.253466, \mathrm{CG}=0.904409, \mathrm{CT}=$ $3.268061, \mathrm{GT}=1.000000$; gamma distribution shape parameter $\alpha=0.488277$. Maximum likelihood bootstrap (ML, black) values > 65\% and Bayesian posterior probabilities (PP, green) > $0.90 \%$ are given above the nodes. The scale bar indicates 0.08 changes. The ex-type strains are in bold, new isolates in blue bold and new genus is in red.

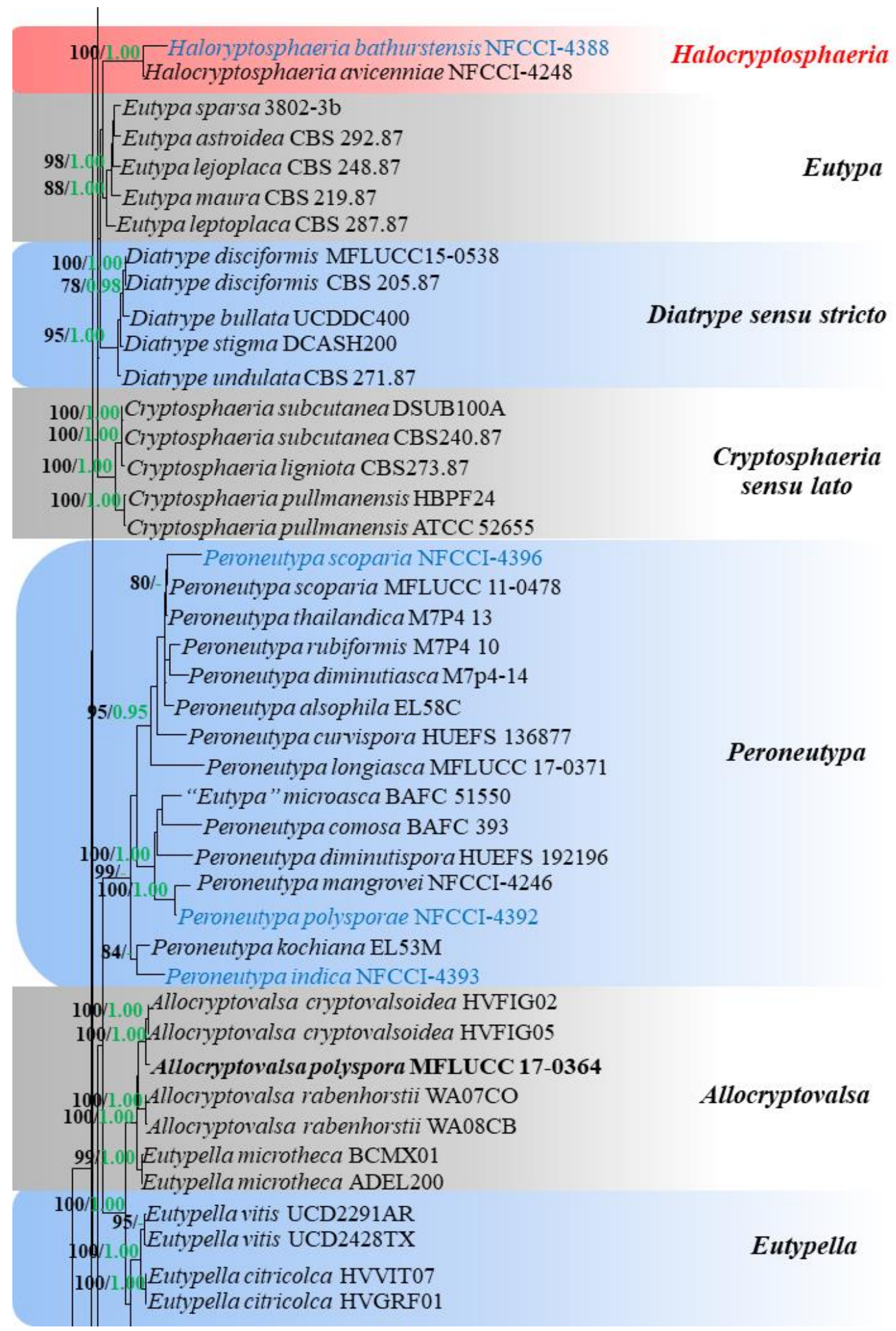

Figure 74 - Continued. 


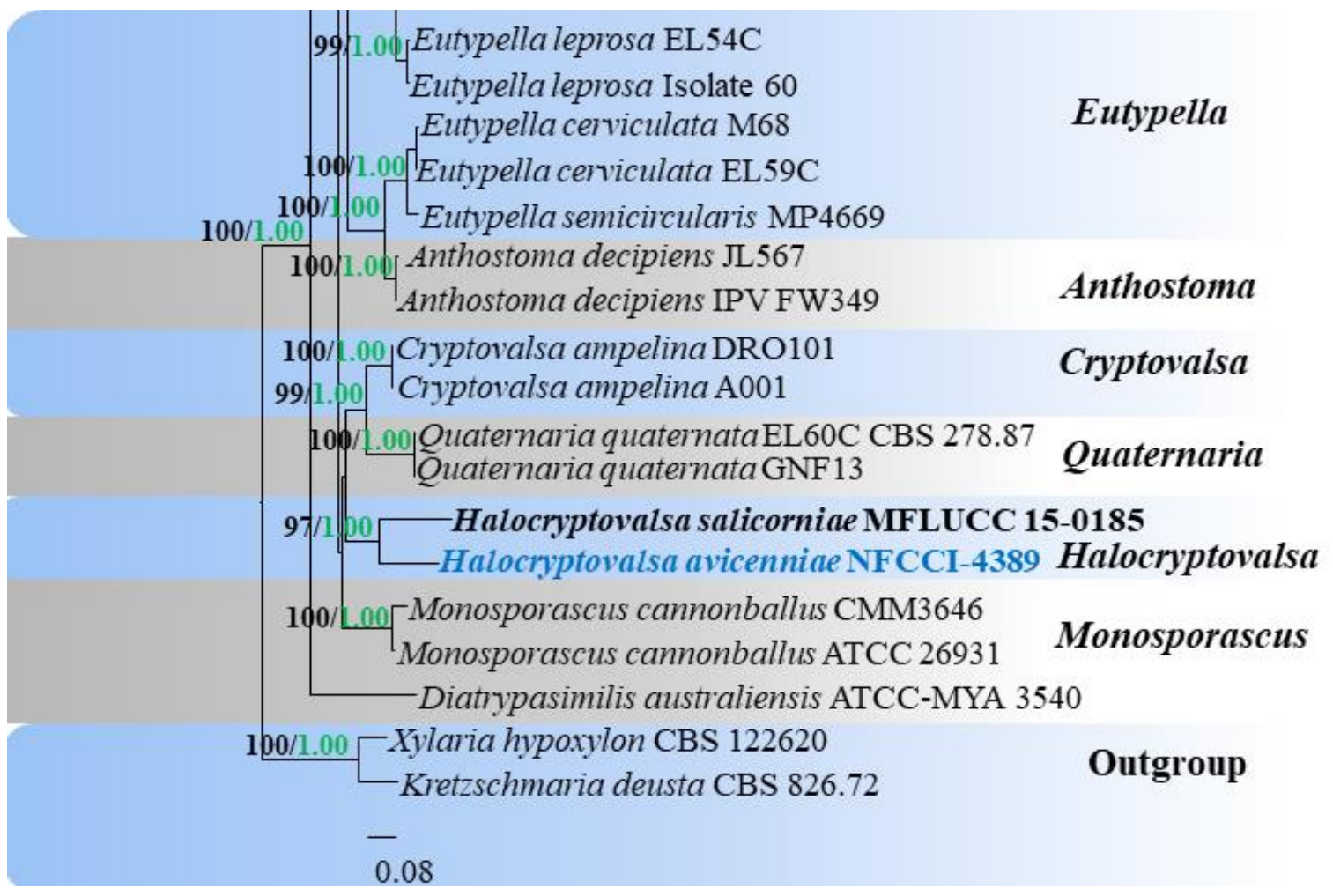

Figure 74 - Continued.

Diatrype Fr., Summa veg. Scand.

Diatrype was established by Fries (1849)with Diatrype disciformis as the type species with taxa often found on decaying wood (Dayarathne et al. 2019c). Several species are reported as canker forming pathogens on forest trees (Senanayake et al. 2015). The asexual morph of Diatrype is reported as libertella-like and dumortieria-like (Kirk et al. 2008, Wijayawardene et al. 2012, 2017b, Maharachchikumbura et al. 2015, 2016, Senanayake et al. 2015, Dayarathne et al. 2019c).Dayarathne et al. (2019c) introduced the first marine Diatrype species D. mangrovei and we provide a new host record with its asexual morph.

Diatrype mangrovei Dayarathne \& K.D. Hyde, Cryptog. Mycol. (2019)

Fig. 75

Facesoffungi number: FoF 03949

Saprobic on submerged decaying wood of Bruguiera cylindrica. Sexual morph: Ascostromata $0.9-2 \times 0.8-1 \mathrm{~cm}$, scattered or aggregated on host, erumpent, arising through cracks on the bark, edges of ascostromata remaining as pointed, angular parts, carbonaceous, with numerous perithecia immersed in one stroma. Ostiole opening through host bark and appearing as black spots, composed of an outer layer of dark brown, small, tightly packed, thin parenchymatous cells and an inner layer of yellowish white, large, loosely packed, parenchymatous cells. Ascomata $450-580 \times 310-336 \mu \mathrm{m}(\overline{\mathrm{x}}=490 \times 325 \mu \mathrm{m}, \mathrm{n}=5)$,perithecia immersed in stromatic tissue, aggregated, brown, globose to sub-globose, narrowing towards the apex and very narrow at the base of ostiolar canal, thin-walled, ostiolate; ostiolar canal, periphysate, ostiolar opening covered with carbonaceous, black cells; periphyses hyaline, filamentous. Peridium 40-42 $\mu \mathrm{m}$ wide, comprising an outer layer of yellow-brown, thick-walled cells of textura angularis and a thin, inner stratum of yellow, thick-walled cells of textura angularis. Asci $85-120 \times 6-8 \mu \mathrm{m}(\overline{\mathrm{x}}=100 \times 7.2$ $\mu \mathrm{m}, \mathrm{n}=30$ ), unitunicate, 8 -spored, with long, narrow, thin-walled stalk, with cylindrical, thickwalled, swollen upper portion, apex flat, with J-, cylindrical, conspicuous apical ring. Ascospores $5-8 \times 1.5-2.5 \mu \mathrm{m}(\overline{\mathrm{x}}=7.5 \times 2 \mu \mathrm{m}, \mathrm{n}=30)$, seriate, hyaline becoming yellowish at maturity, allantoid, unicellular, thin-walled, with small fat globules at each end, smooth-walled. Asexual morph: Conidiomata erumpent, sub-globose to globose, $200-450 \times 150-240(\overline{\mathrm{x}}=230 \times 180 \mu \mathrm{m}, \mathrm{n}$ 
$=6$ ), solitary to aggregated, deeply immersed in a stroma with the ascomata of the sexual stage, pale yellow to light brown. Peridium 15-25 thick, comprising brown, thick-walled textura angularis and pseudoparenchymatous cells merged with the host tissue. Conidiophores $25-45 \times 1-$ $2.5(\overline{\mathrm{x}}=30.5 \times 2 \mu \mathrm{m}, \mathrm{n}=10)$, aseptate, straight or curved, hyaline, rarely branched with one conidiogenous cell. Conidiogenous cells 10-25 $\times 1-2.5(\overline{\mathrm{x}}=18 \times 1.4 \mu \mathrm{m}, \mathrm{n}=10)$, cylindrical, mostly straight, discrete or integrated, arising from pseudoparenchymatous cells, hyaline, unicellular, with wide base producing conidia at the apex. Conidia $20-40 \times 0.5-1.8(\overline{\mathrm{x}}=30.2 \times 1$ $\mu \mathrm{m}, \mathrm{n}=30$ ), hyaline, numerous, filiform, straight, curved or hook like, with blunt ends.

Culture characteristics - Colonies on PDA reaching $5 \mathrm{~cm}$ diam. after 2 weeks at $20-25{ }^{\circ} \mathrm{C}$, medium dense, irregular, flat, surface smooth with undulate edge, colony from above yellow at the margin, greenish yellow at the center; from below yellowish white at the margin, greenish yellow at the center; mycelium greenish yellow, not produced pigmentation.

Material examined - THAILAND, Krabi Province, Phang Nga, on mangrove sp., 31 August 2017, M.C. Dayarathne, MCD 101 (MFLU 17-2585); ibid., (HKAS102029), living culture (MFLUCC 17-2460).

GenBank numbers - ITS: MN047112

Notes - Diatrype mangrovei was introduced by Dayarathne et al. (2019c) from intertidal attached wood of Bruguiera cylindrica from Ranong, Thailand. Our new isolate (MFLUCC 172460) grouped in a clade comprising D. mangrovei (MFLUCC 17-0412, MFLUCC 17-0391, MFLUCC 17-0394) with high statistical support (96\% ML, 1.00 PP) (Fig. 74) Furthermore, the new isolate and their ITS sequences are identical to D. mangrovei. Hence, we confirm the strain MFLUCC 17-2460 as D. mangrovei and this is the first record of this species from Rhizophora wood and collected from Krabi which expands its occurrence on a new host. Furthermore, we present the first report of the asexual morph (libertella-like) of this species.

Halocryptosphaeria Dayarathne, Devadatha, V.V. Sarma \& K.D. Hyde, gen. nov.

Index Fungorum number: IF556800; Facesoffungi number: FoF 06495

Saprobic on decaying wood of Avicennia marina. Sexual morph: Stromata immersed, blackening the wood surface. Entostroma poorly developed, dorsally limited by a black zone binding the stromatic area. Ascomata spherical to sub spherical, regularly spaced, submerged in the wood, occasionally deeply buried, long necked, raised, and blackening the wood surface. Ostiole poorly developed or conical, not sulcate. Peridium wide, comprising thin white line under the black hymenium, composed of three layers; a subhymenial layer of hyaline hyphae of textura globosaangularis mixed with ascogenous elements, a middle layer comprising guttulate hyaline cells, forming a textura globosa, an outer most layer composed of melanized cells interdispersed with wood elements, wider near the ostiolar canal. Hamathecium lining the whole cavity. Paraphyses numerous, hyaline, aseptate, persistent. Asci clavate, J-, long pedicellate. Ascospores light-brown to olive-brown, aseptate, allantoid, containing oil droplets and limited by a thin epispore, lacking sheath or appendages. Asexual morph Phomopsis like. Conidiomata immersed, sub-globose to globose, solitary to aggregated, deeply immersed in a stroma with the ascomata of the sexual stage, pale yellow to light brown, occurring on the host. Conidiomatal wall thick, comprising brown, thick-walled textura angularis and pseudoparenchymatous cells merged with the host tissue. Conidiophores lacking septa, straight or curved, hyaline, rarely branched, with one conidiogenous cell. Conidiogenous cells cylindrical, mostly straight, discrete or integrated, arising from pseudoparenchymatous cells, hyaline, unicellular, with wide base producing conidia at the apex. Conidia hyaline, numerous, filiform, straight or curved or hook-like, with blunt ends.

Type - Halocryptosphaeria bathurstensis (K.D. Hyde \& Rappaz) Dayarathne \& K.D. Hyde

Notes - Halocryptosphaeria is characterized in having poorly developed entostroma, dorsally limited by a black zone binding the stromatic area, submerged or occasionally deeply buried long necked ascomata and olive-brown, aseptate ascospores. The genus Halocryptosphaeria resembles Cryptosphaeria. Morphologically Halocryptosphaeria is distinct from Cryptosphaeria ligniota and Cryptosphaeria pulmanensis in having light-brown ascospores containing oil droplets versus pale 
yellow ascospores in the latter two, and also by occurring in a marine habitat (Rappaz 1987).
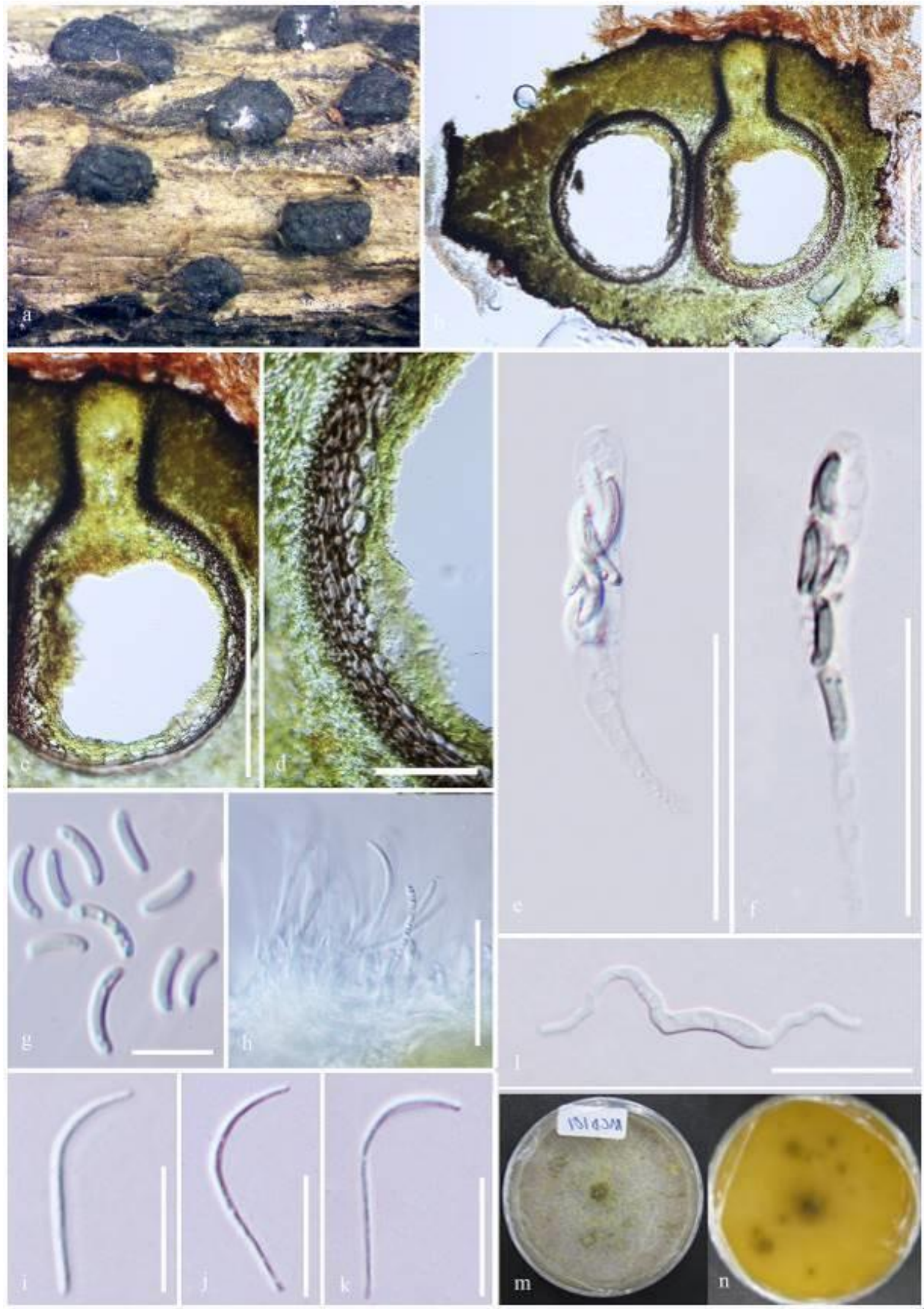

Figure 75 - Diatrype mangrovei (MFLUCC 17-2460), a Appearance of ascostromata on host. b Section through ascostromata. c Section through ascoma. d Peridium. e, f Asci. g Ascospores. $\mathrm{h}$ Conidiogenous cells and conidiophores. $\mathrm{i}-\mathrm{k}$ Conidia. 1 Germinating ascospore. $\mathrm{m}, \mathrm{n}$ Culture on 
PDA (m-upper, $\mathrm{n}$-lower). Scale bars: $\mathrm{b}=500 \mu \mathrm{m}, \mathrm{c}=200 \mu \mathrm{m}, \mathrm{e}, \mathrm{f}=100 \mu \mathrm{m}, \mathrm{d}=50 \mu \mathrm{m}, \mathrm{i}-\mathrm{k}=20$ $\mu \mathrm{m}, \mathrm{g}=5 \mu \mathrm{m}$.

The species Cryptosphaeria ligniota, Cryptosphaeria pullmanensis and Cryptosphaeria subcutanea are highly specific to host plants in Salicaceae (Populus and Salix spp.), and reported from terrestrial habitats (Rappaz 1987). Cryptosphaeria pullmanensis has oblong to reniform, occasionally septate, brown ascospores, Cryptosphaeria subcutanea has allantoid to cylindrical, brown ascospores, whereas Cryptosphaeria ligniota has allantoid pale yellow ascospores. While Cryptosphaeria ligniota and Cryptosphaeria subcutaneae have $\mathrm{J}^{+}$asci, Halocryptosphaeria species discussed in this paper have $\mathrm{J}^{-}$asci (Clement \& Shear 1931). In our phylogenetic analyses Halocryptosphaeria species formed a well-supported (100\% ML, $1.00 \mathrm{pp)}$ clade (Fig. 74). This species also resembles Halodiatrype species in lacking stromatic tissues and nature of ascospores. However, ascomta of Halodiatrype species are deeply immersed in a darkened pseudostroma while stromata of Halocryptosphaeria are immersed but blackening the wood surface with a poorly developed entostroma, which is dorsally limited by a black zone binding the stromatic area. Therefore, by considering distinct morphological characteristics and phylogenetic placement we introduce a novel genus Halocryptosphaeria to accomadate H. bathurstensis and $H$. avicenniae (=Cryptosphaeria avicenniae).

Halocryptosphaeria bathurstensis (Dayarathne \& K.D. Hyde) Dayarathne, Devadatha, V.V. Sarma \& K.D. Hyde, comb. nov. Fig. 76

E Eutypa bathurstensis K.D. Hyde \& Rappaz

Index Fungorum number: IF556801; Facesoffungi number: FoF 04597

Saprobic on decaying wood of Avicennia marina. Sexual morph: Stromata extend up to 0.5-2 $\mathrm{cm}$ long, immersed, blackening the wood surface. Entostroma poorly developed, dorsally limited by a black zone binding the stromatic area. Ascomata $250-600 \times 200-450 \mu \mathrm{m},(\overline{\mathrm{x}}=402 \times 347 \mu \mathrm{m}$, $\mathrm{n}=5$ ), spherical to sub spherical, regularly spaced, submerged in the wood, occasionally deeply buried, long necked, raised, and blackening the wood surface. Ostiole up to 60-200 $\times 60-100 \mu \mathrm{m}$ $(\overline{\mathrm{x}}=142 \times 80 \mu \mathrm{m}, \mathrm{n}=5)$, poorly developed or conical, not sulcate. Peridium $10-30 \mu \mathrm{m}(\overline{\mathrm{x}}=19 \mu \mathrm{m}$, $\mathrm{n}=5$ ), wide, comprising thin white line under the black hymenium, composed of three layers; a subhymenial layer of hyaline hyphae of textura globosa-angularis mixed with ascogenous elements, a middle layer comprising guttulate hyaline cells, forming a textura globosa, an outer most layer composed of melanized cells interdispersed with wood elements, wider near the ostiolar canal. Hamathecium lining the whole cavity. Paraphyses numerous, hyaline, aseptate, persistent. Asci $42-50 \times 5-8 \mu \mathrm{m}(\overline{\mathrm{x}}=46 \times 6 \mu \mathrm{m}, \mathrm{n}=10)$, 8-spored, clavate, J-, long pedicelate. Ascospores 5$10 \times 1-2.5 \mu \mathrm{m}(\overline{\mathrm{x}}=8 \times 1.5 \mu \mathrm{m}, \mathrm{n}=30)$, olive-brown, aseptate, allantoid, guttulate. Asexual morph Phomopsis like

Culture characteristics - Ascospores germinating on seawater agar within 24 hours, germ tubes arising from both sides of the ascospores. Colonies on MEA with moderate growth, reaching 30-50 $\mathrm{mm}$ diameter after 15 days of incubation at room temperature, white to cream, reverse pale brown, cottony, surface undulate, irregular. Culture isolated from the single ascospore remained non-sporulating even after incubation at room temperature for one month.

Material examined - INDIA, Tamil Nadu, Parangipettai mangroves $\left(11.59^{\circ} \mathrm{N} 79.5^{\circ} \mathrm{E}\right)$, on decaying wood of Avicennia marina (Acanthaceae), 23 April 2016, B. Devadatha (AMH-9952, reference specimen designated here), living culture (NFCCI-4248).

GenBank numbers - ITS: MN061366; BTUB: MN431496

Notes - Halocryptosphaeria bathurstensis (三Eutypa bathurstensis) collected from Parangipettai mangroves is morphologically similar to Halocryptosphaeria bathurstensis (三Eutypa bathurstensis) reported by Hyde \& Rappaz (1993). With strong morphological support we designate this specimen (AMH-9952) as a reference specimen for H. bathurstensis (sensu Ariyawansa et al. 2014) with the objective of providing the availability of a reliable herbarium material in good condition and corresponding molecular data for future studies. Eutypella naqsii 
resembles Halocryptosphaeria bathurstensis but clearly distinct in having small groups of ascomata and ascospores that are hyaline to pale yellow. Hence, a new combination Halocryptosphaeria bathurstensis has been introduced for Eutypa bathurstensis based on both morphological characteristics and its closer relationship in phylogenetic analysis with Cryptosphaeria by Dayarathe et al. (2019c). Halocryptosphaeria bathurstensis and H. avicenniae share identical morphological characteristics and overlapping dimensions of the ascomata and ascospores. However, H. bathurstensis is distinct from $H$. avicenniae in having longer necks, shorter asci bearing spore part and olive-brown ascospores. Furthermore, pairwise alignment comparison of ITS gene regions of $H$. bathurstensis and $H$. avicenniae resulted in a difference of $2.89 \%$ (out of $461 \mathrm{bp}$ ).

\section{Halocryptovalsa Dayarathne \& K.D. Hyde}

Halocryptovalsa was introduced by Dayarathne et al. (2019c), which includes cryptovalsalike marine based diatrypaceous fungi with poorly developed stromata that lack horizontal or vertical furrows within the ascomatal necks (Dayarathne et al. 2019c). Two species are recognized: Halocryptovalsa avicenniae and Halocryptovalsa salicorniae under this genus. ITS and BTUB sequence data has been generated for Halocryptovalsa avicenniae for the first time in this study. Our phylogenetic analyses with combined ITS and BTUB confirmed the previous inclusion of Halocryptovalsa avicenniae based only on LSU and SSU data within the genus Halocryptovalsa (Dayarathne et al. 2019c).

Halocryptovalsa avicenniae (Abdel-Wahab, Bahkali \& E.B.G. Jones) Dayarathne \& K.D. Hyde, Cryptog. Mycol. (2019)

Fig. 77

Facesoffungi number: FoF 03947

Etymology - Epithet refers to the host, Avicennia sp., on which the species was found.

Holotype - MFLU 17-2588

Saprobic on decaying wood of Avicennia marina. Sexual morph Ascomata 120-327 $\mu \mathrm{m}$ high, 150-350 $\mu \mathrm{m}$ diam. $(\overline{\mathrm{x}}=237 \times 225 \mu \mathrm{m}, \mathrm{n}=5)$, deeply immersed in a single layer of a widespreading stroma, flask-shaped, single or aggregated and sometimes confluent. Necks 100-140 $\mu \mathrm{m}$ long, 50-70 $\mu \mathrm{m}$ diam. $(\overline{\mathrm{x}}=113 \times 60 \mu \mathrm{m}, \mathrm{n}=5)$, ostiolate, periphysate with a small papilla protruding above the substrate and lacking furrows. Peridium 18-30 $\mu \mathrm{m}$ diam., $(\overline{\mathrm{x}}=23 \mu \mathrm{m}, \mathrm{n}=5)$, forming textura angularis; outer layer of small, thick-walled, melanized cells, brown to darkbrown, interspersed with cells of the substrate; and an inner layer of hyaline, elongate cells of textura angularis. Paraphyses hyaline, septate, deliquescent. Asci $100-140 \times 10-16 \mu \mathrm{m}(\overline{\mathrm{x}}=113 \times$ $12 \mu \mathrm{m}, \mathrm{n}=15)$, polysporous (128-256 ascospores per ascus), cylindric fusoid, tapering to the pedicel, tapering to the upper part to a truncate, thick ended apex, with a faint, subapical, nonamyloid ring at the base of an invagination of the ascus apex. Ascospores 4-8 $\times 1-2 \mu \mathrm{m}(\overline{\mathrm{x}}=6 \times$ $1.5 \mu \mathrm{m}, \mathrm{n}=25$ ), allantoid, unicellular, yellow-brown to brown. Asexual morph Undetermined.

Material examined - INDIA, Tamil Nadu, Parangipettai mangroves $\left(11.59^{\circ} \mathrm{N} 79.5^{\circ} \mathrm{E}\right)$, on decaying wood of Avicennia marina )Acanthaceae(, 23 April 2018, B. Devadatha, AMH-10006, living culture, NFCCI-4389.

GenBank numbers - ITS: MN062160, BTUB: MN520613

Notes - Halocryptovalsa avicenniae (三Cryptovalsa avicenniae) and its asexual morph were reported by Abdel-Wahab et al. (2017) from decayed intertidal wood of Avicennia marina from Tarut mangrove, Arabian Gulf, Saudi Arabia. Recently Dayarathne et al. (2019c) introduced Halocryptovalsa based on the combined SSU and LSU phylogenetic analyses. The $H$. avicenniae strains and $H$. salicorniae grouped together in a monophyletic clade and were distantly related to Cryptovalsa species (Dayarathne et al. 2019c). Halocryptovalsa avicenniae can be distinguished from Cryptovalsa species and other members of Diatrypaceae in having larger ascomata that lack papillial furrows and a greater number of ascospores per ascus (Abdel-Wahab et al. 2017). Our collection of Halocryptovalsa avicenniae (AMH-10006) from Parangipettai mangroves shares similar characters with $H$. avicenniae (MAW-2017a) from Tarut mangrove (Abdel-Wahab et al. 
2017). However, the former is distinct in having smaller ascomata and we did not observe the asexual morph on the host, but both share characters of overlapping asci and ascospore dimensions and occur on Avicennia marina (Abdel-Wahab et al. 2017. Furthermore, phylogenetic analysis based on LSU rDNA revealed that Halocryptovalsa avicenniae (NFCCI-4389) clustered together with $H$. avicenniae strains (MAW-2017a( in a monophyletic clade with significant support from ML 100\%. Mutli-loci phylogeny with ITS and BTUB genes showed that Halocryptovalsa avicenniae )NFCCI-4389( nested between H. salicorniae and Cryptovalsa ampelina with low bootstrap support. Halocryptovalsa avicenniae strains (MAW-2017a) lack ITS and BTUB sequences for comparison with our strain. Based on morphological and molecular data we confirm our collection of Halocryptovalsa avicenniae )NFCCI-4389( as similar to H. avicenniae strains (MAW-2017a) as reported by Abdel-Wahab et al. (2017).

Halodiatrype Dayarathne \& K.D. Hyde

Dayarathne et al. (2016) introduced the genus Halodiatrype as it differs from other genera in this family by having ascomata lacking stromatal tissues, comparatively large ascospores with septa and a libertella-like asexual morph. Generally, Diatrypaceae species have well-developed ascostromata with aseptate ascospores (Maharachchikumbura et al. 2015, Dayarathne et al. 2019c). This genus currently comprises $H$. avicenniae, $H$. mangrovei and $H$. salinicola while Dayarathne et al. (2019c) amended the generis description to include asexual morph characteristics of $H$. avicenniae. Our collection from Krabi yielded $H$. salinicola from Rhizophora sp. while the previous record was from unidentified mangrove wood (Dayarathne et al. 2016).

Halodiatrype salinicola Dayarathne \& K.D. Hyde, Mycosphere 7(5): 617 (2016)

Fig. 78

Facesoffungi number: FoF02021

Saprobic on submerged decayed wood of Rhizophora sp. Sexual morph Ascomata 120-135 $\mu \mathrm{m}$ high, 100-120 $\mu \mathrm{m}$ diam., solitary to scattered, lacking stromatic tissues, deeply immersed, dark brown to black, globose to subglobose, uni-loculate, ostiolate, papillate. Ostioles central, apex composed of brown outer amorphous layer and inner yellow cells of textura porrecta and ostiolar canal filled with periphyses. Peridium up to $2.5 \mu \mathrm{m}$ wide, thick, a single layer of amorphous fungal tissue fused with the host cells, incorporating occasionally in the host tissues. Paraphyses 2-3.5 $\mu \mathrm{m}$ wide, arising from the base of perithecia, composed of long, wide, filamentous, thin-walled cells, guttulate, unbranched, septate, slightly constricted at septum, narrow towards the apex, with apex blunt. Asci $45-50 \times 6-10 \mu \mathrm{m}(\overline{\mathrm{x}}=48 \times 7.2 \mu \mathrm{m}, \mathrm{n}=20), 8$-spored, unitunicate, clavate, long pedicellate, apically rounded, with $\mathrm{J}$ - subapical ring, initially deliquescing. Ascospores $6-8.5 \times 2-3$ $\mu \mathrm{m}(\overline{\mathrm{x}}=7.2 \times 2.4 \mu \mathrm{m}, \mathrm{n}=30)$, overlapping bi- to tetra-seriate, allantoid, light brown, aseptate, 1 septate at maturity, not constricted at the septum, smooth-walled with one to few small guttules, slightly curved. Asexual morph Undetermined.

Culture characteristics - Colonies on PDA, reaching $10 \mathrm{~cm}$ diam. after 2 weeks at $20-25^{\circ} \mathrm{C}$, medium dense, irregular, slightly raised, surface slightly rough, with uneven edge, undulate margin, cottony, colony from above: white to grey; from below: yellowish white at the margin, yellow to brown at the centre; mycelium greenish-grey, not produced pigmentation on PDA media.

Material examined - THAILAND, Krabi Province, Phang Nga, on mangrove wood, 31 August 2017, M.C. Dayarathne MCD 113 (MFLU 17-2595); ibid (HKAS102038), living culture (MFLUCC 17-2468).

GenBank numbers - ITS: MN047113

Notes - Halodiatrype salinicola introduced by Dayarathne et al. (2016) is characterized by immersed ascomata with a cylindrical or subconical, periphysate ostiole, apically rounded, clavate asci and allantoid, 0-1-septate, and light brown ascospores. Our collection (MFLU 17-2595) is morphologically similar to Halodiatrype salinicola. Comparison of ITS nucleotides between Halodiatrype avicenniae and $H$. salinicola resulted in 9.9\% (out of $532 \mathrm{bp}$ ), which reveals that both are different species. 


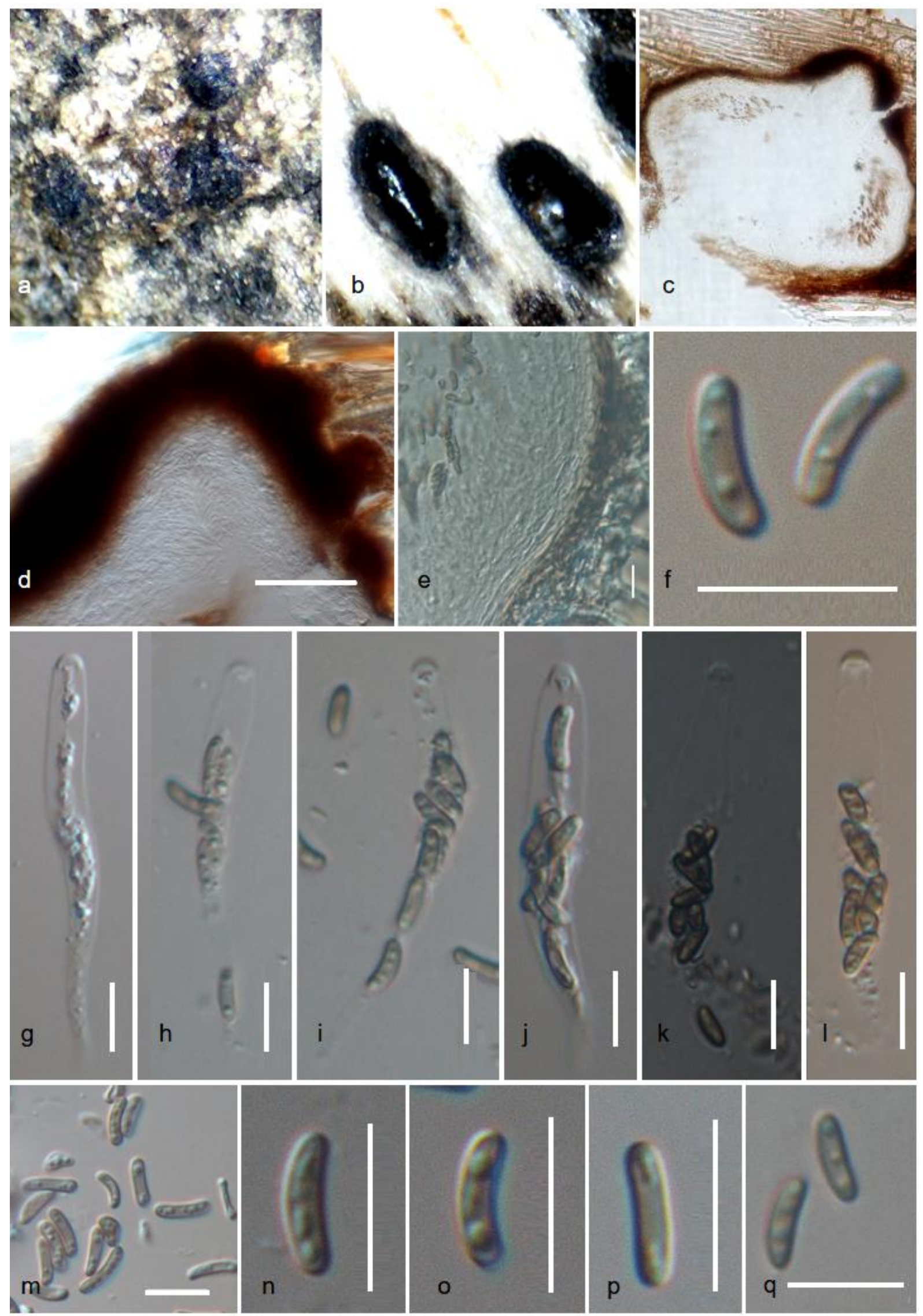

Figure 76 - Halocryptosphaeria bathurstensis (AMH-9952). a Ascomata erumpent, immersed in decaying wood of Avicennia marina. b Horizontal sections of ascoma. c Vertical section of ascoma. d Ostiole. e Peridium. g-1 Immature and mature asci. f, m-q Ascospores. Scale bars: $\mathrm{c}=100 \mu \mathrm{m}, \mathrm{d}$ $=50 \mu \mathrm{m}, \mathrm{e}-\mathrm{q}=5 \mu \mathrm{m}$. 

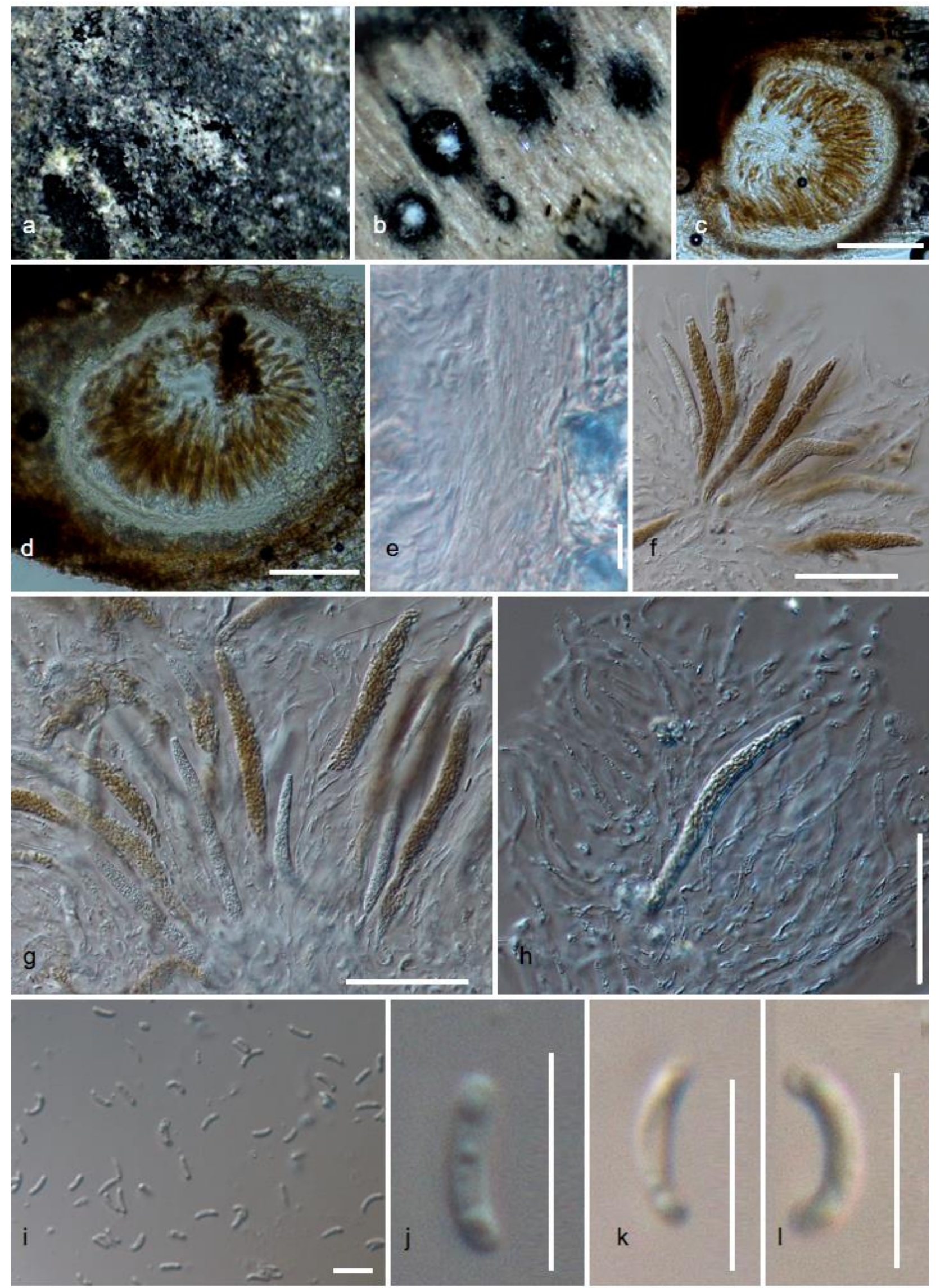

Figure 77 - Halocryptovalsa avicenniae (AMH-10006). a, b Ascomata immersed in the decaying wood. c, d Longitudinal sections of ascomata. e Section showing peridium. h Paraphyses. f-g Immature and mature asci. i-1 Ascospores. Scale bars: $\mathrm{c}-\mathrm{d}=100 \mu \mathrm{m}, \mathrm{f}-\mathrm{h}=50 \mu \mathrm{m}, \mathrm{i}-\mathrm{l}=10 \mu \mathrm{m}$. 


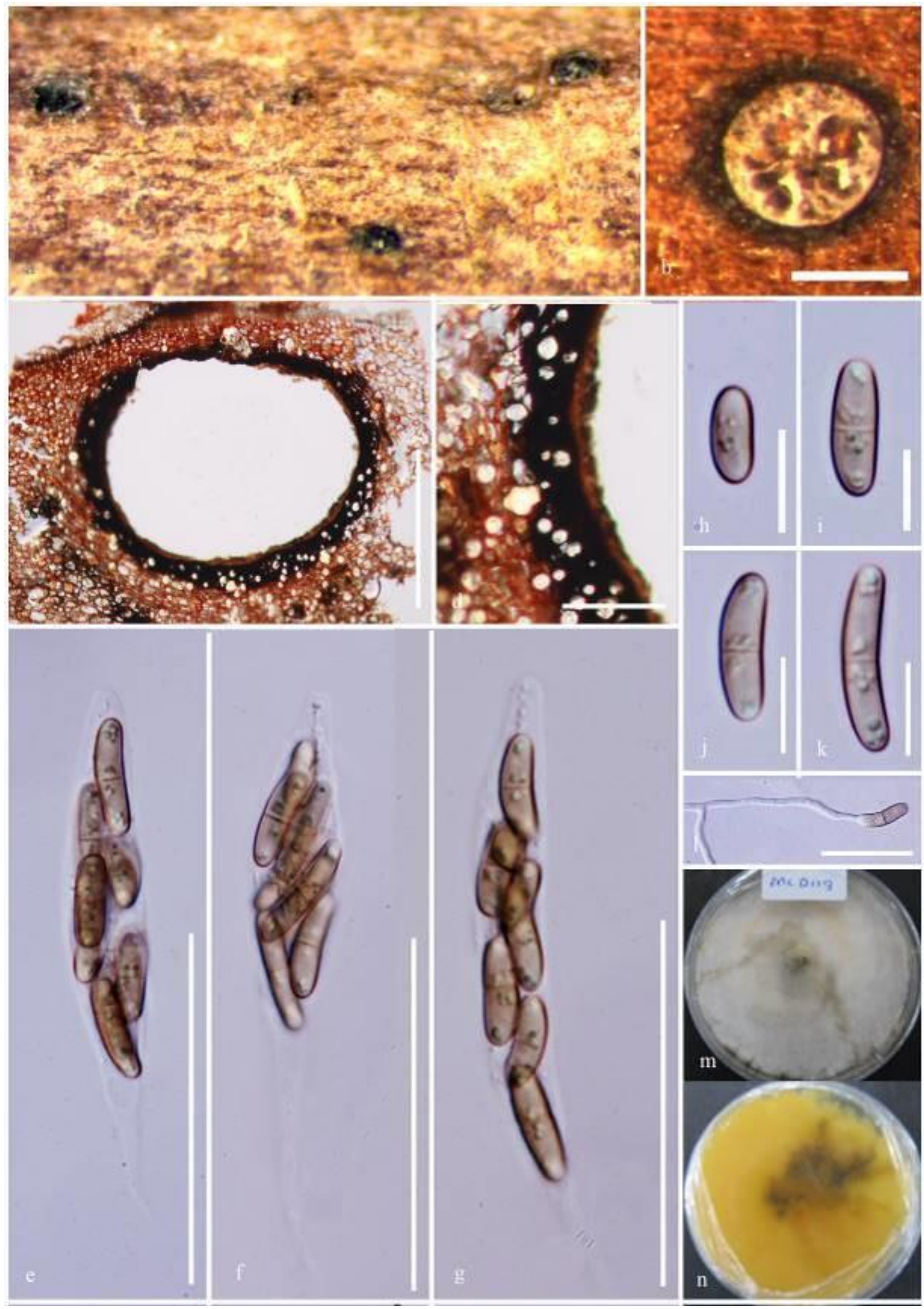

Figure 78 - Halodiatrype salinicola (MFLUCC 17-2468), a Appearance of ascomata on host. b Transverse section of ascoma on the host. c Vertical section through ascoma. d Peridium. e-g Asci. $\mathrm{h}-\mathrm{k}$ Ascospores. 1 Germinating spore. $\mathrm{m}, \mathrm{n}$ Culture on MEA $(\mathrm{m}=$ from above, $\mathrm{n}=$ from below). Scale bars: $b, c=100 \mu \mathrm{m}, \mathrm{e}-\mathrm{g}=20 \mu \mathrm{m}, \mathrm{d}, \mathrm{h}-\mathrm{k}=5 \mu \mathrm{m}$. 


\section{Peroneutypa Berl.}

Berlese (1902) introduced the genus Peroneutypa to include $P$. bellula, $P$. corniculata and $P$. heteracantha but without designating a type species. Rappaz (1987) proposed $P$. bellula as the type species and the genus was considered to be a synonym of Eutypella. However, based on morphological characteristics and phylogenetic data )Acero et al. 2004(, Peroneutypa was reinstated by Carmarán et al. (2006). The species of Peroneutypa are saprobes or pathogens and are widely distributed in terrestrial habitats and are also found in marine habitats )Lumbsch \& Huhndorf 2010, Maharachchikumbura et al. 2015, Shang et al. 2017, Hyde et al. 2019(. Peroneutypa species formed a well-supported (99\% ML) distinct clade in our phylogram (Fig. 74).

Peroneutypa scoparia (Schwein.) Carmarán \& A.I. Romero, in Carmarán, Romero \& Giussani, Fungal Diversity 23: 84 (2006)

Fig. 79

Facesoffungi number: FoF 01998

Saprobic on decaying wood of Avicennia marina. Sexual morph Stromata 1-2 cm wide, poorly developed between perithecial necks, perithecia gregarious, dark brown to black, semiimmersed to raised, erumpent through the host tissue with superficial necks. Ascomata 200-300 $\mu \mathrm{m}$ high, $150-300 \mu \mathrm{m}$ diam. $(\overline{\mathrm{x}}=257 \times 185 \mu \mathrm{m}, \mathrm{n}=10)$, immersed to erumpent, globose to sub globose, gregarious to solitary, ostiolate, with short-beaks, periphysate, brown to black. Ostiolar canals $60-100 \mu \mathrm{m}(\overline{\mathrm{x}}=75 \mu \mathrm{m}, \mathrm{n}=5)$ wide, with moderate neck length $30-60 \mu \mathrm{m}(\overline{\mathrm{x}}=45 \mu \mathrm{m}, \mathrm{n}=$ 5), cylindrical, straight, dark-brown to black. Periphyses filamentous, short, $0.5-2 \mu \mathrm{m}(\overline{\mathrm{x}}=1.5 \mu \mathrm{m}$, $\mathrm{n}=10)$. Peridium $15-35 \mu \mathrm{m}(\overline{\mathrm{x}}=22 \mu \mathrm{m}, \mathrm{n}=10)$ wide, comprising two layers, inner stratum with many layers of hyaline cells of textura angularis and outer stratum with 2-3 layers of light brown to black cells of textura angularis. Hamathecium composed of paraphyses that are $1-2 \mu \mathrm{m}(\overline{\mathrm{x}}=1$ $\mu \mathrm{m}, \mathrm{n}=20$ ) wide, filamentous, longer than asci, septate, embedded in a gelatinous matrix. Asci 19$24 \times 3-5 \mu \mathrm{m}(\overline{\mathrm{x}}=20 \times 4 \mu \mathrm{m}, \mathrm{n}=20), 8$-spored, unitunicate, cylindrical to clavate, apically rounded to truncate with a J-apical ring, short pedicellate. Ascospores $3-5 \times 1-1.5 \mu \mathrm{m}(\overline{\mathrm{x}}=4 \times 1 \mu \mathrm{m}, \mathrm{n}=$ 30 ), uniseriate to biseriately arranged, overlapping, hyaline to pale yellow, oblong to allantoid or slightly curved, aseptate, smooth-walled, with small guttules. Asexual morph Undetermined.

Culture characteristics - Colonies on MEA fast growing, reaching 50-80 mm diameter after 15 days of incubation at room temperature, white initially, becoming light grey at maturity, reverse light yellow, cottony, punctiform, flat, circular, entire.

Material examined - INDIA, Puducherry, Karaikal mangroves $\left(11.5^{\circ} \mathrm{N} 79.5^{\circ} \mathrm{E}\right)$, on submerged decaying wood of Avicennia marina (Acanthaceae), 14 April 2016, B. Devadatha (AMH-10007), living culture, NFCCI-4396

GenBank numbers - ITS: MN061369, BTUB: MN431499

Notes - Our collection (AMH-10007) shares similar morphological characters with the type of Peroneutypa scoparia such as ascomata, overlapping asci and ascospore dimensions (Carmarán et al. 2006, Shang et al. 2018). Hence, we consider our collection as $P$. scoparia, which forms the first report of this fungus from a marine habitat in India (Jones et al. 2015), as it was earlier reported from a marine habitat in Thailand (Haye et al. 2019). Peroneutypa scoparia is reported as a severe pathogen of grapevine and also produces "nasty compounds" (Helaly et al. 2018).

Peroneutypa indica Devadatha, V.V. Sarma \& E.B.G Jones, sp. nov.

Fig. 80

Index Fungorum number: IF556226; Facesoffungi number: FoF 06187

Etymology - Specific epithet in reference to the country India.

Saprobic on decaying wood of Suaeda monoica. Sexual morph: Stromata well-developed between perithecial necks, perithecia gregarious, dark brown to black, semi-immersed to raised, erumpent through the host tissue with superficial necks. Ascomata 350-600 $\mu \mathrm{m}$ high, 130-300 $\mu \mathrm{m}$ diam. $(\overline{\mathrm{x}}=375 \times 202 \mu \mathrm{m}, \mathrm{n}=10)$, erumpent to immersed, globose to sub globose, gregarious to solitary, brown to black, ostiolate, periphysate. Ostiolar canal 100-250 $\mu \mathrm{m}(\overline{\mathrm{x}}=175 \mu \mathrm{m}, \mathrm{n}=5)$ wide, with moderate neck length $100-350 \mu \mathrm{m}(\bar{x}=231 \mu \mathrm{m}, \mathrm{n}=5)$, cylindrical, straight, darkbrown to black. 

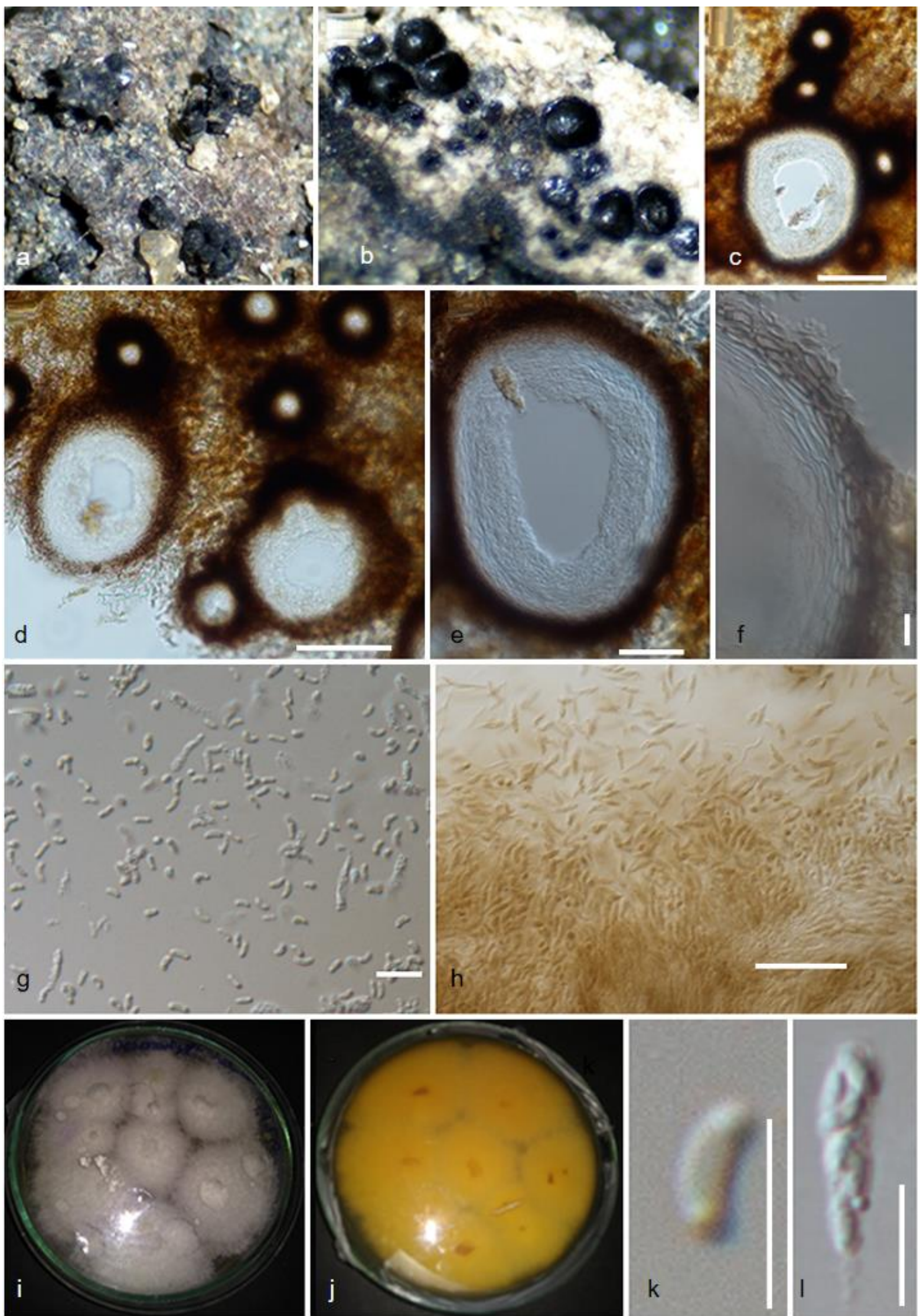

Figure 79 - Peroneutypa scoparia (AMH-10007). a, b Ascomata erumpent and semi-immersed in the decaying wood of Avicennia marina. c-e Longitudinal sections of ascomata. f Section showing peridium. h, 1 Immature and mature asci. g, k Ascospores. i-j Front and reverse view of culture. Scale bars: $\mathrm{c}-\mathrm{e}=100 \mu \mathrm{m}, \mathrm{h}=50 \mu \mathrm{m}, \mathrm{g}, \mathrm{k}-\mathrm{l}=10 \mu \mathrm{m}$. 
Peridium 15-35 $\mu \mathrm{m}(\overline{\mathrm{x}}=22 \mu \mathrm{m}, \mathrm{n}=10)$ wide, comprising two layers, inner stratum with many layers of hyaline cells of textura angularis and outer stratum with 2-3 layers of light brown to black cells of textura angularis. Hamathecium composed of paraphyses that are $1-2 \mu \mathrm{m}(\overline{\mathrm{x}}=1 \mu \mathrm{m}$, $\mathrm{n}=10)$ wide, filamentous, embedded in a gelatinous matrix. Asci 35-47 $\times 3-4 \mu \mathrm{m}(\overline{\mathrm{x}}=42 \times 3.5$ $\mu \mathrm{m}, \mathrm{n}=20$ ), 8-spored, unitunicate, cylindrical to clavate, apically rounded to truncate with a Japical ring, short pedicellate. Ascospores $4-8 \times 1-2 \mu \mathrm{m}(\overline{\mathrm{x}}=5.5 \times 1.3 \mu \mathrm{m}, \mathrm{n}=30)$, uniseriate to biseriately arranged, overlapping, hyaline, straight to allantoid, aseptate, smooth-walled, lacking guttules, light brown in mass. Asexual morph: Undetermined.

Culture characteristics - Colonies on malt extract agar fast growing, reaching $50-80 \mathrm{~mm}$ diam. after 15 days of incubation at room temperature, white initially, becoming light grey at maturity, reverse light yellow, cottony, punctiform, flat, circular, entire.

Material examined - INDIA, Tamil Nadu, Tiruvarur, Muthupet mangroves $\left(10.4^{\circ} \mathrm{N} 79.5^{\circ} \mathrm{E}\right)$, on decaying wood of Suaeda monoica )Amaranthaceae(, 28 November 2015, B. Devadatha, (AMH-10002, holotype), ex-type living culture, NFCCI-4393.

GenBank numbers - ITS: MN061368, BTUB: MN431498

Notes - Peroneutypa indica shares similar morphological characters with $P$. kochiana in having hyaline allantoid ascospores and overlapping ascospore dimensions )Carmarán et al. 2006(. However, Peroneutypa indica is distinct from P. kochiana in having longer asci (35-47vs 18-28 $\mu \mathrm{m}$ long) with J-ve apical ring and occurs in a marine habitat. Whereas Peroneutypa kochiana has shorter asci with $\mathrm{J}+$ apical rings and reported from terrestrial habitats Carmarán et al. 2006).Perneutypa species such as P. cosmosa, P. mangrovei, P. mackenziei, $P$. rubiformis and $P$. scoparia have shorter asci in contrast to $P$. Indica (Senwanna et al. 2017, Shang et al. 2017, 2018). Phylogenetic results also revealed that Peroneutypa indica clusters with $P$. kochiana in a monophyletic clade with a significant support from ML 82\%. Furthermore, a comparison of ITS nucleotides between our taxon and P. kochiana (GenBank: AJ302462) resulted in 7\% difference (out of $528 \mathrm{bp}$ ). Based on the significant support from morpho-molecular data we introduce Peroneutypa indica as a new species in Peroneutypa.

Peroneutypa polysporae Devadatha, V.V. Sarma \& E.B.G Jones, sp. nov.

Fig. 81

Index Fungorum number: IF556227; Facesoffungi number: FoF 06188

Etymology - Specific epithet in reference to polysporous asci.

Saprobic on decaying wood of Suaeda monoica. Sexual morph: Ascomata 200-430 $\mu \mathrm{m}$ high, 100$370 \mu \mathrm{m}$ diam. $(\overline{\mathrm{x}}=286 \times 223 \mu \mathrm{m}, \mathrm{n}=10)$, deeply immersed in a single layer of a wide-spreading stroma, flask-shaped, single or aggregated and sometimes confluent, ostiolate, periphysate, with a small papilla protruding above the substrate and having furrows. Ostiolar canal 130-250 $\mu \mathrm{m}$ long, 60-100 $\mu \mathrm{m}$ diam. $(\overline{\mathrm{x}}=113 \times 60 \mu \mathrm{m}, \mathrm{n}=5)$. Peridium $15-50 \mu \mathrm{m}$ diam. $(\overline{\mathrm{x}}=23 \mu \mathrm{m}, \mathrm{n}=5)$, forming textura angularis; outer layer of small, thick-walled, melanized cells, brown to dark-brown, interspersed with cells of the substrate; and an inner layer of hyaline, elongate cells of textura angularis. Hamathecium: Paraphyses hyaline, septate, deliquescent. Asci 110-155 $\times 5-7.5 \mu \mathrm{m}(\overline{\mathrm{x}}=$ $113 \times 12 \mu \mathrm{m}, \mathrm{n}=15$ ), polysporous, cylindric fusoid, tapering towards the pedicel, tapering to the upper part to a truncate, thick ended apex, with a faint, subapical, non-amyloid ring at the base of an invagination of the ascus apex. Ascospores 5-15 $\times 1-2.5 \mu \mathrm{m}(\overline{\mathrm{x}}=9 \times 1.8 \mu \mathrm{m}, \mathrm{n}=25)$, multiseriate, allantoid, unicellular, hyaline to pale yellow. Asexual morph: not observed.

Material examined - INDIA: Tamil Nadu, Tiruvarur, Muthupet mangroves ) $10.4^{\circ} \mathrm{N} 79.5^{\circ} \mathrm{E}$ ), on decaying wood of Suaeda monoica (Amaranthaceae) 28 November 2015, B. Devadatha )AMH10016, holotype(, ex-type living culture, NFCCI-4392

GenBank numbers - ITS: MN061367; BTUB: MN431497 


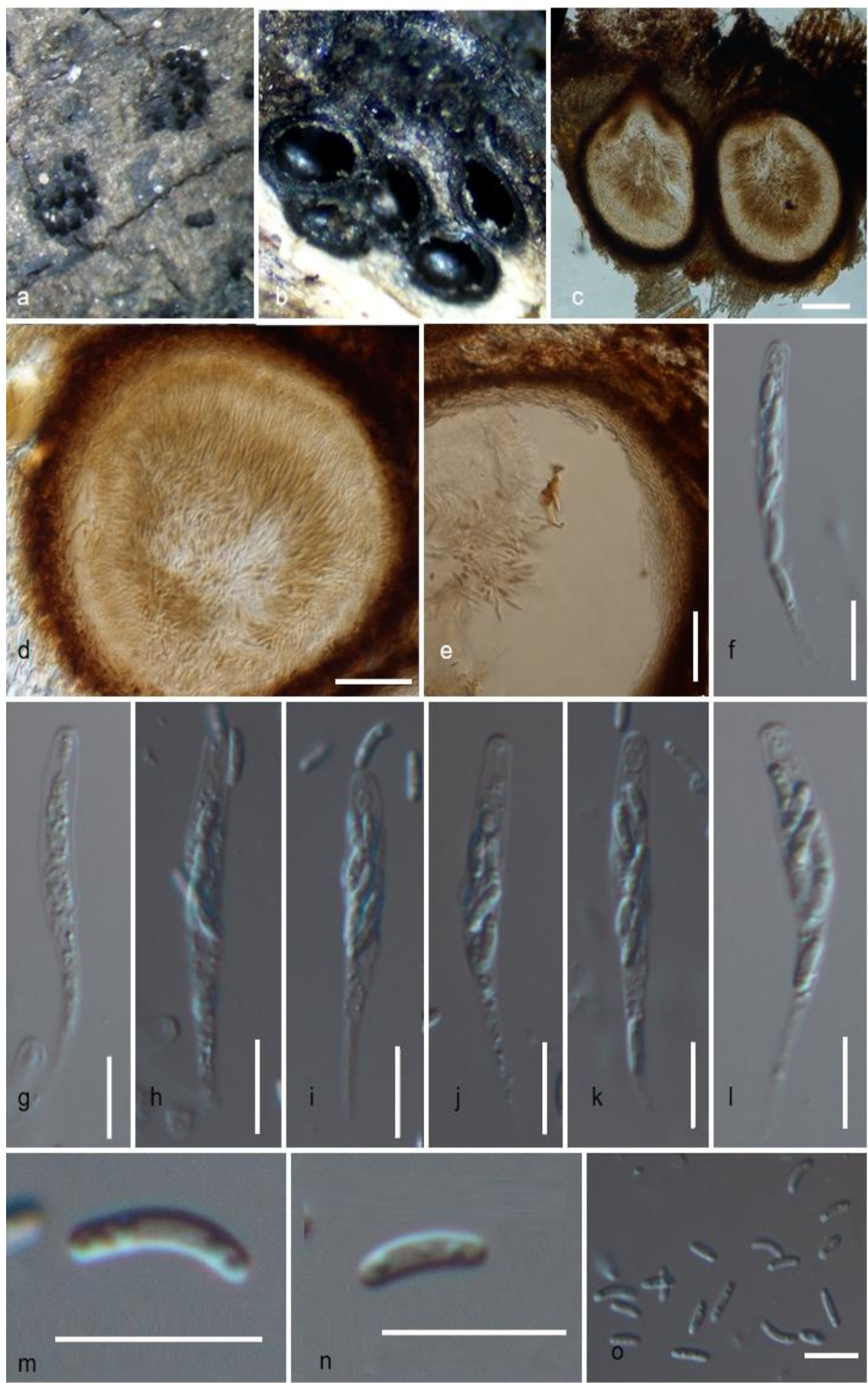

Figure 80 - Peroneutypa indica (AMH-10002, holotype). a Ascomata erumpent and semiimmersed in the decaying wood of Suaeda monoica. b-d Longitudinal sections of ascomata. e Section showing peridium. $\mathrm{f}-\mathrm{l}$ Immature and mature asci. $\mathrm{m}-\mathrm{o}$ Ascospores. Scale bars: $\mathrm{c}-\mathrm{d}=100$ $\mu \mathrm{m}, \mathrm{e}-\mathrm{O}=10 \mu \mathrm{m}$. 

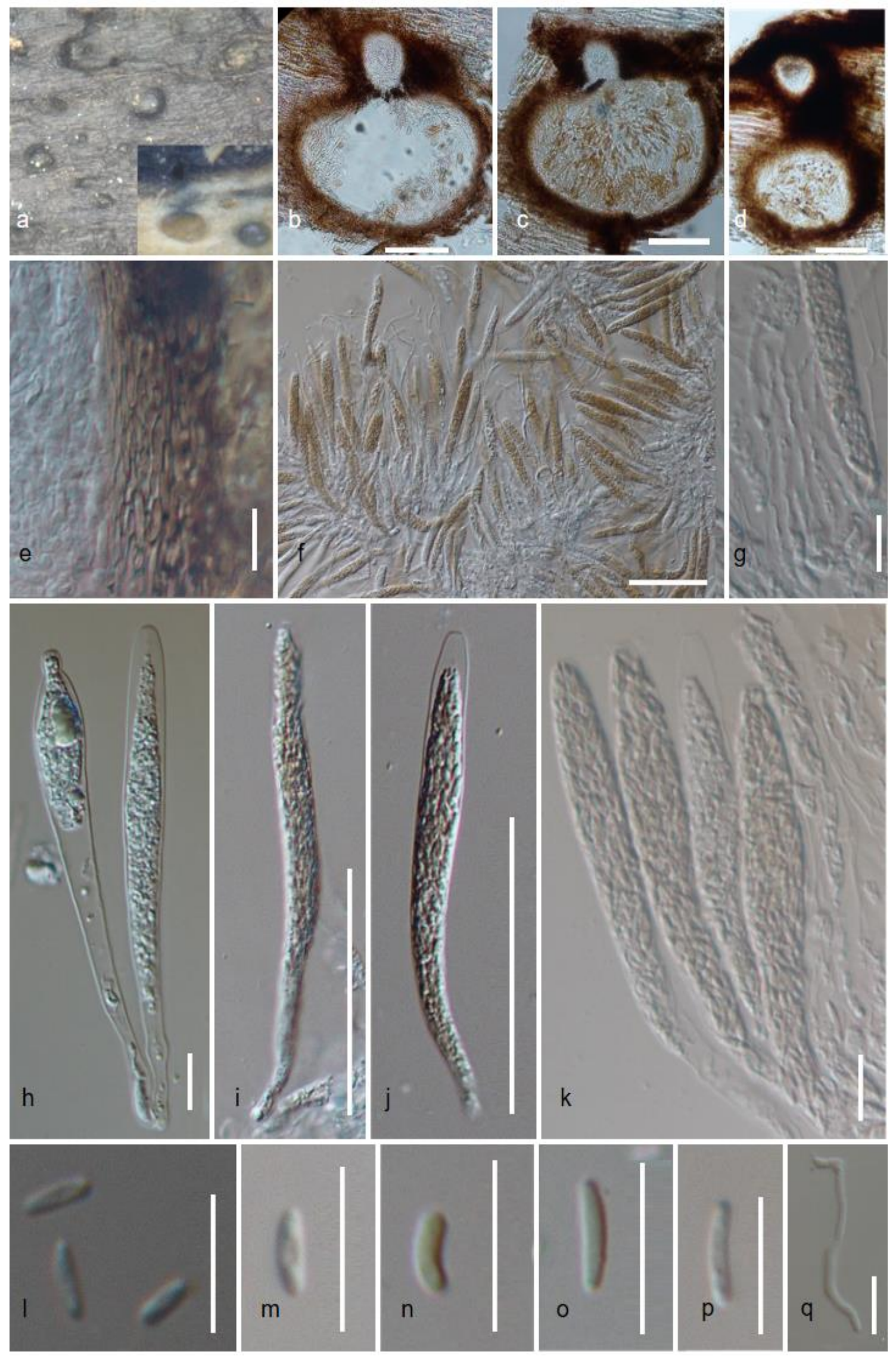

Figure 81 - Peroneutypa polysporae (AMH-10016, holotype). a Ascomata semi-immersed in the decaying wood of Suaeda monoica. b-d Longitudinal sections of ascomata. e Section showing peridium. g Paraphyses. $\mathrm{f}-\mathrm{k}$ Immature and mature asci. $\mathrm{l}-\mathrm{p}$ Ascospores. $\mathrm{q}$ Germinating ascospore. Scale bars: $b-d=100 \mu \mathrm{m}, \mathrm{f}-\mathrm{j}=50 \mu \mathrm{m}, \mathrm{h}, \mathrm{k}, \mathrm{l}-\mathrm{q}=10 \mu \mathrm{m}$. 
Notes - Peroneutypa polysporae shares similar morphological characters with Cryptovalsa suaedicola in having immersed ascomata, cylindric-fusoid, multi-spored asci and ascospores that are hyaline (Spooner 1981). However, Peroneutypa polysporae is different from Cryptovalsa suaedicola in having longer asci (110-155 vs 80-130 $\mu \mathrm{m}$ long) and ascospores (5-15 vs 4-6 $\mu \mathrm{m}$ long) (Spooner 1981). Cryptovalsa mangrovei and Halocryptovalsa avicenniae are distinguishable from Peroneutypa polysporae in having larger ascomata and yellow to brown ascospores (Inderbitzin et al. 1999). Halocryptovalsa salicorniae and Cryptovalsa halosarceicola differ from Peroneutypa polysporae in possessing smaller ascomata, asci and ascospores )Hyde 1993a(. The phylogenetic analyses based on individual LSU gene data and combined ITS and BTUB genes placed our taxon under Peroneutypa. Peroneutypa polysporae clusters with $P$. mangrovei in a monophyletic clade with a significant support from ML $100 \%$ and 1.00 PP. Furthermore, a nucleotide difference of $4.8 \%$ (out of 517 bp with gaps) was found within ITS gene region of Peroneutypa polysporae and $P$. mangrovei. Peroneutypa polysporae is distinct from $P$. mangrovei and other species of Peroneutypa in having multispored asci. Peroneutypa species usually have 8sproed asci. Interestingly, however, our Peroneutypa polysporae, though possesses polysporous asci, clustered along with other species of Peroneutypa in our multigene phylogenetic analyses thus suggesting that Peroneutypa can also accommodate taxa with polysporous asci (Shang et al. 2017, 2018). Molecular phylogenetic results also suggest that Cryptovalsa and Halocrytpovalsa are distantly related to Peroneutypa polysporae. Hence a new species, Peroneutypa polysporae is introduced in the genus Peroneutypa based on the significant support from morphology and phylogeny.

\section{Hypoxylaceae DC., in Lamarck \& de Candolle}

Hypoxylaceae, is one of the most species-rich family of Ascomycota and has also been studied intensively for their wealth of biologically active secondary metabolites (Helaly et al. 2018). Polyphasic approaches by Daranagama et al. (2018) and Wendt et al. (2018), has resulted in a more reliable classification for Hypoxylaceae, however, some genera are still unresolved (Lambert et al. 2019). At present there are 20 genera in this family (Wijayawardene et al. 2018, De Long et al. 2019, Lambert et al. 2019).

\section{Hypoxylon Bull.}

The genus Hypoxylon is one of the largest genera within the family Hypoxylaceae with over 300 species (Wijayawardene et al. 2018). Hypoxylon species are cosmopolitan in distribution (Hyde et al. 2017). Most Hypoxylon species produce stromata and have been shown to produce high yields of secondary metabolites, which show characteristic colour reactions in potassium hydroxide solutions. This feature that is used to discriminate between species (Lambert et al. 2019). Analytical chromatographic methods (HPLC) to recognize the stromatal compounds and secondary metabolite profiles of Hypoxylon species provide more reliable evidence in species identification (Kuhnert et al. 2014). These chemical profiles are mostly species specific and important to validate the erection of new species (Cheng et al. 2015). This genus was revised by Ju \& Rogers (1996), and later re-evaluate by Hsieh et al. (2005). This genus was last revised by Ju \& Rogers (1996), and the first molecular phylogeny resulted in the segregation of the former sect. Annulata s. Wendt et al. (2018) accommodated this genus within Hypoxylaceae, which was resurrected and emended. Wendt et al. (2018) segregated Jackrogersella from Annulohypoxylon and also resurrected the genus Pyrenopolyporus for the species of Hypoxylon polyporus complex. Hyponomtagnella was recently recognized as separate genus and contains species of the Hypoxylon monticulosum complex, but even the remainder of Hypoxylon appears rather heterogeneous and was divided into several clades in the recently published multi-locus genealogies. This suggests that Hypoxylon must eventually be subdivided furthermore, but this should only be undertaken once fresh material representing the numerous old species that had already been described in the $19^{\text {th }}$ and early $20^{\text {th }}$ century has been collected and sequenced. Hypoxylon croceum and H. teeravasati are the only 
reports of Hyoxylon species from marine environment, which shows more species remain unexplored (Phookamsak et al. 2019).

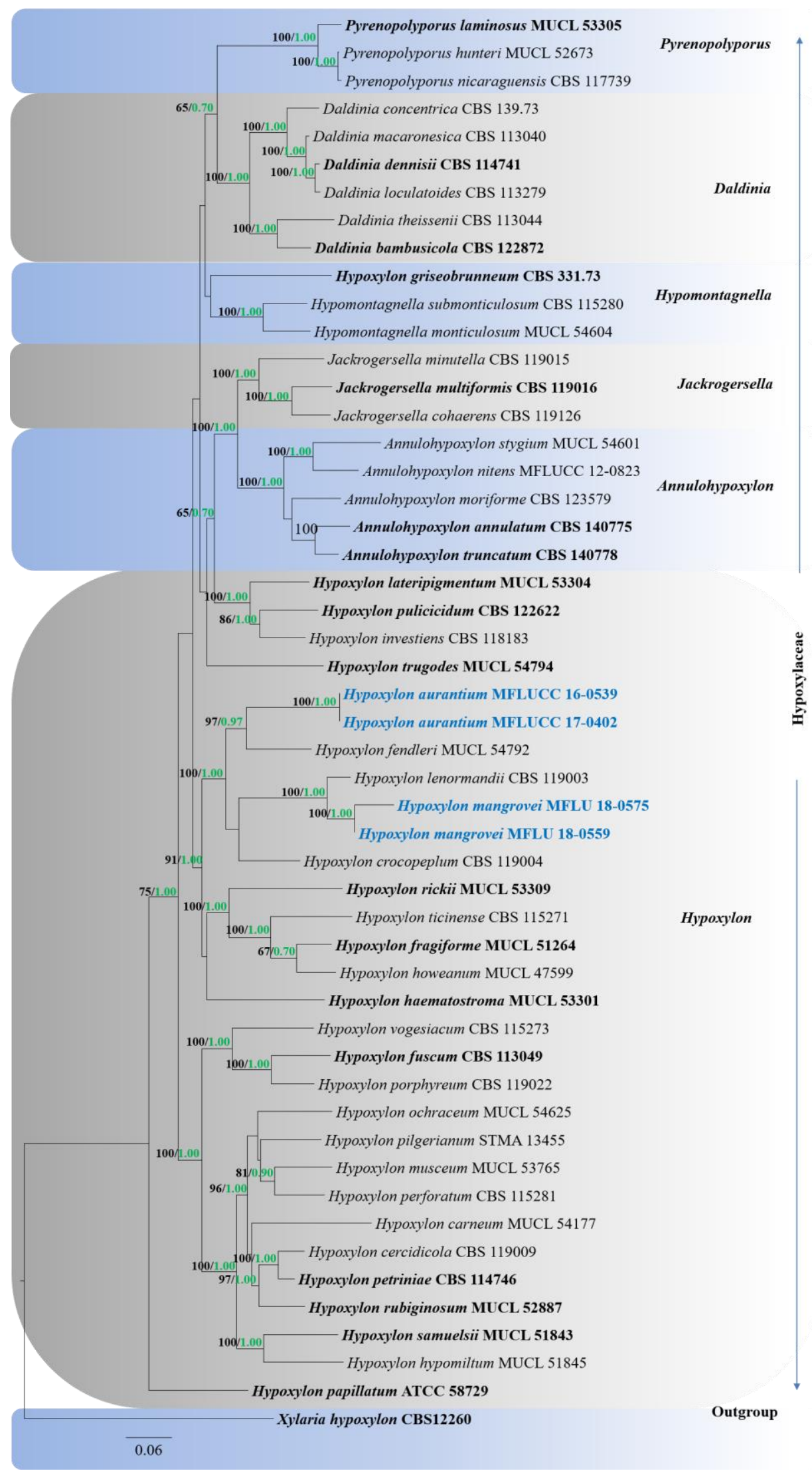

Figure 82 - Maximum likelihood analysis with 1000 bootstrap replicates yielded a best tree with the likelihood value of -56278.895136 . The combined LSU, ITS, RPB2 and BTUB sequence 
datasets comprised 64 strains of Hypoxylaceae and Xylaria hypoxylon (CBS12260) as the outgroup taxa. Tree topology of the ML analysis was similar to the BI. The matrix had 2107 distinct alignment patterns, with $12.73 \%$ of undetermined characters or gaps. Estimated base frequencies were as follows; $\mathrm{A}=0.237999, \mathrm{C}=0.265221, \mathrm{G}=0.254759, \mathrm{~T}=0.242022$, substitution rates $\mathrm{AC}$ $=1.436086, \mathrm{AG}=4.571825, \mathrm{AT}=1.596379, \mathrm{CG}=1.014392, \mathrm{CT}=6.218983, \mathrm{GT}=1.000000 ;$ gamma distribution shape parameter $\alpha=0.268346$. Maximum likelihood bootstrap (ML, black) values $>65 \%$ and Bayesian posterior probabilities (PP, green) $>0.90 \%$ are given above the nodes. The scale bar indicates 0.06 changes. The ex-type strains are in bold and new isolates in blue bold.

Hypoxylon aurantium Dayarathne, E.B. G. Jones \& K.D. Hyde, sp. nov.

Fig. 83

Index Fungorum number: IF556597; Facesoffungi number: FoF 06189

Etymology - Epithet signifies the bright orange Ascostromata

Saprobic on wood. Sexual morph: Ascostromata $1.5-2 \times 0.08-1 \times 0.06-0.12 \mathrm{~cm}(\overline{\mathrm{x}}=1.8 \times$ $0.085 \times 0.07 \mathrm{~cm}, \mathrm{n}=5$ ), effuse-pulvinate, with conspicuous perithecial mounds, surface bright orange; orange red granules immediately beneath surface and between ascomata, with KOH extractable pigments orange, the tissue below the perithecial layer inconspicuous. Ascomata 130 $150 \times 7-9.5 \mu \mathrm{m},(\overline{\mathrm{x}}=145 \times 8.2 \mu \mathrm{m}, \mathrm{n}=15)$, globose to sub globose, ostiolate. Paraphyses $2.5-3.8$ $\mu \mathrm{m}$ wide, hyaline, aseptate, unbranched. Asci 110-125 $\times 5.8-9 \mu \mathrm{m},(\overline{\mathrm{x}}=118 \times 6.2 \mu \mathrm{m}, \mathrm{n}=15), 8$ spored, unitunicate, cylindrical, pedicellate, with an inamyloid ascal apical apparatus. Ascospores $12-14 \times 7-9.5 \mu \mathrm{m}(\overline{\mathrm{x}}=12.4 \times 6.5 \mu \mathrm{m}, \mathrm{n}=25)$, uniseriate, one-celled, ellipsoid, with narrowly rounded ends, initially light brown, becoming brown to dark brown, with a straight, germ slit sporelength, smooth or with inconspicuous coil-like ornamentation, epispore smooth. Asexual morph: Undetermined.

Culture characteristics - Colonies on MEA at $25-28^{\circ} \mathrm{C}$ covering $15 \mathrm{~cm}$ diam. within 14 days, at first white, becoming greenish yellow, with diffuse margins, usually with vinaceous-buff to isabelline pigments diffusing beyond colonies; reverse amber to olivaceous.

Material examined - THAILAND, Krabi Province, Tha Pom Khlong Song Nam (N 08¹2'50.4”, E 98 46'42.7'), on submerged decaying mangrove wood, 16 December 2015, M. C. Dayarathne KLA009 (MFLU 16-1202, holotype); ibid., (HKAS101986, isotype), ex-type living cultures MFLUCC 16-0539. THAILAND, Ranong Province, Amphoe Maung, Mu 4 Tombol Ngao, Ranong Mangrove Research Center (GPS: $9^{\circ} 43^{\prime}$ to $9^{\circ} 57^{\prime} \mathrm{N}$; $98^{\circ} 29^{\prime}$ to $98^{\circ} 39^{\prime} \mathrm{E}$ ) on submerged decaying wood of Rhizophora apiculata (Rhizophoraceae), 06 December 2016, M.C. Dayarathne, MCD 044 (MFLU 18-0531), living culture MFLUCC 17-0402

GenBank numbers - LSU: MN017878, MN017879; ITS: MN047114, MN047115; RPB2: MN077081

Additional GenBank numbers - SSU MN017936, MN017937

Notes - Hypoxylon aurantium is a distinctive Hypoxylon species in possessing a bright orange ascostromatal surface which is somewhat similar to H. fendleri (Vasilyeva et al. 2007b). Furthermore, $H$. aurantium formed a sister lineage to $H$. fendleri with high statistical support (100\% ML, 1.00 PP) (Fig. 82). Nevertheless, H. aurantium has an inamyloid ascal apical apparatus while $H$. fendleri has amyloid ascal apical apparatus (Vasilyeva et al. 2007b). We also compared the base pair for ITS and BTUB gene loci accounts 52 out of 604 (84\%) and 163 bp out of 1028 bp (15\%) respectively. Furthermore, the occurrence of $H$. aurantium is on mangrove wood in Thailand while $H$. fendleri is a neotropical species. Hence, $H$. aurantium is warranted as a novel species within Hypoxylon.

Hypoxylon mangrovei Dayarathne, E.B.G. Jones \& K.D. Hyde, sp. nov.

Fig. 84

Index Fungorum number: IF556598; Facesoffungi number: FoF 06190

Etymology - Epithet refers to the mangrove host

Saprobic on submerged mangrove wood. Sexual morph: Ascostromata 2-3.5 $\times 1.5-2.8 \times \times$ $0.4-1 \mathrm{~mm}(\overline{\mathrm{x}}=3 \times 2 \times 0.8 \mathrm{~mm}, \mathrm{n}=15)$, glomerate, with inconspicuous perithecial mounds, surface dark vinaceous, dark brick or orange red granules immediately beneath surface and between 
perithecia, with $\mathrm{KOH}$ extractable pigments orange, the tissue below the ascomata layer inconspicuous.

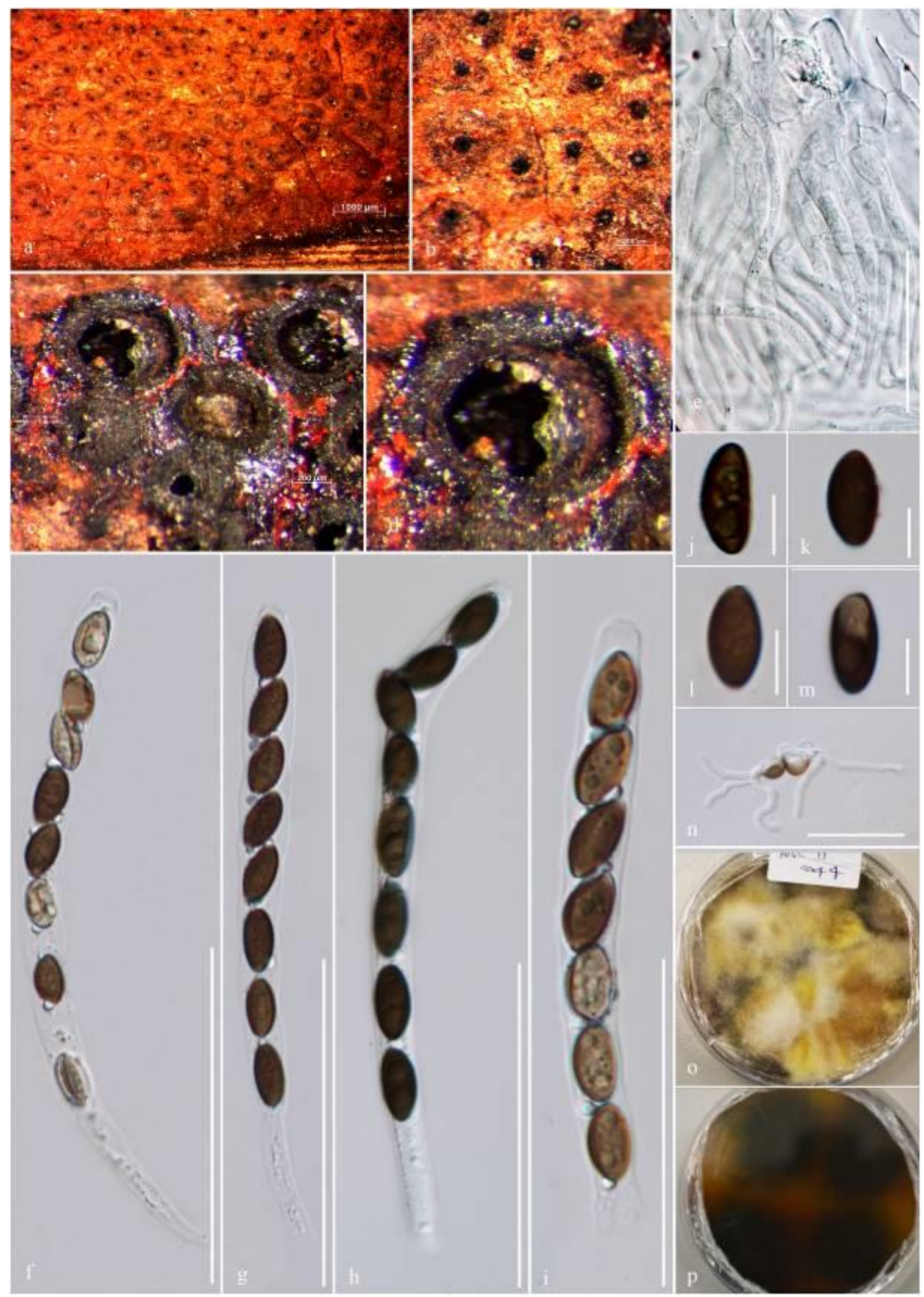

Figure 83 - Hypoxylon aurantium (MFLU 16-1202, holotype). a, b Ascostromata in wood. c, d Horizontal section through ascostromata. e Paraphyses. $\mathrm{f}-\mathrm{i}$ Asci. $\mathrm{j}-\mathrm{m}$ Ascospores. $\mathrm{n}$ Germinating ascospore. o, $p$ Cultures on MEA (o upper, $p$ lower). Scale bars: $a, b=1 \mathrm{~mm}, \mathrm{c}=200$ $\mu \mathrm{m}, \mathrm{e}-\mathrm{i}=50 \mu \mathrm{m}, \mathrm{j}-\mathrm{m}=10 \mu \mathrm{m}$. 

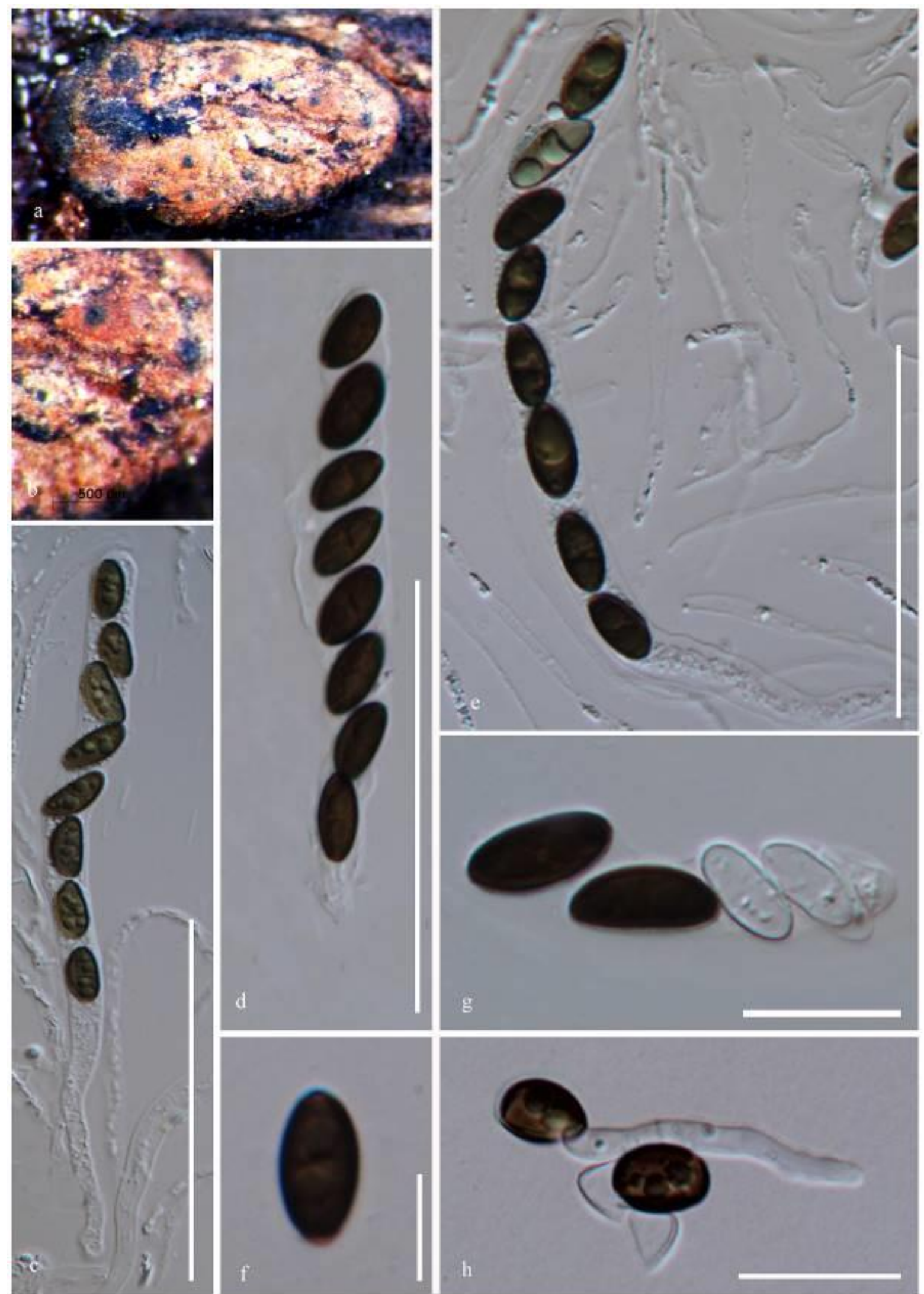

Figure 84 - Hypoxylon mangrovei (MFLU 18-0559 holotype). a Stromata in wood. b Surface of stromata with ostioles. c-e Asci and paraphyses. f, g Ascospores. h Mature ascospore with dehiscent perispore in KOH. Scale bars: $b=500 \mu \mathrm{m}, \mathrm{d}=100 \mu \mathrm{m}, \mathrm{c}, \mathrm{e}=50 \mu \mathrm{m}, \mathrm{f}-\mathrm{h}=10 \mu \mathrm{m}$.

Ascomata $0.3-0.6 \mathrm{~mm}$ in diameter, perithecial, globose, ostiolate. Paraphyses 3-4.5 $\mu \mathrm{m}$, hyaline, aseptate, unbranched. Asci 130-150 $\times 7-9.5 \mu \mathrm{m},(\overline{\mathrm{x}}=145 \times 8.2 \mu \mathrm{m}, \mathrm{n}=15), 8$ - spored, unitunicate, 
cylindrical, pedicellate, with a J- apical ring. Ascospores $12-14.5 \times 5-6.5 \mu \mathrm{m},(\overline{\mathrm{x}}=12.8 \times 5.8 \mu \mathrm{m}$, $\mathrm{n}=30$ ), uniseriate, one-celled, ellipsoid-inequilateral, with narrowly rounded ends, brown to dark brown, with sigmoid germ slit spore-length, smooth or with inconspicuous coil-like ornamentation, epispore smooth. Asexual morph: Undetermined.

Material examined - THAILAND, Prachaub Kiri Khan Province, Pranburi, Sirinath Rajini center for mangrove forest studies on decaying wood of Rhizophora sp. (Rhizophoraceae), 02 December 2016, M.C. Dayarathne, MCD 085 (MFLU 18-0559 holotype); ibid., (HKAS102092 isotype). THAILAND, Phetchaburi Province, Cha-am, on decaying submerged mangrove wood, 18 January 2018, M.C. Dayarathne, MCD 190 (MFLU 18-0575).

GenBank numbers - LSU: MN017880; ITS: MN047116, MN047117; BTUB: MN077053, MN077054

Additional GenBank number - SSU: MN017938

Notes - Strains of H. mangrovei formed a well-separated (100\% ML, $1.00 \mathrm{PP}$ ) lineage which phylogenetically closely resembles $H$. lenormandii (Fig. 82). Hypoxylon lenormandii is different from $H$. mangrovei by the size of stromata $(2-3.5 \times 1.5-2.8 \times 0.4-1 \mathrm{~mm} v s \quad 13-85 \times 6-27 \times 0.5-1$ $\mathrm{mm}$ ) (Kuhnert et al. 2015). Considering the base pair differences of $H$. mangrovei and $H$. lenormandii for ITS, 27 bp out of 470 bp (5.7\%) and BTUB 73 out of 594 (12.3\%) and RPB2 data which warrants two clearly distinct taxa. Hypoxylon mangrovei, $H$. fendleri, $H$. trugodes and $H$. crocopeplum share similar stromatal characters (Liu et al. 2015). However, H. fendleri, H. trugodes and $H$. crocopeplum are distantly placed from $H$. mangrovei in our phylogram.

\section{Xylariaceae Tul. \& C. Tul.}

Tulasne \& Tulasne (1963) introduced the family Xylariaceae with the term "Xylariei" and by then the family concept had not even been established (Stadler et al. 2013). The exact number of accepted genera of this family is doubtful while the recent outline of Ascomycota (Wijayawardene et al. 2018) listed 44 genera among the 38 genera are established by molecular data. The segregation of Xylariaceae into the subfamilies Hypoxyloideae and Xylarioideae has been supported by molecular data and several genera of Xylariaceae have transferred to various families i. e. Graphostromataceae and Lopadostomataceae (Tang et al. 2007, Stadler et al. 2013, Daranagama et al. 2015, Maharachchikumbura et al. 2015, 2016).

Halorosellinia Whalley et al.

Halorosellinia was introduced by Whalley et al. (1999) as a monotypic genus to accommodate Halorosselinia oceanica (previously referred to as Hypoxylon oceanicum). The genus is characterized by uniperitheciate ascomata which are immersed in a pseudostroma (Hyde al. 2016). Halorosellinia currently comprises three species (Hyde et al. 2016, Wijayawardene et al. 2018).

Halorosellinia rhizophorae Dayar., E.B.G. Jones \& K.D. Hyde, in Li et al., Fungal Diversity78: 10.1007/s13225-016-0366-9, [117] (2016)

Fig. 86

Facesoffungi number: FoF 01811

Saprobic on decaying wood of Rhizophora sp. attached to the plant. Sexual morph: Pseudostromata $1-2.5 \times 0.9-1.5 \mathrm{~mm}(\overline{\mathrm{x}}=2 \times 1.2 \mathrm{~mm}, \mathrm{n}=5)$, semi-immersed, pulvinate to hemisphaerical, in clusters of up to 20 uni peritheciate pseudostromata, surface black, carbonaceous, lacking ascomatal projections. In section pseudostromata comprises host cells, filled with amorphous black fungal material. Ascomata 345-360 $\times 90-100 \mu \mathrm{m}(\overline{\mathrm{x}}=350 \times 100 \mu \mathrm{m}, \mathrm{n}=$ 10), immersed in pseudostroma, subglobose to hemisphaerical, black, ostioles papillate. Peridium 25-38 $\mu \mathrm{m}$ wide, two-layered, outer layer of cells of textura angularis, black, fusing at the outside with the pseudostromata, inner layer of elongate cells, dark brown to black. Paraphyses $1-3 \mu \mathrm{m}$ wide, hyaline, abundant, persistent, aseptate. Asci 160-270 × 12-18 $\mu \mathrm{m}(\overline{\mathrm{x}}=220 \times 15 \mu \mathrm{m}, \mathrm{n}=20)$, overlapping, 8-spored, cylindrical, long pedicellate, unitunicate, with $\mathrm{J}+$, rectangular apical ring. 


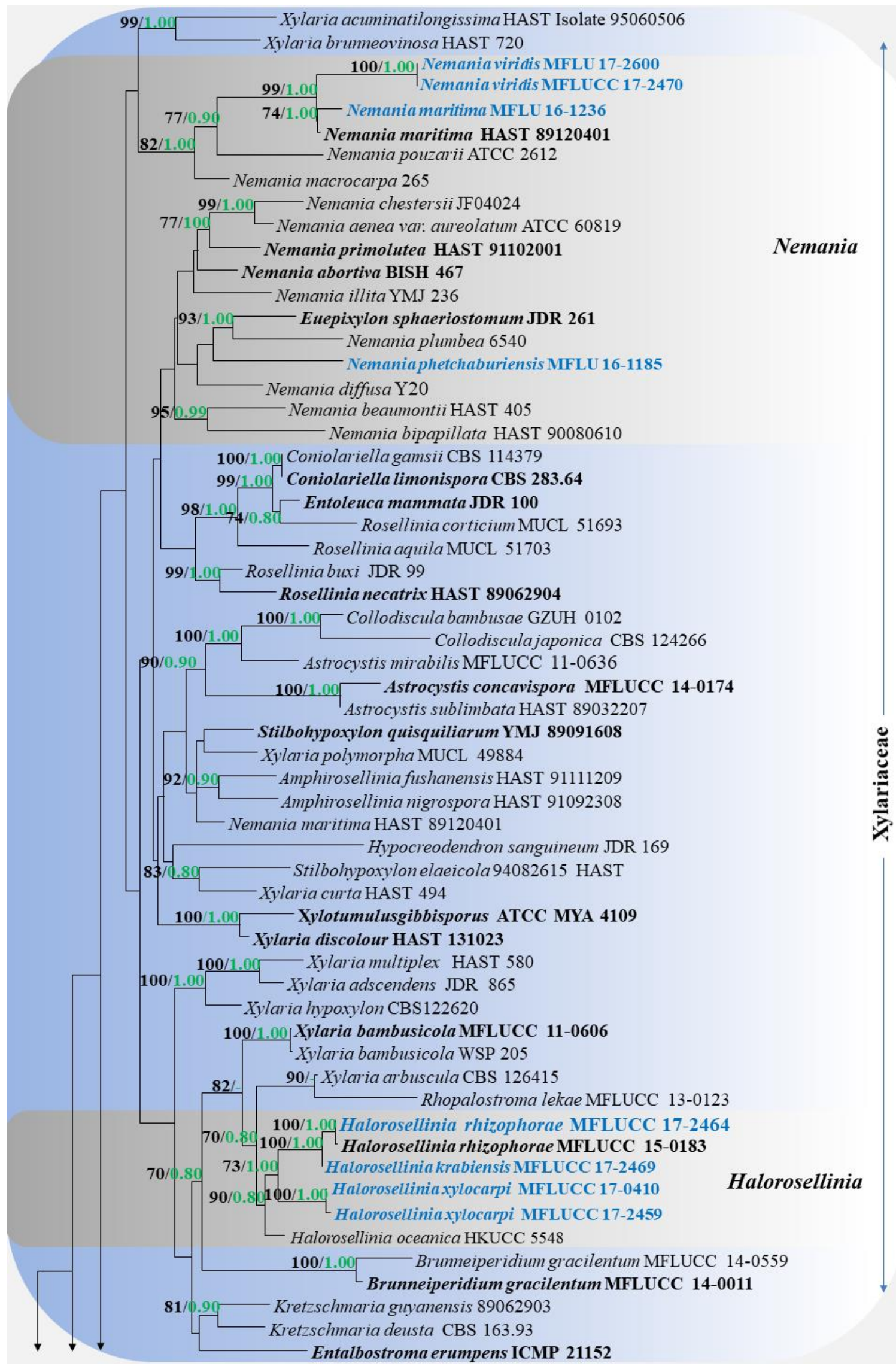

Figure 85 - Maximum likelihood analysis with 1000 bootstrap replicates yielded a best tree with the likelihood value of -56278.895136 . The combined LSU, ITS BTUB and RPB2 sequence datasets comprised 114 strains of Xylariales and Achaetomium macrosporum (CBS 532.94), Chaetomium elatum (CBS374.66) and Sordaria fimicola (CBS 723.96) as the outgroup taxa. Tree 
topology of the ML analysis was similar to the BI. The matrix had 2107 distinct alignment patterns, with $37.32 \%$ of undetermined characters or gaps. Estimated base frequencies were as follows; $\mathrm{A}=$ $0.237999, \mathrm{C}=0.265221, \mathrm{G}=0.260159, \mathrm{~T}=0.242022$; substitution rates $\mathrm{AC}=1.436086, \mathrm{AG}=$ 4.571825, $\mathrm{AT}=1.596379, \mathrm{CG}=0.254759, \mathrm{CT}=6.218983, \mathrm{GT}=1.000000$; gamma distribution shape parameter $\alpha=0.268346$. Maximum likelihood bootstrap (ML, black) values $>65 \%$ and Bayesian posterior probabilities (PP, green) $>0.90 \%$ are given above the nodes. The scale bar indicates 0.1 changes. The ex-type strains are in bold and new isolates in blue bold.

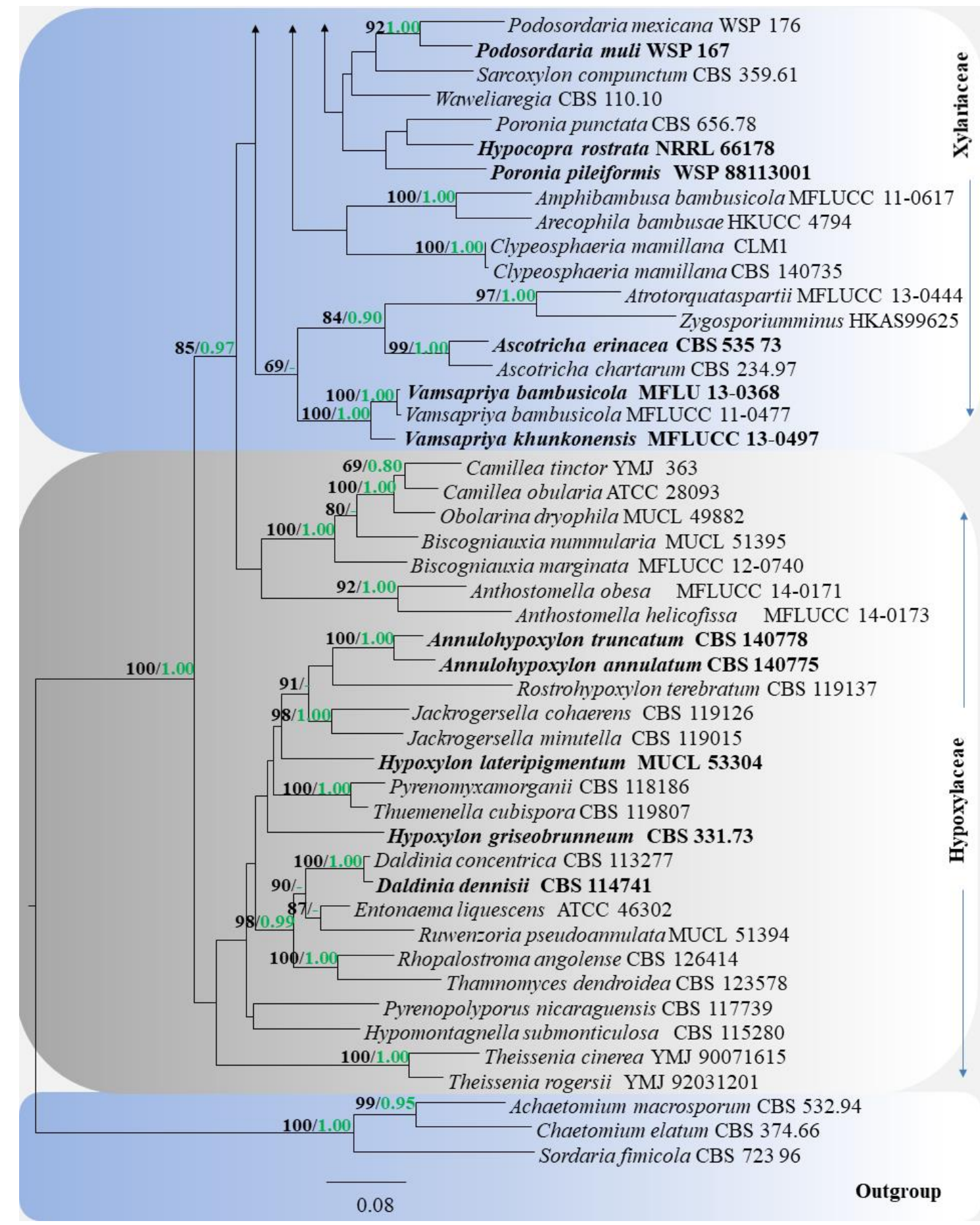

Figure 85 - Continued. 


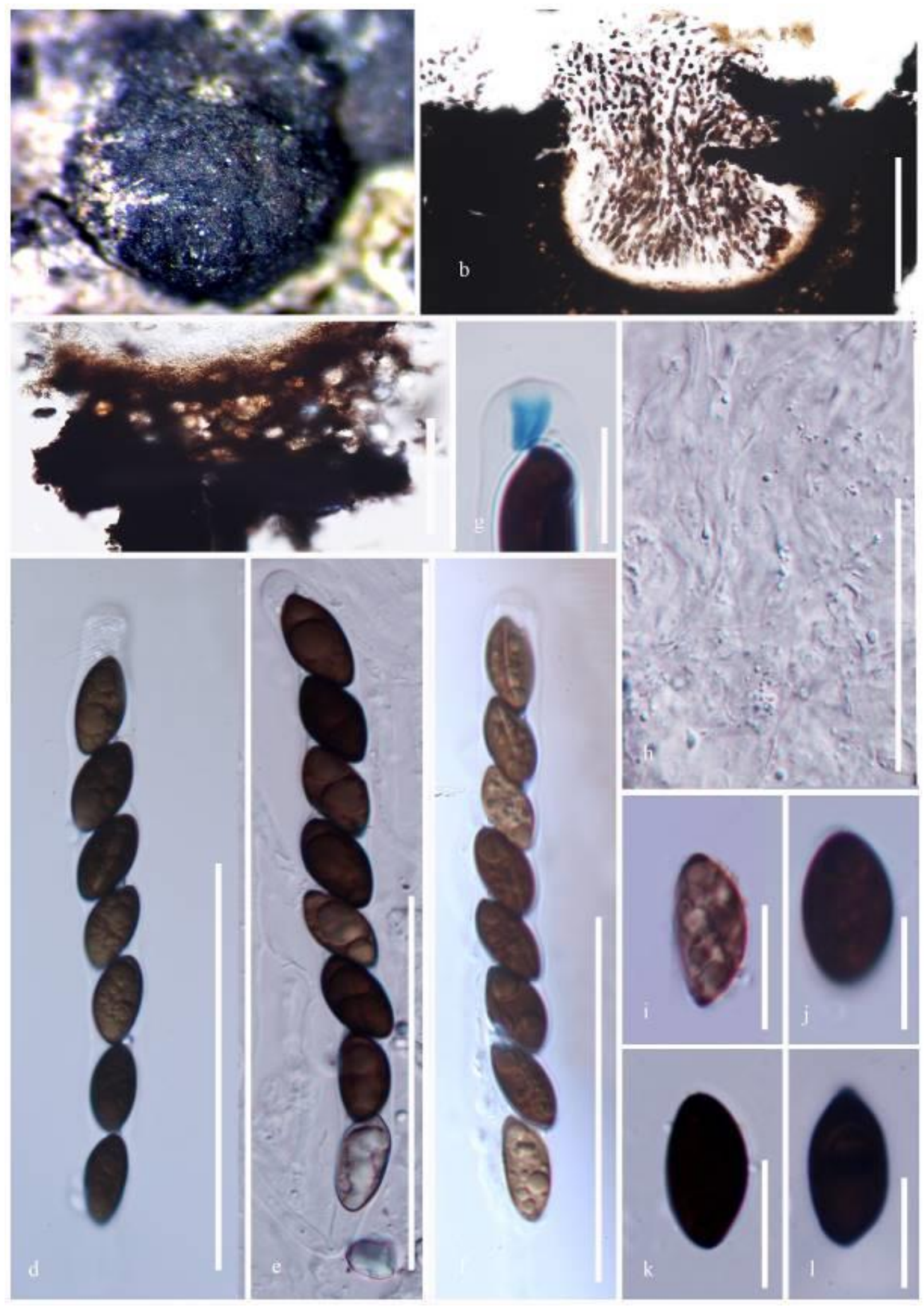

Figure 86 - Halorosellinia rhizophorae (MFLU 17-2591). a Appearance of psudostromata on host. b Vertical section through pseudostroma. c Peridium. d-f Asci. g Apical apparatus stained blue with Melzer's reagent. h Paraphyses. i-1 Ascospores. Scale bars: $b=200 \mu \mathrm{m}, \mathrm{d}-\mathrm{f}=100 \mu \mathrm{m}, \mathrm{c}, \mathrm{d}, \mathrm{h}=50$ $\mu \mathrm{m}, \mathrm{i}-\mathrm{l}=20 \mu \mathrm{m}, \mathrm{g}=10 \mu \mathrm{m}$. 
Ascospores $20-35 \times 10-15 \mu \mathrm{m}(\mathrm{x}=30 \times 12 \mu \mathrm{m}, \mathrm{n}=30)$ overlapping uniseriate, light brown when immature, dark to opaque brown when mature, more or less equilaterally ellipsoid, ventral side varying in degree of convex curvature, upper end broadly rounded, lower end slightly pointed, 1celled, 1-2-guttulate, without appendages, germ slit on the ventral side, straight, $3 / 4$ total length of spore. Asexual morph: Undetermined.

Culture characteristics - Colonies on PDA at $25-28{ }^{\circ} \mathrm{C}$ reaching $10 \mathrm{~cm}$ in 14 days, whitish colonies, zonate with diffuse margins, reverse at first whitish and turning light brown after 3-4 days.

Material examined - THAILAND, Krabi Province, Phang Nga, on mangrove sp. (Rhizophoraceae) wood, 31 August 2017, M.C. Dayarathne MCD 108 (MFLU 17-2591); ibid., HKAS102036. Living culture MFLUCC 17-2464.

GenBank numbers - LSU: MN017882; ITS: MN047118; BTUB: MN431492

Additional GenBank number - SSU: MN017939

Notes - Our new strain (MFLU 17-2591) is morphologically similar to Halorosellinia rhizophorae which formed a sister group (Fig. 80). Halorosellinia rhizophorae differs from the type $H$. oceanica in lacking ascomatal projections (Whalley et al. 1999). This is the second collection of this species from Krabi, Thailand. Our earlier collection of this species was from submerged decaying wood while this collection is from an above ground decaying wood which was not inundated in marine water. BTUB sequence data for this species is provided for the first time.

Halorosellinia krabiensis Dayarathne, \& K.D. Hyde, sp. nov.

Index Fungorum number: IF556599; Facesoffungi number: FoF 06191

Fig. 87

Etymology - Name referring to the location, Krabi, Thailand where the species found.

Holotype - MFLU 17-2596

Saprobic on decaying mangrove wood submerged in marine habitats. Sexual morph: Pseudostromata $1.5-2 \times 0.8-1.2 \mathrm{~mm}(\overline{\mathrm{x}}=1.8 \times 1 \mathrm{~mm}, \mathrm{n}=5)$, semi-immersed, pulvinate to hemisphaerical to conical, in clusters of uni-peritheciate pseudostromata, surface black, carbonaceous, lacking ascomatal projections. In section pseudostromata comprises host cells, filled with amorphous black fungal material. Ascomata immersed in pseudostroma, subglobose to hemisphaerical, black, ostioles papillate. Paraphyses 1-2 $\mu \mathrm{m}$ wide, hyaline, abundant, persistent, aseptate. Asci $118-128 \times 15-18.5 \mu \mathrm{m}(\overline{\mathrm{x}}=126 \times 16 \mu \mathrm{m}, \mathrm{n}=20), 8$-spored, cylindrical, long pedicellate, unitunicate, with $\mathrm{J}+$, rectangular apical ring. Ascospores $14-18 \times 8-10.5 \mu \mathrm{m}(\overline{\mathrm{x}}=16 \times$ $9.5 \mu \mathrm{m}, \mathrm{n}=30$ ) overlapping biseriate, light brown when immature, becoming dark brown when mature, more or less equilaterally ellipsoid, ventral side varying in degree of convex curvature, ends broadly pointed, lower end sometimes slightly rounded, 1-celled, 1-2-guttulate, without appendages, germ slit on the ventral side, straight. Asexual morph: Undetermined.

Culture characteristics - Colonies on PDA at $25-28{ }^{\circ} \mathrm{C}$ reaching $3 \mathrm{~cm}$ in 7 days, whitish, zonate with diffuse margins, reverse at first whitish and turning light brown after 3-4 days.

Material examined - THAILAND, Krabi Province, Phang Nga, on mangrove wood, 31 August 2017, M.C. Dayarathne MCD 114 (MFLU 17-2596, holotype); ibid., (HKAS102035 isotype), ex-type living culture MFLUCC 17-2469.

GenBank numbers - LSU: MN017883; ITS: MN047119; BTUB: MN431493

Notes - Halorosellinia krabiensis shares distinctive features of Halorosellinia including a poorly developed pseudostromata which lack extractable pigments in $\mathrm{KOH}$, asci with a relatively large apical apparatus that becomes dark blue in Melzer's reagent and ascospores with a prominent, straight germ slit on the ventral side (Whalley et al. 1999). Halorosellinia krabiensis is similar to $H$. oceanica and $H$. rhizophorae in ascospore morphology being one-celled, brown ascospores at maturity, more or less equilaterally ellipsoid with a germ slit at the ventral side (Whalley et al. 1999). The new species, is clearly different from the type Halorosellinia oceanica in lacking ascomatal projections and asci and ascospore measurements (Table 7). Halorosellinia oceanica was collected from Rhzophora in Florida, USA but it is a widely occurring mangrove species (Pang et al. 2011). Halorosellinia krabiensis has ascospores with pointed ends, and the lower end sometimes 
slightly rounded while the ascospores of $H$. rhizophorae have broadly rounded upper ends, slightly pointed lower ends (Liu et al. 2015). Ascospore arrangement within the asci is the most distinguishable character of these two species with $\mathrm{H}$. krabiensis having overlapping biseriate and $H$. rhizophorae in uniseriate ascospores. Phylogenetic analyses of combined ITS, LSU, BTUB, RPB2 data confirmed the placement of $\mathrm{H}$. krabiensis within the family Xylariaceae and formed a sister clade to $H$. rhizophorae with high statistical support of $100 \%$ ML, 1.00 pp (Fig. 85). Base pair differences for ITS and BTUB of $\mathrm{H}$. krabiensis and H. rhizophorae are $2 \mathrm{bp}$ out of $597 \mathrm{bp}$ $(0.3 \%)$ and $16 \mathrm{bp}$ out of $920 \mathrm{bp}(1.7 \%)$ respectively.

Halorosellinia xylocarpi Dayarathne \& K.D. Hyde, sp. nov.

Fig. 88

Index Fungorum number: IF556600; Facesoffungi number: FoF 06192

Etymology - Name referring to the host genus Xylocarpus.

Holotype - MFLU 18-0545

Saprobic on submerged mangrove wood in marine habitats. Sexual morph: Pseudostromata $0.6-1.0 \times 0.5-0.8 \mathrm{~mm}(\mathrm{x}=0.8 \times 0.6 \mathrm{~mm}, \mathrm{n}=5)$, semi-immersed, pulvinate to hemisphaerical, in clusters of uni-peritheciate pseudostromata, surface black, carbonaceous, lacking ascomatal projections. In section pseudostromata comprises host cells, filled with amorphous black fungal material. Ascomata 300-340 $\times 340-352 \mu \mathrm{m}(\overline{\mathrm{x}}=335 \times 348 \mu \mathrm{m}, \mathrm{n}=5)$, immersed in pseudostroma, subglobose to hemisphaerical, black, ostioles papillate. Peridium 25-38 $\mu \mathrm{m}$ wide, two-layered, outer layer of cells of textura angularis, black, fusing at the outside with the pseudostromata, inner layer of elongate cells, dark brown to black. Paraphyses 2-3 $\mu \mathrm{m}$ wide, hyaline, abundant, persistent, aseptate. Asci 126-135 × 20-28 $\mu \mathrm{m}(\overline{\mathrm{x}}=130 \times 25 \mu \mathrm{m}, \mathrm{n}=20)$, 8-spored, cylindrical, long pedicellate, unitunicate, with $\mathrm{J}+$, cylindrical apical ring. Ascospores $20-26 \times 10-14 \mu \mathrm{m}(\overline{\mathrm{x}}=$ $24 \times 12 \mu \mathrm{m}, \mathrm{n}=30$ ) overlapping bi-seriate, hyaline and becoming opaque green and dark brown when mature, more or less equilaterally ellipsoid, straight or ventral side varying in degree of convex curvature, both ends often pointed, sometimes lower end broadly rounded, 1-celled, 1-2guttulate, without appendages, germ slit on the ventral side, straight, total length of spore. Asexual morph: Undetermined.

Culture characteristics - Colonies on PDA at $25-28{ }^{\circ} \mathrm{C}$ reaching $6 \mathrm{~cm}$ in 7 days, whitish, zonate with diffuse margins, reverse at first whitish and turning light brown after 3-4 days.

Material examined - THAILAND, Ranong Province, Ranong, on decaying, submerged Xylocarpus sp. (Meliaceae) wood, 07 December 2016, M.C. Dayarathne, MCD 62 (MFLU 180545, holotype); ibid., (HKAS102084, isotype), ex-type living cultures (MFLUCC 17-0410). THAILAND, Krabi Province, Phang Nga, on decaying submerged wood of Rhizophora sp. (Rhizophoraceae), 31 August 2017, M.C. Dayarathne, MCD 100 (MFLU 17-2584); ibid., (HKAS102028), living culture (MFLUCC 17-2459).

GenBank numbers - LSU: MN017884, MN017885; ITS: MN047120, MN047121; BTUB: MN077076

Additional GenBank numbers - SSU MN017940, MN017941

Notes - Halorosellinia xylocarpi is distinguishable for all the other Halorosellina species by the unique opaque green colouration of the ascospores. Halorosellinia xylocarpi formed a wellsupported lineage (100\% ML, $1.00 \mathrm{PP}$ ) basal to a clade comprising strains $H$. rhizophorae and $H$. krabiensis (Fig. 85). Base pair differences of $H$. xylocarpi and H. krabiensis for ITS and BTUB are $68 \mathrm{bp}$ out of $597 \mathrm{bp}(11 \%)$ and 38 bp 938 bp (4\%), respectively. In ITS locus 60 bp out of 593 bp $(10 \%)$ are different among $H$. xylocarpi and $H$. oceanica. Psudostromata, asci, ascospores and paraphyses measurements of all the Halorosellinia species are presented in Table 7.

\section{Nemania Gray}

Nemania was erected for a heterogeneous assemblage of taxa by Gray (1821). Subsequently, Nemania was emended and reinstated by Pouzar (1985) to accommodate the Hypoxylon selpenscomplex of Hypoxylon subsection Prinocinerea of Miller (1961). As emended by Pouzar (1985) Nemania species develop superficial stromata, lacking both a subiculum and bright pigments that 
are soluble in $\mathrm{KOH}$, and also possess a $\mathrm{J}+$ or $\mathbf{J}-$, rectangular apical apparatus that is higher than it is broad. The apical ring is more similar to those of Kretzschmaria and Xylaria than those of Hypoxylon (Pouzar 1985, Smith \& Hyde 2001).

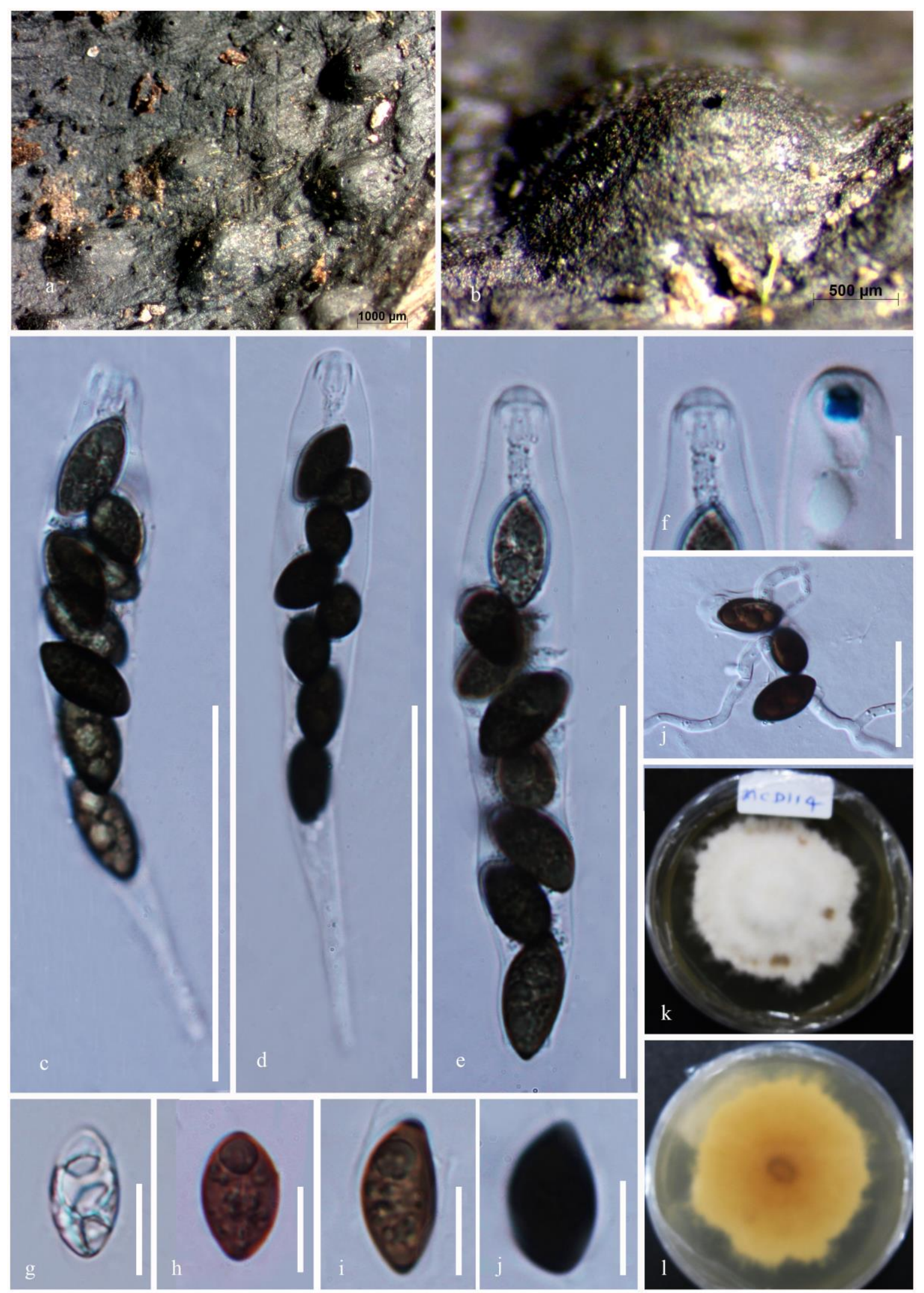

Figure 87 - Halorosellinia krabiensis (MFLU 17-2596 holotype). a, b Appearance of psudostromata on host. f Apical apparatus before and after staining blue with Melzer's reagent. c-e Asci. g-j Ascospores. Scale bars: $\mathrm{b}=200 \mu \mathrm{m}, \mathrm{c}=100 \mu \mathrm{m}, \mathrm{d}, \mathrm{e}=20 \mu \mathrm{m}, \mathrm{f}-\mathrm{i}=50 \mu \mathrm{m}, \mathrm{j}-\mathrm{m}=20 \mu \mathrm{m}$. 


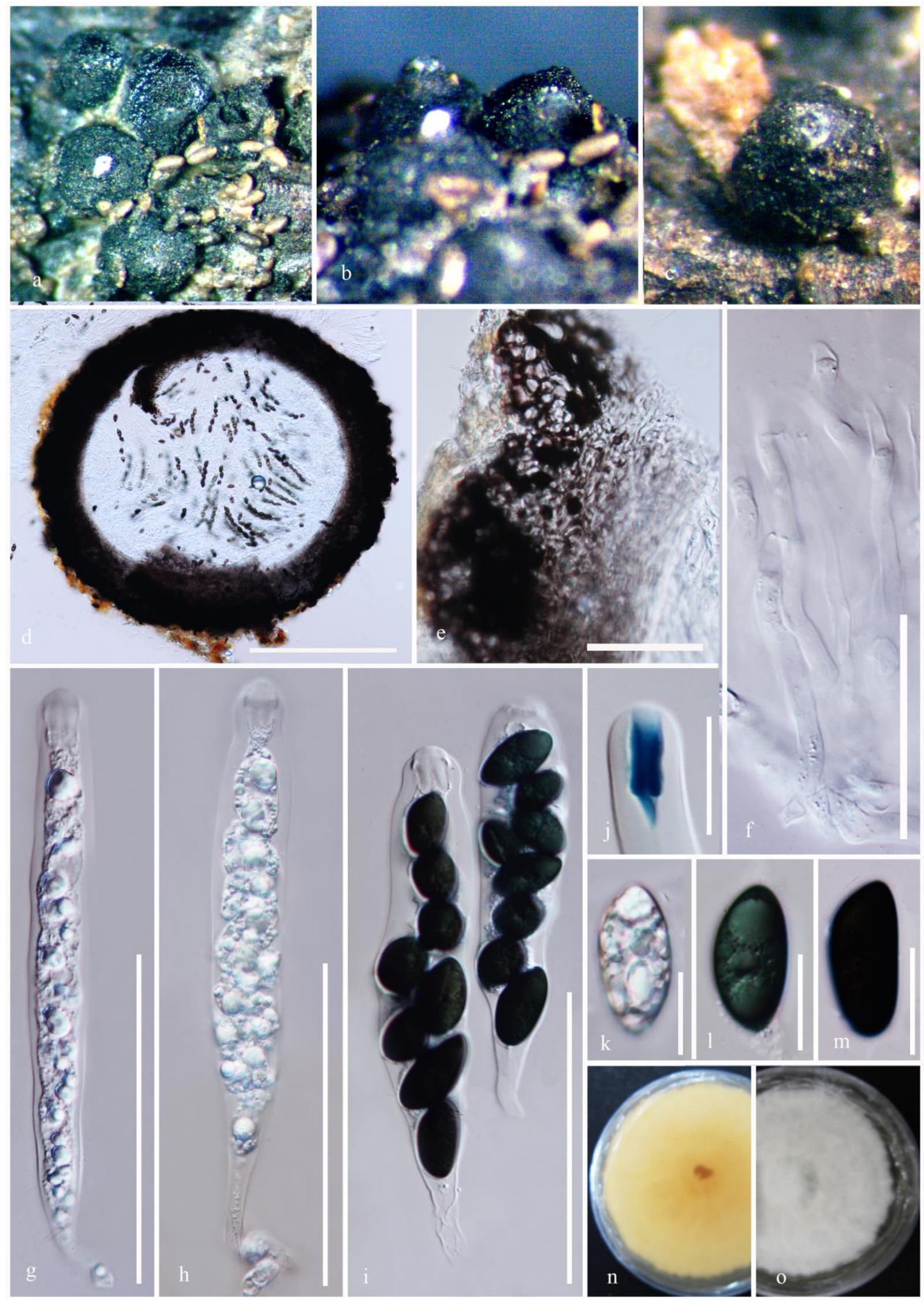

Figure 88 - Halorosellinia xylocarpi (MFLU 18-0545, holotype). a, b Appearance of psudostromata on host. b Horizontal section through pseudostroma. c Section through stromata. d Peridium. e Apical apparatus stained blue with Melzer's reagent. f-h Asci. I Paraphyses. j-m Ascospores. Scale bars: $\mathrm{b}=200 \mu \mathrm{m}, \mathrm{c}=100 \mu \mathrm{m}, \mathrm{d}, \mathrm{e}=20 \mu \mathrm{m}, \mathrm{f}-\mathrm{i}=50 \mu \mathrm{m}, \mathrm{j}-\mathrm{m}=20 \mu \mathrm{m}$. 
Table 7 Morphological comparison of Halorosellinia species.

\begin{tabular}{|c|c|c|c|c|}
\hline Characters & H. oceanica & H. krabiensis & H. xylocarpi & H. rhizophorae \\
\hline $\begin{array}{l}\text { Pseudostromata } \\
\text { (mm) }\end{array}$ & $0 \pm 4-0 \pm 8$ in diam. & $1.5-2 \times 0.8-1.2$ & $0.6-1.0 \times 0.5-0.8$ & $1.5-2.5 \times 0.9-1$ \\
\hline $\operatorname{Asci}(\mu \mathrm{m})$ & $177-219$ & $\begin{array}{l}118-128 \times 15- \\
18.5\end{array}$ & $126-135 \times 20-28$ & $165-270$ \\
\hline $\begin{array}{l}\text { Ascospores } \\
(\mu \mathrm{m})\end{array}$ & $\begin{array}{l}(17 \pm 9-) 18 \pm 7-26(- \\
28) \neg 7 \pm 5-13(- \\
13 \pm 5)\end{array}$ & $14-18 \times 8-10.5$ & $20-26 \times 10-14$ & $24-36 \times 10-15$ \\
\hline $\begin{array}{l}\text { Paraphyses } \\
(\mu \mathrm{m})\end{array}$ & $2-2 \pm 5$ wide & 1-2 wide & $2-3$ wide & 1-3 wide \\
\hline
\end{tabular}

Nemania maritima Y.M. Ju \& J.D. Rogers, Nova Hedwigia 74(1-2): 102 (2002)

Fig. 89

Facesoffungi number: FoF 06193

Saprobic on submerged root of Rhizophora sp. Sexual morph: Stromata 0.4-0.6 mm diam., scattered, subglobose to globose, enclosing one to several perithecia, erumpent, with lower to middle part embedded in the substrate, surface dark brown, smooth; carbonaceous immediately beneath the surface and between the perithecia, tissue beneath the perithecial layer inconspicuous, ostioles obtusely conical, black. Asci 65-90 $\times 4-7 \mu \mathrm{m}(\overline{\mathrm{x}}=70 \times 6 \mu \mathrm{m}, \mathrm{n}=20)$, short-stipitate, with apical ring bluing in Melzer's iodine reagent, cuneate. Ascospores $6.5-10 \times 3-6 \mu \mathrm{m}(\overline{\mathrm{x}}=7.8 \times 4$ $\mu \mathrm{m}, \mathrm{n}=30$ ), uni-seriate, light brown to brown, unicellular, ellipsoidal, with broadly rounded ends, guttulate, with straight germ slit much less than spore-length. Asexual morph: Undetermined.

Material examined - THAILAND, Krabi Province, Krabi, 8²5'52" N, 98³1'42" E, 0 m asl., on submerged root of Rhizophora sp., 7 December 2014, M.C. Dayarathne, KRB 016 (MFLU 161236); ibid., HKAS102022.

GenBank numbers - LSU: MN017886; ITS: MN047122

Notes - Our new strain (MFLU 16-1236) is morphologically similar to N. maritima with subglobose to globose stromata which enclose one to several perithecia, asci with a J-apical ring bluing in Melzer's iodine reagent and with light brown to brown, unicellular, ellipsoidal, guttulate ascospores with broadly rounded ends and straight germ slit shorter than its spore-length (Ju \& Rogers 2002). Furthermore, strain (MFLU 16-1236) grouped together with Nemania maritima (JF 03075) in a well-supported clade (67\% ML, 1.00 PP) (Fig. 85). This was reported from Kandelia candel while our collection is from Rhizophora sp.

Nemania viridis Dayarathne \& K.D. Hyde, sp. nov.

Fig. 90

Index Fungorum number: IF556601; Facesoffungi number: FoF 06194

Etymology - Epithet derived from the Latin word for the characteristic opaque green ascospores.

Holotype - MFLU 17-2600

Saprobic on submerged wood of Rhizophora sp. (Rhizophoraceae). Sexual morph: Stromata 0.5-0.8 mm diam, pulvinate to effused-pulvinate, superficial, surface black, plane or with inconspicuous perithecial mounds, carbonaceous tissue immediately beneath the surface and between the perithecia; tissue beneath the perithecial layer inconspicuous to conspicuous, blackish brown. Ascomata spherical to globose, ostioles higher than the stromatal surface, with openings papillate to coarsely papillate, with surrounding area slightly flattened. Peridium $25-38 \mu \mathrm{m}$ wide, two-layered, outer layer of cells of textura angularis, black, fusing at the outside with the pseudostromata, inner layer of elongate cells, dark brown to black. Asci $136-150 \times 8-12 \mu \mathrm{m}(\overline{\mathrm{x}}=$ $147 \times 10 \mu \mathrm{m}, \mathrm{n}=20$ ), broad, 8-spores, cylindrical, short pedicellate, unitunicate, with a J- apical ring. Ascospores $15-17 \times 6-8 \mu \mathrm{m}(\overline{\mathrm{x}}=16.8 \times 6.8 \mu \mathrm{m}, \mathrm{n}=30)$, uni-seriate, initially hyaline, becoming opaque green, brown when mature, unicellular, ellipsoid, with narrowly rounded ends, guttulate, with straight, conspicuous germ slit. Asexual morph: Undetermined. 
Culture characteristics - Colonies on sea water PDA at $25-28{ }^{\circ} \mathrm{C}$ reaching $15 \mathrm{~cm}$ in 14 days, medium dense, circular, pulvinate, smooth, with entire margins, from about white, reverse at first whitish and turning yellow to light brown when mature.

Material examined - THAILAND, Phetchaburi Province, Cha-am, on submerged, decaying Rhizophora sp. (Rhizophoraceae) wood, 30 August 2017, M.C. Dayarathne, MCD 119 (MFLU 172600, holotype); ibid., (HKAS102033, isotype), living culture MFLUCC 17-2470.

GenBank numbers - LSU: MN017887, ITS: MN047123

Notes - Nemania viridis shares morphological similarities with N. maritima. Nemania viridis formed a well separated distinct lineage from N. maritima with high statistical support (74\% ML, 1.00 PP) (Fig. 85). Ascospores of both species are unicellular, ellipsoid, with narrowly rounded ends, guttulate, with a straight, conspicuous germ slit (Ju \& Rogers 2002), however, N. viridis has characteristic opaque brown ascospores while N. maritima has brown ascospores. Additionally, ascospores of $N$. viridis are larger $(136-150 \times 8-12 \mu \mathrm{m} v s 65-90 \times 4-7 \mu \mathrm{m})$ and asci are longer than $(15-17 \times 6-8 \mu \mathrm{m} v s 6.5-10 \times 3-6 \mu \mathrm{m})$ that of $N$. maritima. We also compared the base pair differences of ITS gene regions of $N$. viridis and $N$. maritima (non-type) are accounted 48 bp out of $561 \mathrm{bp}(8 \%)$.
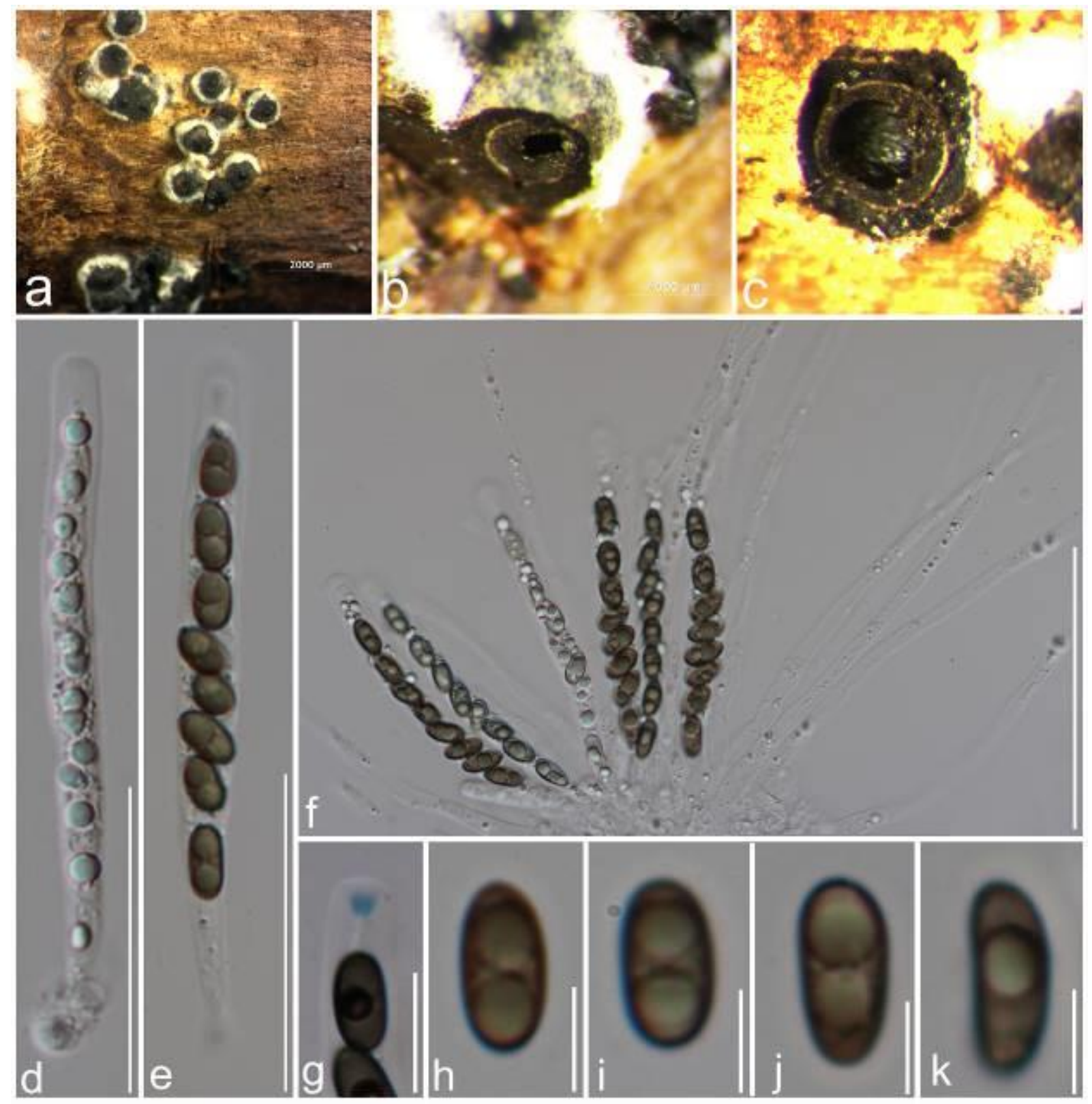

Figure 89 - Nemania maritima (MFLU 16-1236). a Stromata on host. b Vertically section of 
ascostromta. c. Horizontally section of ascostromata. d-f Asci and paraphyses. g. Apical ring stained dark blue with Melzer's reagent. h-k Ascospores. Scale bars: $\mathrm{f}=100 \mu \mathrm{m}, \mathrm{d}, \mathrm{e}=50 \mu \mathrm{m}$, $\mathrm{g}=10 \mu \mathrm{m} \mathrm{h}-\mathrm{k}=5 \mu \mathrm{m}$.
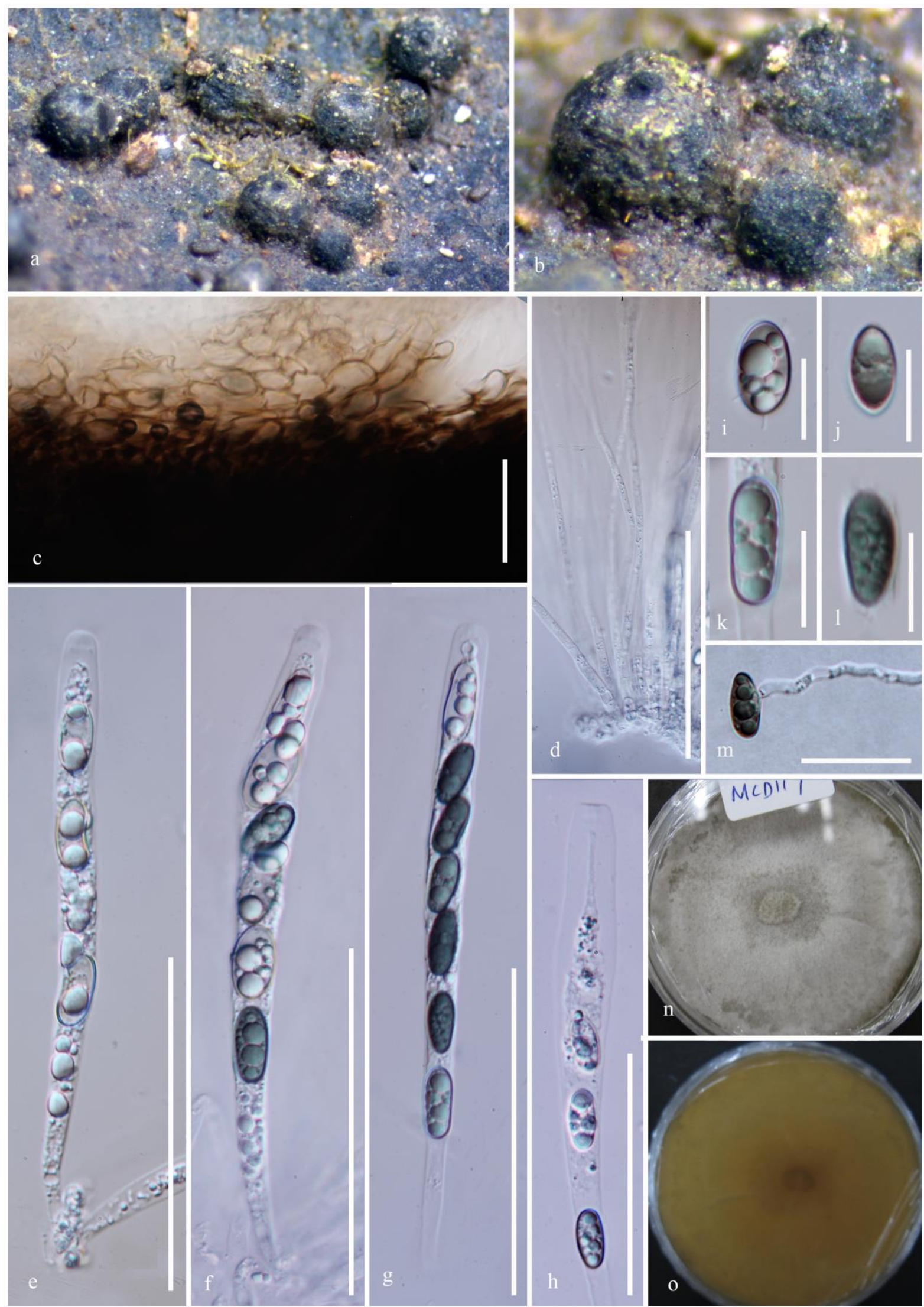

Figure 90 - Nemania viridis (MFLU 17-2600, holotype). a, b Appearance of psudostromata on 
host. c Peridium. d Paraphyses. e-h Asci i-l Ascospores. m Germinating ascospore. n, o Culture on sea water PDA (n upper, o lower). Scale bars: $\mathrm{e}-\mathrm{g}=100 \mu \mathrm{m}, \mathrm{d}, \mathrm{h}, \mathrm{m}=50 \mu \mathrm{m}, \mathrm{f}-\mathrm{i}=50 \mu \mathrm{m}$, c, $\mathrm{i}-1=20 \mu \mathrm{m}$.

Nemania phetchaburiensis Dayarathne, E.B.G. Jones. \& K.D. Hyde, sp. nov.

Fig. 91

Index Fungorum number: IF556602; Facesoffungi number: FoF 06195

Etymology - name referring to the host genus Rhizophora.

Holotype - MFLU 16-1185

Saprobic on root pieces of Rhizophora sp. submerged in marine water. Sexual morph: Ascostromata 800-1600 $\times 1300-2100 \mu \mathrm{m}(\overline{\mathrm{x}}=1200 \times 1700 \mu \mathrm{m}, \mathrm{n}=5)$, semi immersed to superficial with base immersed pulvinate to hemispherical, in clusters of up to 20 uniperitheciate stromata, shiny, surface black, carbonaceous. In section, stromata comprising host cells filled with amorphous black fungal material. Ascomata immersed in stroma, subglobose to hemispherical, black, ostioles papillate. Peridium $80-135 \mu \mathrm{m}$ wide two-layered, outer layer of cells of textura angularis fusing at the outside with the pseudostromata, inner layer of lighter elongate cells. Paraphyses 2-3 $\mu \mathrm{m}$ wide, filamentous, hyaline, septate, flexuous, branched, numerous and embedded in a gelatinous matrix. Asci $90-150 \times 12-13 \mu \mathrm{m}(\overline{\mathrm{x}}=120 \times 12.515 \mu \mathrm{m}, \mathrm{n}=20)$, 6-8spored, cylindrical, overlapping, short pedicellate, unitunicate, apical ring apically truncate with a 5 $\times 2.3 \mu \mathrm{m}$ wedge-shaped, subapical ring which becomes dark blue in Melzer's reagent. Ascospores 14-16 $\times 6-8 \mu \mathrm{m}(\overline{\mathrm{x}}=15 \times 6.5 \mu \mathrm{m}, \mathrm{n}=20)$ overlapping uniseriate, light brown at immature stage, dark to greenish brown when mature, more or less inequilaterally ellipsoid, ventral side varying in degree of convex curvature, upper and lower ends slightly pointed, one-celled, 1-2 guttules, germination slit usually clearly seen on the ventral side, straight, conspicuous. Asexual morph: Undetermined.

Culture characteristics - Colonies on sea water PDA at $25-28{ }^{\circ} \mathrm{C}$ reaching $5 \mathrm{~cm}$ in 7 days, whitish colonies, zonate with diffuse margins, reverse at first whitish and turning yellow to light brown after 3-4 days.

Material examined - THAILAND, Phetchaburi Province, Hat Chao Samran, 47 72506' E, $40^{\circ} 25038^{\prime}$ N, 0 m asl., on intertidal decayed wood of Rhizophora sp. at a mangrove stand, 28 August 2015, M.C. Dayarathne, CHAM007 (MFLU 16-1185, holotype); ibid., (HKAS 97420, isotype), ex-type living culture MFLUCC 15-0953.

GenBank numbers - LSU: MF615402; ITS: MN047124

Additional GenBank number - SSU: MN017943

Notes - Nemania phetchaburiensis is characterized by having pulvinate to hemispherical stromata in clusters of up to 20 uniperitheciate stroma and 1-2 guttulate, inequilaterally ellipsoid ascospores with the ventral side varying in degree of convex curvature and with a clearly seen germination slit usually on the ventral side. Nemania phetchaburiensis grouped closely to $N$. diffusa (isolate NC1333) and N. plumbea (JF TH 04-01), but with weak statistical support (Fig. 89). Morphologically $N$. phetchaburiensis and $N$. diffusa have effused-pulvinate ascostromata with spherical to obovoid perithecia (Ju \& Rogers 2002). They can be distinguished by ascospore size $(14-16 \times 6-8 \mu \mathrm{m} v s$ 9.5-13.5 × 5-6 $\mu \mathrm{m})(\mathrm{Ju} \&$ Rogers 2002). Furthermore, $98 \mathrm{bp}$ of ITS locus are different out of 645 bp $(15 \%)$ between $N$. phetchaburiensis and $N$. diffusa. Nemania phetchaburiensis and $N$. plumbea also have effused-pulvinate ascostromata like in $N$. phetchaburiensis, but, ascomata of $N$. plumbea are spherical to ellipsoid, while $N$. phetchaburiensis has subglobose to hemispherical ascomata (Tang et al. 2007). There are 102 base pair difference of ITS locus out of $642 \mathrm{bp}(15.2 \%)$ of these two species. However, further collections of this novel taxon are required as no DNA sequence data from protein coding genes are available for this species. 

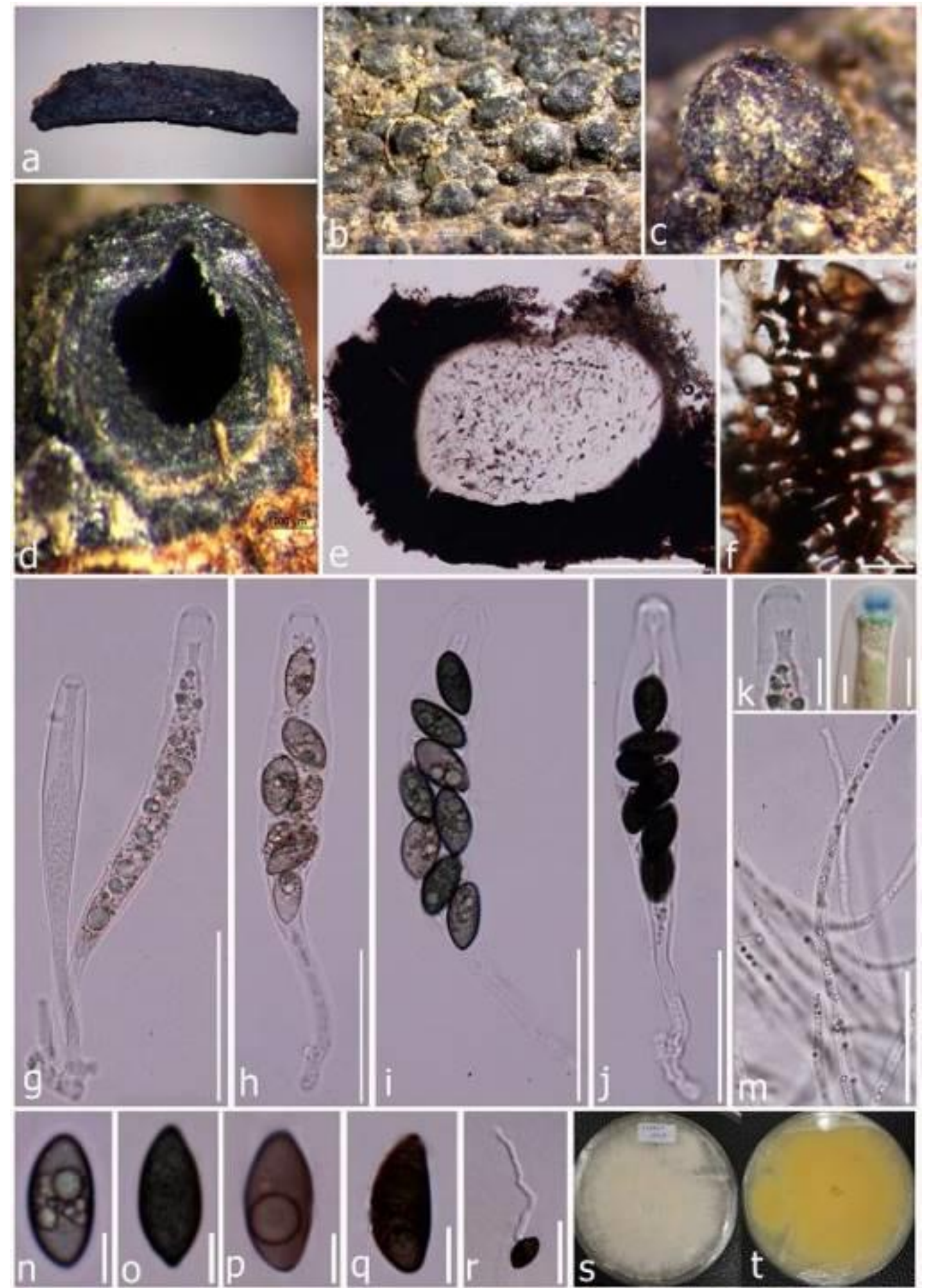

Figure 91 - Nemania phetchaburiensis (MFLU 16-1185, holotype). a, b, c Stromata on host. $\mathrm{d}$, e Section through stroma. f Peridium. $\mathrm{g}-\mathrm{j}$ Asci. k Apical ring without staining. 1. Apical ring stained dark blue with Melzer's reagent. m Paraphyses. $n-q$ Ascospores. $r$ Germinating ascospore. $\mathrm{s}, \mathrm{t}$ Cultures on PDA (s from above, $\mathrm{t}$ from below). Scale bars: $\mathrm{b}, \mathrm{d}=1000 \mu \mathrm{m}, \mathrm{e}=500 \mu \mathrm{m}$, $\mathrm{h}-\mathrm{j}=50 \mu \mathrm{m}, \mathrm{g}, \mathrm{m}, \mathrm{r}=20 \mu \mathrm{m}, \mathrm{f}=10 \mu \mathrm{m}, \mathrm{n}-\mathrm{q}=5 \mu \mathrm{m}$. 


\section{Acknowledgements}

We are grateful to the Thailand Research Fund (TRF) grant no RSA5980068 entitled Biodiversity, phylogeny and role of fungal endophytes on above parts of Rhizophora apiculata and Nypa fruticans; National Research Council of Thailand (NRCT) for a grant entitled Diseases of mangrove trees and maintenance of good forestry practice (Grant number: 60201000201) and Thailand Research Fund (TRF) grant no MRG6080089. E.B. Gareth Jones acknowledges the award of a Distinguished Scientist Fellowship Program (DSFP), King Saud University, Kingdom of Saudi Arabia. The Swedish Species Initiative ('ArtDatabanken') is thanked for support within the project 'Marine fungi in Sweden' (SLU.dha.2017.4.3-73) to Dr. Sanja Tibell. All the staff members at Ranong Mangrove Research Center, Ranong are highly appreciated for providing permission to obtain material and their great support in collecting samples. V.V. Sarma would like to offer his sincere gratitude to the grant of Ministry of Earth sciences, Govt. of India, under (Sanction order: MOES/36/OO1S/Extra/40/2014/PC-IV dt.14.1.2015), District Forest Office, Tiruvarur and PCCF, Forest Department of Tamil Nadu, India for providing permission to collect samples, Department of Biotechnology, Pondicherry University for providing the laboratory facilities and Devadatha thanks Ministry of Earth sciences, Govt. of India for providing a fellowship. Dr. Shaun Pennycook is acknowledged for the help in Latin diagnosis for the fungal names. Monika Dayarathne offers her deepest gratitude to Prof. Alan J. L. Phillips, Prof. Mark Stadler, Dr. Dhanushka Wanasinghe, Mr. Danuska Tennakoon and Mr. Rashika Sajith for their helpful comments and advice.

\section{References}

Abdel-Wahab MA, Bahkali AHA. 2012 - Taxonomy of filamentous anamorphic marine fungi: morphology and molecular evidence. In: Jones EBG, Pang KL (eds) Marine fungi and fungallike organisms. Walter De Gruyter GmbH \& Co. KG, Berlin/Boston, pp 65-90.

Abdel-Wahab MA, Dayarathne MC, Suetrong S, Guo SY et al. 2017 - New saprobic marine fungi and a new combination. Botanica Marina 60, 469-488.

Abdel-Wahab MA, Hodhod MS, Bahkali AHA, Jones EBG. 2014 - Marine fungi of Saudi Arabia. Botanica Marina 57, 323-335.

Abdel-Wahab MA, Jones EBG. 2000 - Three new marine ascomycetes from driftwood in Australian sand dunes. Mycoscience 41, 379-388.

Abdel-Wahab MA, Jones EBG. 2003 - Decaisnella formosa sp. nov. (Ascomycota, Massariaceae) from an Australian sandy beach. Canadian Journal of Botany 81, 598-600.

Abdel-Wahab MA, Nagahama T. 2011 - Gesasha (Halosphaeriaceae, Ascomycota), a new genus from ther Gesashi mangroves in Japan. Nova Hedwigia 92, 497-512.

Abdel-Wahab MA, Pang KL, Nagahama T, Abdel-Aziz F, Jones EBG. 2010 - Phylogenetic evaluation of anamorphic species of Cirrenalia and Cumulospora with the description of eight new genera and four new species. Mycological Progress 9, 537-558.

Acero FJ, González V, Sánchez-Ballesteros J, Rubio V et al. 2004 - Molecular phylogenetic studies on the Diatrypaceae based on rDNA-ITS sequences. Mycologia 96, 249-259.

Ahmed SA, González GM, Tirado-Sánchez A, Moreno-López LM, De Hoog S, Bonifaz A. 2018 Nigrograna mackinnonii, not Trematosphaeria grisea (syn., Madurella grisea), is the main agent of black grain eumycetoma in Latin America. Journal of Clinical Microbiology 56(3), e01723-17.

Ahmed SA, Van De Sande WWJ, Stevens DA, Fahal A et al. 2014 - Revision of agents of blackgrain eumycetoma in the order Pleosporales. Persoonia: Molecular Phylogeny and Evolution of Fungi 33, 141-154.

Alias SA, Jones EBG. 2009 - Marine fungi from mangroves of Malaysia. Institute of Ocean and Earth Sciences, University of Malaya.

Alias SA, Jones EG, Torres J. 1999 - Intertidal fungi from the Philippines, with a description of Acrocordiopsis sphaerica sp. nov. (Ascomycota). Fungal Diversity 2, 35-41. 
Alias SA, Zainuddin N, Jones EBG. 2010 - Biodiversity of marine fungi in Malaysian mangroves. Botanica Marina 53, 545-554.

Andersson K, Eriksson OE, Landvik S. 1995 - Boliniaceae transferred to Sordariales (Ascomycota). Systema Ascomycetum 14: 1-16.

Ariyawansa HA, Hawksworth DL, Hyde KD, Jones EG et al. 2014 - Epitypification and neotypification: guidelines with appropriate and inappropriate examples. Fungal Diversity 69(1), 5-10.

Ariyawansa HA, Hyde KD, Jayasiri SC, Buyck B et al. 2015a - Fungal diversity notes 111-252 taxonomic and phylogenetic contributions to fungal taxa. Fungal Diversity 75, 27-274.

Ariyawansa HA, Thambugala KM, Manamgoda DS, Jayawardena R et al. 2015b - Towards a natural classification and backbone tree for Pleosporaceae. Fungal Diversity 71, 85-139.

Asgari B, Zare R, Gams W. 2007 - Coniochaeta ershadii, a new species from Iran, and a key to well-documented Coniochaeta species. Nova Hedwigia 84, 175-187.

Atkinson TJ, Miller AN, Huhndorf SM, Orlovich DA. 2007 - Unusual new Chaetosphaeria species from New Zealand: Intrafamilial diversity and elucidations of the Chaetosphaeriaceae-Lasiosphaeriaceae relationship (Sordariomycetes, Ascomycotina). New Zealand Journal of Botany 45, 685-706.

Atlas RM. 2006 - The handbook of microbiological media for the examination of food: 314 . CRC Press, pp 314

Aveskamp MM, De Gruyter H, Woudenberg J, Verkley G, Crous PW. 2010 - Highlights of the Didymellaceae: a polyphasic approach to characterize Phoma and related pleosporalean genera. Studies in Mycology 65, 1-60.

Bakhshi M, Arzanlou M, Groenewald JZ, Quaedvlieg W et al. 2019 - Parastagonosporella fallopiae gen. et sp. nov. (Phaeosphaeriaceae) on Fallopia convolvulus from Iran. Mycological Progress 18, 203-214.

Barghoorn ES, Linder DH. 1944 - Marine fungi: their taxonomy and biology. Farlowia 1, 395-467.

Barluenga S, Dakas PY, Ferandin Y, Meijer L, Winssinger N. 2006 - Modular asymmetric synthesis of Aigialomycin D, a Kinase-Inhibitory scaffold. Angewandte Chemie International Edition 45, 3951-3954.

Barr ME 1978 - The Diaporthales in North America: with emphasis on Gnomonia and its segregates. Mycologia Memoirs 7, 1-232.

Barr ME 1982 - On the Pleomassariaceae (Pleosporales) in North America. Mycotaxon 15, 349383.

Barr ME 1990a - Melanommatales (Loculoascomycetes). North American Flora, Series II, Part 13, $1-129$.

Barr ME 1990b - Some dictyosporous genera and species of Pleosporales in North America. Memoirs of the New York Botanical Garden 62, 1-92.

Barr ME. 1979 - On the Massariaceae in North America; Mycotaxon 9, 17-37

Berlese AN. 1902 - Icones Fungorum Omnium Hucusque Cognitorum. (1900-1905). 3, pp. 80-82.

Berner D, Cavin C, Woudenberg JH, Tunali B et al. 2015 - Assessment of Boeremia exigua var. rhapontica, as a biological control agent of Russian knapweed (Rhaponticum repens). Biological Control, 81, pp.65-75.

Bezerra JD, Oliveira RJ, Paiva LM, Silva GA et al. 2017 - Bezerromycetales and Wiesneriomycetales ord. nov. (class Dothideomycetes), with two novel genera to accommodate endophytic fungi from Brazilian cactus. Mycological Progress, 16, 297-309.

Boehm EW, Mugambi GK, Miller AN, Huhndorf SM et al. 2009a - A molecular phylogenetic reappraisal of the Hysteriaceae, Mytilinidiaceae and Gloniaceae (Pleosporomycetidae, Dothideomycetes) with keys to world species. Studies in Mycology 64, 49-83.

Boehm EW, Schoch CL, Spatafora JW. 2009b - On the evolution of the Hysteriaceae and Mytilinidiaceae (Pleosporomycetidae, Dothideomycetes, Ascomycota) using four nuclear 390 genes. Mycological Research 113, 461-479. 
Boerema GH, Gruyter J de, Noordeloos ME, Hamers MEC. 2004 - Phoma identification manual: differentiation of specific andinfra-specific taxa in culture. CABI

Boise J. 1985 - An amended description of Trematosphaeria. Mycologia 77, 230-237.

Boonmee S, D'souza MJ, Luo Z, Pinruan U et al. 2016 - Dictyosporiaceae fam. nov. Fungal Diversity 80, 457-482

Boonmee S, Rossman AY, Liu JK, Li WJ et al. 2014 - Tubeufiales, ord. nov., integrating sexual and asexual generic names. Fungal Diversity 68, 239-298.

Boonmee S, Zhang Y, Chomnunti P, Chukeatirote E et al. 2011 - Revision of lignicolous Tubeufiaceae based on morphological reexamination and 6979 phylogenetic analysis. Fungal Diversity 51, 63-102.

Boonyuen N, Chuaseeharonnachai C, Suetrng S, Sri-Indrasutdhi V et al. 2011 - Savoryellales (Hypocreomycetideae, Sordariomycetes): a novel lineage of aquatic ascomycetes inferred from multiple-gene phylogenies of the genera Ascotaiwania, Ascothailandia and Savoryella. Mycologia 103, 1351-1350.

Booth T, Kenkel N. 1986 - Ecological studies of lignicolous marine fungi: a distribution model based on ordination and classification. The Biology of Marine Fungi. (ed. S T Moss) Cambridge University Press, pp 297-310.

Borman AM, Desnos-Ollivier M, Campbell CK, Bridge PD et al. 2016 - Novel taxa associated with human fungal black-grain mycetomas - Emarellia grisea gen. nov. et sp. nov. and Emarellia paragrisea sp. nov. - Journal of Clinical Microbiology 54, 1738-1745.

Borse BD. 1987 - New species Aigialus from India. British Mycological Society 88, 424-426.

Brahmanage RS, Lu YZ, Bhat DJ, Wanasinghe DN et al. 2017 - Phylogenetic investigations on freshwater fungi in Tubeufiaceae (Tubeufiales) reveals the new genus Dictyospora and new species Chlamydotubeufia aquatica and Helicosporium flavum. Mycosphere 8: 917-933.

Cain RF. 1961 - Studies of soil fungi: iii. New species of Coniochaeta, Chaetomidium, and Thielavia. Canadian Journal of Botany 39, 1231-1239.

Cannon PF, Hawksworth L. 1984 - A revision of the genus Neocosmospora (Hypocreales). Transactions of the British Mycological Society 82, 673-688.

Cannon PF, Kirk PM. 2007 - Fungal Families of the World. CABI, Egham, U.K.

Cantrell SA, Hanlin RT, Emiliano A. 2007 - Periconia variicolor sp. nov., a new species from Puerto Rico. Mycologia 99(3), 482-487

Carbone I, Kohn LM. 1999 - A method for designing primer sets for speciation studies in filamentous ascomycetes. Mycologia 91, 553-556.

Carmarán CC, Novas MV. 2003 - A review of Spegazzini taxa of Periconia and Sporocybe after over 115 years. Fungal Diversity 14, 67-76.

Carmarán CC, Romero AI, Giussani LM. 2006 - An approach towards a new phylogenetic classification in Diatrypaceae. Fungal Diversity 23, 67-87.

Carson ML. 2005 - Yield loss potential of Phaeospharia leaf spot of maize caused by Phaeosphaeria maydis in the United States. Plant Disease 89, 986-988.

Castro LG, Salebian A, Sotto MN. 1990 - Hyalohyphomycosis by Paecilomyces lilacinus in a renal transplant patient and a review of human Paecilomyces species infections. Journal of Medical and Veterinary Mycology 28, 15-26.

Cawthorn RJ. 2011 - Diseases of American lobsters (Homarus americanus): a review. Journal Invertebrate Pathology 106, 71-78.

Chalermpongse A. 1991 - Fungal diseases in mangrove ecosystem. In: Proceeding, the $5^{\text {th }}$ Silviculture Seminar in Thailand, Division of Silviculture, Royal Forest Department, Bangkok, Thailand, 307-338.

Chatmala I, Sakayaroj J, Somrithipol S, Phongpaichit S. 2004 - Marine hyphomycetes of Thailand and Cumulospora varia sp. nov. Fungal Diversity 17, 1-9.

Chaverri P, Salgado C, Hirooka Y, Rossman AY, Samuels GJ. 2011 - Delimitation of Neonectria and Cylindrocarpon (Nectriaceae, Hypocreales, Ascomycota) and related genera with Cylindrocarpon-like anamorphs. Studies in Mycology 68, 57-78. 
Chen Q, Hou LW, Duan WJ, Crous PW, Cai L. 2017 - Didymellaceae revised. Studies in Mycology 87, 105-156.

Chen YS, Cheng MJ, Hsiao Y, Chan HY et al. 2015 - Chemical constituents of the endophytic fungus Hypoxylon sp. 12F0687 isolated from Taiwanese Ilex formosana. Helvetica Chimica Acta 98, 1167-1176.

Cheng X, Li W, Cai L. 2015 - Molecular phylogeny of Ascotricha, including two new marine algae-associated species. Mycologia 107(3), 490-504.

Chevallier FF. 1826 - Flore Ge'ne'rale des Environs de Paris, vol. 1. Ferra Jeune, Paris, pp 1-674.

Chomnunti P, Hongsanan S, Aguirre-Hudson B, Tian Q et al. 2014 - The sooty moulds. Fungal Diversity 66, 1-36.

Clements FE, Shear CL. 1931 - The Genera of Fungi. HW Wilson Co. Publ., Minneapolis, MN, U.S.A.

Clements FE. 1909 - The Genera of Fungi. HW Wilson Company.

Clendenin I. 1896 - Lasiodiplodia E. \& E., n. gen. Botanical Gazette 21, 92-92.

Cole GT, Kendrick B. 1981 - Biology of Conidial Fungi. Academic Press, New York.

Corda ACI. 1836 - Mykologische Beobachtungen. in Weitenweber, Beitrage zur gesammten Natur- und Heilwissenschaften (Prague)

Corda ACI. 1838 - Icones Fungorum hucusque Cognitorum 2: i-viii, 1-43. Czechoslovakia, Prague; J.G. Calve [Fridericum Ehrlich].

Crane JL, Schoknecht JD. 1982 - A new species of Acrodontium from Brazil. Transactions of the British Mycological Society 79, 345-347.

Cribb AB, Cribb W. 1955 - Marine fungi from Queensland-I. University of Queensland Papers, Department of Botany 3, 77-81.

Crous PW, Shivas RG, Quaedvlieg W, van der Bank M et al. 2014 - Fungal Planet description sheets: 214-280. Persoonia 32, 184-306.

Damm U, Fourie PH, Crous PW. 2010 - Coniochaeta (Lecythophora), Collophora gen. nov. and Phaeomoniella species associated with wood necroses of Prunus trees. Persoonia 24, 60-80.

Daranagama DA, Hyde KD, Sir EB, Thambugala KM et al. 2018 - Towards a natural classification and backbone tree for Graphostromataceae, Hypoxylaceae, Lopadostomataceae and Xylariaceae. Fungal Diversity 88, 1-165

Daranagama DA, Liu X, Chamyuang S, Stadler M. et al. 2015 - Rhopalostroma brevistipitatum sp. nov. from Thailand with an extended generic description for Rhopalostroma. Phytotaxa, 227, 229-242.

Das M, Royer TV, Leff LG. 2007 - Diversity of fungi, bacteria, and actinomycetes on leaves decomposing in a stream. Applied and Environmental Microbiology 73, 756-767.

Dayarathne MC, Maharachchikumbura SSN, Jones EBG, Chomnunti P et al. 2019a - Sexual morph of Phaeoacremonium aureum from Rhizophora mucronata collected in Southern Thailand, Phytotaxa 387, 21-39.

Dayarathne MC, Maharachchikumbura SSN, Jones EBG, Wei D et al. 2019b - The evolution of Savoryellaceae and evidence for its ranking as a subclass, Frontiers in Microbiology 10, 840.

Dayarathne MC, Phookamsak R, Hyde KD, Manawasinghe IS et al. 2016 - Halodiatrype, a novel diatrypaceous genus from mangroves with $H$. salinicola and $H$. avicenniae spp. nov. Mycosphere 7, 612-627.

Dayarathne MC, Wanasinghe DN, Devadatha B, Abeywickrama P et al. 2019c - Modern taxonomic approaches to identifiying diatrypaceous fungi from marine habitats, a novel genus Halocryptovalsa and expansion of Halodiatrype, Cryptogamie Mycologie )accepted(

Dayarathne MC, Wanasinghe DN, Jones EBG, Chomnunti P, Hyde KD. 2018 - A novel marine genus, Halobyssothecium (Lentitheciaceae) and epitypification of Halobyssothecium obiones comb. nov., Mycological Progress 17, 1161-1171.

De Almeida DAC, Gusmao LFP, Miller AN. 2014 - A new genus and three new species of hysteriaceous ascomycetes from the semiarid region of Brazil. Phytotaxa 176, 298-308. 
De Almeida DAC, Gusmão LFP, Miller AN. 2016 - Taxonomy and molecular phylogeny of Diatrypaceae (Ascomycota, Xylariales) species from the Brazilian semi-arid region, including four new species. Mycological Progress 15, 1-27.

De Gruyter J, Woudebnerg JHC, Aveskamp MM, Verkley GJM. 2013 - Redisposition of phomalike anamorphs in Pleosporales. Studies in Mycology 75, 1-36.

De Gruyter J. Boerema GH. 2002 - Contributions towards amonograph of Phoma (Coelomycetes) - IV. Section Heterospora: Taxa with large sized conidial dimorphs, in vivo sometimes as Stagonosporopsis synanamorphs. Persoonia-Molecular Phylogeny and Evolution of Fungi 16, 335-371.

De Gruyter JD, Aveskamp MM, Woudenberg JHC, Verkley GJM et al. 2009 - Molecular phylogeny of Phoma and allied anamorph genera: towards a reclassification of the Phoma complex. Mycological Research 113, 508-519.

De Long Q, Liu LL, Zhang X, Wen TC et al. 2019 - Contributions to species of Xylariales in China-1. Durotheca species. Mycological Progress 18, 495-510.

De Souza Sebastianes FL, Romao-Dumaresq AS, Lacava PT, Harakava R et al. 2013 - Species diversity of culturable endophytic fungi from Brazilian mangrove forests. Current Genetics 59, 153-166.

Dethoup T, Manoch L. 2009 - Diversity of marine fungi in eastern Thailand. Kasetsart Journal (Natural Science) 43, 100-106.

Devadatha B, Sarma VV, Ariyawansa HA, Jones EBG. 2018 - Deniquelata vittalii sp. nov., a novel Indian saprobic marine fungus on Suaeda monoica and two new records of marine fungi from Muthupet mangroves, East coast of India. Mycosphere 9, 565-582

Devadatha B, Sarma VV, Wanasinghe DN, Hyde KD, Jones EBG. 2017 - Introducing the new Indian mangrove species, Vaginatispora microarmatispora (Lophiostomataceae) based on morphology and multigene phylogenetic analysis. Phytotaxa 329(2), 139-149.

Dissanayake AJ, Camporesi E, Hyde KD, Phillips AJL et al. 2016 - Dothiorella species associated with woody hosts in Italy. Mycosphere 7, 51-63.

Dissanayake AJ, Phillips AJL, Hyde KD, Yan JY et al. 2017 - The current status of species in Diaporthe. Mycosphere 8(5), 1106-1156.

Doilom M, Dissanayake AJ, Wanasinghe DN, Boonmee S et al. 2017 - Microfungi on Tectona grandis (teak) in Northern Thailand. Fungal Diversity 82, 107-182

Doilom M, Dissanayake AJ, Wanasinghe DN, Boonmee S. et al. 2016 - Microfungi on Tectona grandis (teak) in Northern Thailand. Fungal Diversity 82, 107-182.

Domsch KH, Gams W, AndersonT-H. 2007 - Compendium of Soil Fungi, $2^{\text {nd }}$ Taxonomically Revised Edition by W. Gams. Eching, Germany, IHW-Verlag.

Durieu MC, Montagne FC. 1846-1850 - Exploration scientifique de l'Algerie.

Ellis JB, Everhart BM. 1894 - New species of fungi from various localities. Proceedings of the Academy of Natural Sciences of Philadelphia 322-386.

Ellis MB, Kellerman WA. 1888 - New Kansas fungi. Journal of Mycology 4, 26-27.

Ellis MB. 1971 - Dematiaceous Hyphomycetes. Commonwealth Mycological Institute, Kew, Surrey, England, pp 608.

Ellis MB.1976 - More dematiaceous hyphomycetes. Commonwealth Mycological Institute, Kew, pp 507.

Eriksson O. 1981 - The families of bitunicate ascomycetes. Nordic Journal of Botany 1, 800-800.

Eriksson O. 1982 - Notes on Ascomycetes and Coelomycetes from NW. Europe. Mycotaxon 15, 189-202

Eriksson OE, Hawksworth DL. 1992 - Notes on ascomycete systematics-Nos. 1294-1417. Systema Ascomycetum 11, 49-82

Fell JW, Master IM. 1973 - Fungi associated with the degradation of mangrove (Rhizophora mangle L.) leaves in South Florida. In: Estuarine Microbial Ecology, eds Stevenson LH, Colwell RR, Univ. S. Carolina Press, Columbia. 
Fernández FA, Huhndorf SM. 2005 - New species of Chaetosphaeria, Melanopsammella and Tainosphaeria gen. nov. from the Americas. Fungal Diversity 18, 15-57.

Fernández FA, Miller AN, Huhndorf SM, Lutzoni FM, Zoller S. 2006 - Systematics of the genus Chaetosphaeria and its allied genera: morphological and phylogenetic diversity in north temperate and neotropical taxa. Mycologia 98, 121-130.

Fiedler Ż, Sosnowska D. 2007 - Nematophagous fungus Paecilomyces lilacinus (Thom) Samson is also a biological agent for control of greenhouse insects and mite pests. Biological Control 52, 547-558.

Fries E. 1849 - Summa Vegetabilium Scandinaviae. - Part 2. Bonnier, Stockholm \& Leipzig.

Gams W, Holubova-Jechova V. 1976 - Chloridium and some other dematiaceous hyphomycetes growing on wood. Studies in Mycology 13, 1-99.

Gams W, Zare R. 2001 - A revision of Verticillium sect. prostrata. III. Generic classification. Nova Hedwigia 72, 329-337.

Gams W. 1971 - Cephalosporium artige schimmelpilze (Hyphomycetes) Gustav Fischer Verlag, Stuttgart 262S.

García D, Stchigel AM, Cano J, Calduch M. et al. 2006 - Molecular phylogeny of Coniochaetales. Mycological Research 110, 1271-1289.

Glass NL, Donaldson GC. 1995 - Development of primer sets designed for use with the PCR to amplify conserved genes from filamentous ascomycetes. Applied and Environmental Microbiology 61, 1323-1330.

Glawe DA, Rogers JD. 1984 - Diatrypaceae in the Pacific Northwest. Mycotaxon 20, 401-460.

Goh TK, Hyde KD, Ho WH. 1999 - A revision of the genus Dictyosporium, with descriptions of three new species. Fungal Diversity 2, 65-100.

Gomes RR, Glienke C, Videira SIR, Lombard L et al. 2013 - Diaporthe: a genus of endophytic, saprobic and plant pathogenic fungi. Persoonia: Molecular Phylogeny and Evolution of Fungi $31,1-41$.

Gräfenhan T, Schroers HJ, Nirenberg HI, Seifert KA. 2011 - An overview of the taxonomy, phylogeny, and typification of nectriaceous fungi in Cosmospora, Acremonium, Fusarium, Stilbella, and Volutella. Studies in Mycology 68, 79-113.

Guterres DC, Galvão-Elias S, Santos MDM, De Souza BCP et al. 2019 - Phylogenetic relationships of Phaeochorella parinarii and recognition of a new family, Phaeochorellaceae (Diaporthales). Mycologia 2, 1-16.

Hall TA. 1999 - BioEdit: a user-friendly biological sequence alignment editor and analysis program for Windows 95/98/NT. Nucleic Acids Symposium Series 41, 95-98.

Harnpicharnchai P, Champreda V, Sornlake W, Eurwilaichitr L. 2009 - A thermotolerant $\beta$ glucosidase isolated from an endophytic fungus, Periconia sp., with a possible use for biomass conversion to sugars. Protein expression and purification 67, 61-69.

Hassett BT, Vonnahme TR, Peng X, Jones EBG, Heuze C. 2019 - Review of planktonic marine fungi, cultured and high-throughput sequencing diversity and ecology. Botanica Marina https://doi.org/10.1515/bot-2018-0113

Hawksworth DL, Booth C. 1974 - A revision of the genus Zopfia Rabenh. Mycological Papers (UK).

Hawksworth DL, Kirk PM, Sutton BC, Pegler DN. 1995 - Ainsworth \& Bisby's dictionary of the fungi, 8th edn. CAB International, Wallingford.

Hawksworth DL. 1979 - Lichenicolous Hyphomycetes.

Helaly SE, Thongbai B, Stadler M. 2018 - Diversity of biologically active secondary metabolites from endophytic and saprotrophic fungi of the ascomycete order Xylariales. Natural Product Reports 35, 992-1014.

Hernández-Restrepo M, Groenewald JZ, Crous PW. 2016 - Taxonomic and phylogenetic reevaluation of Microdochium, Monographella and Idriella. Persoonia: Molecular Phylogeny and Evolution of Fungi 36, 57-82. 
Hirooka Y, Rossman AY, Chaverri P. 2011 - A morphological and phylogenetic revision of the Nectria cinnabarina species complex. Studies in Mycology 68, 35-56.

Hodhod MS, Abdel-Wahab MA, Bahkali AH, Hyde KD. 2012 - Amarenographium solium sp. nov. from Yanbu mangroves in the Kingdom of Saudi Arabia. Cryptogam Mycologie 33, 285295.

Holubova-Jechova V. 1990 - Problems in the taxonomy of the dematiaceous Hyphomycetes. Studies in Mycology 32, 41-48.

Hsieh HM, Ju YM, Rogers JD. 2005 - Molecular phylogeny of Hypoxylon and closely related genera. Mycologia 97, 844-865. http://tree.bio.ed.ac.uk/software/figtree/.

Hu DM, Cai L, Hyde KD. 2012 - Three new ascomycetes from freshwater in China. Mycologia 104, 1478-1489

Huelsenbeck JP, Ronquist F. 2001 - MRBAYES: Bayesian inference of phylogenetic trees. Bioinformatics 17, 754-755.

Hughes G. 1986 - Biogeography and the marine fungi Moss, S.T. (Ed.), The Biology of Marine Fungi, Cambridge University Press, Cambridge pp. 275-295.

Hughes GC. 1974 - Geographical distribution of the higher mariner fungi. Veröffentlichungen des Instituts für Meeresforschung in Bremerhaven Supplemen 10, 419-441.

Huhndorf SM, Fernández FA, Taylor JE, Hyde KD. 2001 - Two pantropical ascomycetes: Chaetosphaeria cylindrospora sp. nov. and Rimaconus, a new genus for Lasiosphaeria jamaicensis. Mycologia 93, 1072-1080.

Huhndorf SM, Miller AN, Fernández FA. 2004 - Molecular systematics of the Sordariales: the order and the family Lasiosphaeriaceae redefined. Mycologia 96, 368-387.

Huhndorf SM, Miller AN. 2008 - A new species of Camarops and phylogenetic analysis of related taxa in the Boliniaceae. North American Fungi 3, 231-239.

Huhndorf SM, Miller AN. 2011 - A molecular re-appraisal of taxa in the Sordariomycetidae and a new species of Rimaconus from New Zealand. Studies in Mycology 68, 203-210.

Hyde KD. 1988 - Studies on the tropical marine fungi of Brunei. Botanical Journal of the Linnean Society $98,135-151$.

Hyde KD. 1989 - Intertidal mangrove fungi from north Sumatra. Canadian Journal of Botany 67, 3078-3082.

Hyde KD. 1991a - Helicascus kanaloanus, Helicascus nypae sp. nov. and Salsuginea ramicola gen. et sp. nov. from intertidal mangrove wood. Botanica Marina 34, 311-318.

Hyde KD. 1992a - Julella avivenniae (Borse. comb. nov. (Thelenellaceae. from intertidal mangrove wood and miscellaneous fungi from the north east coast of Queensland. 95, 939942.

Hyde K. 1992b - Aigialus striatispora sp. nov. from intertidal mangrove wood. Mycological Research 96, 1044-1046.

Hyde KD. 1993a - Tropical Australian freshwater fungi. VI. Tiarosporella paludosa and Clohesyomyces aquaticus gen. et sp. nov. (Coelomycetes). Australian Systematic Botany 6, 169-173.

Hyde KD. 1993b - Cryptovalsa halosarceicola sp. nov. an intertidal saprotroph of Halosarceia halocnemoides. Mycological Research 97, 799-800.

Hyde KD.1991b - Phomopsis mangrovei, from intertidal prop roots of Rhizophora spp. Mycological Research 95, 1149-1151.

Hyde KD, Jones EBG 1988 - Marine mangrove fungi. Marine Ecology 9, 15-33.

Hyde KD, Chaiwan N, Norphanphoun C, Boonmee S et al. 2018 - Mycosphere notes 169-224. Mycosphere 9, 271-430.

Hyde KD, Chalermpongse A, Boonthavikoon T. 1990 - Ecology of intertidal fungi at Ranong mangrove, Thailand. Transactions of the Mycological Society of Japan 31, 17-27. 
Hyde KD, Fryar S, Tian Q, Bahkali AH, Xu J. 2015 - Lignicolous freshwater fungi along a northesouth latitudinal gradient in the Asian/Australian region; can we predict the impact of global warming on biodiversity and function? Fungal Ecology 19, 190-200.

Hyde KD, Hongsanan S, Jeewon R, Bhat DJ et al. 2016 - Fungal diversity notes 367-490: taxonomic and phylogenetic contributions to fungal taxa. Fungal Diversity 80, 1-270.

Hyde KD, Jones EBG, Liu JK, Ariyawansa H et al. 2013 - Families of Dothideomycetes. Fungal Diversity 63, 1-313.

Hyde KD, Jones EBG. 1989a - Hypophloeda rhizophora Hyde et Jones gen. et sp. nov., a new ascomycete from intertidal prop roots of Rhizophora spp. Transactions of the Mycological Society of Japan 30, 61-68.

Hyde KD, Jones EBG. 1989b - Intertidal Mangrove Fungi from Brunei. Lautospora gigantea gen. et sp. nov., a new Loculoascomycete from prop roots of Rhizophora spp. Botanica Marina 32, 479-482.

Hyde KD, Jones EBG. 1992 - Intertidal mangrove fungi: Pedumispora gen. nov. (Diaporthales). Mycological Research 96, 78-80.

Hyde KD, Lee SY. 1995 - Ecology of mangrove fungi and their role in nutrient cycling: what gaps occur in our knowledge? Hydrobiologia 295, 107-118.

Hyde KD, McKenzie EHC, KoKo TW. 2011 - Towards incorporating anamorphic fungi in a natural classification - checklist and notes for 2010. Mycosphere 2, 1-88.

Hyde KD, Mouzouras R. 1988 - Passeriniella savoryellopsis sp. nov., a new ascomycete from intertidal mangrove wood. Transactions of the British Mycological Society 91, 179-185.

Hyde KD, Nilsson RH, Alias SA, Ariyawansa HA et al. 2014 - One stop shop: backbones trees for important phytopathogenic genera: I (2014). Fungal Diversity 67(1), 21-125.

Hyde KD, Norphanphoun C, Abreu VP, Bazzicalupo A et al. 2017 - Fungal diversity notes 603708: taxonomic and phylogenetic notes on genera and species. Fungal Diversity 87, 1-235.

Hyde KD, Rappaz F. 1993 - Eutypa bathurstensis sp. nov. from intertidal Avicennia. Mycological Research 97, 861-864.

Hyde KD, Sarma VV, Jones EBG. 2000a - Morphology and taxonomy of higher marine fungi. In: Marine Mycology-A Practical Approach (eds. K.D. Hyde and S.B. Pointing). Fungal Diversity Research Series 1, 172-204.

Hyde KD, Taylor JE, Fröhlich J. 2000b - Genera of Ascomycetes from Palms. Fungal Diversity Press, Hong Kong.

Hyde KD, Tennakoon DS, Jeewon R, Bhat JD et al. 2019 - Fungal diversity notes 1036-1150: taxonomic and phylogenetic contributions on genera and species of fungal taxa. Fungal Diversity 96, 1-242.

Hyde KD, Wong SW, Jones EBG. 1998 - Diluviocola capensis gen. and sp. nov., a freshwater ascomycete with unique polar caps on the ascospores. Fungal Diversity 1, 133-146.

Hyde KD, Wong WSW, Aptroot A. 2002 - Marine and estuarine species of Lophiostoma and Massarina. In: Fungi in Marine Environments (Hyde KD, ed.). Fungal Diversity Research Series 7, 93-109.

Hyde KD. 1989 - Intertidal mangrove fungi from north Sumatra. Canadian Journal of Botany 67, 3078-3082.

Inderbitzin P, Abdel-Wahab MA, Jones EBG, Vrijmoed LLP. 1999 - A new species of Cryptovalsa from Mai Po mangrove in Hong Kong. Mycological Research 103, 1628-1630.

Index Fungorum 2019 - http://www.indexfungorum.org/Names/Names.asp. )accessed: January 2019.

Inglis PW, Tigano MS. 2006 - Identification and taxonomy of some entomopathogenic Paecilomyces spp. (Ascomycota) isolates using rDNA-ITS sequences. Genetics and Molecular Biology 29, 132-136.

Isaka M, Suyarnsestakorn C, Tanticharoen M, Kongsaeree P, Thebtaranonth Y. 2002 Aigialomycins AE, new resorcylic macrolides from the marine mangrove fungus Aigialus parvus. The Journal of Organic Chemistry 67, 1561-1566. 
Ismail AM, Cirvilleri G, Polizzi G, Crous PW et al. 2012 - Lasiodiplodia species associated with dieback disease of mango (Mangifera indica) in Egypt. Australasian Plant Pathology 41, 649-660.

Itin PH, Frei R, Lautenschlager S, Buechner SA et al. 1998 - Cutaneous manifestations of Paecilomyces lilacinus infection induced by a contaminated skin lotion in patients who are severely immunosuppressed. Journal of the American Academy of Dermatology 39, 401409.

Ito T, Nakagiri A, Tantichaoren M, Manoch L. 2001 - Mycobiota of mangrove forests in Thailand. Research Communications, Institute for Fermentation, Osaka 20, 50-60.

Jaklitsch WM, Voglmayr H. 2016 - Hidden diversity in Thyridaria and a new circumscription of the Thyridariaceae. Studies in Mycology 85, 35-64.

Jayasiri SC, Hyde KD, Abd-Elsalam KA, Abdel-Wahab MA et al. 2015 - The Facesoffungi database: fungal names linked with morphology, molecular and human attributes. Fungal Diversity 74, 3-18.

Jayasiri SC, Hyde KD, Jones EBG, McKenzie EHC et al. 2019 - Diversity, morphology and molecular phylogeny of Dothideomycetes on decaying wild seed pods and fruits. Mycosphere $10,1-186$.

Jayasiri SC, Hyde KD, Jones EBG, Peršoh D et al. 2018 - Taxonomic novelties of hysteriform Dothideomycetes. Mycosphere 9, 803-837.

Jayawardena RS, Hyde KD, Jeewon R, Ghobad-Nejhad M et al. 2019 - One stop shop II: taxonomic update with molecular phylogeny for important phytopathogenic genera: 26-50 Fungal Diversity 94, 41-129.

Jeewon R, Hyde KD. 2016 - Establishing species boundaries and new taxa among fungi: recommendations to resolve taxonomic ambiguities. Mycosphere 7, 1669-1677.

Johnson TW, Sparrow FK. 1961 - Fungi in Oceans and Estuaries. Weinheim (Germany), J. Cramer; Codicote, Herts, Wheldon \& Wesley, Ltd.; New York, N.Y., Hafner Publishing Co.

Jones AS. 1973 - The concentration of copper, lead, zinc and cadmium in shallow marine sediments, Cardigan Bay (Wales). Marine Geology 14(2), M1-M9.

Jones EBG, Abdel-Wahab MA. 2005 - Marine fungi from the Bahamas Islands. Botanica Marina 48, 356-373.

Jones EBG, Chatmala I, Pang KL. 2006 - Two new genera of the Halosphaeriaceae isolated from marine habitats in Thailand: Pseudoligninicola and Thalespora. Nova Hedwigia 83, 219-232.

Jones EBG, Moss ST. 1978 - Ascospore appendages of marine ascomycetes: an evaluation of appendages as taxonomic criteria. Marine Biology 49, 11-26.

Jones EBG, Pang KL (eds.) 2012 - Marine fungi and fungal-like organisms. Walter de Gruyter $\mathrm{GmbH}$ and Co. KG, Berlin/Boston.

Jones EBG, Pang KL, Abdel-Wahab MA, Scholz B et al. 2019 - An online resource for marine fungi. Fungal Diversity 96, 347-433.

Jones EBG, Sakayaroj J, Suetrong S, Somrithipol S, Pang KL. 2009 - Classification of marine Ascomycota, anamorphic taxa and Basidiomycota. Fungal Diversity 35, 1-187.

Jones EBG, Suetrong S, Cheng WH, Rungjindamai N et al. 2014 - An additional fungal lineage in the Hypocreomycetidae (Falcocladium species) and the taxonomic re-evaluation of Chaetosphaeria chaetosa and Swampomyces species, based on morphology, ecology and phylogeny. Cryptogamie Mycologie 35, 119-138.

Jones EBG, Suetrong S, Sakayaroj J, Bahkali AH et al. 2015 - Classification of marine Ascomycota, Basidiomycota, Blastocladiomycota and Chytridiomycota. Fungal Diversity 73, $1-72$.

Jones EBG, Pang KL, Abdel-Wahab MA, Scholz B, et al. 2019 - An online resource for marine fungi. Fungal Diversity 96: 347-433.

Jones EBG. 1976 - Lignicolous and algicolous fungi. In: EBG. Jones ed. Recent Advances in Aquatic Mycology. London: Elek Science. 1-49. 
Jones EBG. 1995 - Ultrastructure and taxonomy of the aquatic ascomycetous order Halosphaeriales. Canadian Journal of Botany 73, 790-801.

Jones EBG. 2000 - Marine fungi: some factors influencing biodiversity. Fungal Diversity 4, 53-73. Jones EBG. 2011 - Are there more marine fungi to be described? Botanica Marina 54, 343-354.

Jones EG, Le Campion-Alsumard T. 1970 - The biodeterioration of polyurethane by marine fungi. International Biodeterioration Bulletin 6(3), 119-124.

Ju Y, Rogers JD. 1996 - A revision of the genus Hypoxylon. American Phytopathological Society (APS Press).

Ju YM, Rogers JD. 2002 - The genus Nemania (Xylariaceae). Nova Hedwigia 74(1-2), 75-120.

Karsten PA. 1873 - Mycologia fennica. Pars secunda. Pyrenomycetes. Bidrag till Kännedom av Finlands Natur och Folk 23, 1-252.

Katoh K, Standley DM. 2013 - MAFFT multiple sequence alignment software version 7: improvements in performance and usability. Molecular Biology and Evolution 30, 772-780.

Kim CM, Lee JS, Lim YW. 2014 - Research Note: A new record of the genus Camarops (Boliniaceae) in Korea. 한국균학회지 42, 341-343.

Kim S, Shin DS, Lee T, Oh KB. 2004 - Periconicins, two new fusicoccane diterpenes produced by an endophytic fungus Periconia sp. with antibacterial activity. Journal of Natural Products 67, 448-450.

Kirk PM, Cannon PF, David JC, Stalpers JA. 2001 - Ainsworth and Bisby's Dictionary of the Fungi (No. Ed. 9). CABI publishing.

Kirk PM, Cannon PF, Minter DW, Stalpers JA. 2008 - Ainsworth \& Bisby's dictionary of the fungi, $10^{\text {th }}$ edn. CABI, Wallingford.

Kirk PM, Sutton BC. 1985 - A reassessment of the anamorph genus Chaetopsina (Hyphomycetes). Transactions of the British Mycological Society 85, 709-717.

Kirschner R, Pang KL, Jones EBG. 2013 - Two cheirosporous hyphomycetes reassessed based on morphological and molecular examination. Mycological Progress 12, 29-36.

Kishino H, Hasegawa M. 1989 - Evaluation of the maximum likelihood estimate of the evolutionary tree topologies from DNA sequence data. Journal of Molecular Evolution 29, 170-179.

Klaysuban A, Sakayaroj J, Jones EBG. 2014 - An additional marine fungal lineage in the Diatrypaceae, Xylariales: Pedumispora rhizophorae. Botanica Marina 57, 413-420.

Koch J, Jones EBG. 1989 - The identity of Crinigera maritima and three new genera of marine cleistothecial ascomycetes. Canadian Journal of Botany 67, 1183-1197.

Koch J. 1986 - Some lignicolous marine fungi from Thailand, including two new species. Nordic Journal of Botany 6, 497-499.

Kohlmeyer BV, Kohlmeyer J. 1993 - Biographic observation on Pacific marine fungi. Mycologia $85,337-346$.

Kohlmeyer J, Kohlmeyer E. 1965 - New marine fungi from mangroves and trees along eroding shoreline. Nova Hedwigia 9, 89-104.

Kohlmeyer J, Kohlmeyer E. 1979 - Marine mycology. The higher fungi. Academic Press, New York.

Kohlmeyer J, Schatz S. 1985 - Aigialus gen. nov. (Ascomycetes) with two new marine species from mangroves. Transactions of the British Mycological Society 85, 699-707.

Kohlmeyer J, Vittal B. 1986 - Lophiostoma mangrovis, a new marine ascomycete from the tropics. Mycologia 78, 485-489.

Kohlmeyer J, Volkmann-Kohlmeyer B. 1990 - Revision of marine species of Didymosphaeria (Ascomycotina). Mycological Research 94, 685-690.

Kohlmeyer J, Volkmann-Kohlmeyer B. 1991 - Illustrated key to the filamentous fungi. Botanica Marina 34, 1-61.

Kohlmeyer J. 1974 - Higher fungi as parasites and symbionts of algae. Veröffentlichungen des Instituts für Meeresforschung in Bremerhaven Supplemen 5, 339-356. 
Kohlmeyer J. 1984 - Tropical marine fungi. Pubblicazioni Della Stazione Zoologica Di Napolii Marine Ecology 5, 329-378.

Kohlmeyer J. 1986 - Ascocratera manglicola gen. et sp. nov. and key to the marine Lucoloascomycetes on mangroves. Canadian Journal of Botany 64, 3036-3042.

Kolařík M, Spakowicz DJ, Gazis R, Shaw J et al. 2017 - Biatriospora (Ascomycota: Pleosporales) is an ecologically diverse genus including facultative marine fungi and endophytes with biotechnological potential. Plant Systematics and Evolution 303, 35-50.

Kolařík M. 2018 - New taxonomic combinations in endophytic representatives of the genus Nigrograna. - Czech Mycology 70, 123-126.

Kuhnert E, Heitkämper S, Fournier J, Surup F, Stadler M. 2014. Hypoxyvermelhotins A-C, new pigments from Hypoxylon lechatii sp. nov. Fungal Biology 118, 242-252.

Kuhnert E, Surup F, Sir EB, Lambert C et al. 2015 - Lenormandins A--G, new azaphilones from Hypoxylon lenormandii and Hypoxylon jaklitschii sp. nov., recognised by chemotaxonomic data. Fungal Diversity 71, 165-184.

Kumar V, Cheewangkoon R, Thambugala KM, Jones EBG et al. 2019 - Rhytidhysteron mangrovei (Hysteriaceae), a new species from mangroves in Phetchaburi Province, Thailand. Phytotaxa 401, 166-178.

Kurtzman CP, Fell JW, Boekhout T. 2011a - Gene sequences analysis and other DNA-based methods for yeast species recognition. In: Kurtzman CP, Fell JW, Boekhout T (eds. The yeasts, a taxonomic study, $4^{\text {th }}$ edn. Elsevier, Amsterdam, pp 293-307.

Kurtzman CP, Fell JW, Boekhout T. 2011b - The yeasts, a taxonomic study, vol $1-3,5^{\text {th }}$ edn. Elsevier, Amsterdam.

Kutorga E, Hawksworth DL. 1997 - A re-assessment of the genera referred to the family Patellariaceae (Ascomycota). Systema Ascomycetum 15, 1-110.

Lambert C, Wendt L, Hladki AI, Stadler M et al. 2019 -Hypomontagnella (Hypoxylaceae): a new genus segregated from Hypoxylon by a polyphasic taxonomic approach. Mycological Progress 18, 187-201.

Lambert C, Wendt L, Hladki AI, Stadler M, Sir EB. 2019 - Hypomontagnella (Hypoxylaceae): a new genus segregated from Hypoxylon by a polyphasic taxonomic approach. Mycological Progress 18(1-2), 187-201.

Lechat C, Rossman A. 2017 - A new species of Fusicolla (Hypocreales), F. ossicola, from Belgium. Ascomycete.org 9, 225-228.

Lepelletier F, Karpov SA. Alacid E, Le Panse S et al. 2014 - Dinomyces arenysensis gen. et sp. nov. (Rhizophydiales, Dinomycetaceae fam. nov.) a chytrid infecting marine dinoflagellates. Protist 165, 230-244.

Leslie JF, Summerell BA. 2006 - Fusarium laboratory workshops - A recent history. Mycotoxin Research 22, 73-74.

Leukel RW. 1948 - Periconia circinata and its relation to milo disease. Journal of Agricultural Research 77, 7-8

Li JY, Sidhu RS, Ford EJ, Long DM et al. 1998 - The induction of taxol production in the endophytic fungus-Periconia sp from Torreya grandifolia. Journal of Industrial Microbiology Biotechnology 20, 259-264.

Li S, Liu C, Huang J, Liu Y et al. 2016 - Transcriptome and biomineralization responses of the pearl oyster Pinctada fucata to elevated $\mathrm{CO}_{2}$ and temperature. Scientific Reports 6, 18493.

Liew ECY, Aptroot A, Hyde, KD. 2000 - Phylogenetic significance of the pseudoparaphyses in Loculoascomycete taxonomy. Molecular Phylogeny and Evolution 16, 392-402.

Lindau G. 1897 - Hysteriineae. In Engler \& Prantl, Naturliche Pftanzenfamilien. I. Teil, I. Abreilung, 265-278.

Link HF. 1809 - Observationes in ordines planta- rum naturales. Magazin der Gesellschaft Naturforschenden Freunde Berlin 3, 3-42.

Liu JK, Hyde KD, Jeewon R, Zhao Q et al. 2017 - Ranking higher taxa using divergence times-a case study in Dothideomycetes. Fungal Diversity 84, 75-99. 
Liu JK, Hyde KD, Jones EBG, Ariyawansa HA et al. 2015 - Fungal diversity notes 1-110: taxonomic and phylogenetic contributions to fungal species. Fungal Diversity 72, 1-197.

Liu JK, Lu YZ, Cheewangkoon R, To-Anun C. 2018 - Phylogeny and morphology of Helicotubeufia gen. nov. with three new species in Tubeufiaceae from aquatic habitats. Mycosphere 9, 495-509.

Liu JK, Phookamsak R, Jones EBG, Zhang Y et al. 2011 - Astrosphaeriella is polyphyletic, with species in Fissuroma gen. nov., and Neoastrosphaeriella gen. nov. Fungal Diversity 51, 135154.

Liu YJ, Whelen S, Hall BD. 1999 - Phylogenetic relationships among ascomycetes: evidence from an RNA polymerase II subunit. Molecular Biology and Evolution 16, 1799-1808.

Lombard L, Van der Merwe NA, Groenewald JZ, Crous PW. 2015 - Generic concepts in Nectriaceae. Studies in Mycology 80, 189-245.

Lu YZ, Boonmee S, Dai DQ, Liu JK et al. 2017 - Four new species of Tubeufia (Tubeufiaceae, Tubeufiales) from Thailand. Mycological progress 16(4), 403-417.

Lu YZ, Boonmee S, Liu JK, Hyde KD et al. 2018a - Multi-gene phylogenetic analyses reveals Neohelicosporium gen. nov. and five new species of helicosporous hyphomycetes from aquatic habitats. Mycological Progress 17, 631-646.

Lu YZ, Liu JKJ, Hyde KD, Jeewon R. et al. 2018b - A taxonomic reassessment of Tubeufiales based on multi-locus phylogeny and morphology. Fungal Diversity 92, 131-344.

Luangsa-ard JJ, Houbraken J, van Doorn T, Hong S-B et al. 2011 - Purpureocillium, a new genus for the medically important Paecilomyces lilacinus. FEMS Microbiology Letters 321, 141149.

Lumbsch HT, Huhndorf SM. 2010 - Myconet volume 14 part one. Outline of Ascomycota-2009. Fieldiana Life and Earth Sciences 1, 1-922.

Luo ZL, Hyde KD, Bhat DJ, Jeewon R et al. 2018 - Morphological and molecular taxonomy of novel species Pleurotheciaceae from freshwater habitats in Yunnan, China. Mycological Progress 17, 511-530.

Luttrell ES. 1955 - The ascostromatic ascomycetes. Mycologia 47, 511-532.

Magnes M. 1997 - Weltmonographie der Triblidiaceae. Bibliotheca Mycologica 165, 119.

Maharachchikumbura SN, Hyde KD, Jones EBG, McKenzie EHC et al. 2016 - Families of Sordariomycetes. Fungal Diversity 79, 1-317.

Maharachchikumbura SS, Ariyawansa HA, Wanasinghe DN, Dayarathne MC et al. 2019 Phylogenetic classification and generic delineation of Hydeomyces desertipleosporoides gen. et sp. nov (Phaeosphaeriaceae) from Jebel Akhdar Mountain in Oman. Phytotaxa 391(1), 28 38.

Maharachchikumbura SSN, Hyde KD, Jones EBG, McKenzie EHC. 2015 - Towards a natural classification and backbone tree for Sordariomycetes. Fungal Diversity 72, 199-301

Manohar CS, Boekhout T, Muller WH, Stoeck T. 2014 - Tritirachium candoliense sp. nov., a novel basidiomycetous fungus isolated from the anoxic zone of the Arabian Sea. Fungal Biology $118,139-149$.

Maria GL, Sridhar KR. 2003 - Diversity of filamentous fungi on woody litter of five mangrove plant species from the southwest coast of India. Fungal Diversity 14, 109-126.

Markovskaja S, Kačergius A. 2013 - Morphological and molecular characterisation of Periconia. Mycologcal Progress, DOI 10.1007/s11557-013-0914-6.

Markovskaja S, Kačergius A. 2014 - Morphological and molecular characterization of Periconia pseudobyssoides sp. nov. and closely related P. byssoides. Mycological Progress 13, 291302.

Mason EW, Ellis MB. 1953 - Brithish species of Periconia. Mycological Papers 56, 1-127.

Matsushima T. 1971 - Microfungi of the Solomon Islands and Papua-New Guinea. Nippon Printing \& Publishing, Osaka.

Matsushima T. 1996 - Matsushima Mycological Memoirs. 9. Matsushima T (published by the author), Kobe. 
Mckeown TA, Alias SA, Moss ST, Jones EBG. 2001 - Ultrastructural studies of Trematosphaeria malaysiana sp. nov. and Leptosphaeria pelagica. Mycological Research 105, 615-624.

Mehl JWM, Slippers B, Roux J, Wingfield MJ. 2014 - Botryosphaeriaceae associated with dieback of Schizolobium parahyba trees in South Africa and Ecuador Forest. Pathology 44, 396-408.

Mehrabi M, Hemmati R, Vasilyeva LN, Trouillas FP. 2015 - A new species and a new record of Diatrypaceae from Iran. Mycosphere 6, 60-68.

Mehrabi M, Roghayeh H, Vasilyeva LN, Trouillas FP. 2016 - Diatrypella macrospora sp. nov. and new records of diatrypaceous fungi from Iran. Phytotaxa 252, 43-55.

Merli S, Garofano L, Rambelli A, Pasqualetti M. 1992 - Chaetopsina nimbae, a new species of dematiaceous hyphomycetes. Mycotaxon 44, 323-331.

Miller JH. 1949 - A revision of the classification of the Ascomycetes with special emphasis on the Pyrenomycetes. Mycologia 41, 99-127.

Miller JH. 1961 - A monograph of the world species of Hypoxylon. University of Georgia Press, Athens, $\mathrm{p} 158$.

Miller MA, Pfeiffer W, Schwartz T. 2010 - Creating the CIPRES science gateway for inference of large phylogenetic trees. Proceedings of the Gateway Computing Environments Workshop (GCE) 1, 1-8.

Minter DW, Hernández MR, Portales JM. 2001 - Fungi of the Caribbean: an annotated checklist. PDMS Publishing p. 946.

Montagne M. 1856 - Note Sur Le Boschia, Nouveau Genre De La Famille Des Hépatiques Découvert Au Brèsil Par M. Weddell. Bulletin de la Société Botanique de France 3, 572-576.

Morgan-Jones G. 1979 - Notes in Hyphomycetes. XXXI. Chaetopsina auburnensis sp. nov. Mycotaxon, 8, 411-416.

Nag Raj TR. 1993 - Coelomycetous anamorphs with appendage-bearing conidia. Mycologue Publications, Waterloo.

Nakagiri A, Newell SY, Ito T, Tan TK. 1996 - Biodiversity and ecology of the oomycetous fungus, Halophytophthora. In Biodiversity and the Dynamics of Ecosystems. (I.M. Turner, CH Diong, SSL, Lim PKL Ng, eds), DIWPA Series 1, 273-280.

Nalim FA, Samuels GJ, Wijesundera RL, Geiser DM. 2011 - New species from the Fusarium solani species complex derived from perithecia and soil in the Old-World tropics. Mycologia 103, 1302-1330.

Nannizzi A. 1934 - Repertorio sistematico dei miceti dell' uomo e degli animali, Poligrafia Meimi, Siena 4, 1-557.

Netto MSB, Assunção IP, Lima GSA, Marques MW et al. 2014 - Species of Lasiodiplodia associated with papaya stem-end rot in Brazil. Fungal Diversity 67, 127-141.

Newell SY. 1976 - Mangrove fungi: The succession in the mycoflora of red mangrove (Rhizophora mangle L.) seedlings. In: Recent Advances in Aquatic Mycology, (E.B.G. Jones, ed.), London, Elek Science pp. 51-91.

Nitschke T. 1870 - Pyrenomycetes Germanici 2, 24

Norphanphoun C, Jeewon R, Mckenzie EHC, Wen TC et al. 2017 - Taxonomic position of Melomastia italica sp. nov. and phylogenetic reappraisal of Dyfrolomyces. Cryptogamie Mycologie 38, 507-525.

Nylander JAA. 2004 - MrModeltest 2.0. Program distributed by the author. Evolutionary Biology Centre, Uppsala University.

Okada G, Sakai N, Yamagishi M. 1995 - Acremonium-like submerged conidiation in Paecilomyces nostocoides and P. lilacinus. Mycoscience 36, 345-351.

Orsi W, Biddle JF, Edgcomb V. 2013 - Deep sequencing of subseafloor eukaryotic rRNA reveals active fungi across marine subsurface provinces. PLoS ONE 8, e56335

Orth B, Frei R, Itin PH, Rinaldi MG et al. 1996 - Outbreak of invasive mycoses caused by Paecilomyces lilacinus from a contaminated skin lotion. Annals of Internal Medicine 125, 799-806. 
Osorio JA, De Beer ZW, Wingfield MJ, Roux, J. 2016 - Ophiostomatoid fungi associated with mangroves in South Africa, including Ophiostoma palustre sp. nov. Antonie van Leeuwenhoek 109(12), 1555-1571.

Pang KL, Alias SA, Chiang MWL, Vrijmoed LLP, Jones EBG. 2010 - Sedecimiella taiwanensis gen. et sp. nov., a marine mangrove fungus in the Hypocreales (Hypocreomycetidae, Ascomycota). Botanica Marina 53, 493-498.

Pang KL, Hyde KD, Alias SA, Suetrong S et al. 2013 - Dyfrolomycetaceae, a new family in the Dothideomycetes, Ascomycota. Cryptogamie Mycologie 34, 223-233.

Pang KL, Jeng JS, Jones EBG. 2011 - Marine Mangrove Fungi of Taiwan. National Taiwan Ocean University, Chilung 1-131

Pang KL, Overy DP, Jones EBG, da Luz Calado M et al. 2016 - Marine fungi' and 'marine-derived fungi' in natural product chemistry research: toward a new consensual definition. Fungal Biology Reviews 30, 163-175.

Pang KL, Tsui CKM, Jones EBG, Vrijmoed LLP. 2015 - Bioprospecting fungi and the Labyrinthulomycetes in ocean-land interface. In: Marine Biomedicine- from Beach to Bedside (ed BJ Baker). CRC Press, Boca Raton, pp. 379-391.

Pang KL. 2012 - Phylogeny of the marine Sordariomycetes. In: Jones, E. B. G., Pang, K. L. (eds. Marine fungi and fungal-like organisms. Walter de Gruyter $\mathrm{GmbH}$ and Co. KG, Berlin/Boston, pp 35-47.

Pastor FJ, Guarro J. 2006 - Clinical manifestations, treatment and outcome of Paecilomyces lilacinus infections. Clinical Microbiology and Infection 12, 948-960.

Perdomo H, Cano J, Gené J, García D et al. 2013 - Polyphasic analysis of Purpureocillium lilacinum isolates from different origins and proposal of the new species Purpureocillium lavendulum. Mycologia 105, 151-161.

Perera RH, Hyde KD, Dissanayake AJ, Jones EBG et al. 2018 - Diaporthe collariana sp. nov., with prominent collarettes associated with Magnolia champaca fruits in Thailand. Studies in Fungi 3, 141-151.

Perera RH, Maharachchikumbura SSN, Bhat JD, Al-Sadi AM et al. 2016 - New species of Thozetella and Chaetosphaeria and new records of Chaetosphaeria and Tainosphaeria from Thailand. Mycosphere 7, 1301-1321.

Petch T. 1938 - British Hypocreales. Transactions of the British Mycological Society 21, 243-305.

Phillips AJL, Alves A, Abdollahzadeh J, Slippers B et al. 2013 - The Botryosphaeriaceae: genera and species known from culture. Studies in Mycology 76, 51-167.

Phillips AJL, Alves A, Pennycook SR, Johnston PR et al. 2008 - Resolving the phylogenetic and taxonomic status of dark-spored teleomorph genera in the Botryosphaeriaceae. Persoonia 21, $29-55$.

Phillips AJL, Hyde KD, Alves A, Liu JK 2019 - Families in Botryosphaeriales: a phylogenetic, morphological and evolutionary perspective. Fungal Divers 94, 1-22.

Phillips NW. 1984 - Role of different microbes and substrates as potential suppliers of specific, essential nutrients to marine detritivores. Bulletin of Marine Science 35, $283-98$.

Phookamsak R, Hyde KD, Jeewon R, Bhat DJ et al. 2019 - Fungal diversity notes 929-1036: taxonomic and phylogenetic contributions on genera and species of fungal taxa. Fungal Diversity 95, 1-273

Phookamsak R, Liu JK, McKenzie EHC, Manamgoda DS et al. 2014 - Revision of Phaeosphaeriaceae. Fungal Diversity 68, 159-238.

Phookamsak R, Lu YZ, Hyde KD, Jeewon R et al. 2018 - Phylogenetic characterization of two novel Kamalomyces species in Tubeufiaceae (Tubeufiales) Mycological Progress 17, 647660.

Phookamsak R, Wanasinghe DN, Hongsanan S, Phukhamsakda C et al. 2017 - Towards a natural classification of Ophiobolus and ophiobolus-like taxa; introducing three novel genera Ophiobolopsis, Paraophiobolus and Pseudoophiobolus in Phaeosphaeriaceae (Pleosporales). Fungal Diversity 87(1), 299-339. 
Phookamsak R., Norphanphoun C, Tanaka K, Dai DQ. 2015 - Towards a natural classification of Astrosphaeriella-like species; introducing Astrosphaeriellaceae and Pseudoastrosphaeriellaceae fam. nov. and Astrosphaeriellopsis, gen. nov. Fungal Diversity 74, 143-197.

Phukhamsakda C, Hongsanan S, Ryberg M, Ariyawansa HA et al. 2016 - The evolution of Massarineae with Longipedicellataceae fam. nov. Mycosphere 7, 1713-1731.

Phukhamsakda C, Jeewon R, McKenzie EHC, Xu JC. 2019 - Morphology and phylogeny of Phaeoseptum mali sp. nov. (Phaeoseptaceae, Pleosporales) on bark of Malus halliana. Asian Journal of Mycology 2, 118-128.

Pinnoi A, Lumyong S, Hyde KD, Jones EBG. 2006 - Biodiversity of fungi on the palm Eleiodoxa conferta in Sirindhorn peat swamp forest, Narathiwat, Thailand. Fungal Diversity 22, 205218.

Pinruan U, Hyde KD, Lumyong S, McKenzie EHC, Jones EBG. 2007 - Occurrence of fungi on tissues of the peat swamp palm Licuala longicalycata. Fungal Diversity 25, 157-173.

Pointing SB, Vrijmoed LLP, Jones EBG. 1998 - A qualitative assessment of lignocellulose degrading enzyme activity in marine fungi. Botanica Marina 41, 293-298.

Poonyth AD, Hyde KD, Aptroot A, Peerally A. 2000 - Mauritiana rhizophorae gen. et sp. nov. (Ascomycetes, Requienellaceae), with a list of terrestrial saprobic mangrove fungi. Fungal Diversity 4, 101-116.

Pouzar Z. 1985 - Proposals for the conservation of five family names of fungi. Taxon 34(4), 709712.

Pouzar Z. 1985 - Reassessment of the Hypoxylon serpens-complex n. Ceska Mykologie 39: 129134.

Prasannarai K, Sridhar KR. 2003 - Abundance and diversity of marine fungi on intertidal woody litter of the west coast of India on prolonged incubation. Fungal Diversity 14, 127-141.

Pudhom K, Teerawatananond T. 2014 - Rhytidenones A-F, spirobisnaphthalenes from Rhytidhysteron sp. AS21B, an endophytic fungus. Journal of Natural Products 77, $1962-$ 1966.

Pugh GJF, Jones EBG. 1986 - Antarctic marine fungi: A preliminary account. The Biology of Marine Fungi 323-225. (ED ST MossI Cambridge Uiniversity Cambridge.

Punithalingam E. 1980 - Plant diseases attributed to Botryodiplodia theobromae In: Bibliotheca Mycologica. J. Cramer, Berlin.

Quandt CA, Kepler RM, Gams W, Araújo JP et al. 2014 - Phylogenetic-based nomenclatural proposals for Ophiocordycipitaceae (Hypocreales) with new combinations in Tolypocladium. IMA Fungus 5, 121-134.

Raghukumar C, Mohandass C, Kamat S, Shailaja MS. 2004 - Simultaneous detoxification and decolorization of molasses spent wash by the immobilized white-rot fungus Flavodon flavus isolated from a marine habitat. Enzyme and Microbial Technology 35, 197-202.

Raghukumar C, Ravindram J. 2012 - Fungi and their role in corals and coral reef ecosystems. In: Raghukumar C (ed.) Biology of Marine Fungi. Springer, Berlin, pp 89-113.

Rämä T, Norden J, Davey ML, Nathiassen GH et al. 2014 - Fungi ahoy! Diversity on marine wooden substrata in the high North. Fungal Ecology 8, 46-58.

Ramaley AW. 1997 - Barrina, a new genus with polysporous asci. Mycologia 89, 962-966.

Rambaut A. 2012 - Fig.Tree. Tree Fig. Drawing Tool, v. 1.4.0

Rambelli A, Lunghini D. 1976 - Chaetopsina ivoriensis a new species of Dematiaceous Hyphomycetes. Plant Biosystem 110, 253-258.

Rambelli A, Lunghini D. 1979 - Chaetopsina species from tropical forest litter. Transactions of the British Mycological Society 72, 491-493.

Rambelli A. 1956 - Chaetopsina nuovo genere di Ifali Demaziacei. Journal of agricultural research III 191-196.

Rao PR, Rao D. 1964 - The genus Periconia from India. Mycopathologia et Mycologia Applicata $22,285-310$. 
Rappaz F. 1987 - Taxonomie et nomenclature des Diatrypacées à asques octosporées. Mycologia helvetica 2, 285-648.

Rateb ME, Ebel R. 2011 - Secondary metabolites of fungi from marine habitats. Natural Product Reports 28, 290-344.

Rayachhetry MB, Blakeslee GM, Webb RS, Kimbrough JW. 1996 - Characteristics of the Fusicoccum anamorph of Botryosphaeria ribis, a potential biological control agent for Melaleuca quinquenervia in South Florida. Mycologia 88, 239-248.

Read ND, Beckett A. 1996 - Centenary review: ascus and ascospore morphogenesis. Mycological Research 100, 1281-1314.

Reblova M, Barr ME, Samuels GJ. 1999 - Chaetosphaeriaceae, a new family for Chaetosphaeria and its relatives. Sydowia 51(1), 49-70.

Réblová M, Miller AN, Rossman AY, Seifert KA. 2016 - Recommendations for competing sexualasexually typified generic names in Sordariomycetes (except Diaporthales, Hypocreales, and Magnaporthales). IMA Fungus 7, 131-153.

Réblová M, Winka K. 2000 - Phylogeny of Chaetosphaeria and its anamorphs based on morphological and molecular data. Mycologia 92, 939-954.

Rees MJ, Begelman MC, Blandford RD, Phinney ES. 1982 - Ion-supported tori and the origin of radio jets. Nature 295, 17-21.

Rehm H. 1896 - Die Pilze: Ascomycetes (Hysteriaceen undDiscomycetes). Leipzig.

Rehner S, Samuels GJ 1994 - Taxonomy and phylogeny of Gliocladium analyzed from nuclear large subunits ribosomal DNA sequences. Mycological Research 98, 625-634.

Richards TA, Leonard G, Mah F, del Campo J et al. 2015 - Molecular diversity and distribution of marine fungi across 130 European environmental samples. Proceedings of the Royal Society B: Biological Sciences 282, 2015-2243.

Rick J. 1931 - Monographia Pezizinearum Riograndensium. Broteria, ser.bot. 25, 65-71.

Rogerson CT. 1970 - The hypocrealean fungi (Ascomycetes, Hypocreales). Mycologia 62, 865910.

Romero AI, Samuels GJ. 1991 - Studies on xylophilous fungi from Argentina. VI. Ascomycotina on Eucalyptusviminalis (Myrtaceae). Sydowia 43, 228-248.

Rossman AY, Adams GC, Cannon PF, Castlerbury LA et al. 2015 - Recommendations of generic names in Diaporthales competing for protection or use. IMA Fungus 6, 145-154

Rossman AY, Farr DF, Castlebury LA. 2007 - A review of the phylogeny and biology of the Diaporthales. Mycoscience 48, 135-144.

Rossman AY, Samuels GJ, Rogerson CT, Lowen R. 1999 - Genera of Bionectriaceae, Hypocreaceae and Nectriaceae (Hypocreales, Ascomycetes). Studies in Mycology 42, 1-248.

Rossman AY. 2000 - Towards monophyletic genera in the holomorphic Hypocreales. Studies in Mycology 45, 27-34.

Saccardo PA. 1880 - Conspectus generum fungorum Italiae inferiorum nempe ad Sphaeropsideas, Melanconieas et Hyphomyceteas pertinentium systemate sporologico dispositorum. Michelia 2, 1-38.

Sakayaroj J, Jones EBG, Chatmala I, Phongpaichit S. 2004 - Marine Fungi. In E.B.G. Jones, M. Tantichareon and K.D. Hyde (eds.). Thai Fungal Diversity BIOTEC. Thailand, pp.107-117.

Sakayaroj J, Pang KL, Jones EBG. 2011 - Multi-gene phylogeny of the Halosphaeriaceae: its ordinal status, relationships between genera and morphological character evolution. Fungal Diversity 46, 87-109.

Sakayaroj J, Preedanon S, Supaphon O, Jones EBG, Phongpaichit S. 2010 - Phylogenetic diversity of endophyte assemblages associated with the tropical seagrass Enhalus acoroides in Thailand. Fungal Diversity 42, 27-45.

Samarakoon MC, Gafforo Y, Liu N, Maharachchikumbura SS et al. 2018 - Combined multi-gene backbone tree for the genus Coniochaeta with two new species from Uzbekistan. Phytotaxa 336, 43-58. 
Samson RA. 1974 - Paecilomyces and some allied hyphomycetes. Studies in Mycology 68, 163191.

Samuels GJ, Blackwell M. 2001 - Pyrenomycetes: fungi with perithecia. In: McLaughlin DJ, McLaughlin EG, Lemke PA (eds) The Mycota: a comprehensive treatise on Fungi as experimental systems for basic and applied research, vol VII. Systematics and evolution: Part A. Springer, Berlin, pp 221-255.

Samuels GJ, Müller E. 1979 - Life-History studies of Brazilian ascomycetes. 1. Rhytidhysteron rufulum and the genus Eutryblidiella. Sydowia 32, 277-2-92.

Samuels GJ. 1985 - Four new species of Nectria and their Chaetopsina anamorphs. Mycotaxon 22, $13-32$.

Sandoval-Denis M, Crous PW 2018 - Removing chaos from confusion: assigning names to common human and animal pathogens in Neocosmospora.Persoonia: Molecular Phylogeny and Evolution of Fungi 41, 109-129.

Sandoval-Denis M, Guarnaccia V, Polizzi G. Crous PW 2018 - Symptomatic Citrus trees reveal a new pathogenic lineage in Fusarium and two new Neocosmospora species. Persoonia: Molecular Phylogeny and Evolution of Fungi 40, 1-25.

Santos JM, Vrandečić K, Ćosić J, Duvnjak T, Phillips AJL. 2011 - Resolving the Diaporthe species occurring on soybean in Croatia. Persoonia 27, 9-19.

Sarma VV, Hyde KD, Vittal BPR. 2001 - Frequency of occurrence of mangrove fungi from the east coasts of India. Hydrobiologia 455, 41-53.

Sarma VV, Hyde KD. 2001 - A review on frequently occurring fungi in mangroves. Fungal Diversity 8, 1-34.

Schmit JP, Shearer CA. 2003 - A checklist of mangrove associated fungi. Mycotaxon 8, 423-477.

Schmit JP, Shearer CA. 2004 - Geographical and host distribution of lignicolous mangrove microfungi. Botanica Marina 47, 496-500.

Schoch CL, Crous PW, Groenewald JZ, Boehm EWA et al. 2009 - A class-wide phylogenetic assessment of Dothideomycetes. Studies in Mycology 64, 1-15.

Seifert K, Morgan-Jones G, Gams W, Kendrick B et al. 2011 - The genera of hyphomycetes. CBSKNAW Fungal Biodiversity Centre, Utrecht.

Seifert KA, Rossman AY. 2010 - How to describe a new fungal species. IMA fungus 1, 109-118.

Senanayake IC, Crous PW, Groenewald JZ, Maharachchikumbura SS et al. 2017 - Families of Diaporthales based on morphological and phylogenetic evidence. Studies in Mycology 86, 217-296.

Senanayake IC, Jeewon R, Chomnunti P, Wanasinghe D. N et al. 2018 - Taxonomic circumscription of Diaporthales based on multigene phylogeny and morphology. Fungal Diversity 93(1), 241-443.

Senanayake IC, Maharachchikumbura SSN, Hyde KD, Bhat JD et al. 2015 - Towards unraveling relationships in Xylariomycetidae (Sordariomycetes). Fungal Diversity 73, 73-144.

Senwanna C, Phookamsak R, Doilom M, Hyde KD et al. 2017 - Novel taxa of Diatrypaceae from Para rubber (Hevea brasiliensis) in northern Thailand; introducing a novel genus Allocryptovalsa. Mycosphere 8, 1835-1855.

Shang QJ, Hyde KD, Jeewon R, Khan S et al. 2018 - Morpho-molecular characterization of Peroneutypa (Diatrypaceae, Xylariales) with two novel species from Thailand. Phytotaxa 356, 1-8.

Shang QJ, Hyde KD, Phookamsak R, Doilom M et al. 2017 - Diatrypella tectonae and Peroneutypa mackenziei sp. nov. (Diatrypaceae) from northern Thailand. Mycological Progress 16, 463-476.

Sharma P, Rawla GS. 1986 - Ascomycetes new to India. III. Nova Hedwigia: Zeitschrift fur Kryptogamenkunde.

Shearer CA, Descals E, Kohlmeyer B, Kohlmeyer J et al. 2007 - Fungal biodiversity in aquatic habitats. Biodiversity and Conservation 16, 49-67. 
Shearer CA, Miller AN, Nelson P, Tanaka K et al. 2009 - The molecular phylogeny of freshwater Dothideomycetes. Studies in Mycology 64, 145-153.

Shoemaker RA, Babcock CE. 1989 - Phaeosphaeria. Canadian Journal of Botany 67, 1500-1599.

Shoemaker RA. 1984 - Canadian and some extralimital Nodulosphaeria and Entodesmium species. Canadian Journal of Botany 62, 2730-2753.

Singh P, Raghukumar C, Verma P, Shouche Y. 2012 - Fungal diversity in deep-sea sediments revealed by culture-dependent and culture-independent approaches. Fungal Ecology 5, 543553.

Slippers B, Boissin E, Phillips AJL, Groenewald JZ et al. 2013 - Phylogenetic lineages in the Botryosphaeriales: a systematic and evolutionary framework. Studies in Mycology 76, 31-49.

Slippers B, Wingfield MJ. 2007 - Botryosphaeriaceae as endophytes and latent pathogens of woody plants: diversity, ecology and impact. Fungal Biology Reviews 21, 90-106.

Smith EF. 1899 - Wilt disease of cotton, watermelon and cowpea. United States Department of Agriculture Bulletin 17, 1-53.

Smith GJ, Hyde KD. 2001 - Fungi from palms. XLIX. Astrocystis, Biscogniauxia, Cyanopulvis, Hypoxylon, Nemania, Guestia, Rosellinia and Stilbohypoxylon. Fungal Diversity 7, 89-127.

Spatafora JW, Blackwell M. 1994 - The polyphyletic origins of ophiostomatoid fungi. Mycological Research 981, 1-9.

Spegazzini CL. 1881 - Fungi argentini additis nonnullis brasiliensibus montevideensibusque. Pugillus quartus Continuacion. Anales de la Sociedad Científica Argentina 12, 174-189

Spegazzini CL. 1921 - Mycetes chilenses. Coni.

Spooner BM. 1981 - New records and species of British microfungi. Transactions of the British Mycological Society 762, 265-301.

Stadler M, Læssøe T, Fournier J, Decock C et al. 2013 - A polyphasic taxonomy of Daldinia (Xylariaceae). Studies in Mycology 77, 1-143

Stamatakis A, Hoover P, Rougemont J. 2008 - A rapid bootstrap algorithm for the RAxML web servers. Systematic Biology 57, 758-771.

Stamatakis A. 2014 - RAxML version 8, a tool for phylogenetic analysis and post-analysis of large phylogenies. Bioinformatics 30, 1312-1313.

Stevens NE, Shear CL. 1929 - Botryosphaeria and Physalospora in the Hawaiian Islands. Mycologia 216, 313-320.

Stukenbrock EH, Banke S, McDonald BA. 2006 - Global migration patterns in the fungal wheat pathogen Phaeosphaeria nodorum. Molecular Ecology 15, 2895-2904.

Suetrong S, Jones EBG. 2006 - Marine discomycetes, A review. Indian Journal of Marine Sciences 354, 291-296.

Suetrong S, Rungjindamai N, Somma, S, Rung-Areerate P et al. 2014 - Wiesneriomyces a new lineage of Dothideomycetes (Ascomycota) basal to Tubeufiales. Phytotaxa 176, 283-297.

Suetrong S, Schoch CL, Spatafora JW, Kohlmeyer J. 2009 - Molecular systematics of the marine Dothideomycetes. Studies in Mycology 64, 155-173.

Sundari R, Vikineswary S, Yusoff M, Jones EBG. 1996 - Observations on tropical arenicolous marine fungi on driftwood from Malaysia and Singapore. Botanica Marina 391-6, 327-334.

Sung DY, Kaplan F. Guy CL. 2001 - Plant Hsp70 molecular chaperones, protein structure, gene family, expression and function. Physiologia Plantarum 1134, 443-451.

Sung GH, Hywel-Jones NL, Sung JM, Luangsa-ard JJ et al. 2007 - Phylogenetic classification of Cordyceps and the clavicipitaceous fungi. Studies in Mycology 57, 5-59.

Sutherland GK. 1915a - New marine Pyrenomycetes. Transactions of the British Mycological Society 5, 147-I55.

Sutherland GK. 1915b - New marine fungi on Pelvelia. New Phytologist 14, 33-42.

Sutherland GK. 1915c - Additional notes on marine Pyrenomycetes. New Phytologist. 14, 183193.

Sutherland GK. 1916 - Marine Fungi Imperfecti. New Phytolgist 15, 35-48. 
Sutton BC, Hodges Jr CS. 1976 - Eucalyptus microfungi, Mycoleptodiscus species and Pseudotracylla gen. nov. [Brazil]. Nova Hedwigia 27, 693-700

Tam WY, Pang KL, Jones EBG. 2003 - Ordinal placement of selected marine Dothideomycetes inferred from SSU ribosomal DNA sequence analysis. Botanica Marina 4, 487-494.

Tanaka K, Hirayama K, Yonezawa H, Sato G et al. 2015 - Revision of the Massarineae Pleosporales, Dothideomycetes. Studies in Mycology 82, 75-136.

Tang AM, Jeewon R, Hyde KD. 2009 - A re-evaluation of the evolutionary relationships within the Xylariaceae based on ribosomal and protein-coding gene sequences. Fungal Diversity 34, $155-153$.

Tang AMC, Jeewon R, Hyde KD. 2007 - Phylogenetic relationships of Nemania plumbea sp. nov. and related taxa based on ribosomal ITSand RPB2 sequences. Mycological Research 111, 392-402.

Taylor JW. 2011 - One fungus, one name, DNA and fungal nomenclature twenty years after PCR. IMA fungus 2, 113-120.

Taylor S, Thordarson DS, Maxfield L, Fedoroff IC et al. 2003 - Comparative efficacy, speed, and adverse effects of three PTSD treatments, exposure therapy, EMDR, and relaxation training. Journal of Consulting and Clinical Psychology 712, 330.

Tennakoon DS, Phookamsak R, Kuo CH, Goh TK et al. 2018 - Morphological and phylogenetic evidence reveal Fissuroma taiwanense sp. nov. (Aigialaceae, Pleosporales) from Hedychium coronarium. Phytotaxa 338, 265-275.

Thambugala KM, Hyde KD, Eungwanichayapant PD, Romero AI et al. 2016 - Additions to the genus Rhytidhysteron in Hysteriaceae. Cryptogamie Mycologie 37, 99-116.

Thambugala KM, Wanasinghe DN, Phillips AJL, Camporesi E et al. 2017 - Mycosphere notes 150: grass (Poaceae) inhabiting Dothideomycetes. Mycosphere 8, 697-796.

Theissen F, Sydow H. 1918 - Vorentwürfe zu den Pseudosphaeriales.

Tibpromma S, Hyde KD, Jeewon R, Maharachchikumbura SSN et al. 2017 - Fungal diversity notes 491-602: taxonomic and phylogenetic contributions to fungal taxa. Fungal Diversity 83, 1261.

Tibpromma S, Hyde KD, McKenzie EH, Bhat DJ et al. 2018 - Fungal diversity notes 840-928: micro-fungi associated with Pandanaceae. Fungal Diversity 93(1), 1-160.

Tigano-Milani MS, Honeycutt RJ, Lacey LA, Assis R. et al. 1995 - Genetic variability of Paecilomyces fumosoroseus isolates revealed by molecular markers. Journal of Invertebrate Pathology 65, 274-282.

Tode HJ. 1791 - Fungi Mecklenburgenses selecti. Luneburg. Fasc. II, Generum novorum appendicem. p. 64 Tab. VIII-XVII.

Travadon R, Lecomte P, Diarra B, Lawrence DP. 2016 - Grapevine pruning systems and cultivars influence the diversity of wood-colonizing fungi. Fungal Ecology 24, 82-93.

Trouillas FP, Pitt WM, Sosnowski MR, Huang R et al. 2011 - Taxonomy and DNA phylogeny of Diatrypaceae associated with Vitis vinifera and other woody plants in Australia. Fungal Diversity 49, 203-223.

Tulasne LR, Tulasne C. 1863 - Selecta Fungorum Carpologia, 2. Selecta Fungorum Carpologia, 2.

Tulasne LR, Tulasne C. 1865 - Selecta fungorum carpologia III. Paris Museum, pp.1-221.

Udayanga D, Liu X, Crous PW, McKenzie EH et al. 2012 - A multi-locus phylogenetic evaluation of Diaporthe Phomopsis. Fungal Diversity 56, 157-171.

Udayanga D, Liu X, McKenzie EH, Chukeatirote E et al. 2011 - The genus Phomopsis: biology, applications, species concepts and names of common phytopathogens. Fungal Diversity 50, 189-225.

Udayanga D, Castlebury LA, Rossman AY, Hyde KD. 2014 - Species limits in Diaporthe: molecular re-assessment of D. citri, D. cytosporella, D. foeniculina and D. rudis. Persoonia $32,83-101$. 
Udayanga D, Castlebury LA, Rossman AY, Chukeatirote E et al. 2015 - The Diaporthe sojae species complex, phylogenetic re-assessment of pathogens associated with soybean, cucurbits and other field crops. Fungal Biology 119, 383-407.

Untereiner WA, Bogale M, Carter A, Hanson SA et al. 2013 - Molecular phylogeny of Boliniales Sordariomycetes with an assessment of the systematics of Apiorhynchostoma, Endoxyla and Pseudovalsaria. Mycologia 105, 564-588.

Valenzuela-Lopez N, Cano-Lira JF, Guarro J, Sutton DA et al. 2018 - Coelomycetous Dothideomycetes with emphasis on the families Cucurbitariaceae and Didymellaceae. Studies in Mycology 90, 1-69.

Van der Aa HA, Boerema GH, Gruyter JD. 2000 - Contributions towards a monograph of Phoma (Coelomycetes) VI-1: section Phyllostictoides: characteristics and nomenclature of its type species Phoma exigua. Persoonia 17, 435-456.

Van Schooneveld T, Freifeld A, Lesiak B, Kalil A et al. 2008 - Paecilomyces lilacinus infection in a liver transplant patient: case report and review of the literature. Transplant Infectious Disease 10, 117-122.

Vasilyeva LN, Rogers JD, Miller AN. 2007b - Pyrenomycetes of the Great Smoky Mountains National Park. V. Annulohypoxylon and Hypoxylon (Xylariaceae). Fungal Diversity 27, 231245.

Vasilyeva LN, Stephenson SL, Miller AN. 2007a - Pyrenomycetes of the Great Smoky Mountains national park. IV. Biscogniauxia, Camaropella, Camarops, Camillea, Peridoxylon and Whalleya. Fungal Diversity 25, 219-231.

Verkley GJM, Dukik K, Renfurm R, Göker M et al. 2014 - Novel genera and species of Coniothyrium-like fungi in Montagnulaceae Ascomycota. Persoonia 32, 25-51.

Verma RK, Sharma N, Soni KK. 2008 - Forest fungi of Central India. Jamaluddin 11-418.

Vilgalys R, Hester M. 1990 - Rapid genetic identification and mapping of enzymatically amplified ribosomal DNA from several Cryptococcus species. Journal of Bacteriology 172, 4238-4246.

Voglmayr H, Gardiennet A. Jaklitsch WM. 2016 - Asterodiscus and Stigmatodiscus, two new apothecial dothideomycete genera and the new order Stigmatodiscales.Fungal Diversity 80, 271-284.

von Arx JA. 1954 - Gattungen der amerosporen Pyrenomyceten. Beiträge zur Kryptogamenflora Schweiz, 11, 1-434.

von Arx JA. 1971 - Testudinaceae, a new family of Ascomycetes.Persoonia-Molecular Phylogeny and Evolution of Fungi. 63, 365-369.

Wanasinghe DN, Hyde KD, Jeewon R, Crous PW et al. 2017 - Phylogenetic revision of Camarosporium Pleosporineae, Dothideomycetes and allied genera. Studies in Mycology 87, 207-256

Wanasinghe DN, Phukhamsakda C, Hyde KD, Jeewon R et al. 2018 - Fungal diversity notes 709839: taxonomic and phylogenetic contributions to fungal taxa with an emphasis on fungi on Rosaceae. Fungal Diversity 89, 1-236.

Weber E, Görke C, Begerow D. 2002 - The Lecythophora-Coniochaeta complex: II. Molecular studies based on sequences of the large subunit of ribosomal DNA. Nova Hedwigia 74, 187200.

Weber E. 2002 - The Lecythophora-Coniochaeta complex, I. Morphological studies on Lecythophora species isolated from Picea abies. Nova Hedwigia 74, 159-185.

Wehmeyer LE. 1933 - The genus Diaporthe Nitschke and its segregates.University of Michigan Press 9, 1-349.

Wehmeyer LE. 1961 - A world nonograph of the genus Pleospora and its segregates. University of Michigan Press, Ann Arbor.

Wei MJ, Zhang H, Dong W, Boonmee S, Zhang D. 2018 - Introducing Dictyochaeta aquatica sp. nov. and two new species of Chloridium (Chaetosphaeriaceae, Sordariomycetes) from aquatic habitats. Phytotaxa 362, 187-199. 
Wendt L, Sir EB, Kuhnert E, Heitkämper S et al. 2018 - Resurrection and emendation of the Hypoxylaceae, recognised from a multigene phylogeny of the Xylariales. Mycological Progress 17, 115-154.

Wessolossky M, Haran JP, Bagchi K. 2008 - Paecilomyces lilacinus olecranon bursitis in an immunocompromised host, case report and review. Diagnostic Microbiology and Infectious Disease 61, 354-357.

Whalley AJ, Jones EBG, Lassǿe T. 1999 - Halorosellinia gen. nov. to accommodate Hypoxylon oceanicum, a common mangrove species. Mycological Research 104, 368-374.

White T, Bruns T, Lee S, Taylor J. 1990 - Amplification and direct sequencing of fungal ribosomal RNA genes for phylogenetics. PCR Protocols, A Guide to Methods and Applications 18, 315-322.

Wijayawardene NN, Crous PW, Kirk PM, Hawksworth DL et al. 2014 - Naming and outline of Dothideomycetes including proposals for the protection or suppression of generic names. Fungal Diversity 69, 11-55.

Wijayawardene NN, Hyde KD, Lumbsch HT, Liu JK et al. 2018 - Outline of Ascomycota, 2017. Fungal Diversity 88, 167-263.

Wijayawardene NN, Hyde KD, Rajeshkumar KC, Hawksworth DL et al. 2017a - Notes fors genera: Ascomycota. Fungal Diversity 86, 1-594.

Wijayawardene NN, Hyde KD, Tibpromma S, Wanasinghe DN, Thambugala KM, Tian Q, Wang Y 2017 b - Towards incorporating asexual fungi in a natural classification: checklist and notes 2012-2016. Mycosphere 8, 1457-1554.

Wijayawardene NN, McKenzie EHC, Hyde KD. 2012 - Towards incorporating anamorphic fungi in a natural classification checklist and notes for 2011. Mycosphere 3, 157-228.

Wingfield MJ. 1987 - A new name for Phialocephala illini. Mycotaxon USA.

www. marinefungi.org 2019 - Accessed 2019 January.

Xavier KV, Nepal KA, Crous PW, Groenewald JZ et al. 2019 - Dwiroopa punicae sp. nov. (Dwiroopaceae fam. nov., Diaporthales), associated with leaf spot and fruit rot of pomegranate (Punica granatum). Fungal Systematics and Evolution 4, 33-41

Xing XK, Chen J, Xu MJ, Lin WH, Guo SX. 2011 - Fungal endophytes associated with Sonneratia Sonneratiaceae mangrove plants on the south coast of China. Forest Pathology 41, 334-340.

Xu W, Gong LF, Pang KL, Luo ZH. 2018 - Fungal diversity in deepsea sediments of a hydrothermal vent system in the Southwest Indian Ridge. Deep-Sea Research Part I 131, 1626.

Yacharoen S, Tian Q, Chomnunti P, Boonmee S et al. 2015 - Patellariaceae revisited. Mycosphere 6, 290-332.

Yang CL, Xu XL, Wanasinghe DN, Jeewon R et al. 2019 - Neostagonosporella sichuanensis gen. et sp. nov. (Phaeosphaeriaceae, Pleosporales) on Phyllostachys heteroclada (Poaceae) from Sichuan Province, China. MycoKeys 46, 119-150.

Zare R, Gams W, Culham A. 2000 - A revision of Verticillium sect. prostrata, I. Phylogenetic studies using ITS sequences. Nova Hedwigia 71, 465-480.

Zhang JF, Liu JK, Hyde KD, Chen YY. et al. 2017 - Two new species of Dyfrolomyces Dyfrolomycetaceae, Dothideomycetes from karst landforms. Phytotaxa 313, 267-277.

Zhang N, Castlebury LA, Miller AN, Huhndorf SM et al. 2006 - An overview of the systematics of the Sordariomycetes based on a four-gene phylogeny. Mycologia 98, 1076-1087.

Zhang N, Wang Z. 2015 - Pezizomycotina: Sordariomycetes and Leotiomycetes. In: McLaughlin DJ, Spatafora JW (eds) The Mycota. Part B, Systematics and Evolution. Springer, Berlin, pp 57-88.

Zhang SN, Hyde KD, Jones EBG, Cheewangkoon R, Liu JK. 2018 - Acuminatispora palmarum gen. et sp. nov. from mangrove habitats. Mycological Progress 17, 1173-1188.

Zhang T, Deng X, Yu Y, Zhang M, Zhang Y. 2016 - Pseudochaetosphaeronema ginkgonis sp. nov, an endophyte isolated from Ginkgo biloba. International Journal of Systematic and Evolutionary Microbiology 66, 4377-4381. 
Zhang Y, Crous PW, Schoch CL, Hyde KD. 2012 - Pleosporales. Fungal Diversity 53, 1-221.

Zhang Y, Fournier J, Phookamsak R, Bahkali AH et al. 2013 - Halotthiaceae fam. nov. (Pleosporales) accommodates the new genus Phaeoseptum and several other aquatic genera. Mycologia 105, 603-609.

Zhang Y, Hyde KD. 2009 - Transfer of Pseudoparodia pseudopeziza to Patellariaceae Patellariales. Nova Hedwigia 88, 211-215.

Zhang Y, Schoch CL, Fournier J, Crous PW et al. 2009 - Multi-locus phylogeny of Pleosporales: a taxonomic, ecological and evolutionary re-evaluation. Studies in Mycology 64, 85-102.

Zhaxybayeva O, Gogarten JP. 2002 - Bootstrap, Bayesian probability and maximum likelihood mapping, exploring new tools for comparative genome analysis. BMC Genomics 3, 4.

Zogg H. 1962 - Die Hysteriaceae s. str. und Lophiaceae unter besonderer Berücksichtigung der mitteleuropäischen Formen. Beitrage zur Krytogamenflora der Schweiz 11, 1-190.

Zucconi L, Rambelli A. 1993 - A new species of Chaetopsina from tropical forest litter. Mycotaxon 48, 5-12. 